Fall 1995

\title{
1995 Miracle Yearbook
}

Cedarville College

Follow this and additional works at: https://digitalcommons.cedarville.edu/yearbooks

Part of the Higher Education Commons, Organizational Communication Commons, and the Public Relations and Advertising Commons

\section{Recommended Citation}

Cedarville College, "1995 Miracle Yearbook" (1995). Yearbooks. 37.

https://digitalcommons.cedarville.edu/yearbooks/37

This Book is brought to you for free and open access by DigitalCommons@Cedarville, a service of the Centennial Library. It has been accepted for inclusion in Yearbooks by an authorized administrator of DigitalCommons@Cedarville. For more information, please contact digitalcommons@cedarville.edu. 

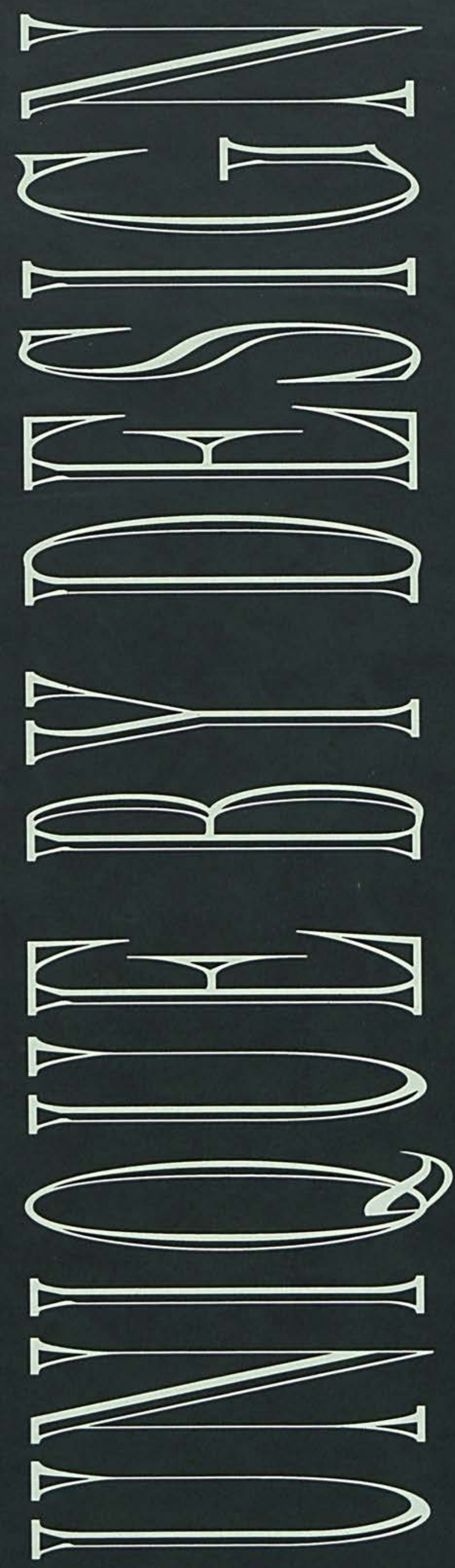


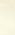



14. 

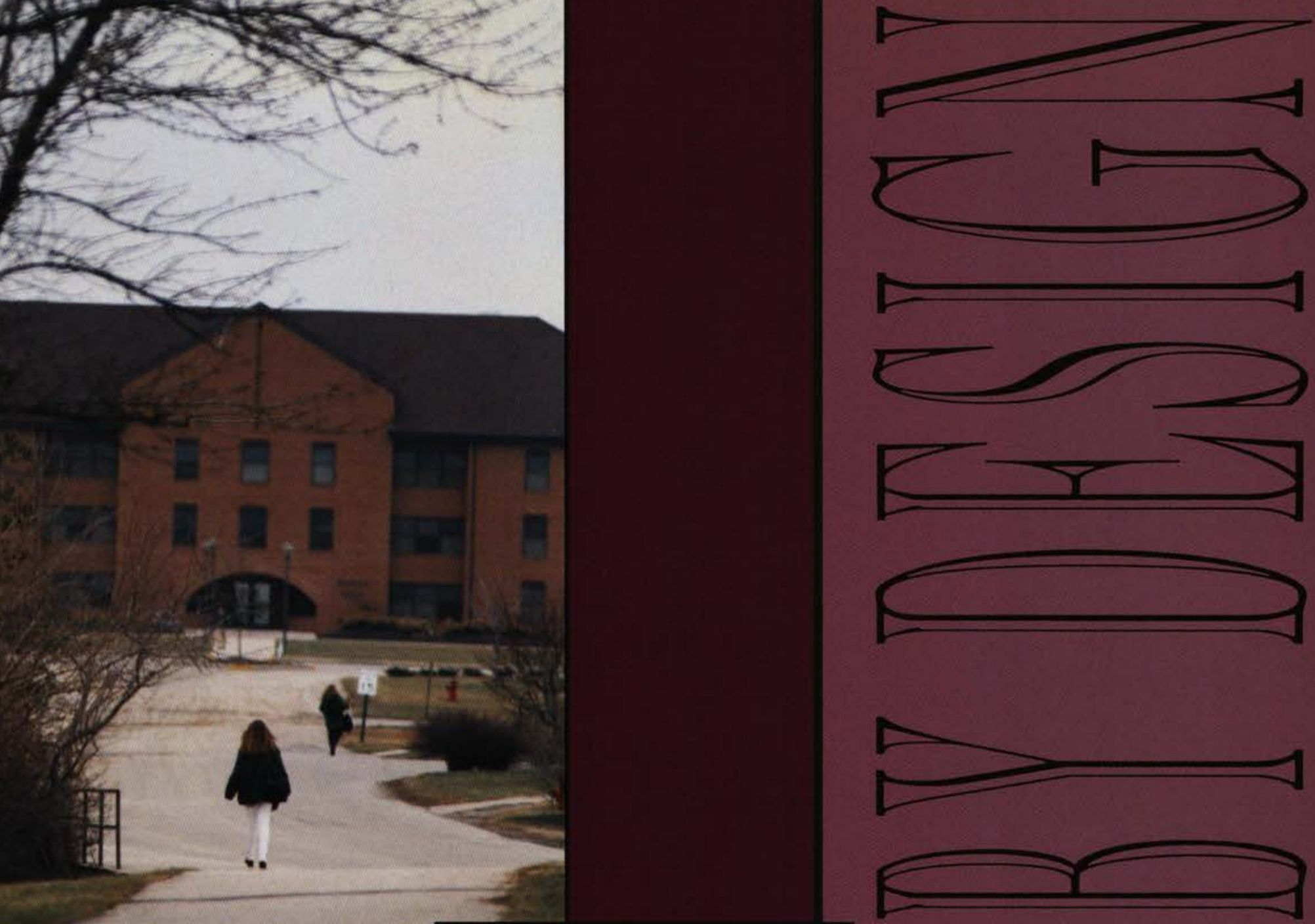

Miracle 1995

Cedarville College

Volume 42

\section{P.O. Box 601}

251 North Main Street Cedarville, OH 45314
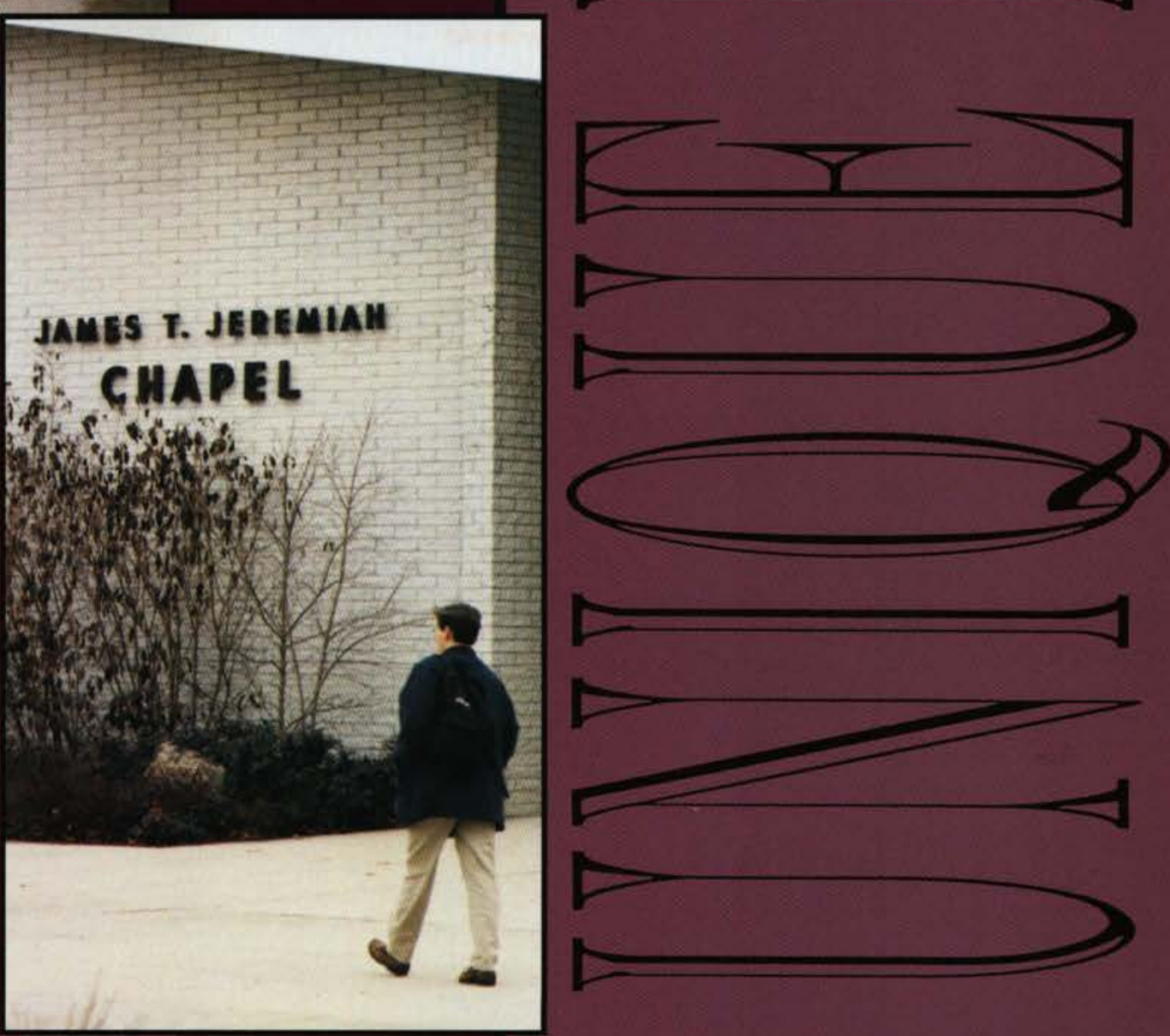


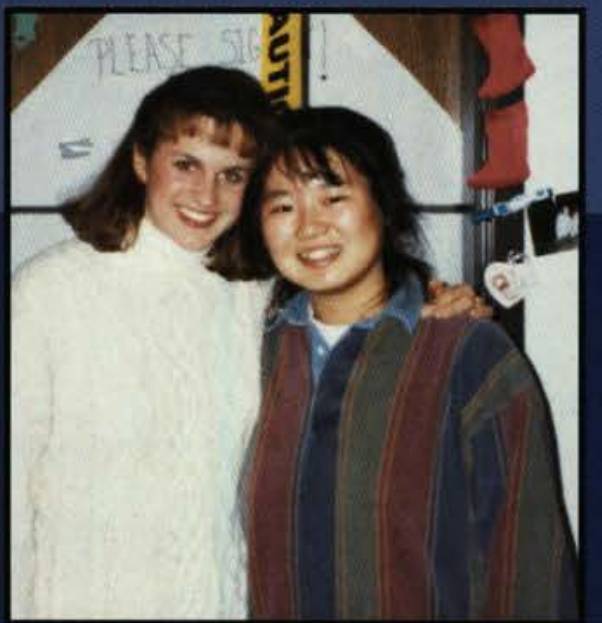

BELOW: Sherri DeClark, Alicii Elmore, Beth Comer, and Tricio Walker have a gats nit

BOTTOM: Beth Abhas and Kristi West share a hug in friendship.

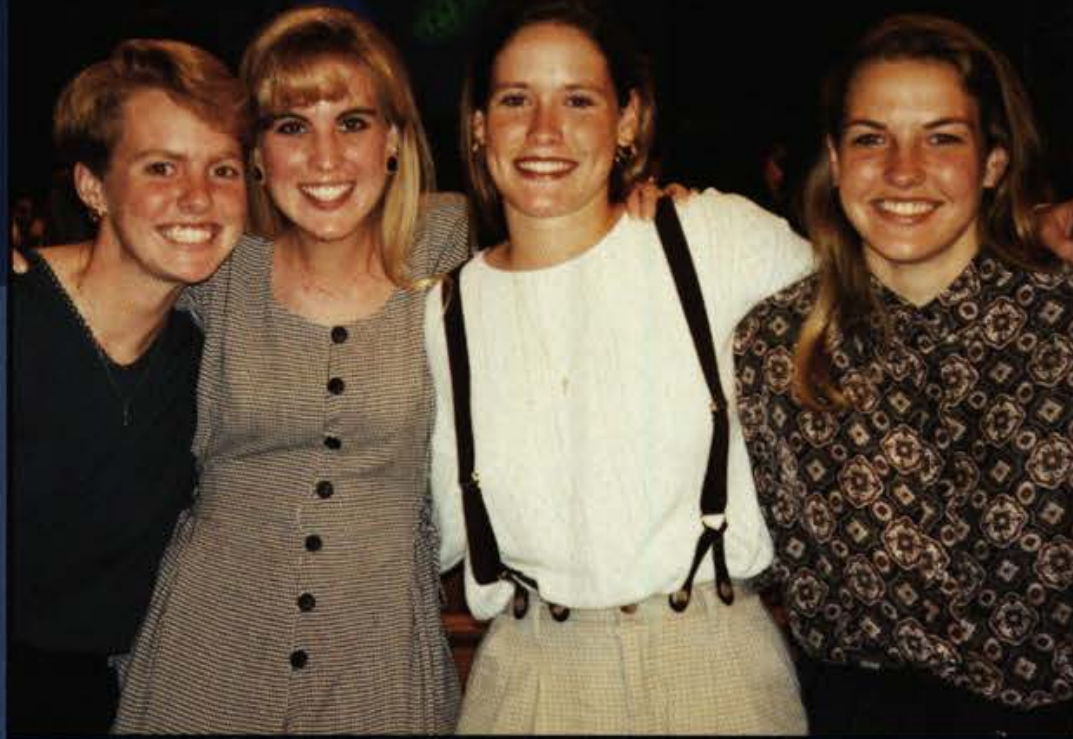

$+\frac{1}{2+2}$
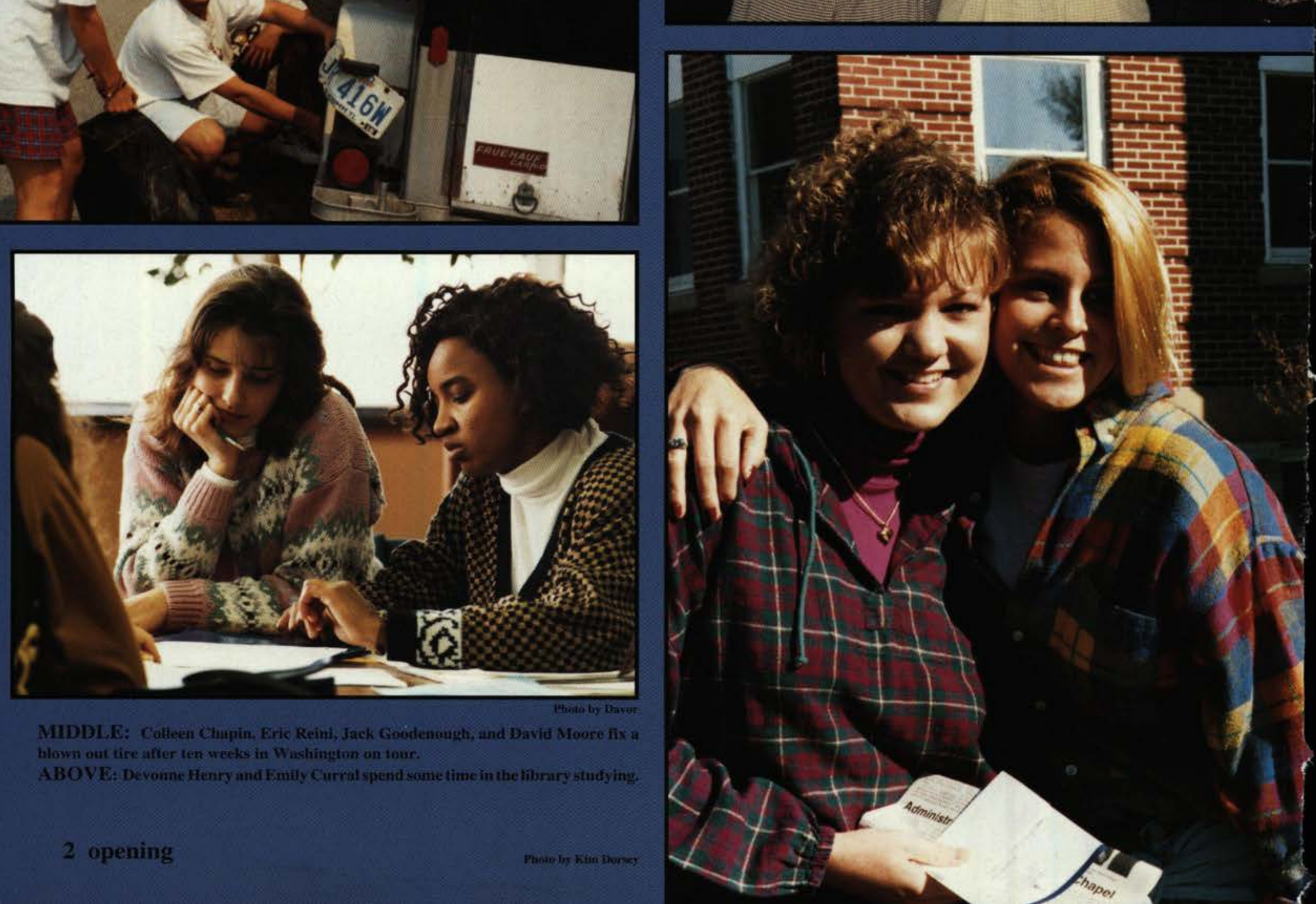

2 opening

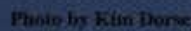



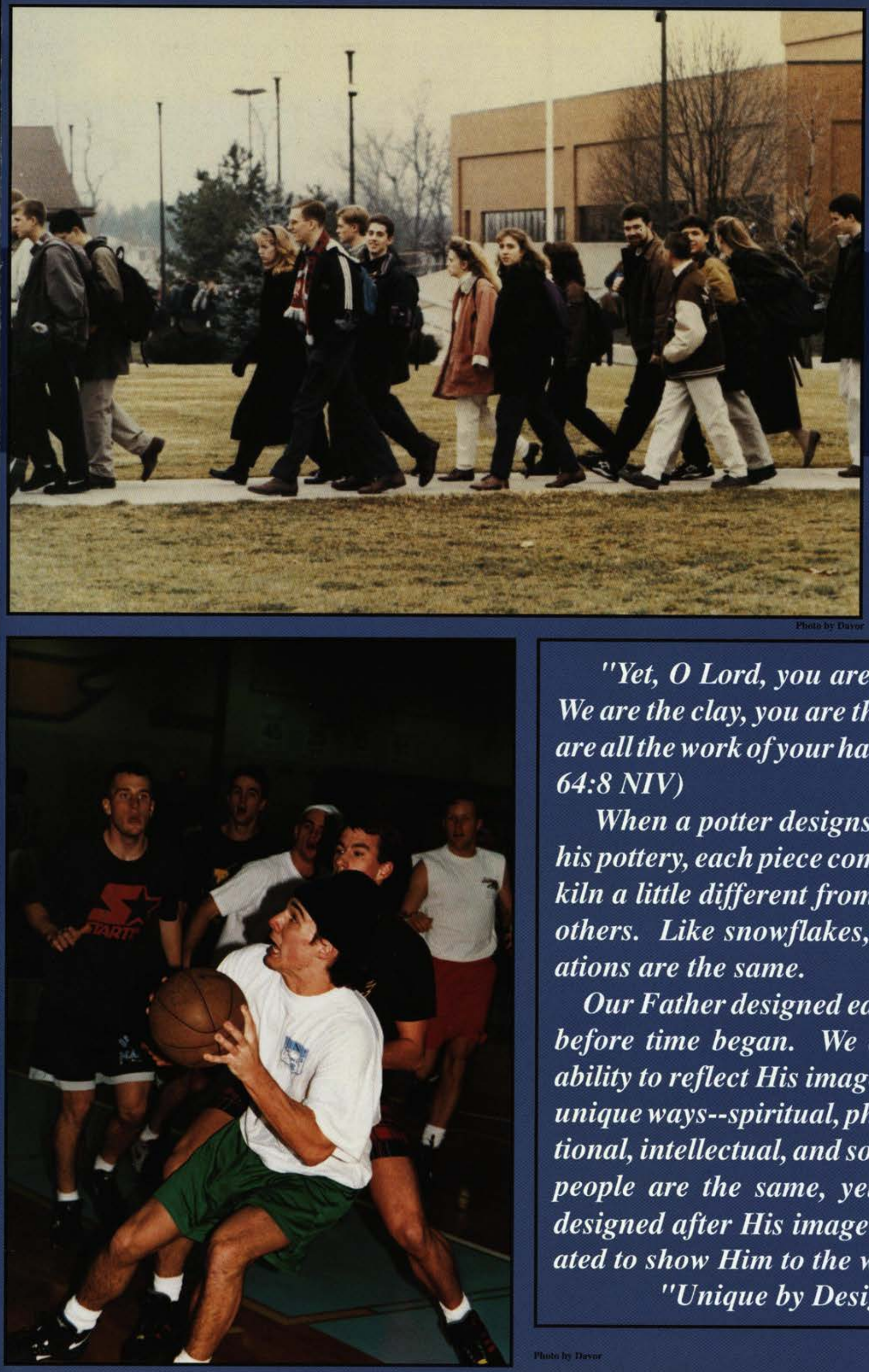

"Yet, O Lord, you are our Father. We are the clay, you are the potter; we are all the work of your hand. " (Isaiah 64:8 NIV)

When a potter designs and creates his pottery, each piece comes out of the kiln a little different from each of the others. Like snowflakes, no two creations are the same.

Our Father designed each one of us before time began. We all have the ability to reflect His image in our own unique ways--spiritual, physical, emotional, intellectual, and social. No two people are the same, yet we are all designed after His image and all created to show Him to the world.

"Unique by Design" 

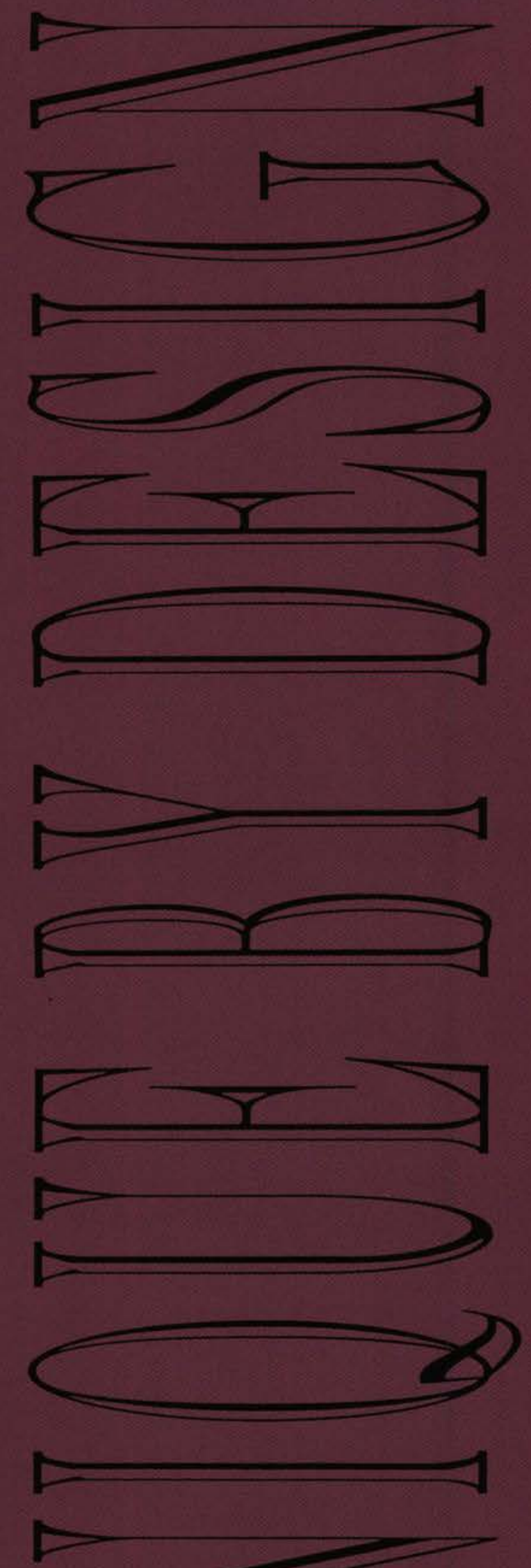

RIGHT: Ann Graham, Stephen Reiter, Aaron Graham, and Ken Nichols fellowship at the Gavelyte.

BELOW: Dave Swasey, Dustin Hughes, Jon Hjembo, Julianne Pletcher, and Andy Miller decide to take a break and have a Pepsi.
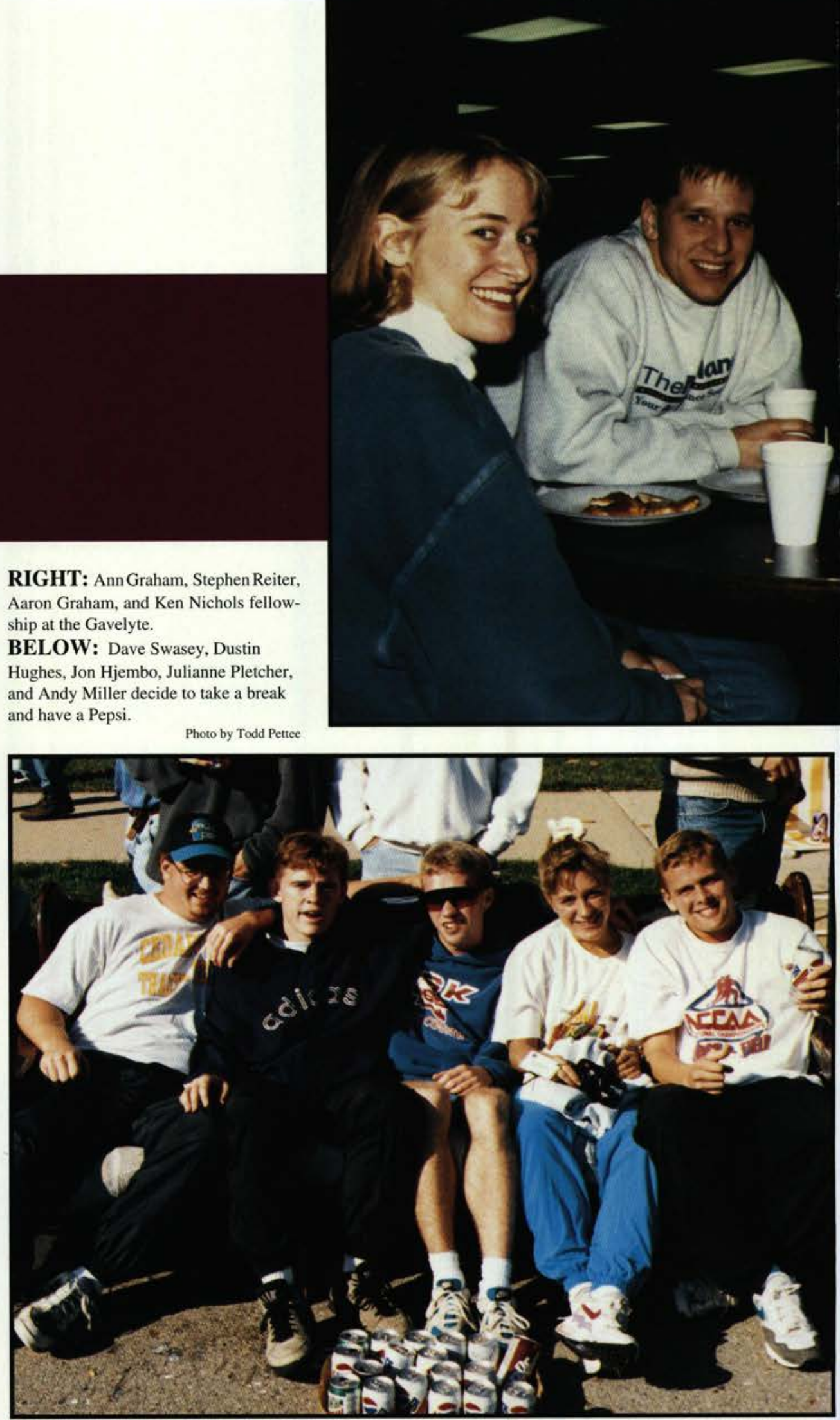


\section{Influencing Others}

\section{Drs. Monroe}

\section{with His Love}

Allen and Beverly Monroe have been a part of the Cedarville College scene for almost three decades. Dr. Allen Monroe joined the faculty in the Department of Social Sciences and History in January of 1966. His broad background in the social sciences enabled him to develop the well-known course Foundations of Social Science which has become a distinctive element in the college culture. $\mathrm{He}$ also teaches courses in geography and political science and is known for his emphasis on Christian Theism. His former student and present colleague, Dr. Kevin Sims, states this about him, "As a freshman, I viewed 'Uncle $\mathrm{Al}^{\prime}$ as someone to be reverentially feared; as an upperclassman, however, I gained a better appreciation of the man. He was still the task-master, the one who demanded excellence and stressed academic rigor in the classroom; yet, he was the one who cultivated in me the ability, as well as the desire, to learn."

Dr. "Mrs." Beverly Monroe, as she is affectionately called, spent several years teaching in the public school system be-
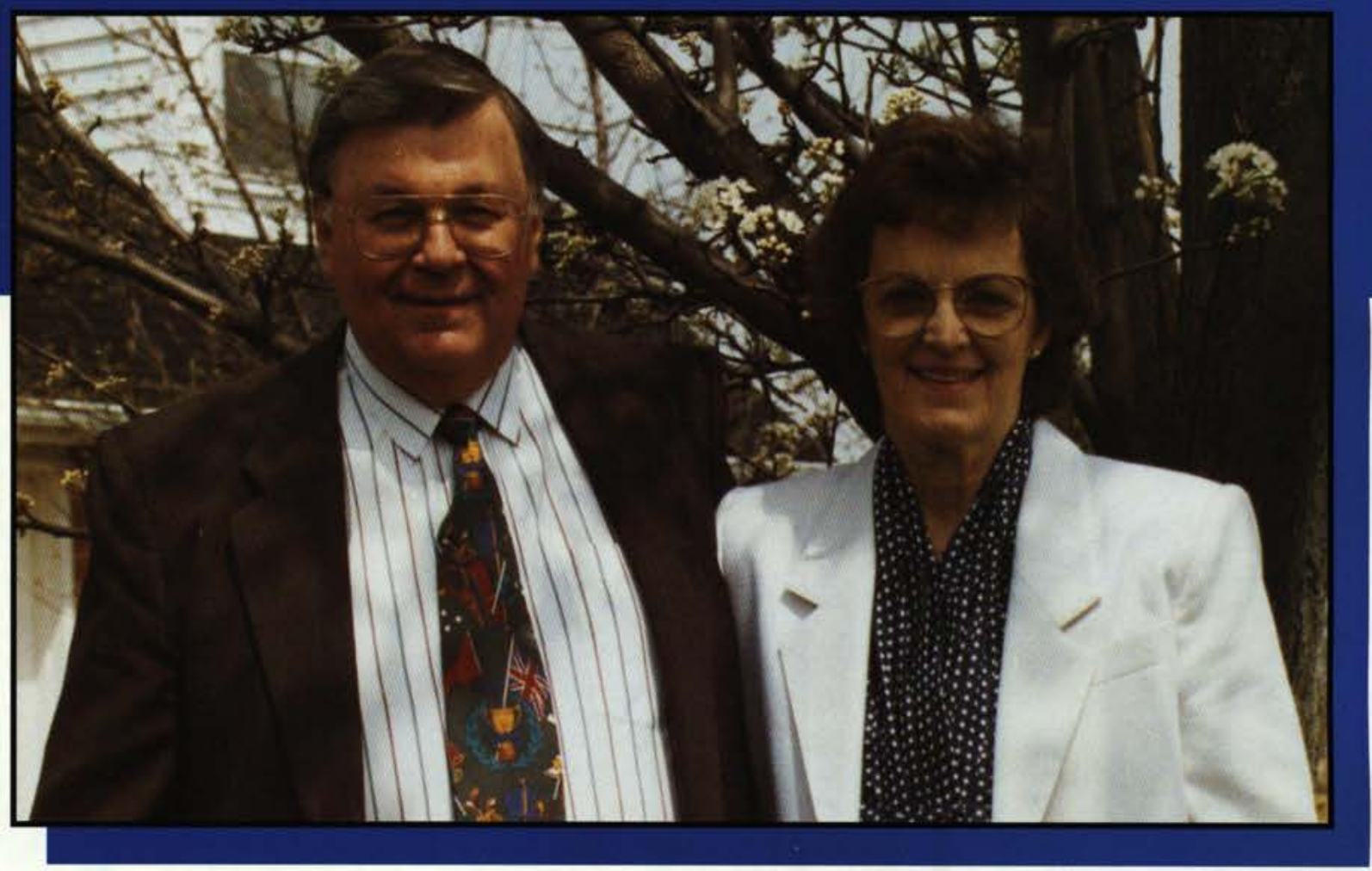

fore coming to the Education Department in 1977. Her areas of expertise include children's literature and several elementary education methods fields: this expertise has led her to minister effectively in several foreign mission schools as well.

The chair of the Education Department, Dr. Merlin Ager, describes her as professional, organized, hardworking, energetic, and demanding of her students. He further says, "Although she is talented and experienced in many areas, children's literature is clearly her first love. When I think of her in the classroom, I see her dressed in a 'Mother Goose' costume demonstrating story telling and communicating her excitement for the world of books to her students. Her office has the appearance of the children's books section of a local library. In fact, her grandchildren, Ryan, Allison, and Caitlyn, call her "Grandmabooks."

The Monroes have travelled extensively throughout the world. Their rich cultural experiences have contributed greatly to the intellectual development of their students. May they continue to be Christian role models in balancing academic, cultural and spiritual excellence to all their future students as they have in the last thirty-plus years.

Murray J. Murdoch

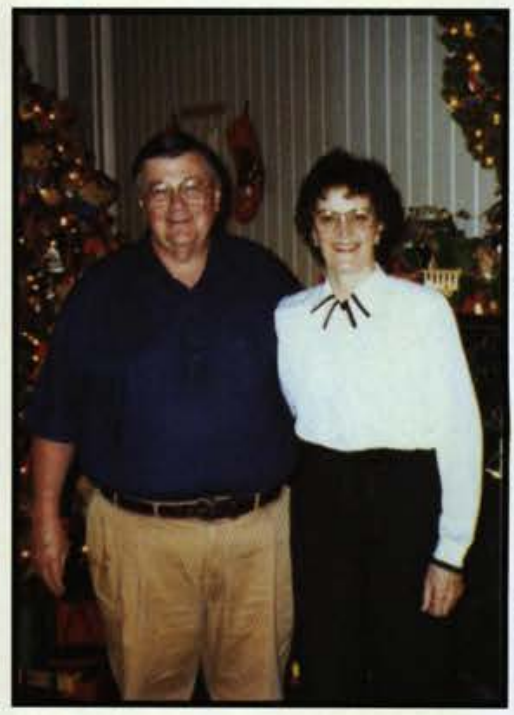


Drs. Allen and Beverly

\section{Monroe}
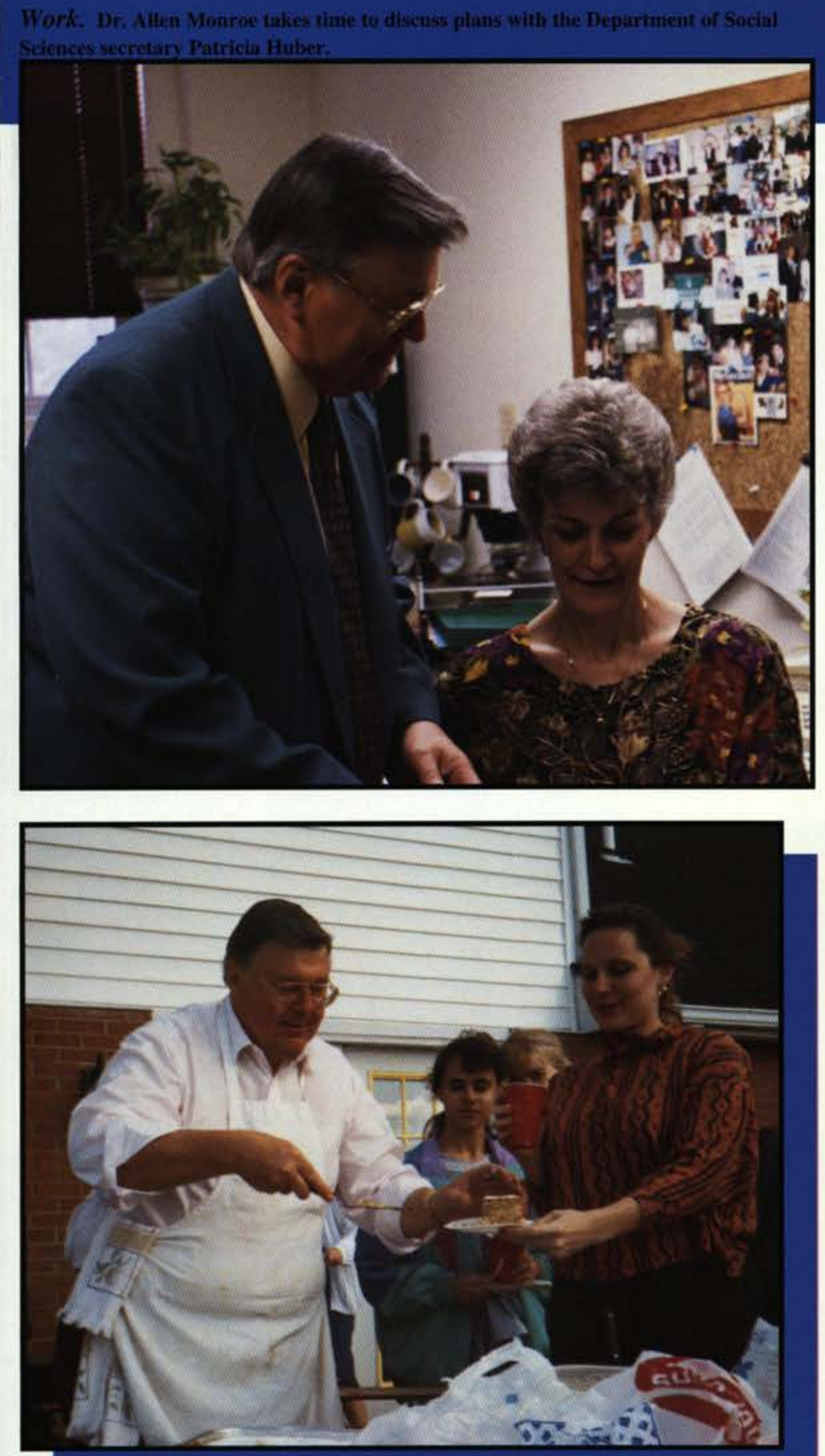

Chef. Dr. Allen Monroe, while hosting a picnic, has a chance to be involved in students' lives on a personal level.
Ministering

to Cedarville

\section{students for}
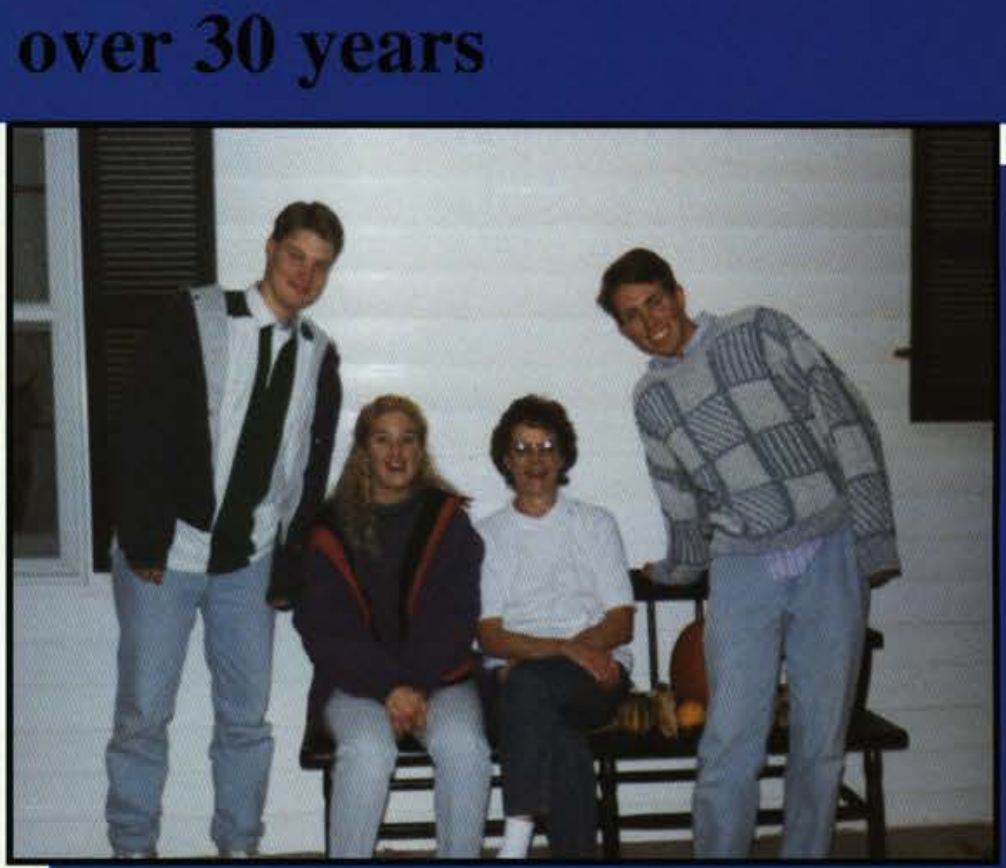

Students. Dr. Beverly Monroe shows genuine interest in student lives when she is surprised and asked to pose for a scavenger hunt picture with Josh Hululko, Heather Comegys, and Bill Droke.

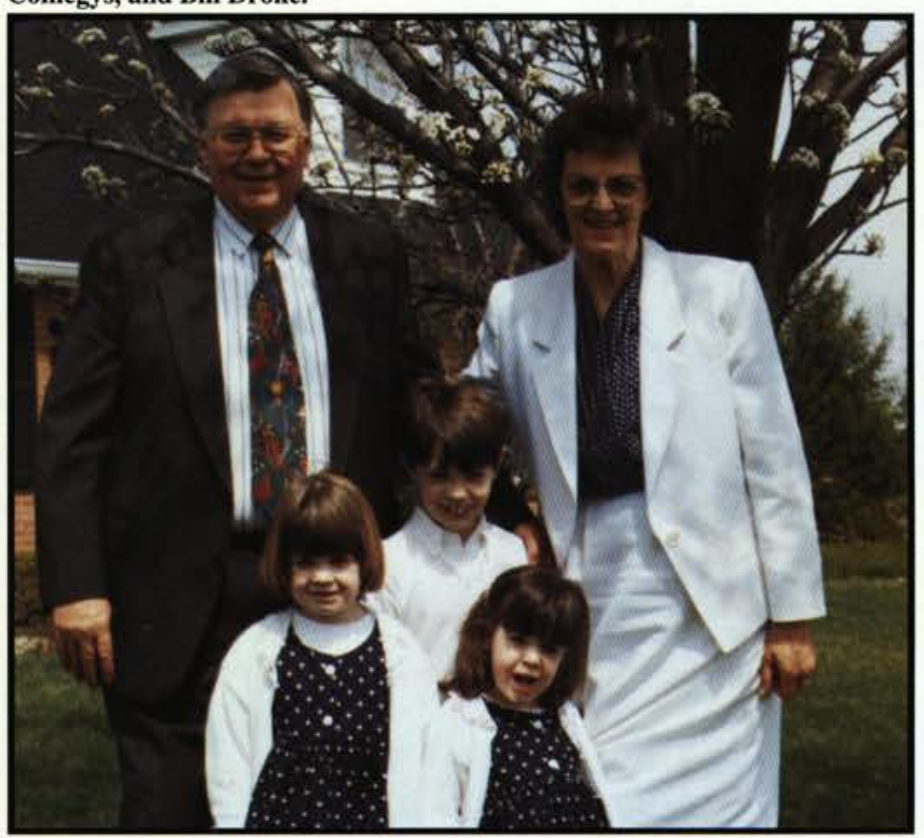

Family. Drs. Monroe treasure each moment they spend with family and especially their three grandchildren, Ryan, Allison, and Caitlyn.

dedication 7 


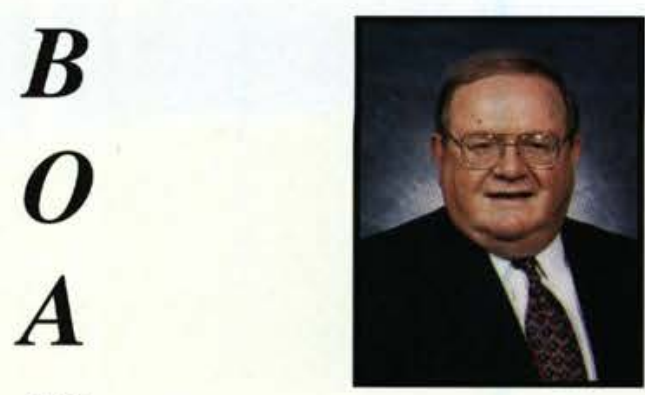

$\boldsymbol{R}$

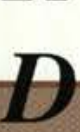

of

1

R

$U$

$S$

T

E

E

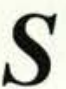

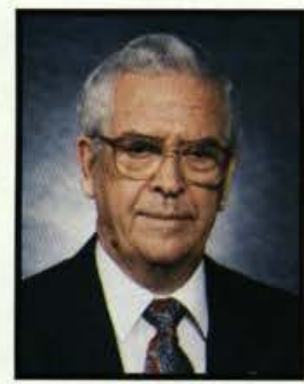

Mr. George O'Bryon

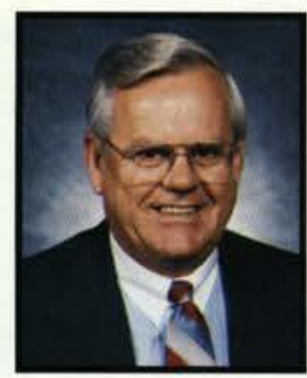

Mr. Albert Stevens
Dr. Eugene Apple

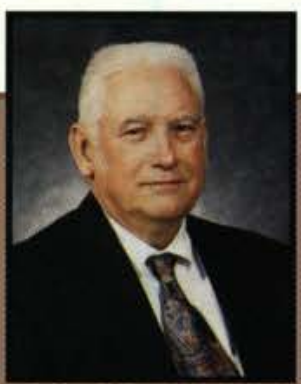

Dr. Jack Cline

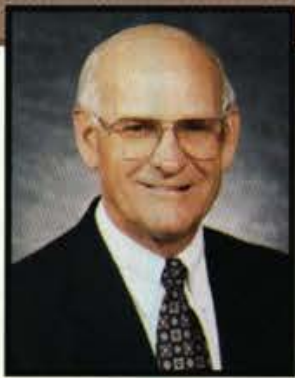

Rev. Joseph Godwin

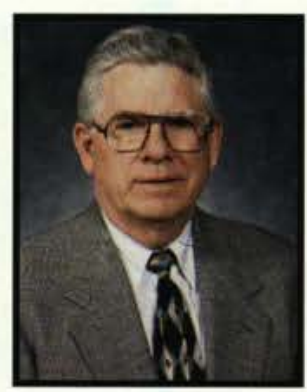

Dr. Jack Jacobs

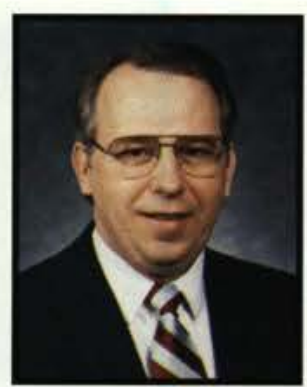

Rev. Randy Patten

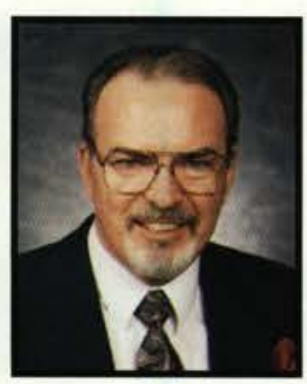

Dr. Paul Tassell

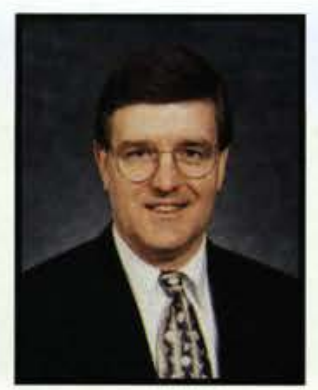

Rev. William Bernhard

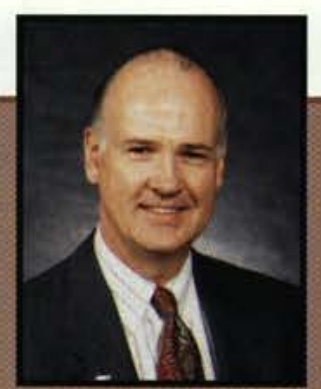

Rev. William Commons

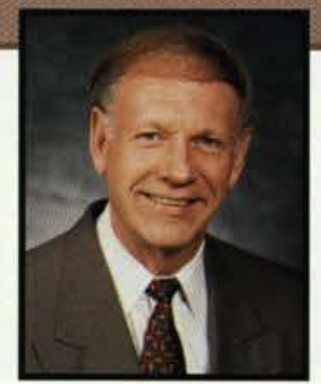

Rev. David Graham

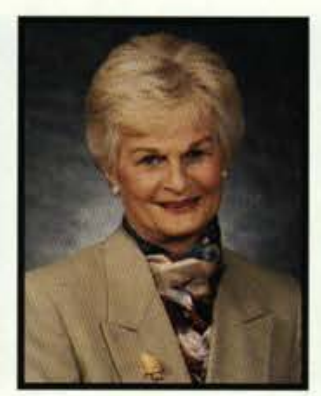

Mrs. Ruth Kempton

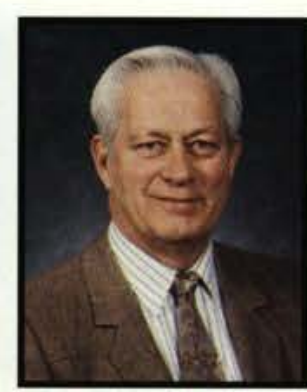

Rev. Lynn Rogers

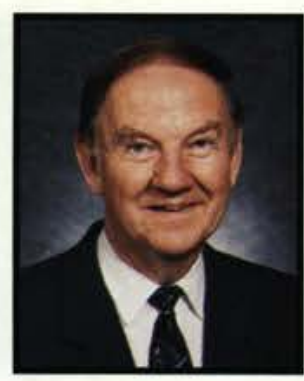

Dr. Donald Tyler

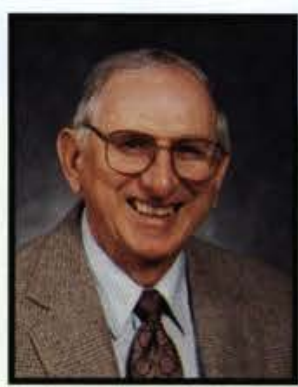

Mr. Francis Bresson

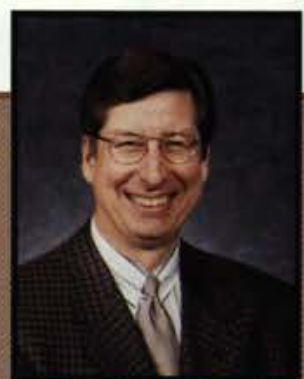

Mr. Daryle Doden

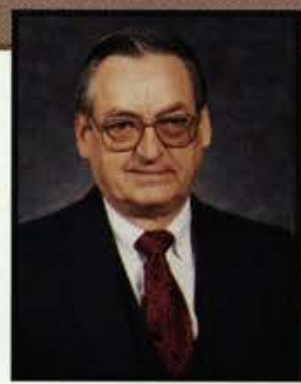

Mr. R. Glenn Guenin

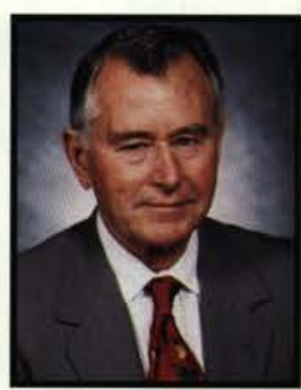

Mr. C. Eugene Miller

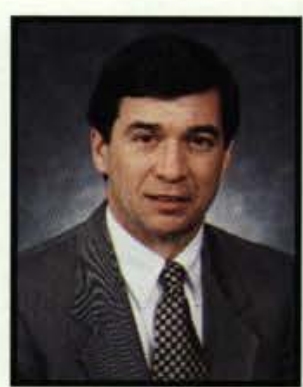

Rev. William Rudd

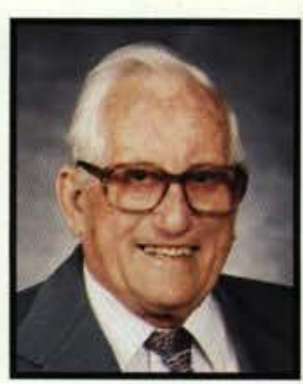

Rev. Earl Umbaugh

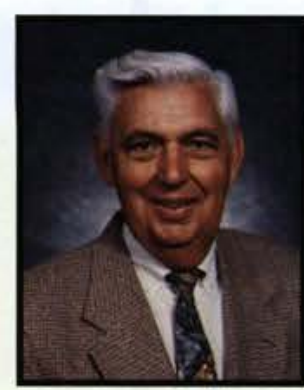

Mr. Gilbert Brueckner

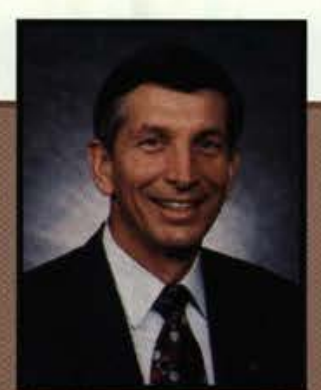

Mr. James Engelmann

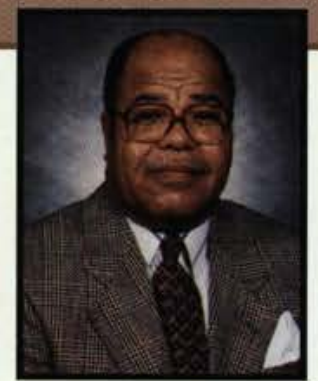

Rev. E. L. Hawkins

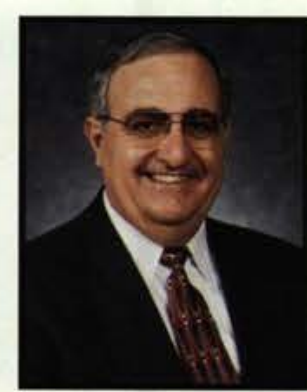

Dr. James Misirian

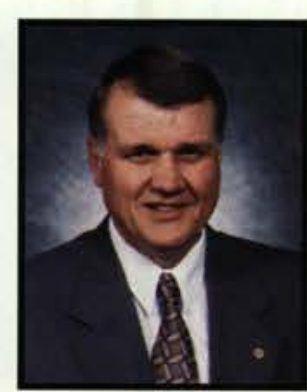

Mr. Lorne Scharnberg

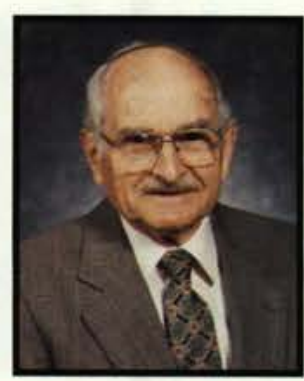

Dr. Paul Vernier

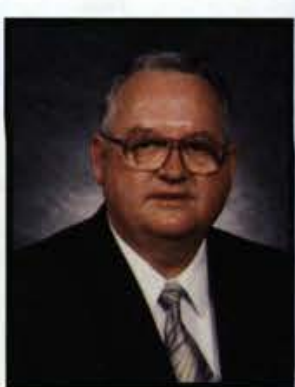

Mr. James Carrahe

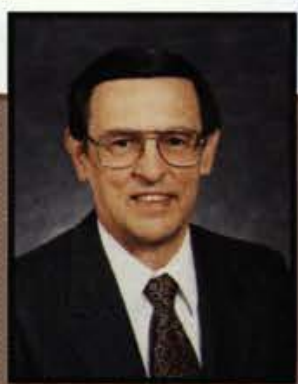

Rev. Larry Fetzer

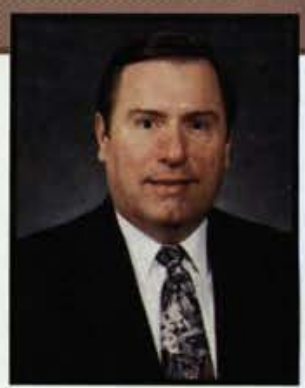

Rev. James Henniger

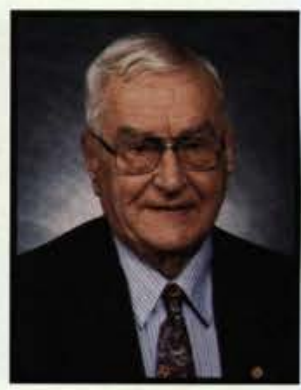

Mr. J. Dale Murphy

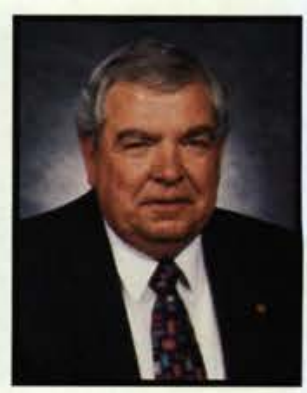

Mr. Bill Smith

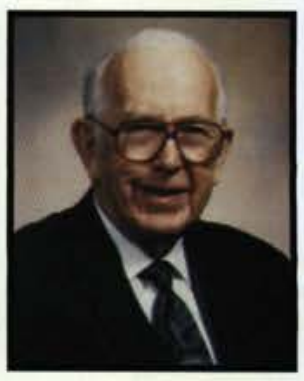

Dr. James T. Jeremiah Chancellor 


\section{Administration}

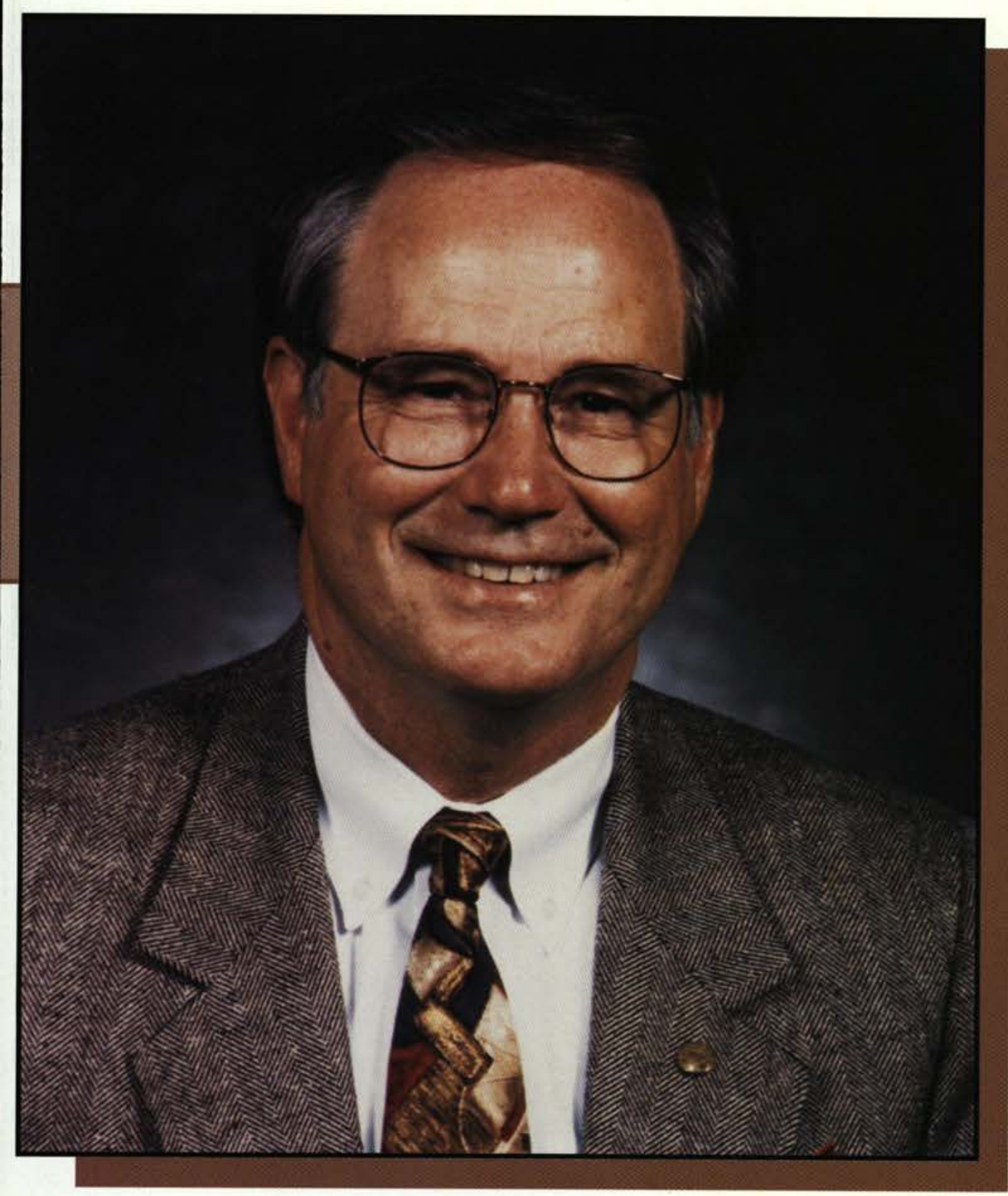

\section{Dr. Paul Dixon}

President

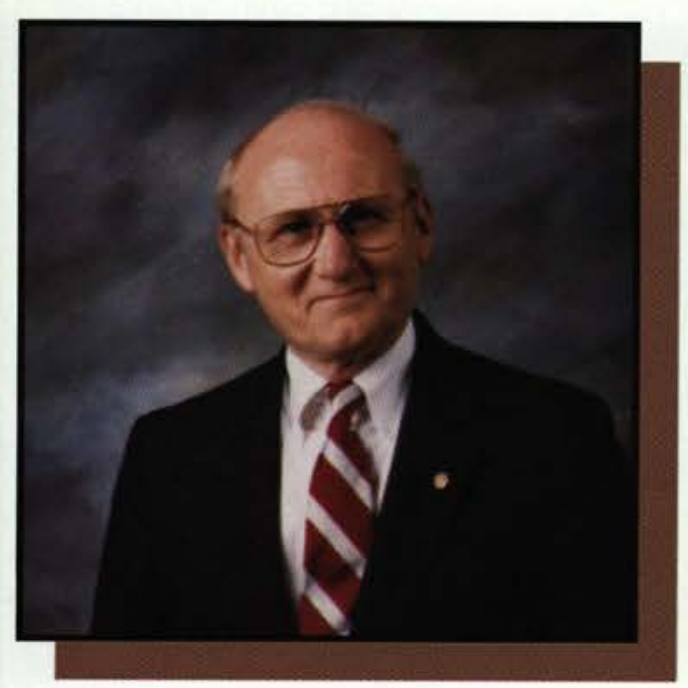

Mr. Donald Rickard

Vice President for Student Services

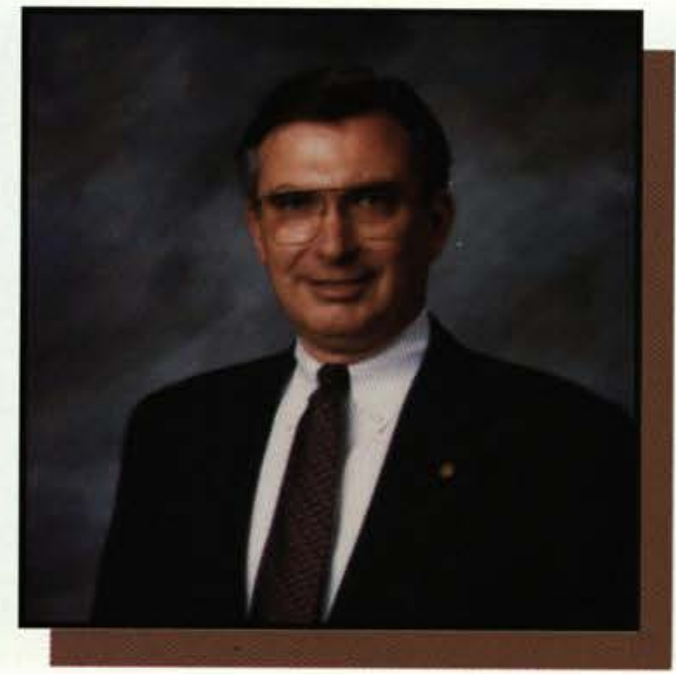

Dr. Martin Clark

Vice President for Development

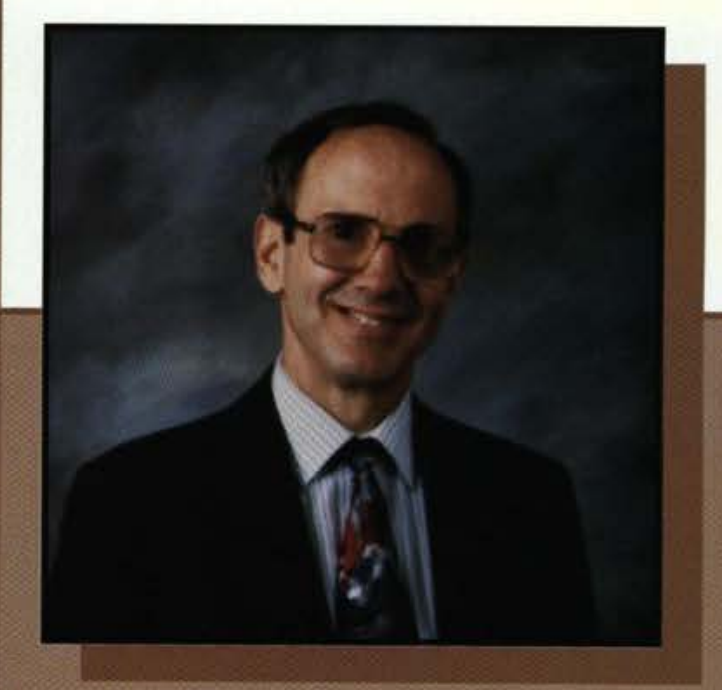

Dr. Duane Wood

Academic Vice President

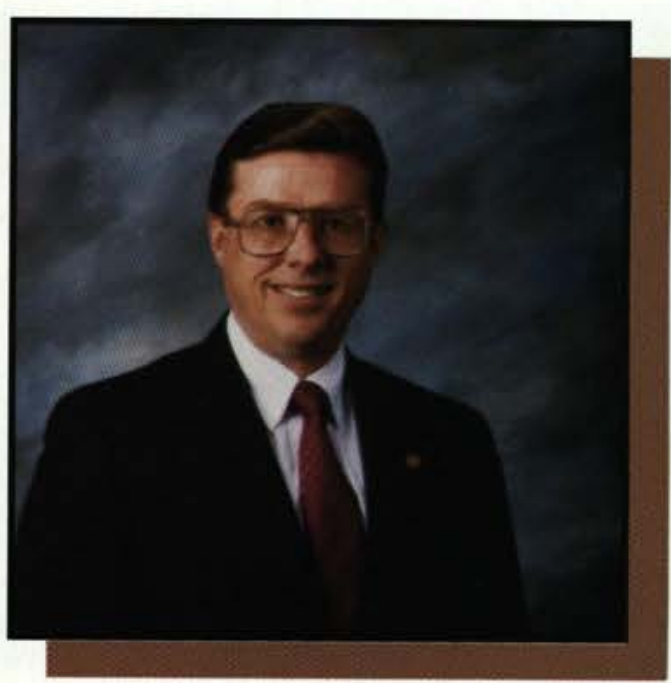

Mr. John Anglea

Vice President for Business

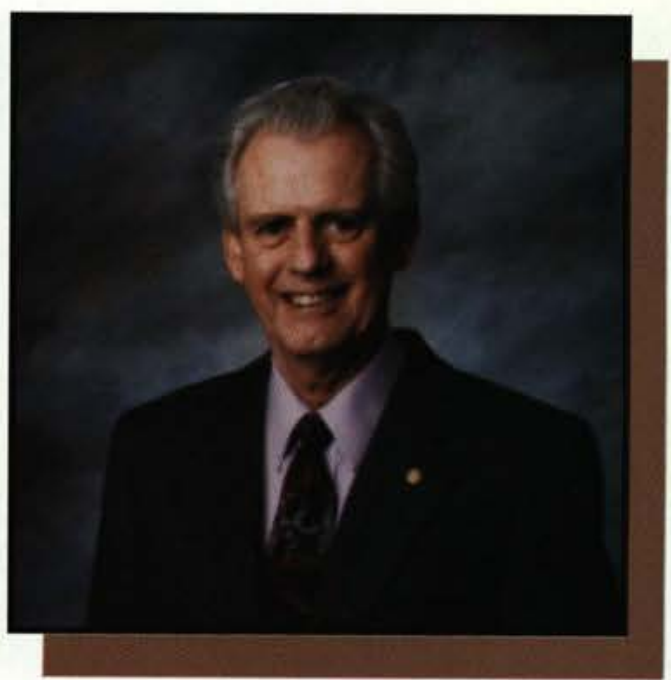

Dr. Harold Green

Vice President for Christian Ministries administration 9 

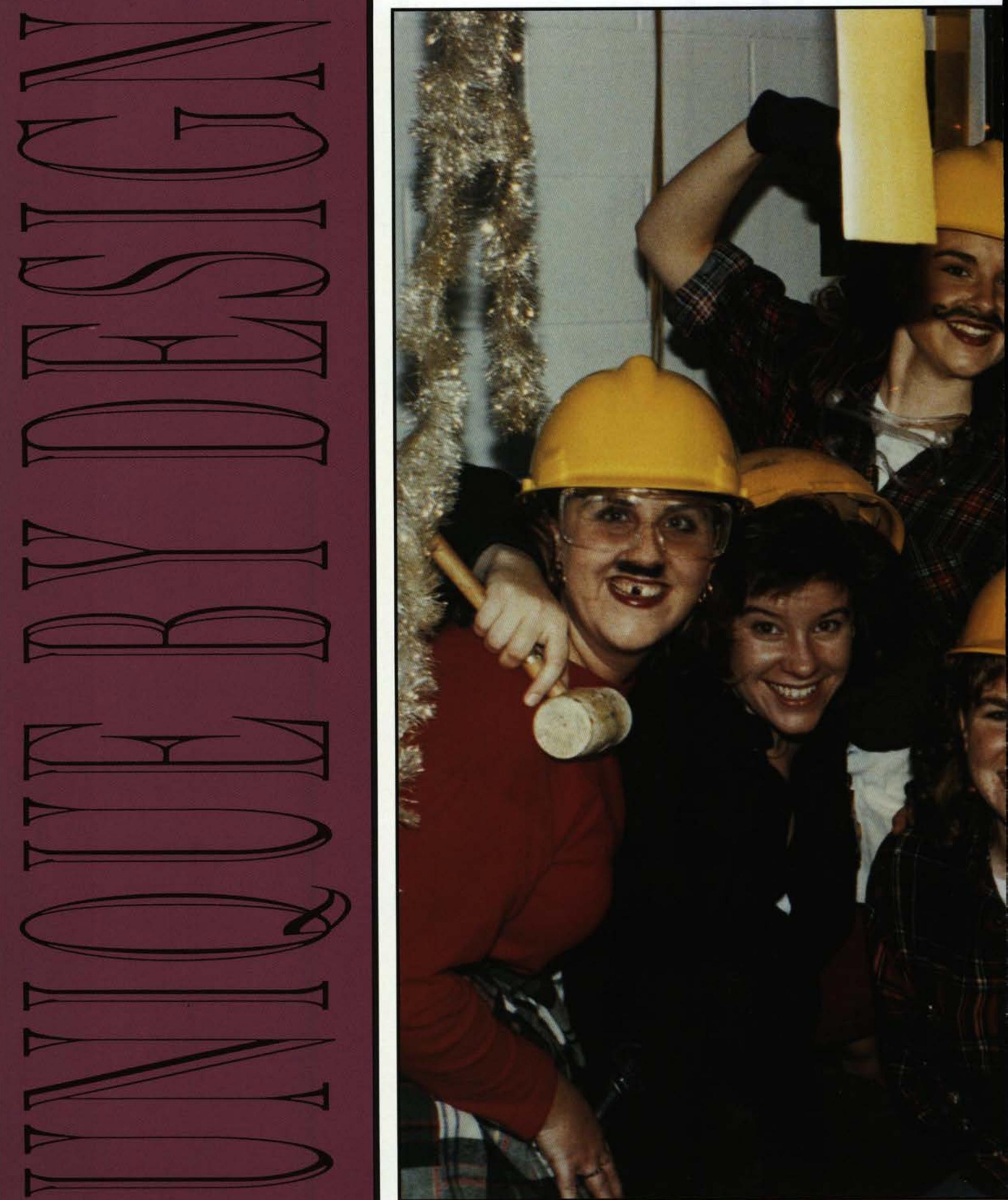


\section{s t u d e n t l i f e}

12 homecoming

18 family days

20 christmas

24 honors day

26 chapel

28 memorial day

30 thursdays live

32 relationships

34 intramurals

36 career day

38 faculty

42 staff

46 freshmen

58 sophomores

70 juniors 


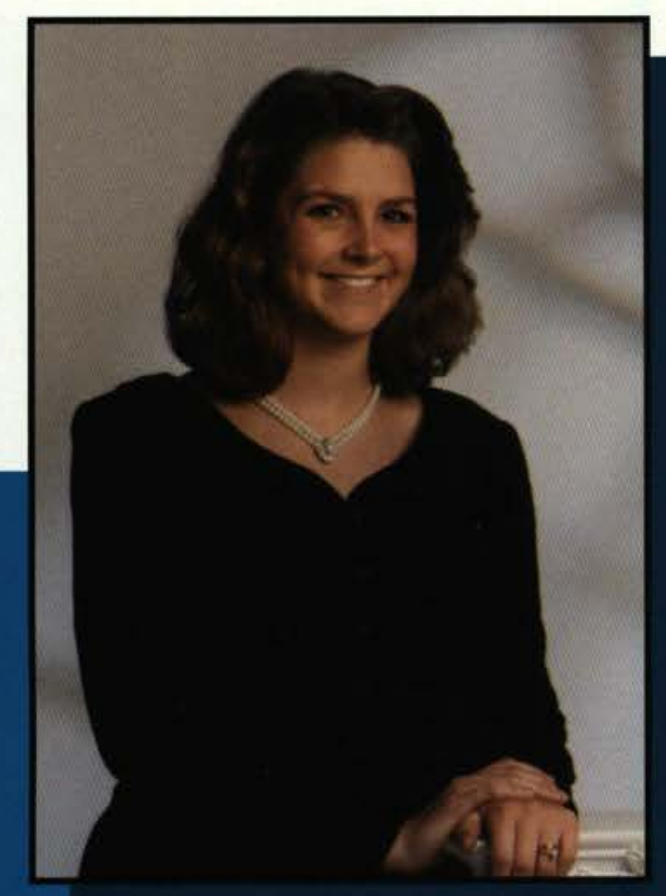

Dacia Borton

Senior Attetidant.

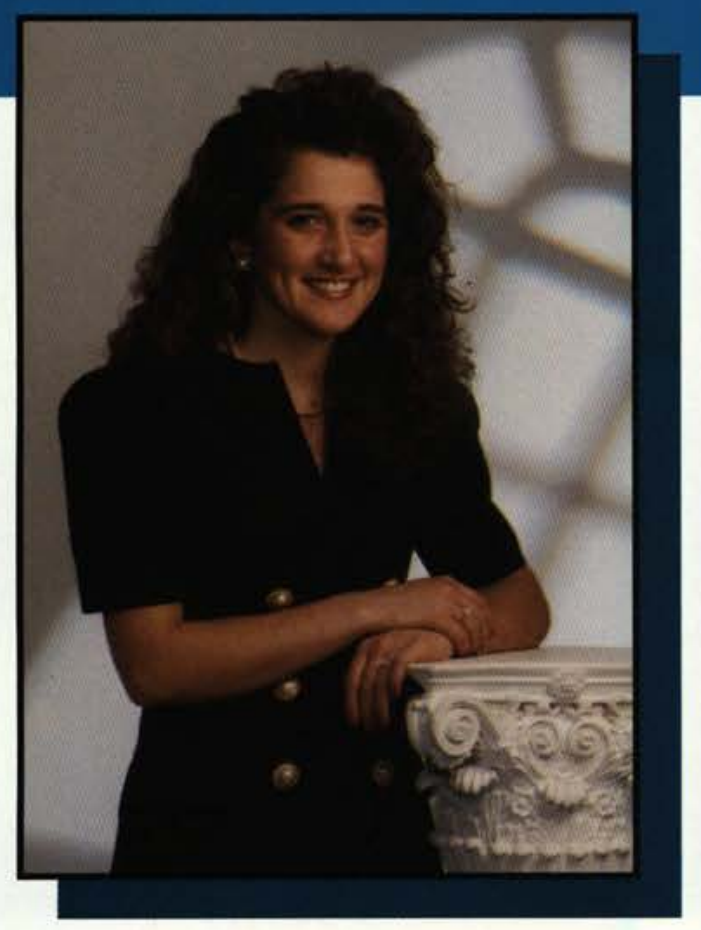

Shelley Fox Senior Attendant

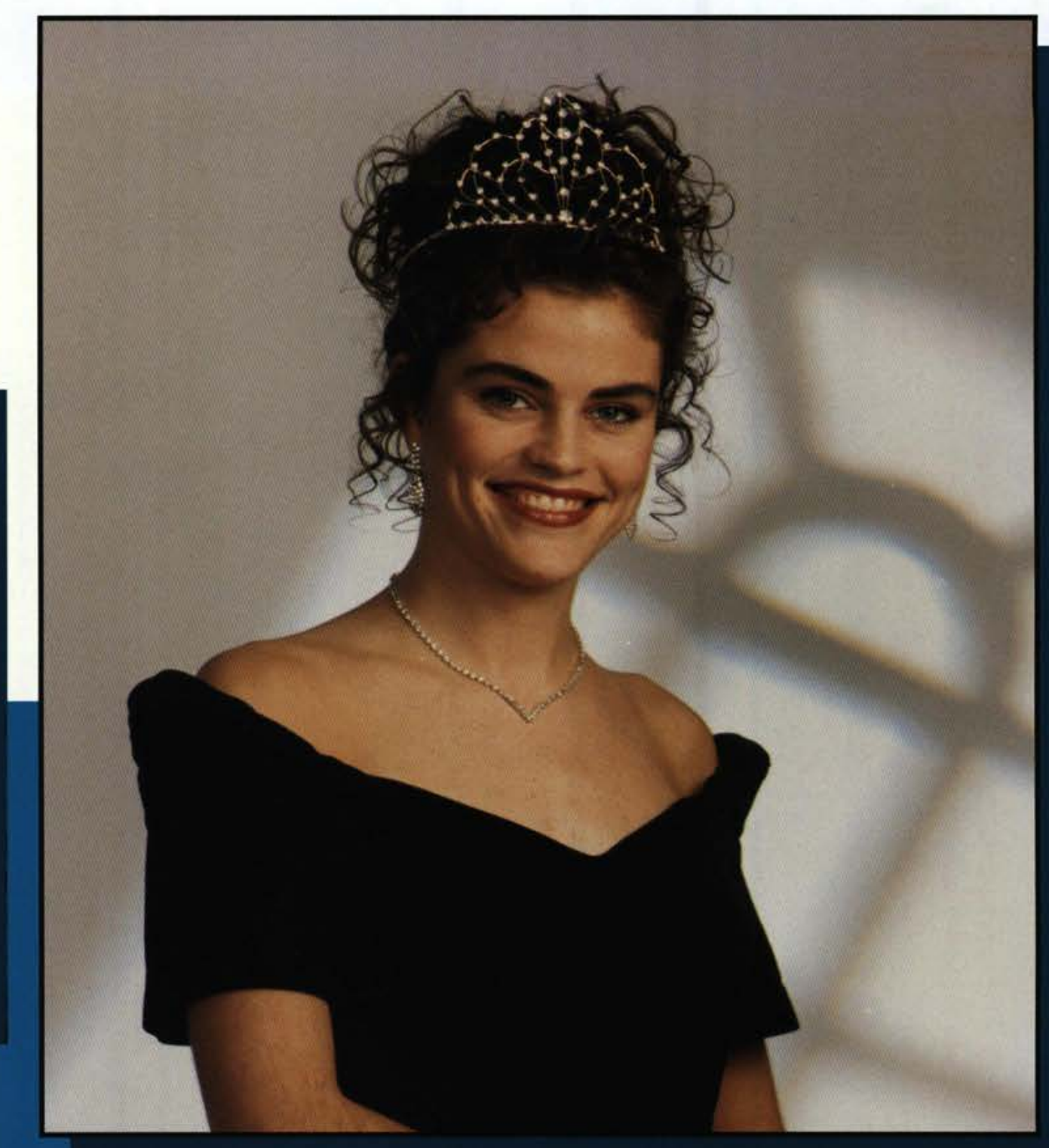

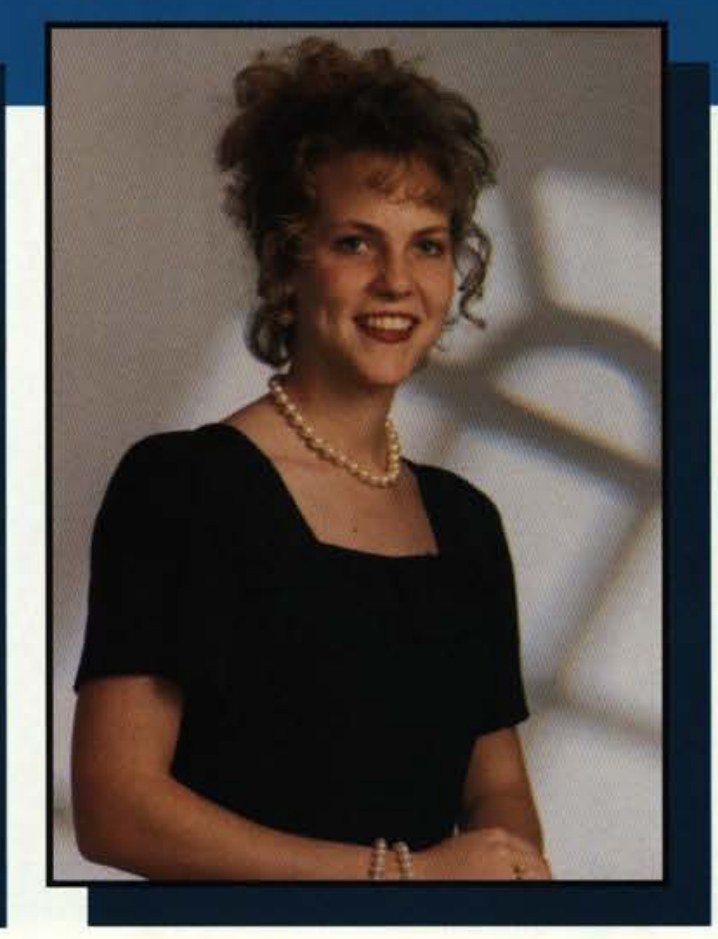

Karyn Hartman Senior Attendant

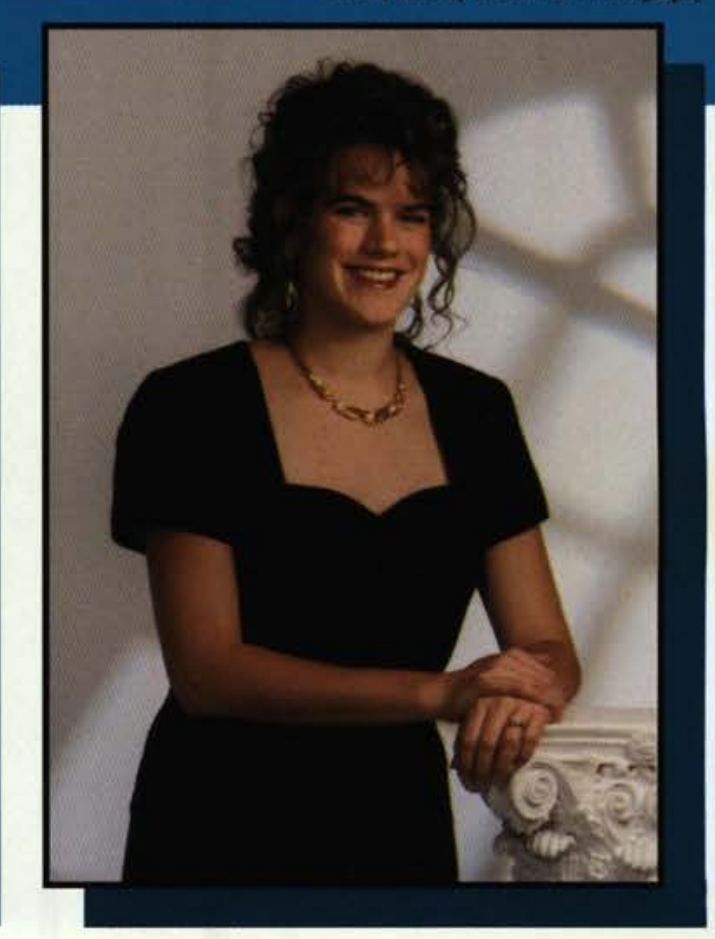

Saraf Kline

Senior Attendant 


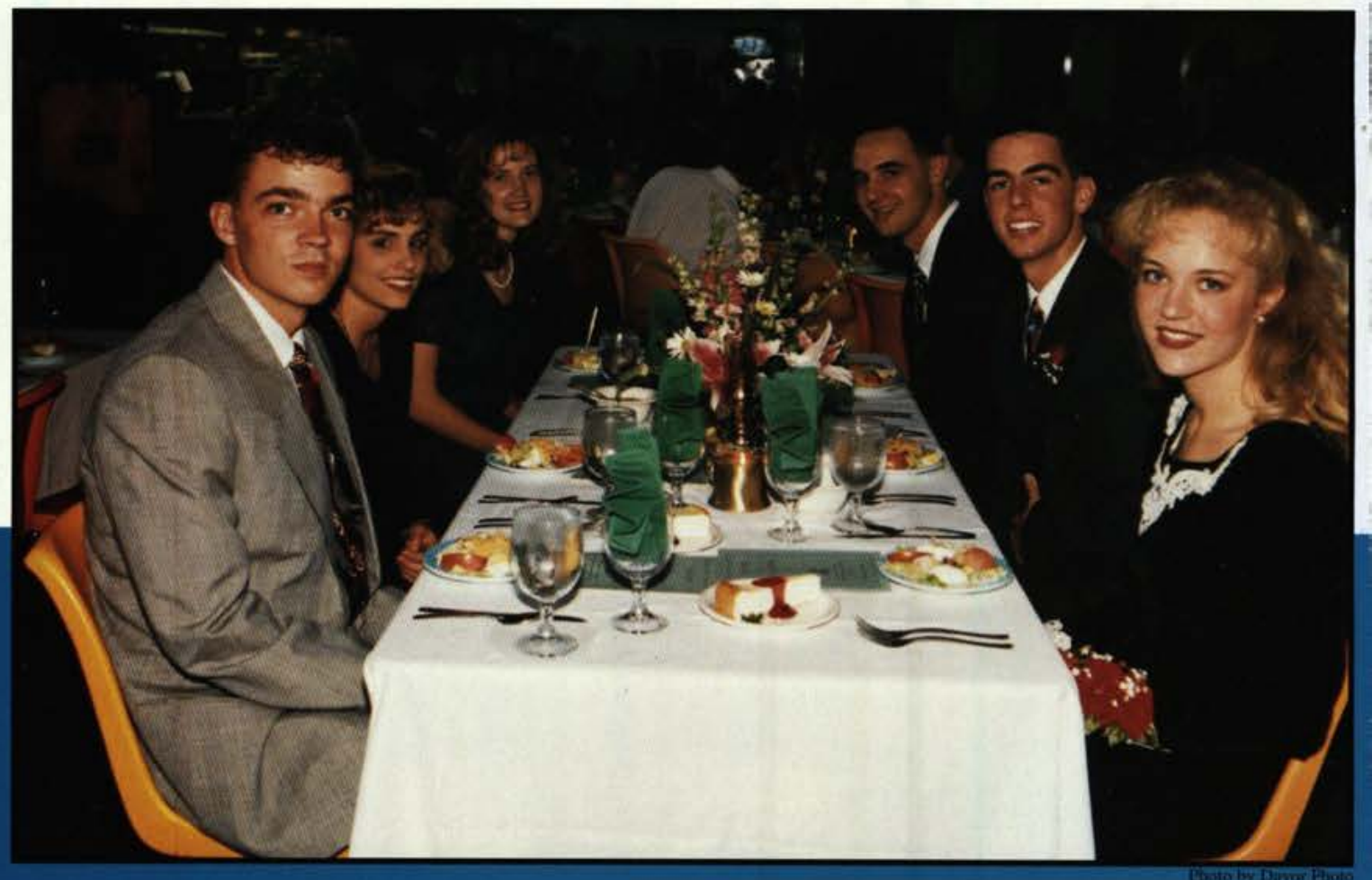

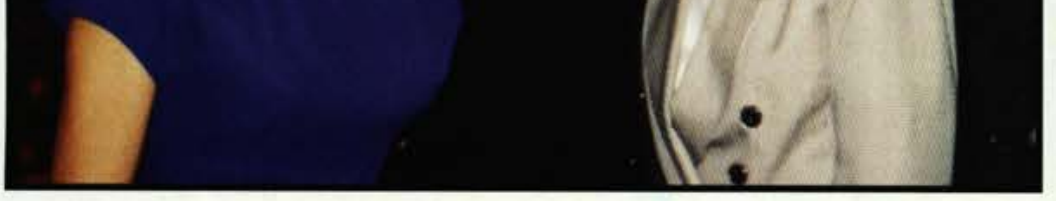

ABOVE: Enjoying the Homecoming atmosphere, Sarah Warnken, Amy Barnes, and Jen Habegger frame their evening smiles for a lasting memory.

RIGHT: Guests Jeff Robey and Jackie Bondorff relax before the banquet.

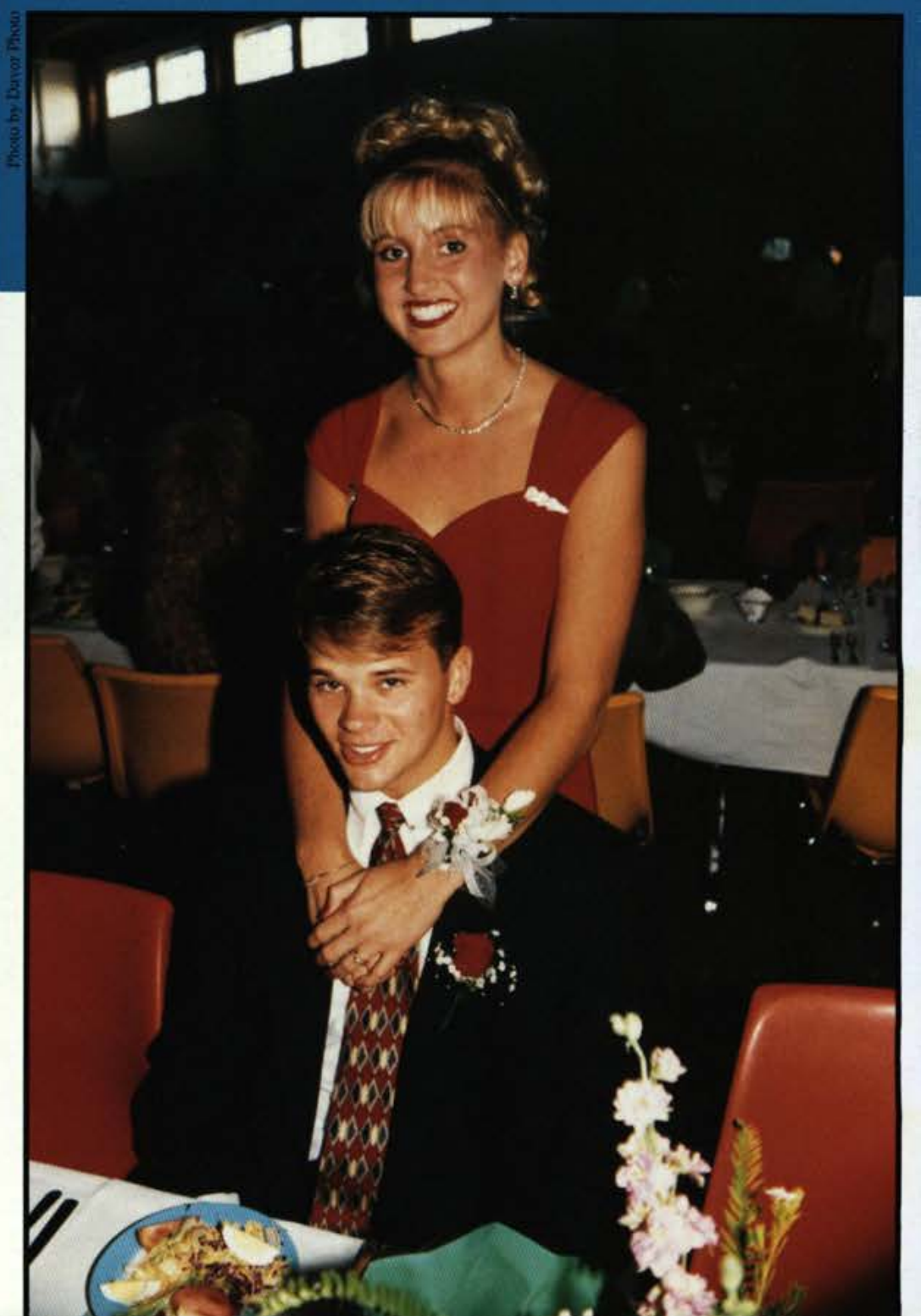




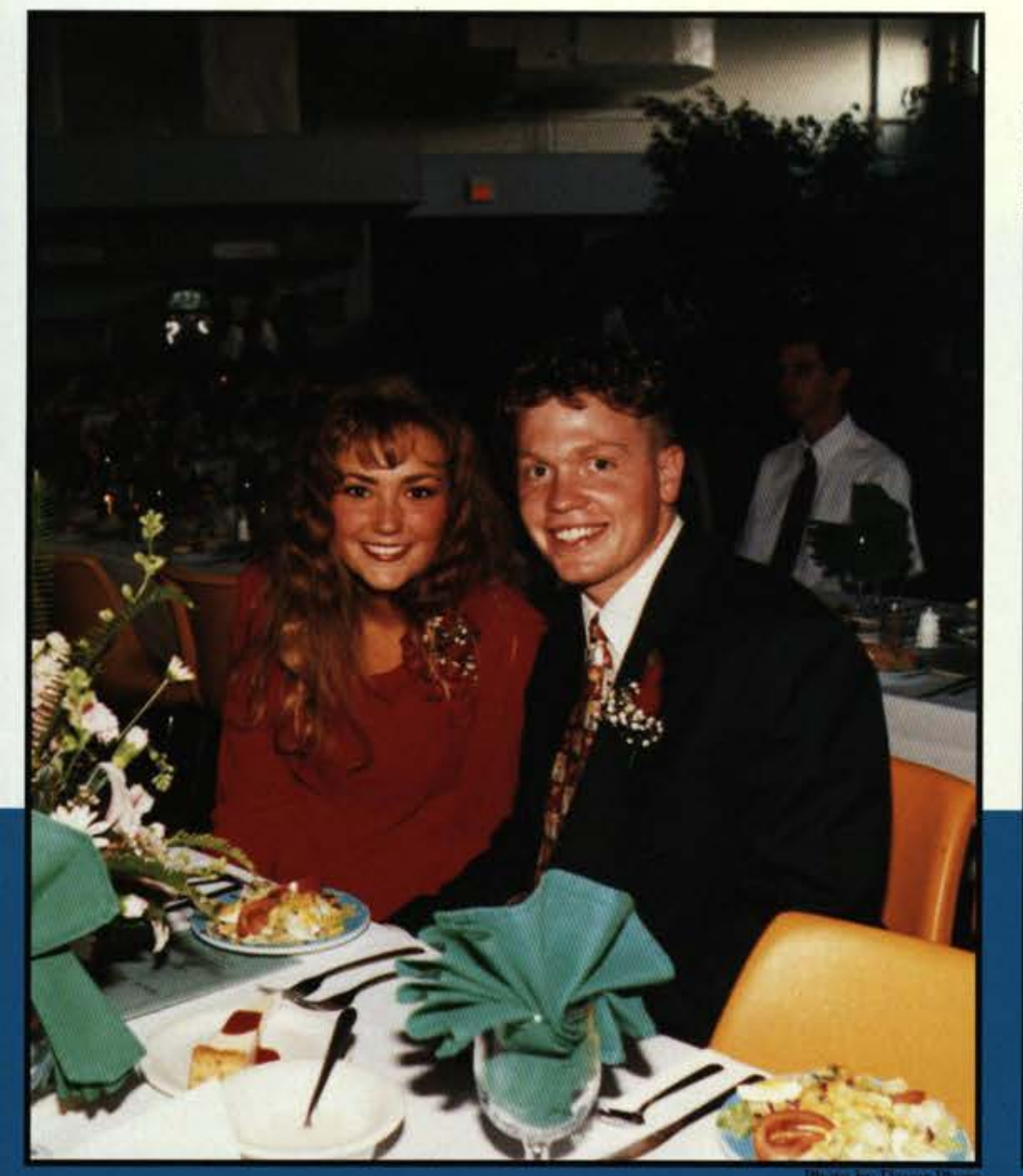

LEFT: Students like Carrie Daniels and Matt Clark look forward to the Homecoming Banquet. BELOW: Larnell Harris brings the entertainment for the evening following the Homecoming Banquet.
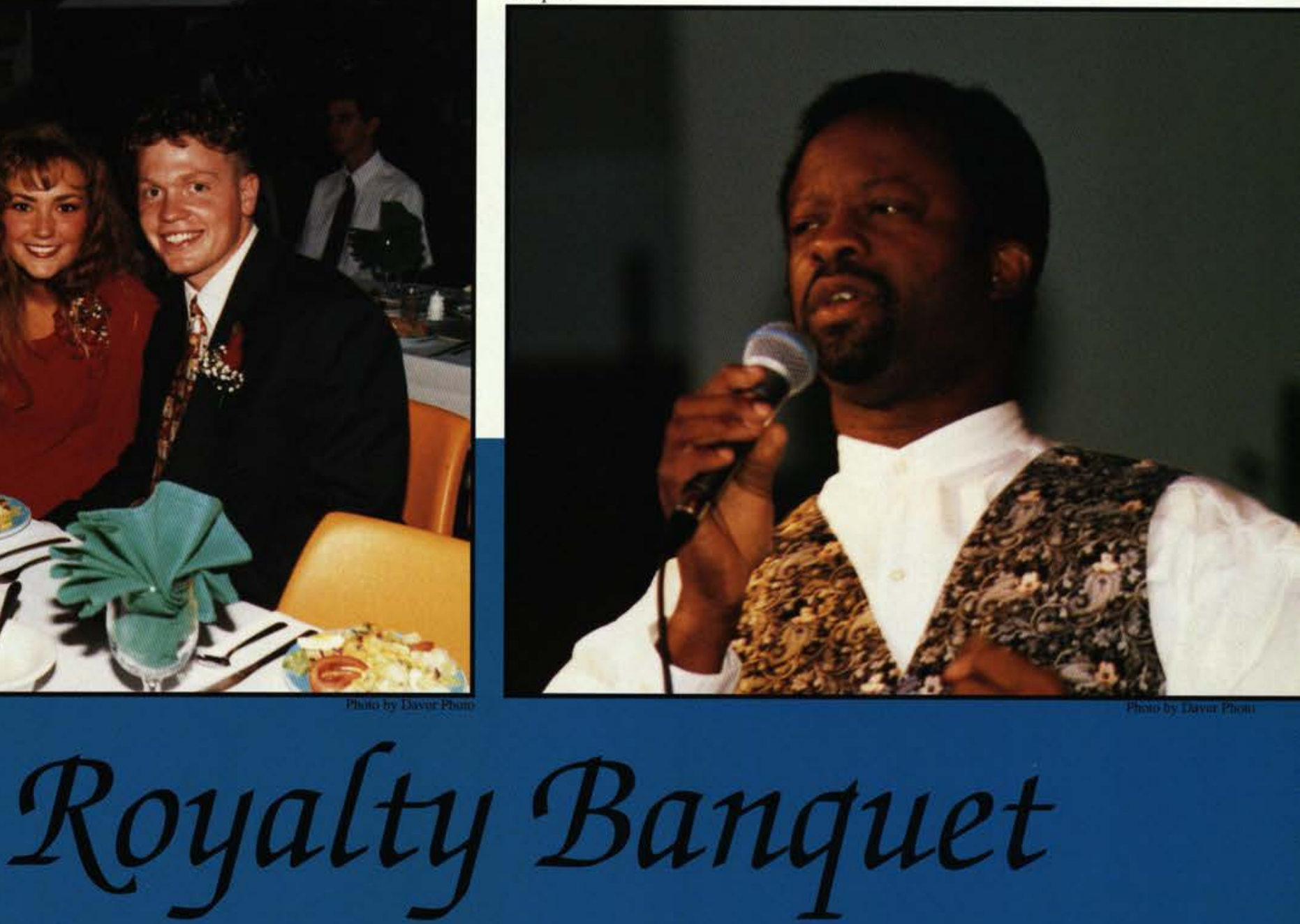

\section{Mysterious Homecoming}

Suspense filled the air as the "Mystery at Greene Manor" began. What started out as an innocent job interview led to crime and eventual murder. The killer viciously plotted fis course so that no one guessed the actions of his deceitful heart. He hid his secret well until his last victim came forth; then she discovered the mystery and escaped from fis deadly grasp. Finally, the "Mystery at Greene Manor" fias been solved.

The final mystery to solve was the crowning of the Homecoming Queen for the '94-'95 school year. The students selected five worthy seniors to represent the class, and $\mathcal{D r}$. and $\mathcal{M} r$ s. Green crowned Amy Barnes queen. After the banquet concluded, Larnelle Harris provided the entertainment and worship for the campus.

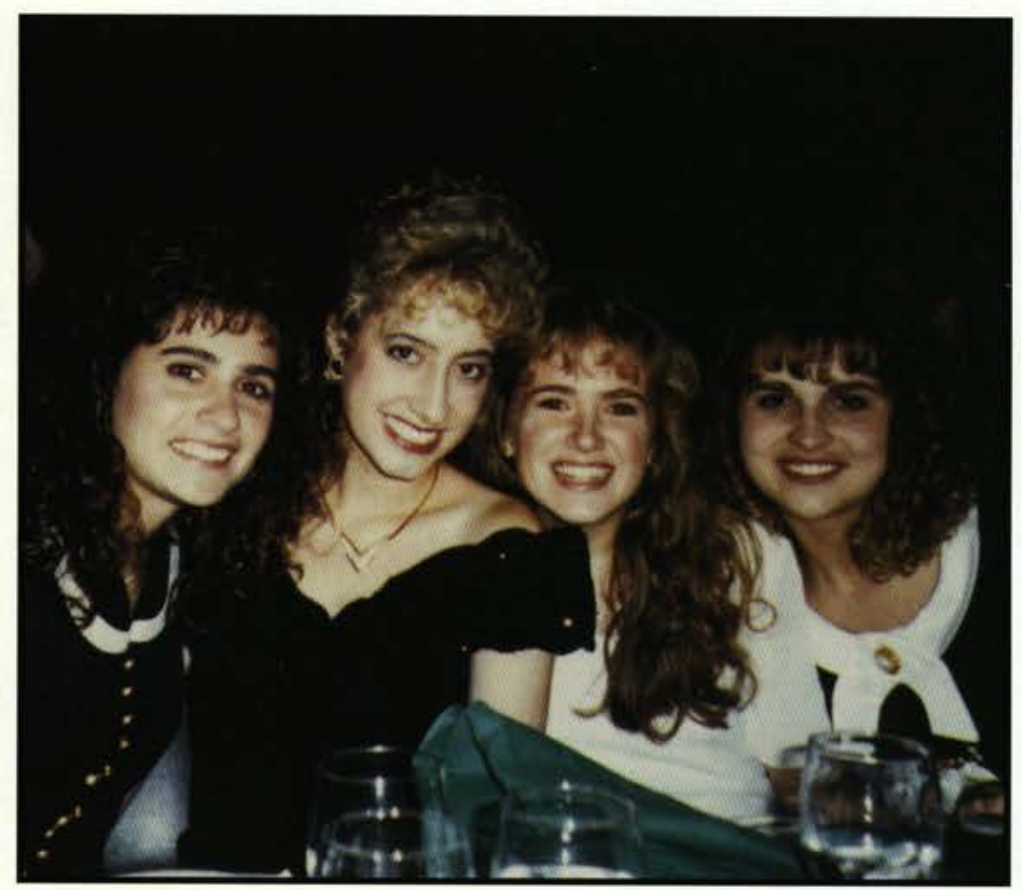

ABOVE: Heather Perry, Lori Scheumann, Colleen Chapin, and Krista Ryan share an eventful evening together. 


\section{A Time to Reminisce}

Homecoming at Cedarville College is an occasion that the current students, faculty, and alumni look forward to with great anticipation. The college family work and plan for weeks, even months, to make this special weekend a success. It is evident that the Administration value the alumni of Cedarville College.

Dr. Dixon kicked off the weekend on Friday morning with the State of the College Address. The alumni spent the remainder of the day attending receptions and other social activities.

With gorgeous weather outside, the college family lined the streets for the annual Homecom- ing Parade. After the parade, the alumni attended a special chapel service in which Dr. Dixon spoke. The afternoon was filled with a variety of activities such as alumni games, alumni auction, and the Homecoming soccer game. Greg Buchanan, a Christian artist and a professional harpist, capped the day's events with a concert.

The Homecoming Weekend's success is accredited to all those who worked hard to make it an unforgettable weekend. The message is clear that alumni are a big part of Cedarville College and the college family will always welcome them back with open arms.

Brenda Kregel
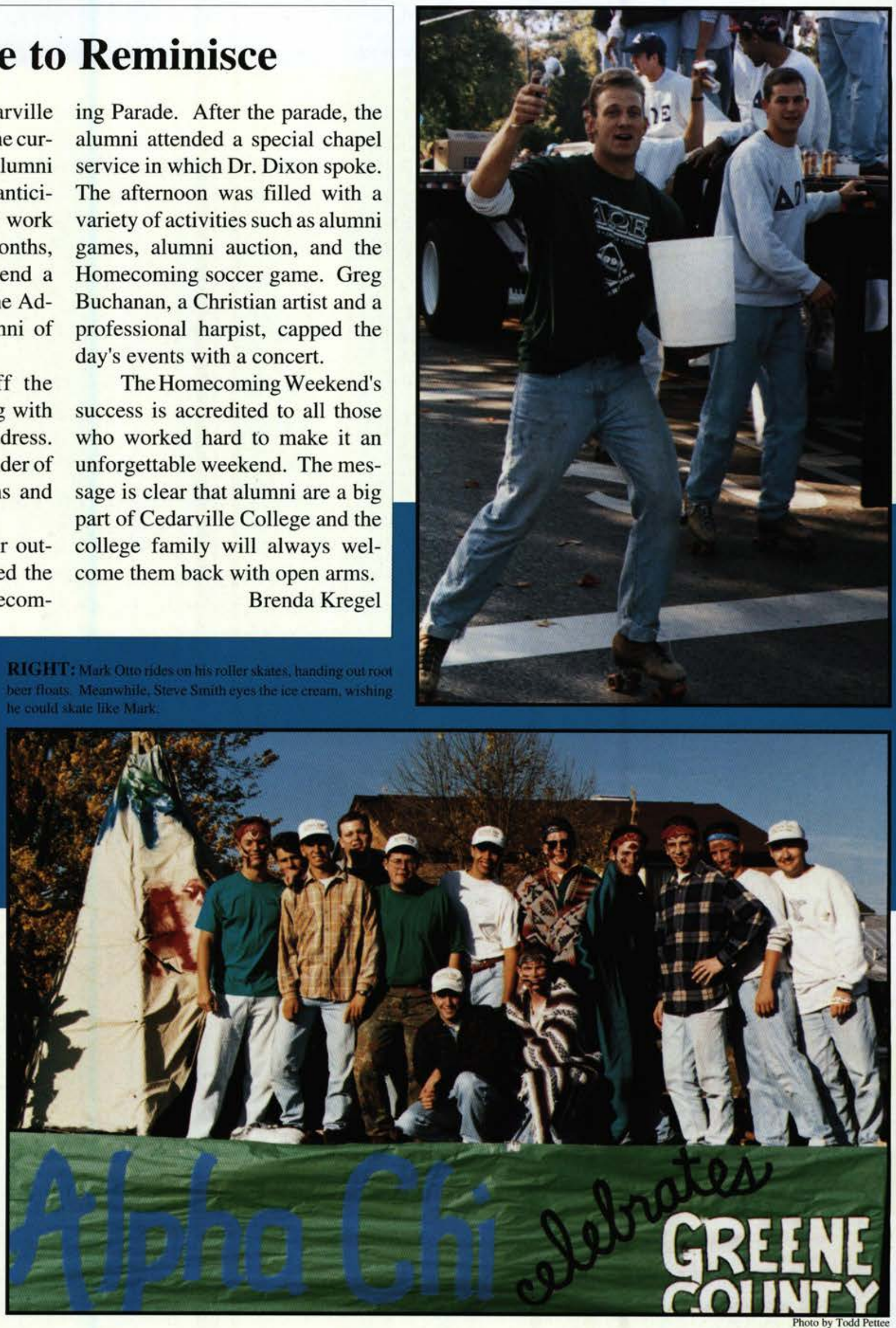

ABOVE: The members of Alpha Chi celebrate Greene County in an Indian style. 


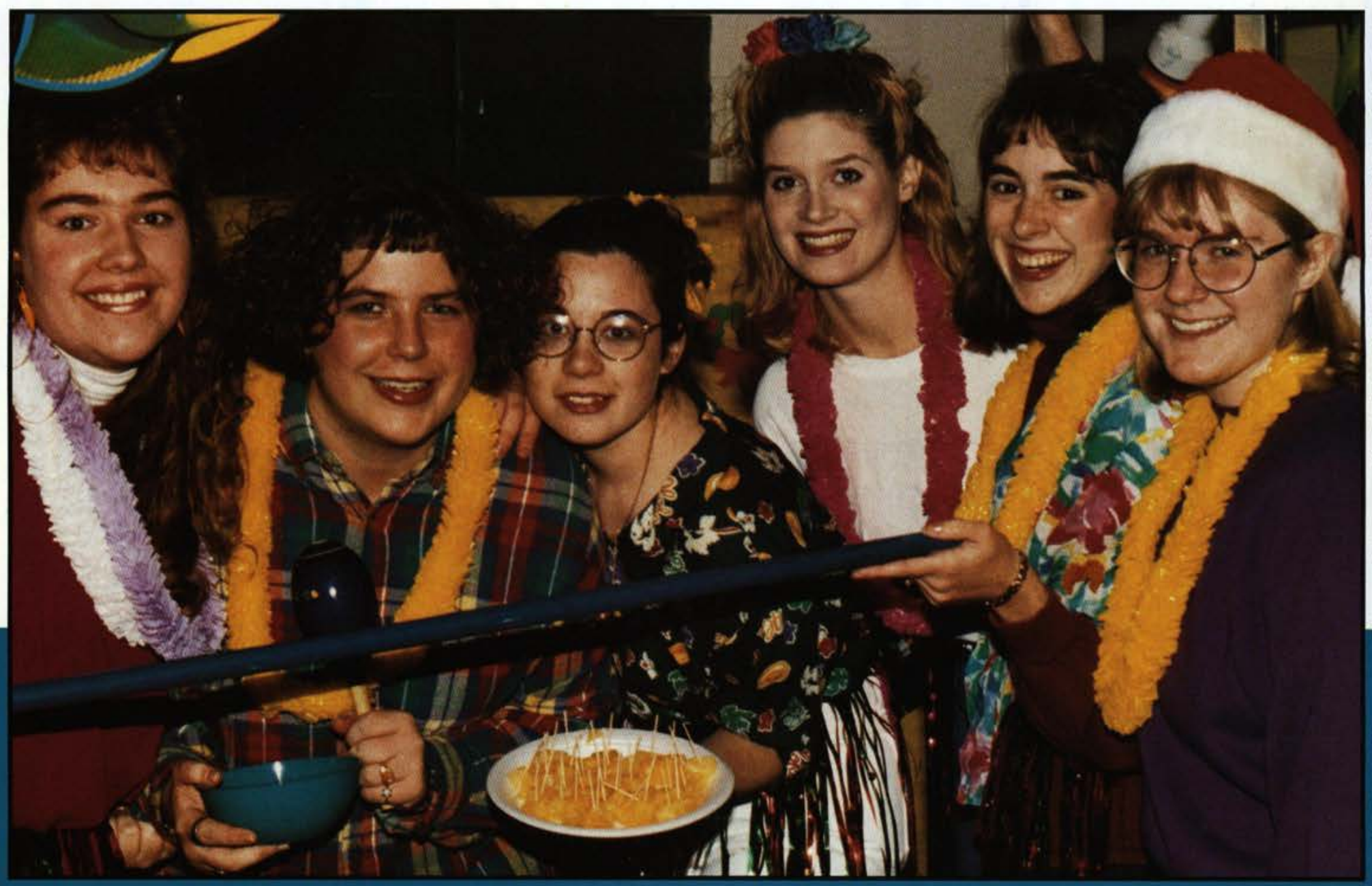

\section{Christmas in the Dorms}

Christmas music, lights, candy, guys and girls visiting each other's dorms, free food. These traditions are all annual features which signify the arrival of Open House. Every year, each hall or unit decorates, hoping to win the contest.

The dorms transform into department stores, Christmas in the Cities, the Love Boat complete with a captain and a band, the Rednecks, the Willett's Memorial including doctors and patients, the Maternity Ward, and other creative themes. Judges choose the halls or units with the best and most creative themes and reward them with a free dinner at The Olive Garden.

The entire evening promises fun because students get to take study breaks, spend time with friends, celebrate the Christmas spirit, and enjoy a free picture with Dr. Dixon.

Lynda Gavitt

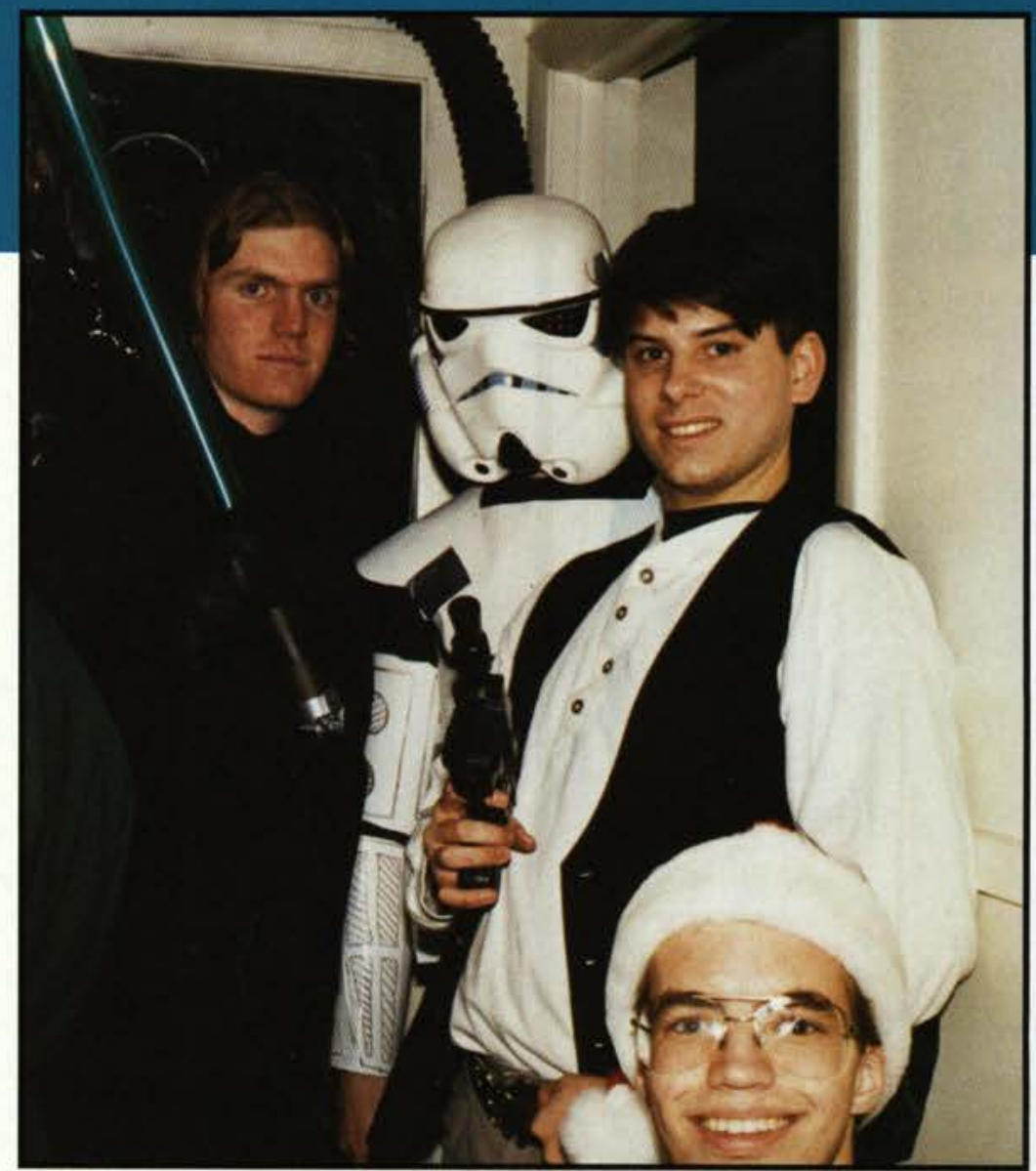

ABOVE: Getting lost en route to China from the North Pole, Santa Claus decided to visit the Jedi to make sure they were having a peaceful Christmas. 

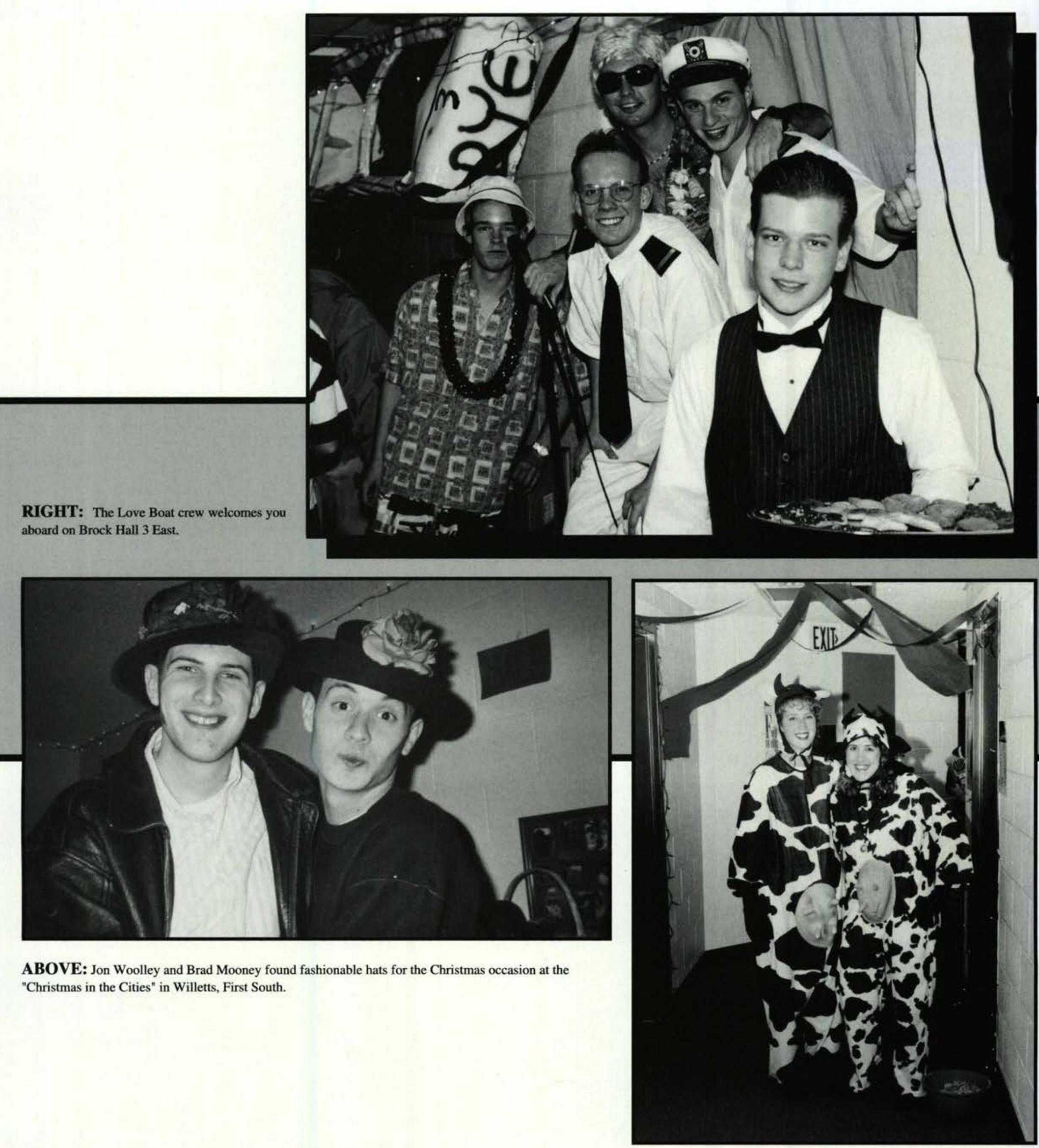

ABOVE: Jon Woolley and Brad Mooney found fashionable hats for the Christmas occasion at the "Christmas in the Cities" in Willetts, First South.

ABOVE: Thinking the grass is greener on the other side, the cow sisters, Janeen Whitney and Rebecca Wright, jumped the fence and wandered into Willetts Hall. They were devastated when they found out that the grass is not greener on the other side. Worse yet, there is no grass at all! 


\section{Honors' Day}

On May 5, 1995, Cedarville College celebrated its 31st annual Academic Honors Day chapel. Purposefully scheduled to coincide with Parents' Weekend, Honors' Day was held in the James T. Jeremiah Chapel to recognize outstanding scholarship among the student body. After a musical prelude and processional from the brass choir, Dr. Dixon opened the ceremony with prayer. Academic Vice President, Duane Wood, followed with a recognition of graduates finishing with honor. Commendation for achieving a grade point average of 3.50 or higher was given to $104 \mathrm{se}-$ niors. The main program consisted of the presentation of awards with individual departments recognizing academic excellence in each major. The Alumni Scholarship was awarded to an outstanding freshman, sophomore, or junior student enrolled in each academic department. Other awards were given in each respective field to acknowledge exceptional scholarship and character.

The service was also used to announce the Faculty and Staff Member of the Year. Faculty Member of the Year was conferred on Dr. Daniel Estes, an associate professor of Bible. Dr. Estes, who also serves as the Assistant Academic Vice President, has proved to be an excellent teacher of God's Word in the classroom. In addition, he has been active in the ministry and in writing. Staff Member of the Year was bestowed on Sherry Coy, who currently serves as the textbook manager in the bookstore. Mrs. Coy formerly worked as secretary for Don Rickard and has had a consistent ministry of encouragement to missionaries and students during her years at Cedarville College.

Todd Entner
Below: Dr. J. Murray Murdoch presents Phillip Snyder with the Edmund Burke Award.
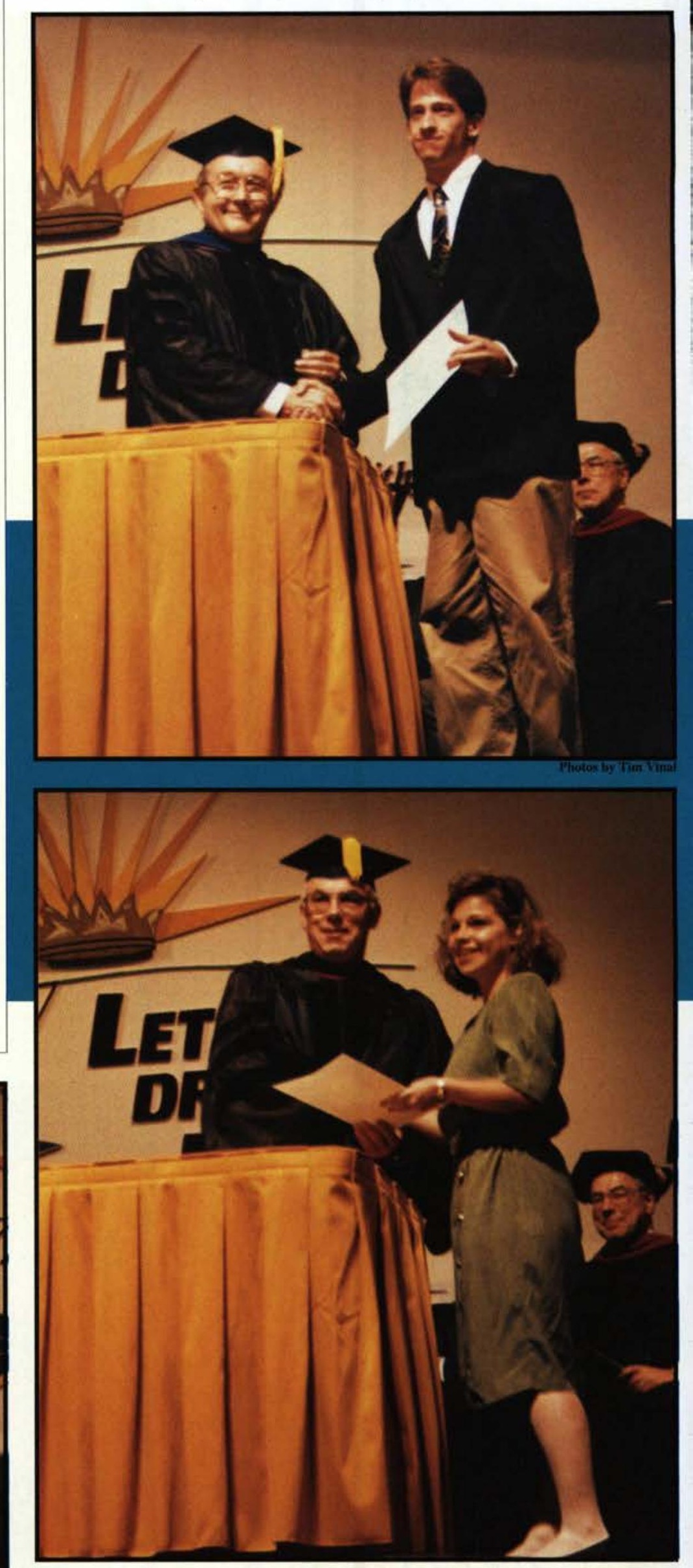

ABOVE: Jennifer Reed receives The CRC Press Chemistry Award from Dr. Daniel Wetzel.

LEFT: The SGA Award was presented to Samuel Olson by Bowe Hoy, the student body President. 

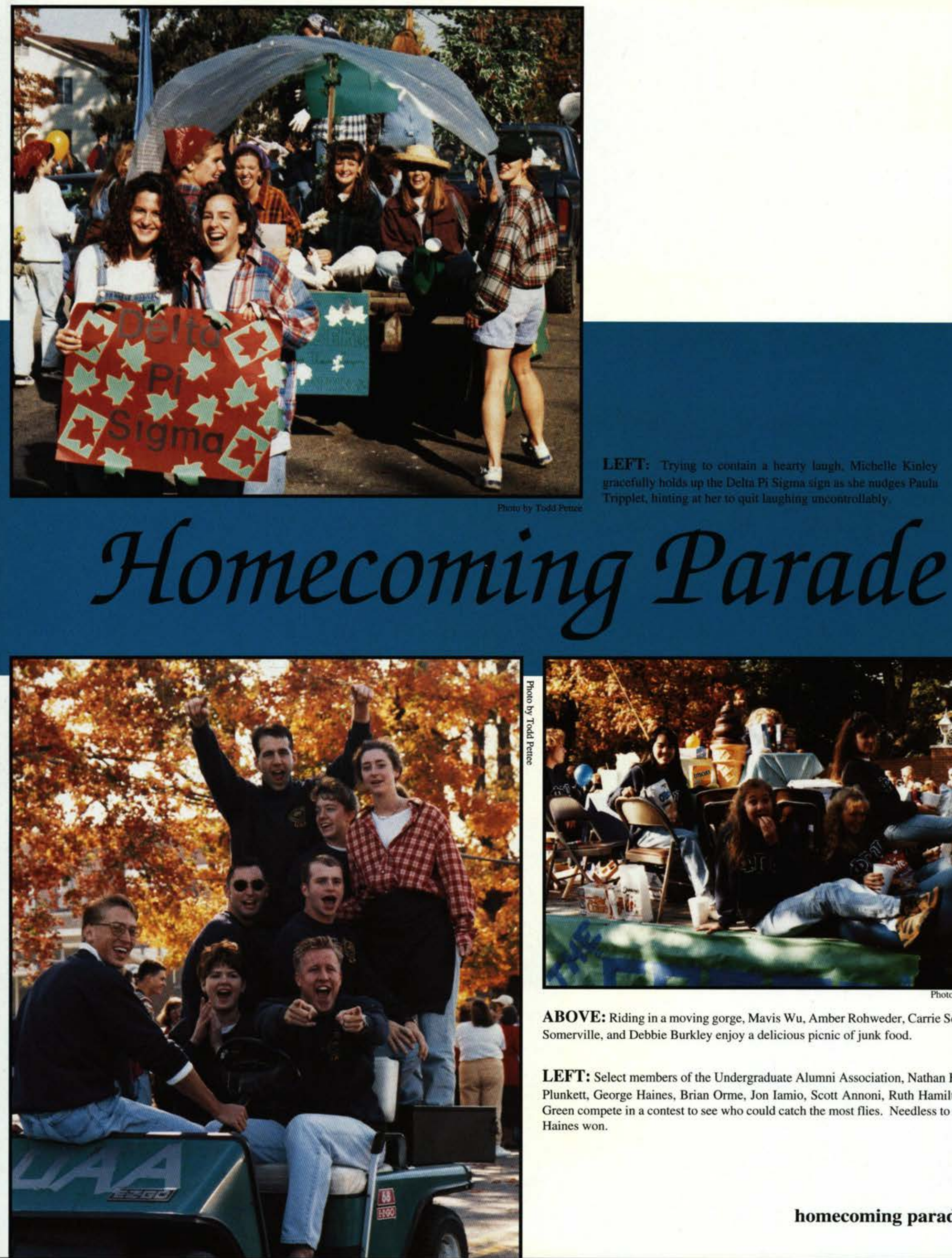

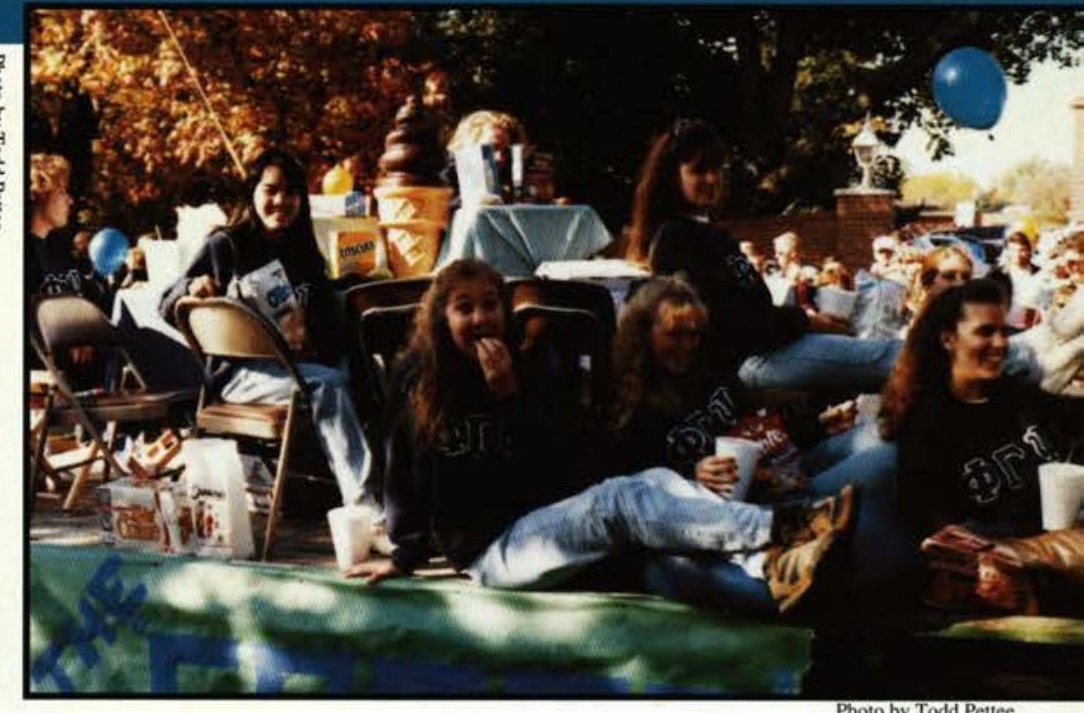

ABOVE: Riding in a moving gorge, Mavis Wu, Amber Rohweder, Carrie Scott, Cherith Somerville, and Debbie Burkley enjoy a delicious picnic of junk food.

LEFT: Select members of the Undergraduate Alumni Association, Nathan Beitler, Julie Plunkett, George Haines, Brian Orme, Jon Iamio, Scott Annoni, Ruth Hamilton, and Jen Green compete in a contest to see who could catch the most flies. Needless to say, George Haines won. 


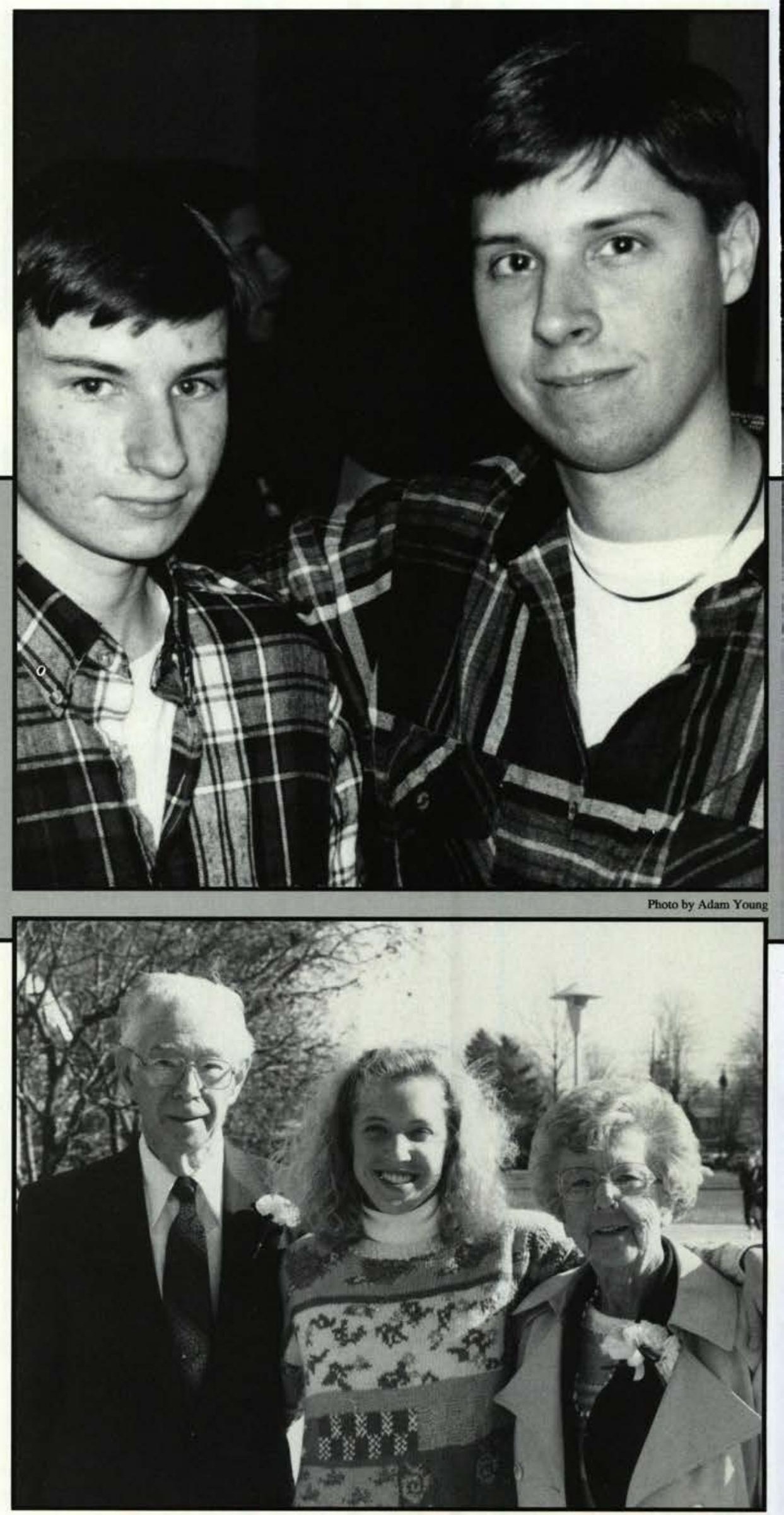

ABOVE: Heidi Bossley and her mother spend quality time together on Parents' Weekend in May.

RIGHT: Grandparents' Weekend is a special opportunity for many to share a special time with important people in our lives. Marianne Palmer and her grandparents. 


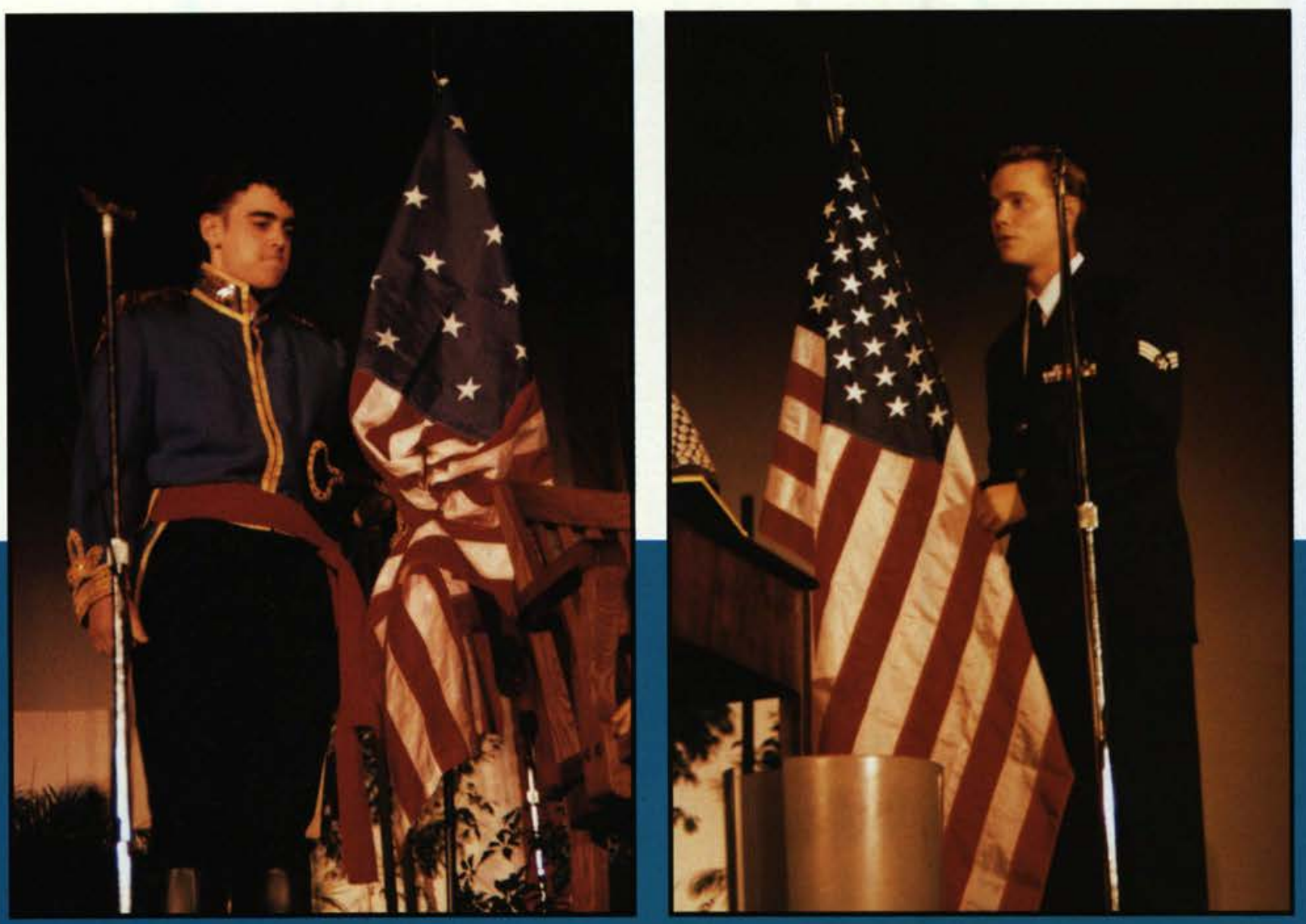

RIGHT: Charlie Dean, Chris Vitarelli, Gregory Dimler, Eric Sorensen, and Tim Crowler gave a drama presentation on the development of the American flag and the lives given for the freedom for which it stands.

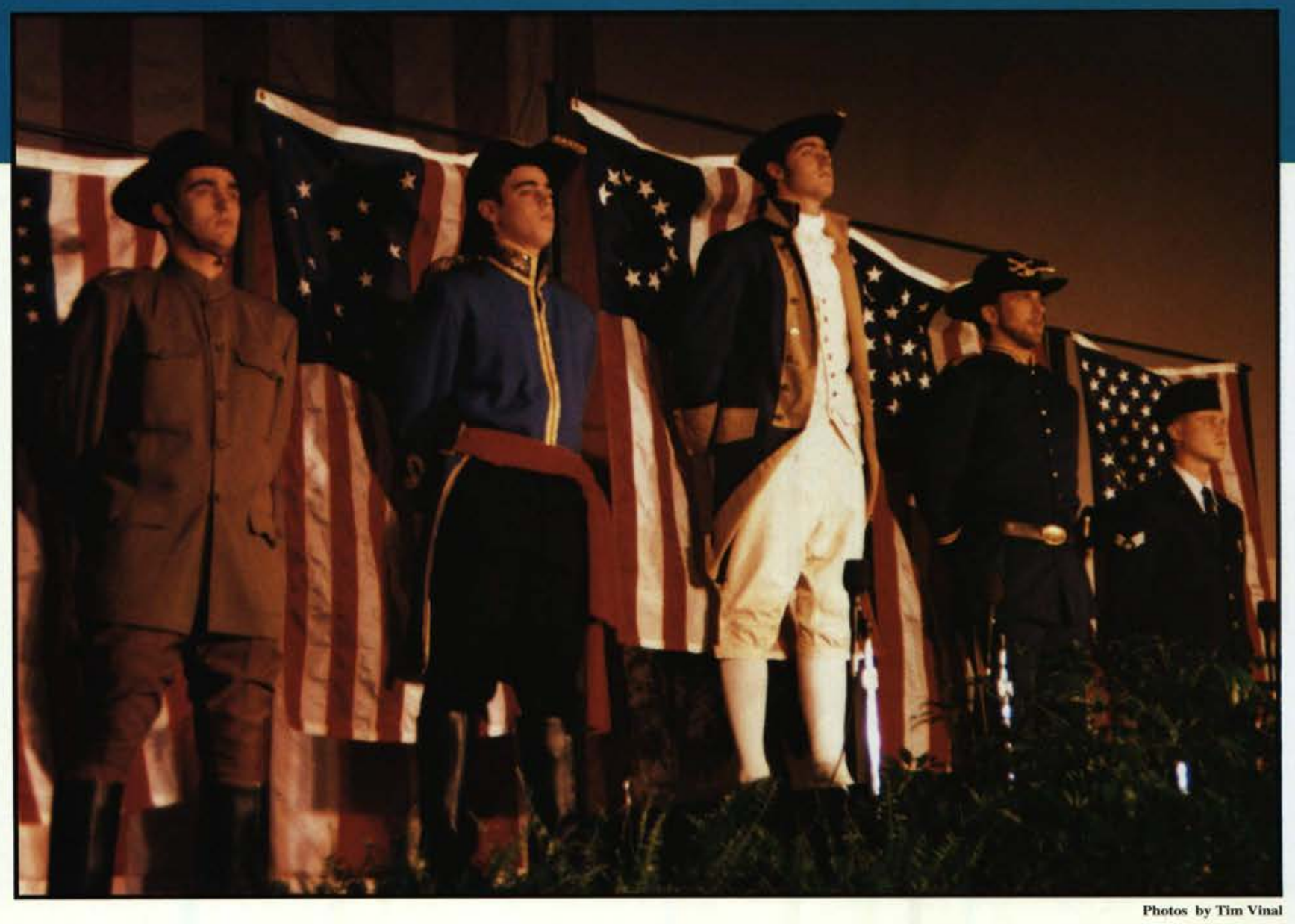



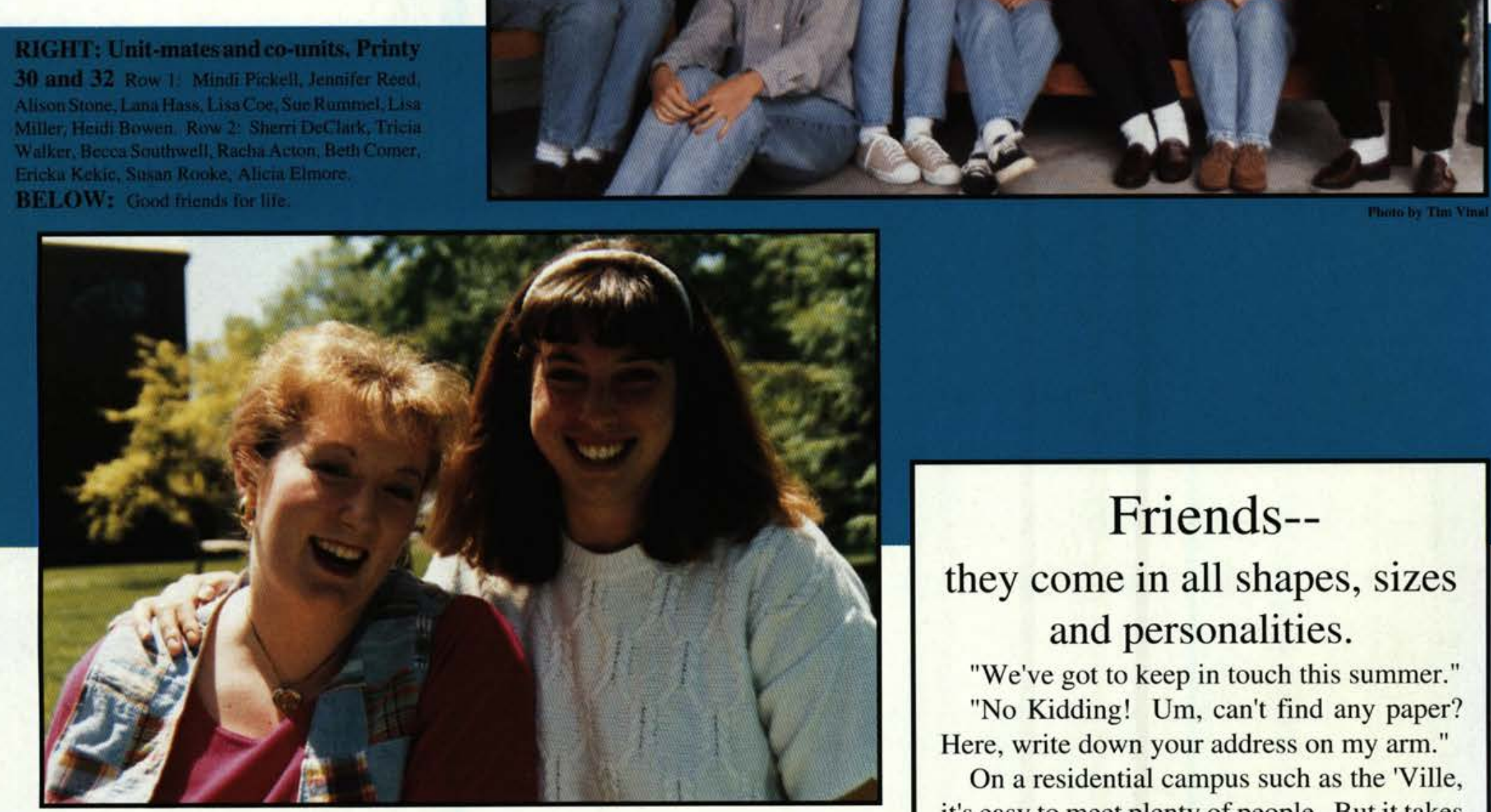

\section{Friends--}

they come in all shapes, sizes and personalities.

"We've got to keep in touch this summer."

"No Kidding! Um, can't find any paper? Here, write down your address on my arm."

On a residential campus such as the 'Ville, it's easy to meet plenty of people. But it takes a special mix of personalities to make really close relationships, whether just friends or dating couples. Some people meet in the Gavelyte while watching television, some over a game of pool or Trivial Pursuit, some in classes, dorms, Young's, Chuck's, TWIRP Week, John Bryan, the Gorge, or through mutual friends. Hundreds of opportunities await to form the bonds of friendship from wild and crazy to calm and peaceful. The bonds and memories formed in the years spent at Cedarville will last a lifetime. Just remember to keep in touch. Kathy Smart 


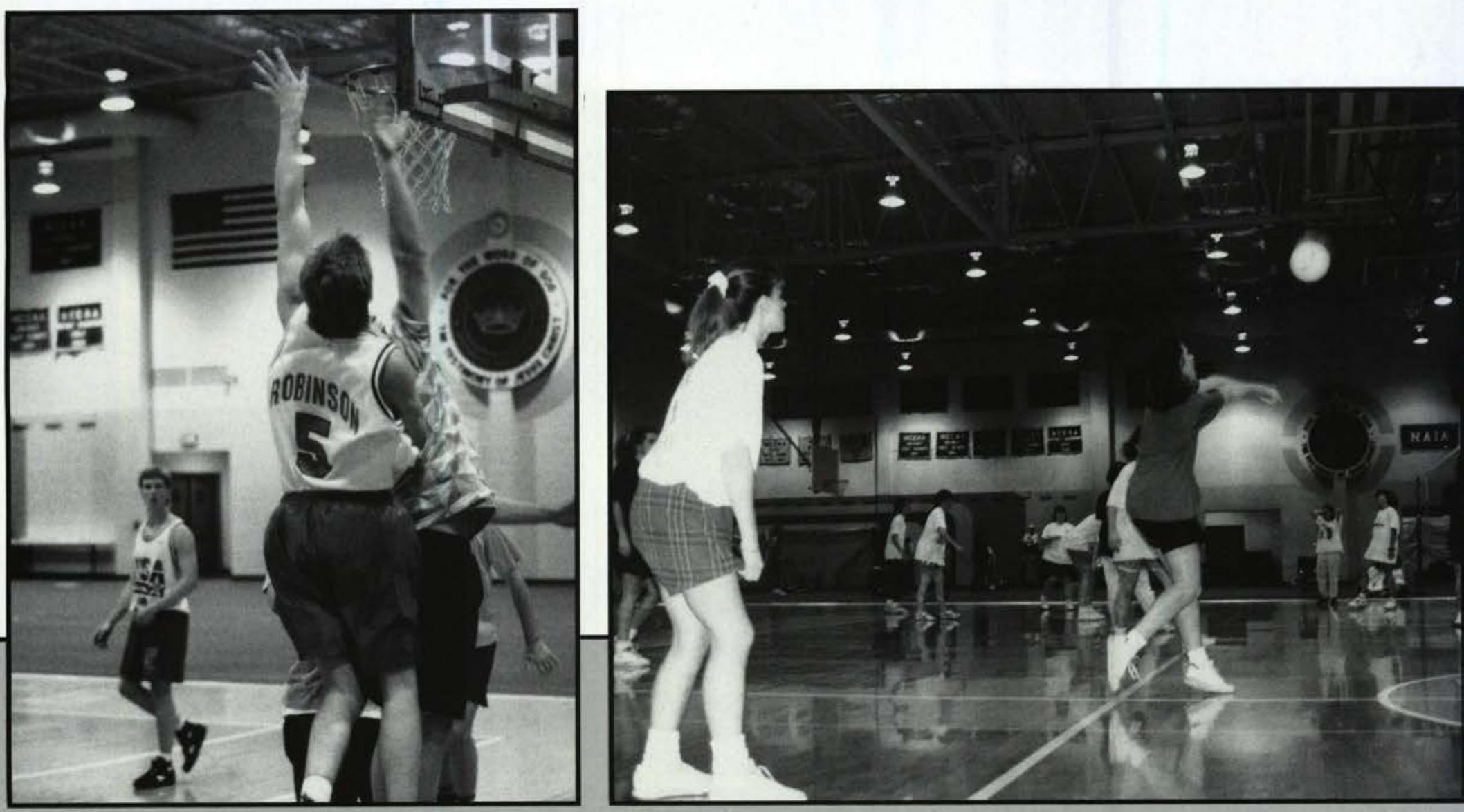

\section{Intramurals}

Flag Football

Powderpuff Football

Sand Volleyball

Volleyball

Soccer

Aerobics

Basketball

Bowling

Racquetball

Wallyball

Softball

Special Events

Bike Hike

Hiking

Horseback Riding

Canoeing

Golf Scramble

Beachball Volleyball

Rock Climbing

Repelling

Skiing

Pool

Ping Pong

Mini-Golf

Floor Hockey

Whitewater Rafting

Ultimate Frisbee

Oozeball

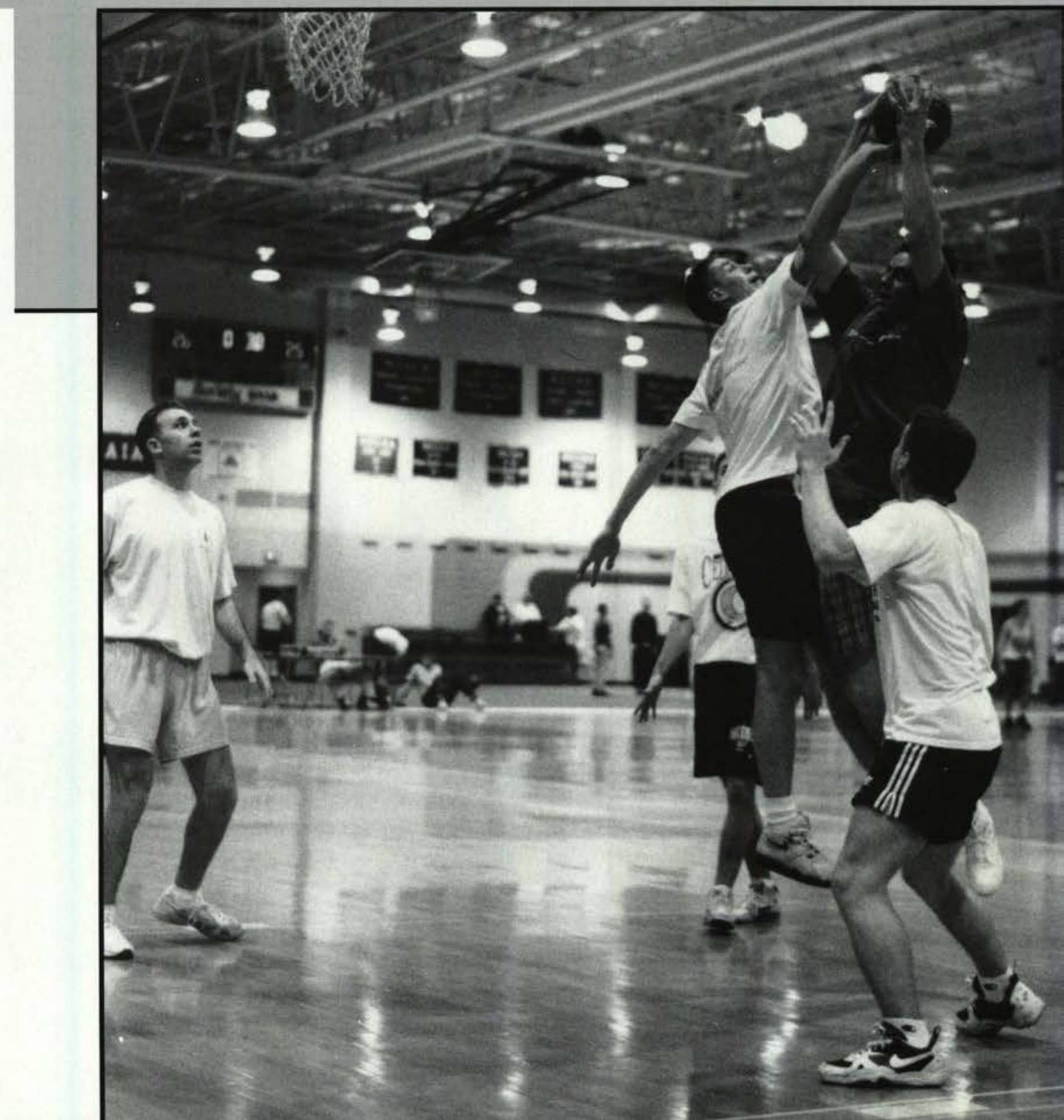




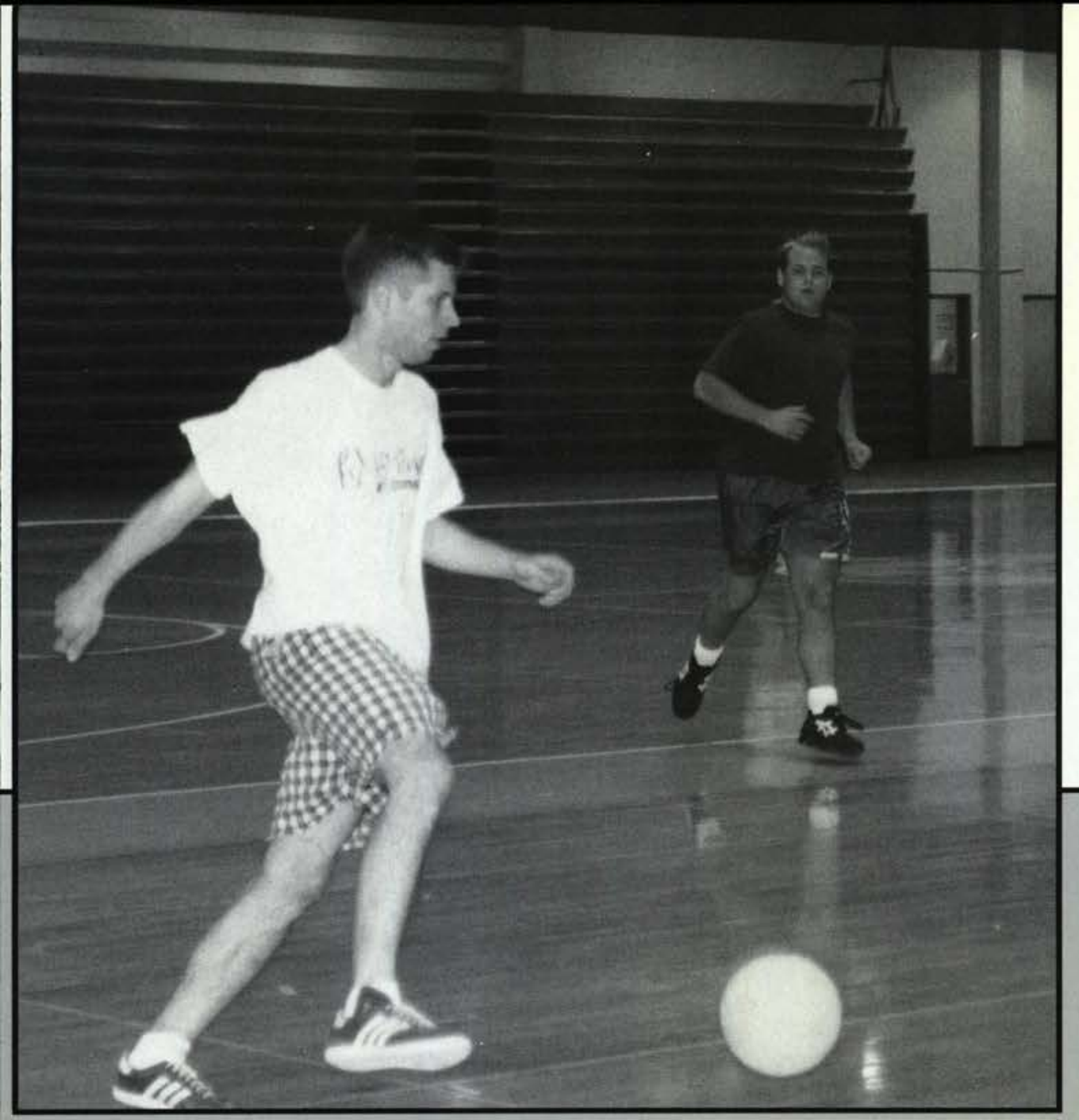

\section{Intramural Stress Relievers}

Exams. Papers. Projects. Meetings. How can students keep their sanity when they are up to their heads with responsibilities that will affect their futures? Easy answer. Play on an intramural sports team.

Intramural sports are designed to give students a competitive and fun activity, yet it does not require the many long hours of practice that an intercollegiate team expects. Whether a student plays soccer, basketball, floor hockey, or softball, the rewards are great, a good time of relaxing fun while spending time with friends. And, of course, the competition is right at the top as each team competes for the intramural championship shirt. Jodi Delich

\section{Intramurals}

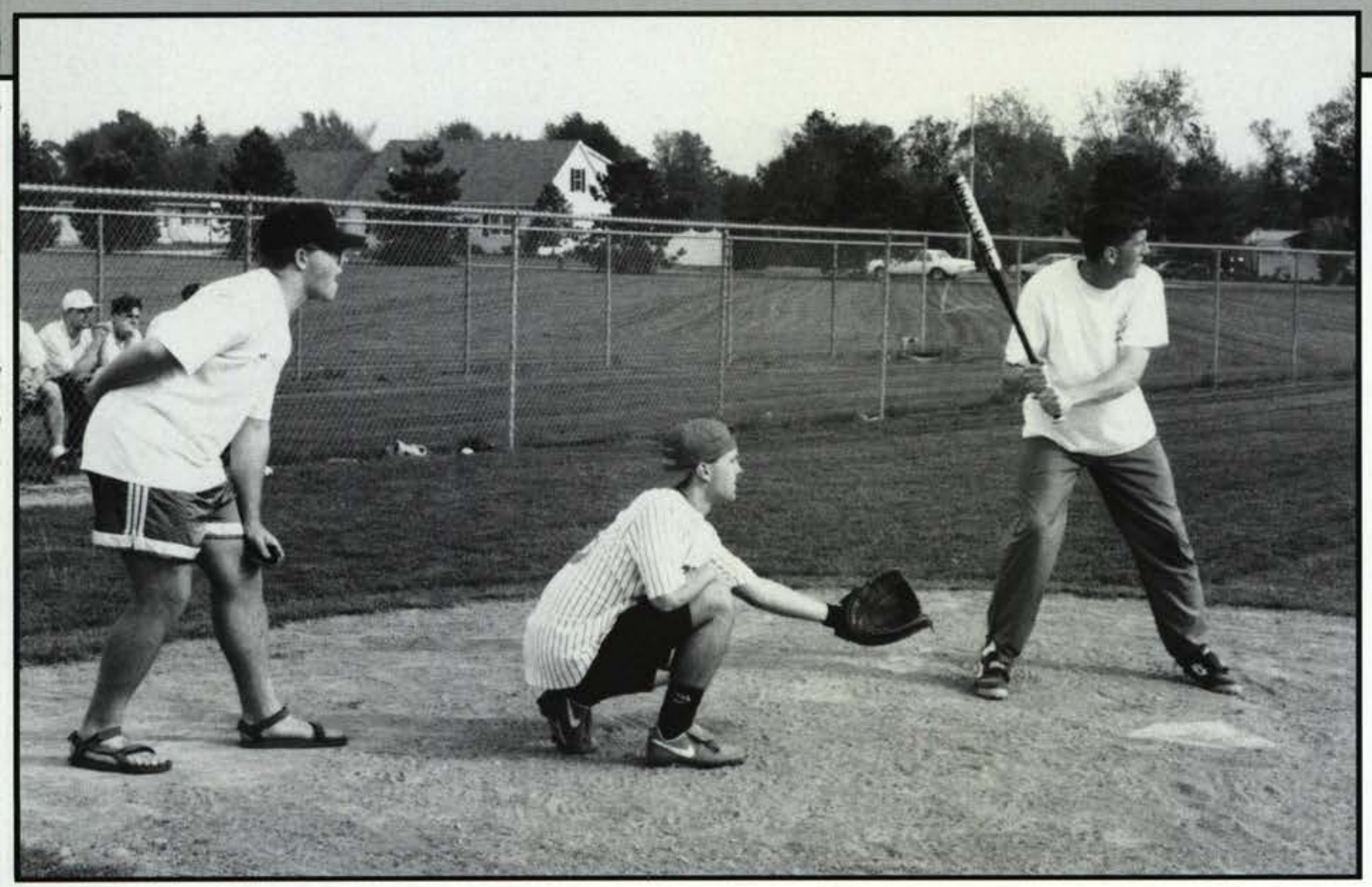


RIGHT: A student discusses the opportunities and advantages of going on to Northwest Baptist Seminary.

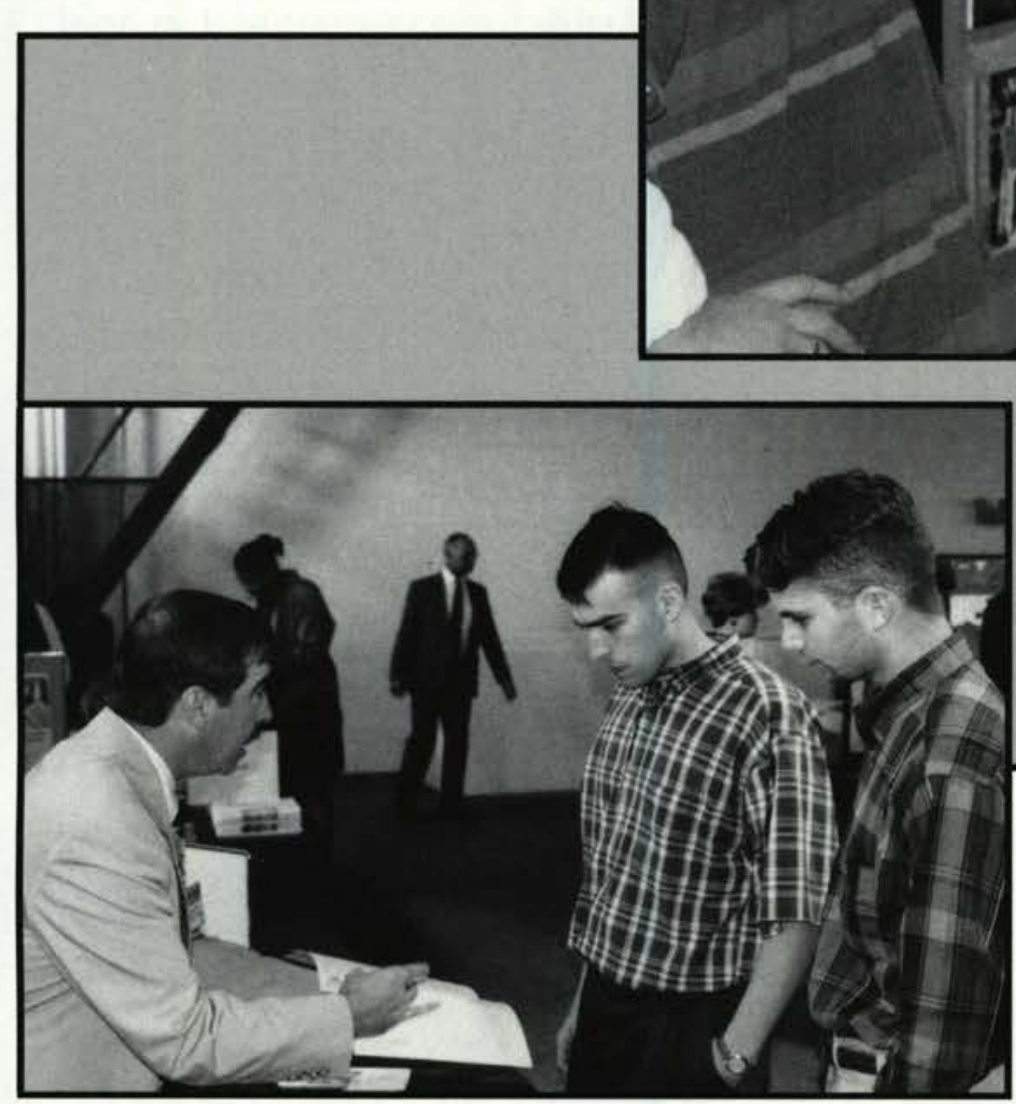

ABOVE: Chris McCaskey and Seth King discuss the possibilty of graduate school. RIGHT: Career Day gives students the chance to discuss seminary, graduate school, and job opportunities with qualified personnel.
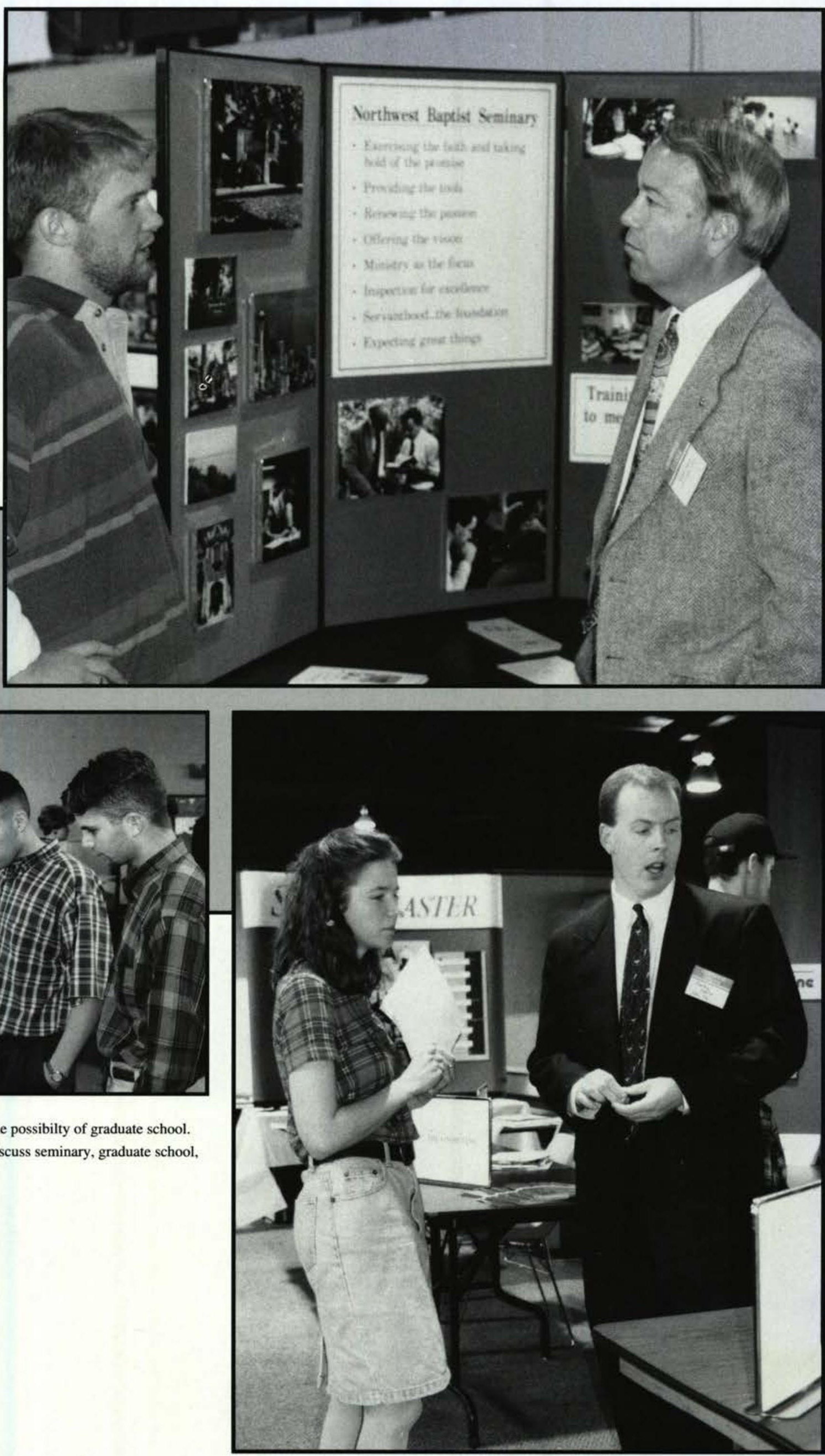


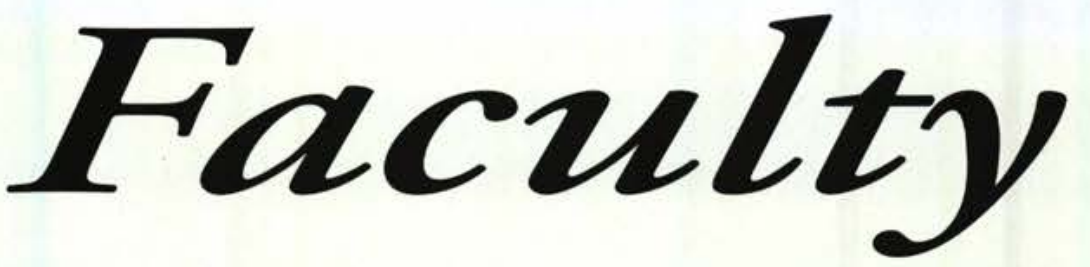

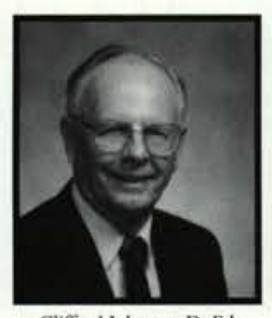

Clifford Johnson, D. E Asst. to President

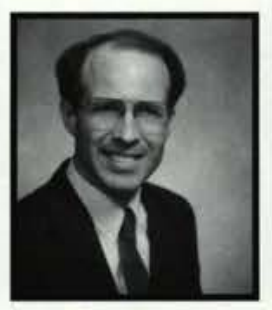

Daniel Estes, Ph.D.

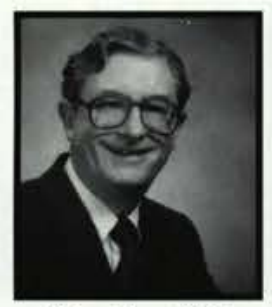

Marinus Hazen, M.B.A.

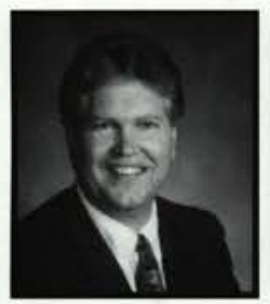

James Kragel, M.A. Communication Arts

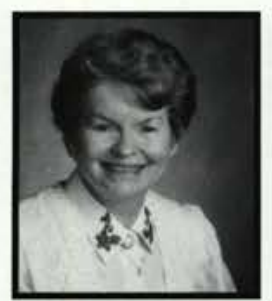

Sally Castle, Ed.S.

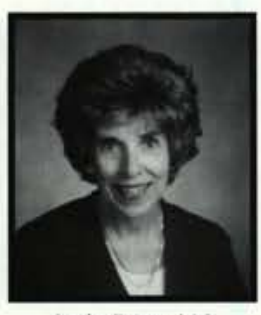

Sandra Entner, M.S. Counseling Services

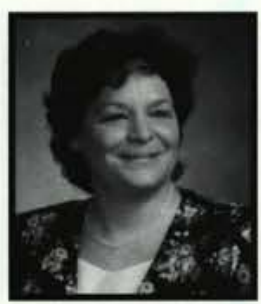

Cheryl Fawcett, Ed.D.

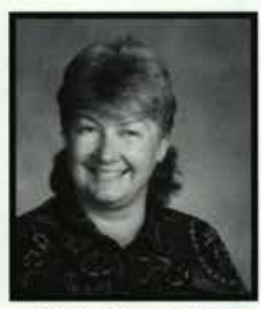

Martha Johnson, M.A.

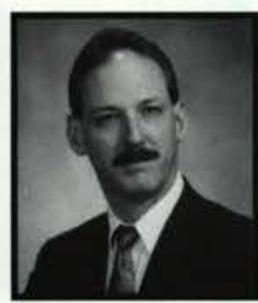

J. Michael Lopez, Ph. D.

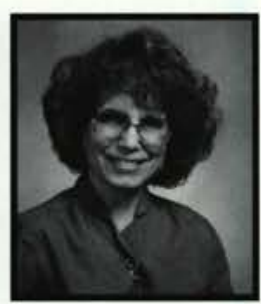

Sharon Eimers, D.Ed.

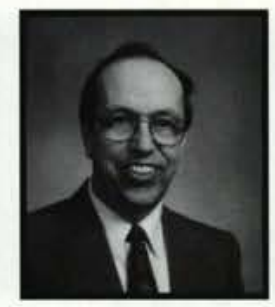

David Rotman, Ph. D. Computer Services

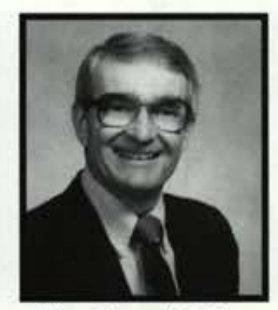

Robert Gromacki, Th.D.

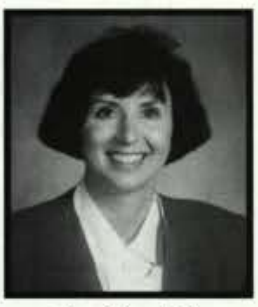

Betty Orme, M.S

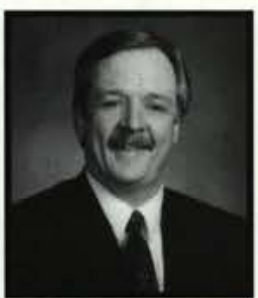

Kurt Moreland, M.A

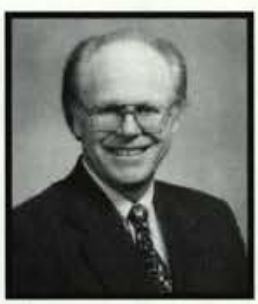

Dwayne Frank, D.Ed.

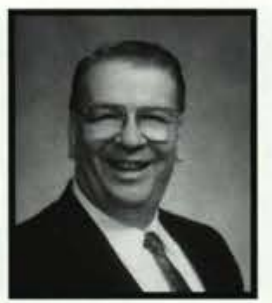

Rich Blumenstock, D. Min Biblical Education

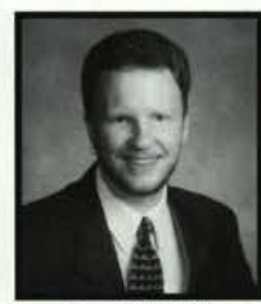

David Mills, M.A.

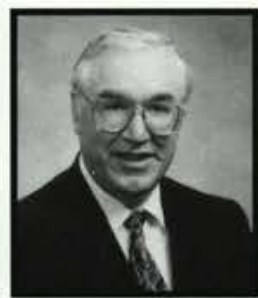

Galen Smith, M.S.

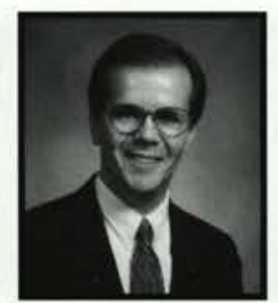

David Robey, Ph.D.

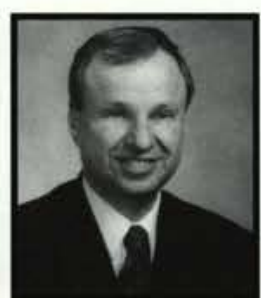

Tim Heaton, M.A

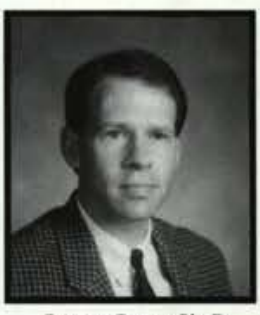

Gregory Couser, Ph. D.

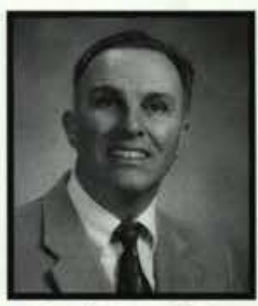

David Warren, Th. M.

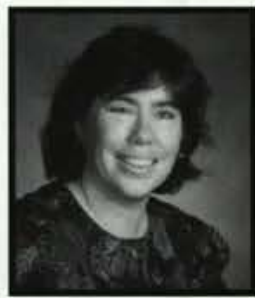

Sarah Smith, Ph. D.

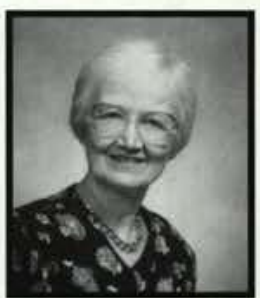

Sue Baker, D.Ed

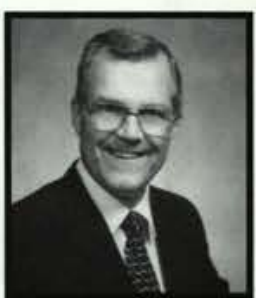

Philip Bruce, M.S. Engineering

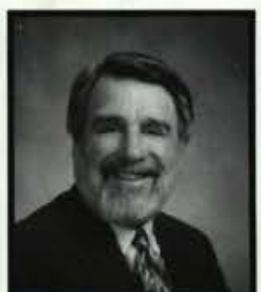

David Drullinger, D. Min.

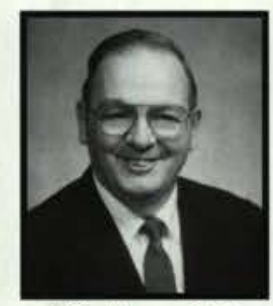

Clifford Fawcett, D.B.A. Business Administratio

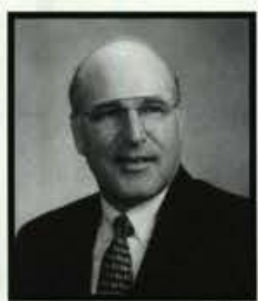

Ronald Walker, D.B.A.

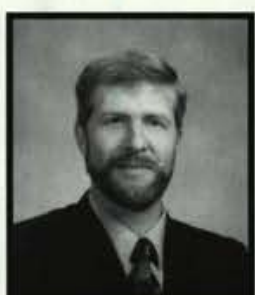

Philip Bassett, Ph.D.

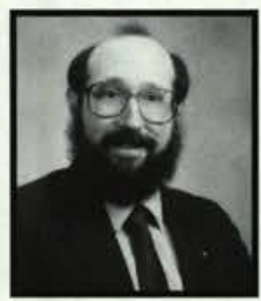

Robert Chasnov, Ph.D.

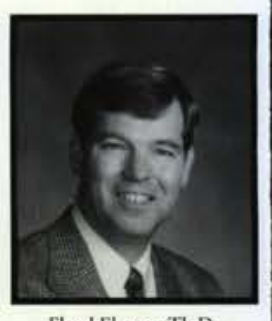

Floyd Elmore, Th.D

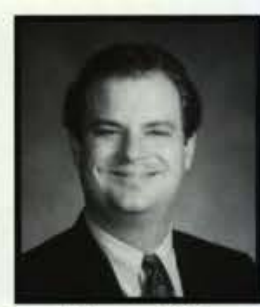

Jeff Fawcett, M.B.A.

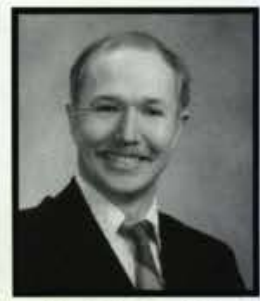

Wesley Sweerser, M.S.

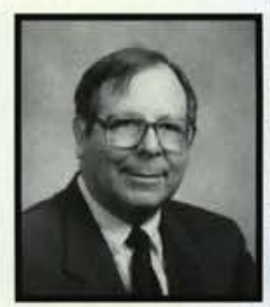

Omer Bonenberger, D.Ed.

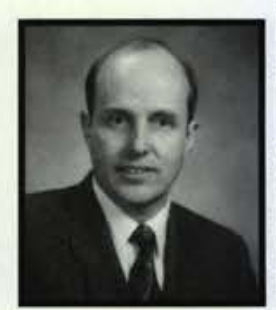

Keith Francis, M.S.E.

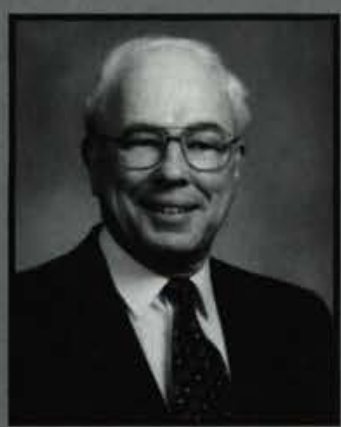

Jack Riggs, Th. D. Biblical

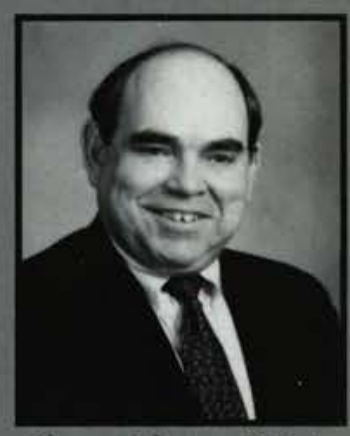

Sharon Johnson, D.B.A

Business

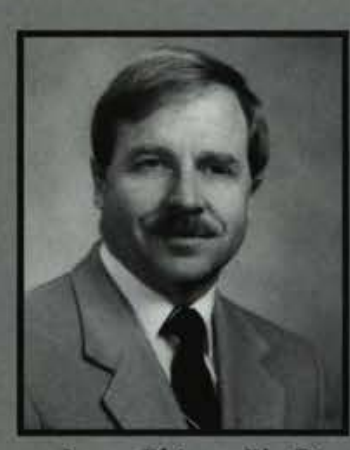

James Phipps, Ph. D.

Communication

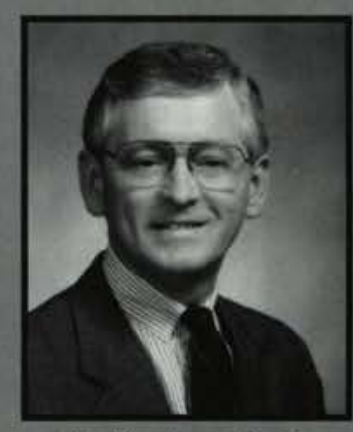

Merlin Ager, Ph. D.

Education

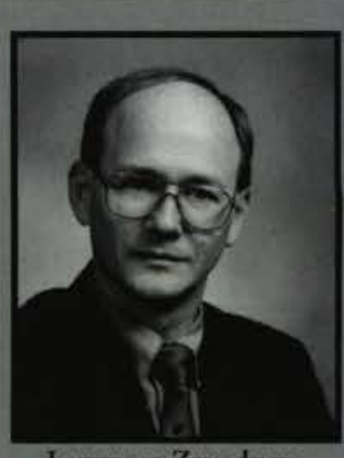

Lawrence Zavodney,

Ph. D. 


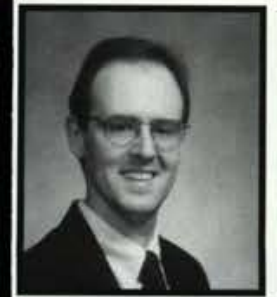

Garth Frazier, Ph.D.

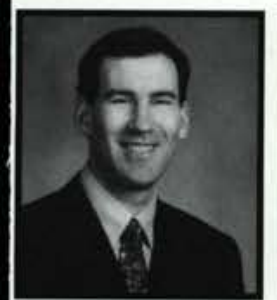

Sam SanGregory, M.S

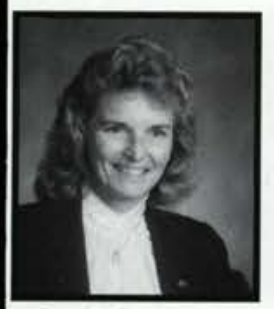

Pamela Johnson, Ph.D.

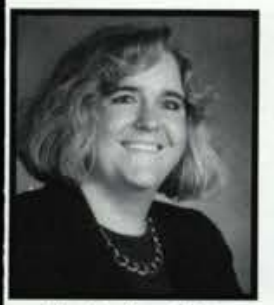

Lisa Davidson, M.A. Lang, \& Lit.

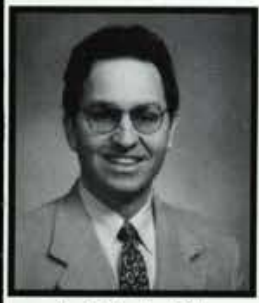

Kevin Heath, M.A.

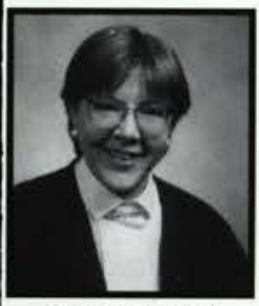

Barbara Loach, Ph.D

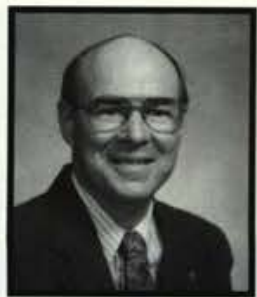

Harwood Hegna, Ph.D.

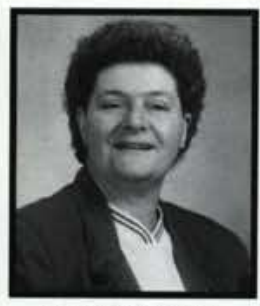

Elaine Brown, Ph. D. Health \& Phys. Ed.

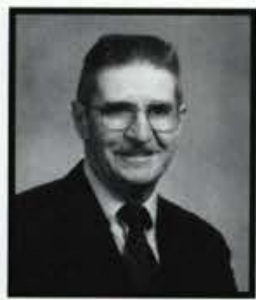

Elvin King, M.Ed.

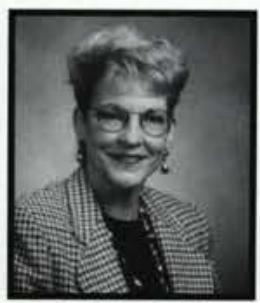

Pat Dixon, M.Ed.

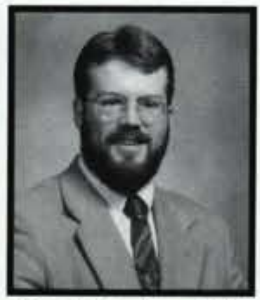

Donald Humphreys, M.S.

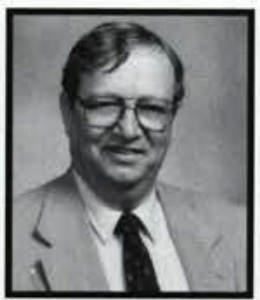

Jack Simons, M.F.A.

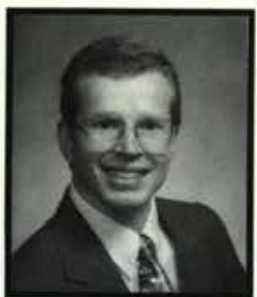

Clint Kohl, Ph.D

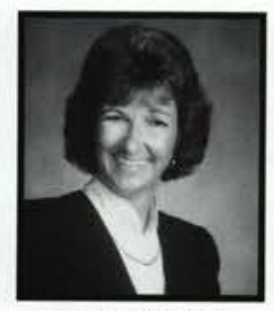

Kathleen Freese, M.S.

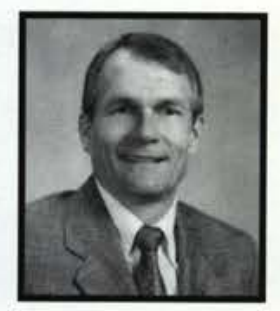

John McGillivray, M.S.

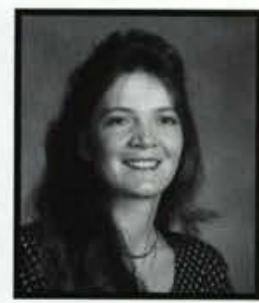

Joy Fagan, B.S.

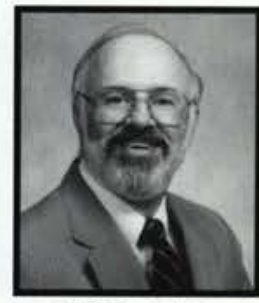

Philip Jones, Ph.D

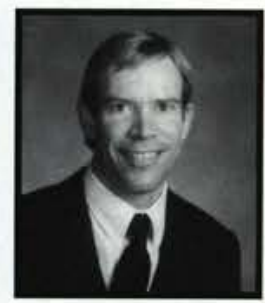

James Snowden, J.D.

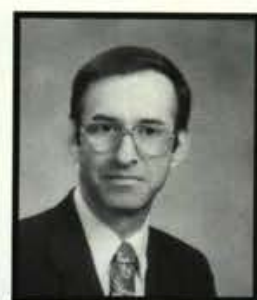

Robert Laramore, M.S.E

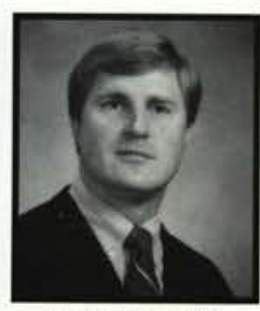

Evan Hellwig, Ph.D.

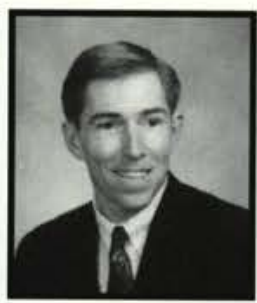

Paul Orchard, M.A.

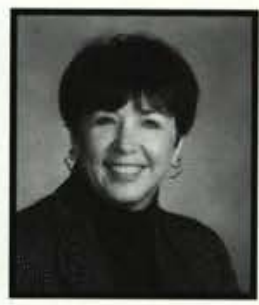

Sandra Harner, M.A

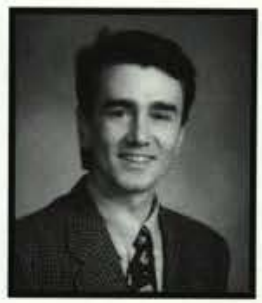

Brian Kennedy, Ph.D.

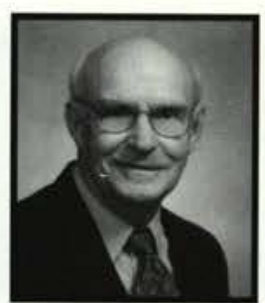

Edward Spencer, M.A.

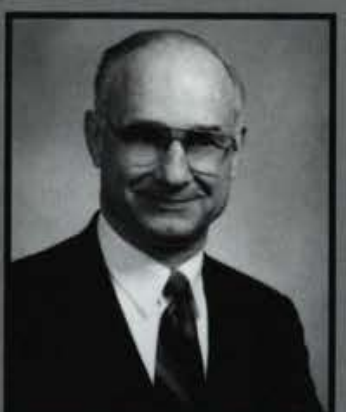

Charles Allport, M.S.E. Engineering

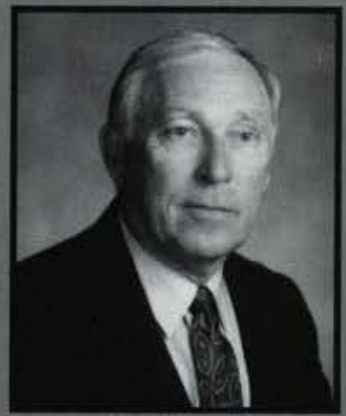

Donald Callan, Ph. D.

Health and Physical

Education

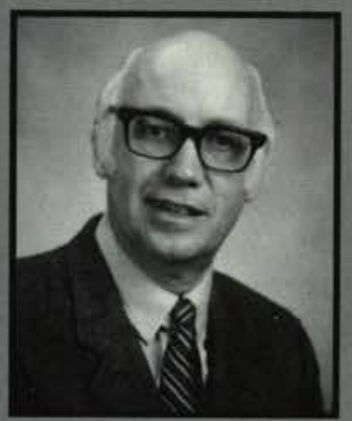

Raymond

Bartholomew, Ph. D.

Lang. \& Lit.

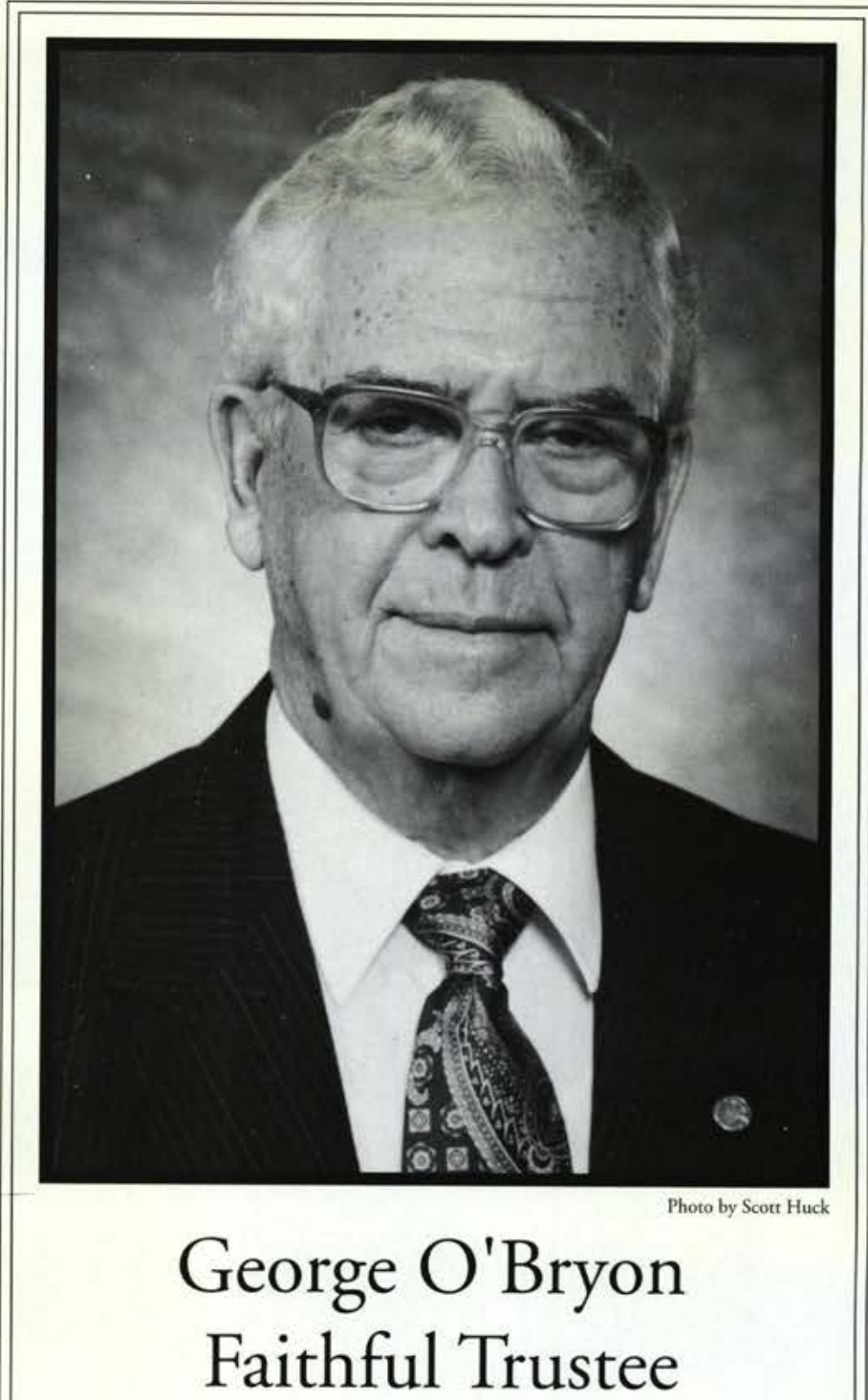

Cedarville College Trustee for over 30 years, George F. O'Bryon, went to be with our Lord and Savior this past February 28, 1995.

Born August 16, 1915 in Iowa, he married Marguerite Bueghly, also of Iowa, in 1934. They had three children, Barbara, Ronald, and Roger, CC '64. Following his service in the U.S. Navy during World War II, George owned and operated O'Bryon Cheverolet-Oldsmobile for over 30 years in Eldora, Iowa.

His service as a Cedarville College Trustee was loyal and faithful. George and his wife were consistently active in their local church and in Bible camps. George served as a deacon and was a board member of the Regular Baptist Camp in Ventura, Iowa for 25 years.

The Miracle expresses its appreciation to the O'Bryons for their very faithful service to the Lord, churches, camps, and the college.

Dr. Clifford Johnson 


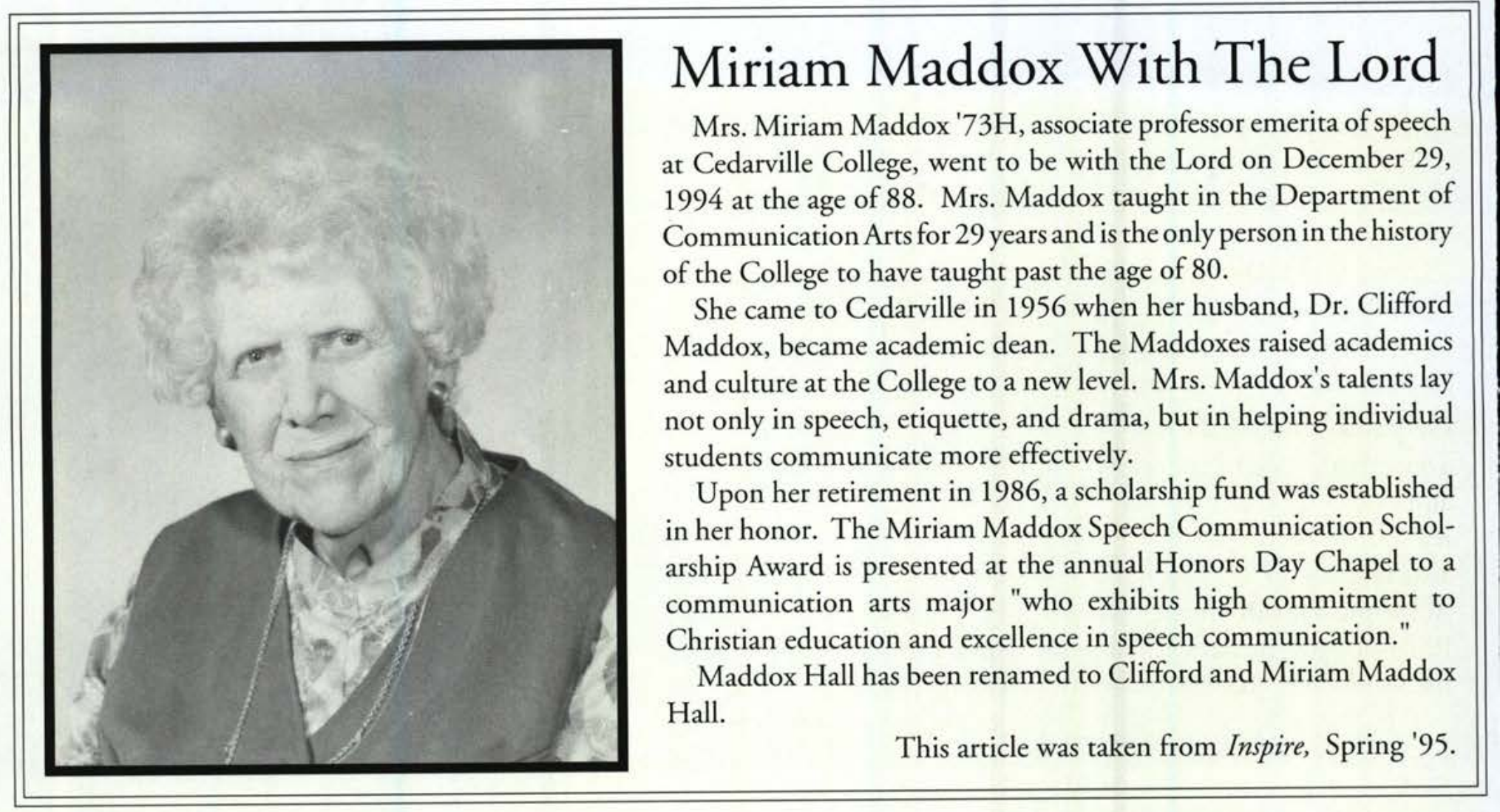

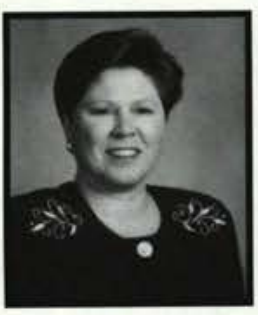

Janice Bosma, M.L.S. Library

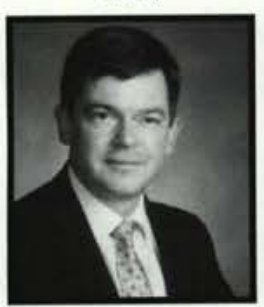

Jerry Rodgers, B.M.

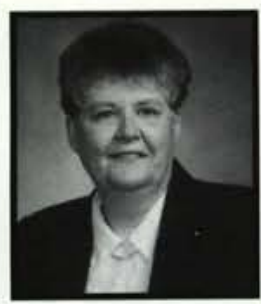

Judith Shrubsole, M.S

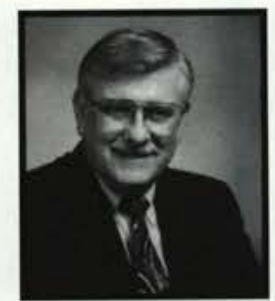

Carl Brandon, M.A

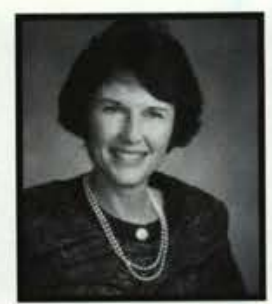

Kathryn Rodgers, M.A.

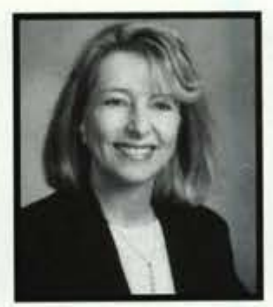

Diane Stribling, M.S

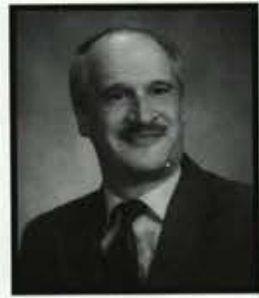

Stephen Brown, M.L.S

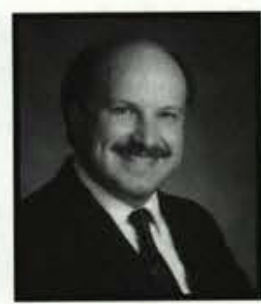

Mark Spencer, D.M.A.

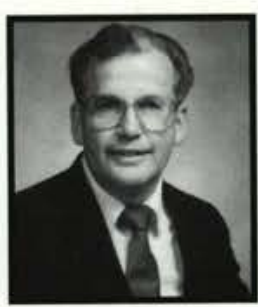

Edwin Braithwaite, Ph.D. Science \& Machematics

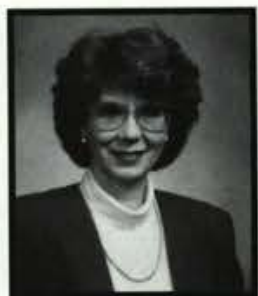

Lynne Funtik, M.L.S.

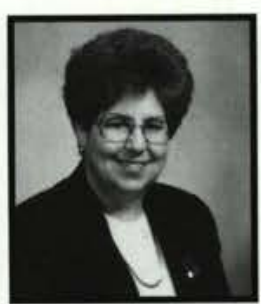

Janet Conway, Ph.D. Nursing

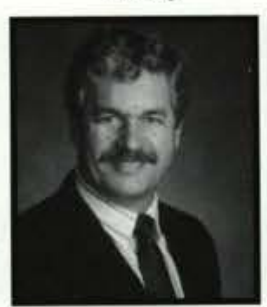

Leroy Eimers, Ph.D.

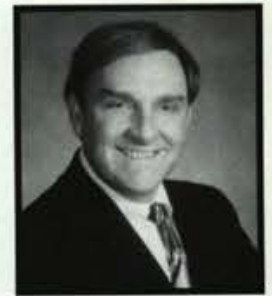

Lyle Anderson, Ph.D. Music

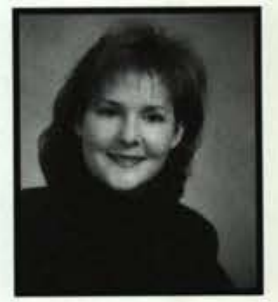

Sandra Pratt, M.S.

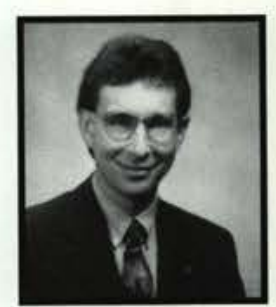

Dennis Flentge, Ph. D.

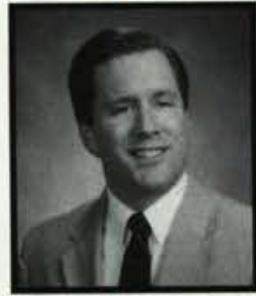

James Colman, Ph.D.

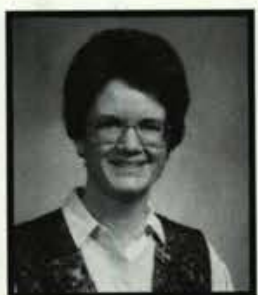

Sharon Rahilly, Ph.D.

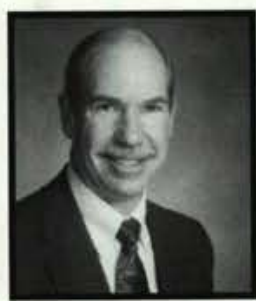

Larry Helmick, Ph.D.

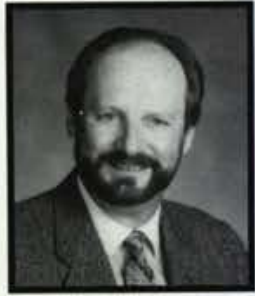

Michael DiCuirci, M.M.

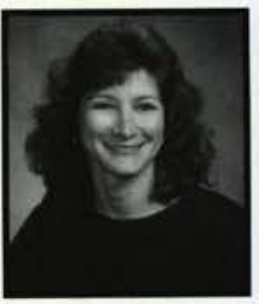

Teena Sanders, M.S.N

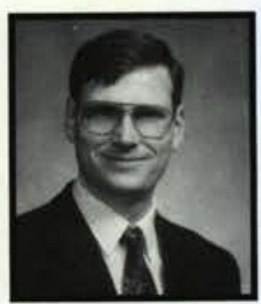

Steven Gollmer, Ph.D.

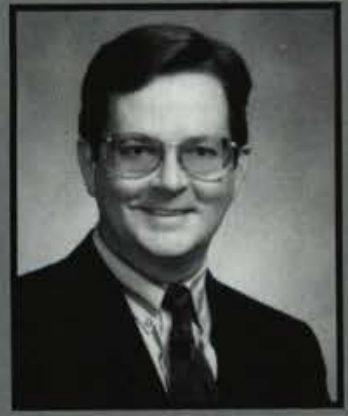

Charles Clevenger, D.M.A. 40 faculty Music

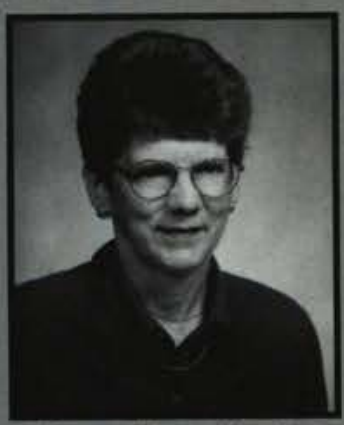

Irene Alyn, Ph. D.

Nursing

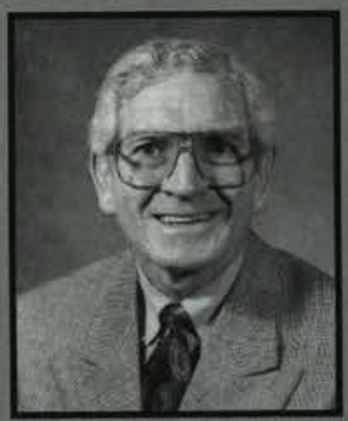

Stanley Ballard,

Ph. D.

Psychology

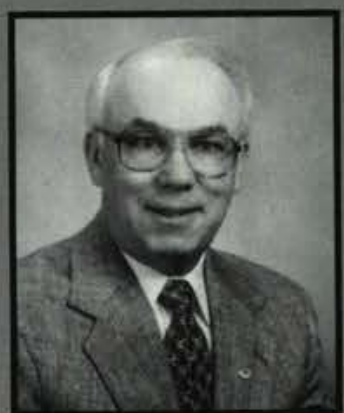

Daniel Wetzel, Ph. D. Science \& Mathematics

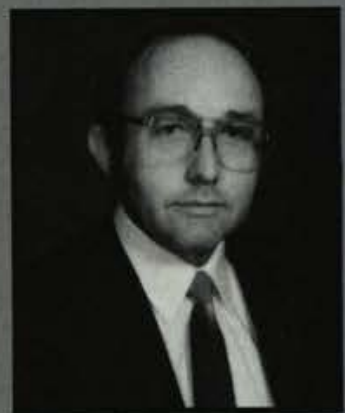

J. Murray Murdoch, Ph. D.

Social Science \& 


\section{Dr. Daniel Estes Faculty Member of the Year}

Repeatedly, people describe the faculty member of the year as one with genuine concern for his students while challenging them toward academic excellence. A fellow colleague described him by saying, "In every area of his life, he is a model of excellence." In his family, he is a dedicated husband and father of three children. His teaching is clear and he uses creativity. In class, he makes the information exciting and relevant to the students' lives. He recently resigned from being the associate pastor at his church in order to serve as the Assistant Academic Vice-President. However, he remains active in ministry. Professionally, he has written many scholarly publications as well as the text for the class he designed, Introduction to Bible Study.

Deborah Rotman

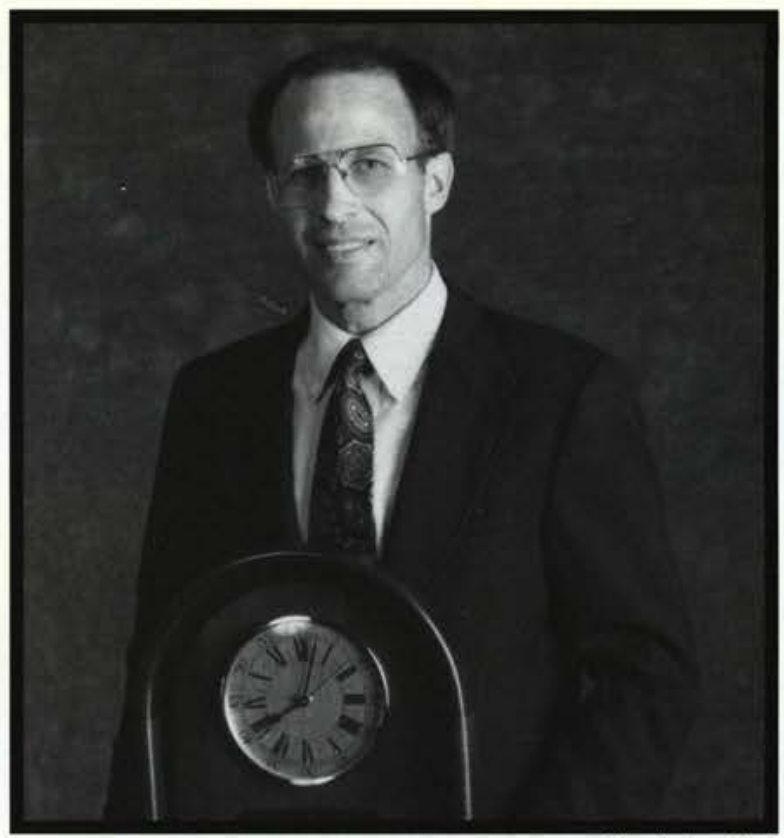

Photo by Scott Huck

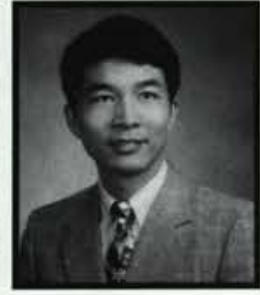

Dali Luo, Ph.D.

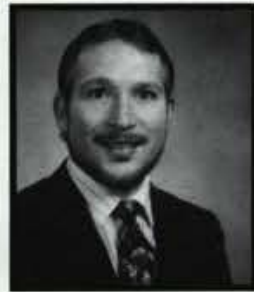

John Whitmore, M.S.

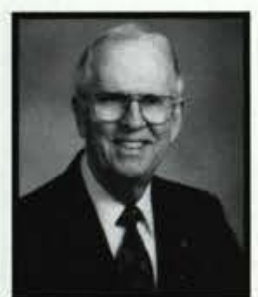

Richard Durham, Th.D. Emertis of Bible Greek

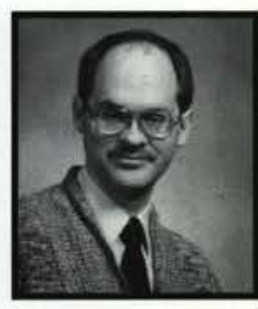

Douglas Miller, Ph.D.

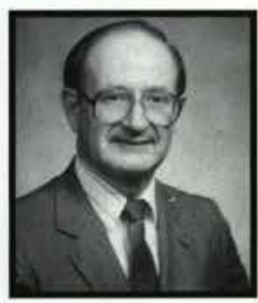

James McGoldrick, Ph.D.

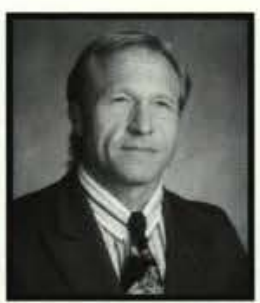

Terry Phipps, Ph.D.

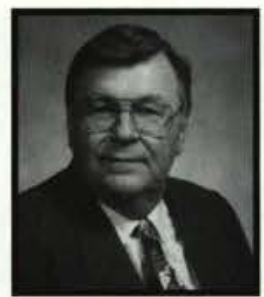

Allen Monroe, Ph.D.

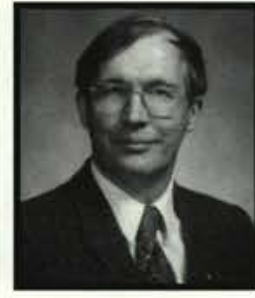

Robert Schumacher, M.S.

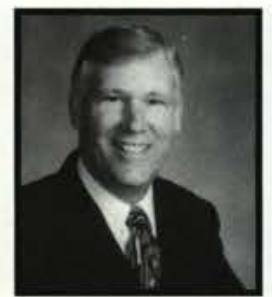

Rober Parr, Ph.D.

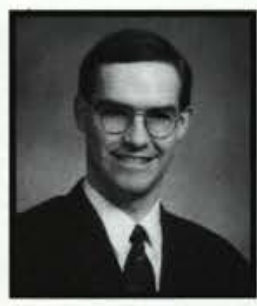

James Sellers, Ph.D.

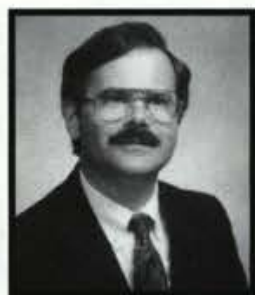

Kevin Sims, Ph.D

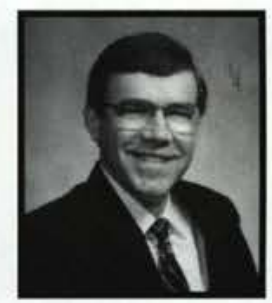

John Silvius, Ph.D.

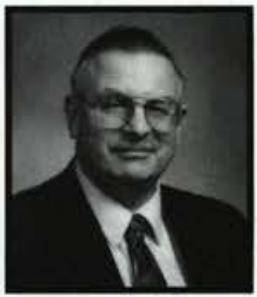

Robert Wiggins, Ph.D. 


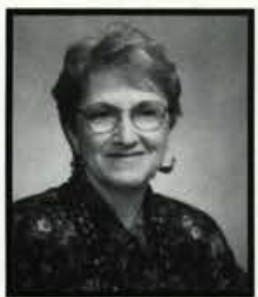

Ruth Ager

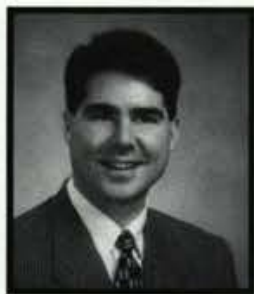

Jeff Beste

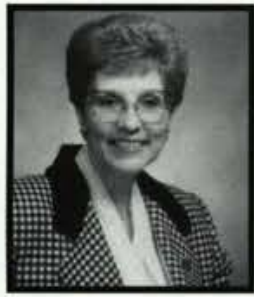

Connic Bradds

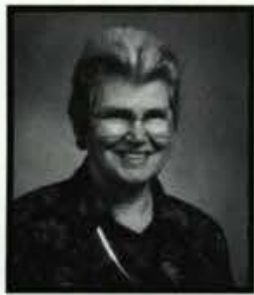

Alberta Carr

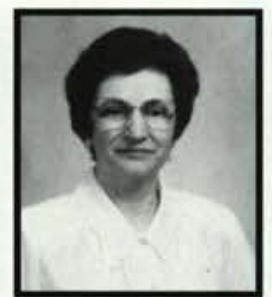

Frances Andrews

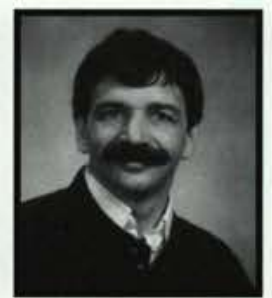

Robert Bielek

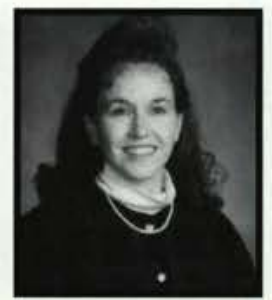

Elizabeth Bucklew

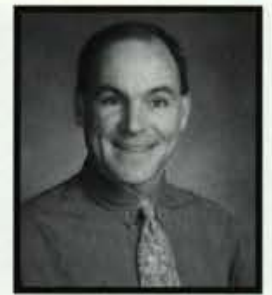

James Cato

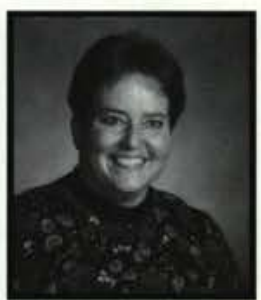

Michal Bader

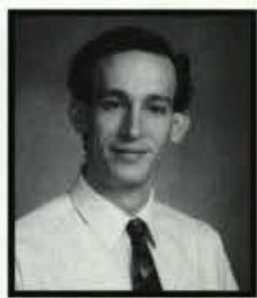

David Bishop

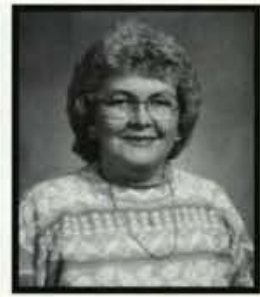

Margarer Burrichter

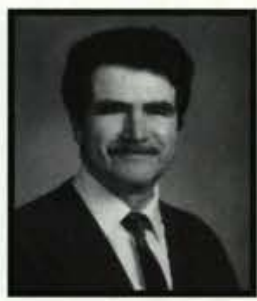

Ronald Coy

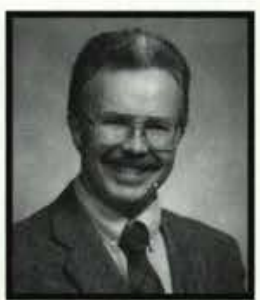

Ronald Bader

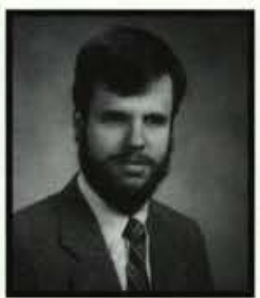

Brian Blair

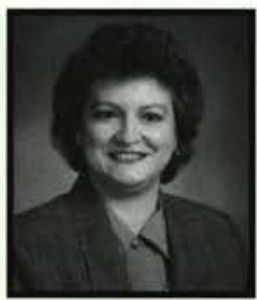

Deborah Cagwin

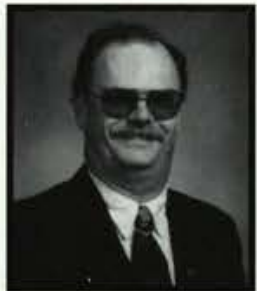

Jeffrey Cunningham

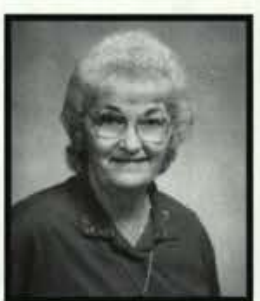

Barbara Baise

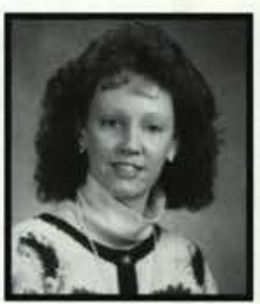

Carol Bliss

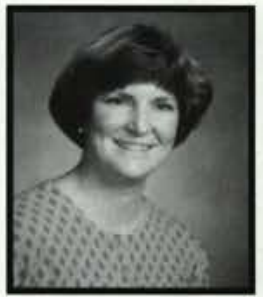

Karen Callan

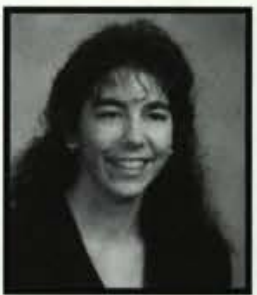

Melody Curtis

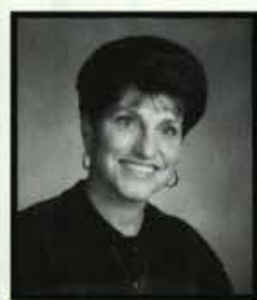

Louann Baise

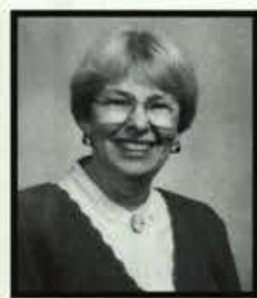

Helen Blumenstock

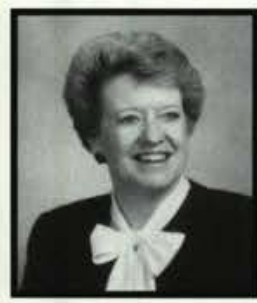

Fran Campbell

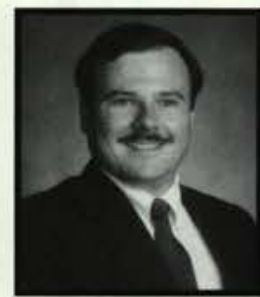

Keith Davis

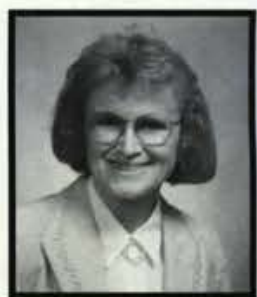

Martha Baldwin

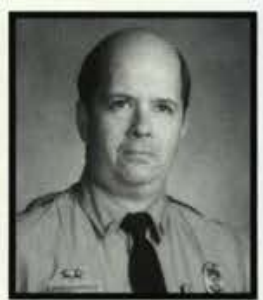

James Bowersox

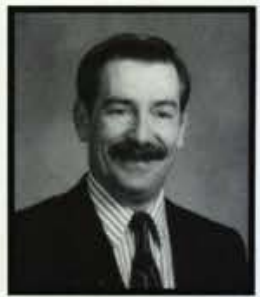

Jack Campbell

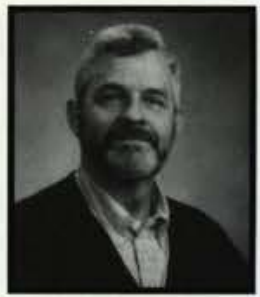

David Denlinger

\section{Beikerts Retire}

Bob and Grace Beikert have been led by God on an interesting journey as they have sought to serve the Lord in their daily walk with Him. It is a long way from Butler, Pennsylvania, Bob's birthplace, to Kings College where he met Grace, to Baptist Bible Seminary, to the Philippine Islands under the ABWE Mission Board, and finally to Cedarville College, Cedarville, Ohio.

Bob began his service to the college as Director of Personnel and as a purchasing agent in 1977 . During this time, one of the projects with which he was involved was the revision and updating of the staff handbook. It has been a profitable guide for many years.

Upon the retirement of Bernice Mick in 1986, Bob became manager of The College Bookstore. There have been many improvements and changes under his direction. The most notable was the renovation in 1990. It made the store more user-friendly by lowering the shelving and redesigning the floor plan to give an open, spacious feeling and look. Under Bob's leadership, an expanded line of clothing was displayed for the interest of the student and family members. A larger area was given to displaying CD's and cassettes of a variety of Christian artists. Grace, who was in charge of cards and gift items, as well as pictures, made a commitment to carry pictures of excellent quality which would glorify God in the home or office.

As Bob and Grace enter this period of life we call retirement, we know they will be active for the Lord wherever He leads them. We wish to thank them for their years of service and commitment to Cedarville College. May God continue to bless them both as they seek to serve Him in their personal ministry for years to come. 


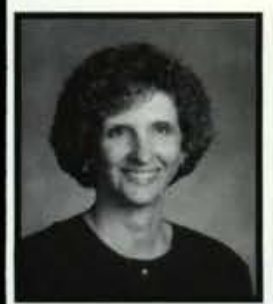

Bethel Dillon

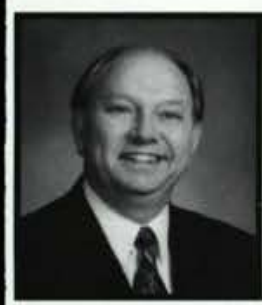

Paul Gathany

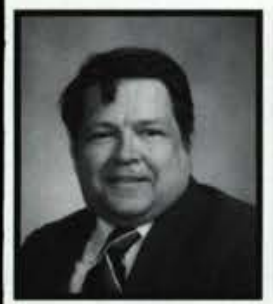

Keith Hague

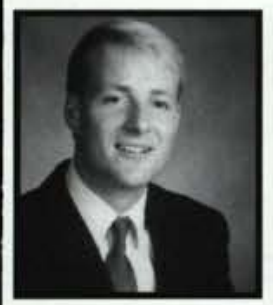

David Hoecke

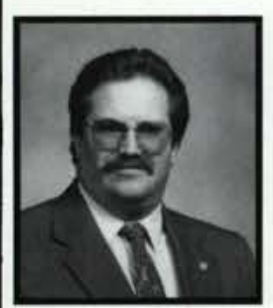

Robert Hunt

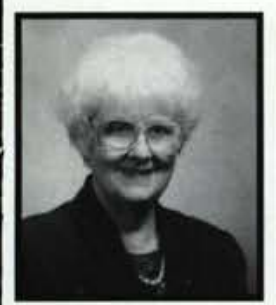

Joanne Kendall

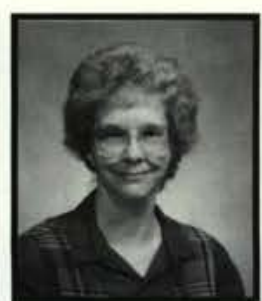

Linda Divan

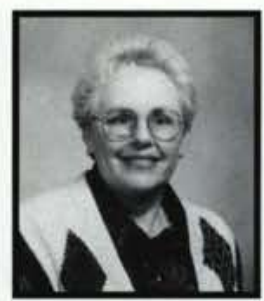

Sheron Gibbs

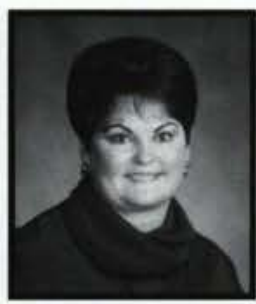

Marsha Halk

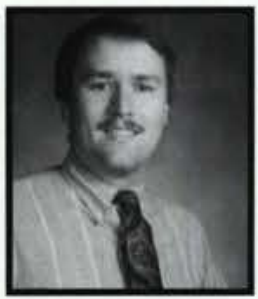

Scott Howder

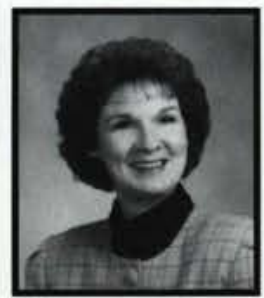

Shirley Johnson

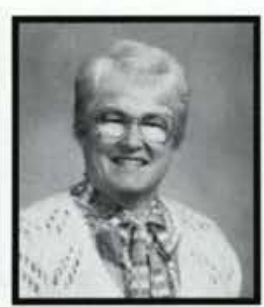

Joyce King

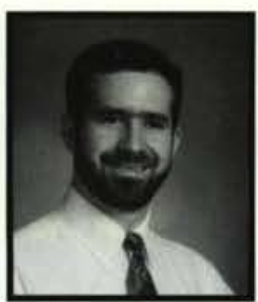

Patrick Drury

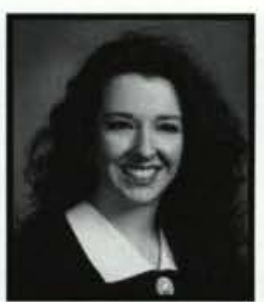

Dana Gosser

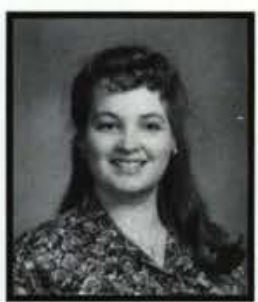

Stephanic Halverson

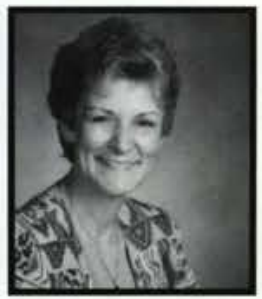

Patricia Huber

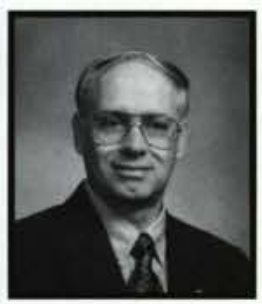

Timothy Johnson

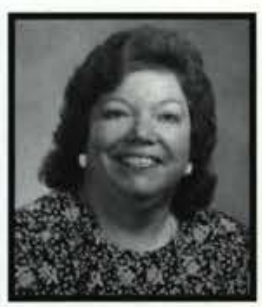

Toi King

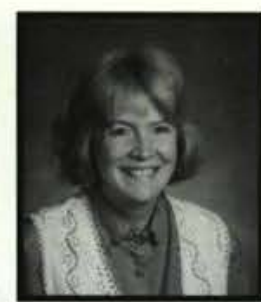

Pamcla Elmore

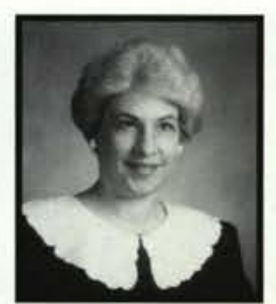

Dianne Gotrwals

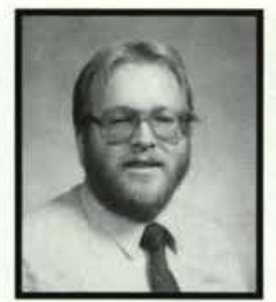

Timothy Hansell

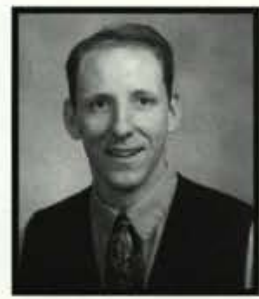

Scott Huck

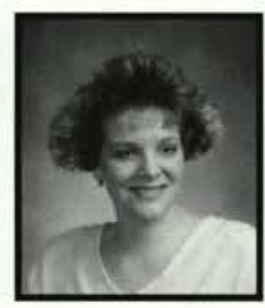

April Johnston

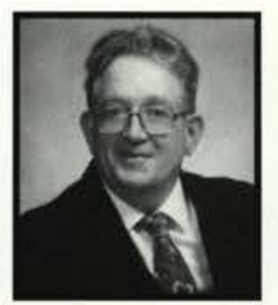

Glenn Knauff

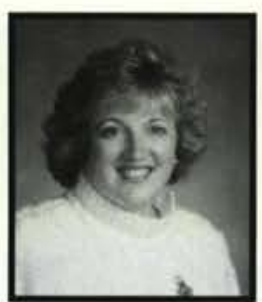

Joyce Farlow

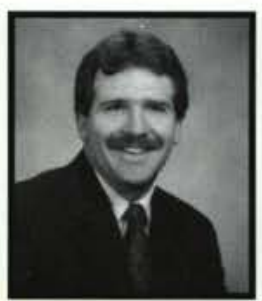

Philip Grafton

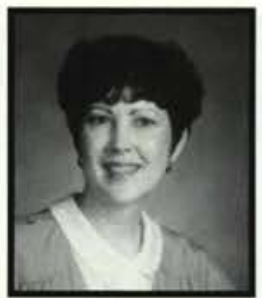

Donna Harrison

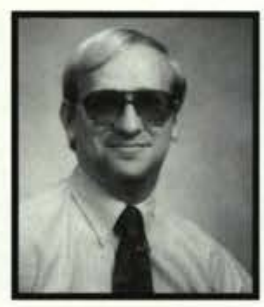

Gary Hull

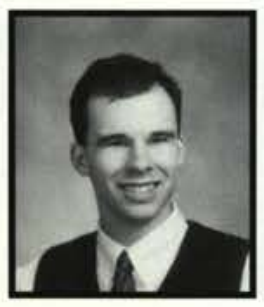

Mark Kakkuri

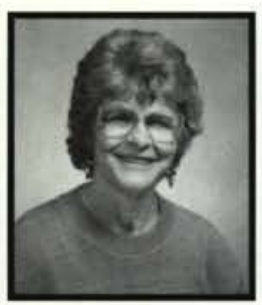

Nancy Knauff

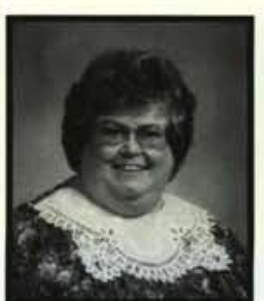

Nancy Fissel

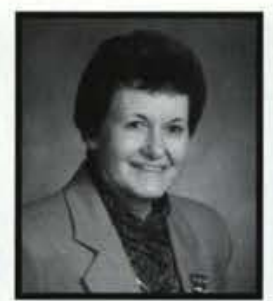

Margaret Green

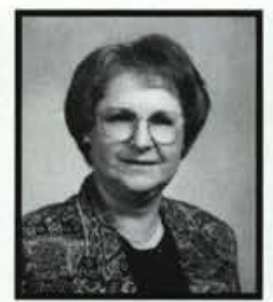

Barbara Helmuth

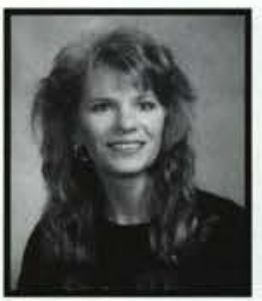

Barbara Hunt

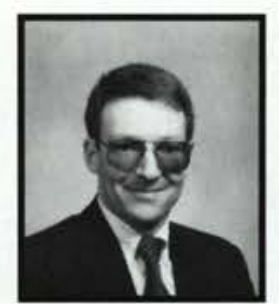

David Kammeyer

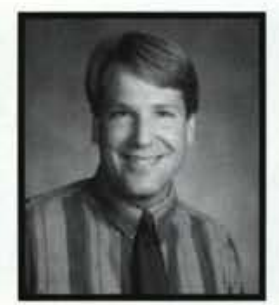

Mark Kordic

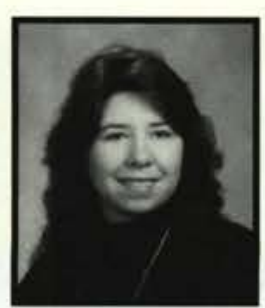

Dara Fraley

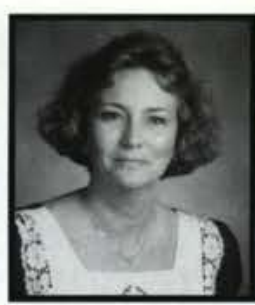

Janice Greenwood

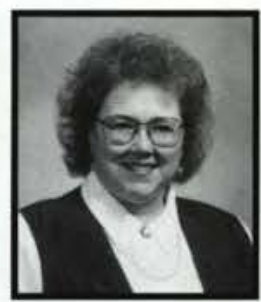

Carolyn Hodson

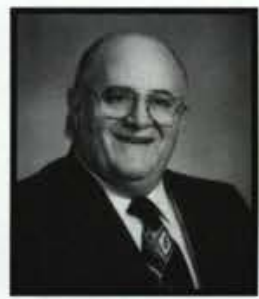

Leigh Hunt

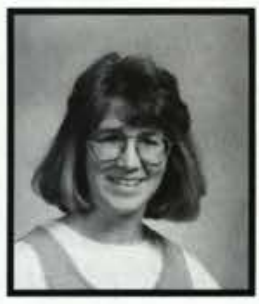

Elaine Keller

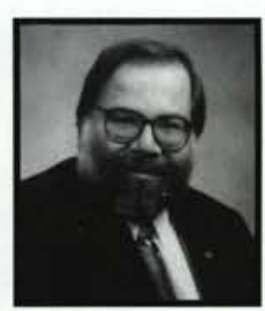

Gregory Kunz
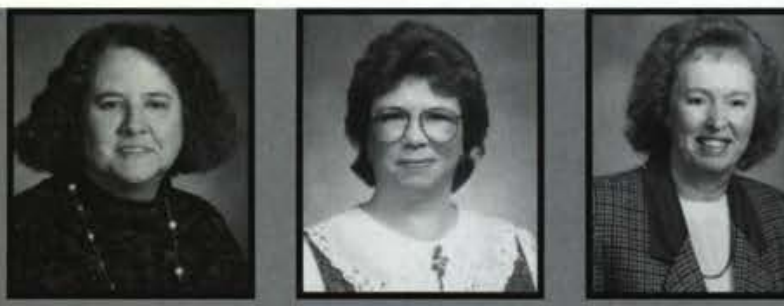


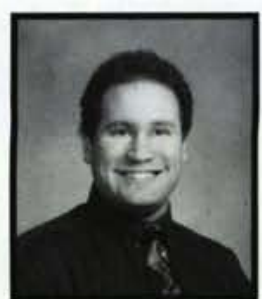

Michael Longo

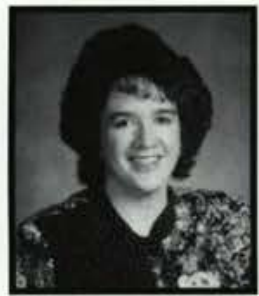

Shawna Mikesell

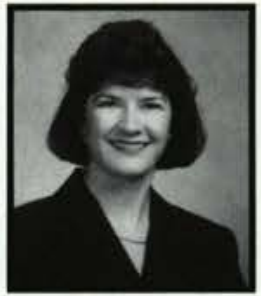

Wendy Orchard

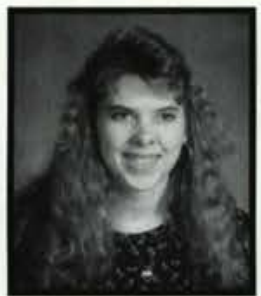

Tamara Rasey

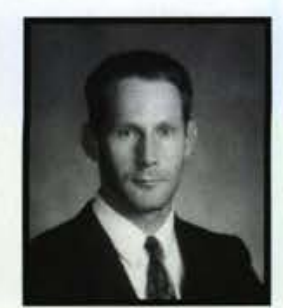

Andy Mahnke

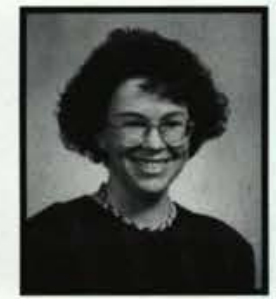

Cheryl Miller

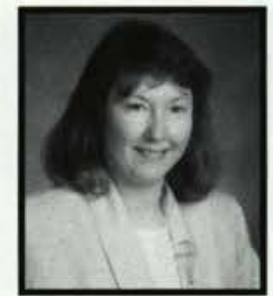

Katherine Parr

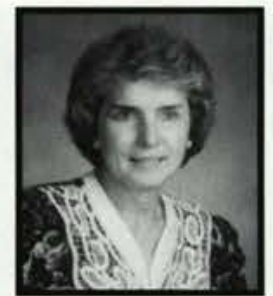

Joyce Reese

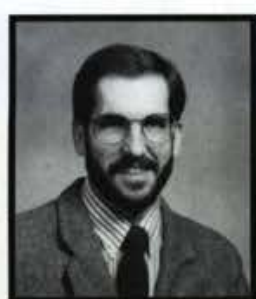

Mark Mathews

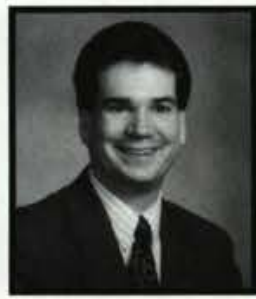

Douglas Miller
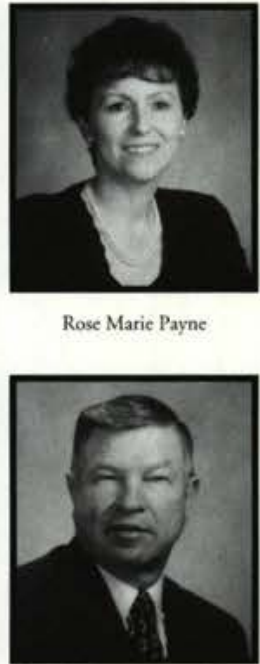

Pete Reese
Rose Maric Payne

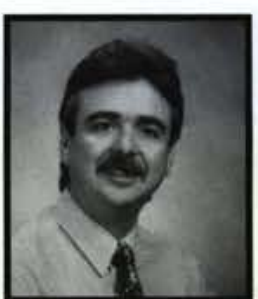

Wayne Maxie

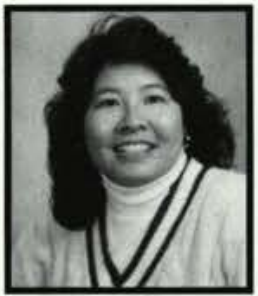

Michelle Miller

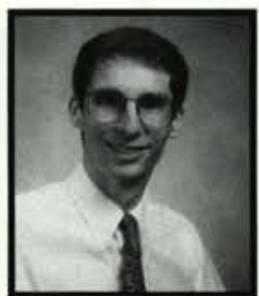

Douglas Phillips

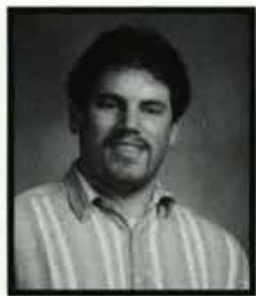

James Rinaldi

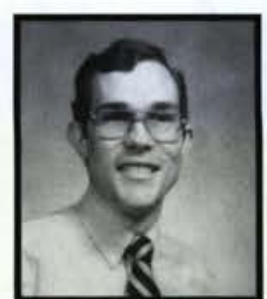

Alan MoCain

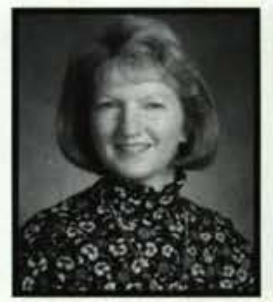

Mary Mitchell

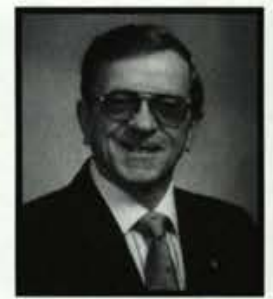

Edmond Phillips

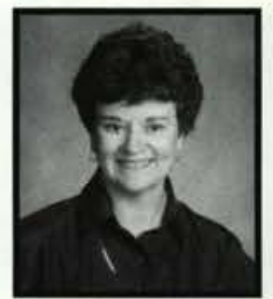

Beverly Robey

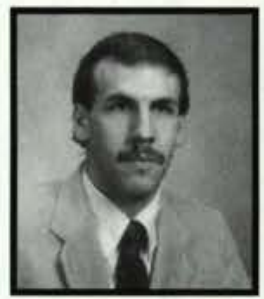

Robert Scott

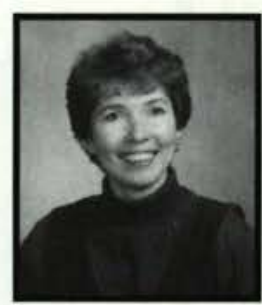

Tammy Slone
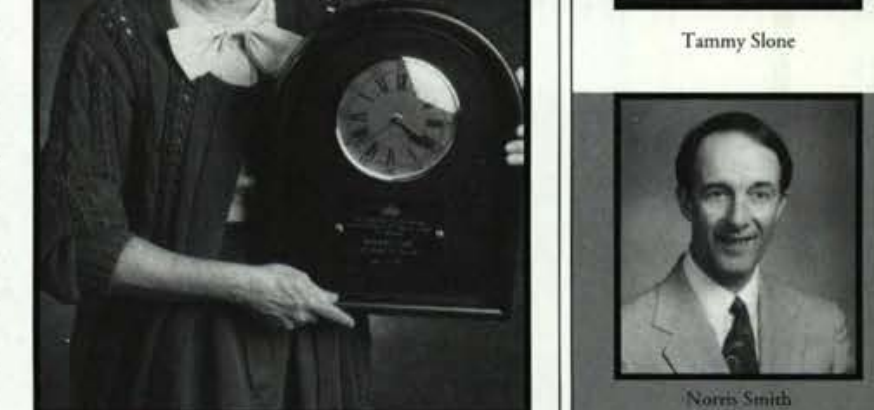

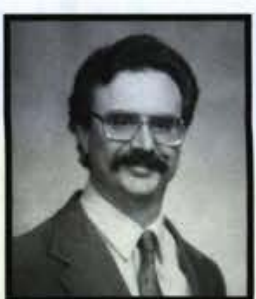

John Mclntosh

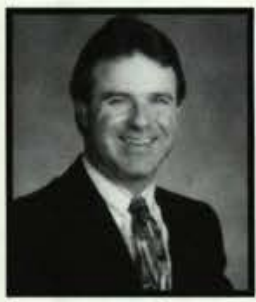

Brian Nester

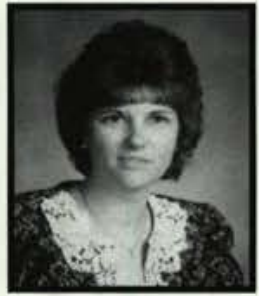

Ruth Prugh

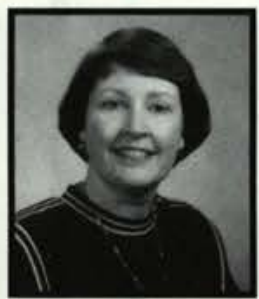

Lynn Rohm

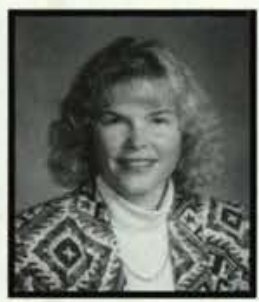

Cheryl Sims

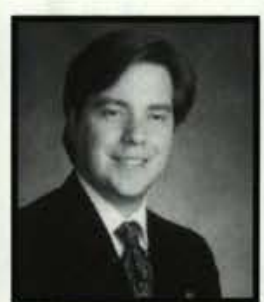

Benjamin Smith

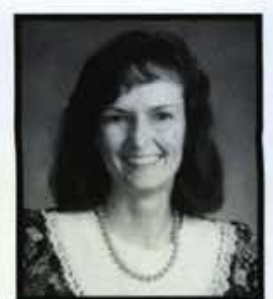

Mischell Mclntosh

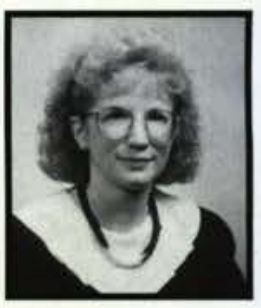

Luann Nicholas

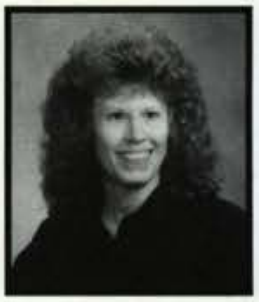

Nancy Ranger

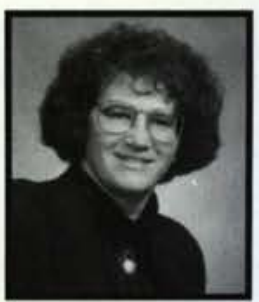

Jayne Russell

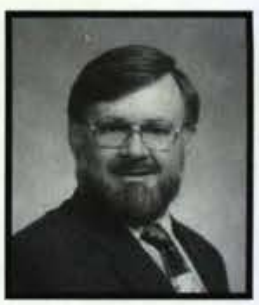

Jon Skillman

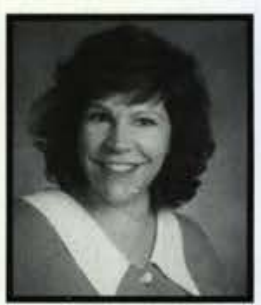

Jane Smith She and her husband were missionaries to Puerto Rico for a year. For twelve years, she served effectively as Don Rickard's secretary. From there, she became the text book manager at the bookstore where she rearranged the whole text book room. She is very well organized, and she encourages departments to order their books by baking cookies for the first department with their order in place.

Deborah Rotman 


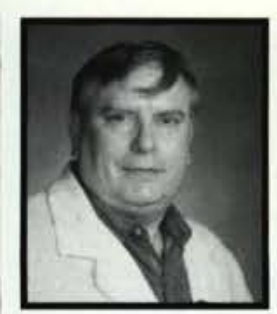

James Stauffer

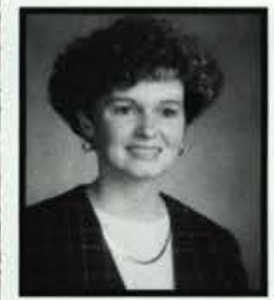

Susan Varotti

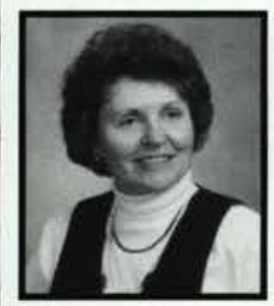

Pat Warren

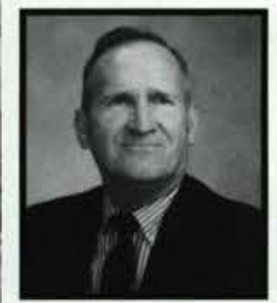

Jay Womack

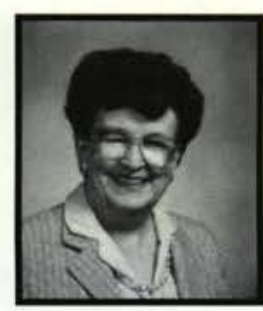

Joan Street

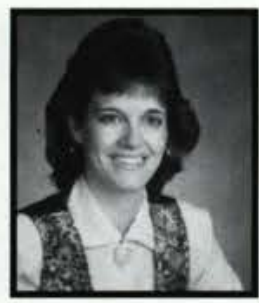

Bonnie Vickman

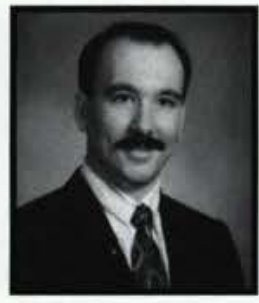

Lee Webb

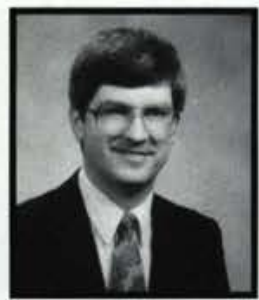

Mark Womack

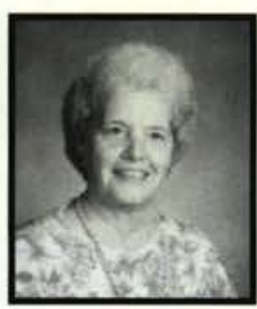

Eleanor Taylor

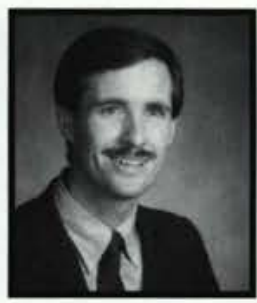

Jeffrey Vickman

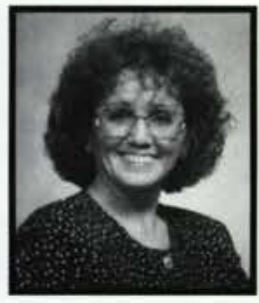

Linda West

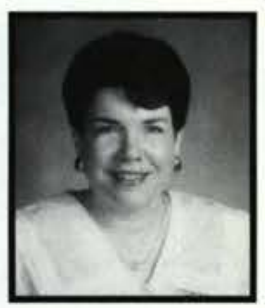

Sherrie Wood

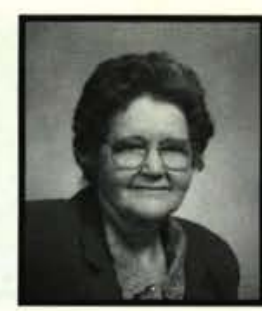

Virginia Taylor

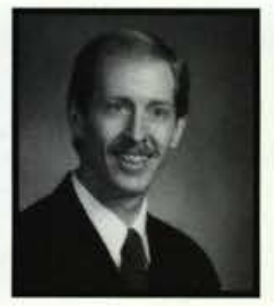

Kenneth Vickman

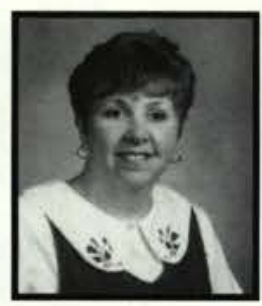

Nellic West

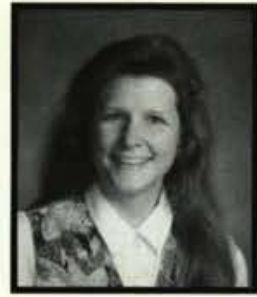

Sue Terkelsen

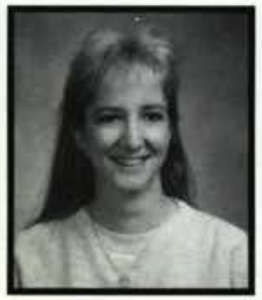

Trudee Wagner

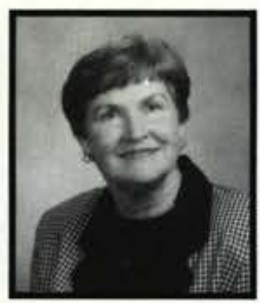

Phyllis Wetzel

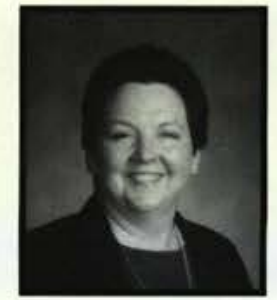

Deborah Thacker

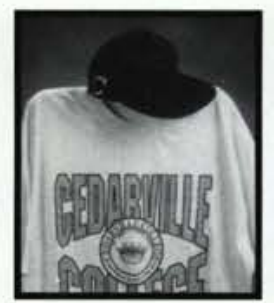

Dick Walker

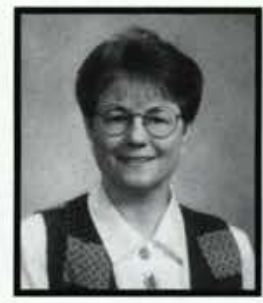

Joy Williams

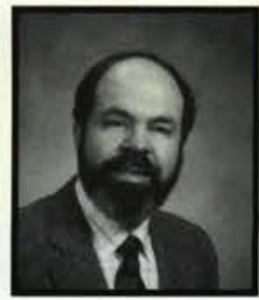

John Tocknell

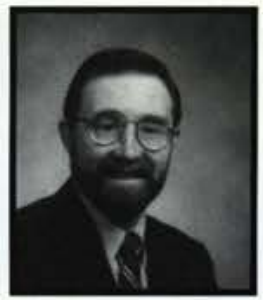

Paul Ware

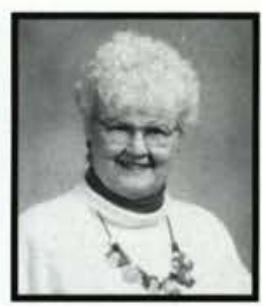

Glenda Womack
Remembering Ma Printy

She was born Beatrice H. Printy on May 29, 1910, but at Cedarville College everyone called her, "Ma." Ma Printy went to be with her Lord on October 8, 1994, but leaves behind a legacy that will last forever.

Printy took the college by storm when she arrived in 1971 at 61 years of age. She first served as dean of women but spent most of her time at Cedarville as the resident director of Maddox Hall. She quickly won the love and respect of those around her. Ma Printy was so loved by everyone that, according to President Paul Dixon, Printy Hall was named for her in June of 1979, seven years before she retired from Cedarville.

Ma Printy devoted herself to the Lord and to other people. Agnes Biddle, a close friend of Printy's and the first resident director of Printy Hall, said, "She was saved late in life and was excited about the Lord right away. Until the week before she died, she was doing visitation."

Everyone who knew Ma Printy would remember her for her high energy level, evident in everything she did. People often called her a character, a campus personality whom everyone loved. She was involved in literally everything going on around the campus.

In 1980, she and Dr. James Phipps '68, chair of the department of communication arts, ran in a "Cedar What" mock election. Even her 70 years did not stop Ma Printy from climbing to the roof of Williams Hall to give a campaign speech!

According to Michael DiCuirci, associate professor of music, Ma Printy did not hesitate to get involved with the pep band at basket-

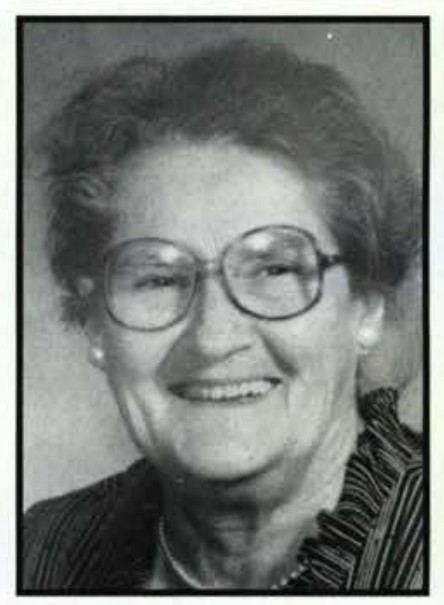
ball games, even though she had no formal training in music.

Ma Printy is remembered and respected for much more than just her funloving side. She was a hero of the faith who made a strong stand for the Lord. "When I think of her, I think of a godly lady with class, someone who really enjoyed life and loved people. She obviously loved the Lord and was faithful in her prayer life," said Don Rickard, vice president of student services.

$\mathrm{Ma}$ Printy was in touch with the students, and everyone knew they could come to her for advice. She was always willing to talk, which she did while shaking her long pointer finger.

Many of this generation of students do not know about the woman behind Printy Hall. She loved Cedarville with all her heart and put all she had into the lives of those who came in contact with her.

It is a very special person indeed who can affect the lives of so many, even after her death. She leaves behind her a challenge to put Christ and others first, to never let your faith grow stale, and to never slack off in your service to others.

This article was taken from "Ma Printy Leaves a Legacy" by Rhonda Carnahan, Cedars (vol. 43, issue 5, 11/11/94) 


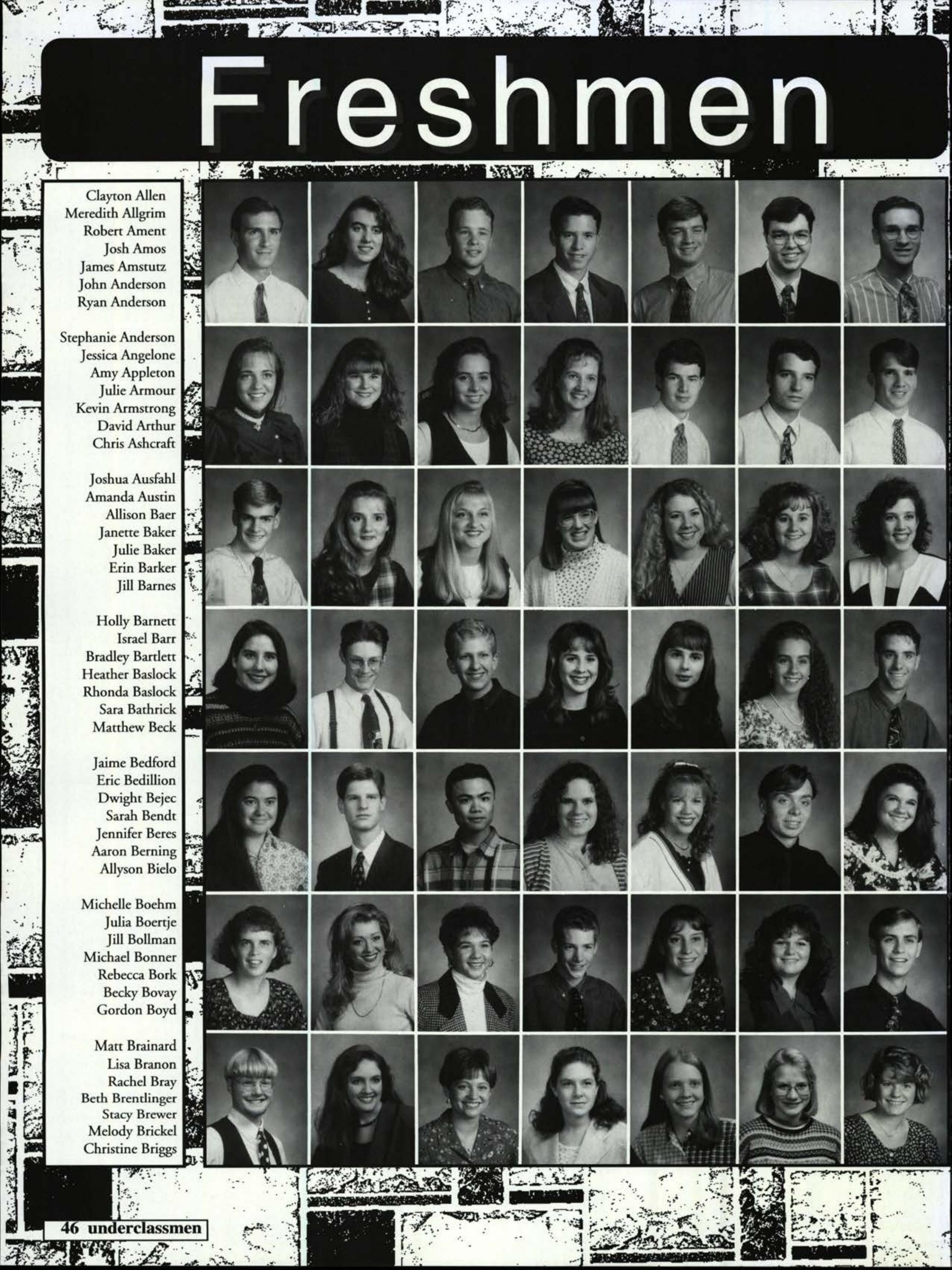




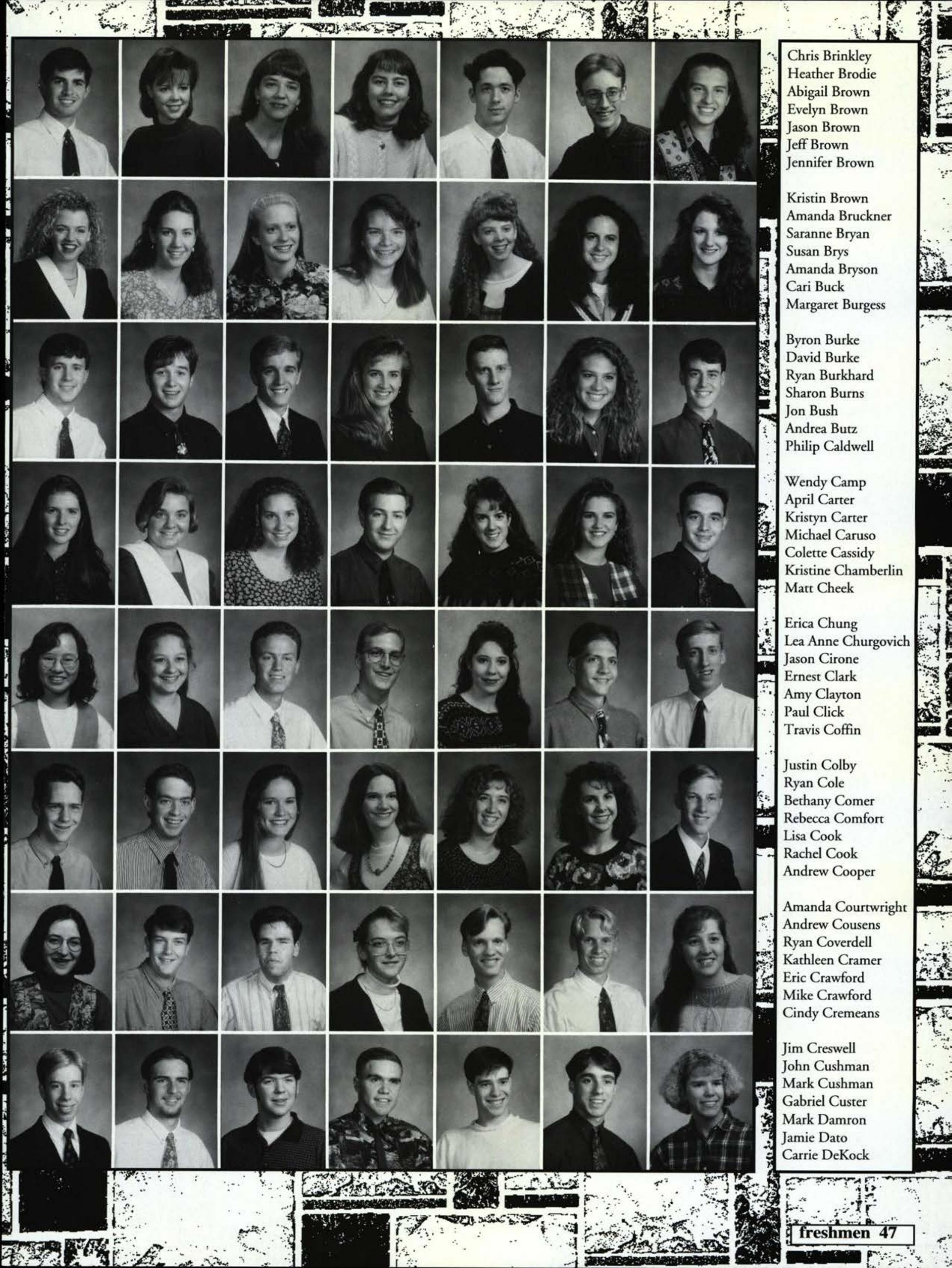




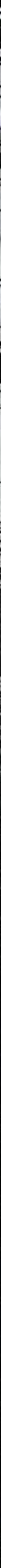




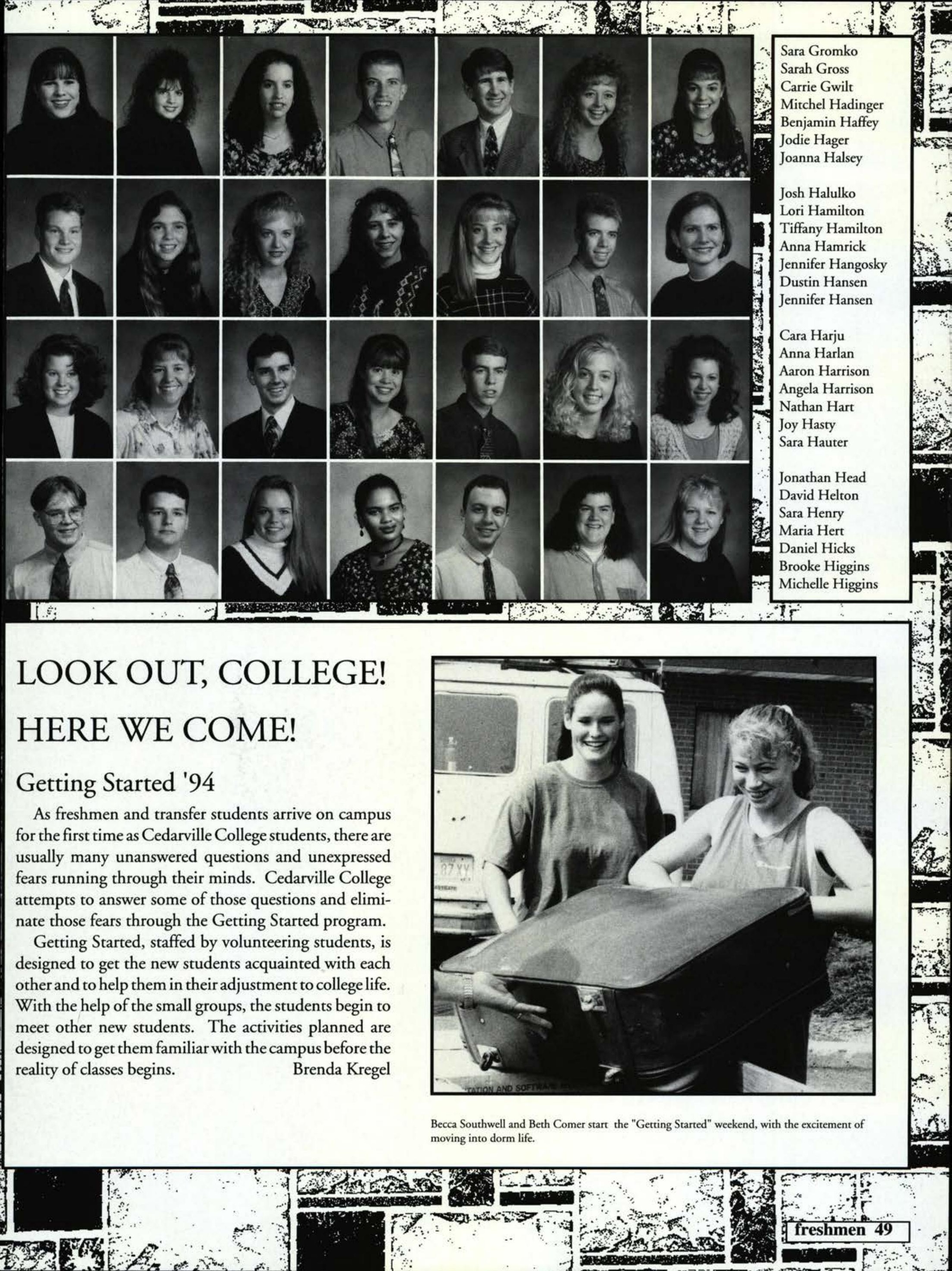




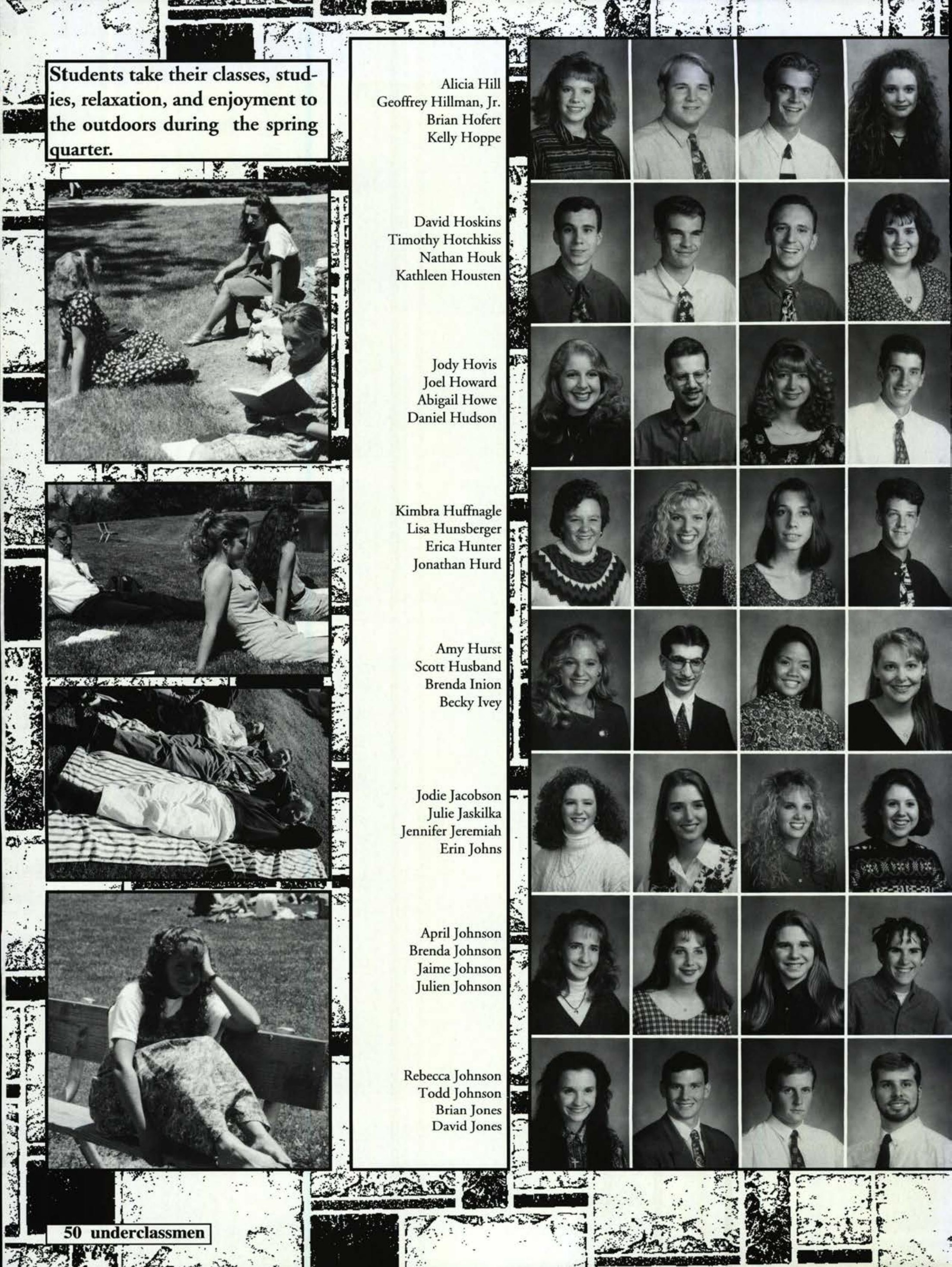




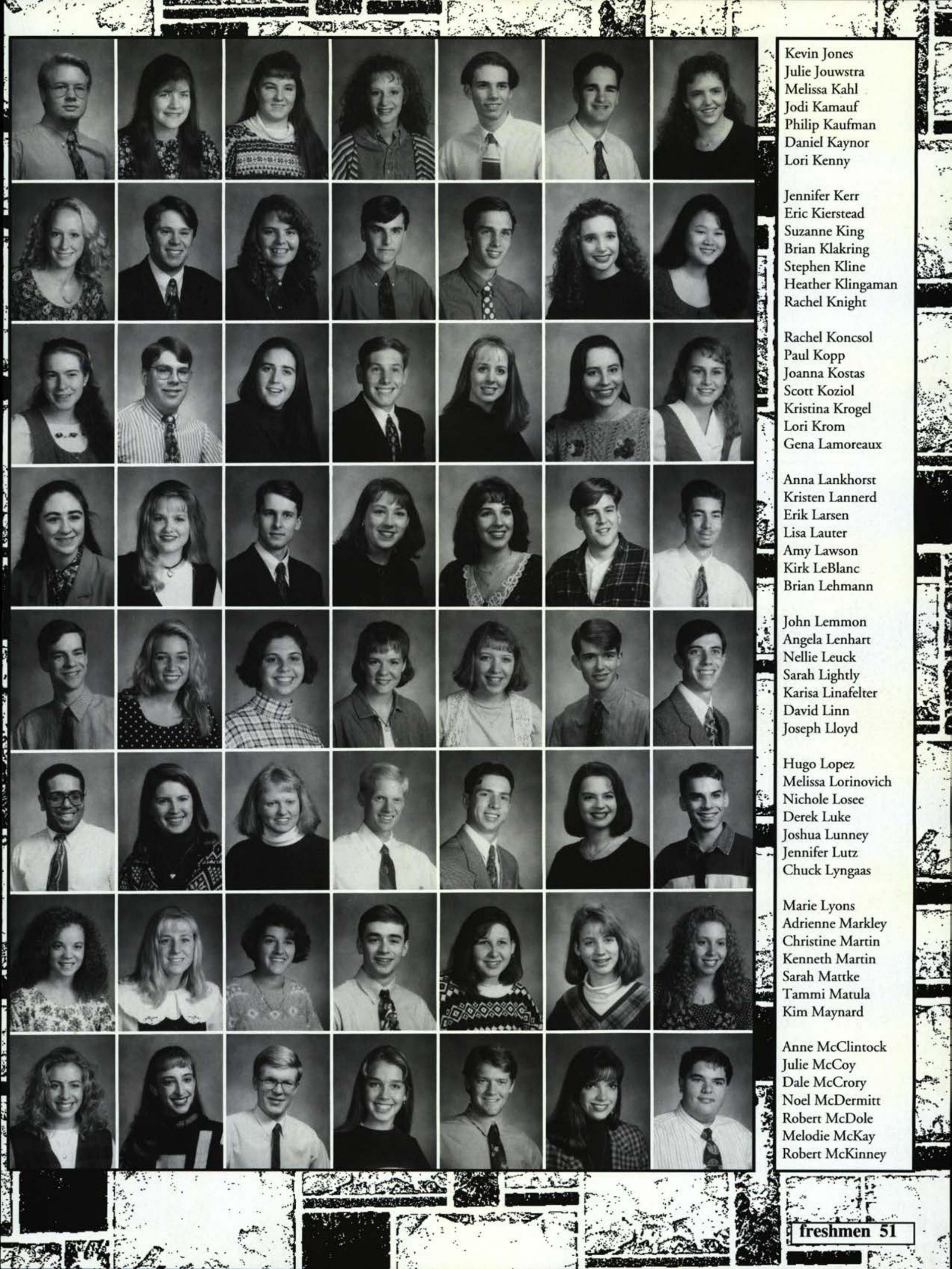




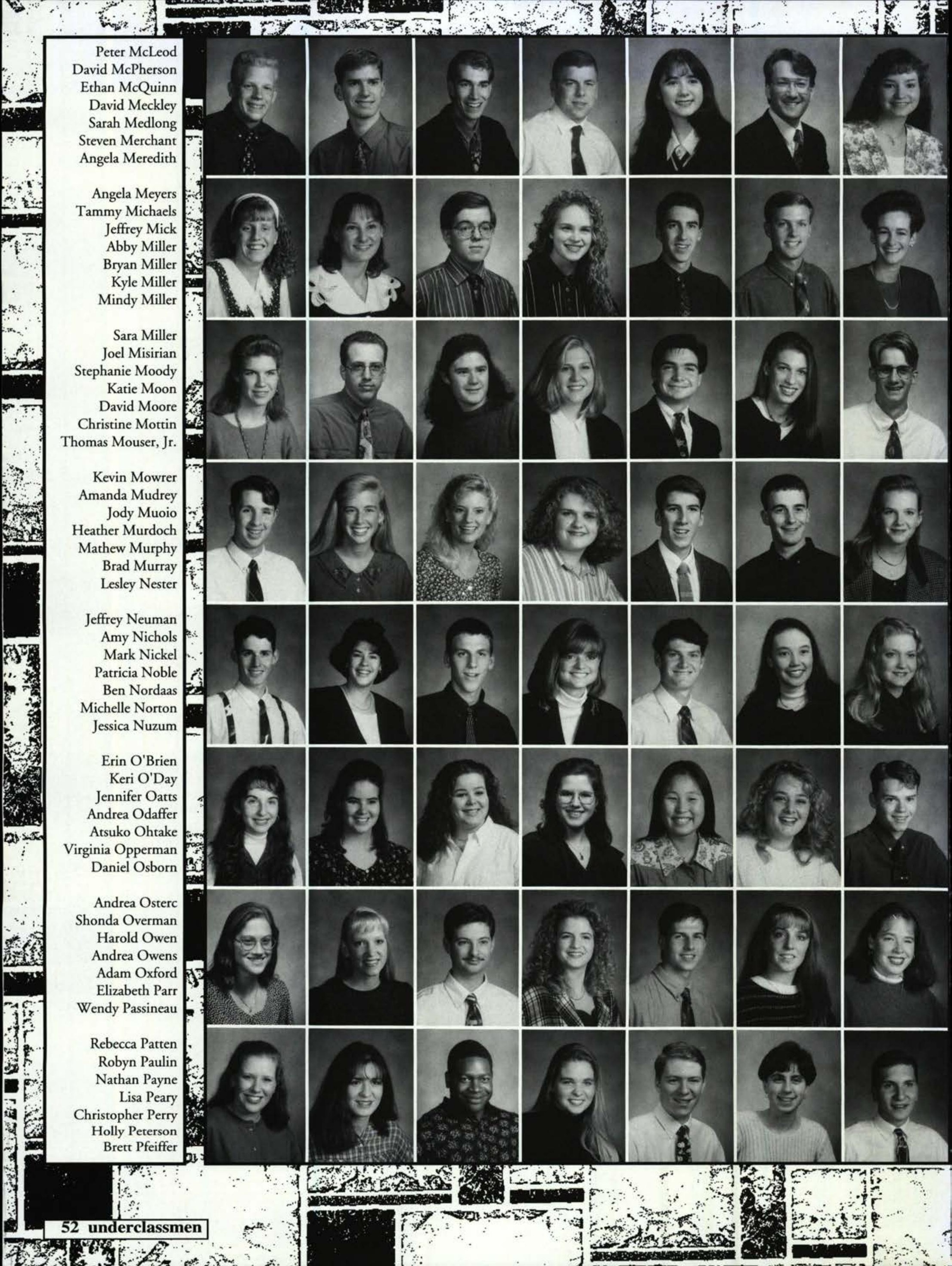




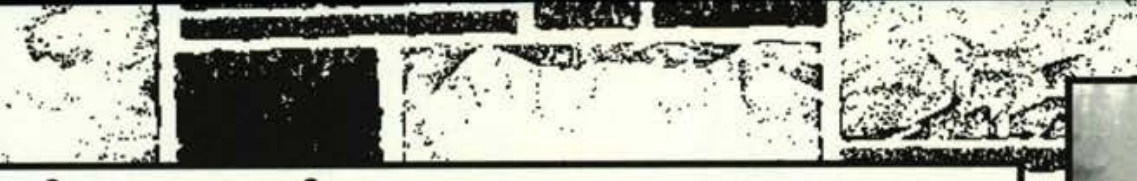

\section{Rain, rain, go away...}

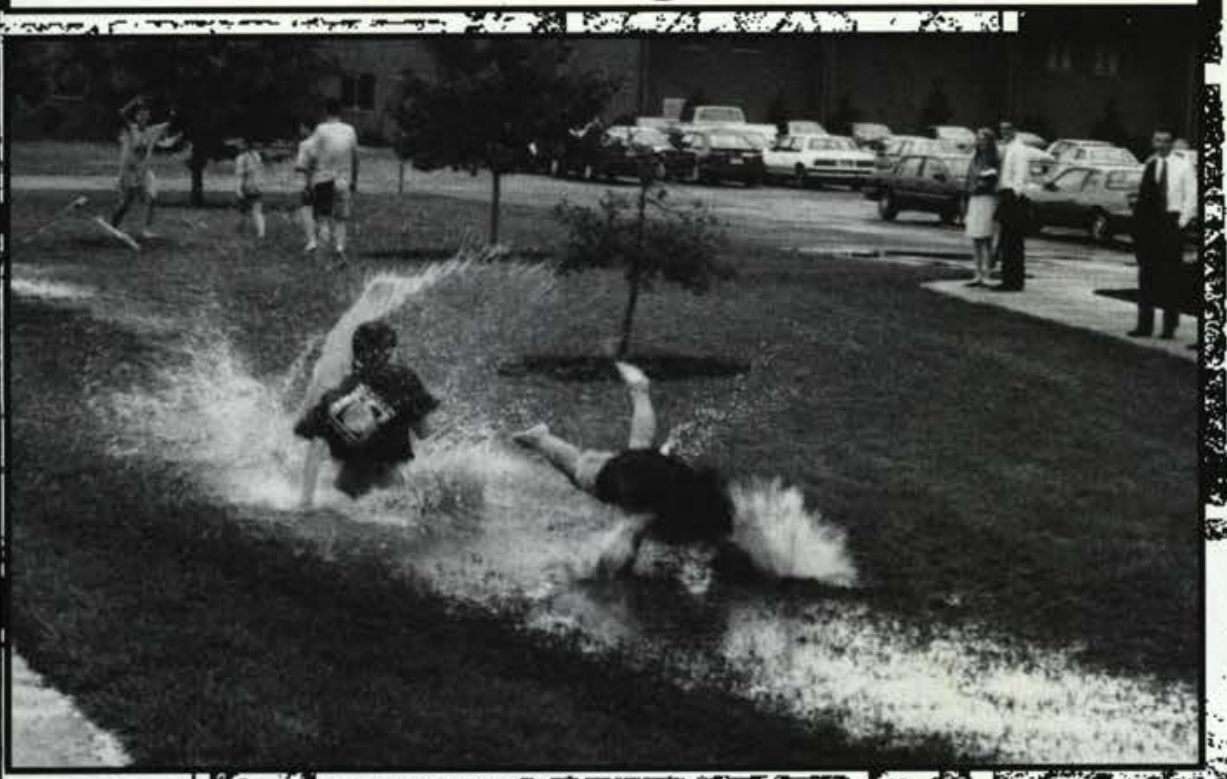

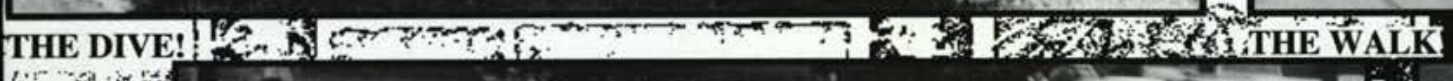

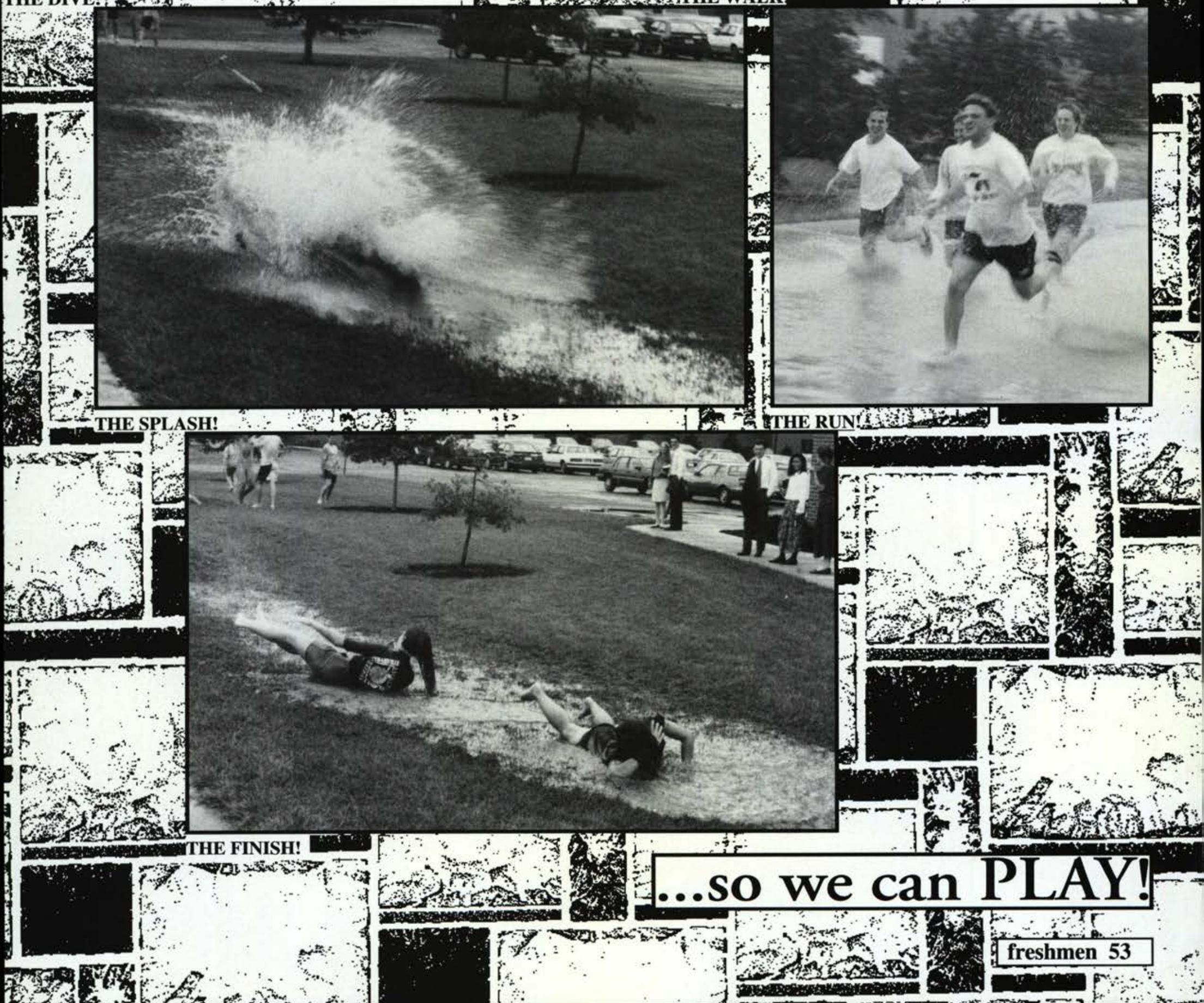


$\sin _{1}$ 


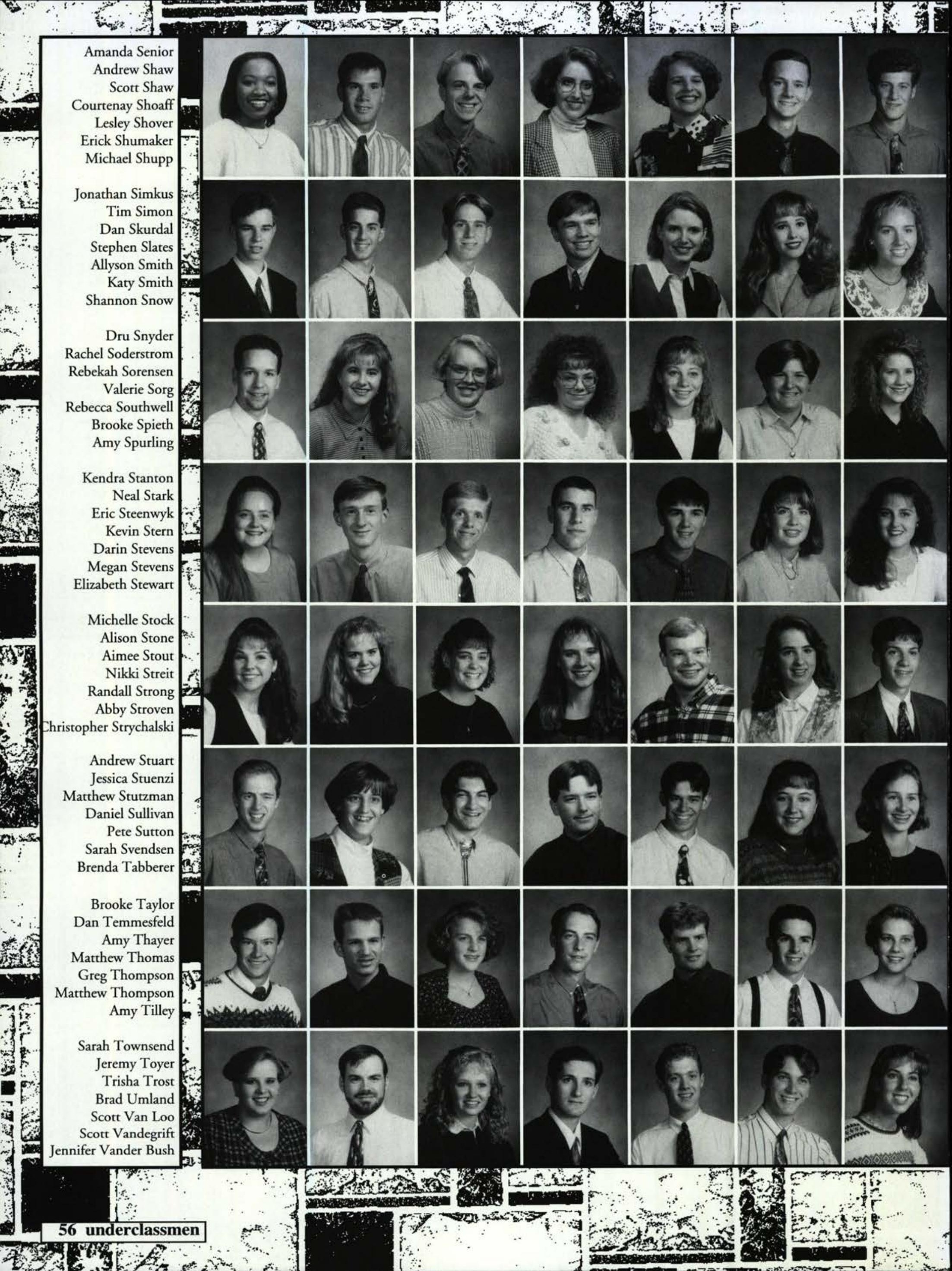




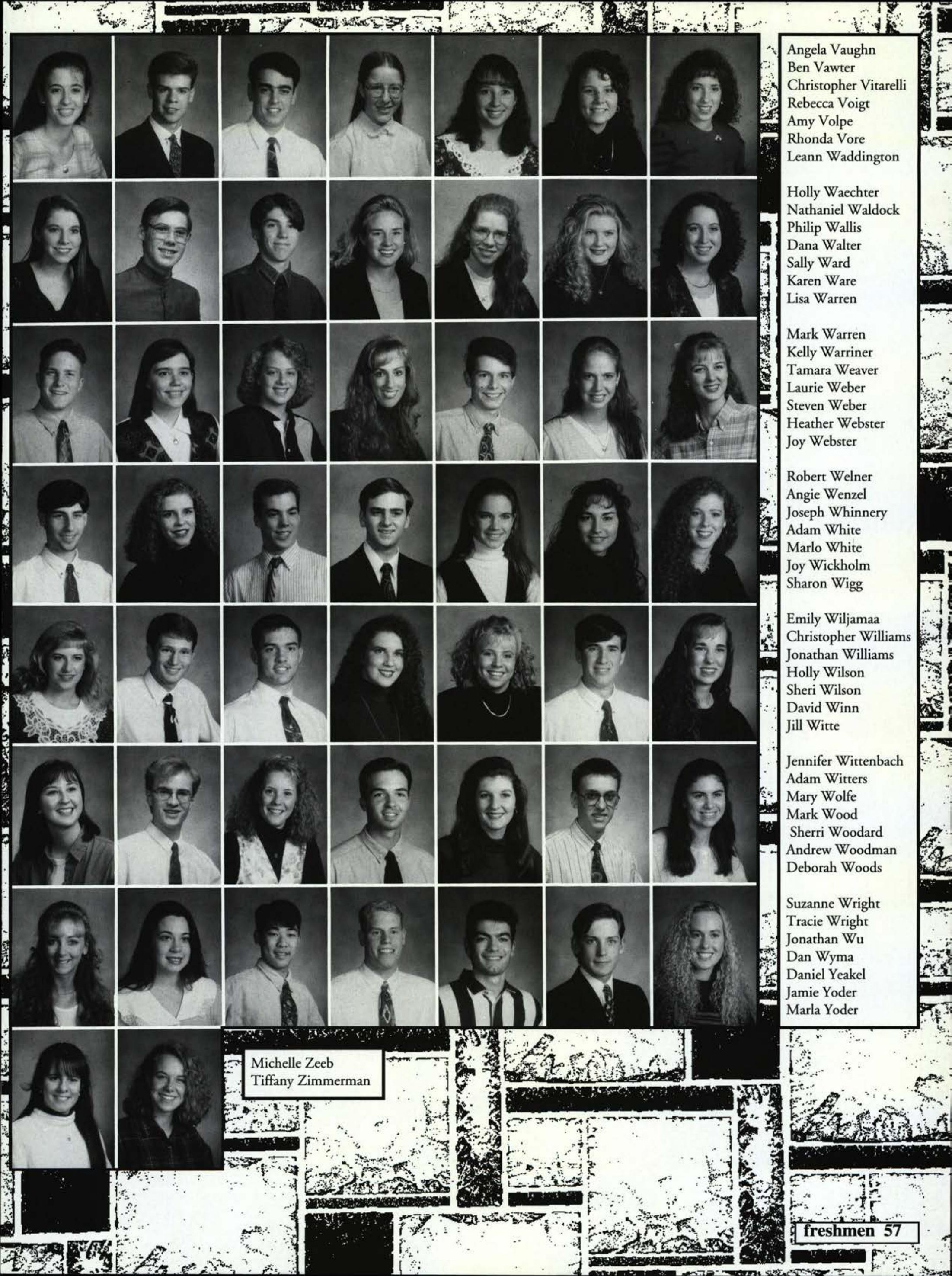



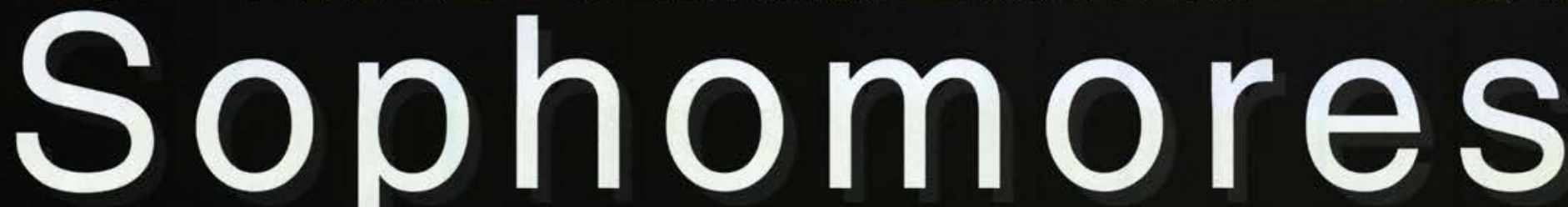

t)

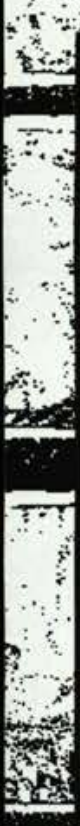

Stephanie Akom

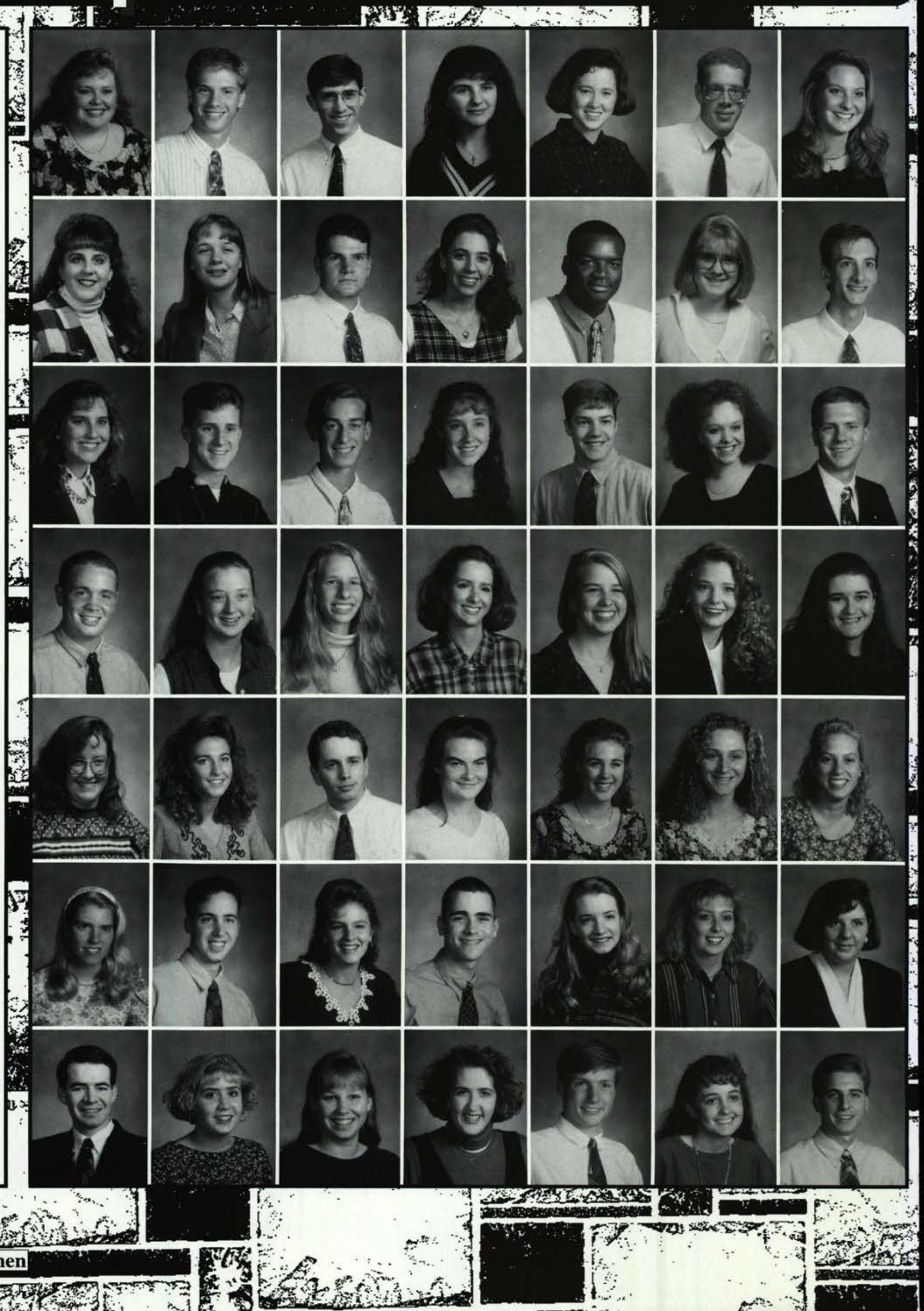

Andrew Alderfer

Kerry Allen

Elizabeth Amos

Doug Amundson

Amy Anderson

Lori Anderson

Adria Andrews

Erik Anglund

Andrea Anthony

William Armistad

Melissa Armitage

Aaron Armour

Valerie Ashurst

Jason Atwell

Nate Auffort

Johannah Augustine

Graig Austin

Jill Avery

Rick Baab

Justin Bailey

Krysty Bailey

Christina Baley

Kimberly Bandy

Carilyn Barber

Virginia Barrett

Rachel Batchelder

Venessa Bateman

Amy Bathrick

Douglas Bayler

Mary Beth Beal

Shannon Bean

Jamie Beck

Joy Beitler

Kimberly Bell

Brent Bergandine

Heather Bethel

Christopher Bibler

Almeda Bierly

Jennifer Blackburn

Mary Jo Blanton

Philip Boggs

Angela Bohlen

Jennifer Bolt

Elizabeth Boone

Robert Bouwens

Angela Boyce

Scott Bradley 


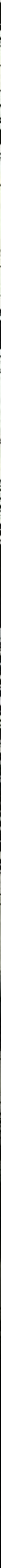




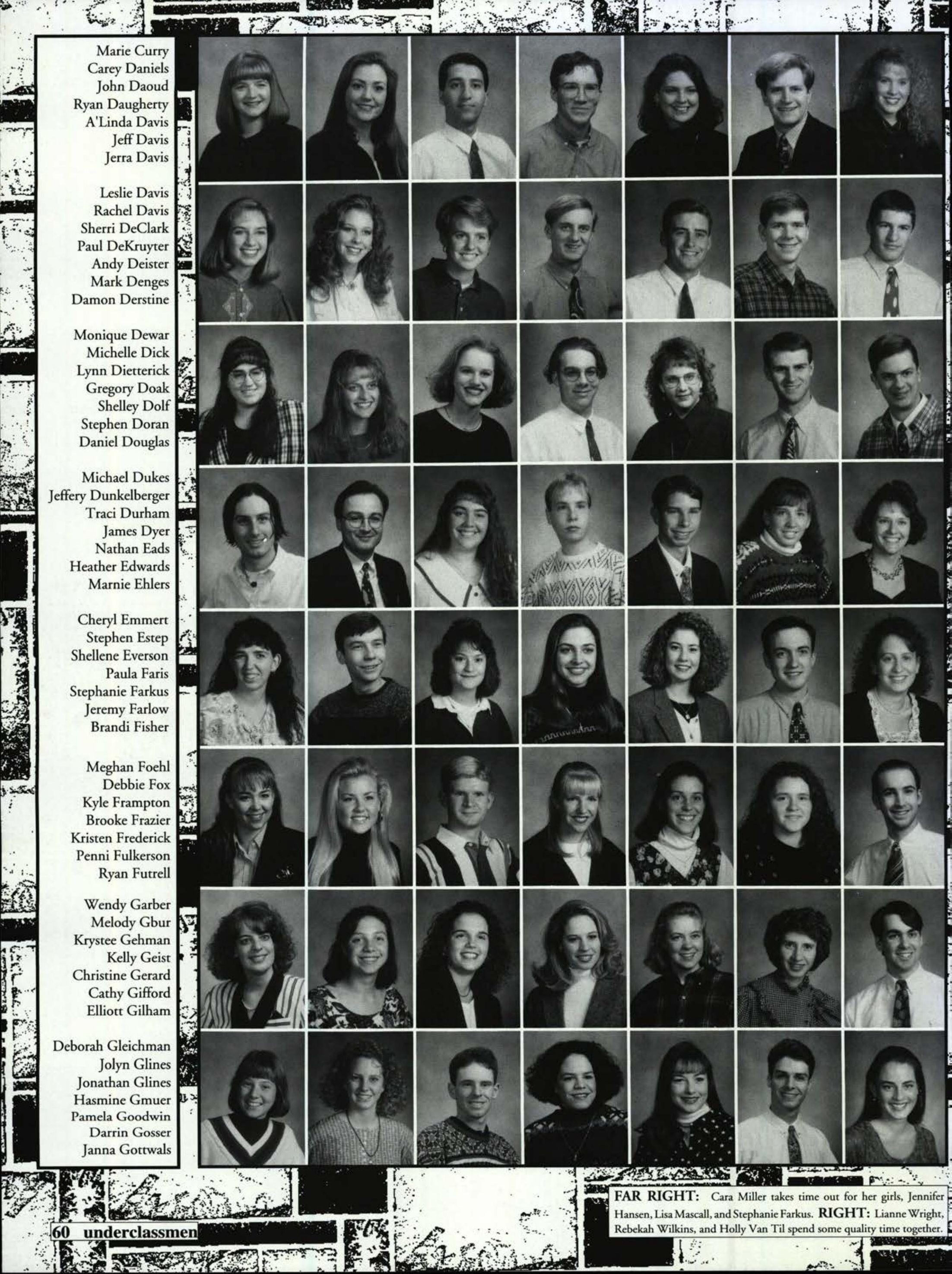




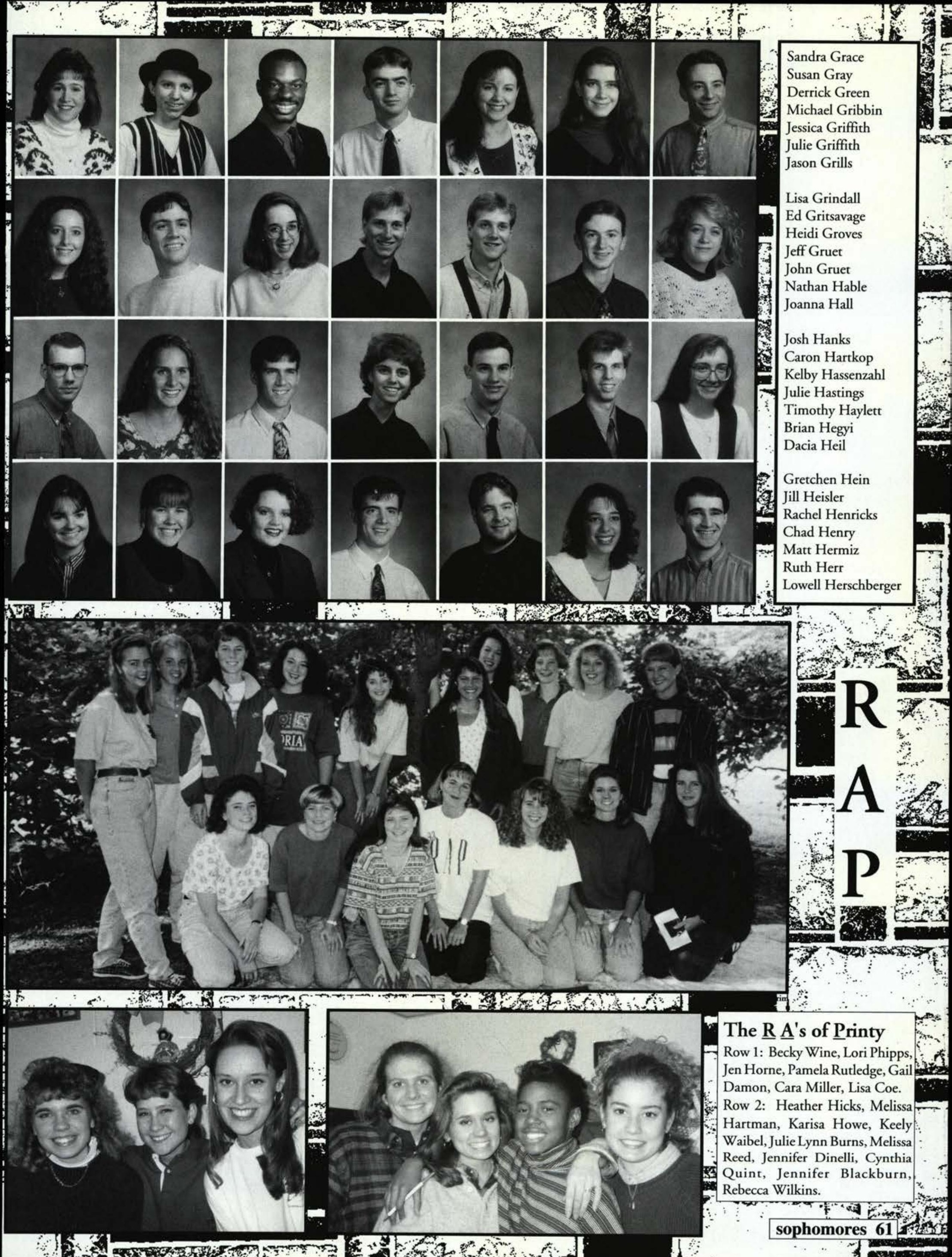





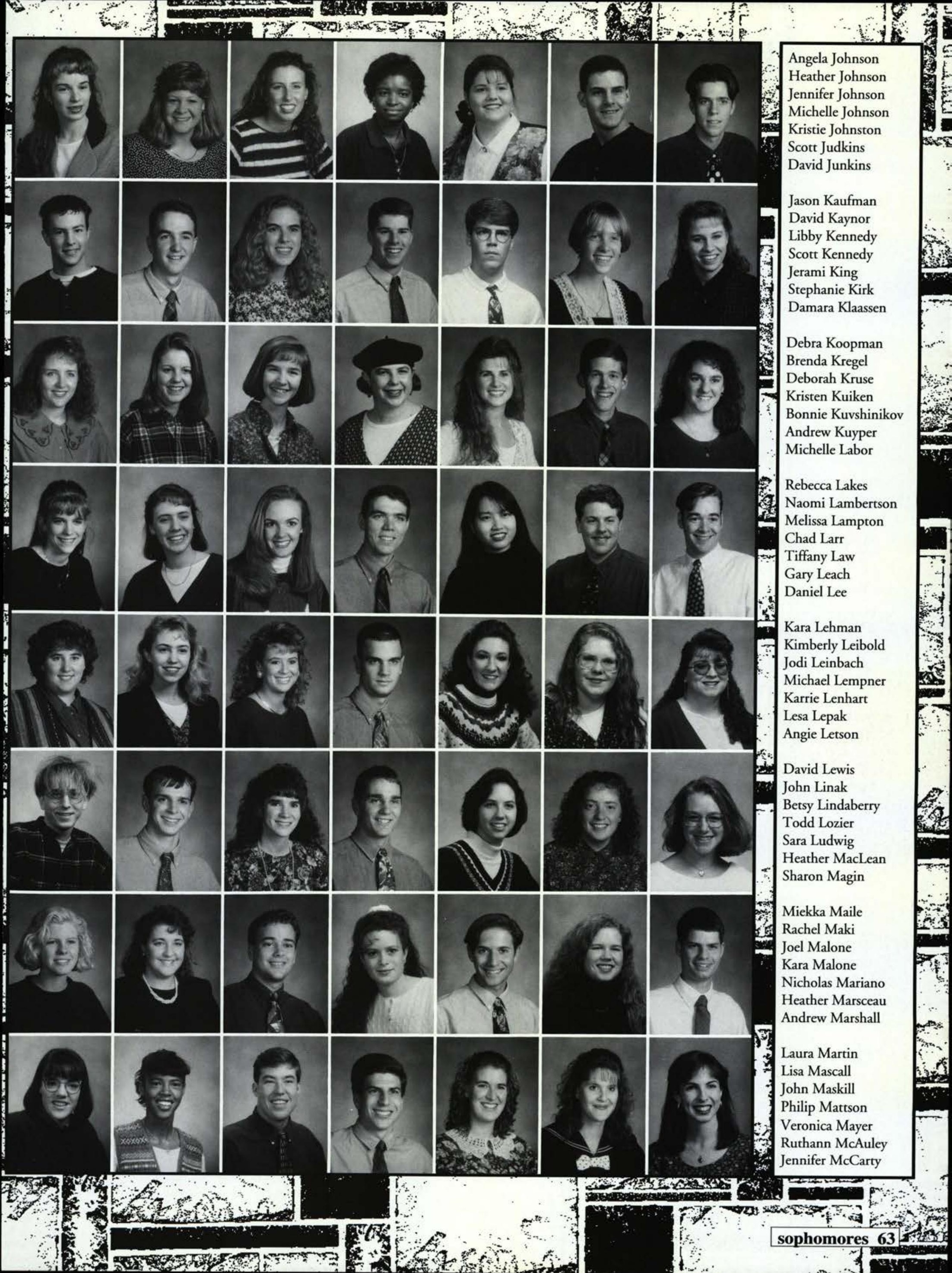




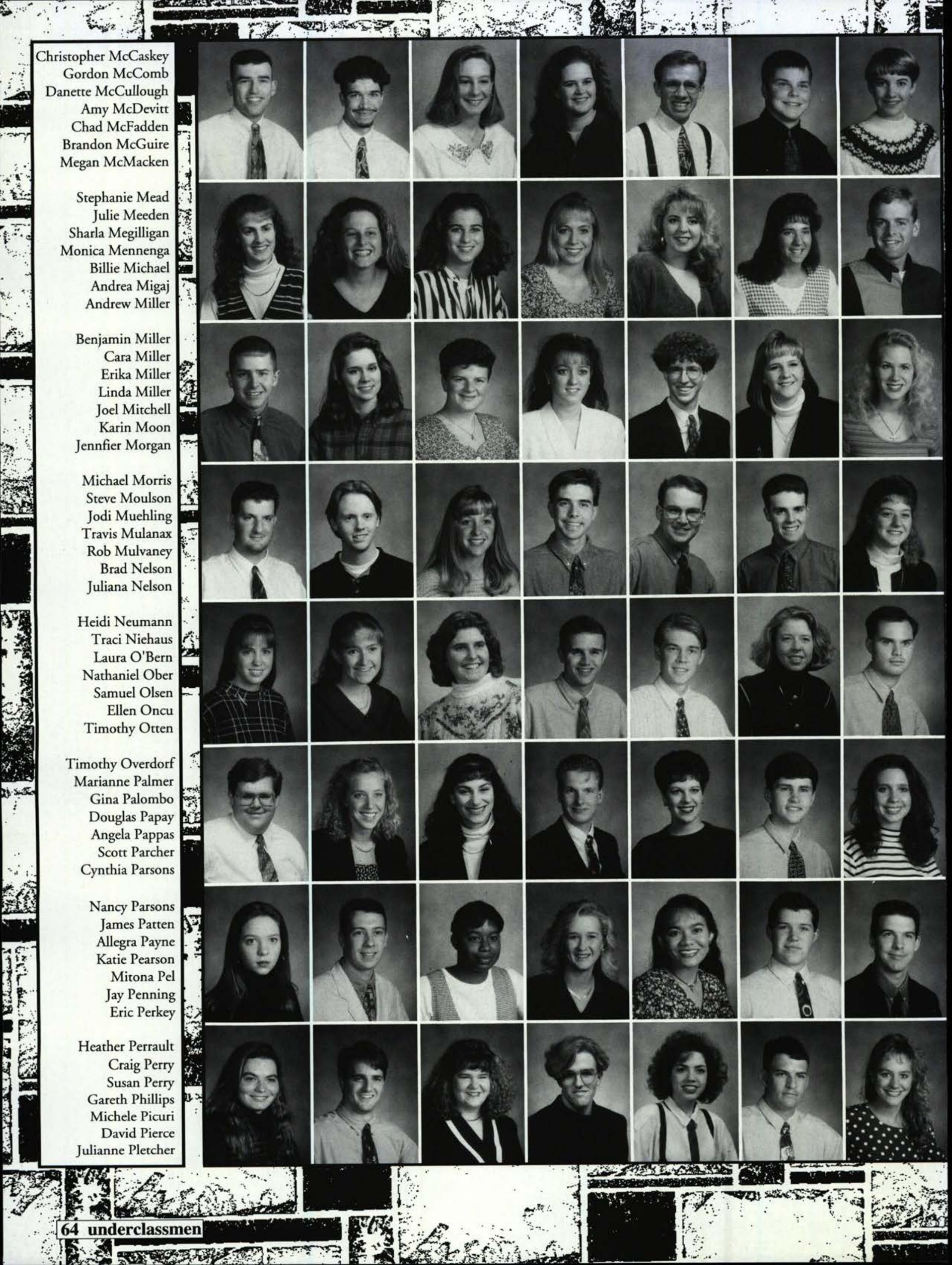




\section{$k_{i}$}




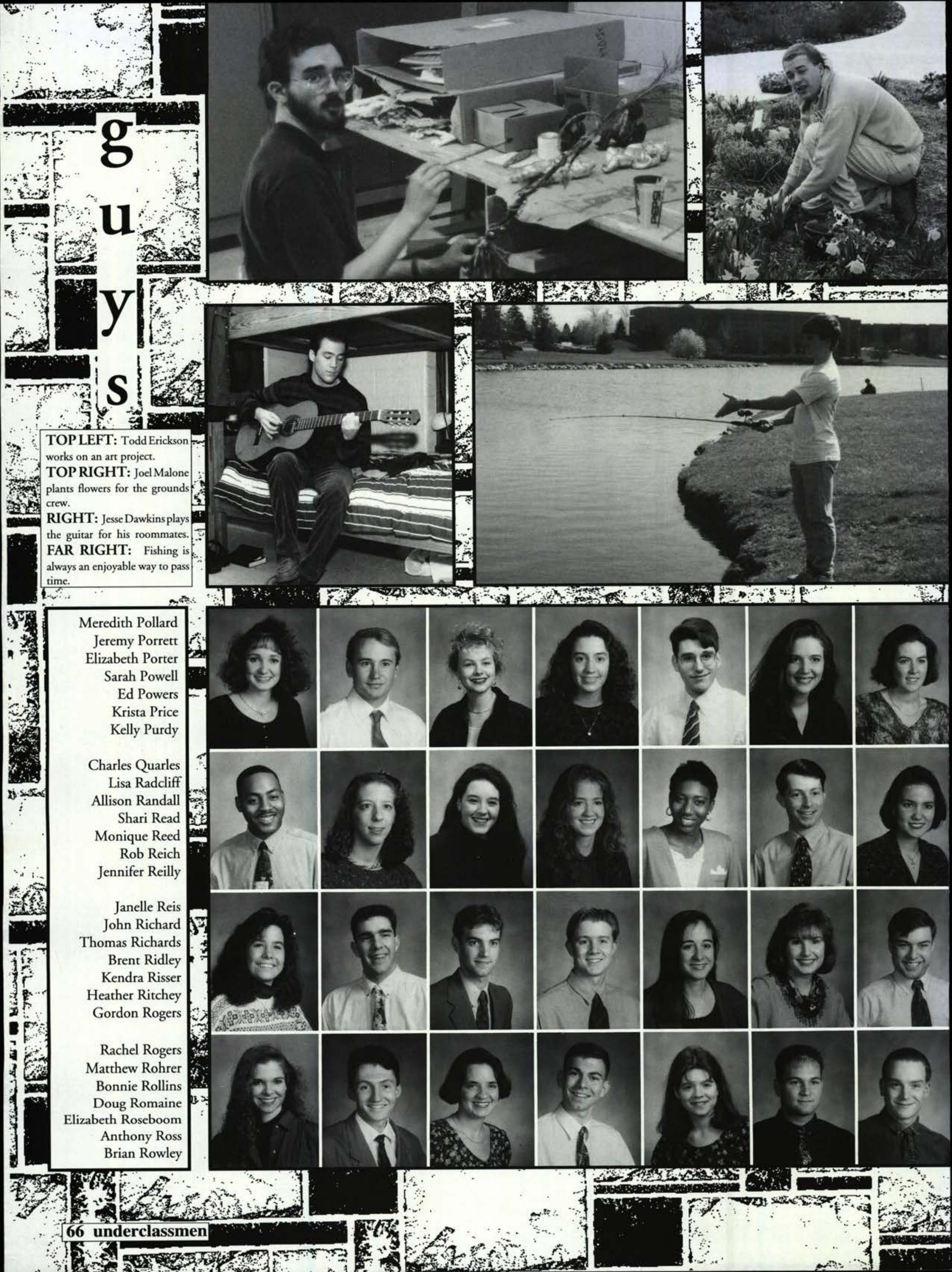




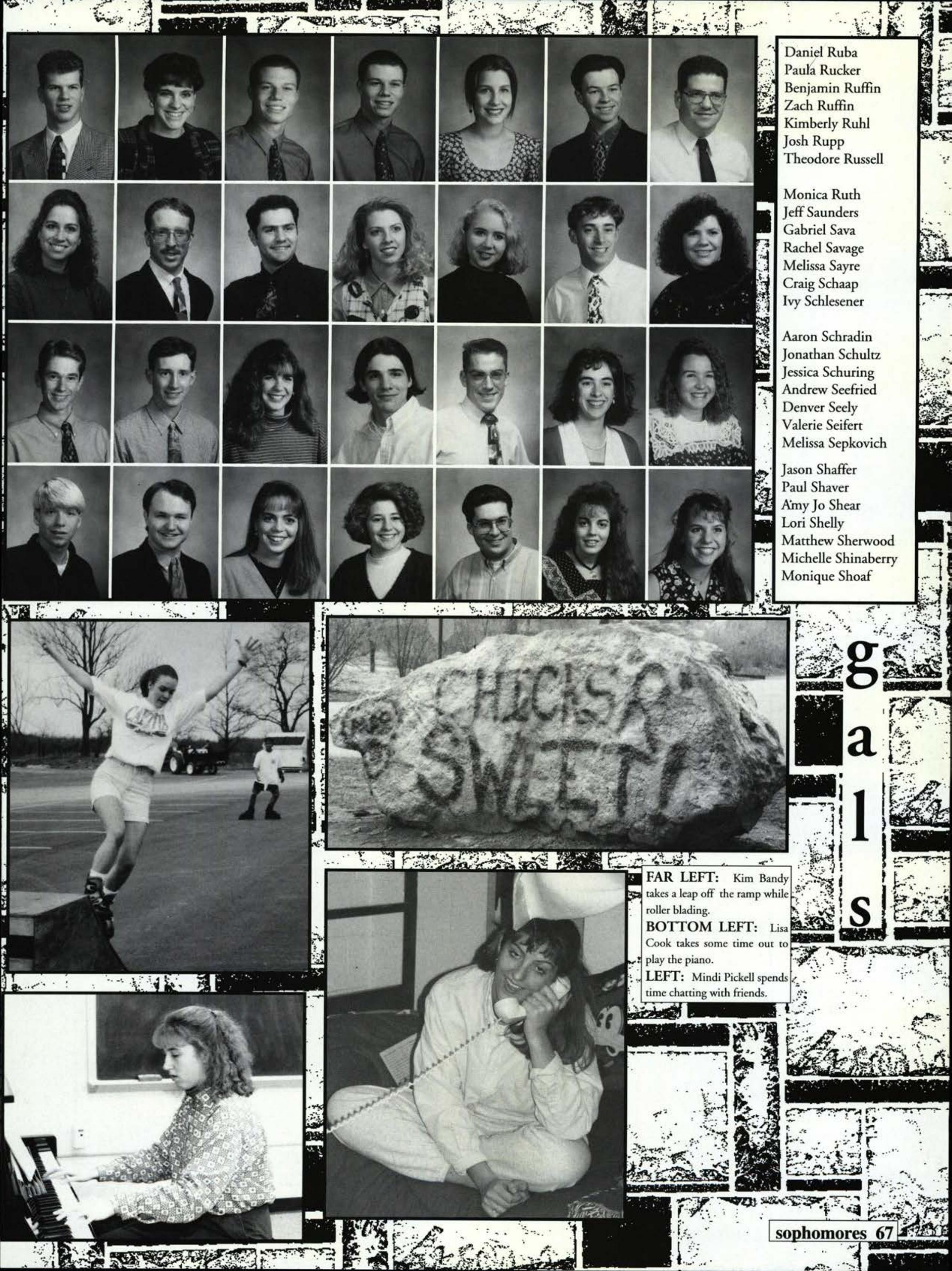


a

Deresa Short Jon Shrubsole Pamela Sibole Melinda Silvius Antionette Sivic Andrew Smith Darrin Smith

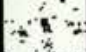
singen

Gwenyth Stambaugh Jeff Starkey

Christina Stauffer Edith Steele Samantha Sternad Melinda Stewart Robert Stiles

Heather Stille Elizabeth Stinson Elizabeth Stone Michael Stone

Tobin Strong Benjamin Stutzman Duane Stutzman

Jennifer Summers

Brodie Swanson David Swasey Deborah Sweeney Tara Swiger Anna Taylor Cathy Taylor

Jamie Tegtmeier Shane Tenny Sarah Terpstra Scott Thomas Scott Thomson Anthony Torlone Matthew Towle

Ray Townsend Renee Tuinstra Hannah Turner Jason VanHeukelum Lisa VanWormer Mark VanderLinden Natalie Vandemark of

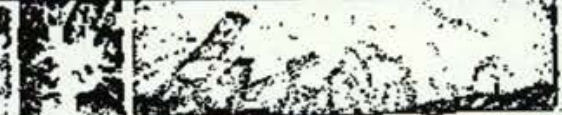
68 underclassmen $5 \times$.

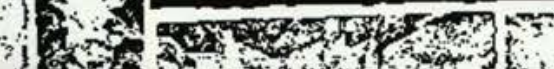

Shannon Snyder
Heidi Sorensen David Southwell 标 得 $\div$ $\rightarrow$ 5

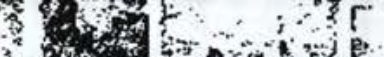

18

.

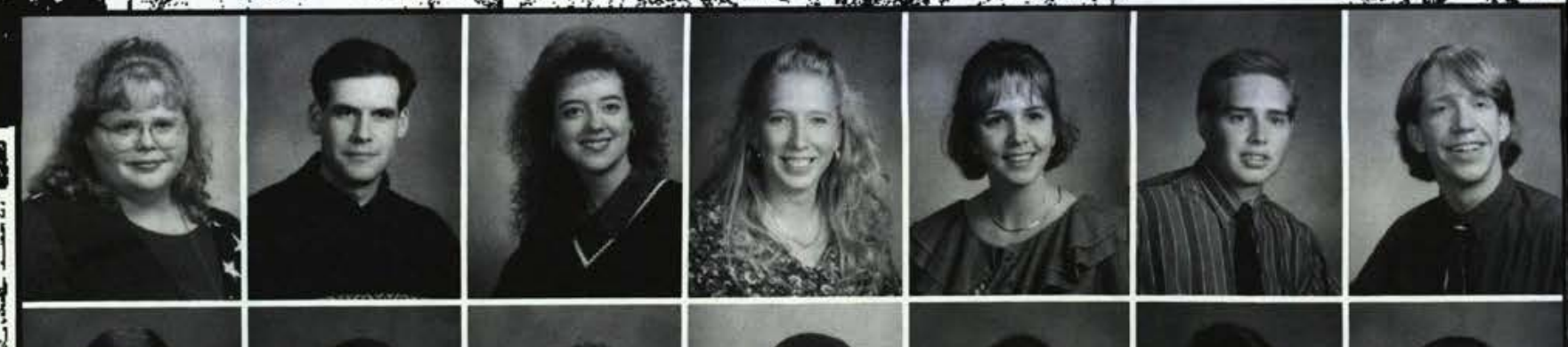
MBM

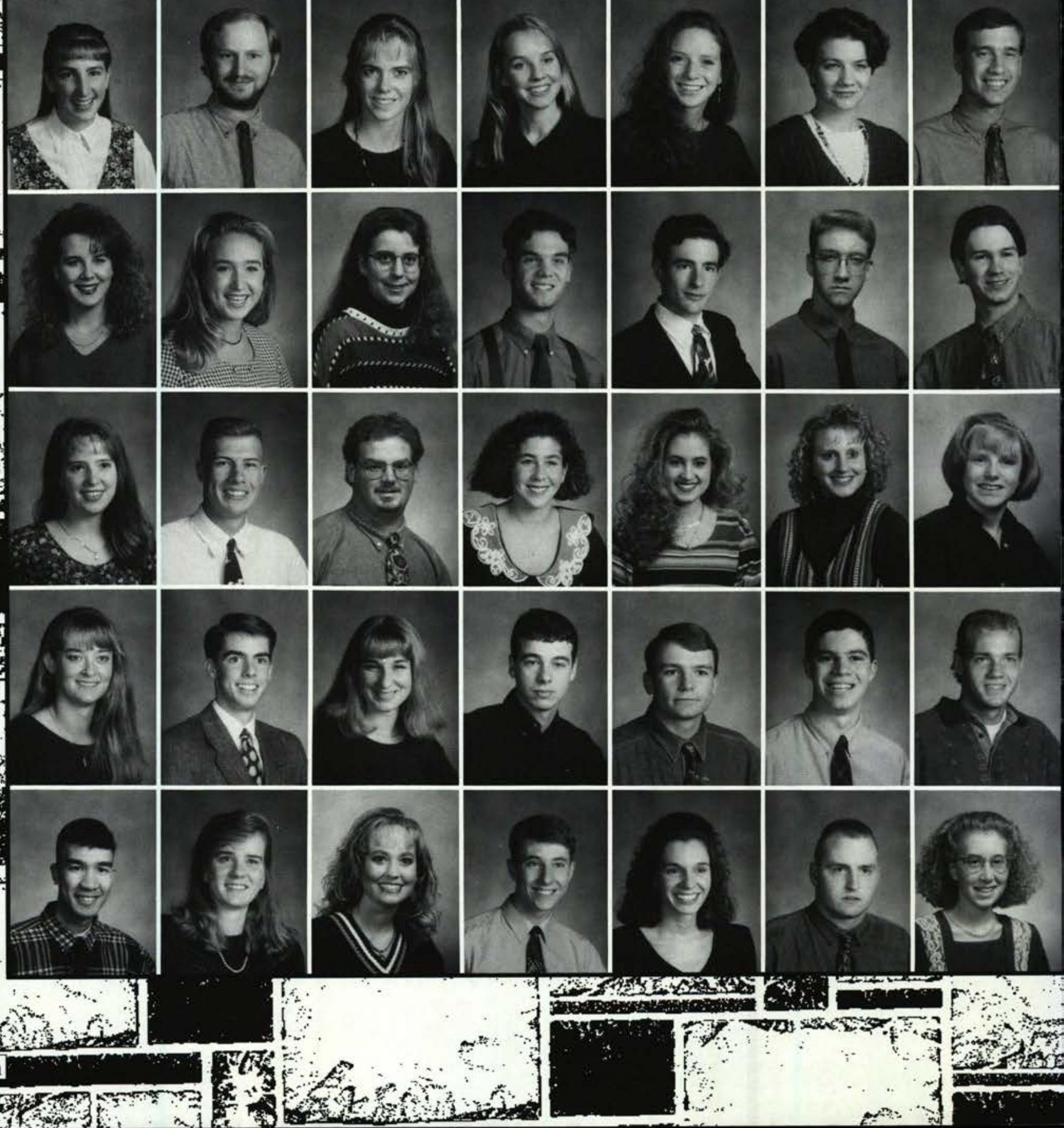




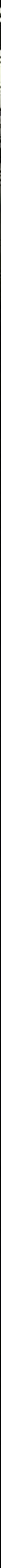




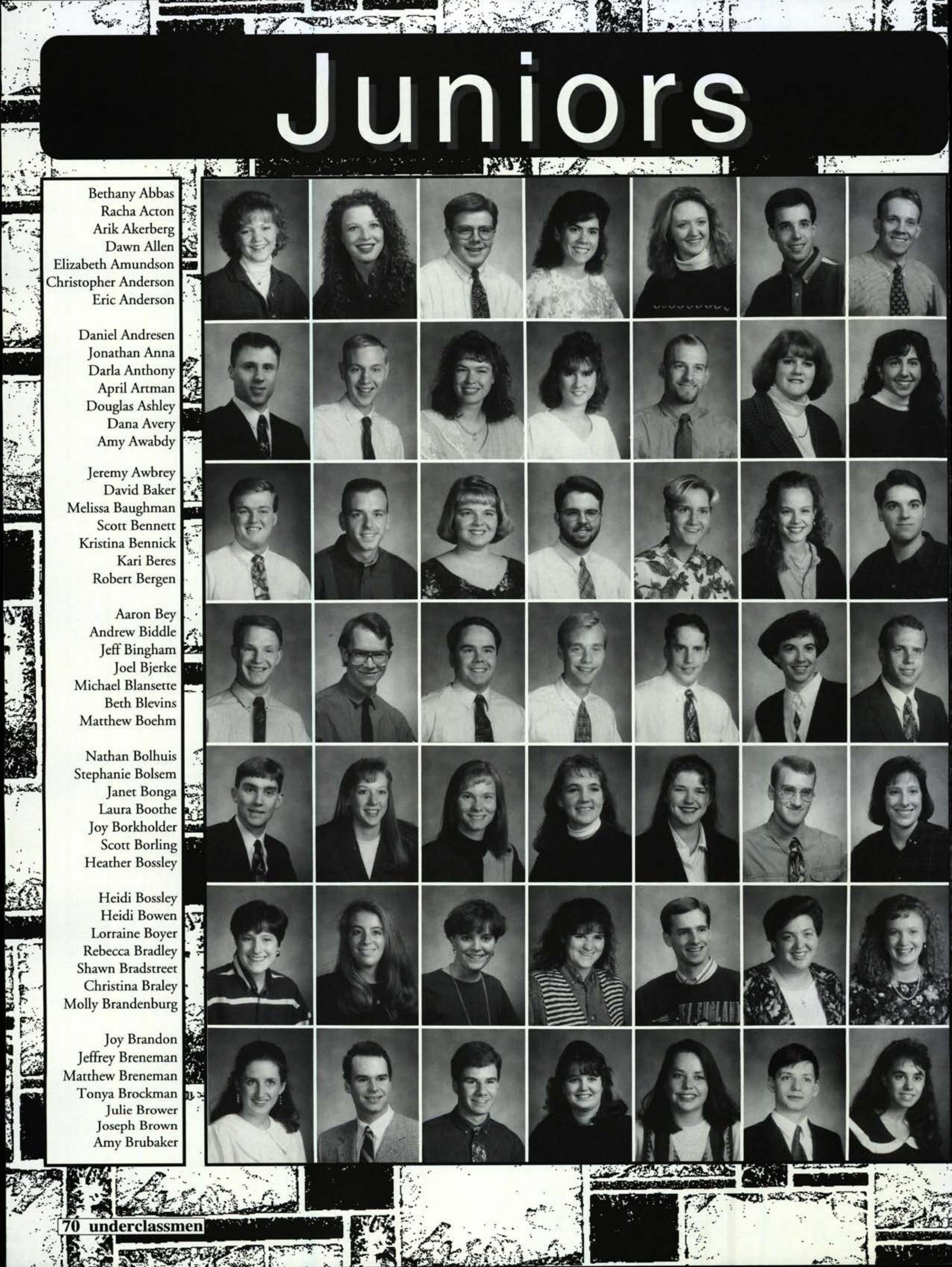




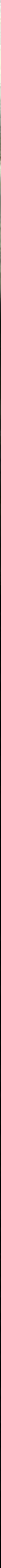


Wh 
$9=$

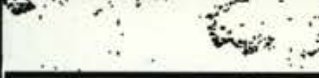

$\therefore 5$

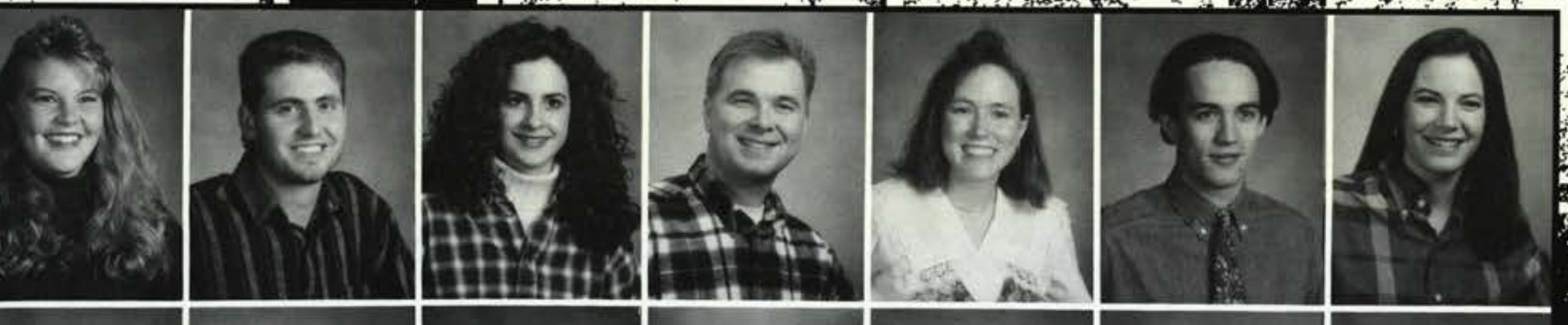

8

Courtney Kilburn

Kurt King

Michelle Kinley

Jason Kinniburgh

Dawn Kirgan

Jeff Kirsch

Teri Kofstad

Kevin Kuczynski

Jason Kuna

Andrew Kunkler

Denise Kurtz

Lori Landwehr

Geoff Lane

Todd Lane

Colleen Lang

Carol Lee

Ken Lee

Philip Lehman

Barrett Lehr

Tabitha Leininger

Steve Lewis

Rebecca Lodge

Jon Longshaw

Lisa Lough

Andy Lutz

$\because-$

Jennifer Lytwynec

Robert MacDonald

5

Laura Maki

Jill Malar

Chad Manifold

Ken Mantle

Dustin Martin

Elisabeth Martin

LaRae Martin

Brenda Mattke

S:

Adam Mattison

Stephen Mays

Sarah McCarty

Pamela McClain

Miquel McCleese

Brian McGuinness

Becky McIntyre

. 3

Brent McKanna

7 Nancy McMillan

帘

.

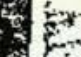

is

5ixe:

कis.

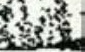

$x$

$\cdots$

.

$\therefore<$

is

10.

(2)

David McMurtry

Amy McNiece

Christopher Melkonia

Dawn Merritt

Kristina Milentis

7)

Amy Miller

Cheryl Miller

- Kimberly Miller

Nathan Miller

Susan Miller

Jared Mills

Donna Mitchell

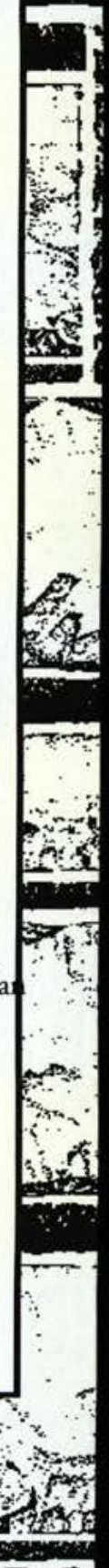

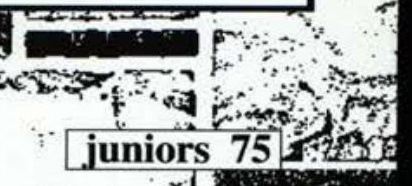


$*{ }^{\prime}$
$\therefore$

$\therefore>C ;$

Melissa Mocny

Douglas Moe

Bethann Mohn

Kaedra Moll

Wayne Morgret

Jennifer Mosby

Jennifer Myers

6

s.t.

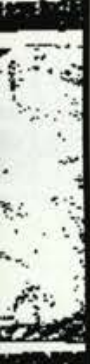

Timothy Nicklas

Andrea Nicodemus

Kara Niemotka Cathy Noble Michelle Nunemaker Julie Nunes

Eric O'Brien

Jason O'Dell

Jason Oesterling

Jim Olinger

Heidi Opgenorth

Monty Orcutt

Amanda Orme

Brian Orme

Dean Osuch

Amy Owens

Stephen Paine

David Paulus

David Peale

Marla Perkins

Kathryn Peterson

Kyle Peterson

David Pfahler

Aimee Phelps

Lori Phipps

Janine Pinkley

Nathan Piovesan

Melissa Pitonyak

Jewelie Plunkett Melissa Pope

Shannon Pope

Erica Porter

Jaimee Potter

Janet Potts

Laura Powers

Christopher Prediger

David Preston

Denise Proudfoot Nicole Pryor Kimberly Quick Jason Quinn Cynthia Quint

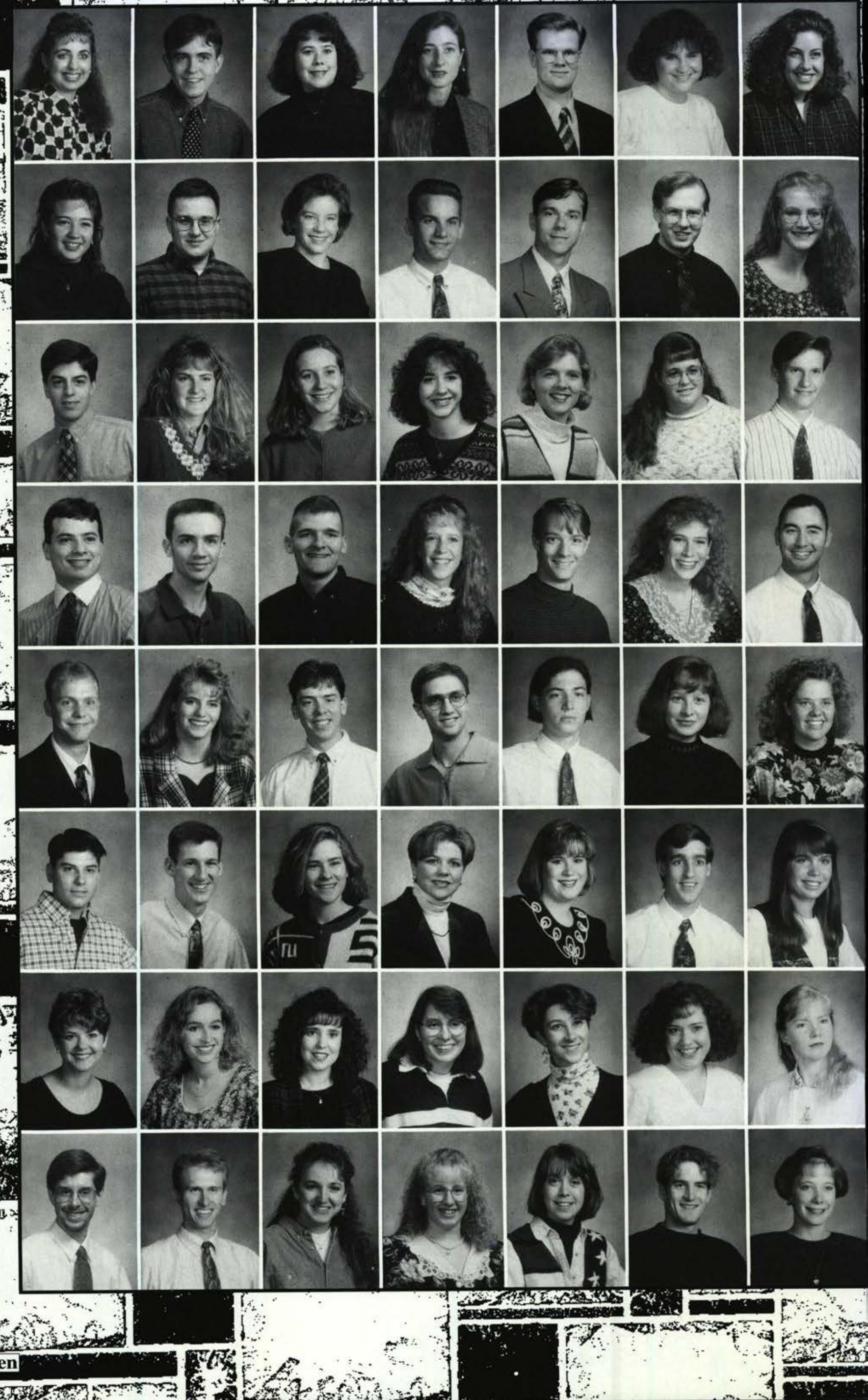

76 underclassmen

Is $x$

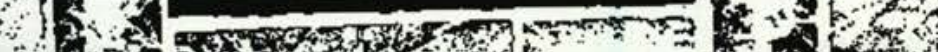




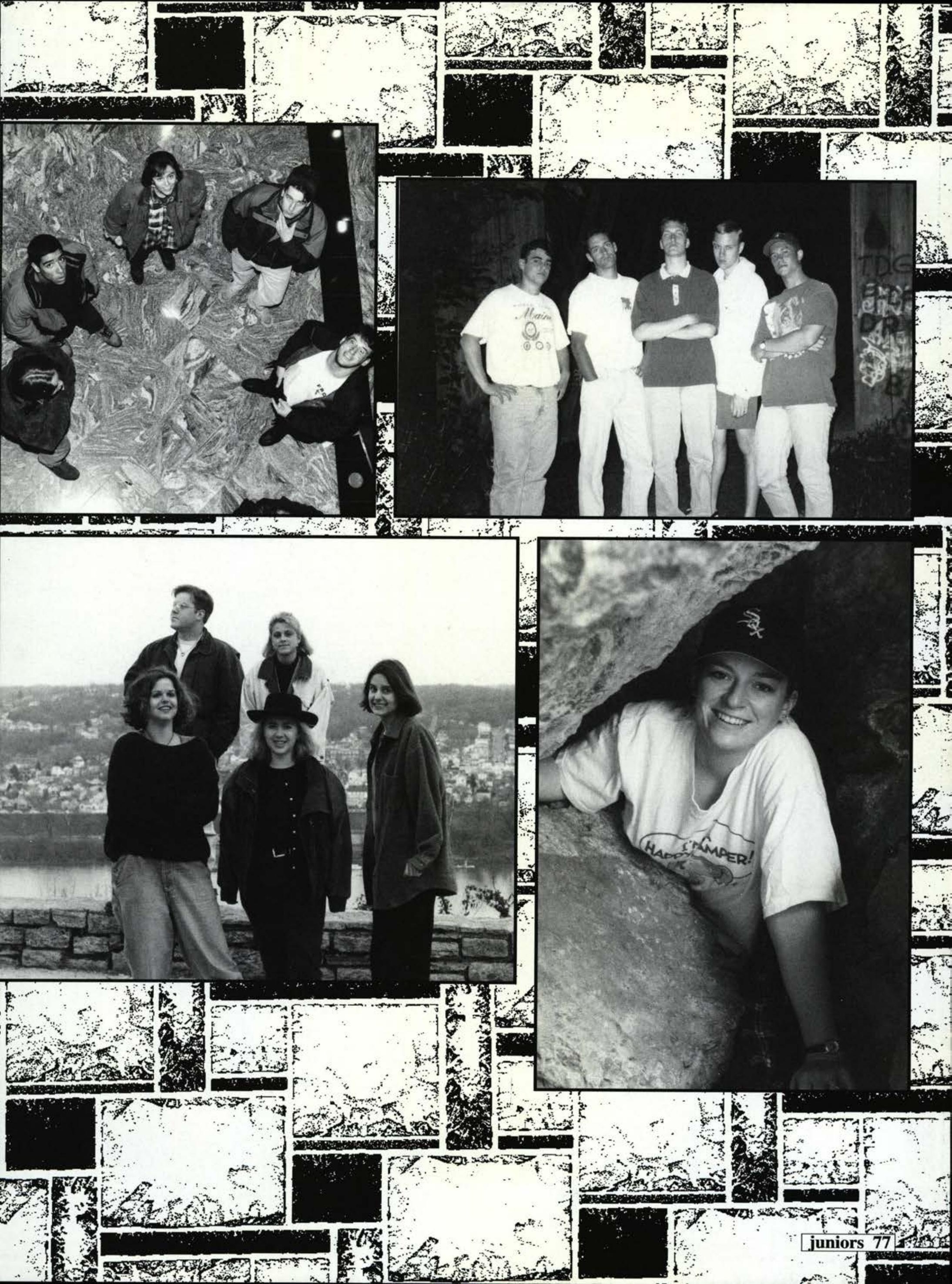




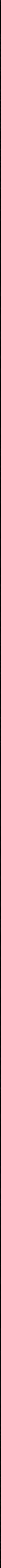


16,1 PT

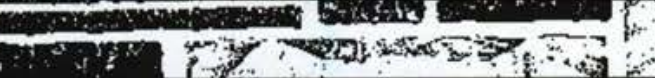

Andrew Sipes

Tamara Sitorius

Sarah Sizemore

Michael Slone

Don Smith

Heidi Smith

Melanie Smith

Molly Smith

Steven Smith

Teresa Smith

Holly Snyder

Chad Sorensen

Michelle Southworth

Julie Stafford

Jeremy Staley

Joanna Staples

Kristen Stanton

JulieAnn Starrett

Janelle Steiner

Jason Stevens

Amy Stewart

Mark Stone Jeff Stratton

Paul Streetman

Sandra Streit

Lynette Strong

Tamara Strong

Amy Stryker

Jason Sulish

Kevin Swanson

James Tanner

Jason Taylor

Jennifer Tew

Beth Tharp

Richard Thomas

Robert Thomas

Veronica Thunder

Jennifer Timblin

Summer Todd

Nadine Tomsa

Crystal Toomey

Flynn Tregay Echo Tuinstra
Timothy Tuinstra

Melany Trimble Virgil Vaduva Harry VanderWal Christopher VanHart Holly VanTil

Amy Varner Marcus Varotti Kevin Vaughn Jeremy Verwys Elizabeth Vivian Kathy Wainwright Kathryn Walbright

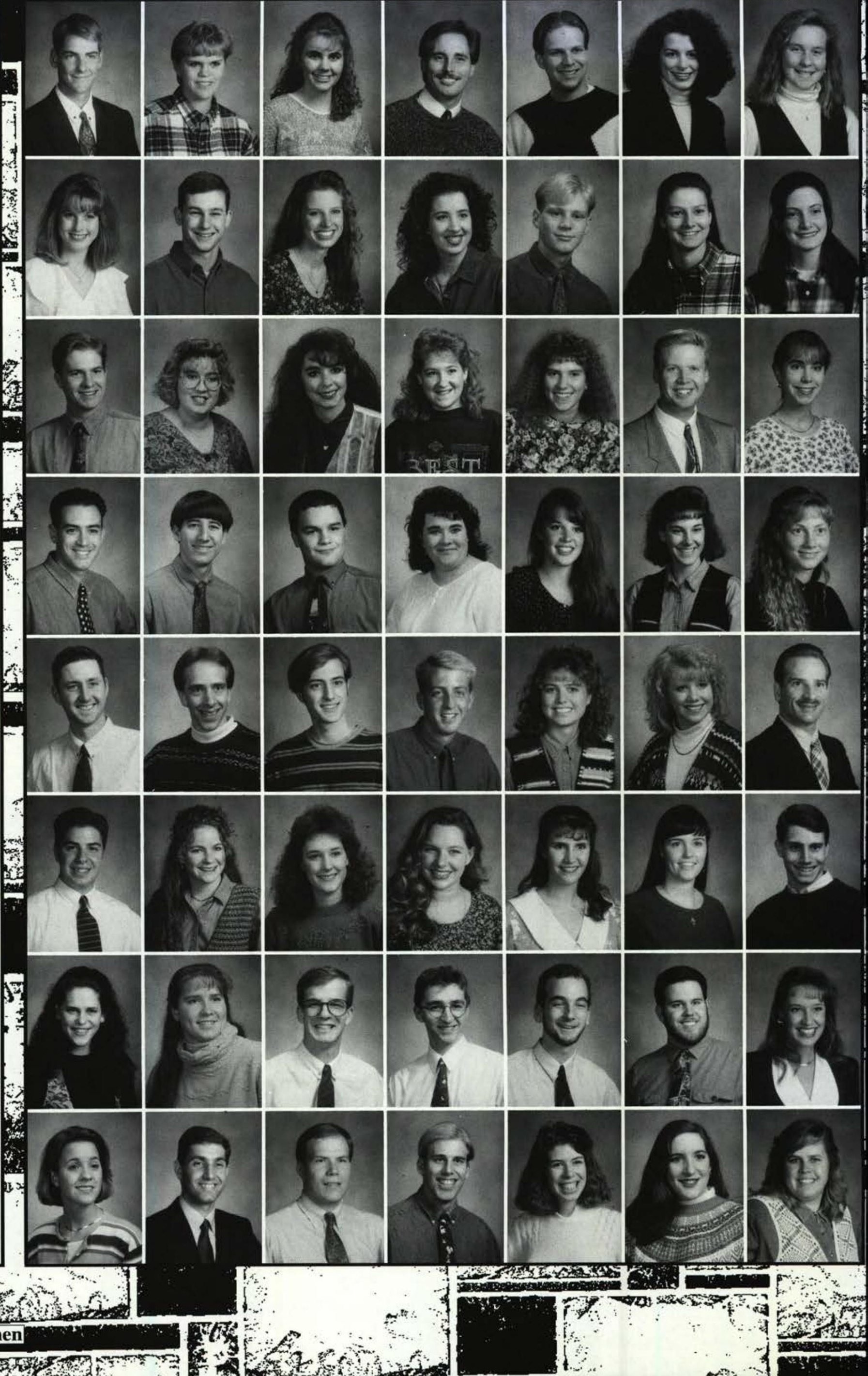




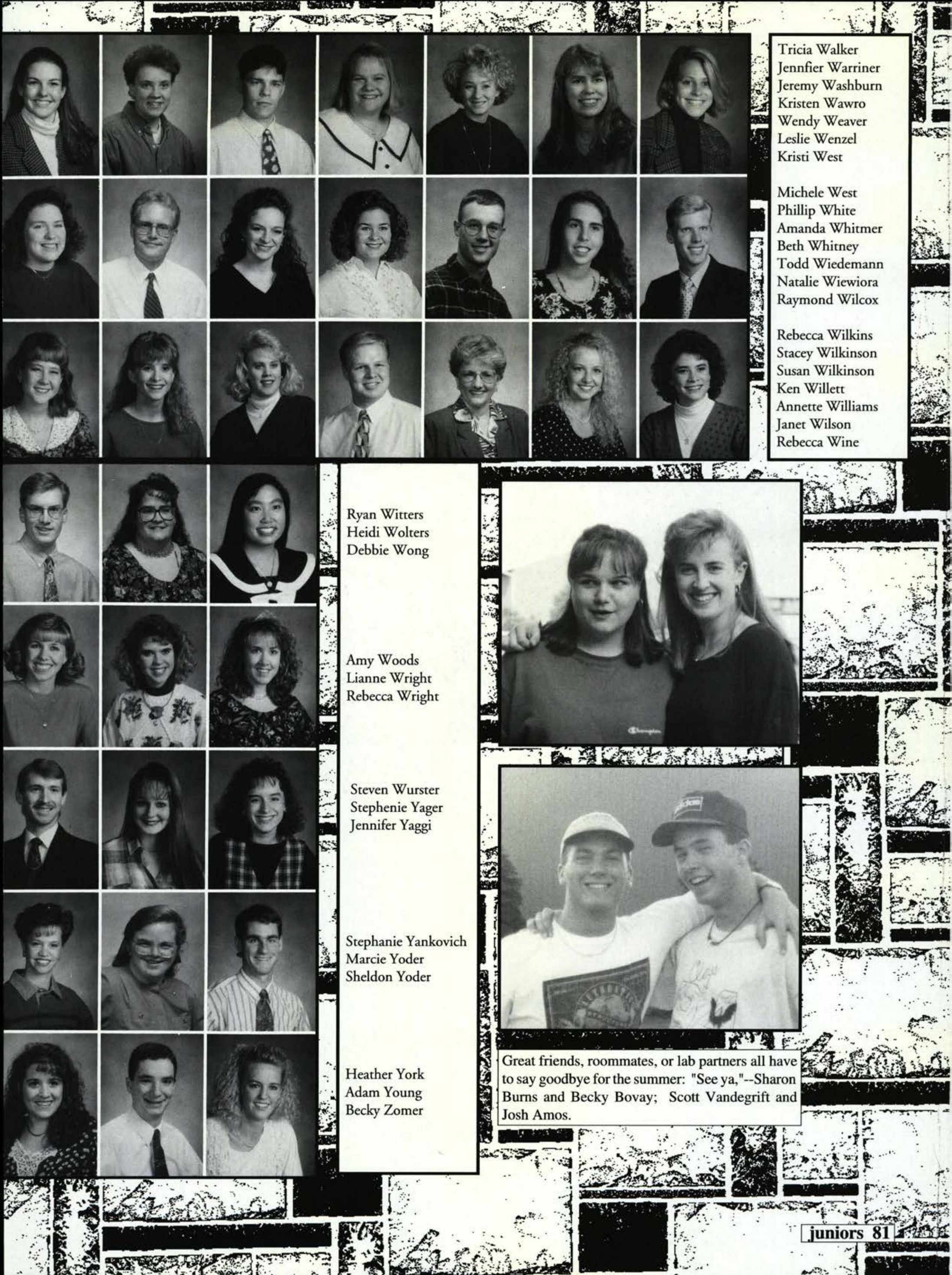



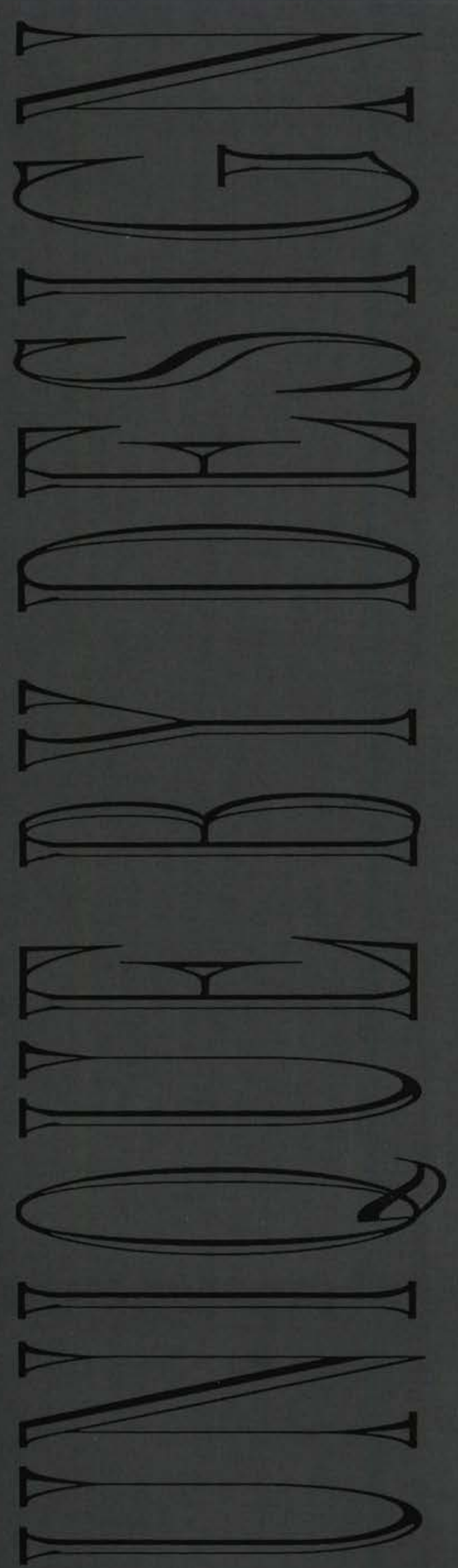

82 christian ministry division 


\section{chr is t i a n $m$ i $n$ is $\mathbf{t} r \mathbf{y}$}

84 community 98 dedication 100 local 106 day of prayer 108 conferences 110 travel teams $114 \mathrm{mis}$

117 ad 7 


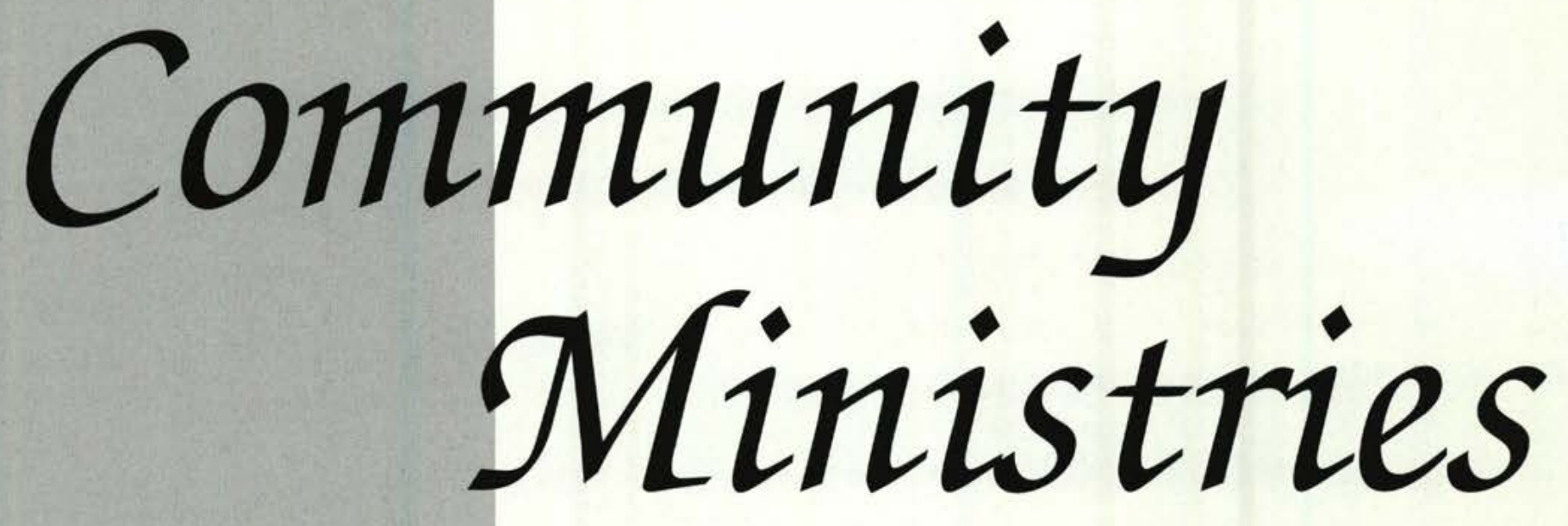

Amanda Foote, Amanda Veach, Mary Beth Beal, Eve Edsell

\section{Adult Literacy}

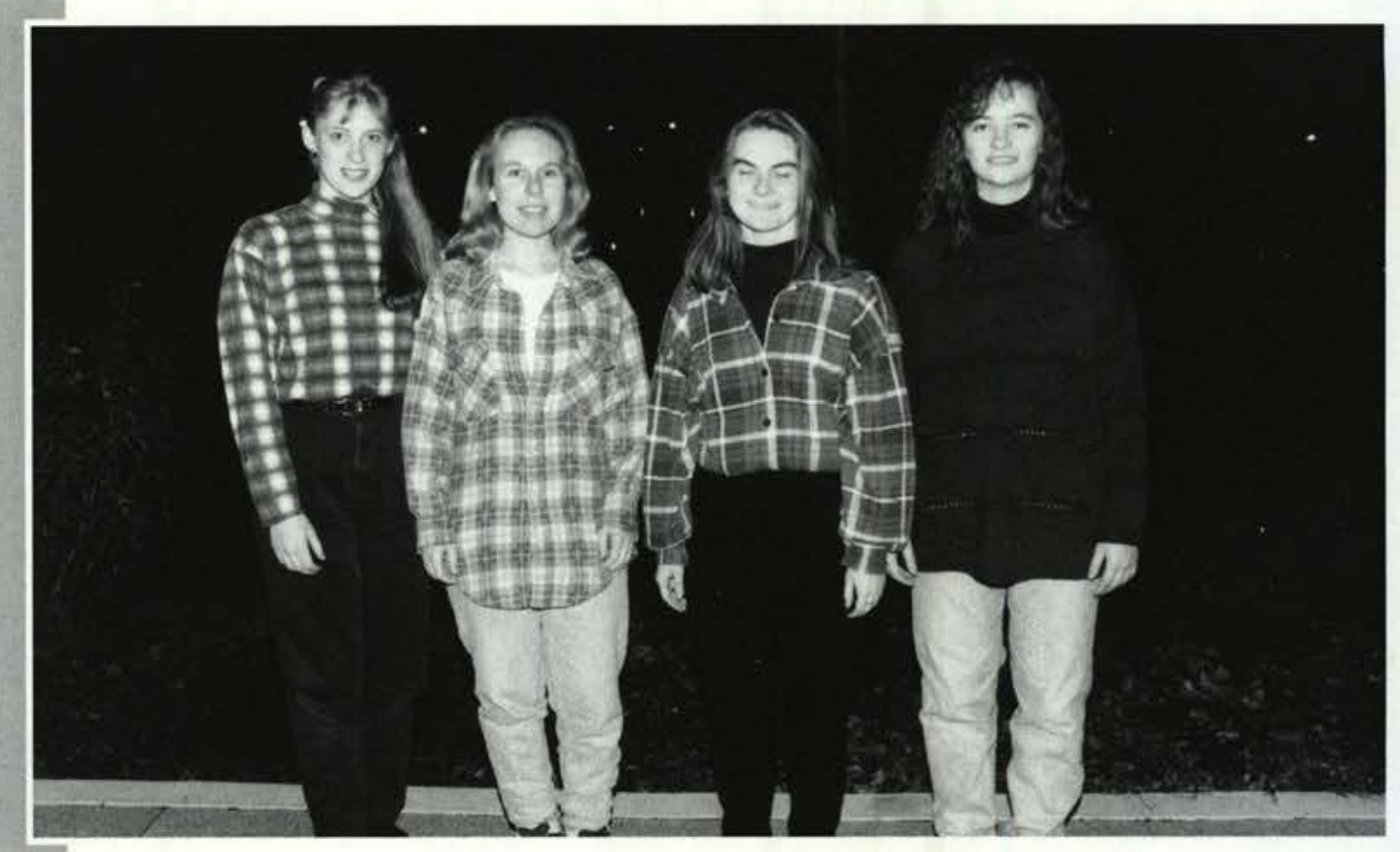

First row: Erik Larsen

Second row: Rob Swanson, Johanna Byrer, Jon Shrubsole

Third row: Colin Smith, Steven Krise Fourth row: Steve Moulson, Gareth Phillips

\section{Antioch College}

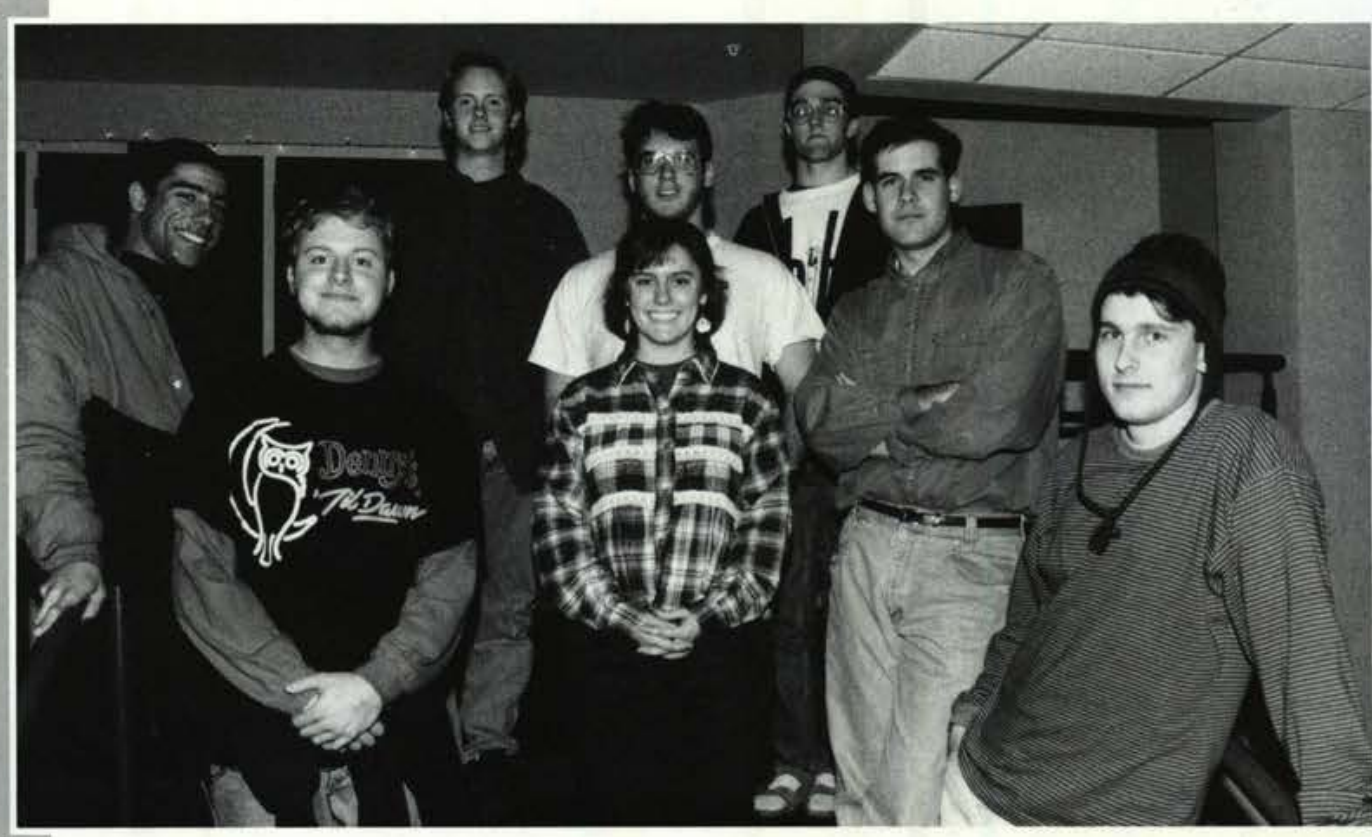



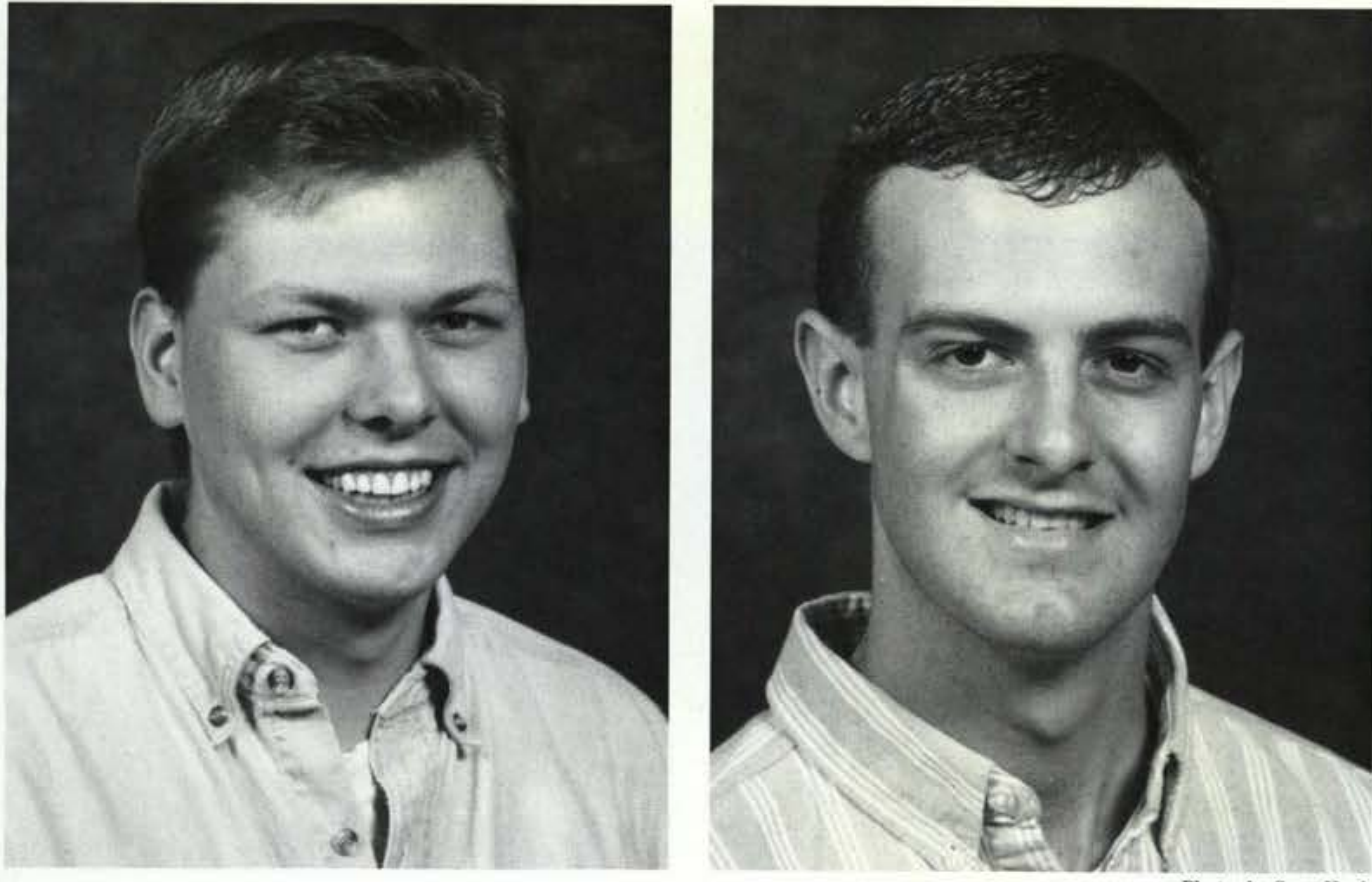

Photos by Scott Huck
Community ministries are involved with outreach and youth, and with visitation and correctional centers. Outreach and youth ministries are involved in campus interaction with local colleges, adult literacy programs, crisis pregnancy centers, Bible clubs, tutoring, and various youth centers. Hospitals, jails, detention centers, health centers, residential homes, and a variety of nursing homes comprise our visitation and correctional ministries.

FAR LEFT:Dennis Moles was the student director for the outreach and youth ministries. LEFT: John Wambold was the student director of our visitation and correctional ministries.
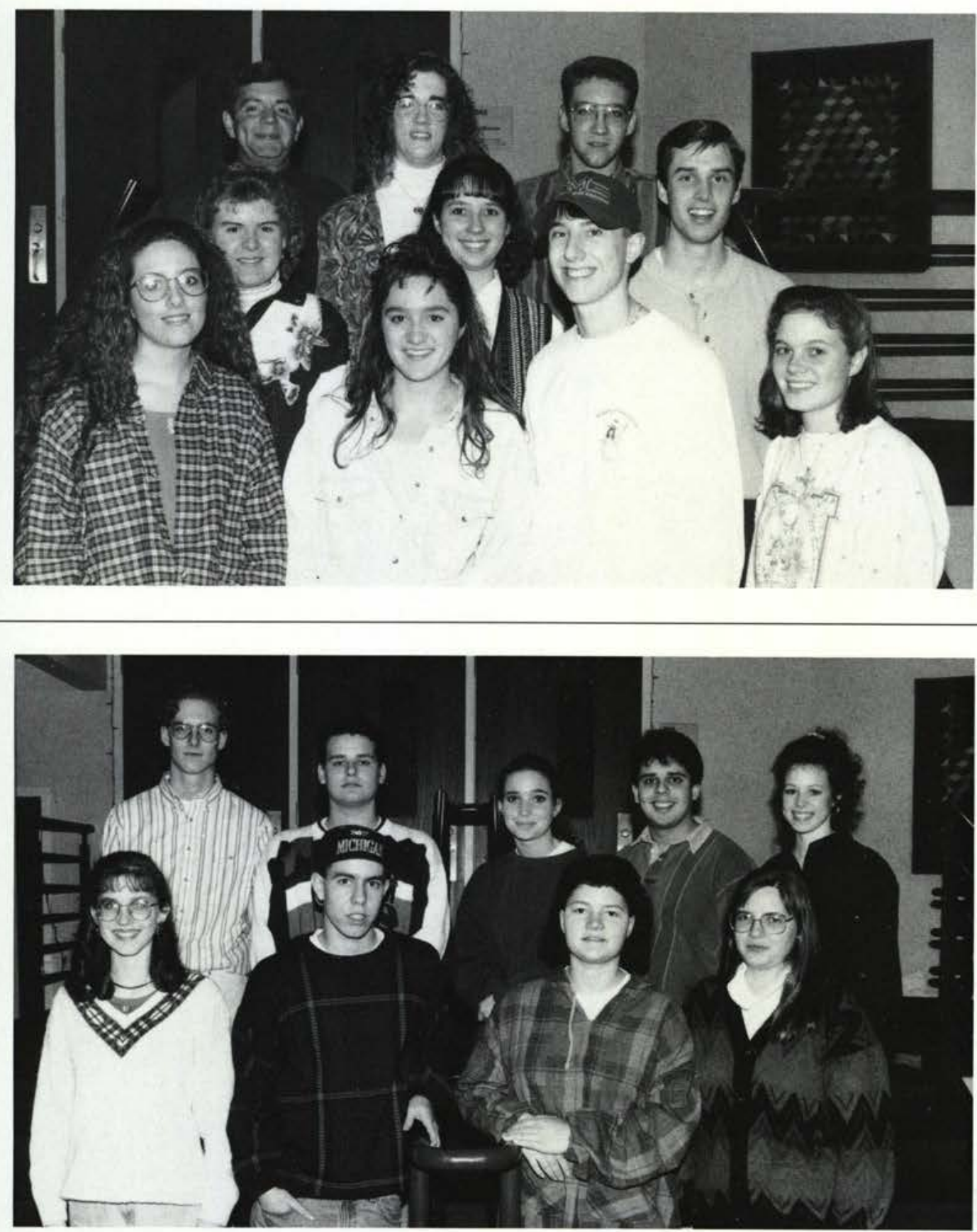

First row: Lisa Grindall, Susan Hunsaker, Jason VanHeukelum Second row: Cynthia Potter, Amy Velpe, Stephen Kline Third row: Gerry Potter, Chris Terry, Ben Statzman

\section{Bible Clubs}

First row: Sarah Youngblood, Nathan Hart, DiAnn Miller, Carla Heim Second row: Aaron Jex, David Helton, Heather Kingaman, Rajan Desai, Sara Hauter

\section{Bristol House}


First row: Laura Lotz, Jill Heisler Back row: Debbie Davidson, Michelle Delaney, Amy McDevitt, Laurie Smith

First row: Bonnie Kuvshinikov, Kay Walbright, Sandy Streit, Angie Harrison, Sarah Medlong, Jennifer Habegger Second row: Ken Mantle, Sean Fox, Melodie Mc Kay, Julie Hastings, Amy Miller

Third row: Dan Braswell, Robert Thomas, Joel Malone, Jim Rowley, Aaron Berning

\section{Cedarkids}

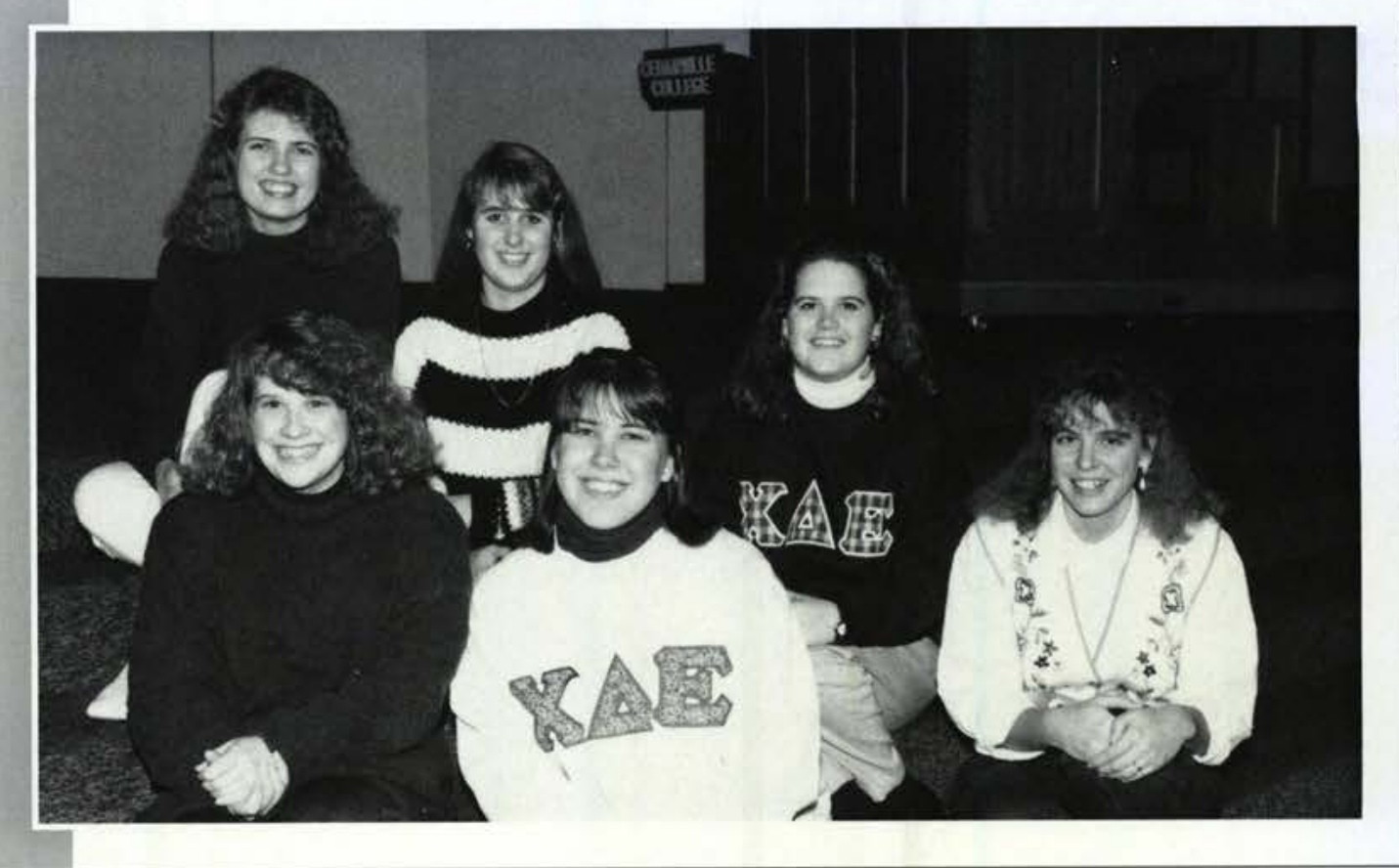

First row: Eric Miller, Melissa Moony, Sarah Holesovsky, Jennifer Keary, Laurie Seibel, Krista Keesling, Amanda Foote, Heather Fourman

Second row: Kristen Kuiken, Ann Gabriel, Martha Shrubsole, Deborah Frank, Amy Brubaker, Martha Failor Third row: Matthew Sherwood, Michelle Dick, Andy Sipes, Gwenyth Stambaugh, Michelle Boehm, Stephen Pierce Fourth row: Josh Hanks, Douglas Romaine

\section{Cedarville Tutoring}
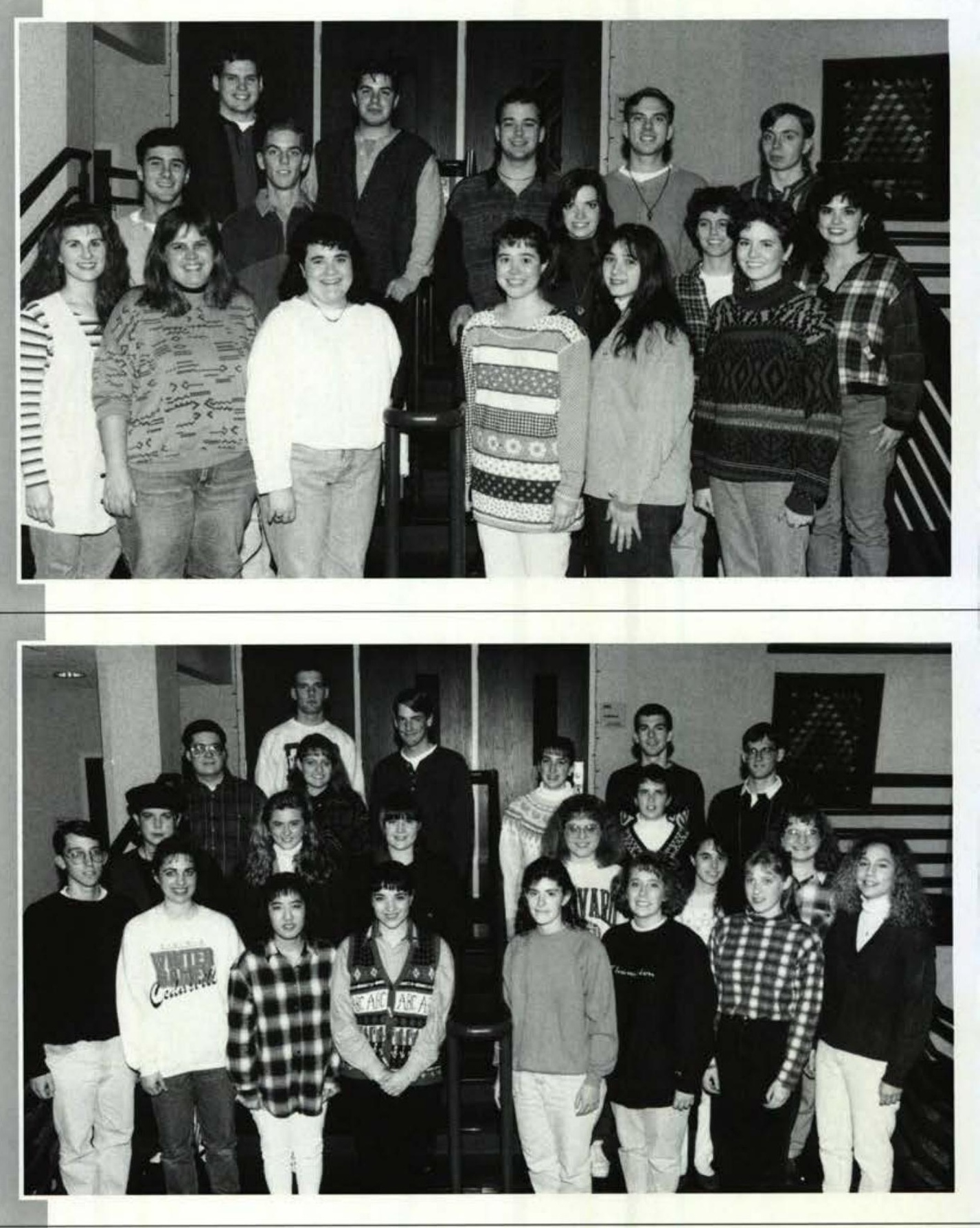

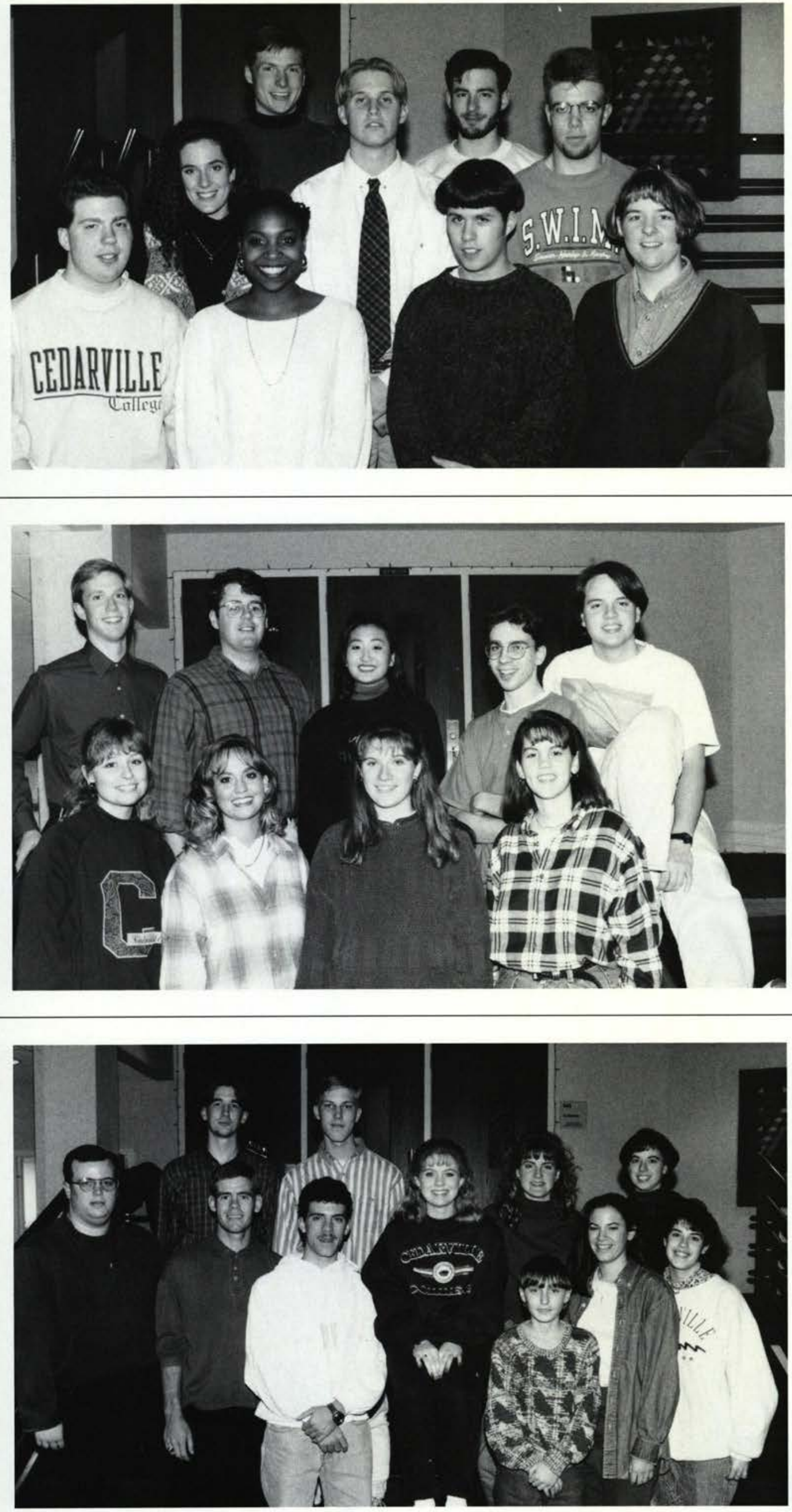

First row: Jason Brown, Paige Smith, Seth Rafferty, Shandy Buffington Second row: Lisa Lough, Brad Deetscreek, Dustin Hansen Third row: Rob Bouwens, Tobin Strong

\section{Central State}

First row: Rhonda Carnahan, Hannah Turner, Nikki Streit, Dawn Merrit Second row: David Peters, Jonathan Weber, Ruthanne Pierson, Noah Buehner, Charlie Walker

\section{Cincinnati Gospel Mission}

First row: Jon Hastings, Robert Cobb, Kerry Anderson, Rebekah Cain, David Brent, Terri Kofstad, Amy Nichols Second row: Andy Sommerfield, Andy Cooper, Andrea Nicodemus, Beth Blevins

\section{College Partners}


First row: Jennie Fisher, Anna Hamrick, Evelyn Brown, Amy Varner, Lara Carlsen

Second row: Pete Sutton, Beverly Keist, Joanna Halsey, William Droke Third row: Tim Simon, Jodie Jacobson, Kevin Gwin, Kelby Hassenzahl

Fourth row: Paul Click, Dan Lee, Jeff Elliott

\section{Dayton Detention Home}

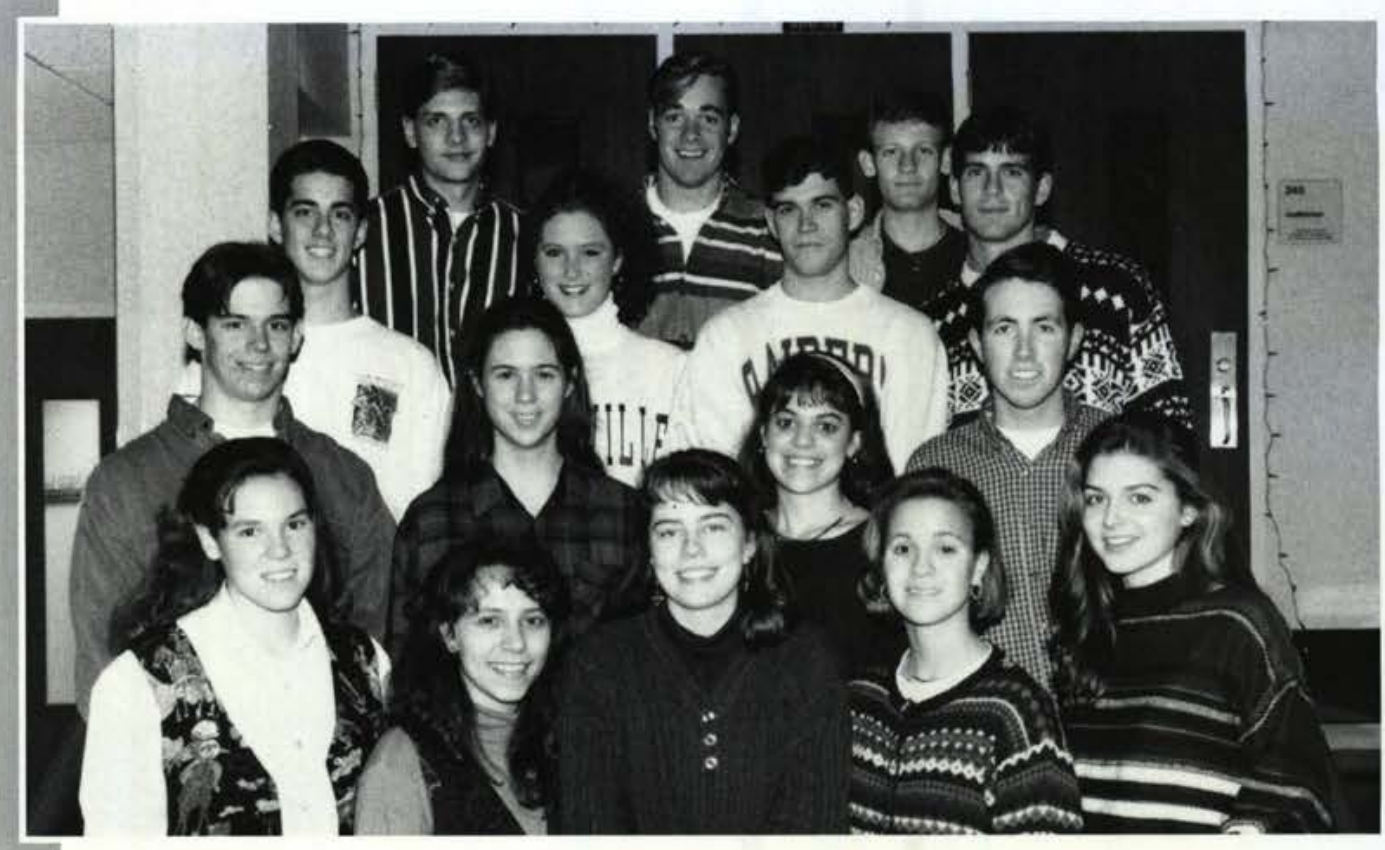

First row: Donna Mitchell, Trish Hochstettler, Brenda Inion, Darrin Smith Second row: Aaron Dunham, Kristen Wawro, Sarah Sizemore

Third row: Jon Pickens, David Peters

\section{Dayton Gospel Mission}

First row: Angela Johnson, Rebecca Comfort

Second row: Kelly Hager, Gena Lamoreaux, Ruth Fox, Ruth Herr Third row: Juliana Nelson, Elliott Gilham

\section{Dayton Mental Health}

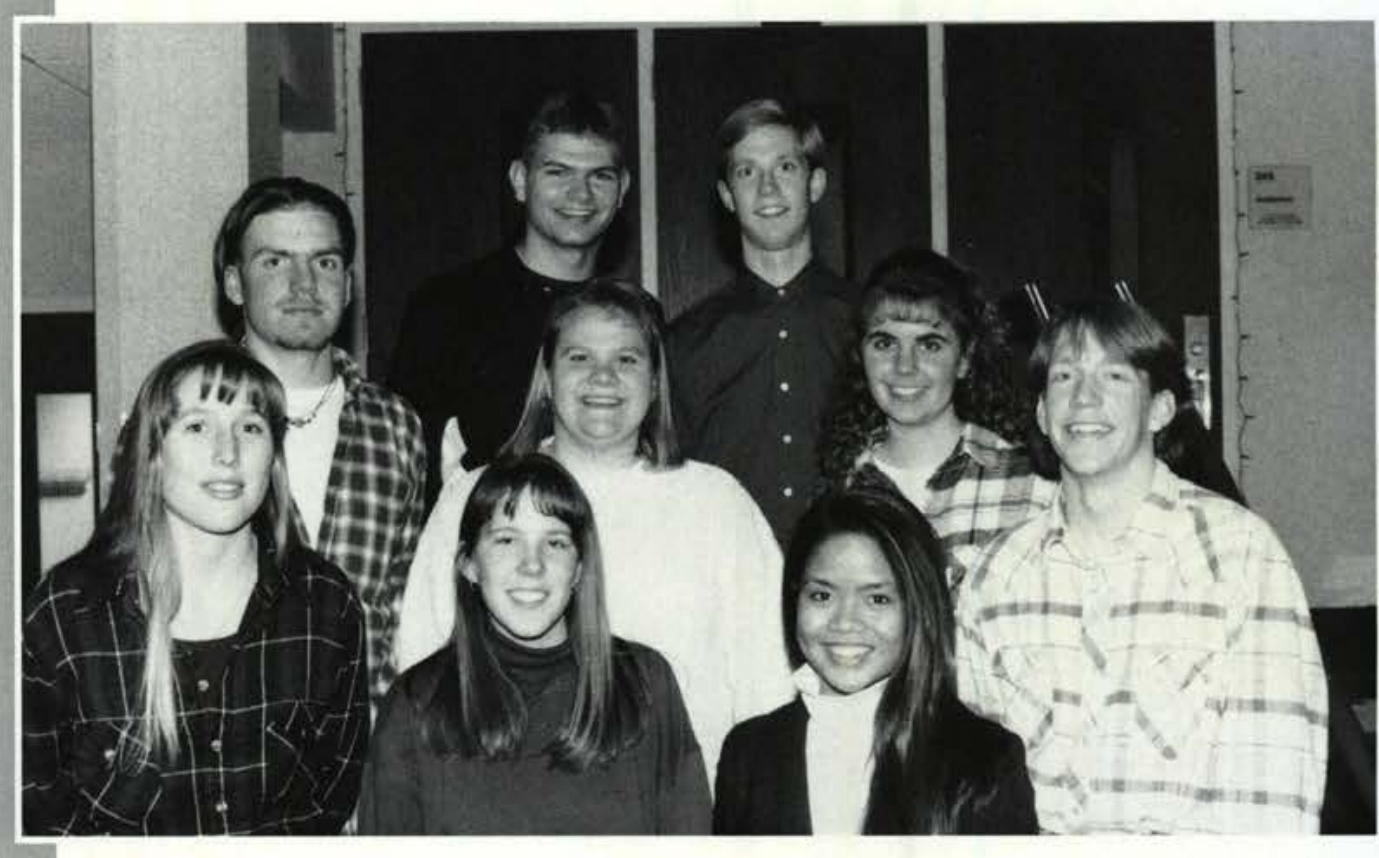




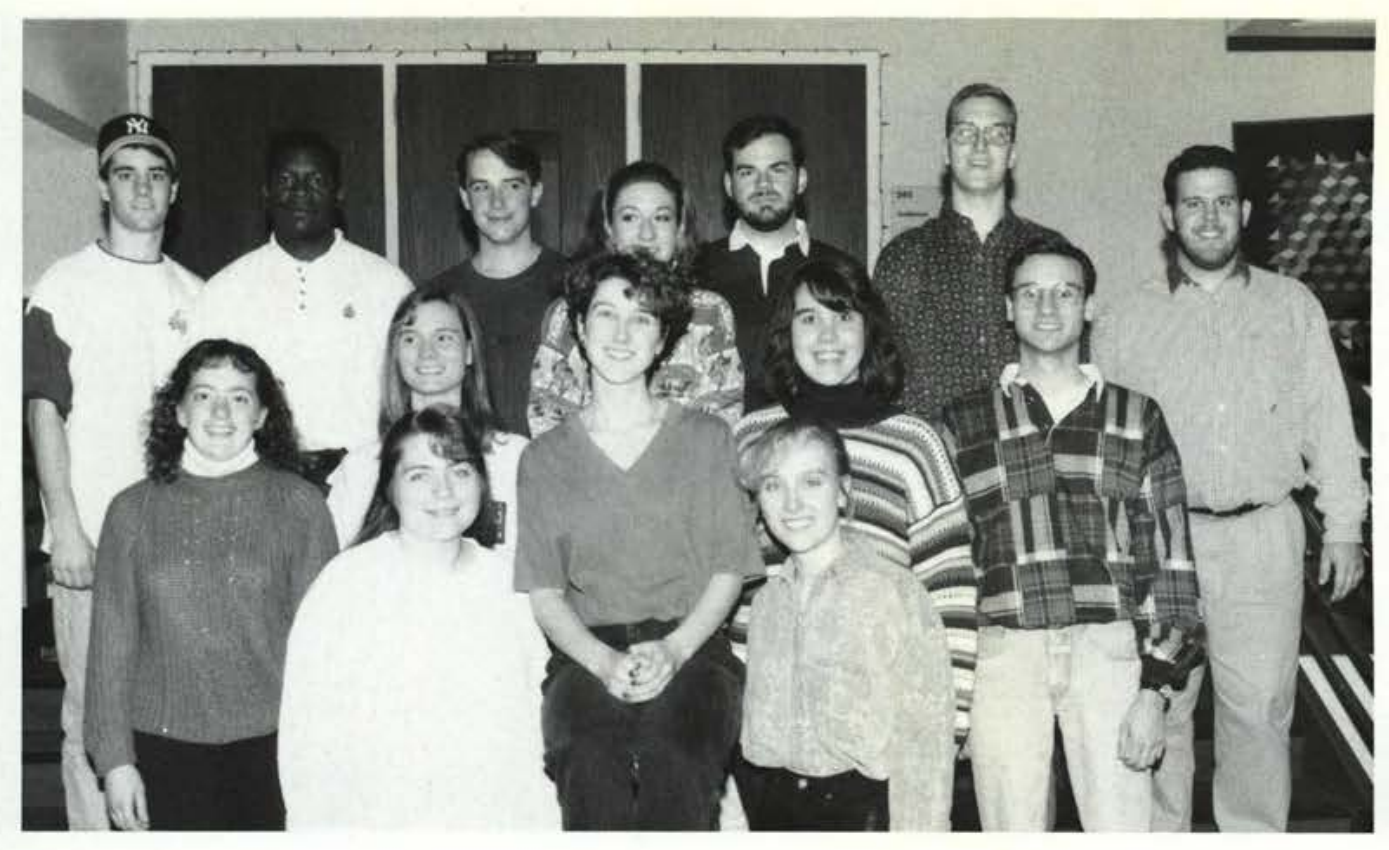

First row: Denise Kurtz, Jaimee Potter, Kristine Illjes

Second row: Heather MacLean, Janet Bonga, Karrie Lenhart, Melanie Mitchell, Ryan Anderson

Third row: Matt Beck, Nathan Payne, Matt Thomas, Jeremy Toyer, Ernest Clark, Christopher VanHart.

\section{First Airborne}

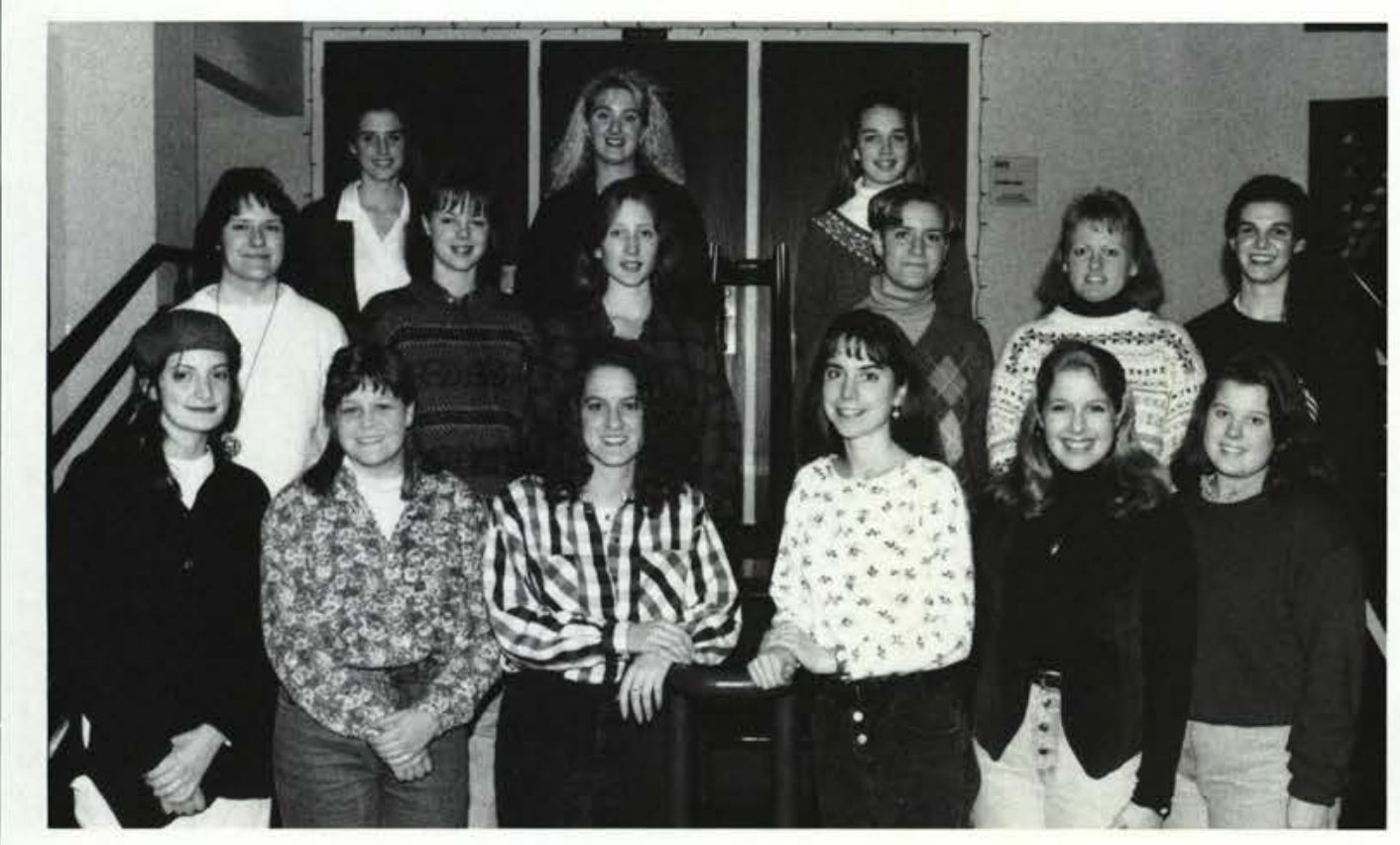

First row: Julie Stafford, Heather Johnson, Beth Ann Pickell, Amy Stewart, Jody Hovis, Cara Harju Second row: Marnie Ehlers, Heather Ann Brodie, Heather Wallace, Kris Bennick, Nichole Losee, Hillary Rinehart Third row: Julie Jaskilka, Heather Comegys, Noel McDermitt

\section{Greene County CPC}

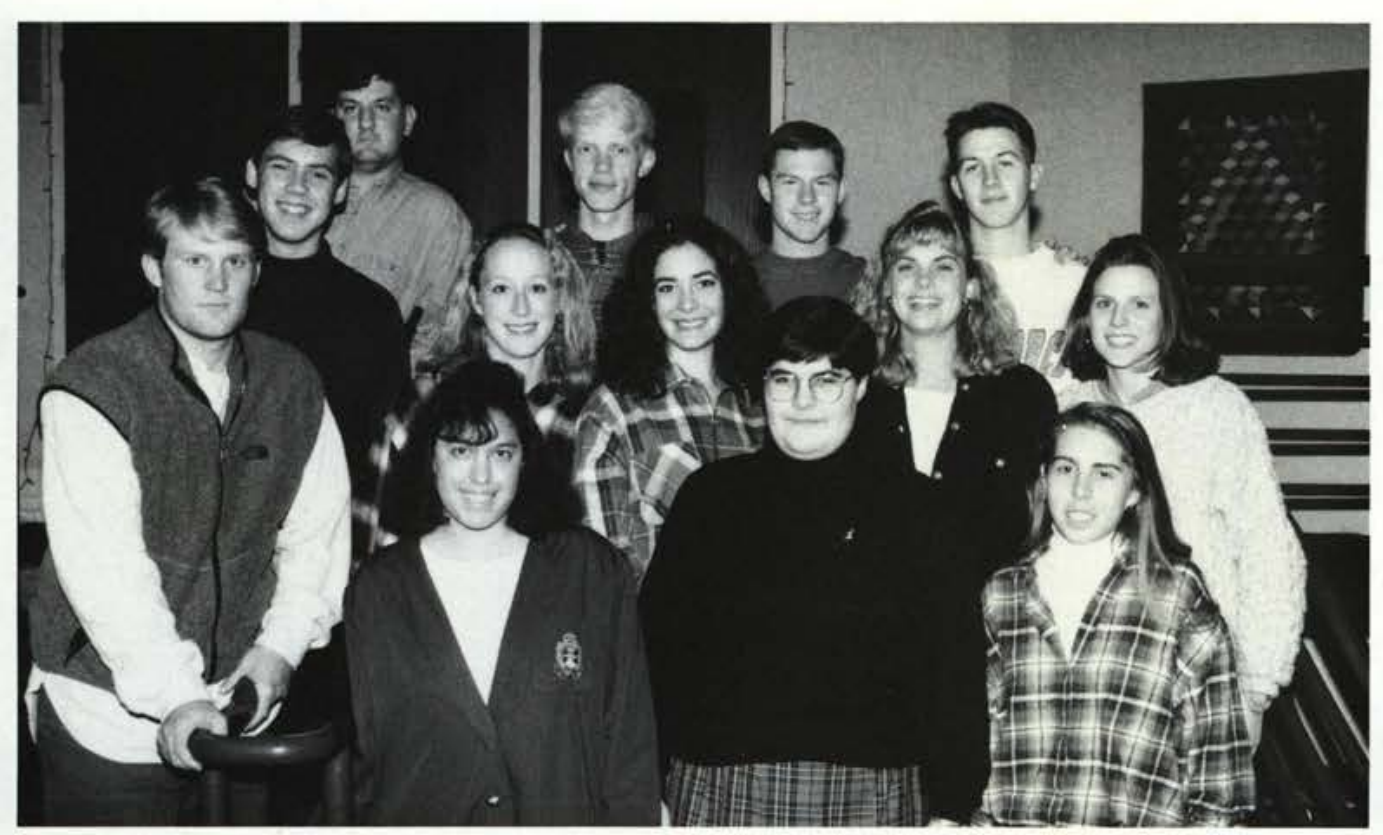

First row: Hans Goldslayer, Debbie Brunner, Jennifer Shrubsole, Natalie Wiewiora

Second row: Nathan Waldock, Jennifer Kerr, Winona Robinson, Angela Wabeke, Melissa Seil

Third row: Mike Morris, Mike Hall, Cliff Scott, Justin Poe

\section{Greene County Jail}


First row: Mina Lehman, Kim Seboe, Sara Howell, Keely Waibel, Carolyn Horton, Natalie Wiewiora

Second row: Lowell Herschberger, Brian Read, Douglas Gentry, Steve Wurster, Daniel Forrest

Third row: Julie Starrett, Tim Haylett, Lynda Gavitt

\section{Greene County Juvenile Detention}

First row: LeRoy Young, Brian Fourman, Lori Shelly, Amy Crawford Second row: Jonathan Crider, Chris Rudolph, Brook Frazier, Susan Wilkinson

Third row: Jodie Enterken, Kerri VanderMolen, Krysty Bailey

Greene County

Residence Men/Ladies
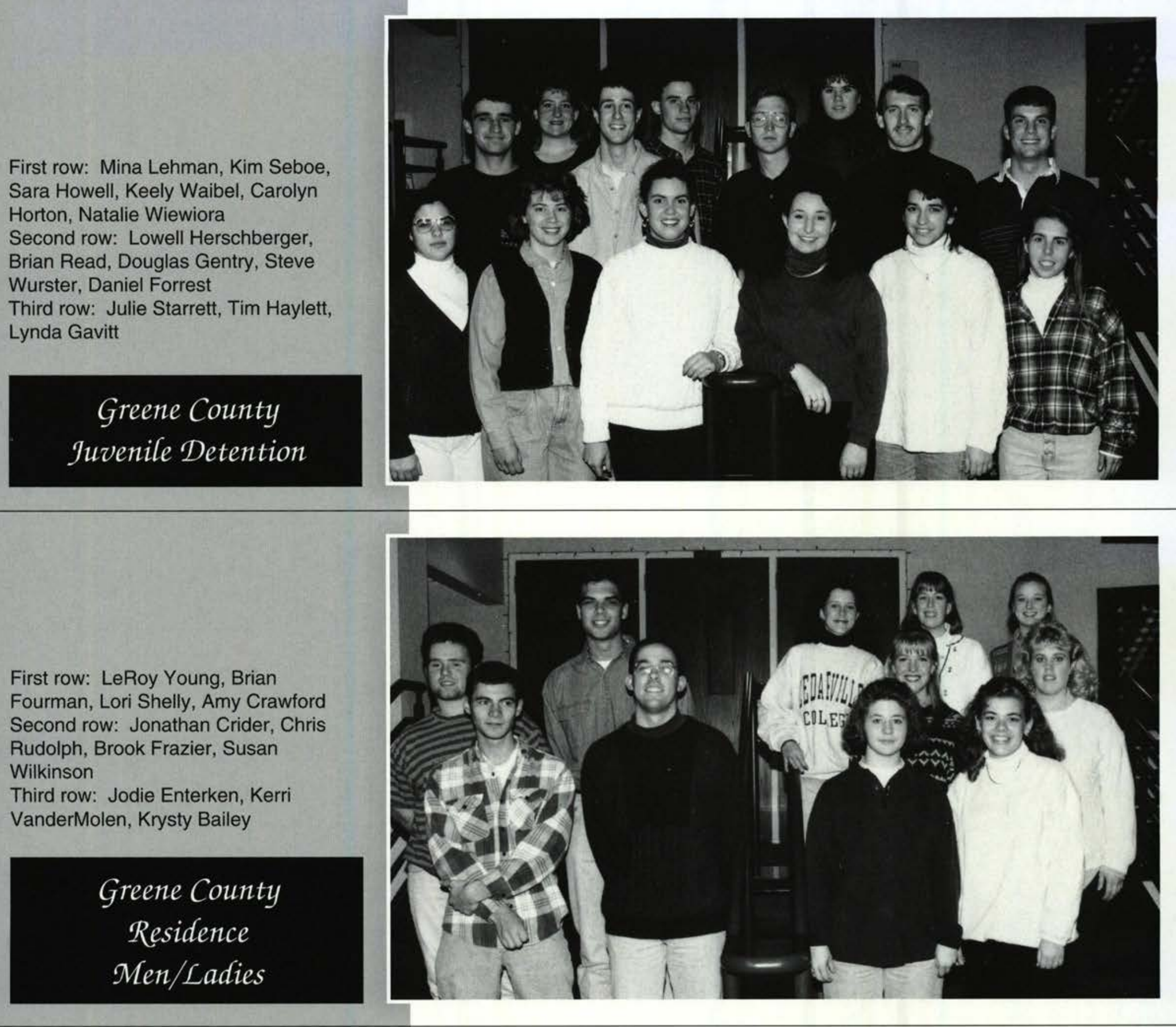

RIGHT: Anthony shows off his Play-Doh creation.

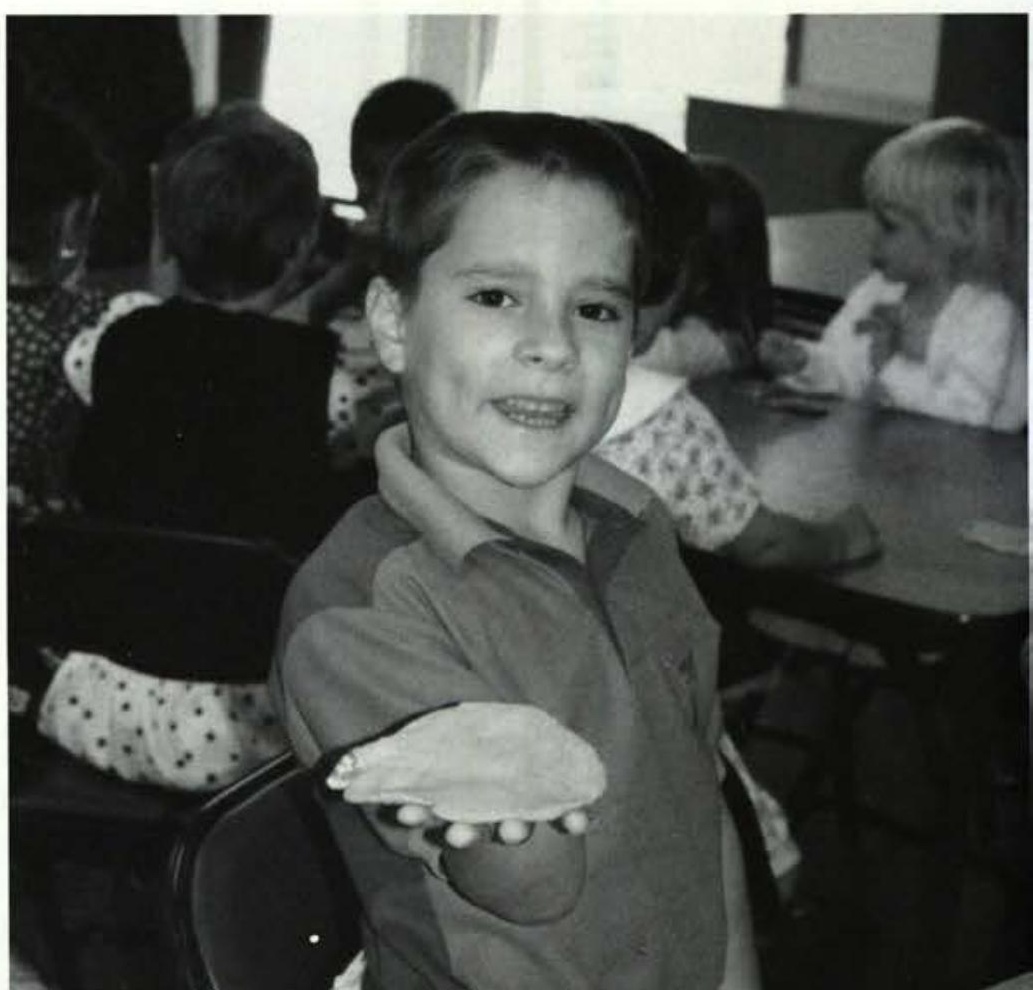




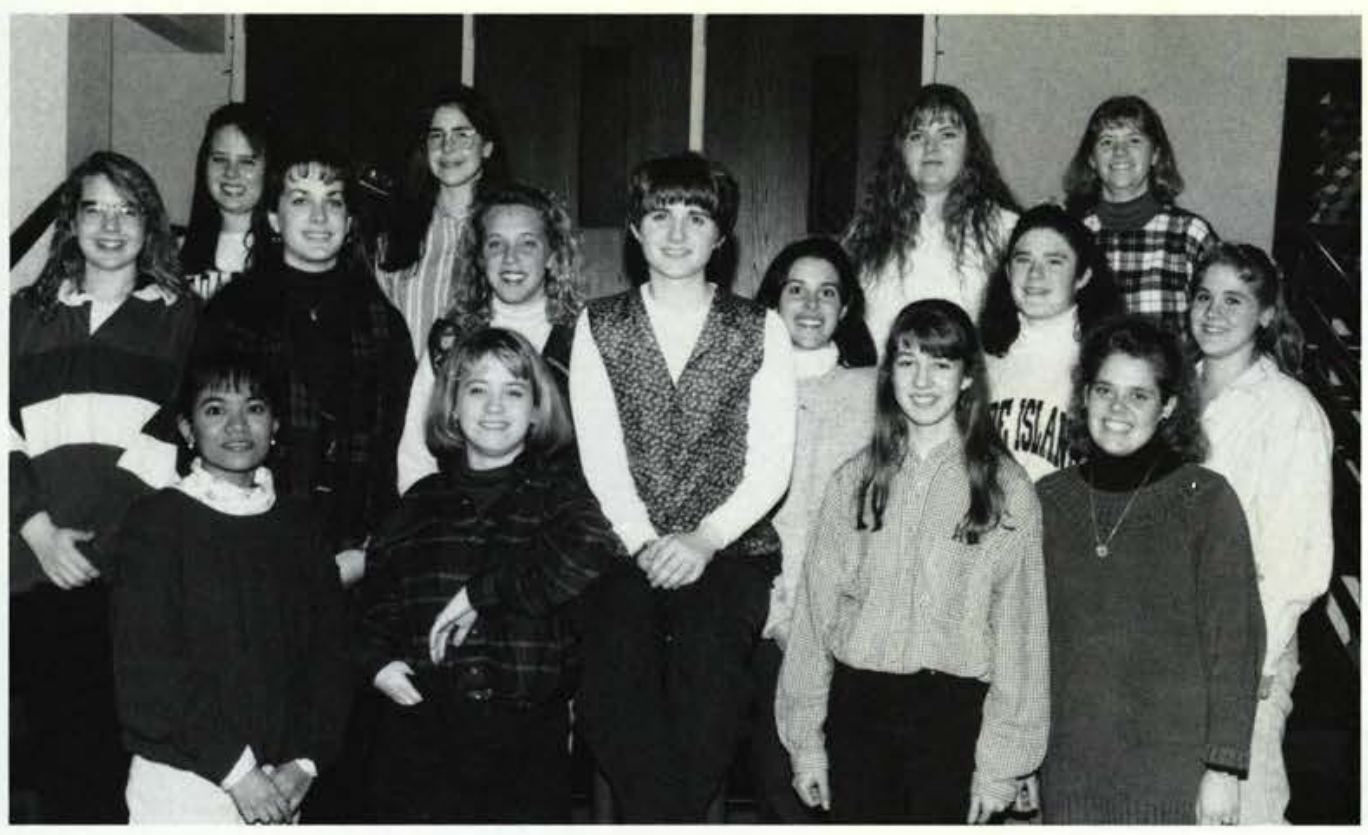

First row: Mitona Pel, Joanna Hall, Winona Monge, Rachel Wirt, Kathy Petersen

Second row: Jessica Schrader, Kristi Mitchell, Marianne Palmer, Kristen Frederick, Stephanie Moody, Beth Hoffman

Third row: Terah Cavell, Elisabeth

Powell, Chasta Roberts, Anna Harlan

\section{Greene Memorial}

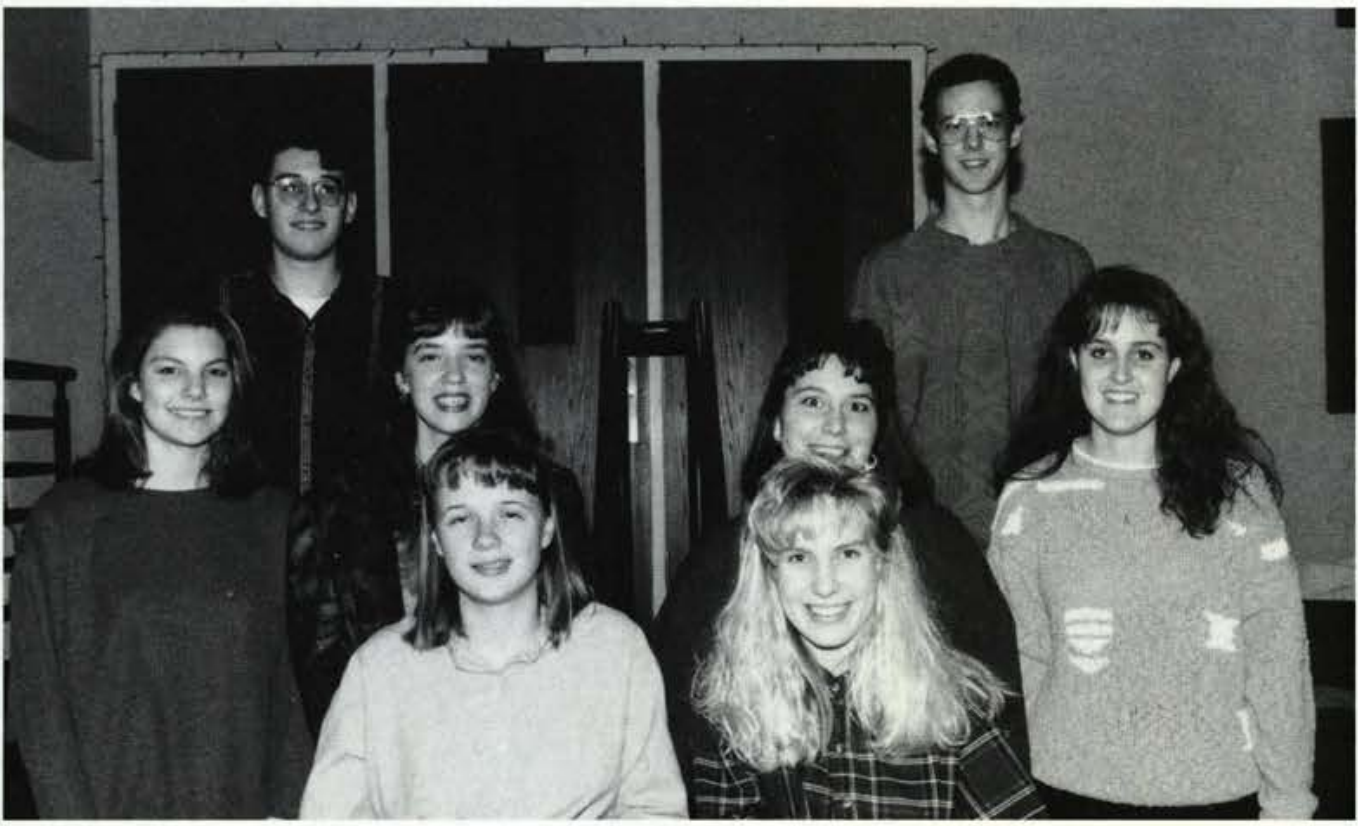

First row: Adria Andrews, Joy Gilson Second row: Amy Carnahan, Abigail Brown, Tabi Leininger, Beth Stewart Third row: Ed Powers, Andy Lawrence

\section{Greenewood Manor}

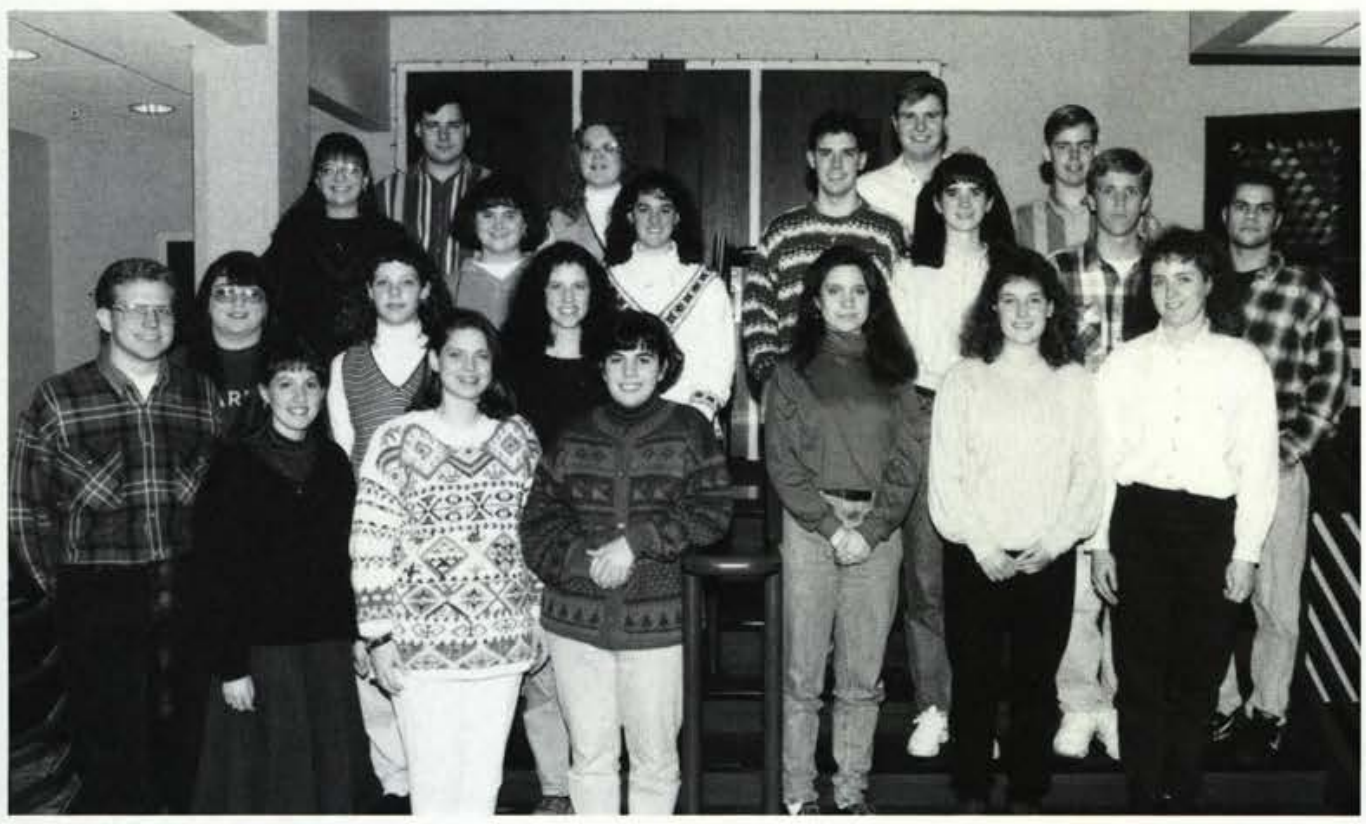

LEFT First row: Chad Wingert, Kim Koziol, Linda Davis, Rebecca Hezlitt Second row: Angie Letson, Sarah Burnet, Amy Cartzendafner

Third row: Carin Michaleski, Jennifer Mosby, Michelle Labor

Fourth row: Ben Diller, Lesa Lepak RIGHT First row: Cindi Parsons, Jennifer Timblin, Debra Koopman Second row: Betsy Lindaberry, Eric Steenwyk, Dave Curtis

Third row: Aaron Harrison, Chris Wilson, Nathan Radford

Heathergreene I
Heathergreene II


First row: Lora Myers, Lisette Cardel, Julianne Edgerton

Second row: Jennifer Berson, Amy

Owens, Christy Hillman, Misty Hetzler

\section{Hillside Independent Living}

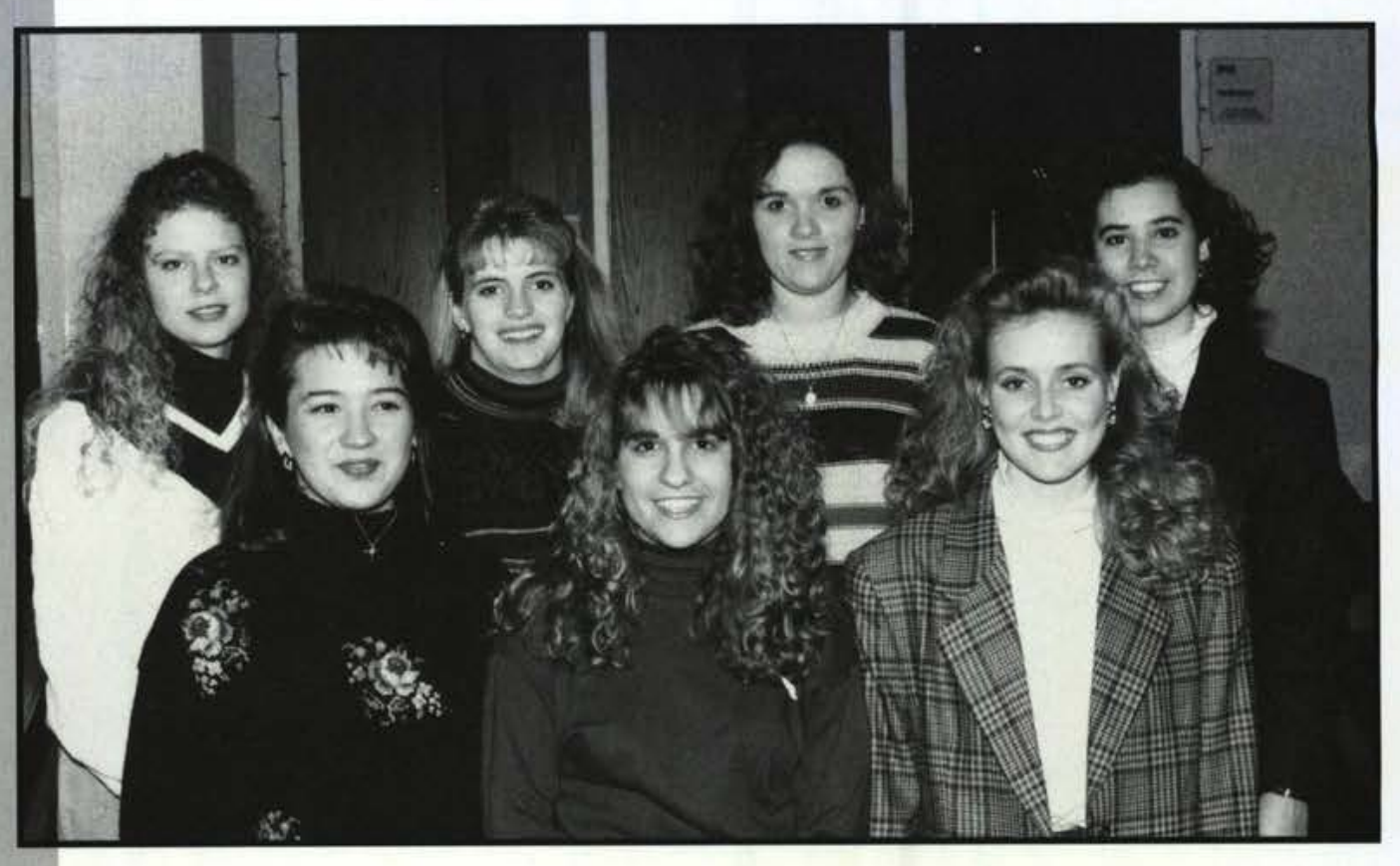

First row: Stephanie Mead, Renee Brown, Atsuko Ohake, Rachel Ross Second row: Brian Kushinikov, Steve Slates

Third row: Jonathan Anna, Don Smith, Don Carlson

\section{$I O O \mathcal{F}$}

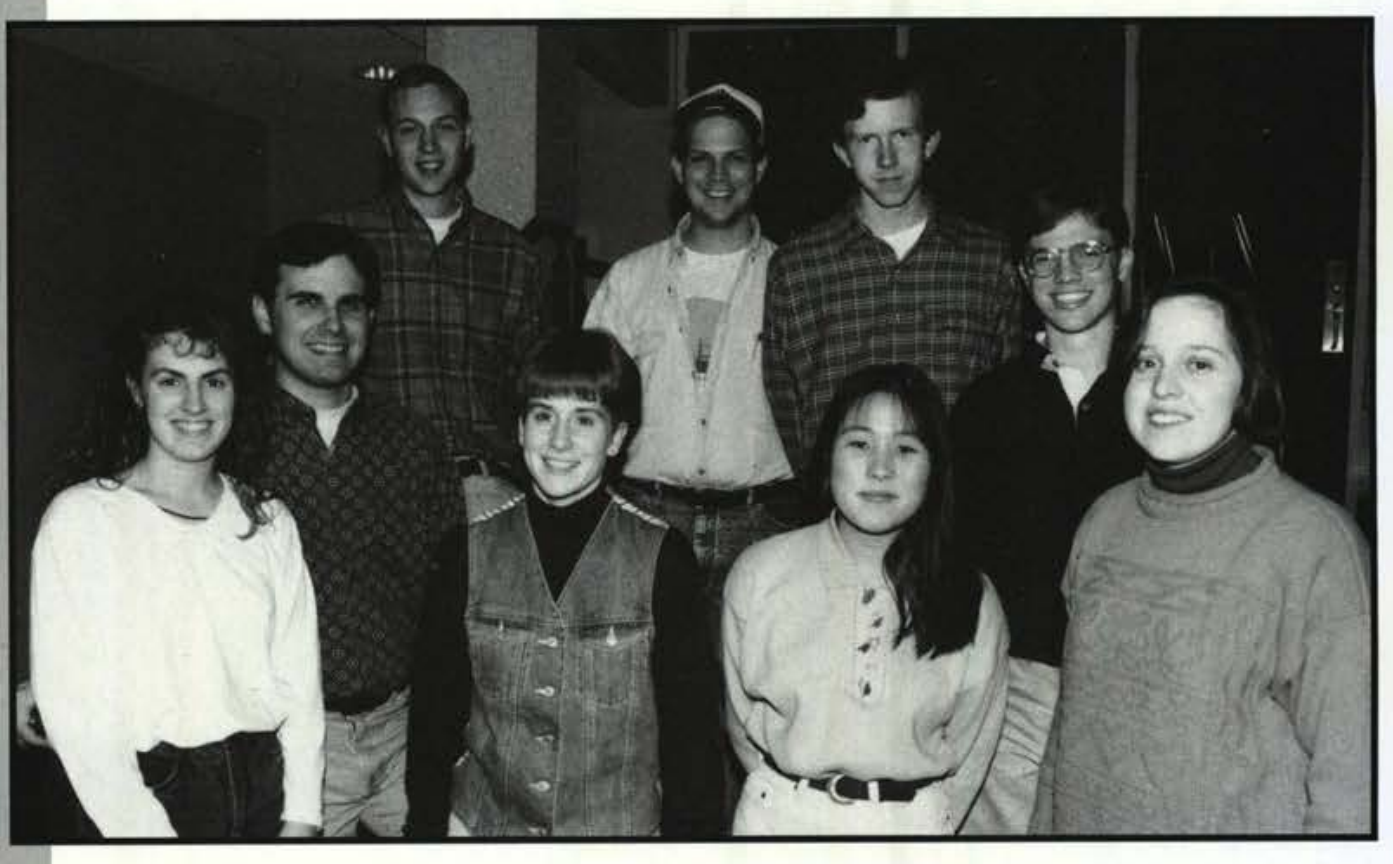

First row: Sharon Burns, Angela Ream, Stacy Saville, Angel St. Armour, Julie Cooper, Melody Gbur

Second row: Paul Click, Andrew Marshall, Joe Lesko, Brad Veneberg, Philip Boggs, Leslie Wenzel

\section{Knights of Pythias}

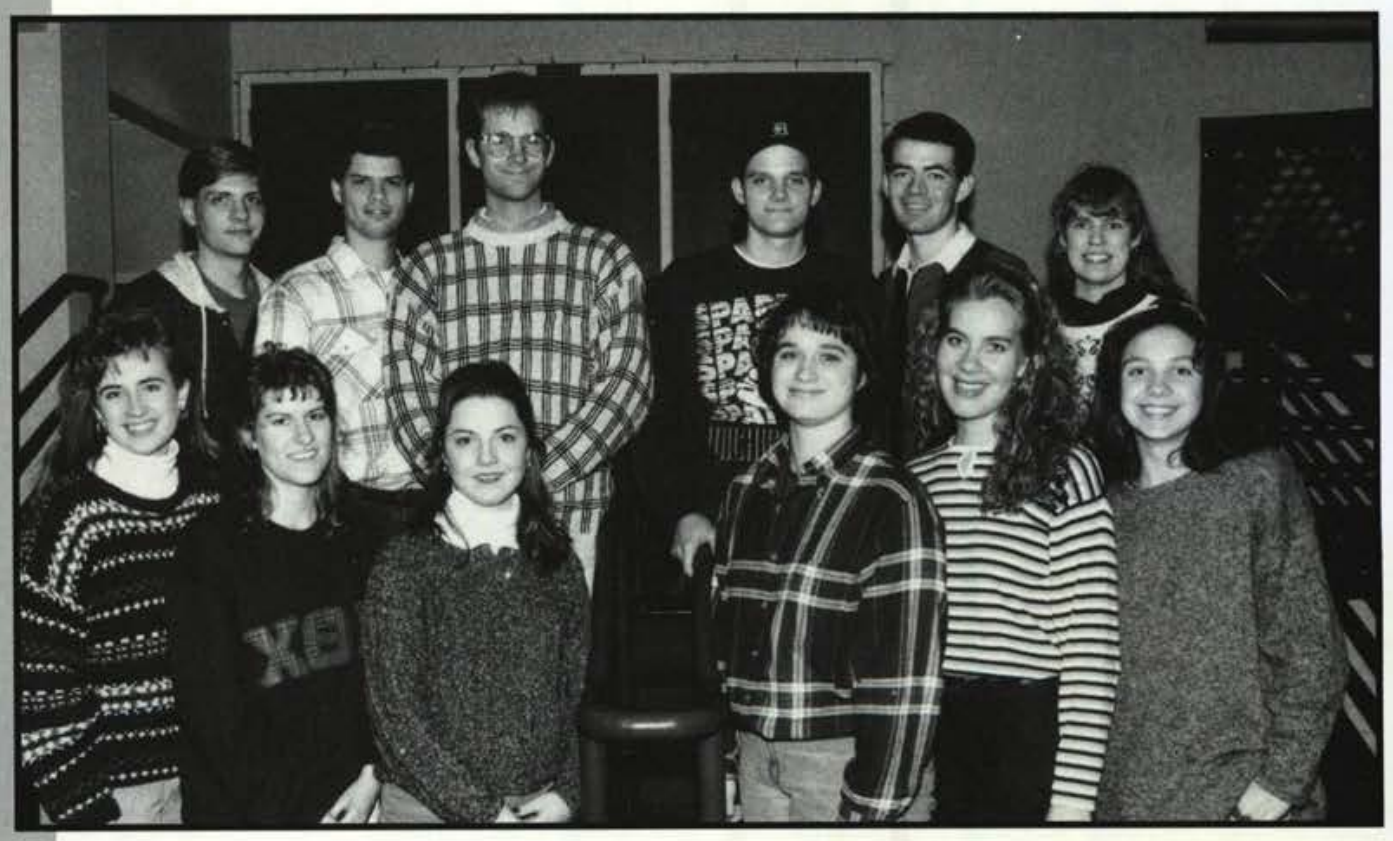




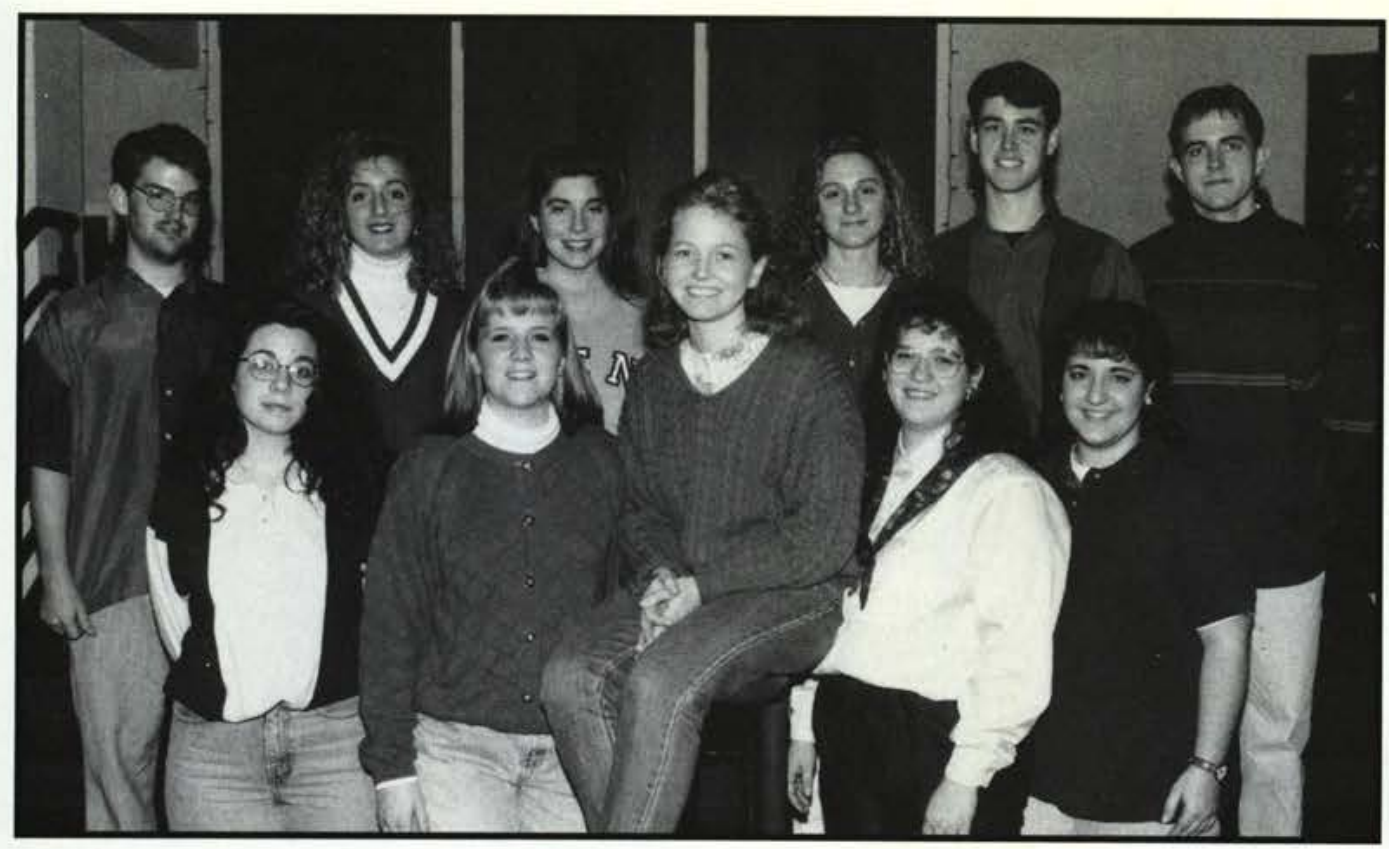

First row: Tracie Wright, Karin Moon, Emily Williams, Elizabeth Sorg, Rachel Maki

Second row: Tim Culberson, Katie

Smith, Rebecca Smith, Jamie Beck, Phil Caldwell, Doug Moe

\section{Mercy Hospital}

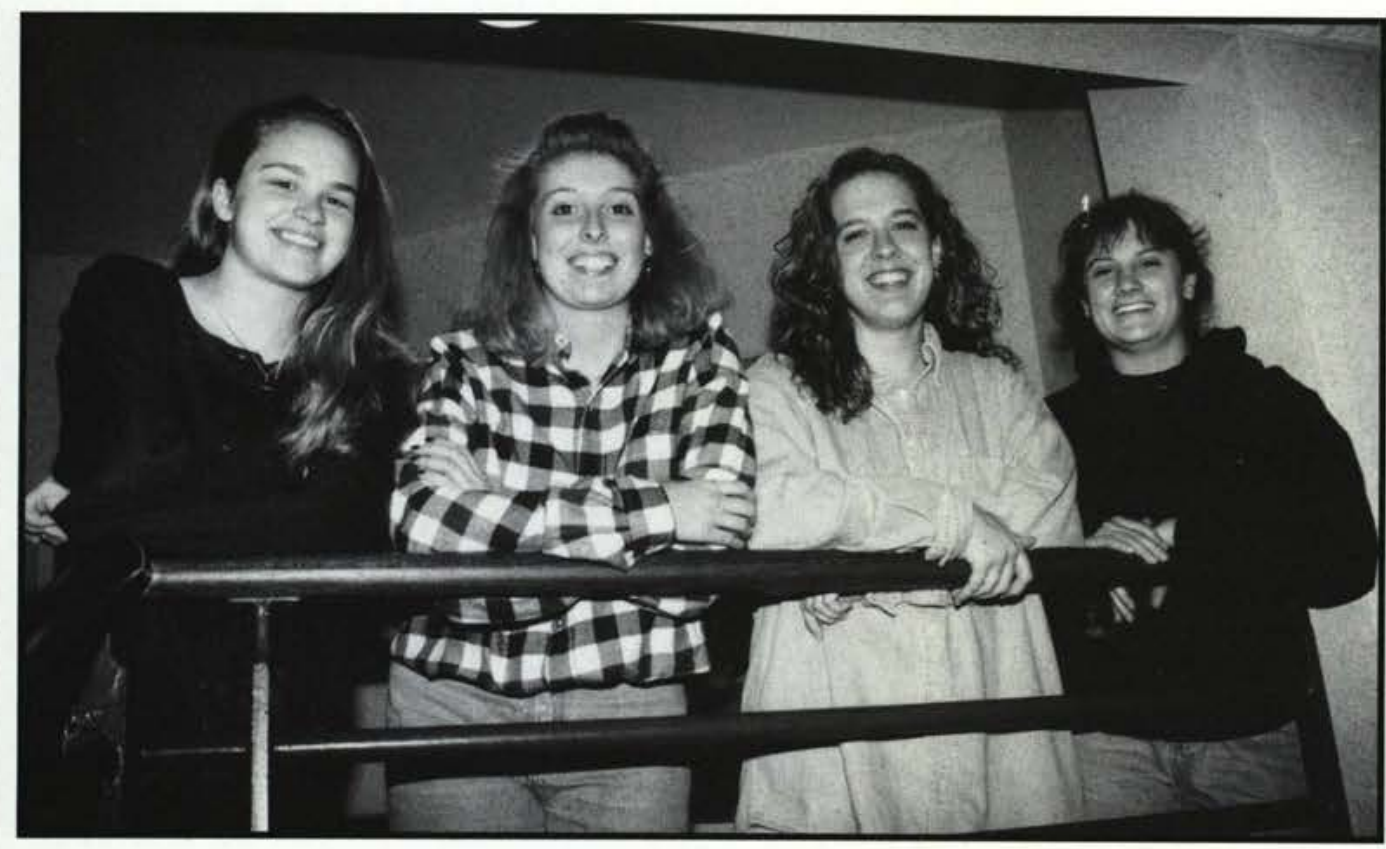

Abby Miller, Jennifer Blackburn, Amy Wannemacher, Sarah Byrer

\section{Miami Valley CPC}

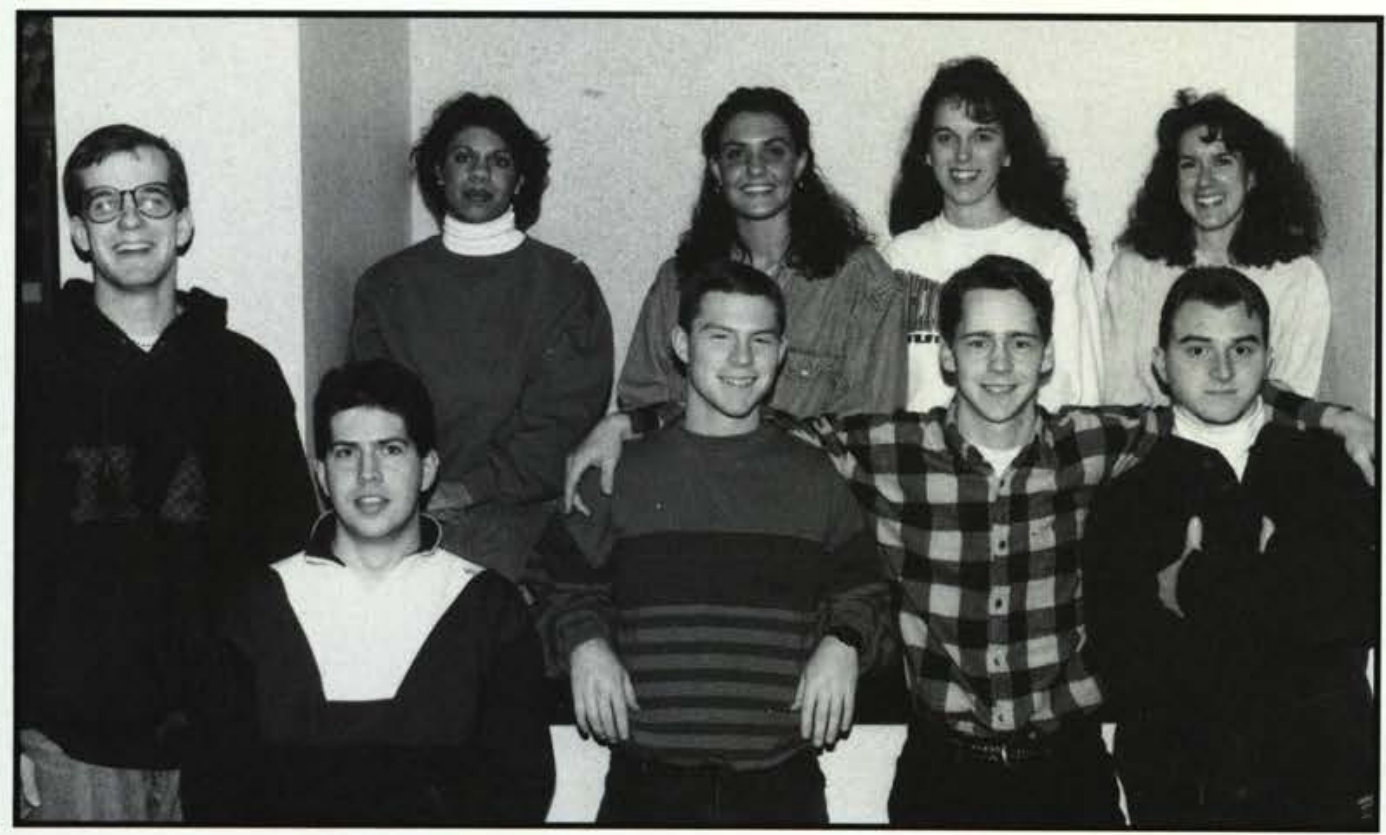

First row: Tim Tuinstra, Randall East, Cliff Scott, Justin Colby, Drew Ireland Second row: Diione Fox, Tracy Weber, Danielle Madding, Colette Cassidy

\section{Operation Rebirth}



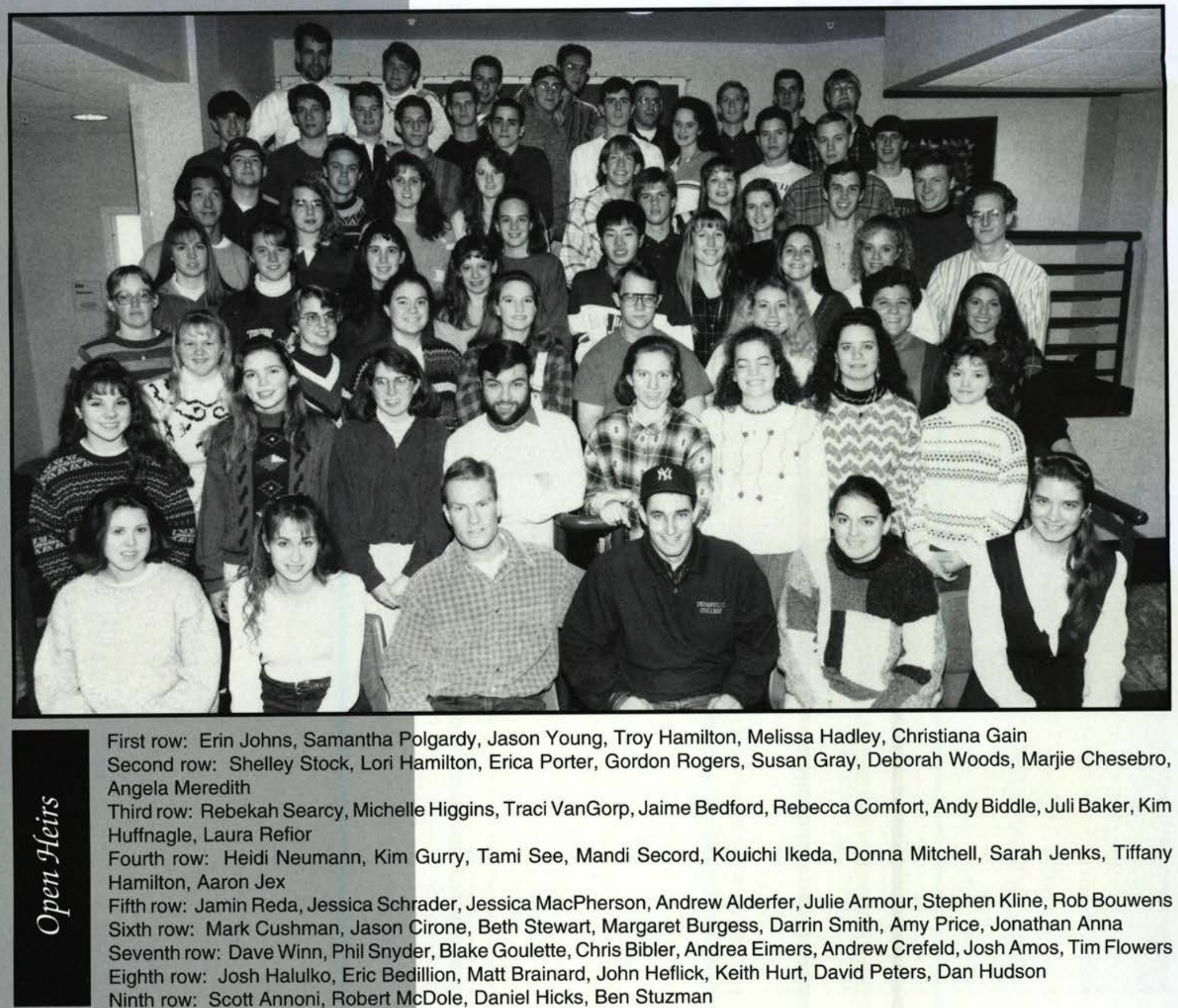

First row: Erin Johns, Samantha Polgardy, Jason Young, Troy Hamilton, Melissa Hadley, Christiana Gain Second row: Shelley Stock, Lori Hamilton, Erica Porter, Gordon Rogers, Susan Gray, Deborah Woods, Marjie Chesebro, Angela Meredith

Third row: Rebekah Searcy, Michelle Higgins, Traci VanGorp, Jaime Bedford, Rebecca Comfort, Andy Biddle, Juli Baker, Kim Huffnagle, Laura Refior

Fourth row: Heidi Neumann, Kim Gurry, Tami See, Mandi Secord, Kouichi Ikeda, Donna Mitchell, Sarah Jenks, Tiffany Hamilton, Aaron Jex

Fifth row: Jamin Reda, Jessica Schrader, Jessica MacPherson, Andrew Alderfer, Julie Armour, Stephen Kline, Rob Bouwens Sixth row: Mark Cushman, Jason Cirone, Beth Stewart, Margaret Burgess, Darrin Smith, Amy Price, Jonathan Anna Seventh row: Dave Winn, Phil Snyder, Blake Goulette, Chris Bibler, Andrea Eimers, Andrew Crefeld, Josh Amos, Tim Flowers Eighth row: Josh Halulko, Eric Bedillion, Matt Brainard, John Heflick, Keith Hurt, David Peters, Dan Hudson Ninth row: Scott Annoni, Robert McDole, Daniel Hicks, Ben Stuzman

First row: Tami Strong

Second row: Julie Griffeth, Katherine Denham, John Schultz, Melanie Ras, Joe Lloyd

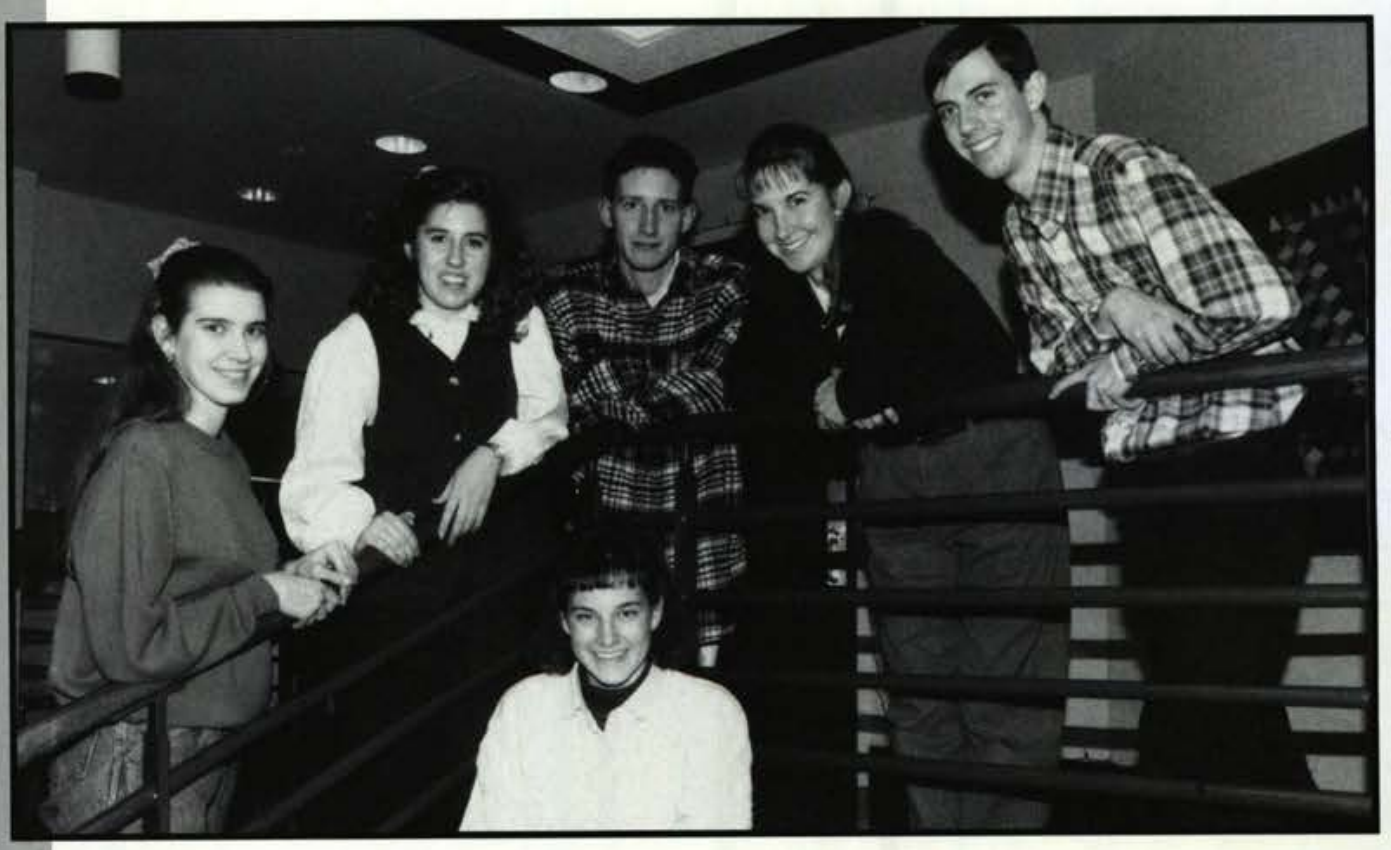




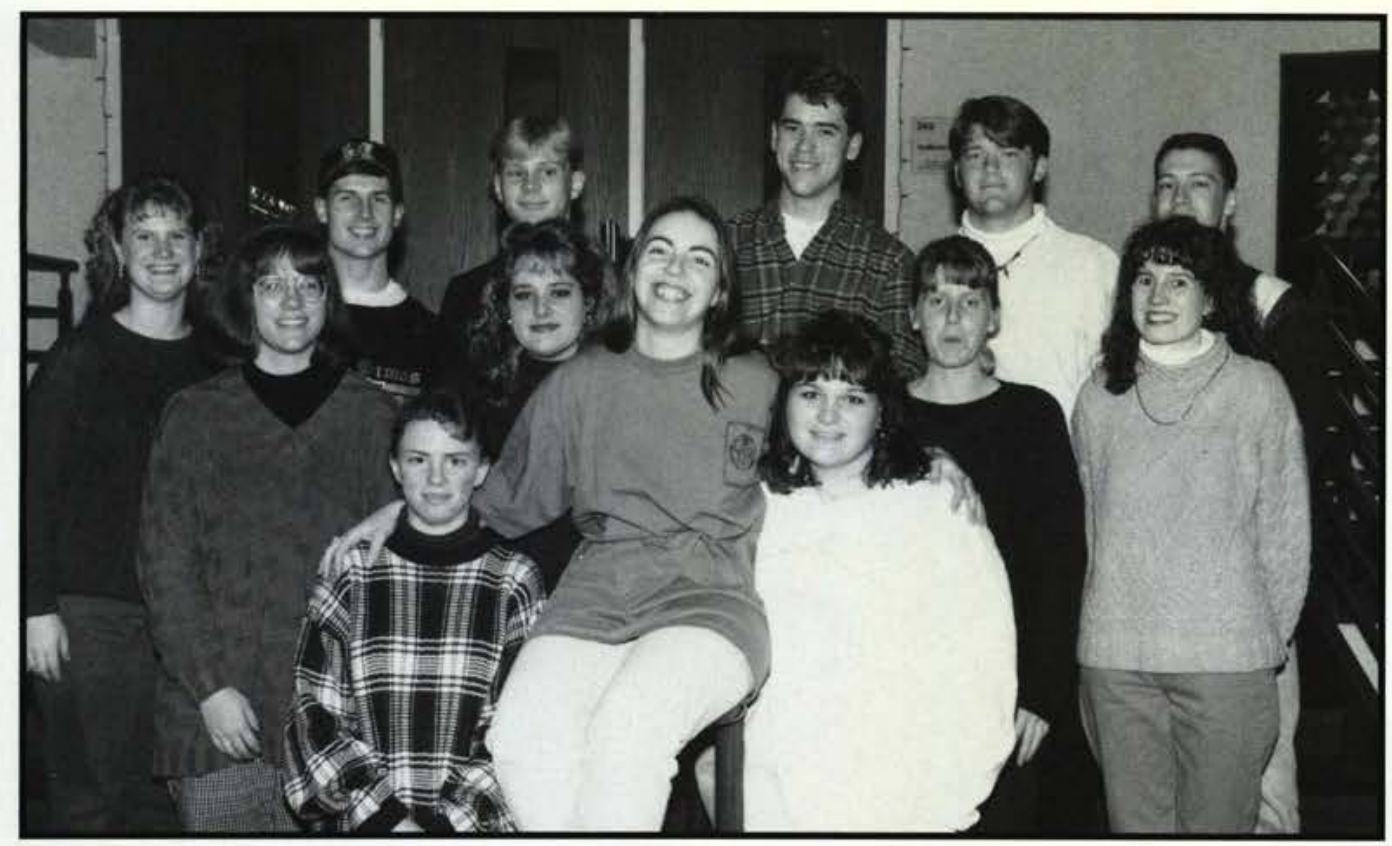

First row: Roni Mower, Elizabeth

Rogers, Becky Bovay

Second row: Jill Gerber, Genny

Opperman, Angela Meyers, Lisa

Devereaux

Third row: Karen Robertson, Adam

Oxford, Chad Sorensen, Stephen

Gerber, Robert McDole, Jim Patten

\section{OVCH--A.M.}

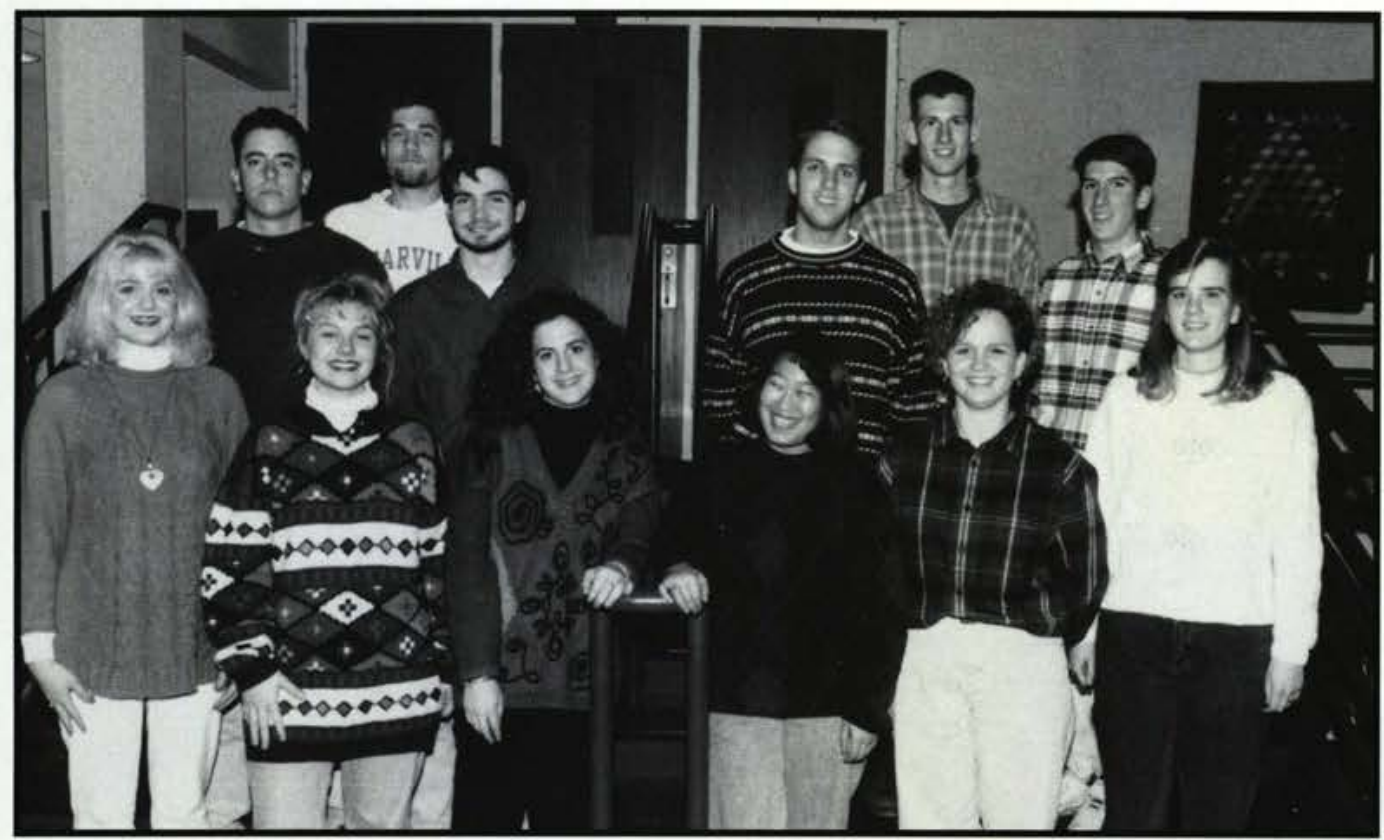

First row: Cari Collins, Elizabeth Porter, Michelle Linley, Sara Dyson

Second row: Matt Robinson, David Moore, Brett Dyson, Matthew Murphy Third row: Dave Geiger, Dave Pfahler

\section{OVCH--Special Friends}

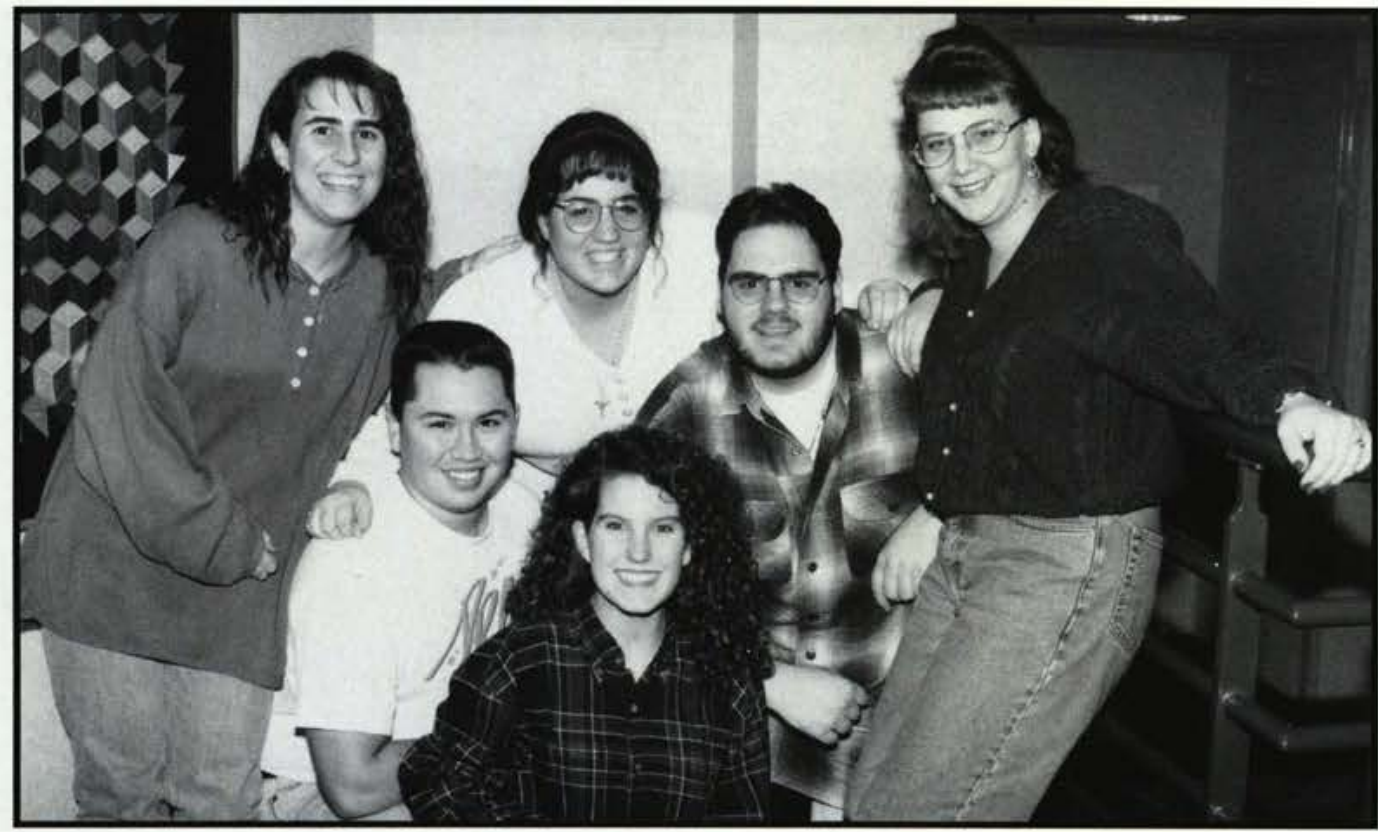

First row: Colleen Lang

Second row: Lori Hockenberry, Sean Wood, Greg Wiesert, Shelly Dolf Third row: Monique Dewar

\section{OVCH--Tutoring}


First row: Tara Swiger, Mandy Orme, Jerra Davis, Jen VanderBush

Second row: Amy Clayton, Alissa

Whitten

Third row: Amy Spurling, Sara Gromko,

Sherri Woodard, Erica Hunter

\section{Ronald McDonald House}

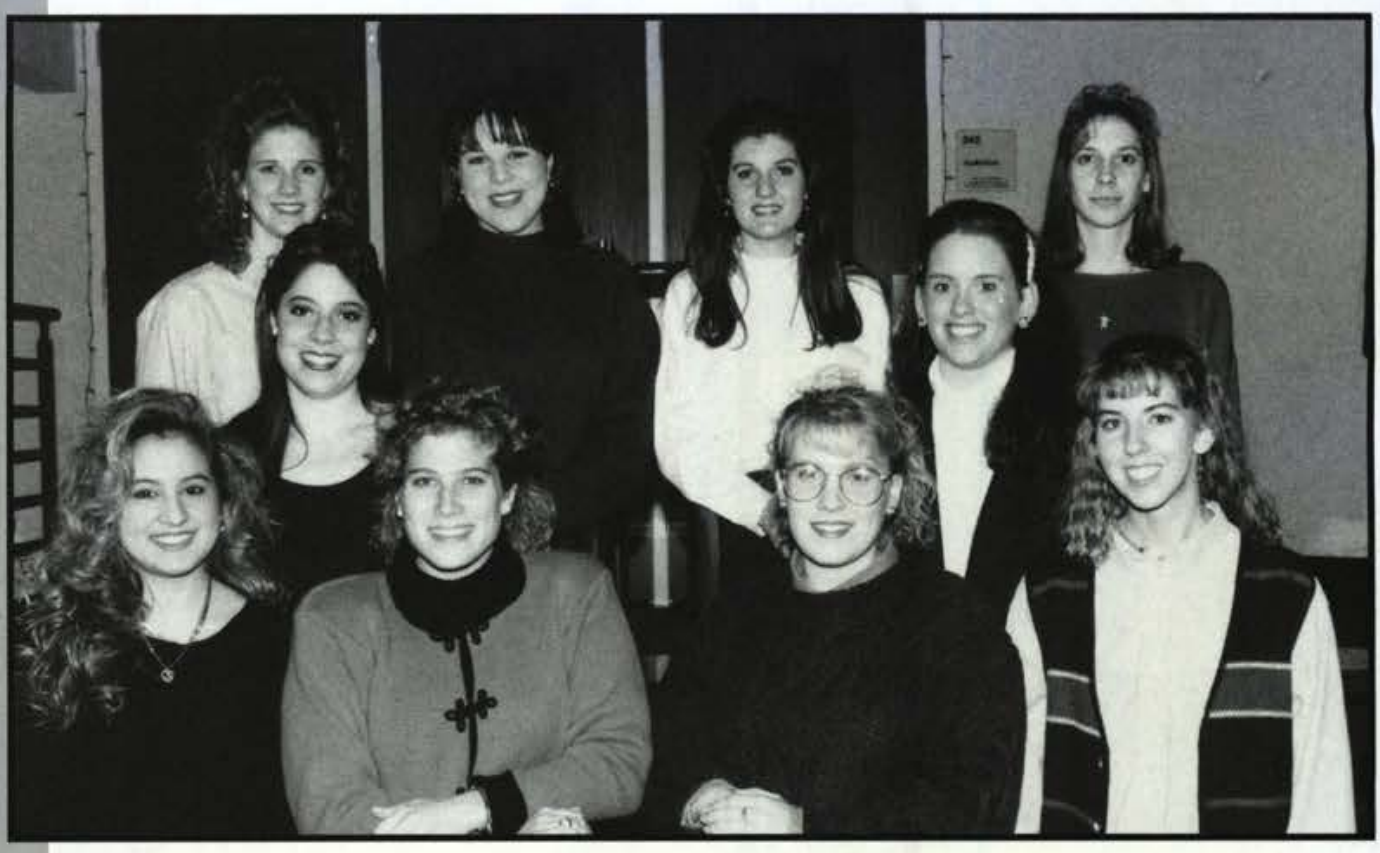

Left to right: Aaron Jex, Jeremy Toyer, David Boyd, Amy Volpe, Abigail Howe, Lisette Cardel

\section{South Fairfield}

First row: Shannon Scott, Lori Cobb, Beth Tharp, Stephanie Johnson Second row: Ruth Hamilton, Renee Hiebert, Amy Hunsaker Third row: Heather Bossley, Leah Hoover, Laura Refior

\section{Springfield CPC}
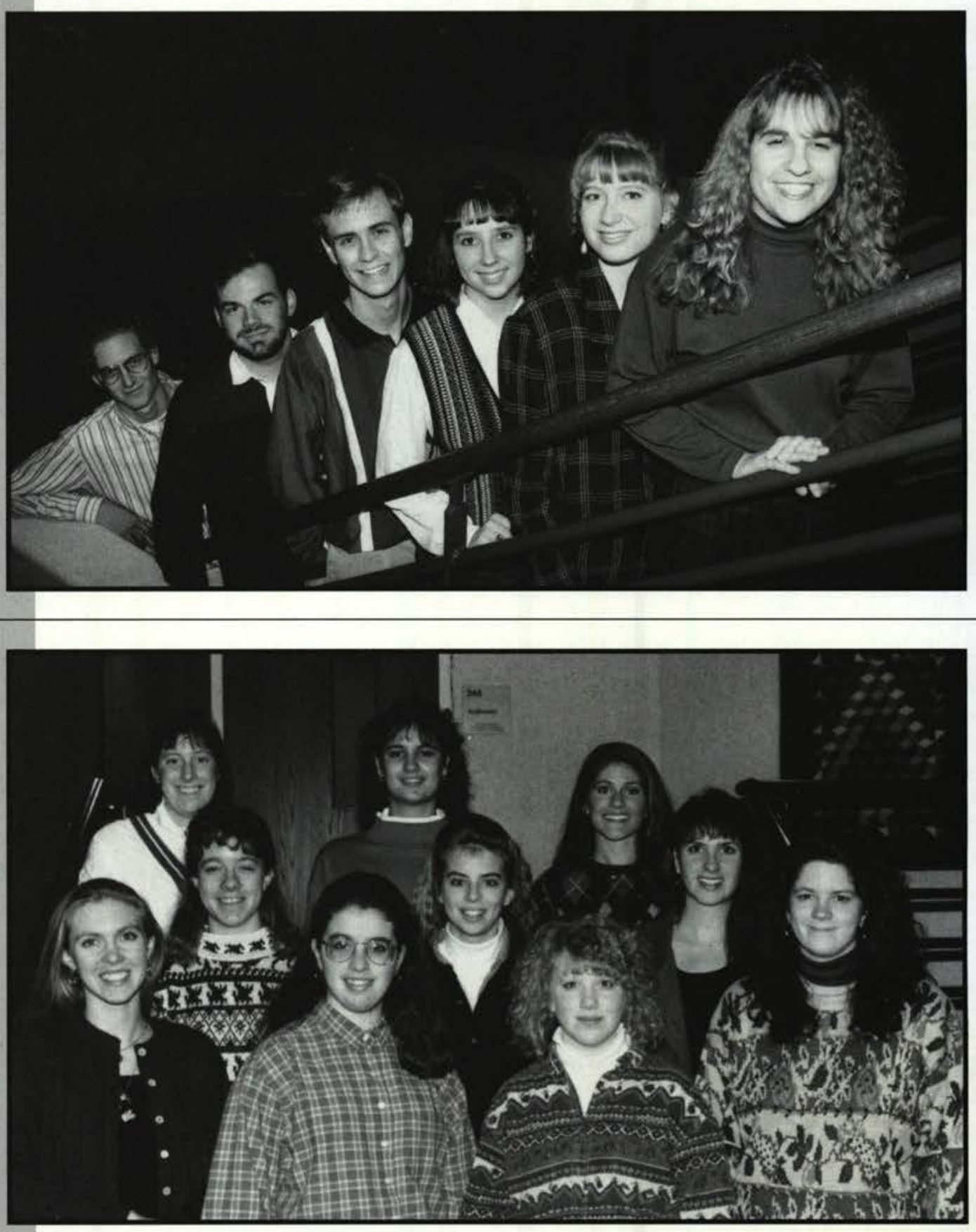


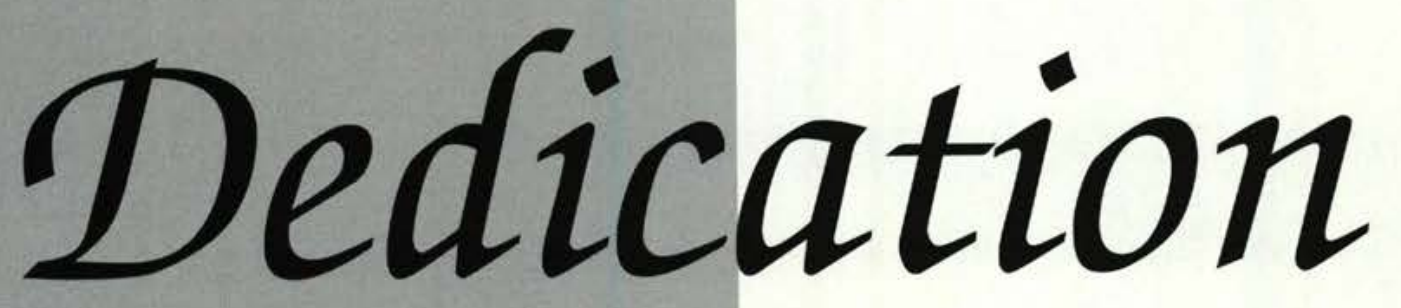

\section{The Christian Ministries Center}

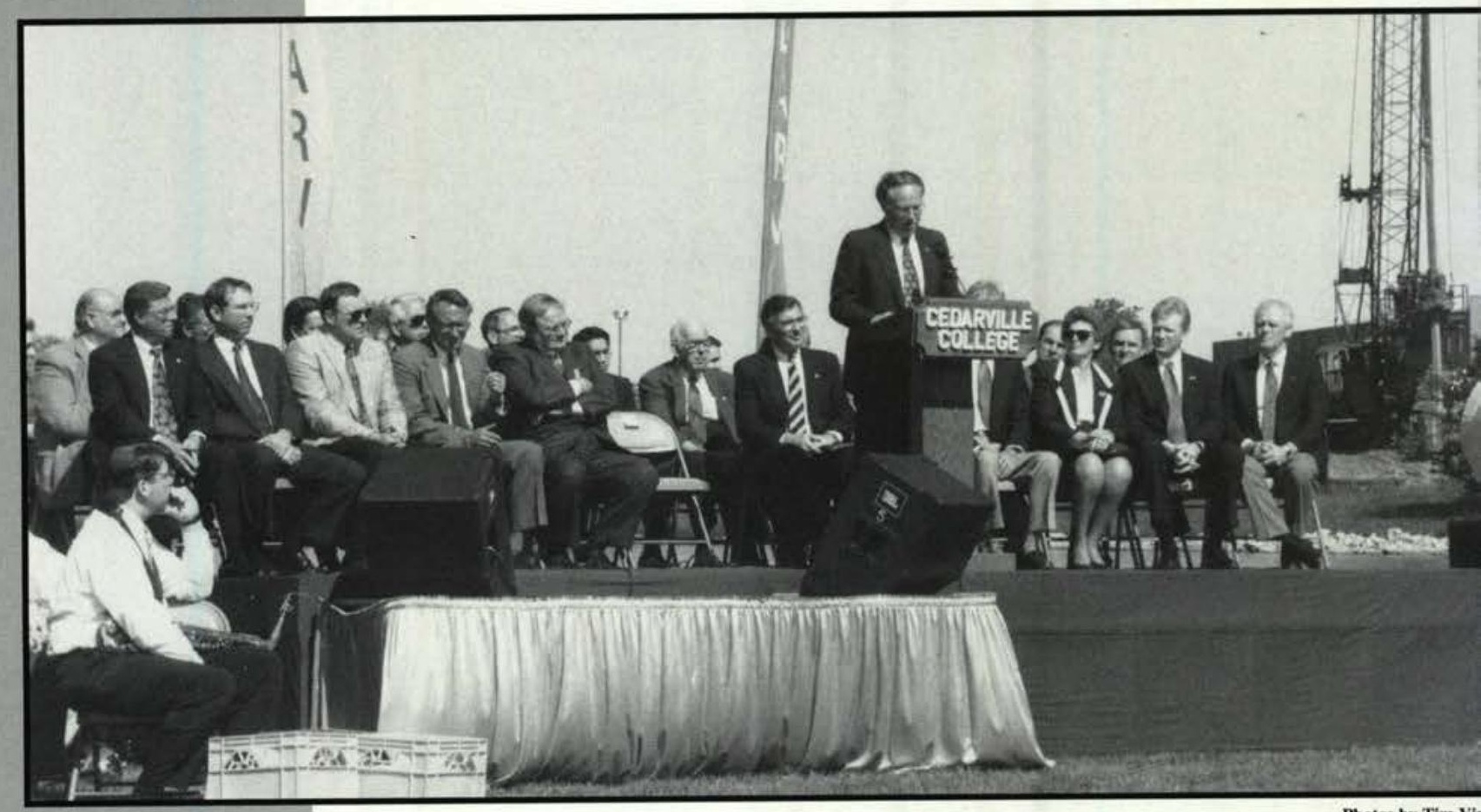

ABOVE: Dr. Dixon gives recognition to members of the task team, research teams, and all those involved in the new building.

RIGHT: The Abundant Life Singers

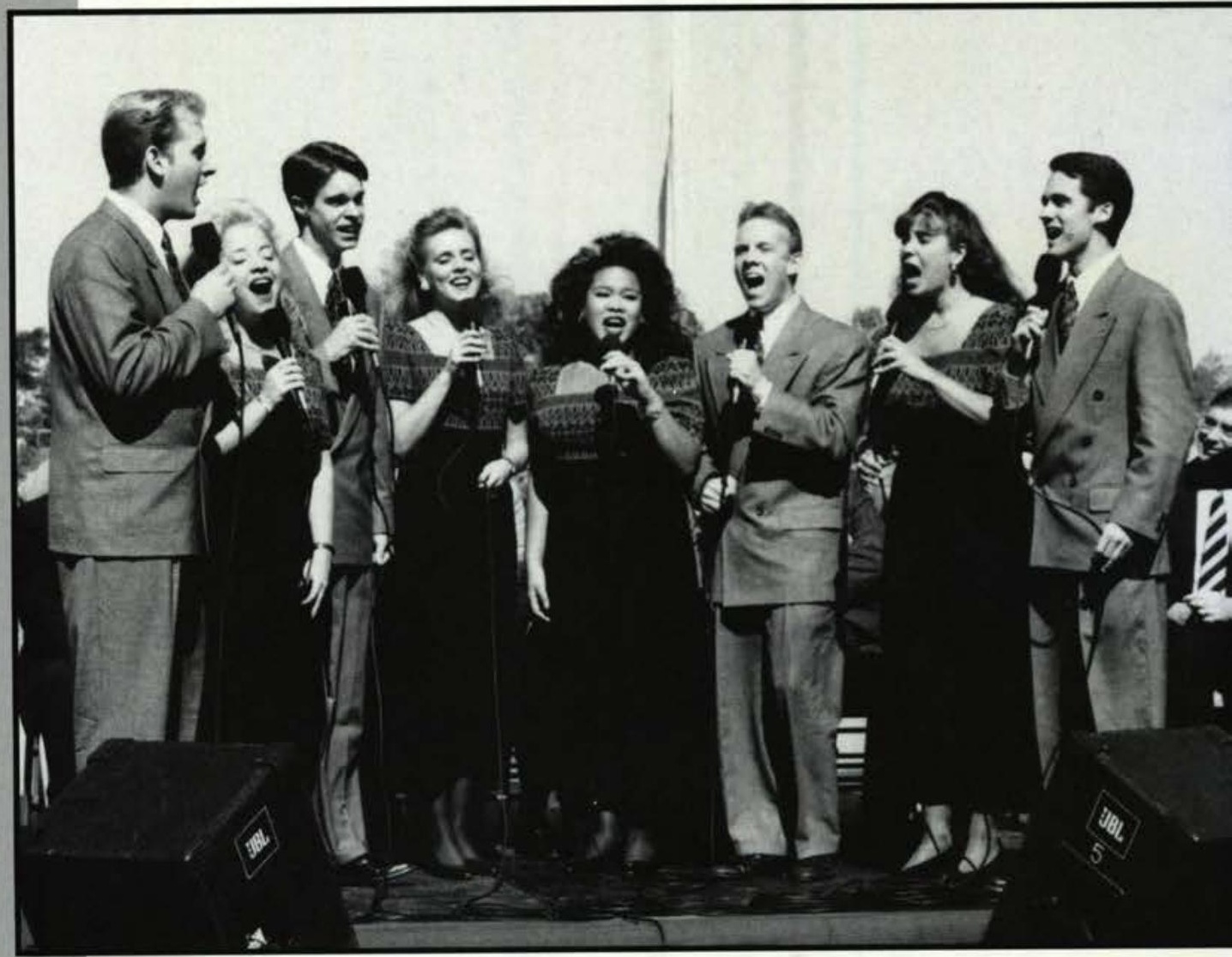

98 christian ministries 

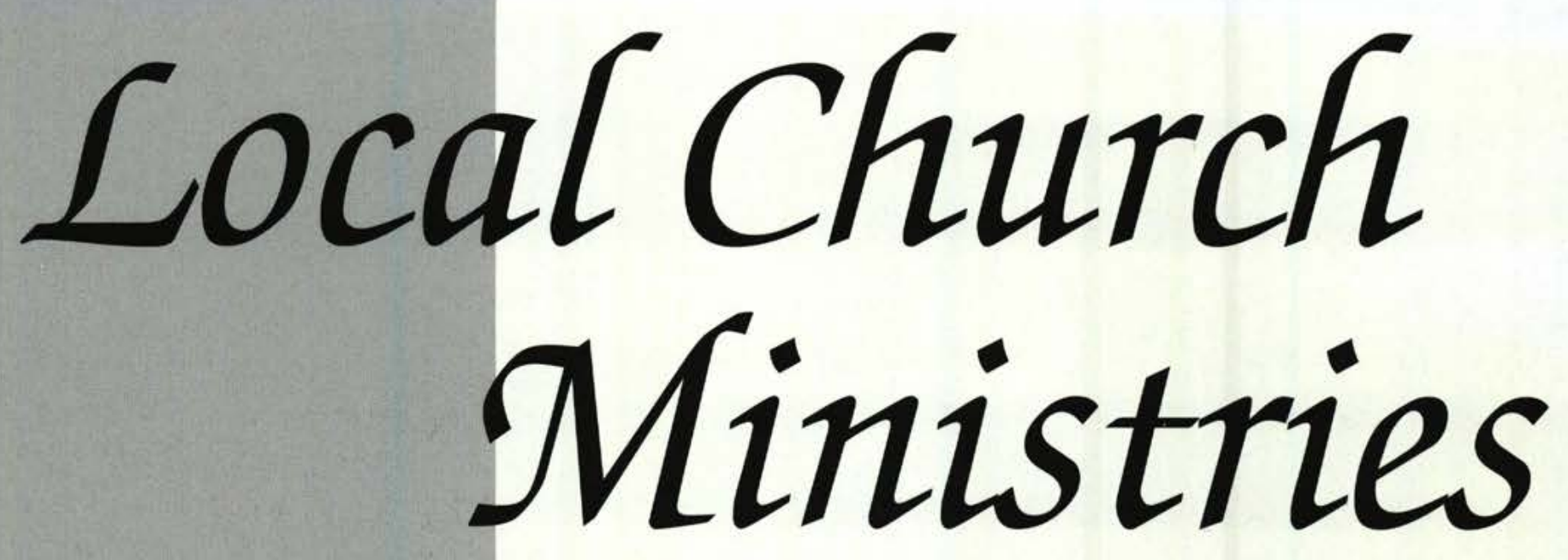

First row: Rajan Desai, Jill Fuller, Hillary Pifer, James Dewald, Chris Prediger, Cynthia Sheets, David Hoskins, Kim Huffy

Second row: Emily Hodel, Renee Cunningham, Amy Humphreys, David Hoskins, Paul KeKruter, Mark Hershner Third row: Jim Rowley, Crystal Toomey, Heather Perrault, Elliott Gilham, Amanda Bruckner, Heather Webster, Gerry Burkett, Julie Jouwstra

Airway Baptist
Bethel Baptist
Berea Bible

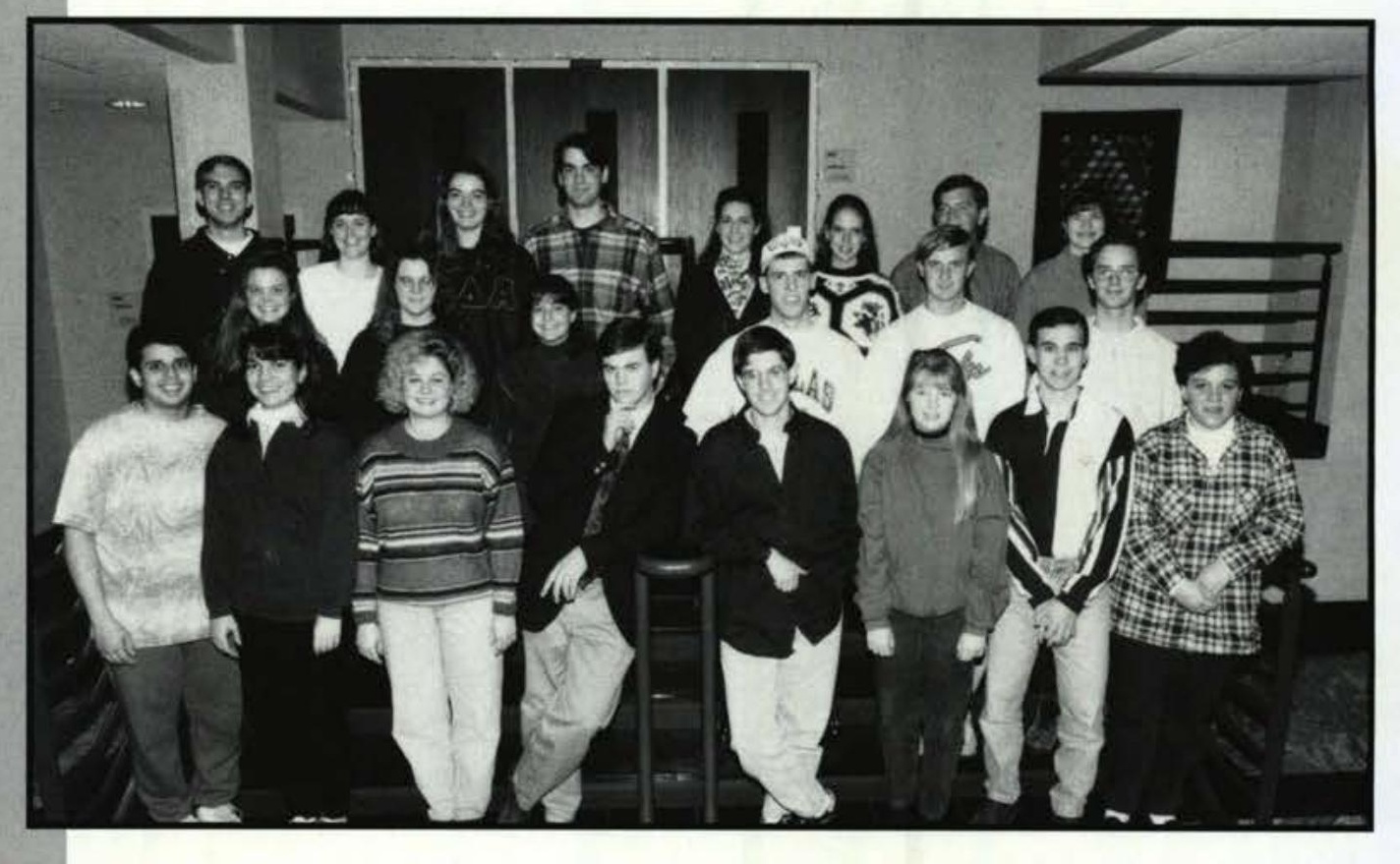

First row: Sarah Moseley, Jason Driesbach, Derrick Green

Second row: Shari Reed, Brenda Tabberer, Christina Stauffer, Charity Rizer, Jennifer Yaggi

\section{Calvary Baptist Calvary Grace Bretfren}

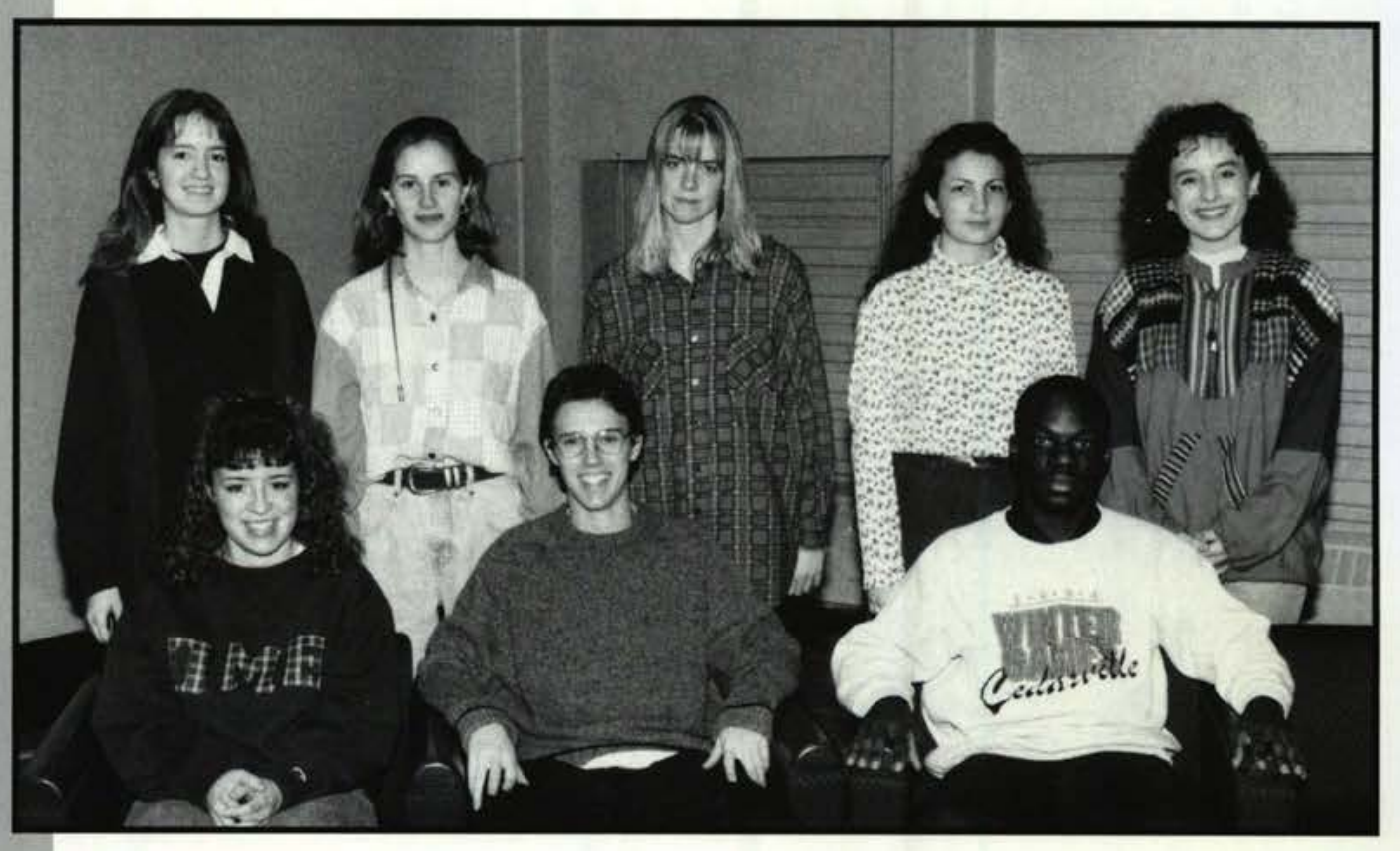




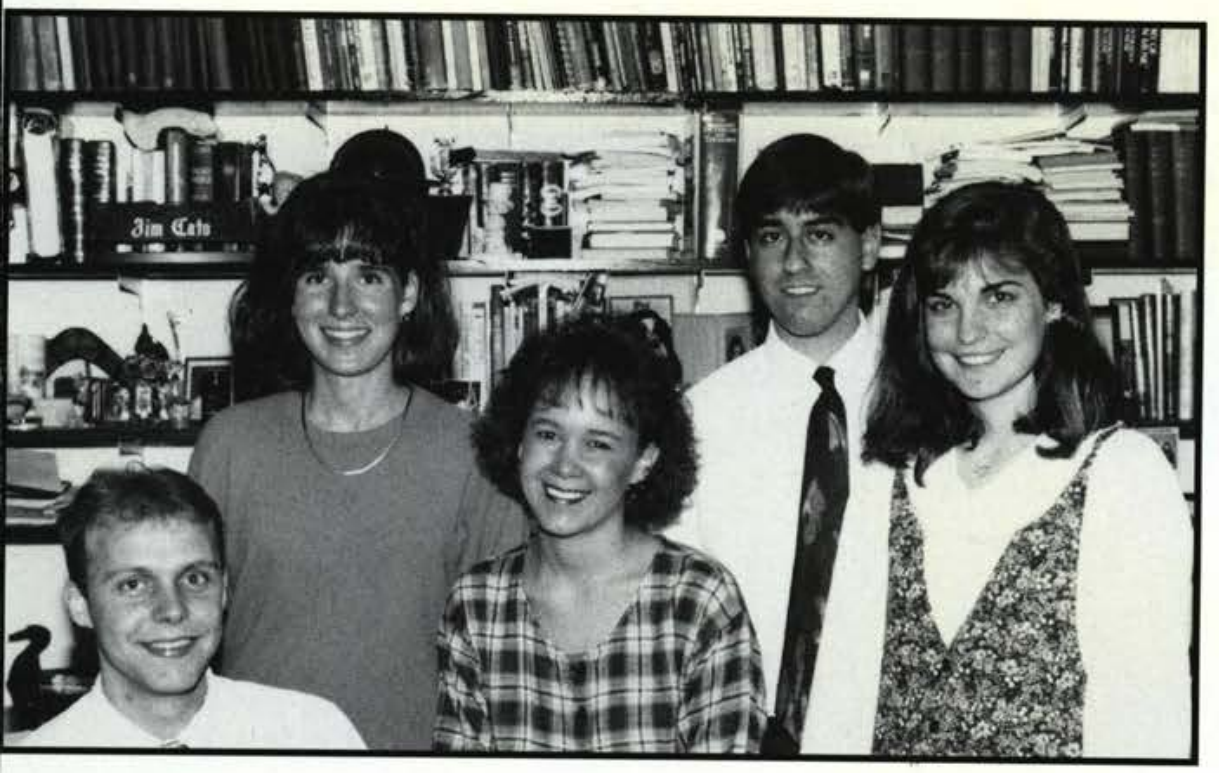

Local church extension teams are a part of the Swordbearers ministry. These teams are small groups of students that go to the same local church each week throughout the school year to assist in everything from nursery work to leading choirs.

\section{Swords Executive Team}

First Row: Dean Osuch, Karen Hatcher, Sarah McCarty Second Row: Sarah Warnken, Mike Pasquale

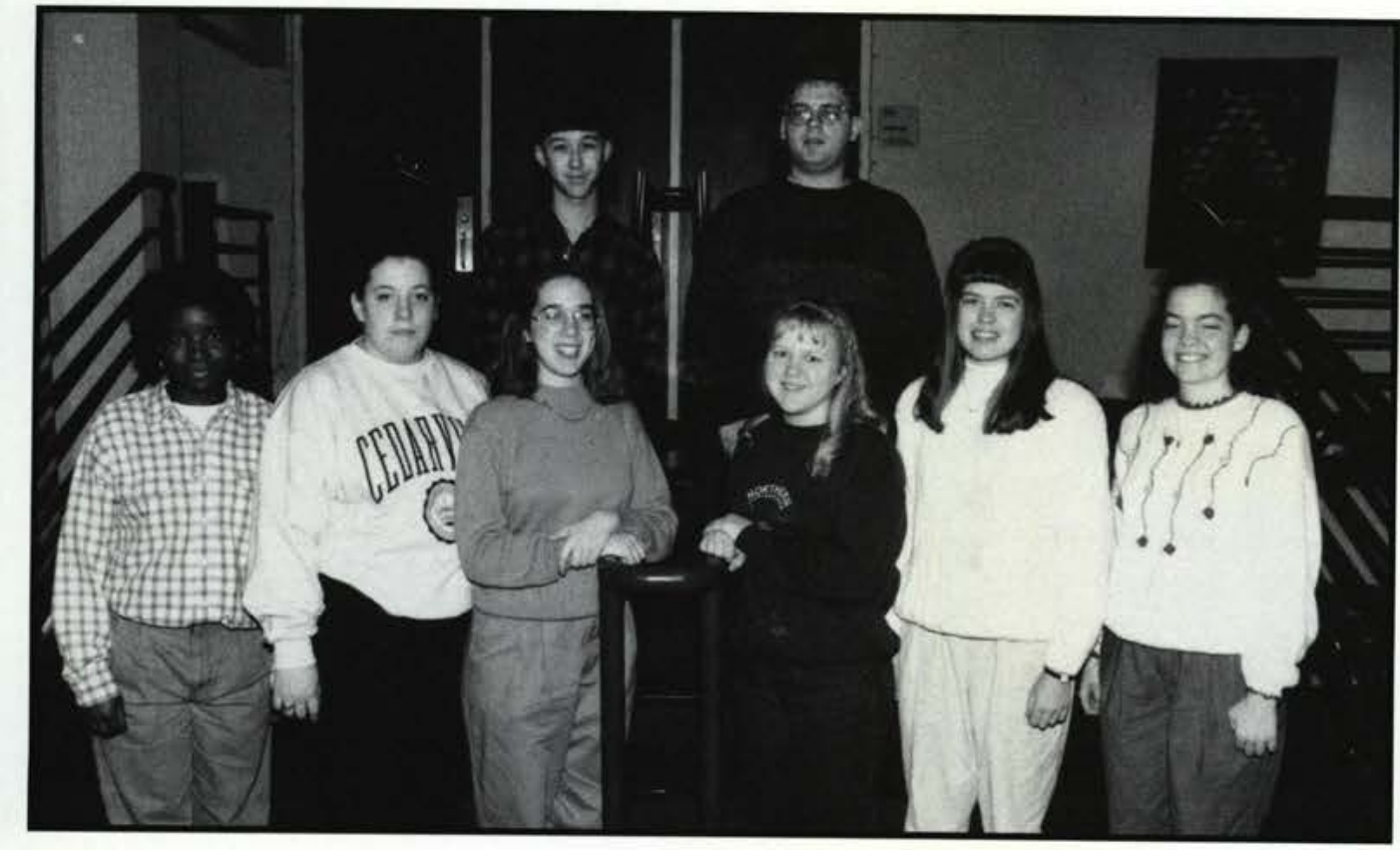

First row: Michelle Johnson, Olivia Carter, Heidi Groves, Michelle Higgins, Darla Anthony, Deborah Woods Second row: Nathan Ho, David Heim

Cornerstone Baptist
Prince of Peace-
United Brethren
Chapel at Ofmer Park

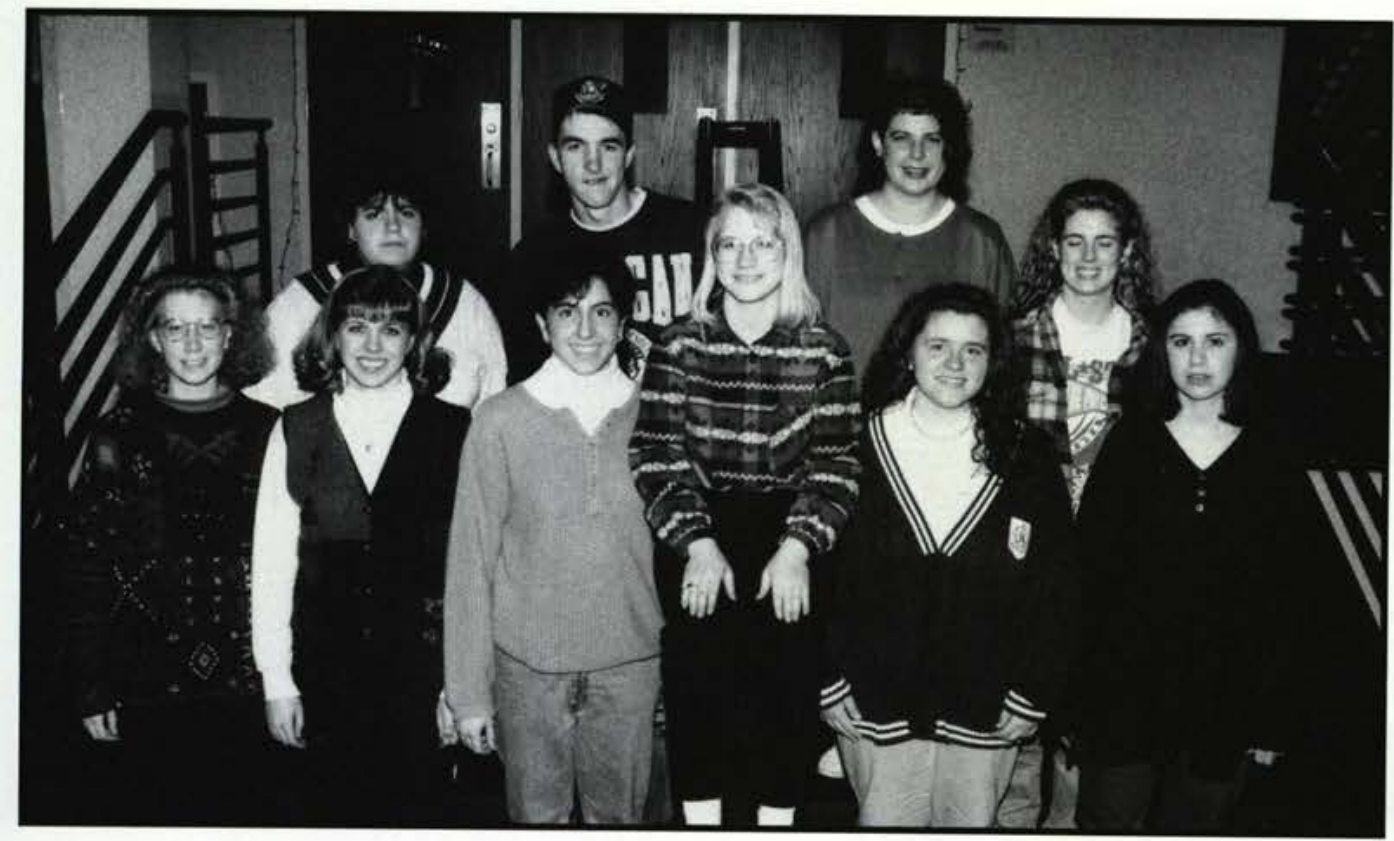

First row: Natalie Vademark, Amy Woods, Amy Awabdy, Melody Brickel, Penni Fulkerson, Debbie Woods Second row: Heidi Comers, David Kaynor, Kristen Kuiken, Jennifer Clark

\section{Emmanuel Baptist}


First row: Chris Hutson, Michaela Murray, Lynette Strong, Janine Pinkley Second row: Scott Judkins, Nate Bolhuis, Shane Blansette, Brian Kigar, Jason Stevens

\section{Fairhaven Church}

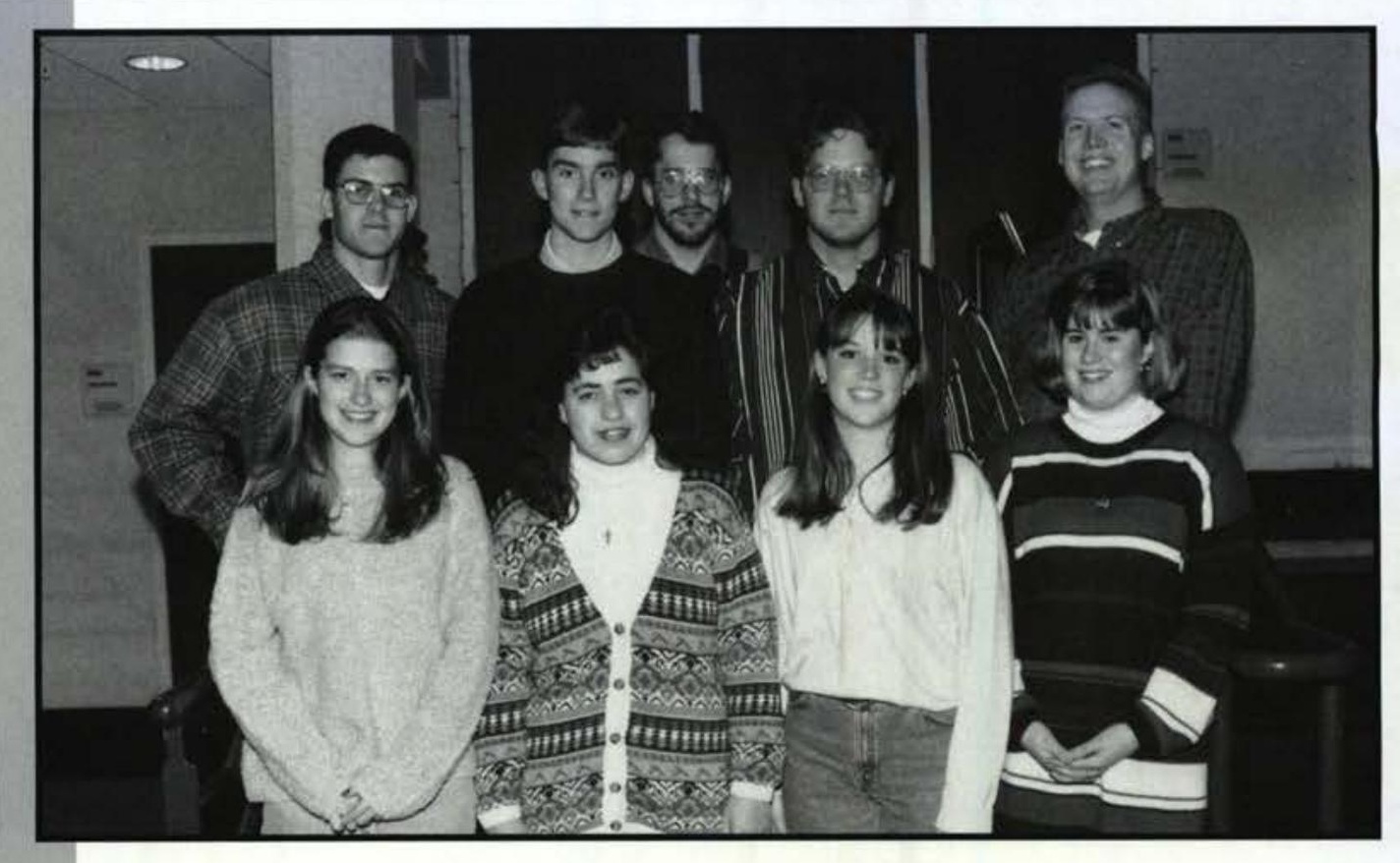

First row: Eric O'Brian, Scott Borling, Maria Redfern, Flynn Tregay, Brenda Matthew, Steve Whalen

Second row: Paul Streetman, Kim Collins, Michelle Zub, Tabi Leininger Third row: Chad Snow, Kathryn Larsen, Elizabeth Roseboom, Marnie Ehlers, Chad Butler, Charles Robinson

\section{Faith Baptist--Wilmington County Line Baptist Dayton Avenue Baptist}

First row: Rebekah Sorensen, Dawn Kirgan, Echo Tuinstra, Harry VanderWal Second row: Karissa Linafelter, Brenda Johnson, Tim Miller, Mindy Abrams Third row: Jolyn Glines, Dean Osuch

First Reformed
First Baptist of Tipp City
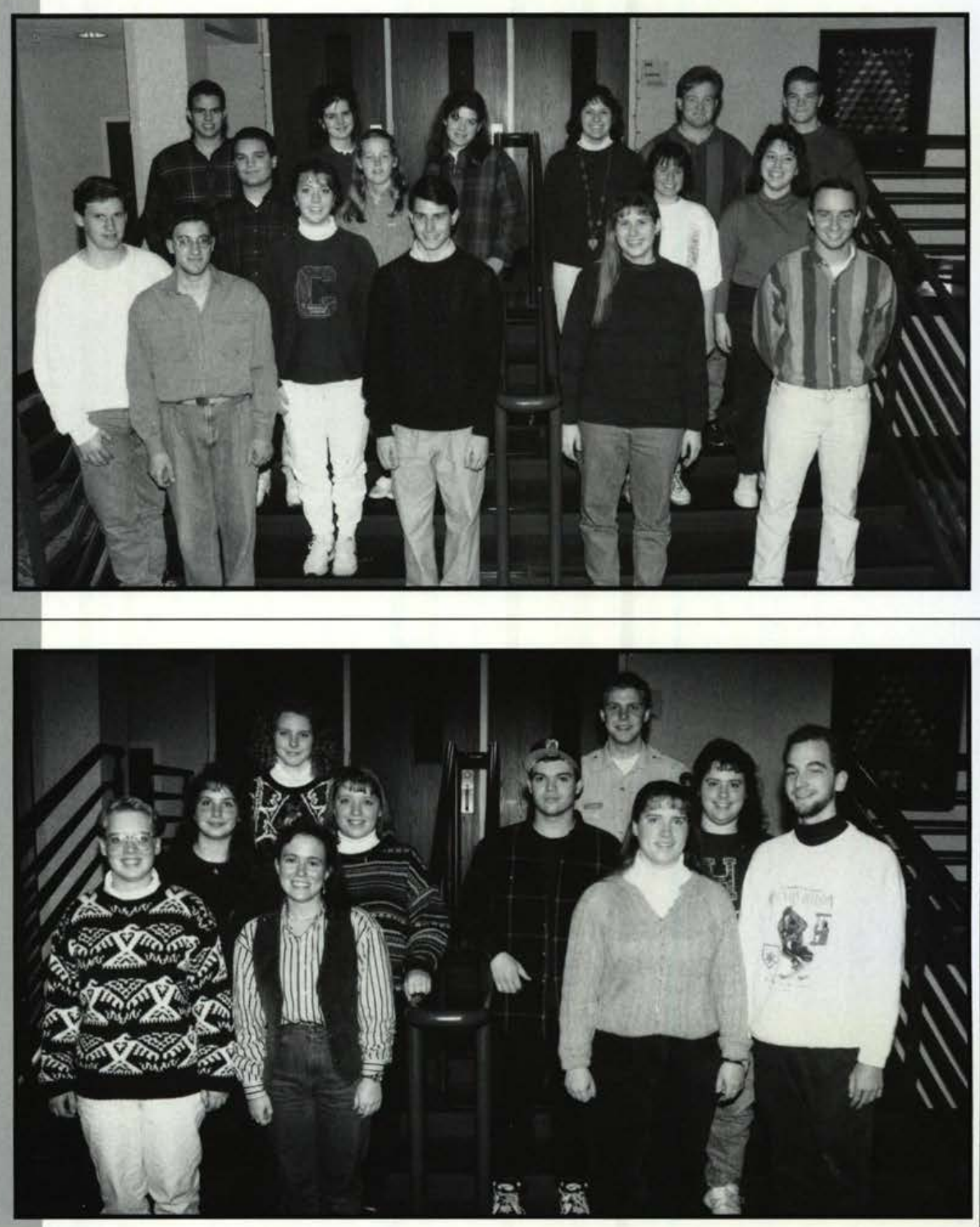
Left to right: Leslie Davis, Jen Whitman, Jim Olinger, Jeremy Awbrey, Andrew Alderfer, Steve Garcia, Dan Huber, Tami See

\section{New Hope Franklin}

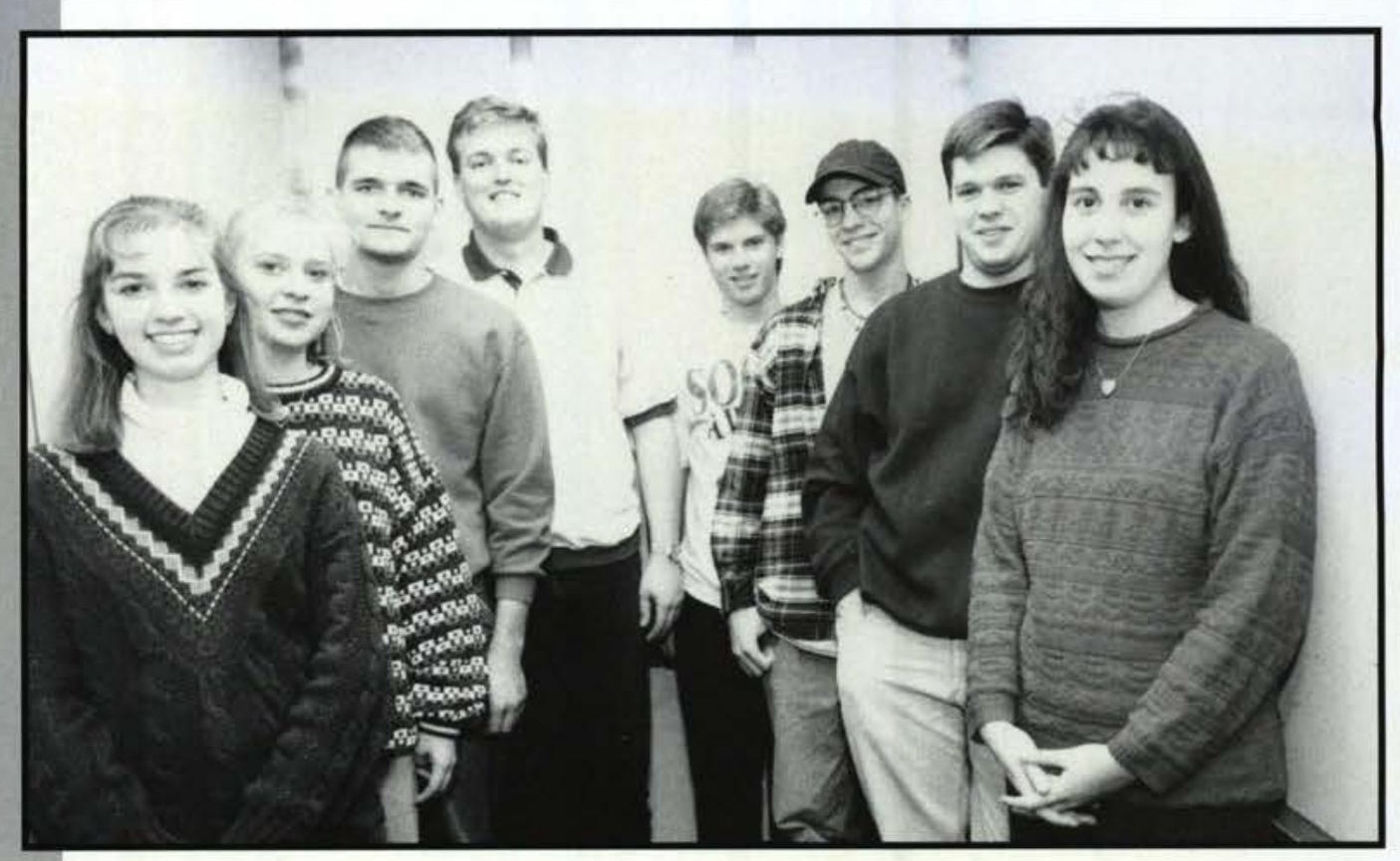

First row: Jim Blumenstock, Karen Ware, Tammy Michaels, Danette McCullough, Sara Powell, Ellen Oncu, Dan Douglas

Second row: Chrystie Ruba, Carrie Glidewell, Amber Snodgrass, Tim Nicklas

Third row: Sally Ward, Debi Wong, Kerry Allen, Debbie Kruse, Amy Butcher, Katie Moon

Fourth row: Thomas Weise, Rob Mulvaney, Nathan Eads, Aaron Bey, Jamie French, Chad Wingert

\section{North Side Awana Southgate Baptist}

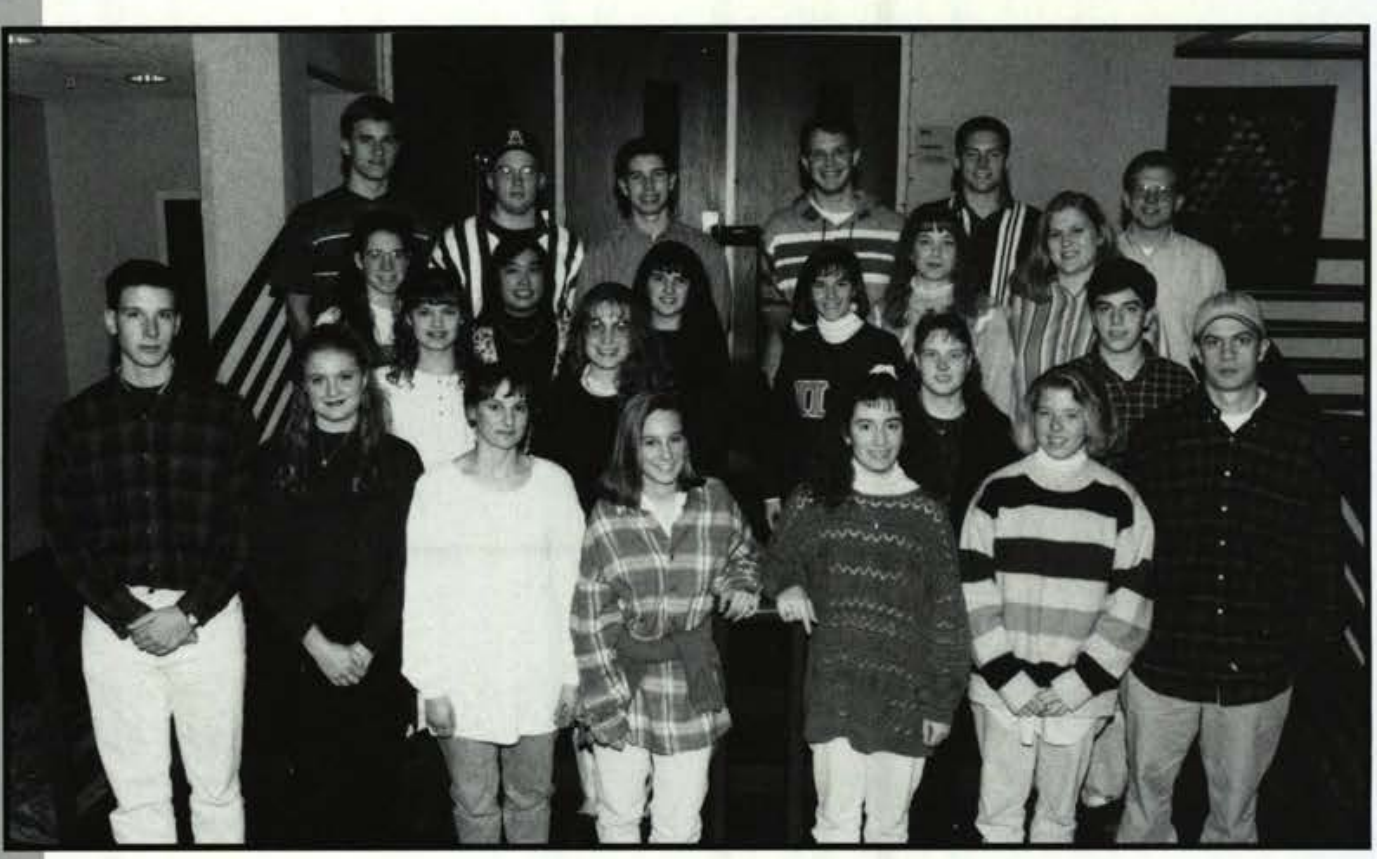

First row: Diana Thompson, Rachel Soderstrom, Jessica Nuzum, Debra Thompson, Kim Koziol, Angela Boyce, Sarah McCarty, Erica Porter

Second row: Presian Smyers, Brian White, Scott Parcher, Stephanie Mead, Amy De Witt

Third row: Brian Kovshinikov, Ken Lee, Rob Bergen

\section{Petre Road Grand Heights Baptist}

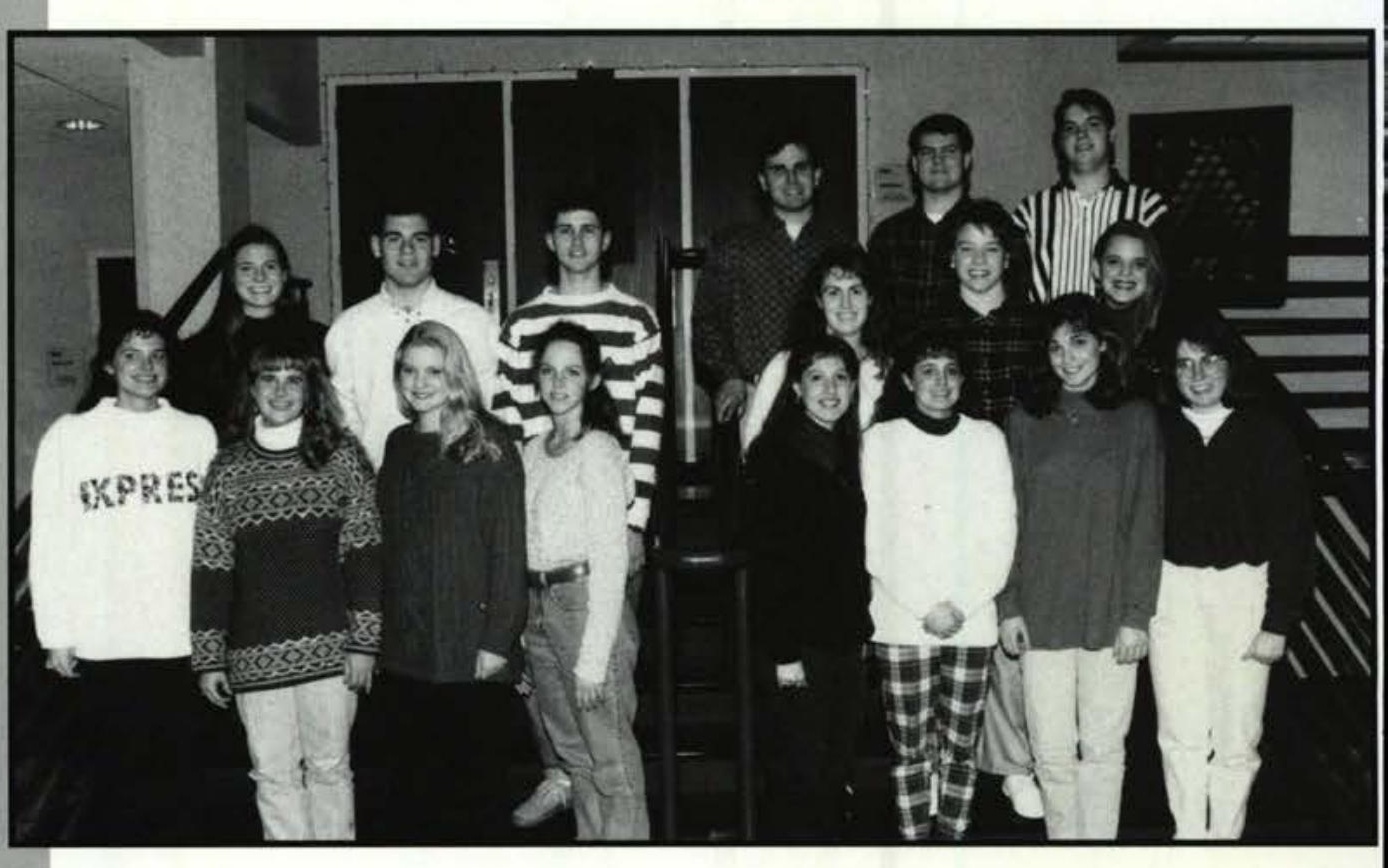




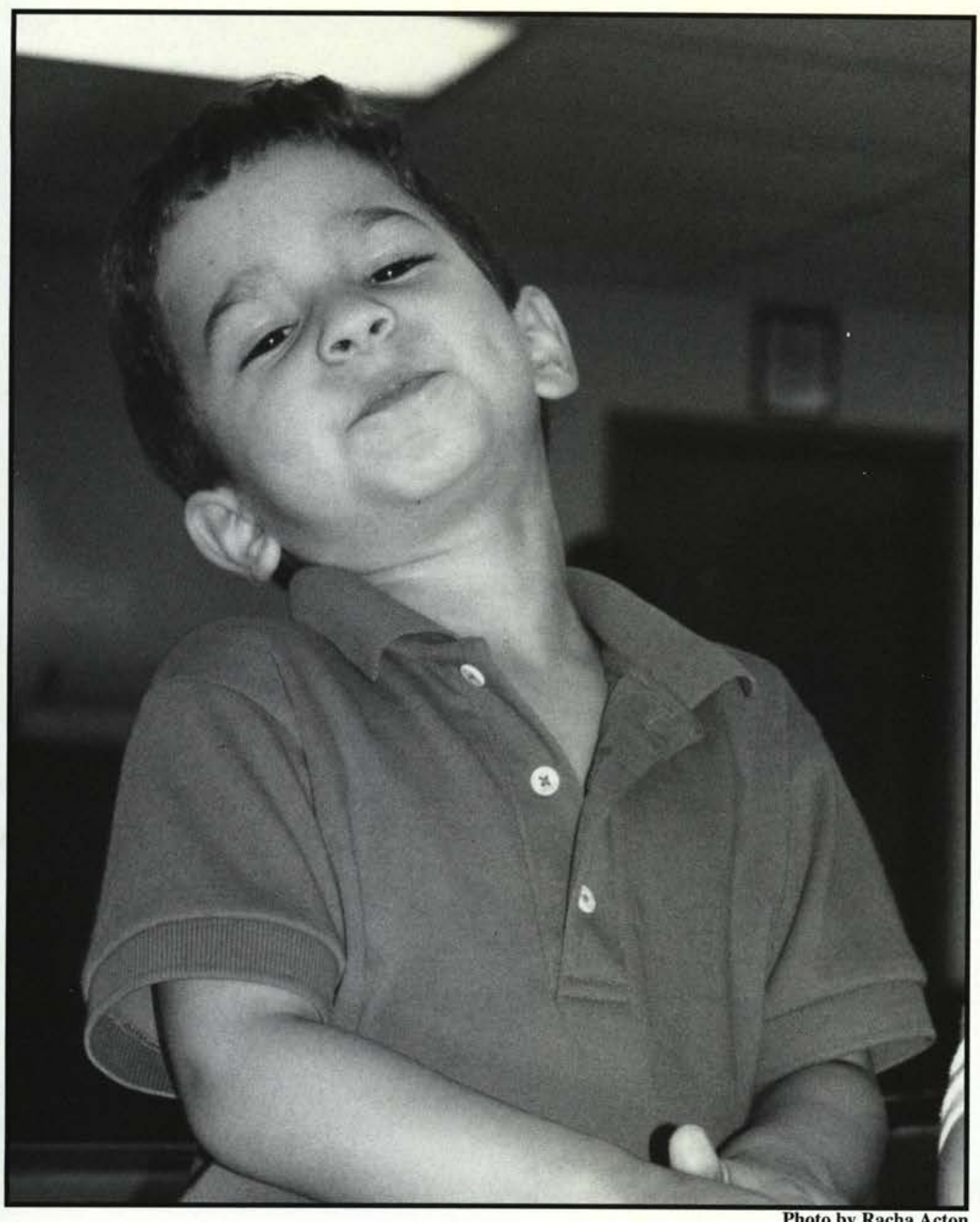

LEFT: Kids! ya just gotta love 'em.

Photo by Racha Acton

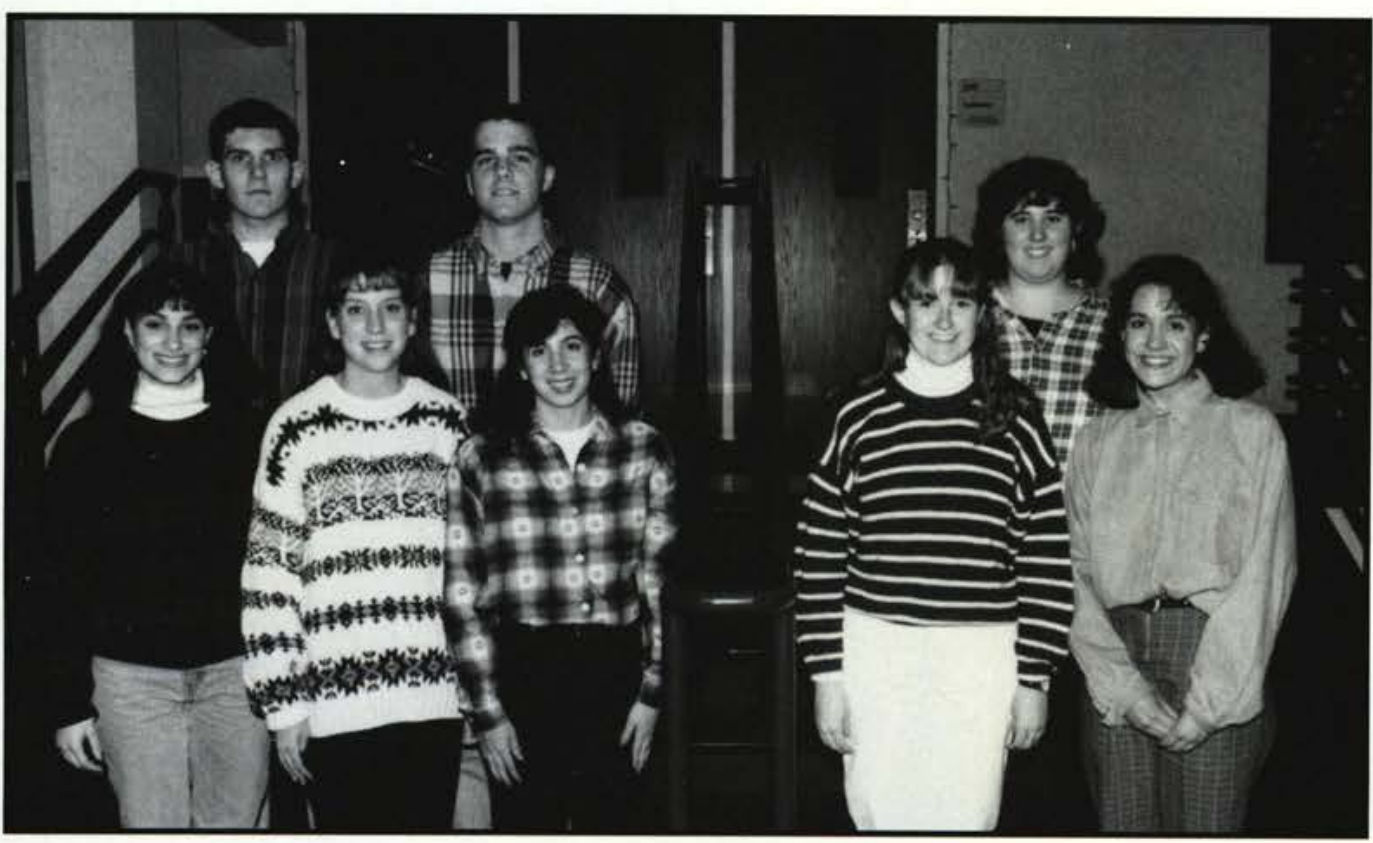

First row: Gina Polombo, Rebecca

Bork, Andi Schimmenti, Traci Niehaus,

Amie Hapeman

Second row: Todd Webster, Matt

White, Kara Lehman

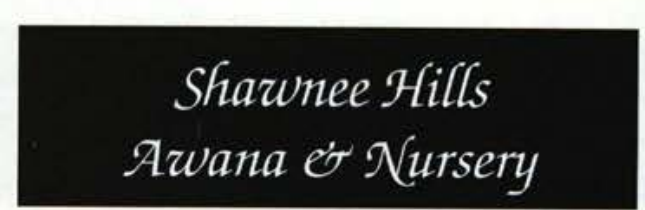


First row: Nicole Hernandez, Bethann Mohn, Meghan Foehl, Elizabeth Sorg Second row: Julie Meeder, Stephen Kline, Sarah Jenks, Ken Howard, Rob Beich

\section{Union Baptist Victory Baptist}

Left to right: Andrea Eimers, Andrew Creffeld, Kathy Bond, Heidi Bowen, Racha Acton

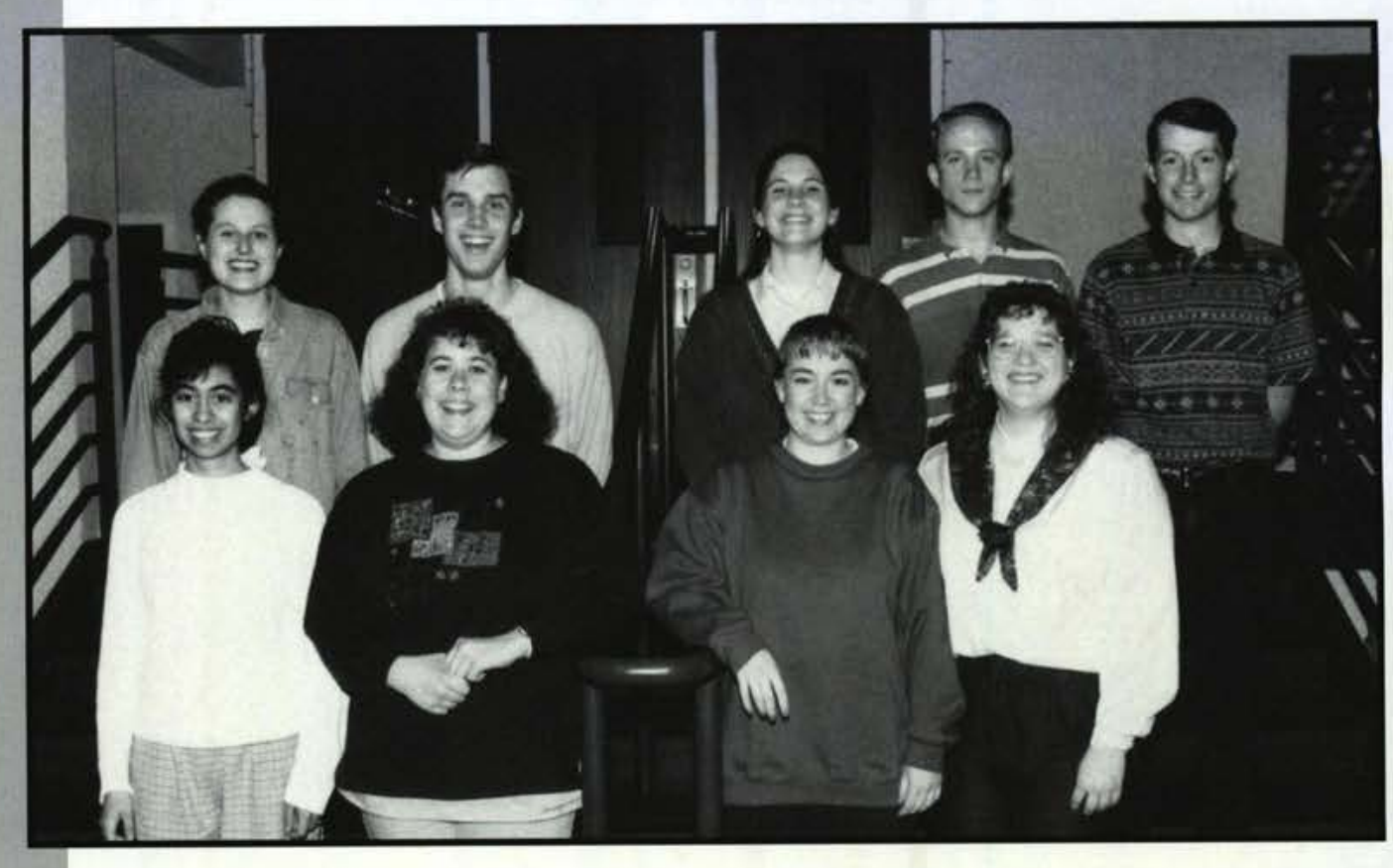

\section{W.P.A.F.P.}

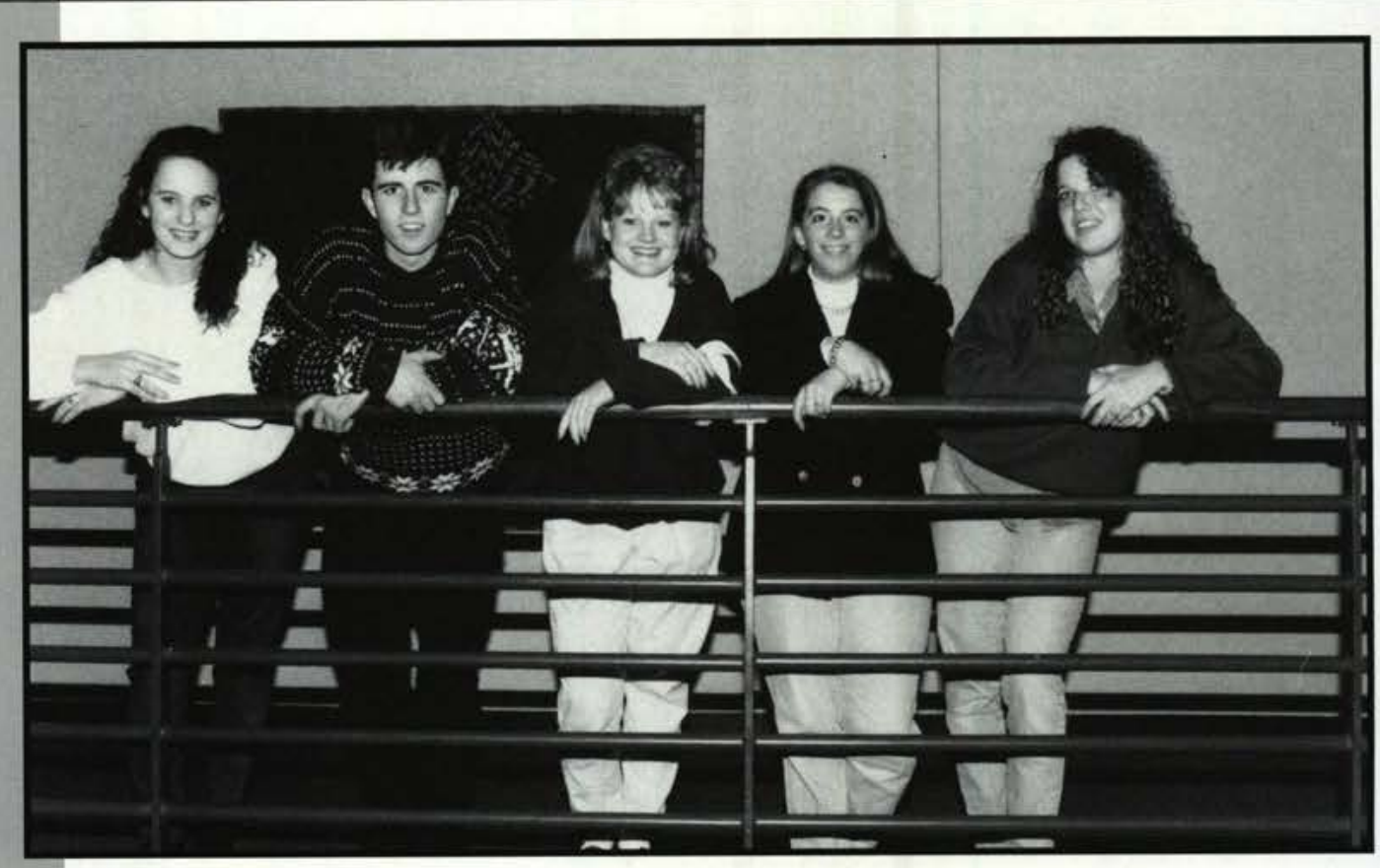

Jim Olinger helps some kids out with their project.

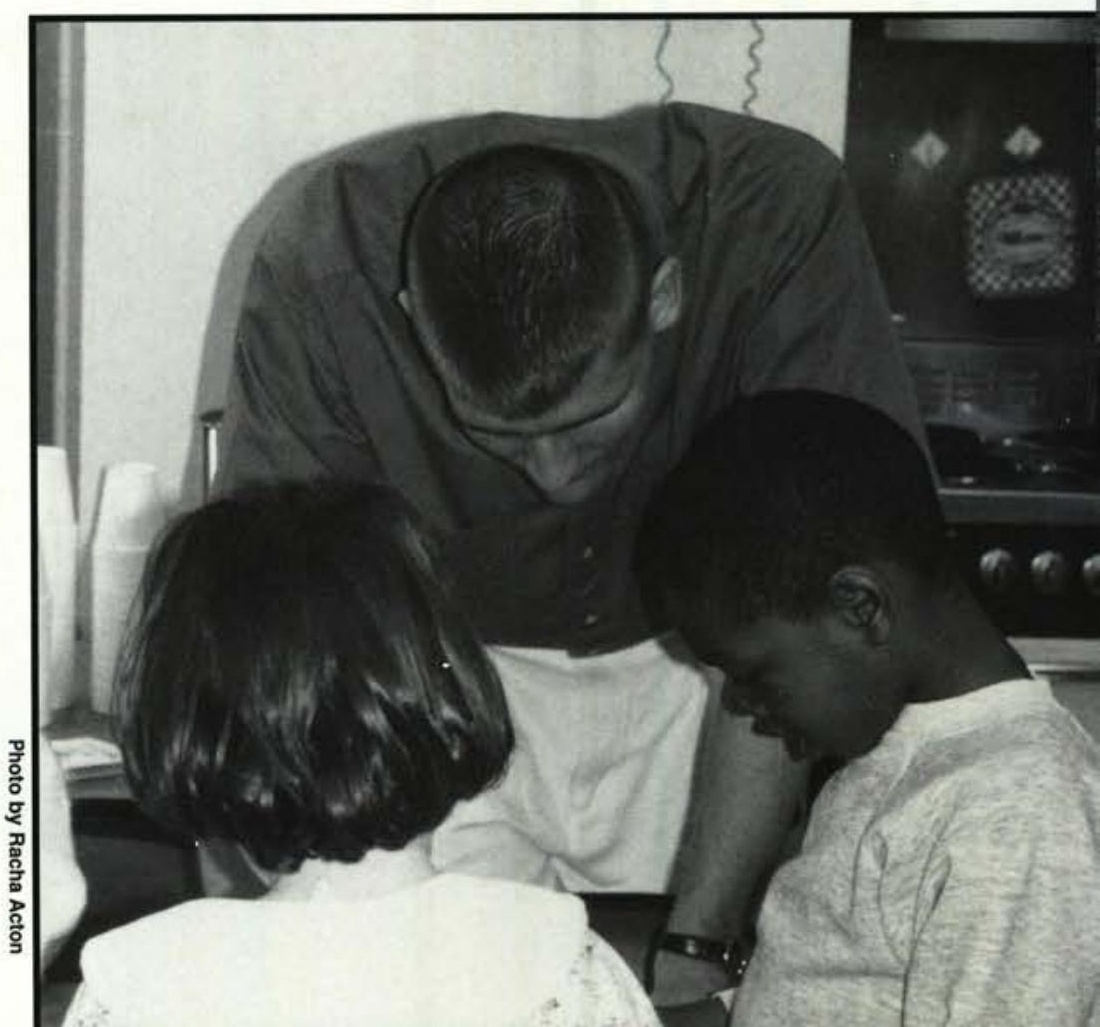




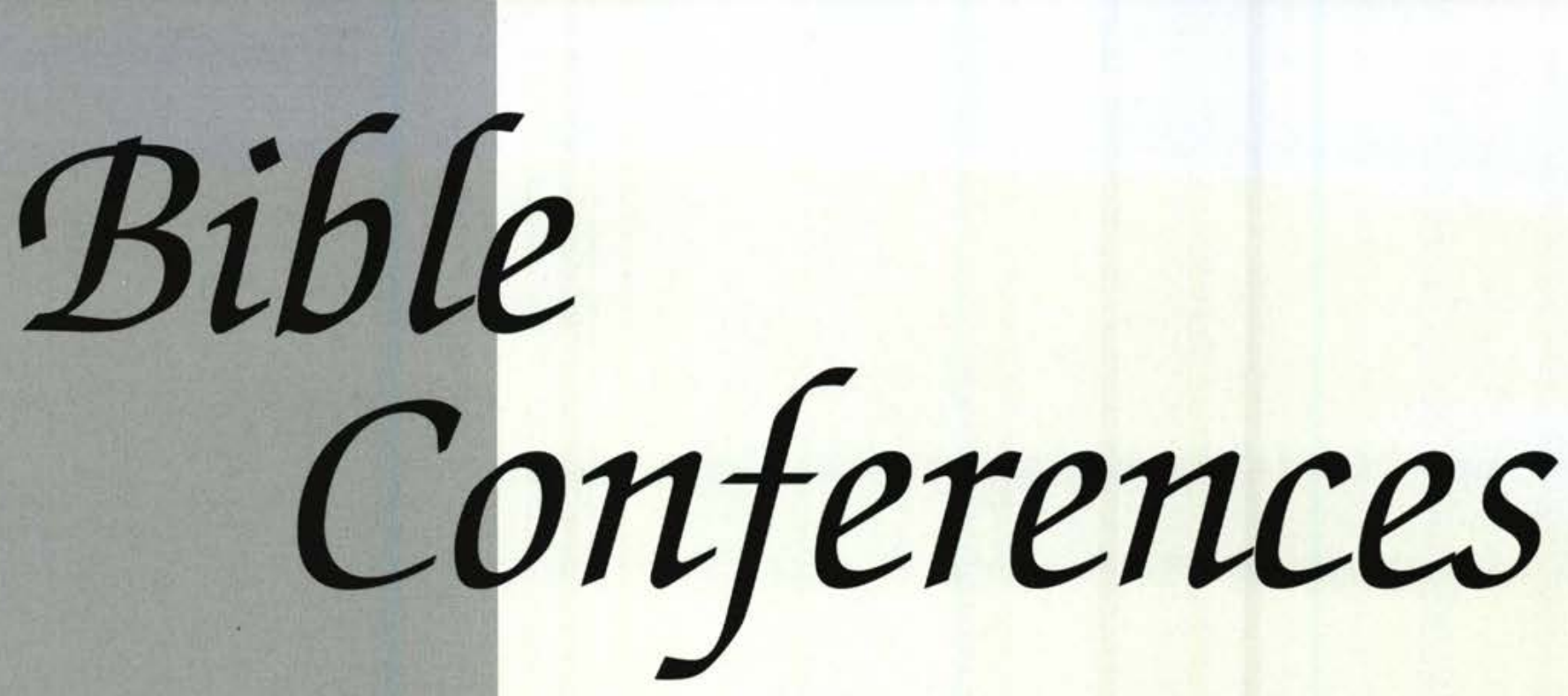

Every quarter at Cedarville College is started off on the right foot and that is to get a focus on God. Doing this requires bringing some of the best speakers in the world to the college to get the students on track.

In the fall quarter, Dr. Warren Wiersbe came and spoke. Wiersbe, who has authored many books, spoke on the importance of a daily disciplined life in Jesus Christ. Many of the students enjoyed him and were challenged by his message.

It did not end there because at the start of the winter quarter, Tony Evans came and spoke on Thursday morning, Thursday evening, and again on Friday morning. He encouraged the students to stand up for Jesus. He said that, "God wants His children to get into the spiritual telephone booth and become the Supermen and Superwomen of God."

The Friday morning service was unique. The lights and sound were out as a result of a power failure. Risking a personal strain on his voice, Evans spoke and stirred the college family to a new dedication to the Lord.

Finally, at the beginning of the spring quarter, Ed Lewis was the key speaker for the missionary conference. He has spoken for the college many times and was enjoyed by all.

It should be interesting to note that one missionary, Grady Tolen, gave a concert mixed with humor and thoughtful lyrics for all to hear.

This year's missionary conference was by far one of the best, and all the conferences will continue to encourage students in the years to come.

Kathy Smart

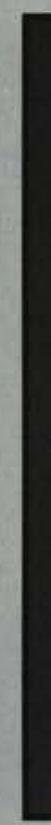




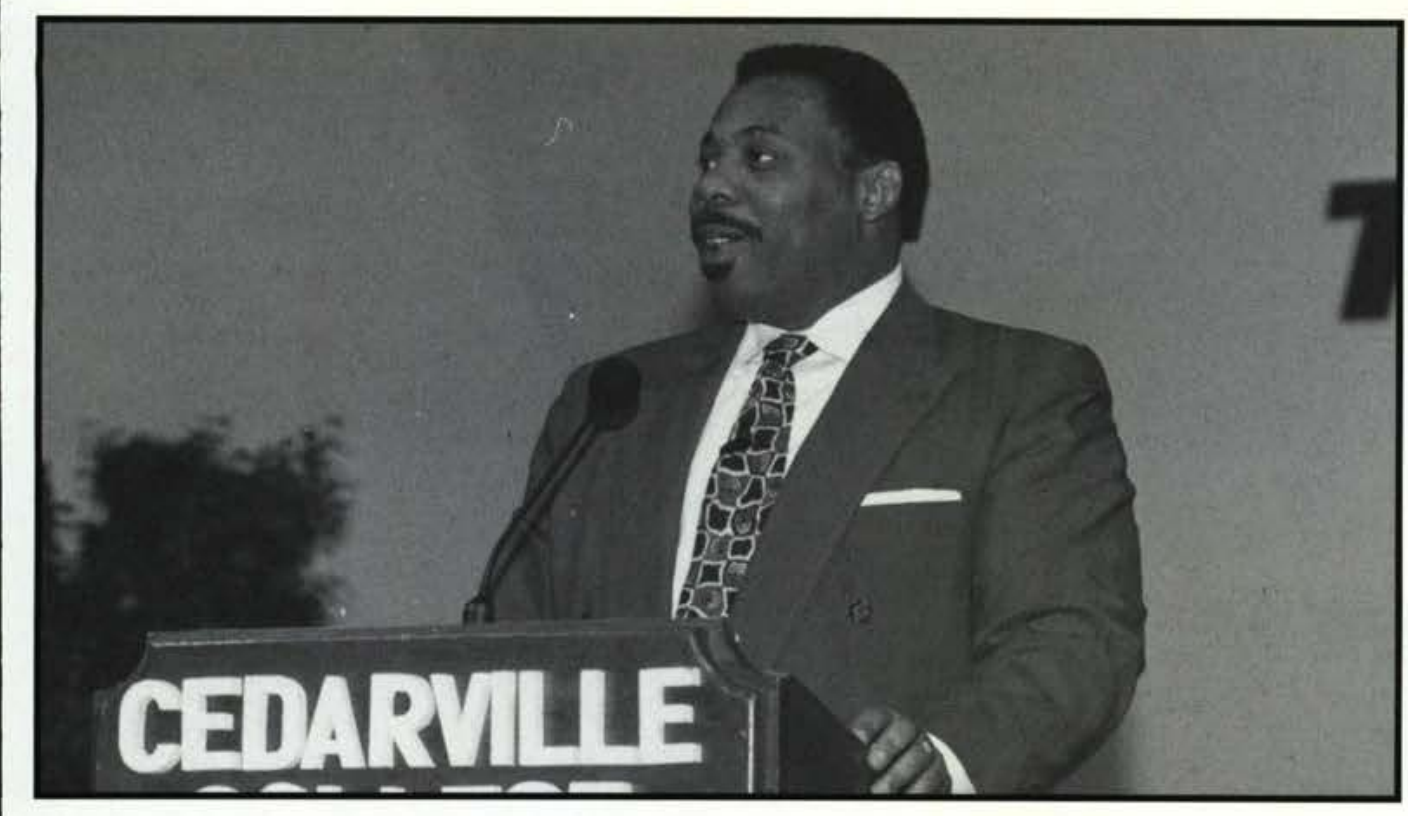

\section{Tony Evans}

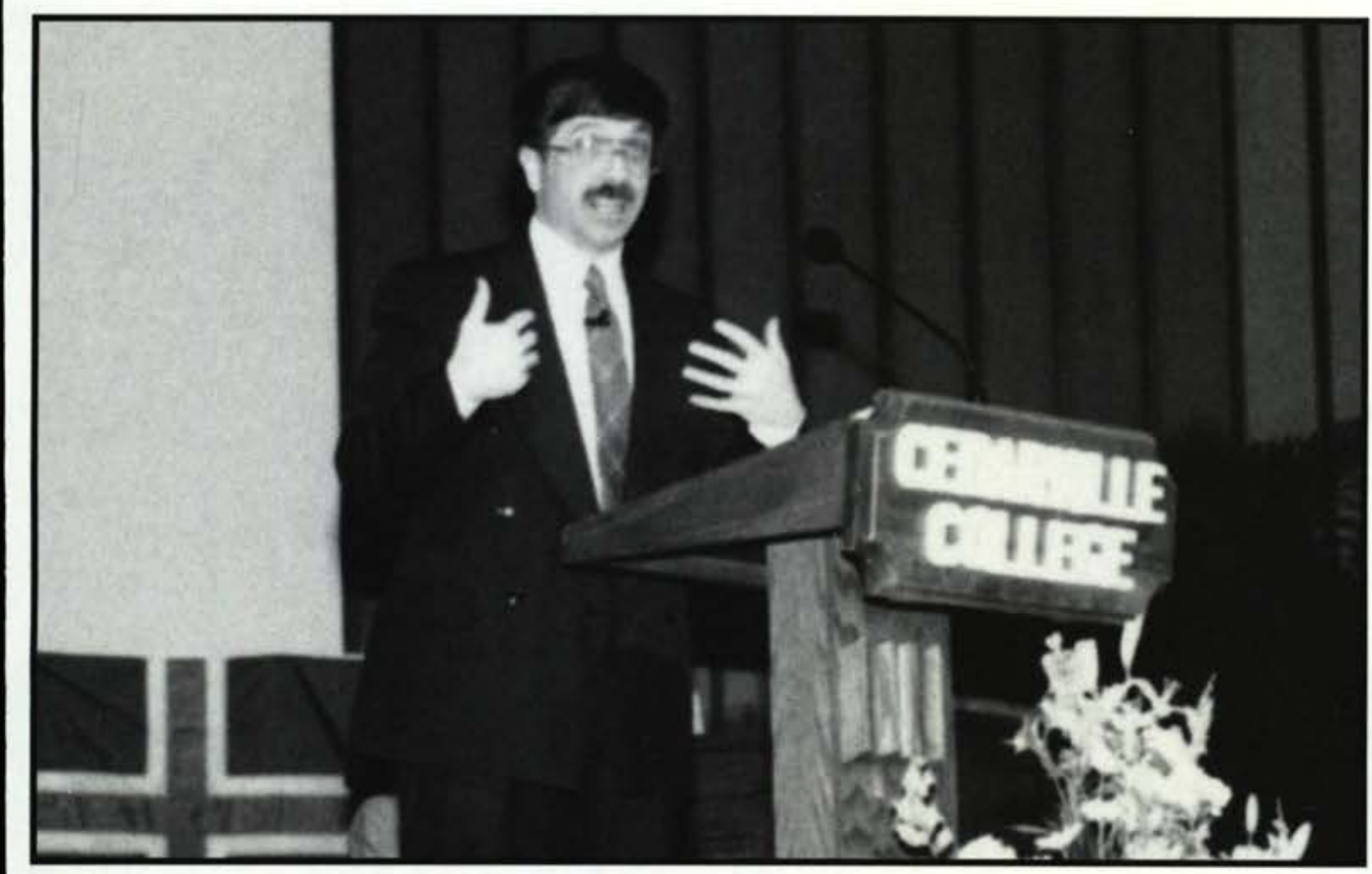

\section{Ed Lewis}

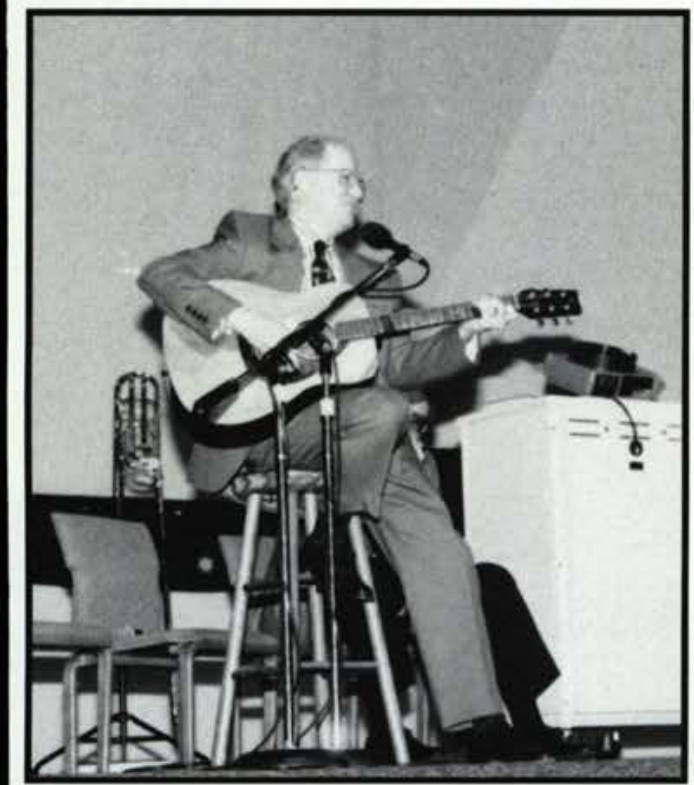

Grady Tolan 


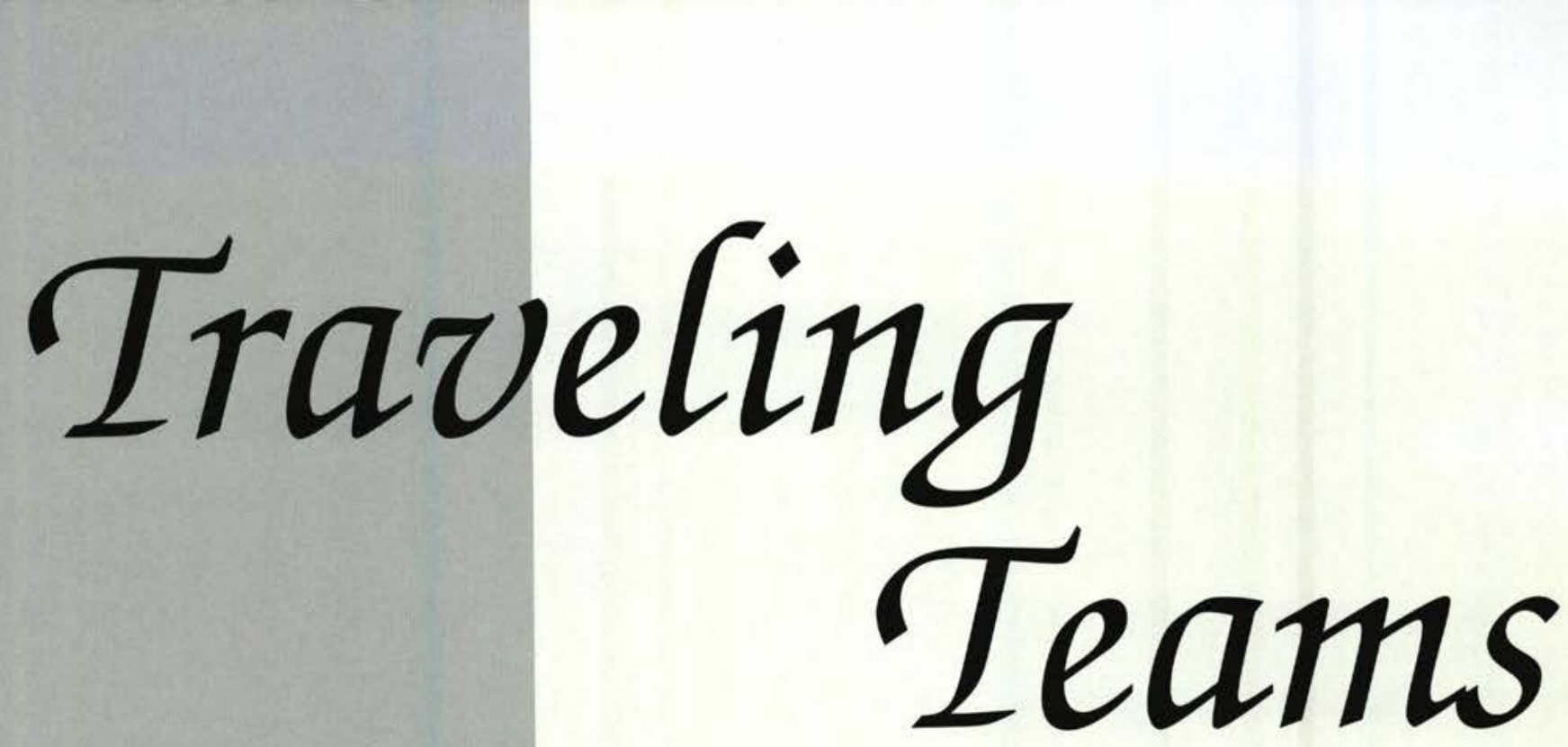

\section{Ministering on the Road}

Lord by serving others" is the mission statement of the Christian Ministries Office. The department offers many opportunities for students to serve in and through churches and community organizations throughout the greater Dayton area and abroad.

In addition, ministry opportunities are numerous even throughout spring break and the summer months. Touring groups such as the Abundant Life Singers, the Kingsmen Quartet, the Lifeline Players, the School Year Master's Puppets, the Summer Master's Puppets, the School Year Swordbearers, and the Summer Swordbearers travel four weekends a quarter during the school year.

The school year teams spent their spring break ministering in various states. The Lifeline Players traveled in Kansas City and St. Louis; the School Year Master's Puppets toured in Indianapolis; and the School Yea Swordbearers schedule included Chicago. The summer teams trekkec across the country for 10 weeks ove the summer and ministered in many churches. The Abundant Life Sing ers ministered in the Mid-Atlantic states; the Summer Master's Puppet: toured in the Midwest states; and the Summer Swordbearers toured in the North-Midwest states. The Kingsme Quartet had both a spring break tou in Florida and a summer tour in the New England states. Jodi Delicl

\section{Julianne Edgerton} Steve Kreitzer Becky Wine Jessica Schuring Johanna Chang Eric Anderson Taryn Campbell Bryan Harju Mark Zuiderveen Steve Caton

\section{Abundant Life}

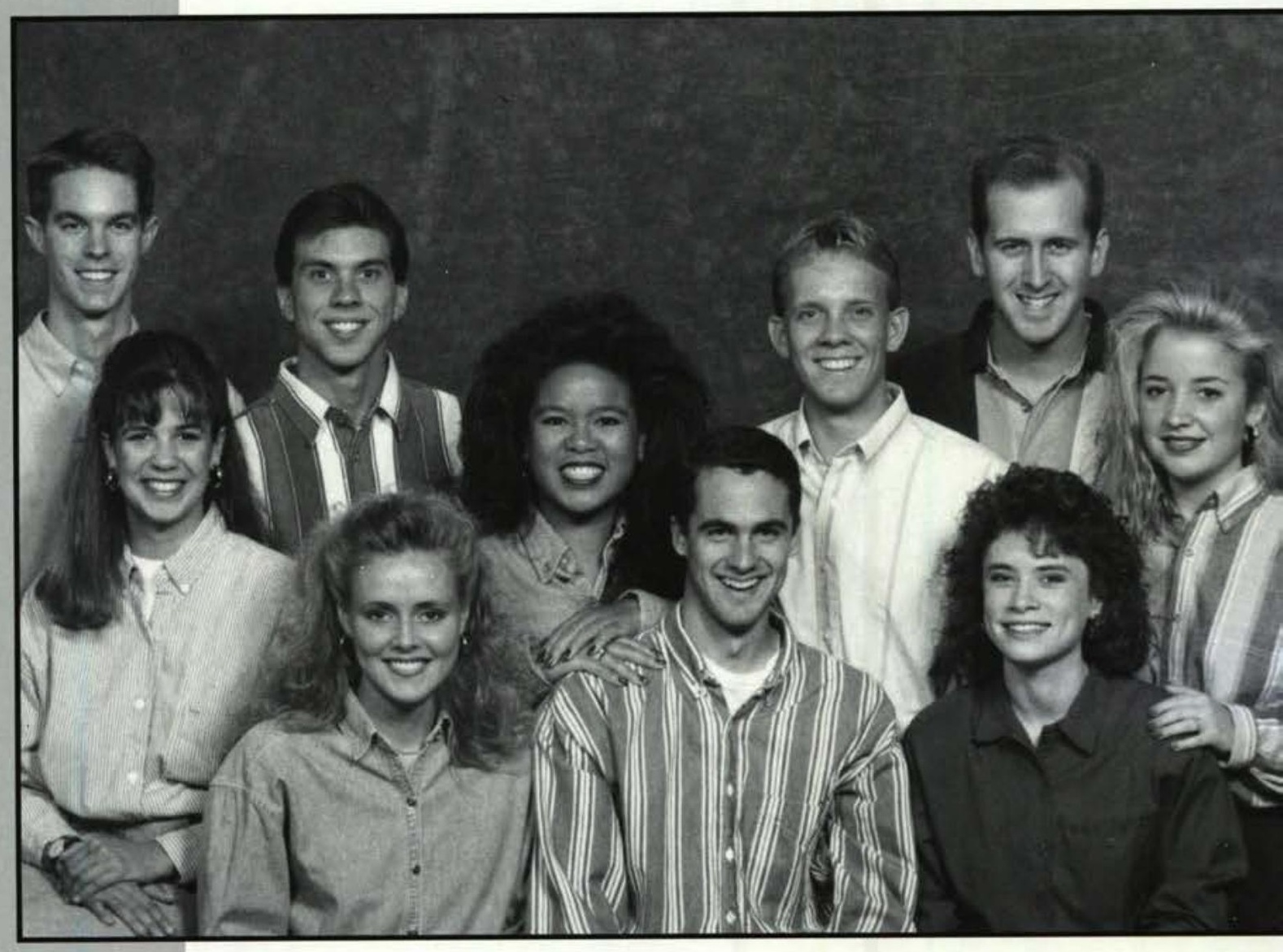


Aimee Stout

Craig Schaap

Trisha Trost

Anthony Torlone

Rebecca Patten

Sara Radford

Iustin Bailey

\section{Master's \\ Puppets}

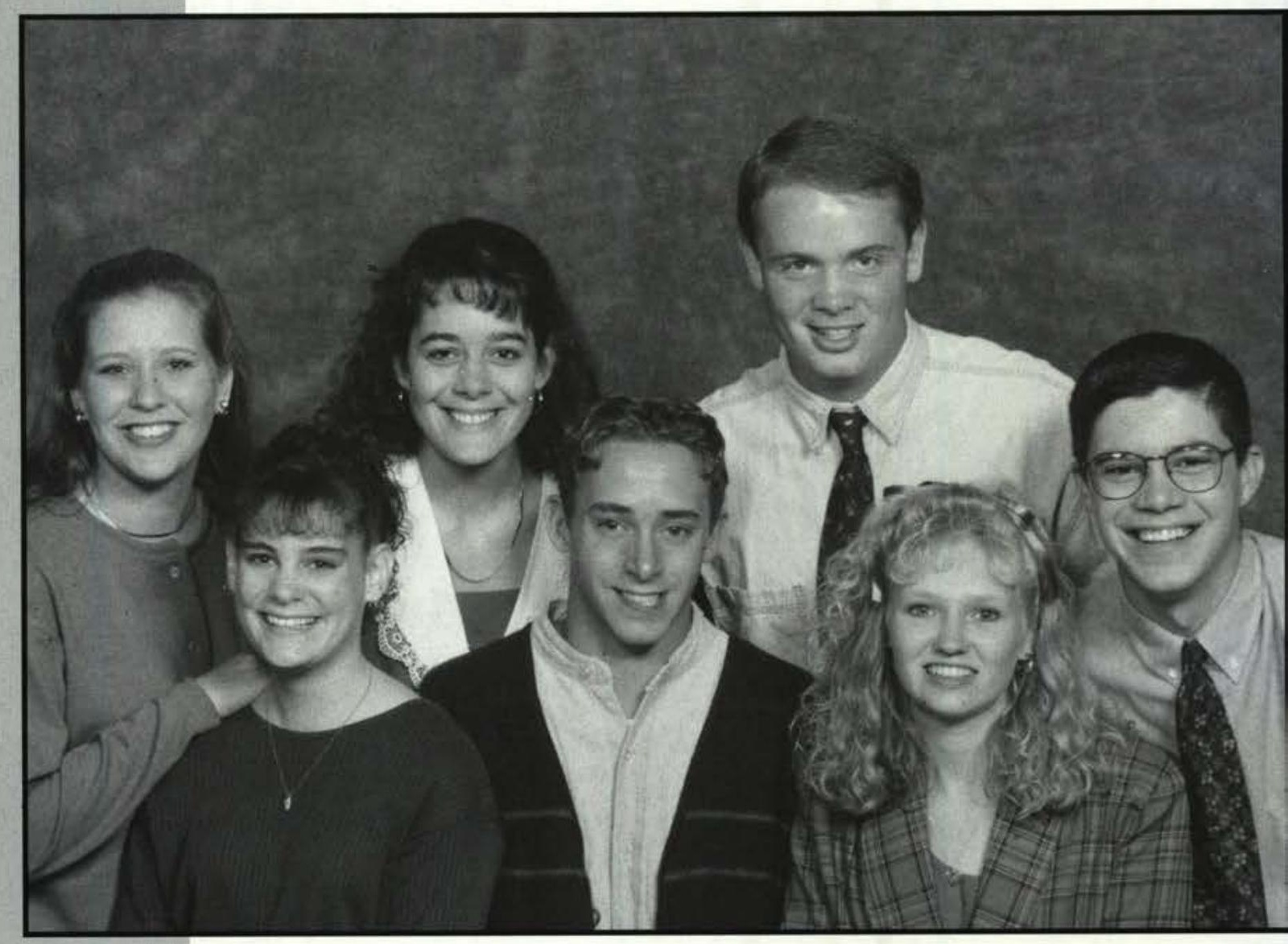

Eric Reini

Krista Price

Benjamin Miller

Scott Kennedy

Krista Ryan

$\mathcal{N}$ ot Pictured:

Kyle Schiwendemann

Summer

Master's

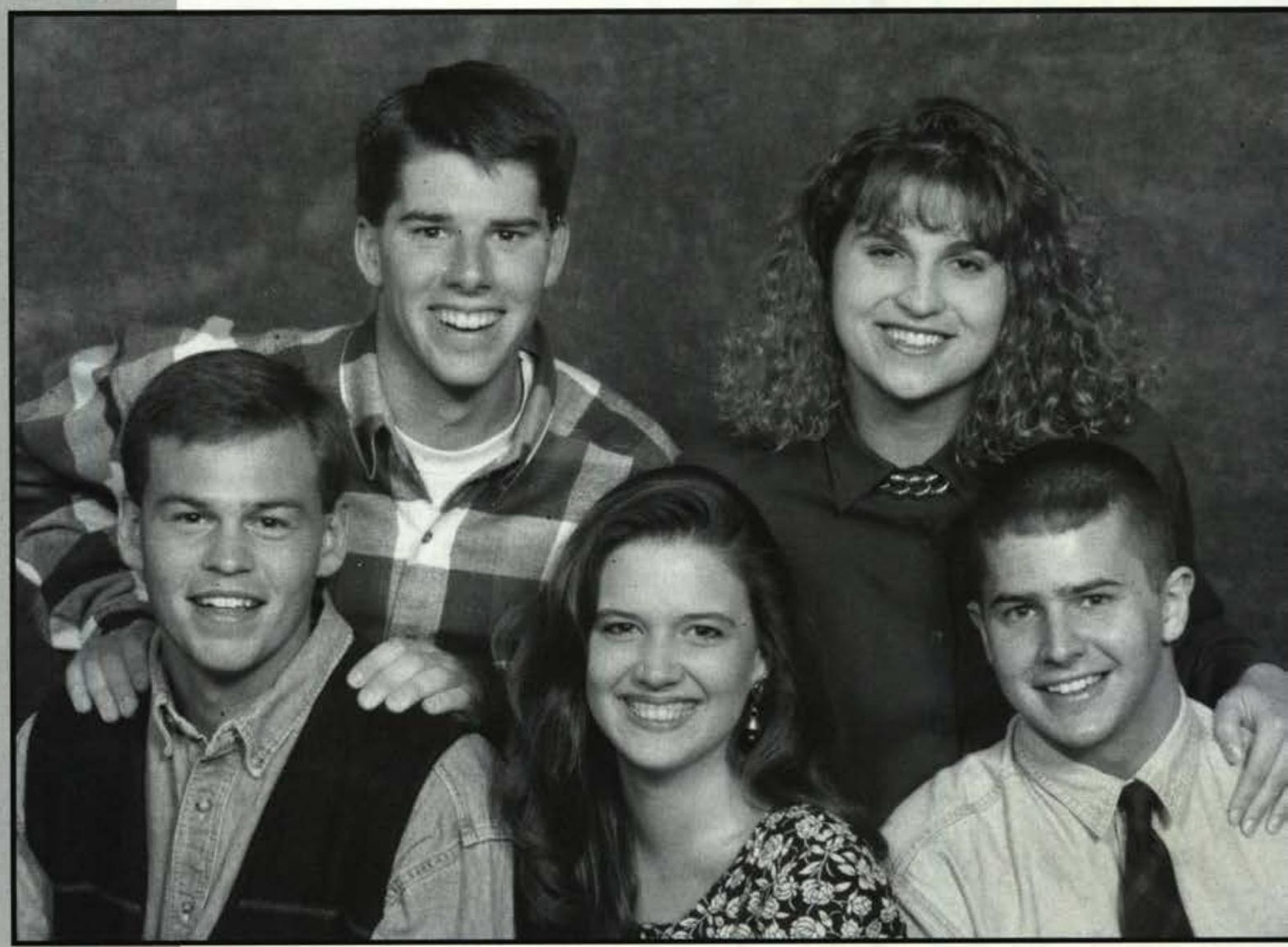


prary

ternship

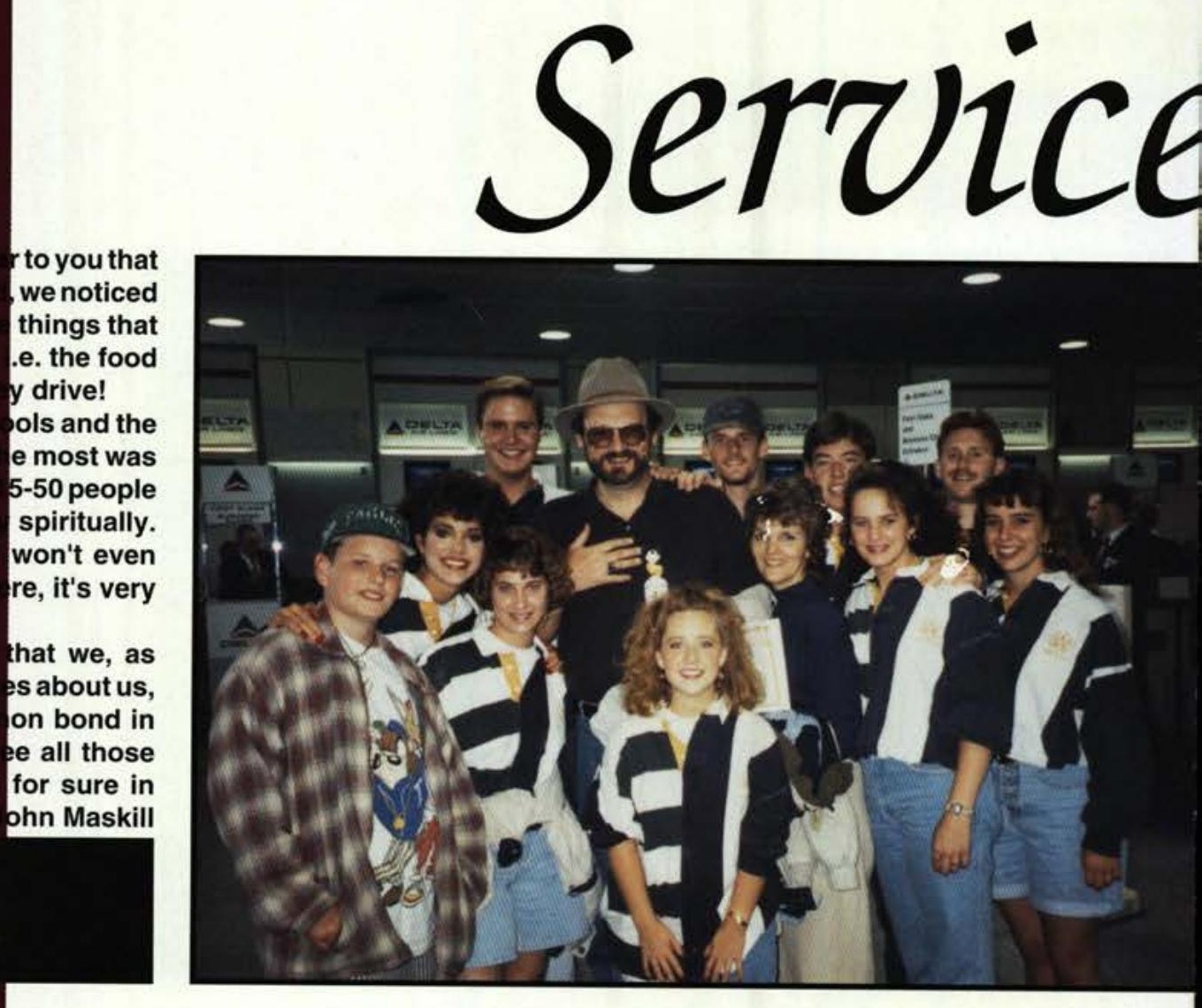

England

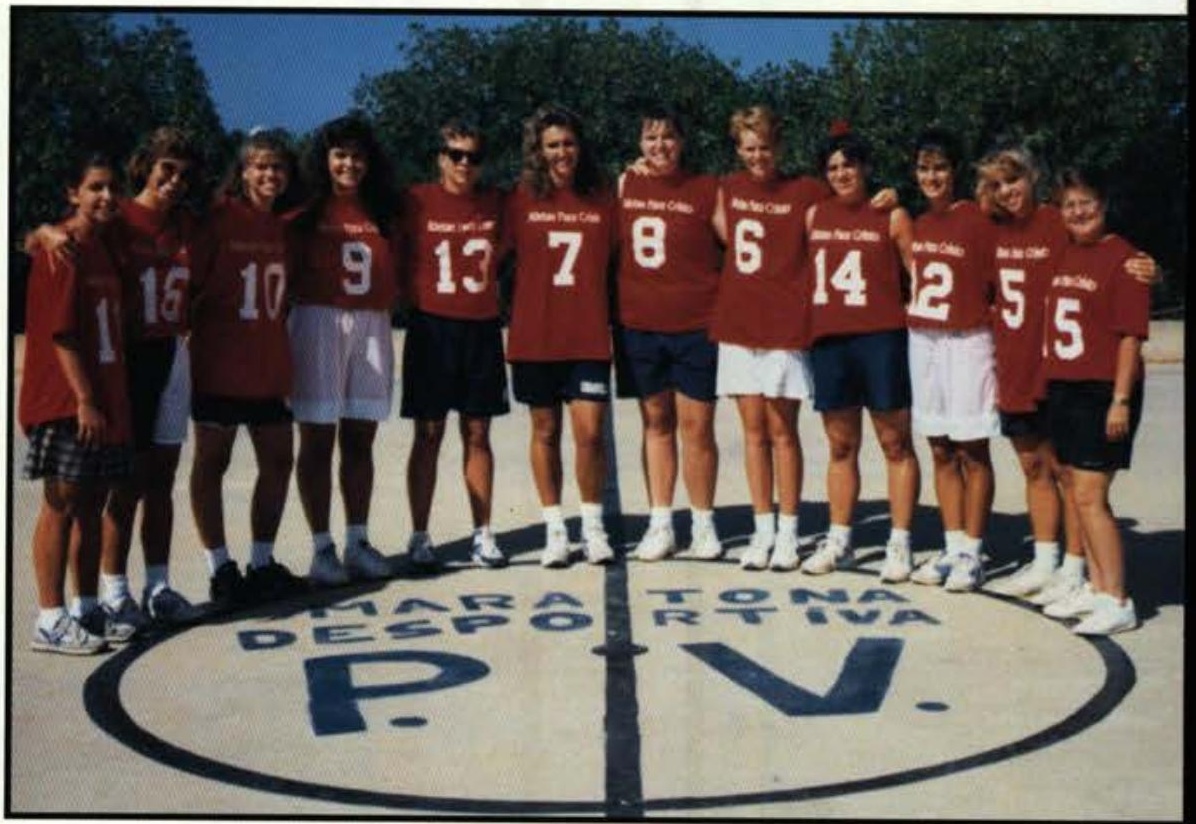



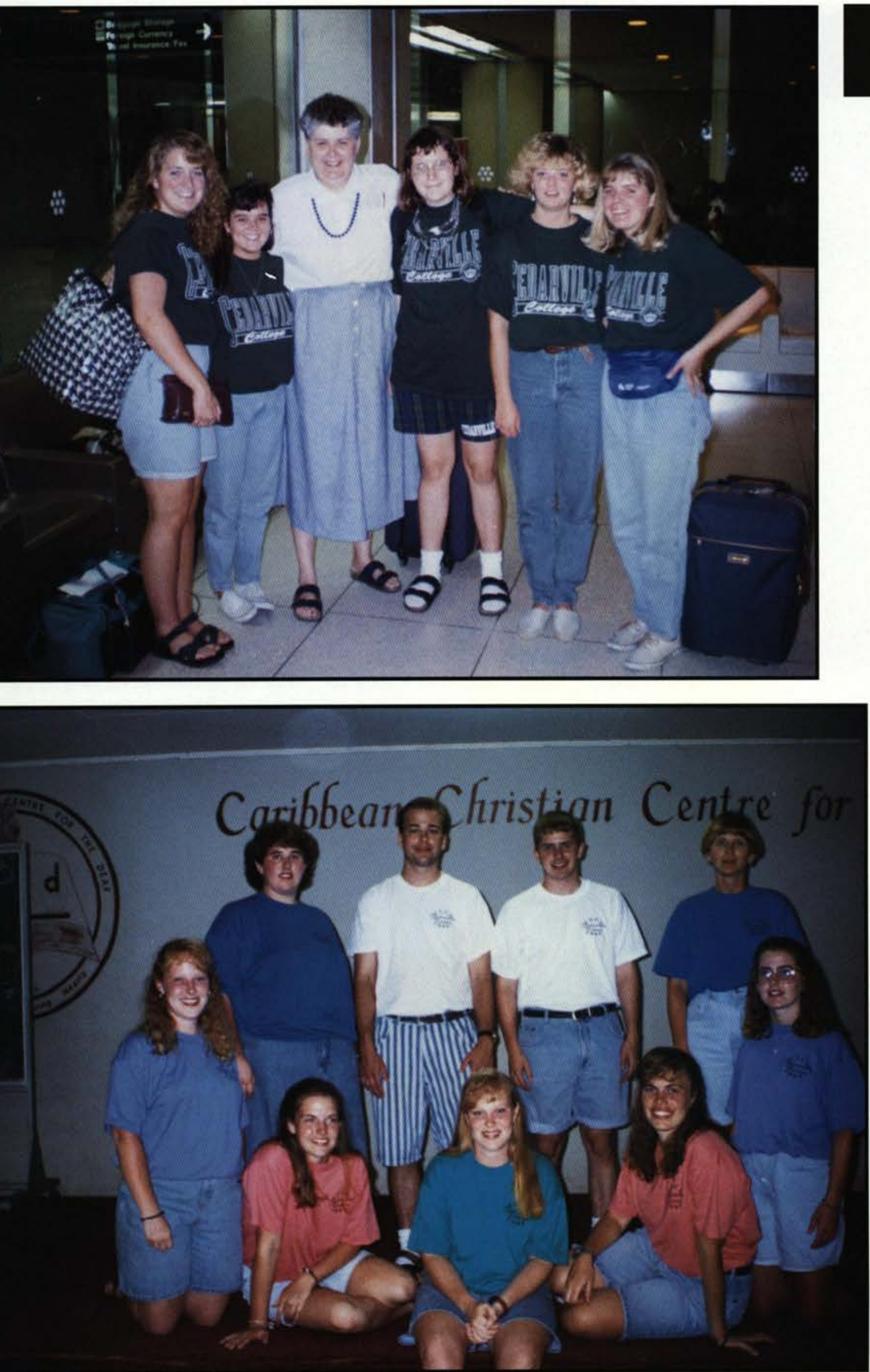

Jamaica typically brings thoughts of beautiful beaches and sun to people's minds. While both of those are true, they are far from being a full representation of the country of Jamaica.

During the summer of $1994, \mathrm{I}$, along with eight teammates, had the opportunity to see a different side of Jamaica. We spent most of our time at the Caribbean Christian Center for the Deaf and helped with a camp for the deaf people of Jamaica. Many of the deaf children and adults were the only ones in their families to know sign language. It was incredible to see their appreciation for the little things and the love they showed for each other and God. In a country where they are often referred to as dumb, they stay strong and don't give up.

Looking back I realize how much that trip really taught me. I now realize how fortunate I am to be able to hear and communicate without difficulty. Some things I take for granted on a daily basis are a luxury elsewhere. The one area that sticks out in my mind the most is the sincerity and thankfulness in prayer that the deaf children taught me. I can now say from personal experience that "actions do speak louder than words." Tricia Walker

\section{Jamaica}




\section{The Ultimate Challenge}

Travel to foreign lands, experience new cultures, meet new people, and expose yourself to broader understanding of the world--these are all results of the MIS experience. MIS (Missionar Internship Service) creates opportunities for the students and faculty to serve the Lord in othe countries.

Any student who has a heart willing to serve may apply to the MIS program. Then the MI program, after selecting individuals and teams, sends them to home and foreign fields. They hav sent approximately 2,211 students to 63 different countries. Some of these countries incluo Scotland, West Germany, Israel, Bermuda, etc.

These ministry teams range from sports teams to singing teams and nursing teams construction teams and independent teams to engineering teams. The fields are so open that ar major can participate in the MIS challenge. Choices vary from basketball to puppets an broadcasting to English and soccer to music, and many more.

MIS provides the individuals involved with a first-hand experience of missionary life, and it als burdens some of the members to return to the fields as missionaries.

Take up this priceless challenge. Travel to Ireland, Kenya, or the Ukraine. Allow God to use you talents and desires as a way to touch other people's lives, and return home with a stronger focus fo those who have never heard the Gospel.

Lynda Gav

RIGHT: Char Grygiel carries a child while on a nursing M.I.S. trip in Africa.

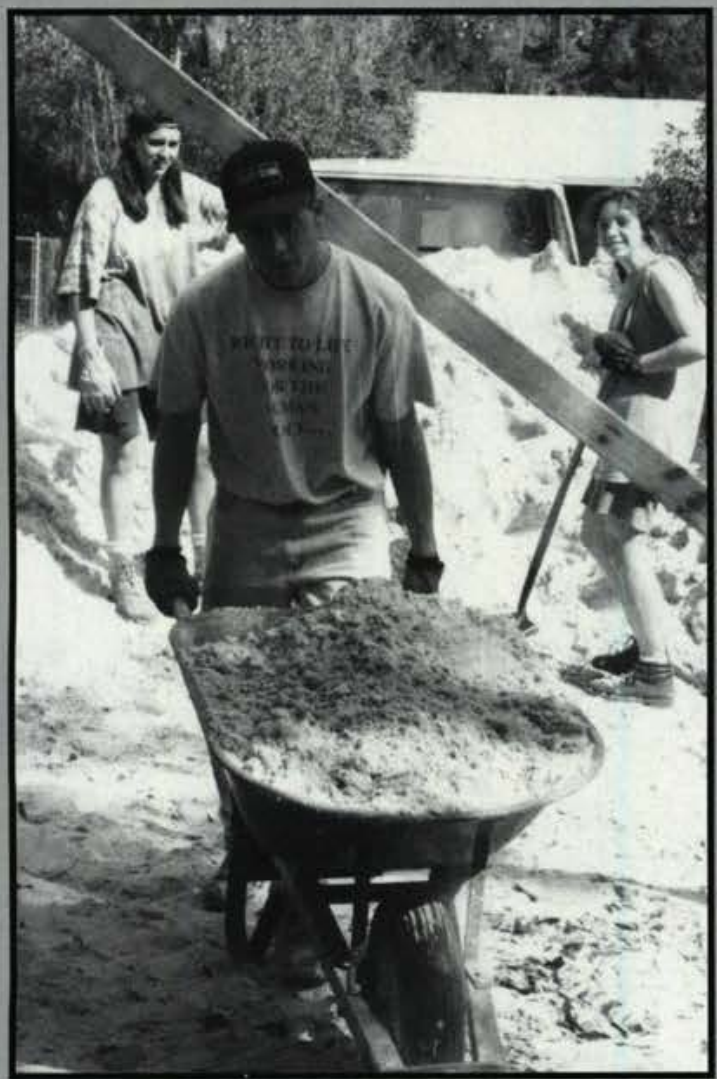

ABOVE: Josh Amos carries sand away to Alicia. RIGHT: Alicia Elmore spreads the sand around to fill the area.

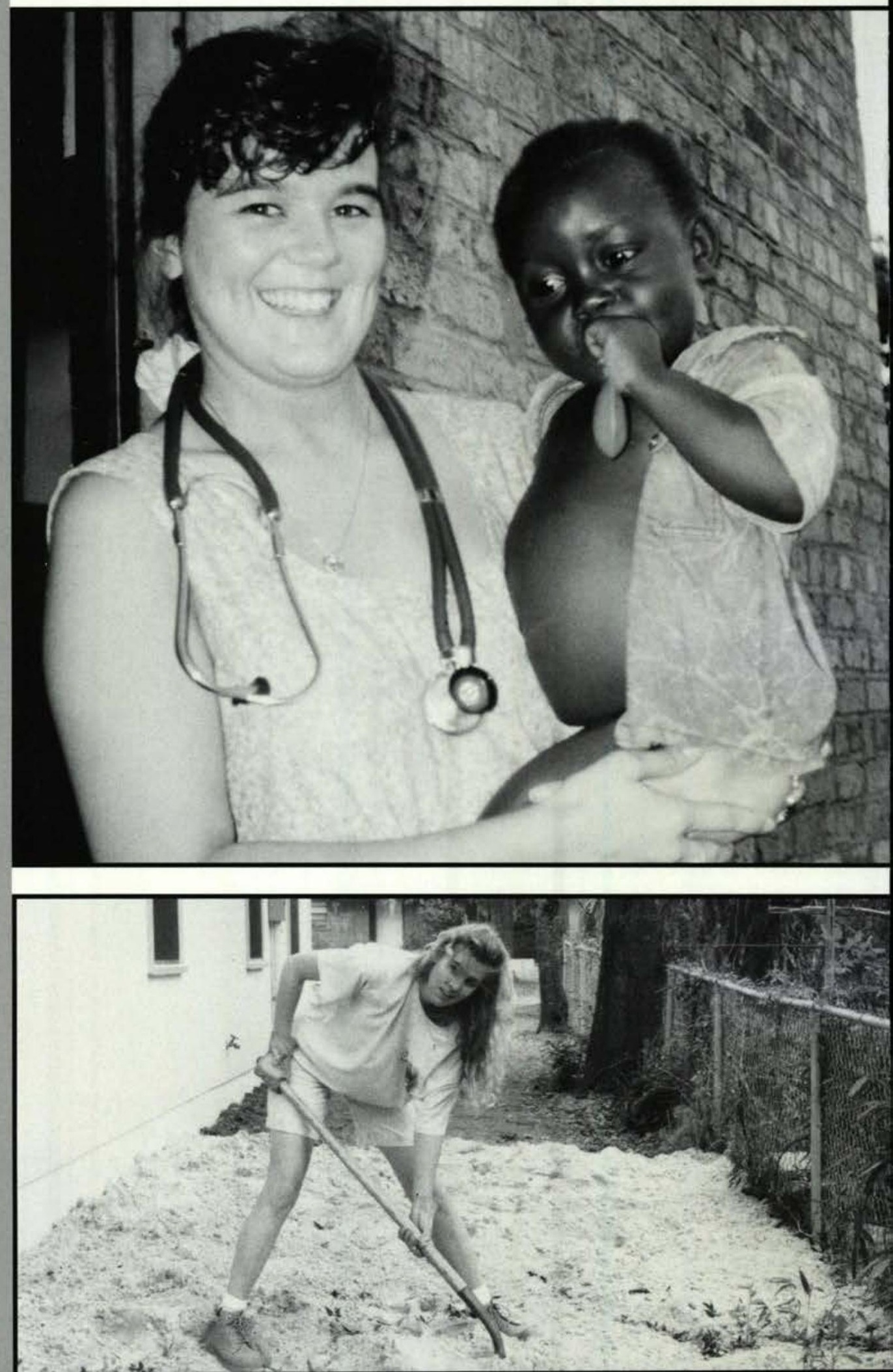




\section{Advisory}
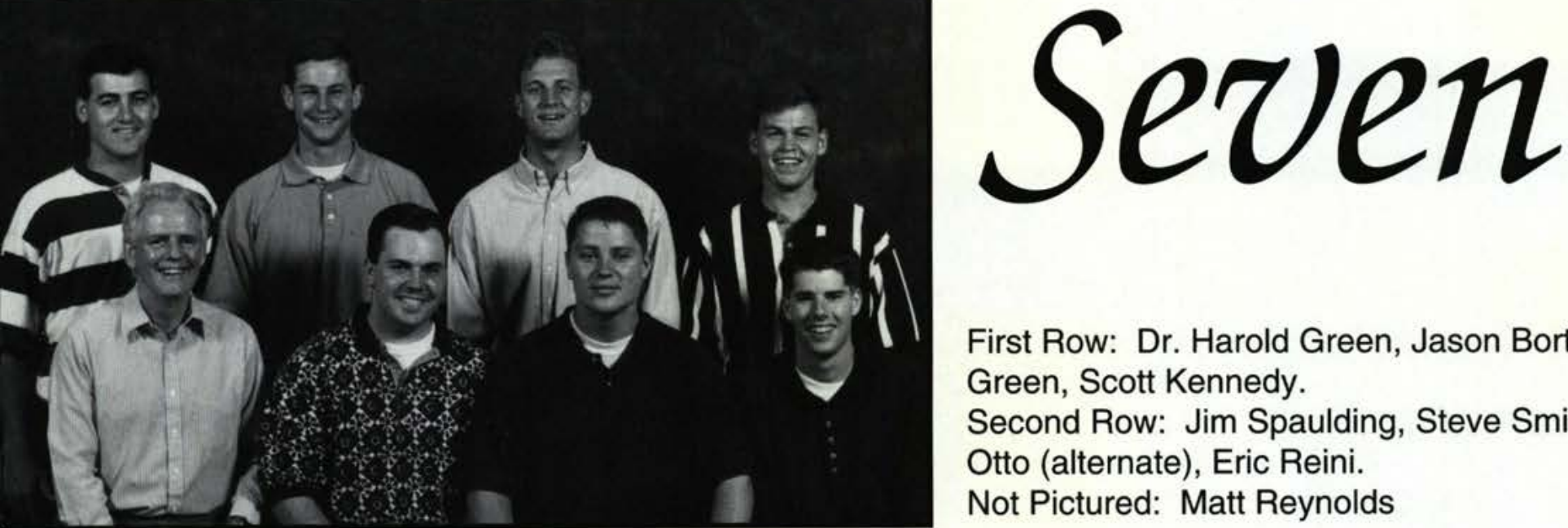

First Row: Dr. Harold Green, Jason Borton, Josh Green, Scott Kennedy.

Second Row: Jim Spaulding, Steve Smith, Mark Otto (alternate), Eric Reini.

Not Pictured: Matt Reynolds
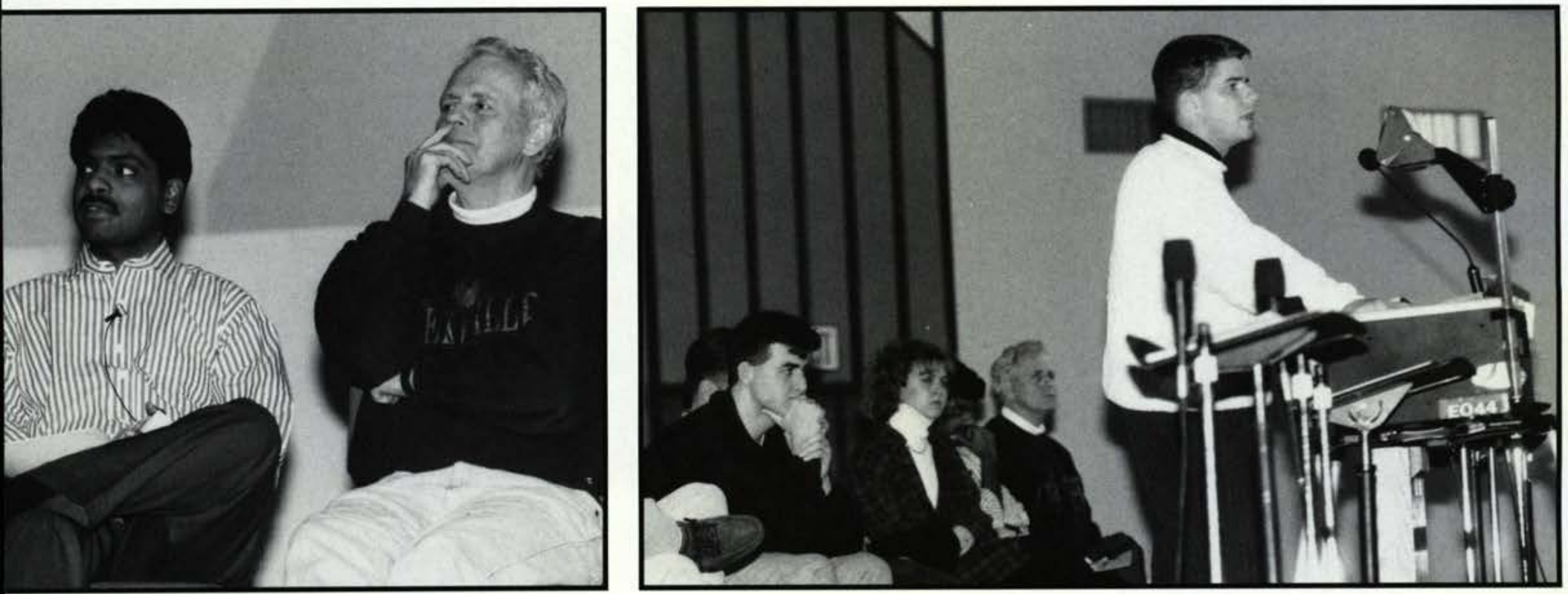

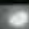

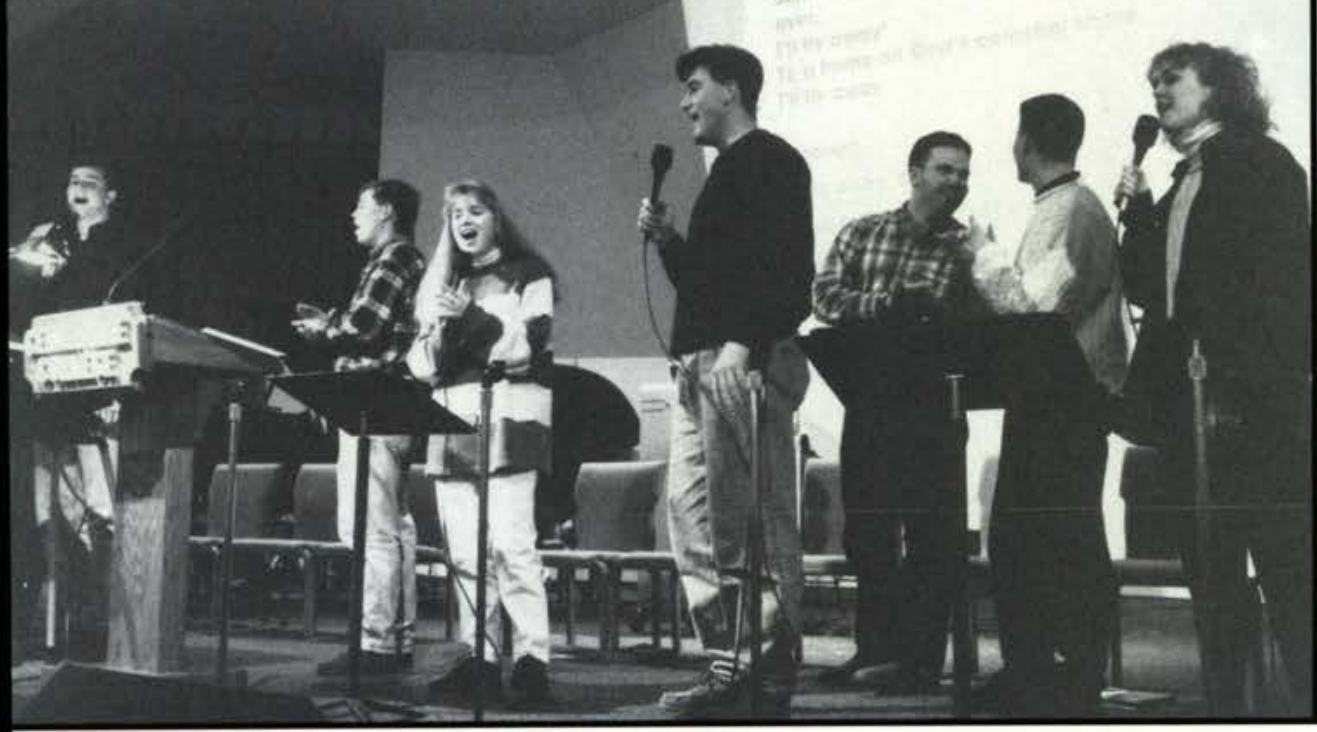

ABOVE LEFT: Pastor Green and a guest speaker ponder the announcements.

ABOVE: Scott Kennedy gives the prayer requests.

LEFT: Jim Spaulding and helpers lead the singing while Jason and Scott try and clap on beat.

The Fellowship was designed to meet the unique needs of the Cedarville student. While this is not an organized church, we do conduct Sunday morning services, Sunday evening services, and Wednesday evening services.

Students can become a vital link in the ministry of the Fellowship by ushering, providing special music, teaching, preaching and more.

Every student is welcome--it is their Fellowship. Students select seven men to serve with Pastor Green. These men are known as the Advisory Seven (AD 7), and they schedule and oversee all the activities of the Fellowship. 


\section{- Baptist Fellowship}
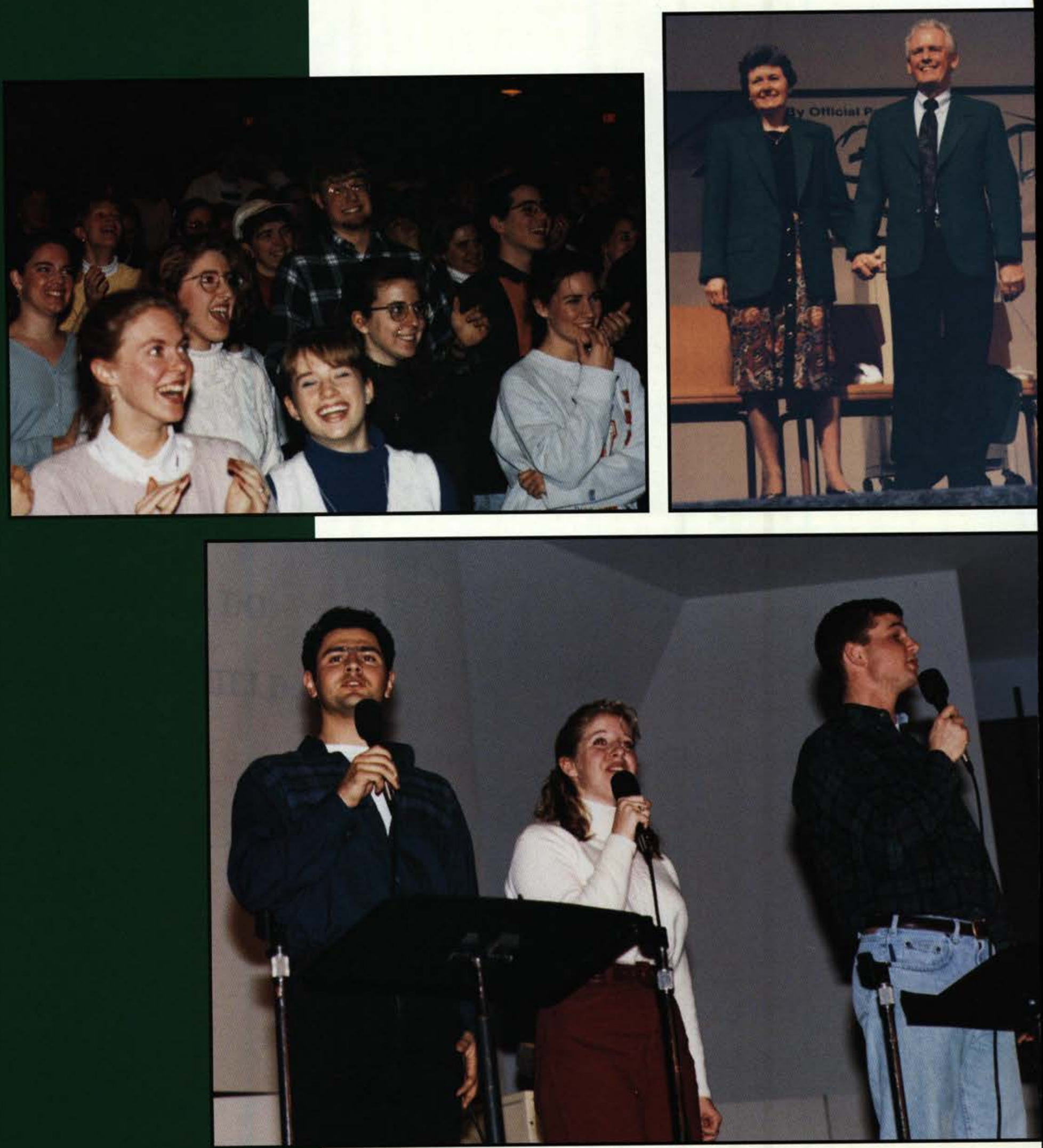

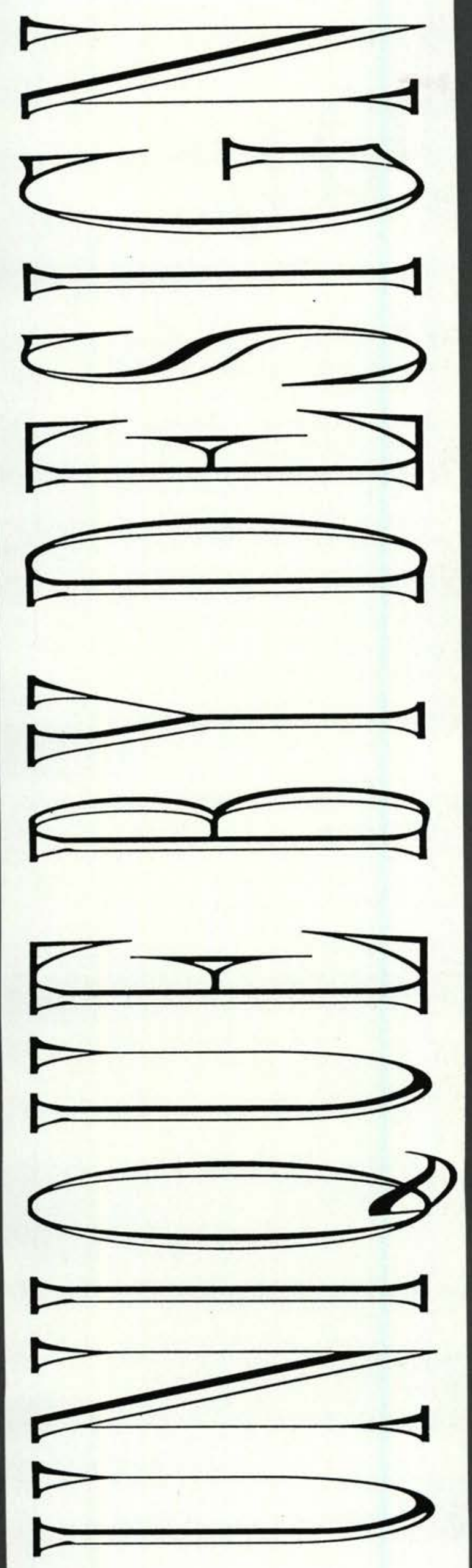

$\sin 6 \mathrm{~d}=\mathrm{t}$ 


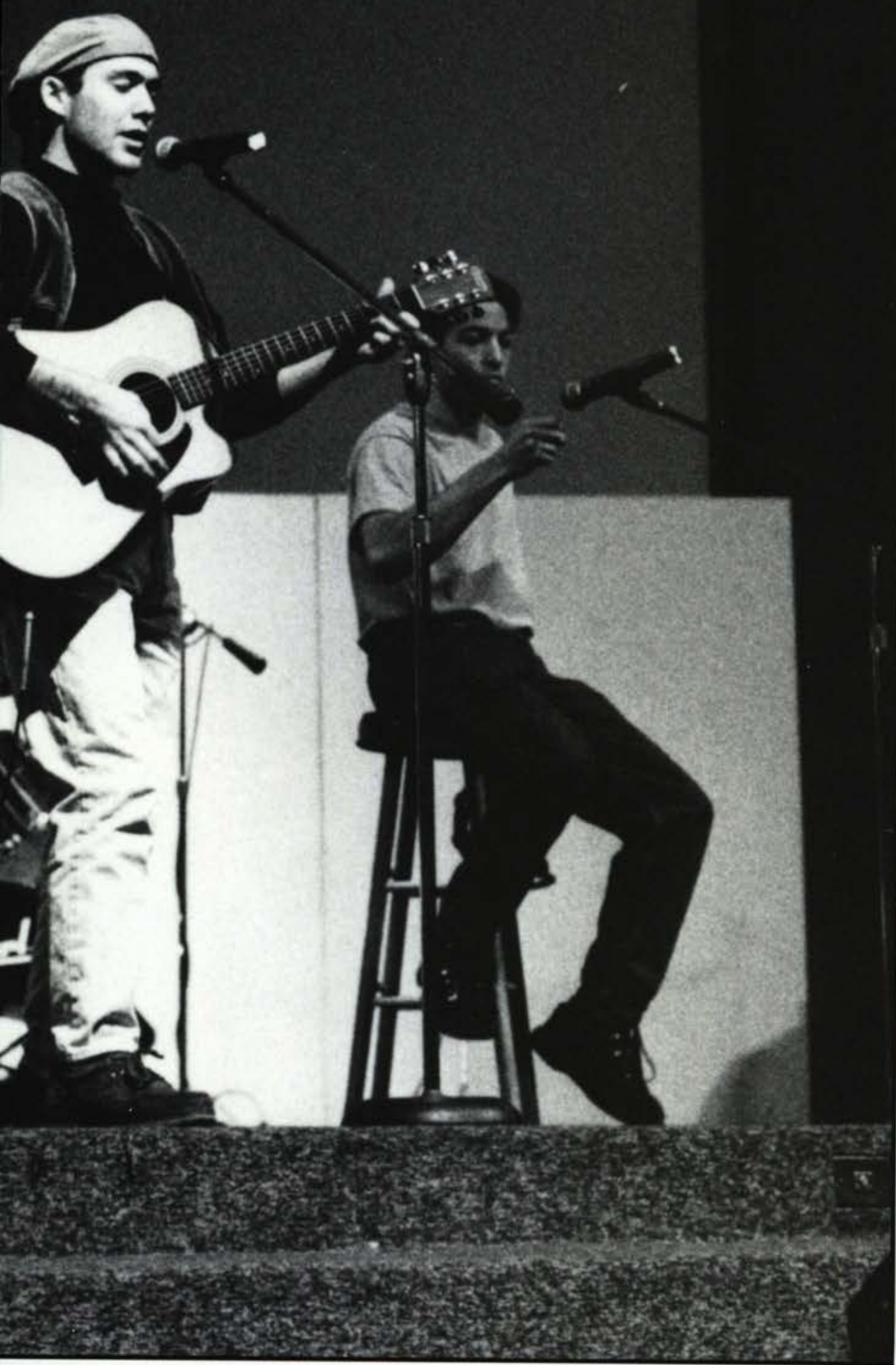

organizations

122 miracle

124 candids

$126 \mathrm{sga} / \mathrm{class}$ officers

128 organizations 
Heidi Bowen

\section{Layout Staff}

Jeff Fortna

Jodie Delich

Heather Bossley

Kim Dorsey

Tim Vinal - Assistant

Editor

Photography Staff Not Pictured:

Todd Hill - Editor

Dawn Kauffman

Todd Pettee

Denver Seely

Heidi Sorensen

Amanda Whitmer
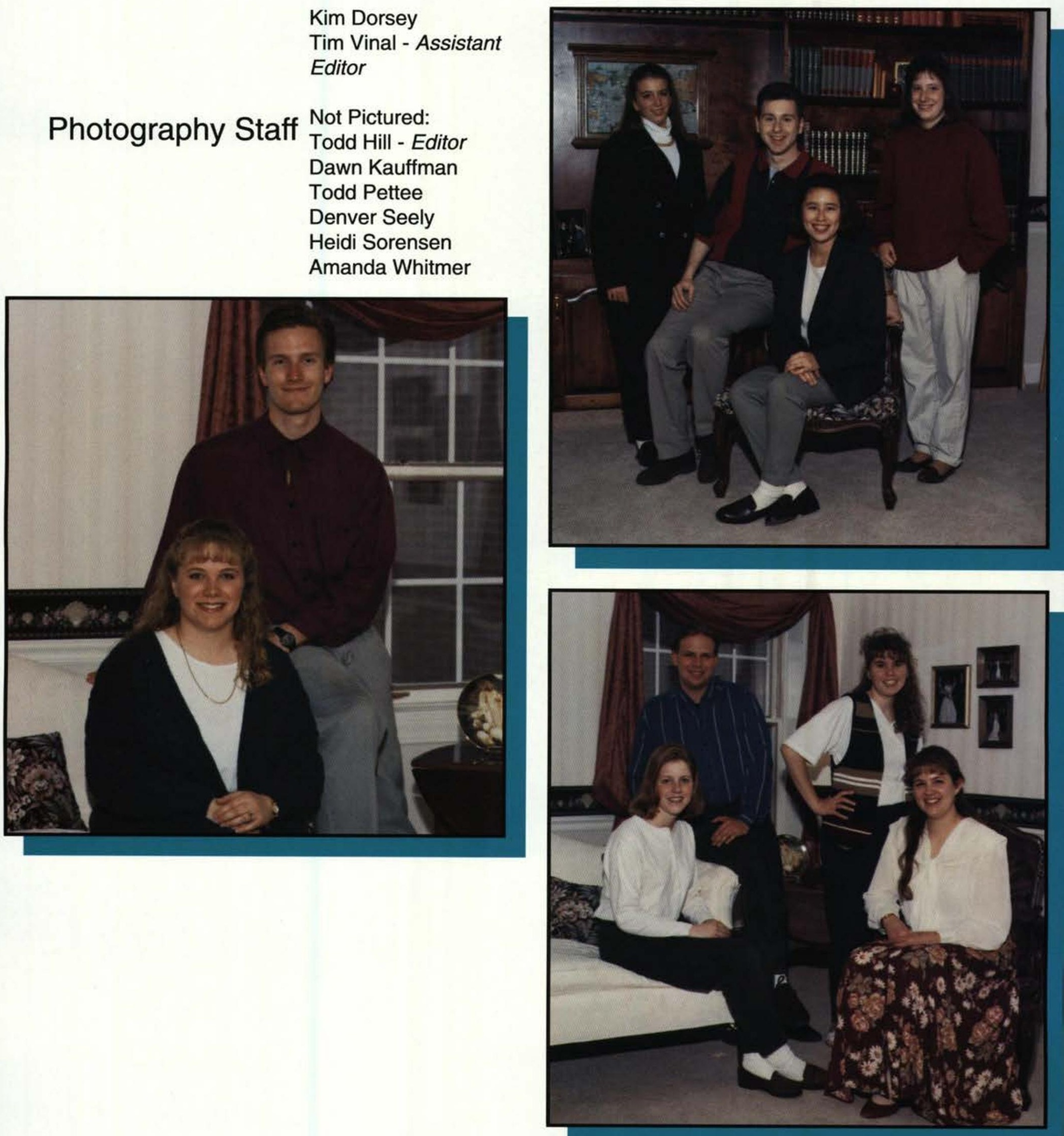

Brenda Kregel

Copy Staff

Don Smith

Lynda Gavitt 


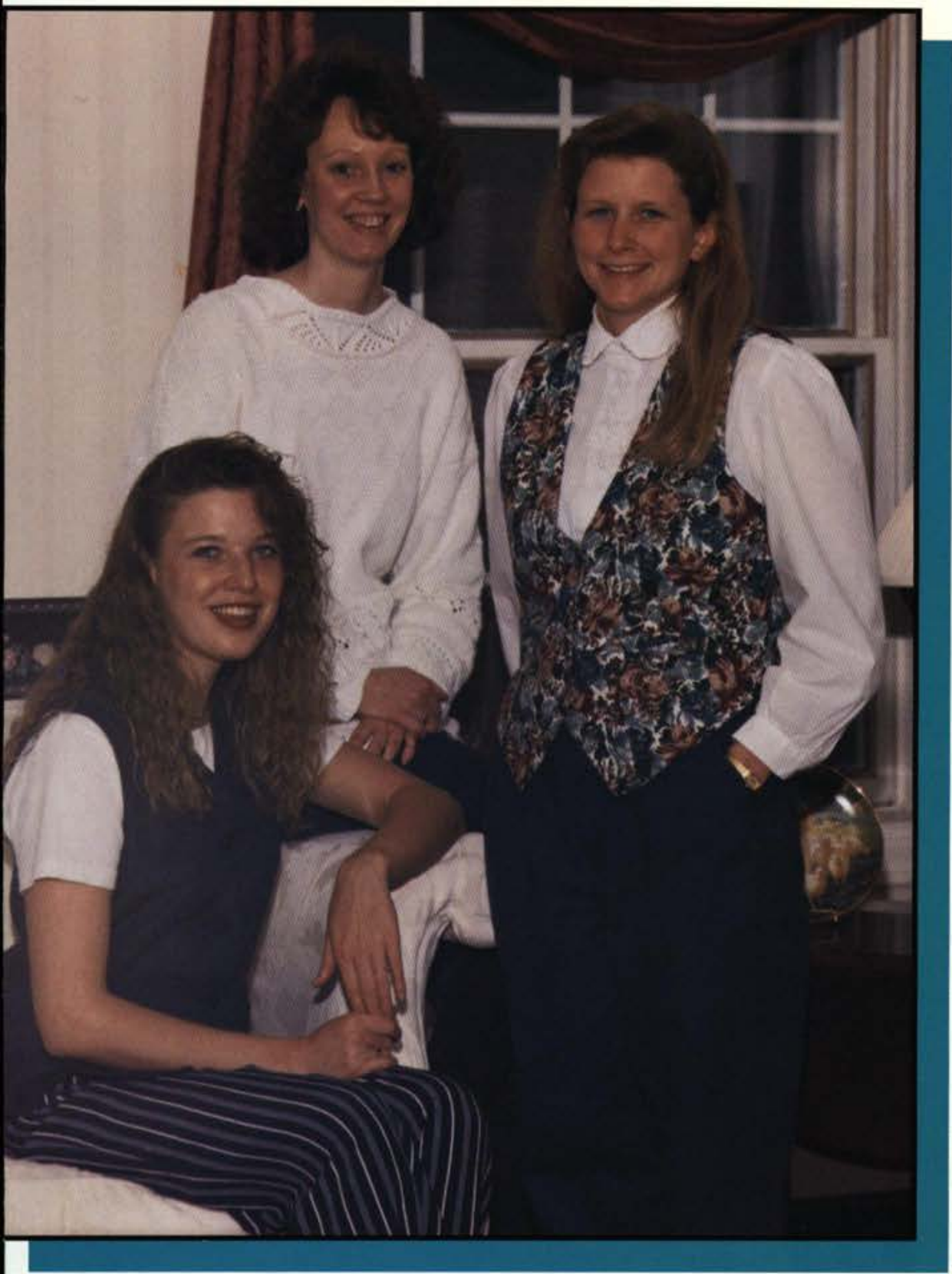

\title{
Racha Acton
}

\author{
Editor \\ Carol Bliss
}

Advisor

\section{Susan Terkelsen}

Advisor

\section{Creating Miracles}

Layout. Copy. Photos. Meetings. "Printer Error!" Will it ever end?

The office looks crowded. Old yearbooks are stacked in every corner. Too bad we can't just slap this year's theme on the old yearbooks and send it through Intracampus mail. (Won't the post office workers love it!) But just when we think nothing else can be done, people pull together from all corners of the campus to create another award-winning yearbook. After all, the sign in our office "Miracles Created Here" isn't on the wall for decoration. It's a daily reminder to the Miracle staff that miracles do happen...although sometimes not soon enough!

Editors in the past have set a precedent to publish a top-notch yearbook each year. This year is no different. Under the direction of Racha Acton, the 1994-1995 Miracle staff is proud to publish yet another fine work of art... a yearbook that students down the road will study and appreciate in the Cedarville College humanities class. After all, isn't that what students are supposed to do in that class?

Unique By Design captures some of the most exciting, favorite, and memorable events of the year; but it represents only a glimpse of the moments that the college family enjoyed. Although time has gone by, its memories will last forever because the memories and friendships students made through the year is "unique by design."

\section{Secretaries}

Jodie Delich

Heather Bossley

Heidi Bossley

Not Pictured:

Janine Pinkley 


\section{Student}

\section{Government Association}

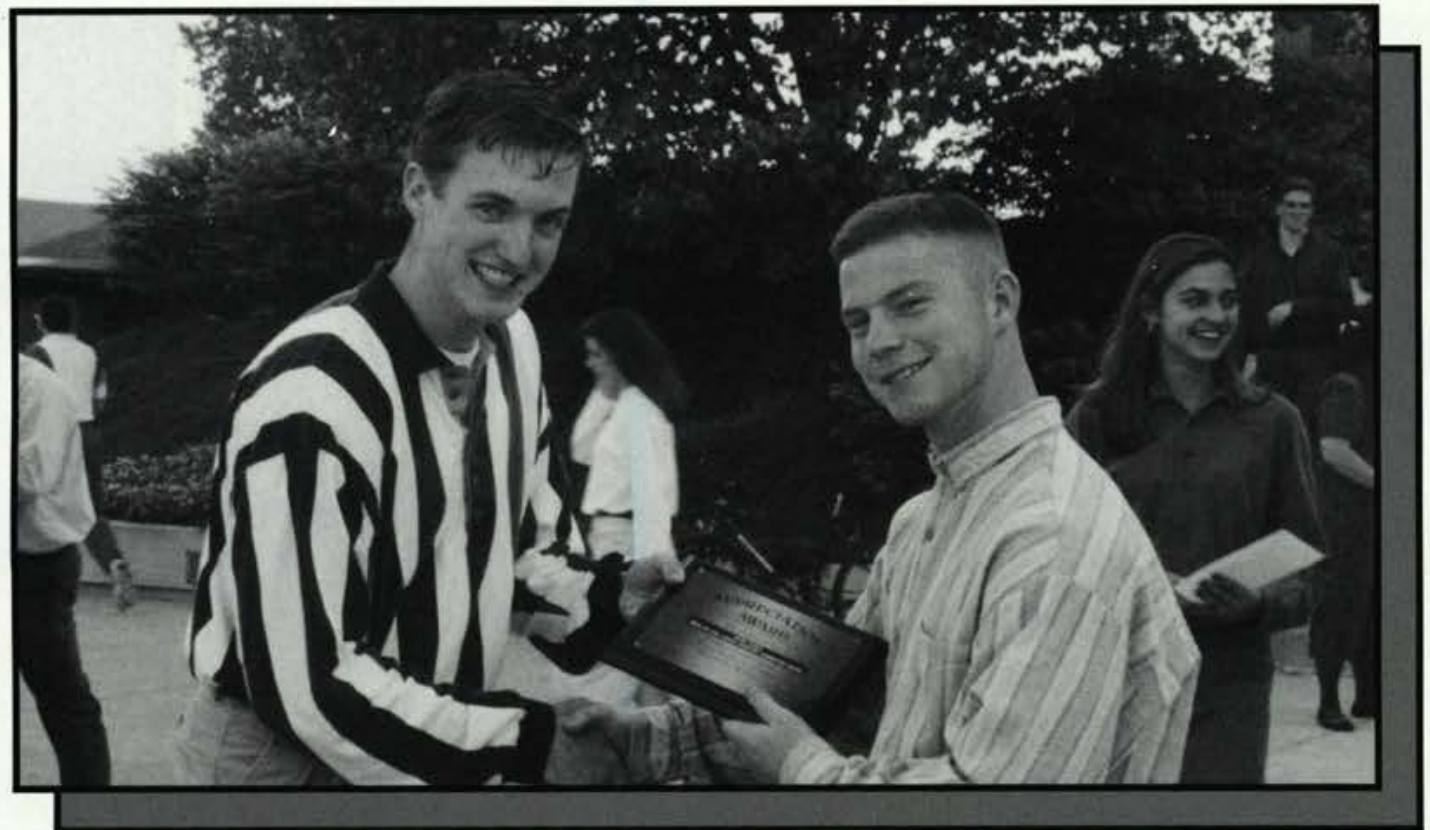

LEFT: Cliff Scott, SGA social services chair man, accepts his Appreciation Award fron Jeremy Farlow and

BELOW: he accepts it again from Dawı Merritt and Jeremy Haskell.

BELOW LEFT: SGA senators waiting fo the rest to arrive for the picture.

RIGHT: Bowe Hoy, SGA President, ofte makes announcements, prays and gives a shor speech in chapel.

FAR RIGHT: Brian White, SGA constitu tions and elections chairman, and Traci Emes SGA secretary, concentrate on taking down names
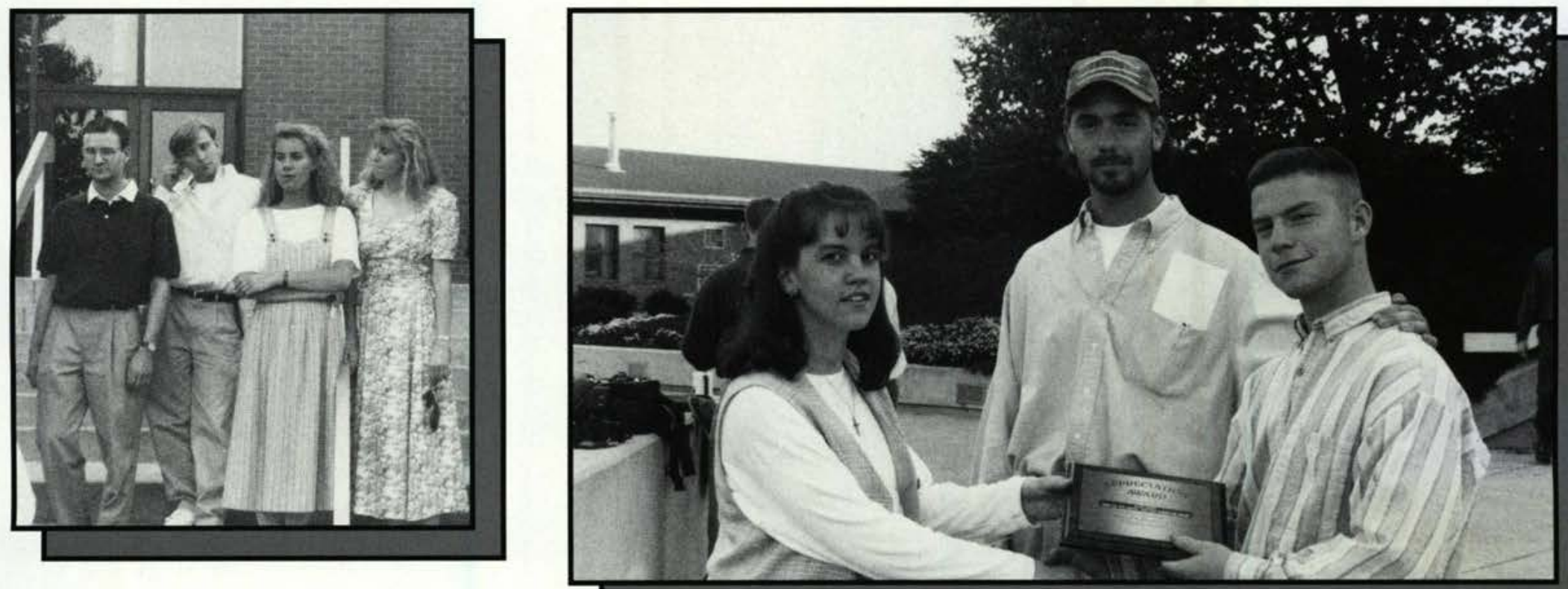

Photos by Kim Dors 


SGA
Elected
Officers
Bowe Hoy
President
Brian Burns
Vice President
Traci Emes
Secretary
Phil Lankford
Treasurer
Erin Weaver
Chaplain
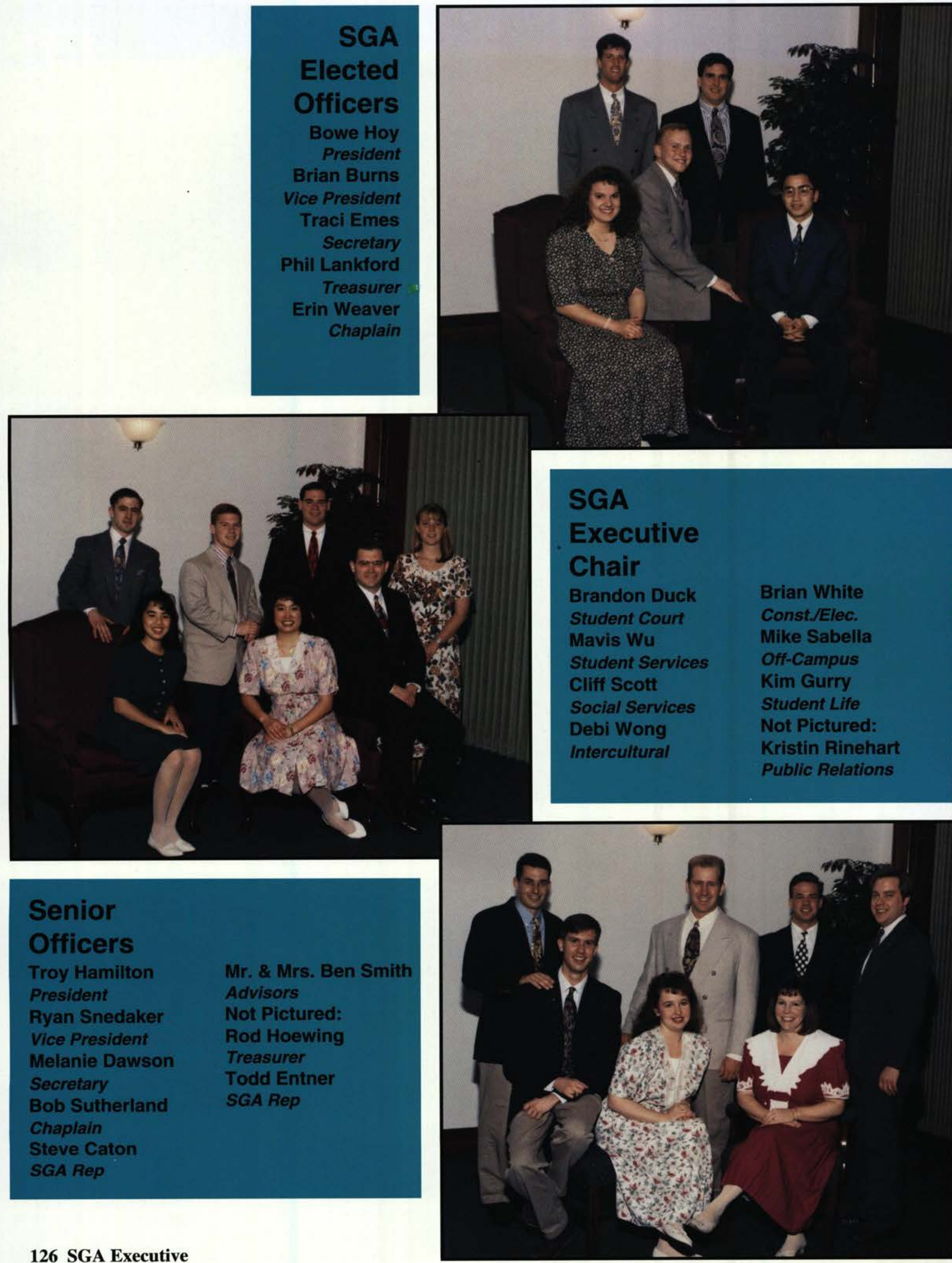


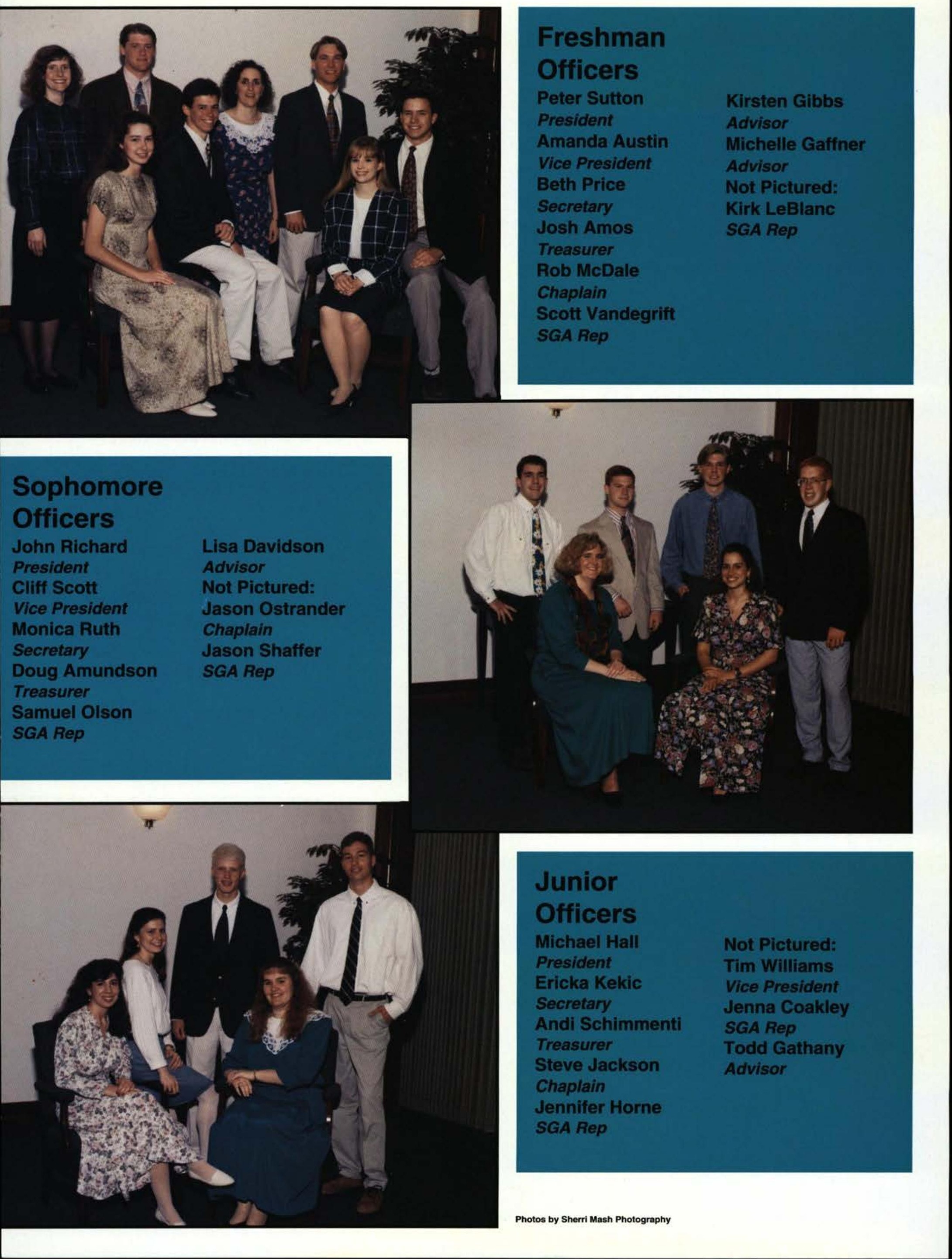


Alpha Chi is a men's service organization endeavoring to promote Christian character, leadership, an attitude of service, a Christcentered social life and an opportunity to be a testimony to others through various service projects and social activities.

Row 1: Andrew Alderfer, Troy Hamilton, Brian Kuvshinikov, Rob James, Kevin Kuczynski, Chris Ashcraft, Ryan Huebner, Doug Moe. Row 2: Daniel Forrest, Jamie Warnshuis, Jonathan Weber, Steve Burdette, Scott Vandegrift, James Dewald, Erik Larsen, Tobin Strong, Jeremy Spieth. Row 3: Jim Gadsby, Joel Misirian, Mike Sabella, Noah Buehner, Scott Husband, Steve Moulson, Dan Huber, Philip Boggs. Row 4: Nathan Houk, Jeff Saunders, Matthew Stutzman, Daniel Zerby, Aaron Jex.
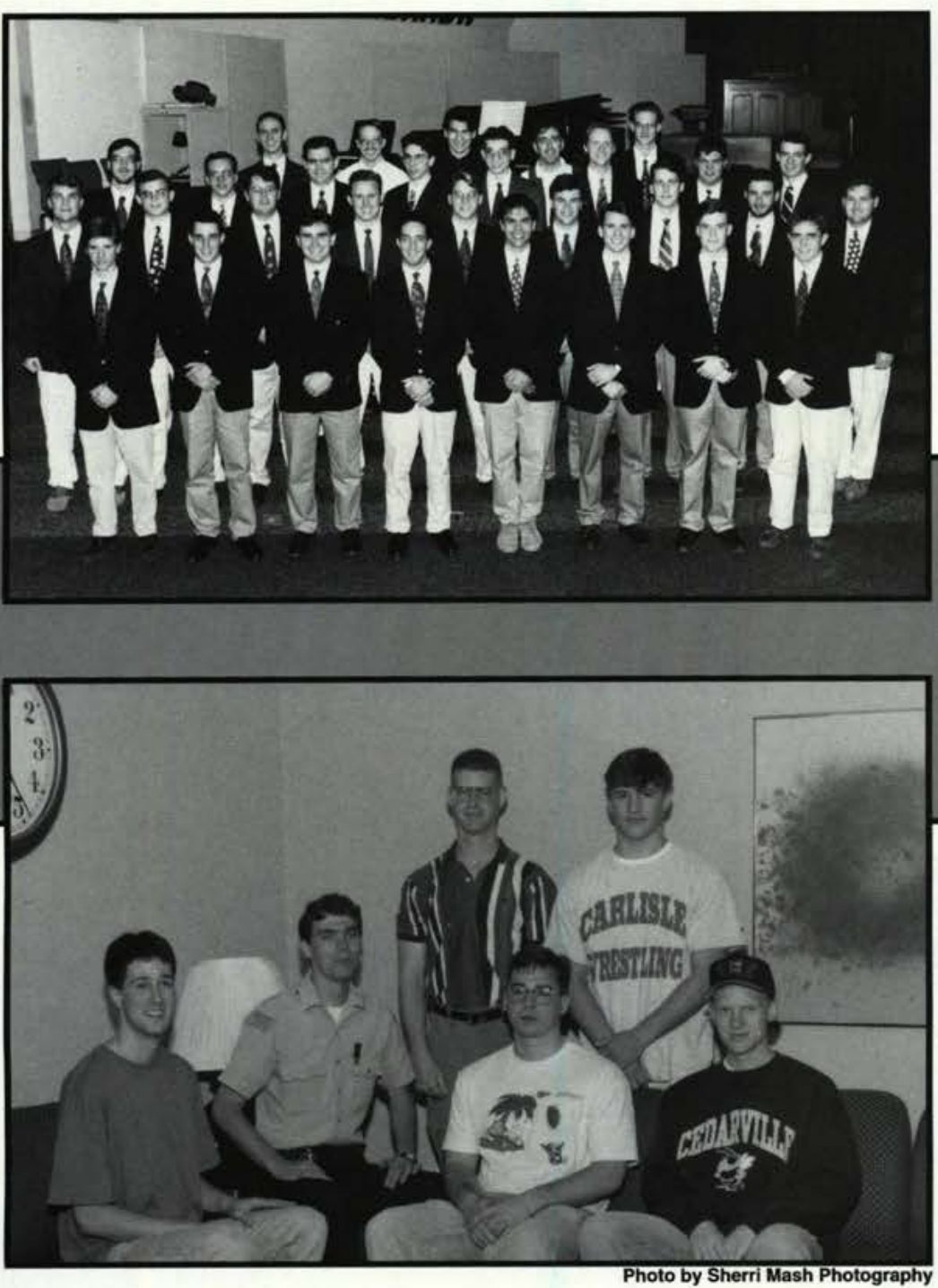

Alpha Delta $\mathbf{N u}$ is an organization composed of criminal justice majors and individuals interested in criminal justice.

Row 1: Brian Read, Chad Larr, Jason Davies, Derek Luke. Row 2: Seth Davis, Damon Derstine. NOT PICTURED: Stephanie McChesney
BELOW: Troy Hamilton entertained everyone, using Bob Stacey as his "dummy during the Alpha Chi Talent Show.
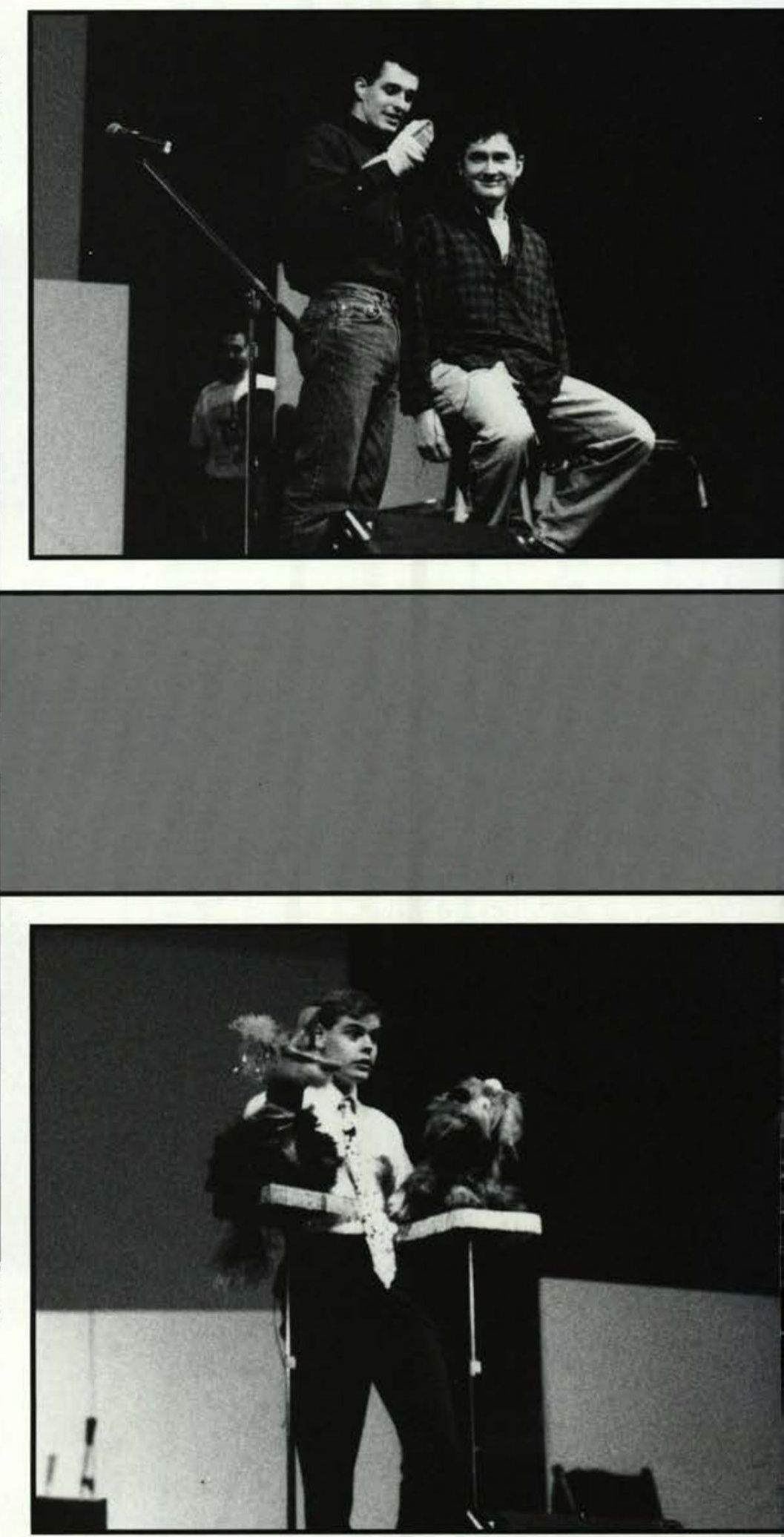

ABOVE: The ventriloquist and his "dummies" was also an enjoyable event of th evening. 
ASME is a student chapter of the American Society of Mechanical Engineers, and the activities of the chapter at Cedarville include plant tours, seminars, conferences, and competitions.

Row1: Nathan Pacarella, Cherish Clark, Ken Lee, Eric O'Brien, David Geiger, Cliff Caldwell. Row 2: Derek Gesler, Will Stoll, Kevin Dutil, Matt Breneman, Dustin Ruhl, David Preston.
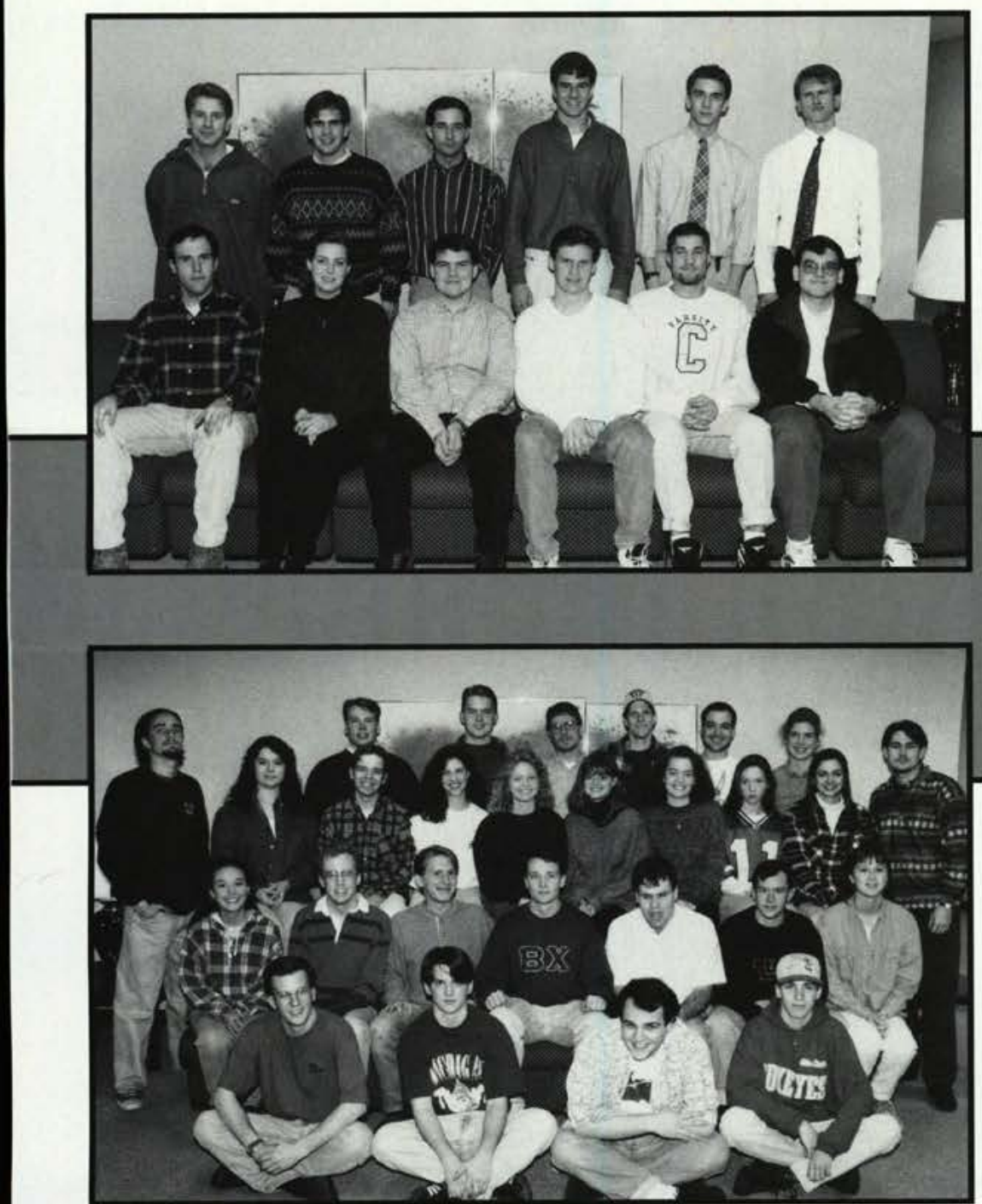

Beta Chi provides service opportunities for its members who either major in broadcasting or are interested in the field.

Row 1: Craig Hulbert, Dan Rudd, Matt Mann, Philip Wallis. Row 2: Michell Norton, Peter Fiveland, Brian Spencer, Keith Hamer, Ryan Coverdell, Brooke Taylor, Jennifer Wittenbach. Row 3: Benjie Cooper, Stephanie Saville, Dallas Hill, Amy Cartzendafner, Emily Williams, Patricia Noble, Deborah Woods, Nancy Parsons, Paula Faris, Nathan Miller. Row 4: Craig Hamer, Mike McCleese, Eric Case, Brad Iten, Mark Button, Sara Miller.
Ginnie Bancett, Tara Prentis, Valerie Ashurst, Mike Young, Brian Schoepke, Bart But and Aaron Bey show us the front page of the Chicago Tribune which they visited wt on their trip to Chicago, with KEA.
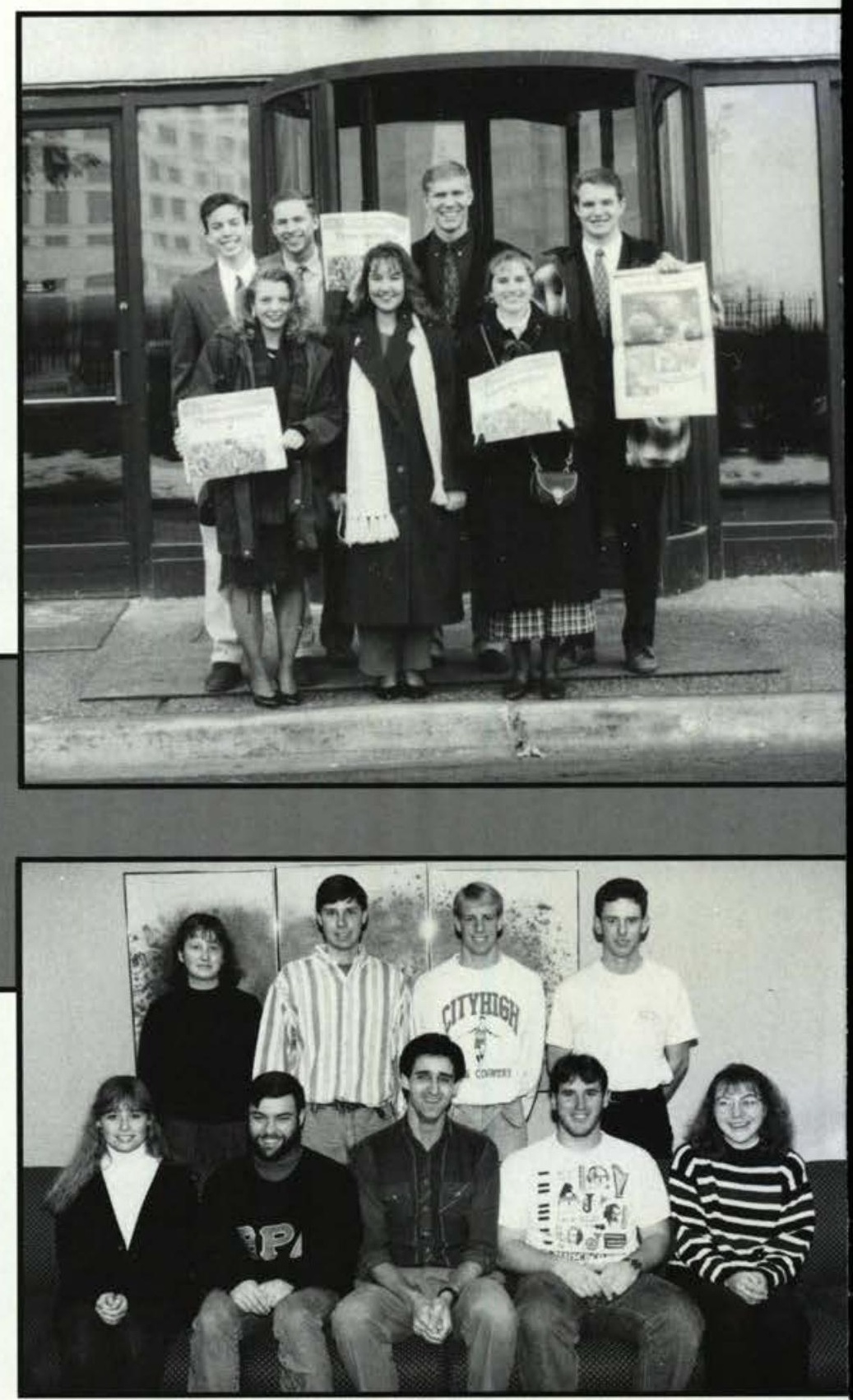

Beta Rho Delta is the German Club which provides an opportunity for those students who would like to become more fluent in German to improve their skills of speaking in this language

Row 1: Rhonda Carnahan, Gordon Rogers, Linford Herschberger, Steven Krise, Charstie Davids. Row 2: Marla Perkins, Jonathan Seeger, Peter Simons, Jonatha Glines. 
CEDARS, the newspaper of Cedarville College, is a bi-weekly publication produced by the students.

Row 1: Julie Plunkett, Jennifer Bartosiewicz. Row 2: Stephen Kellogg, Adam Young, Marc Marsdale, Adam Lenhart.
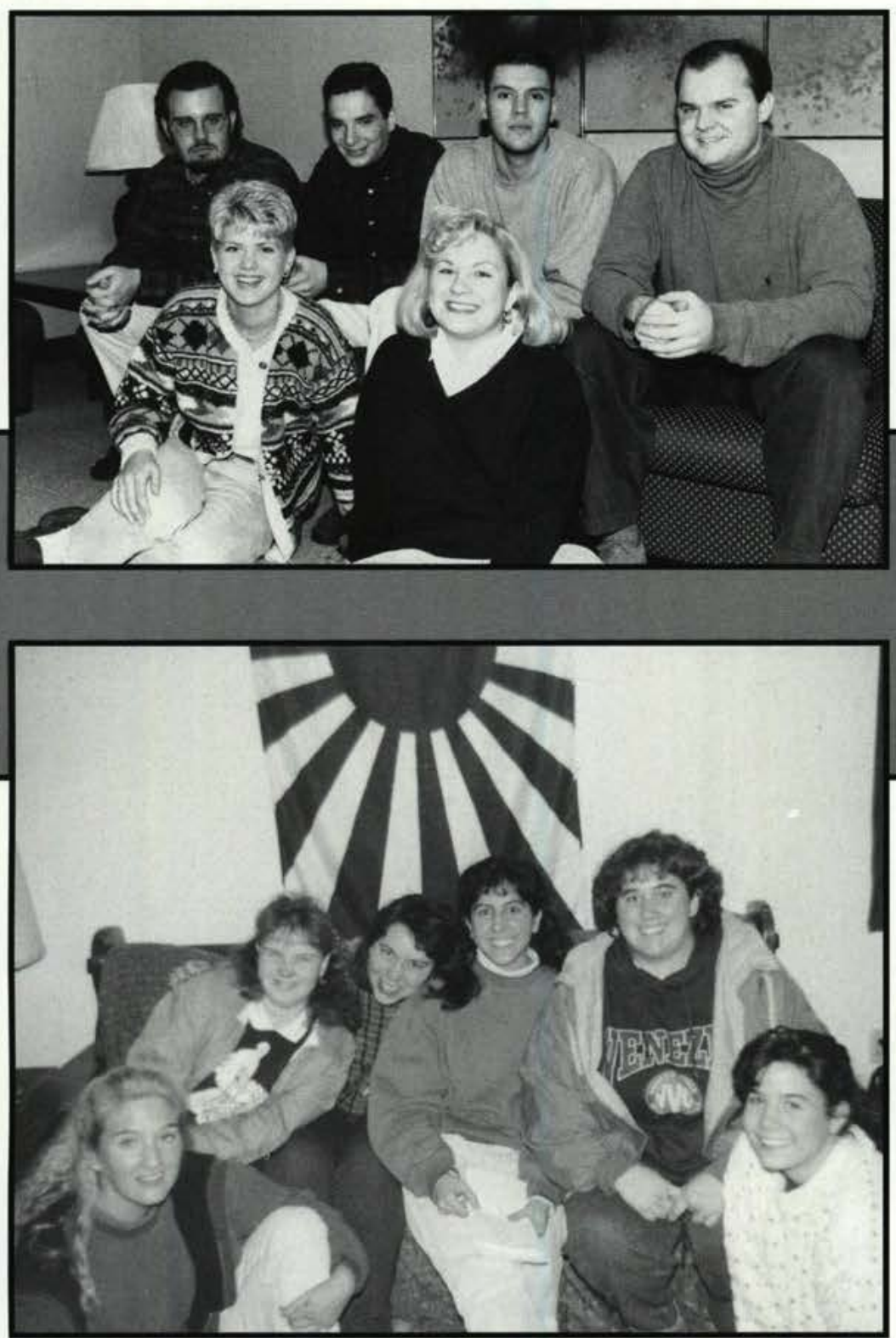

Teachers stick together and so do these gals: Heather Comegys, Amber Snodgrass, Tabi Leininger, Amy Awabdy, Kara Lehman, and Janelle Reis.
BELOW: Chi Delta Epsilon shows that "A" is for Apple, their favorite fruit at the Organizational Fair.
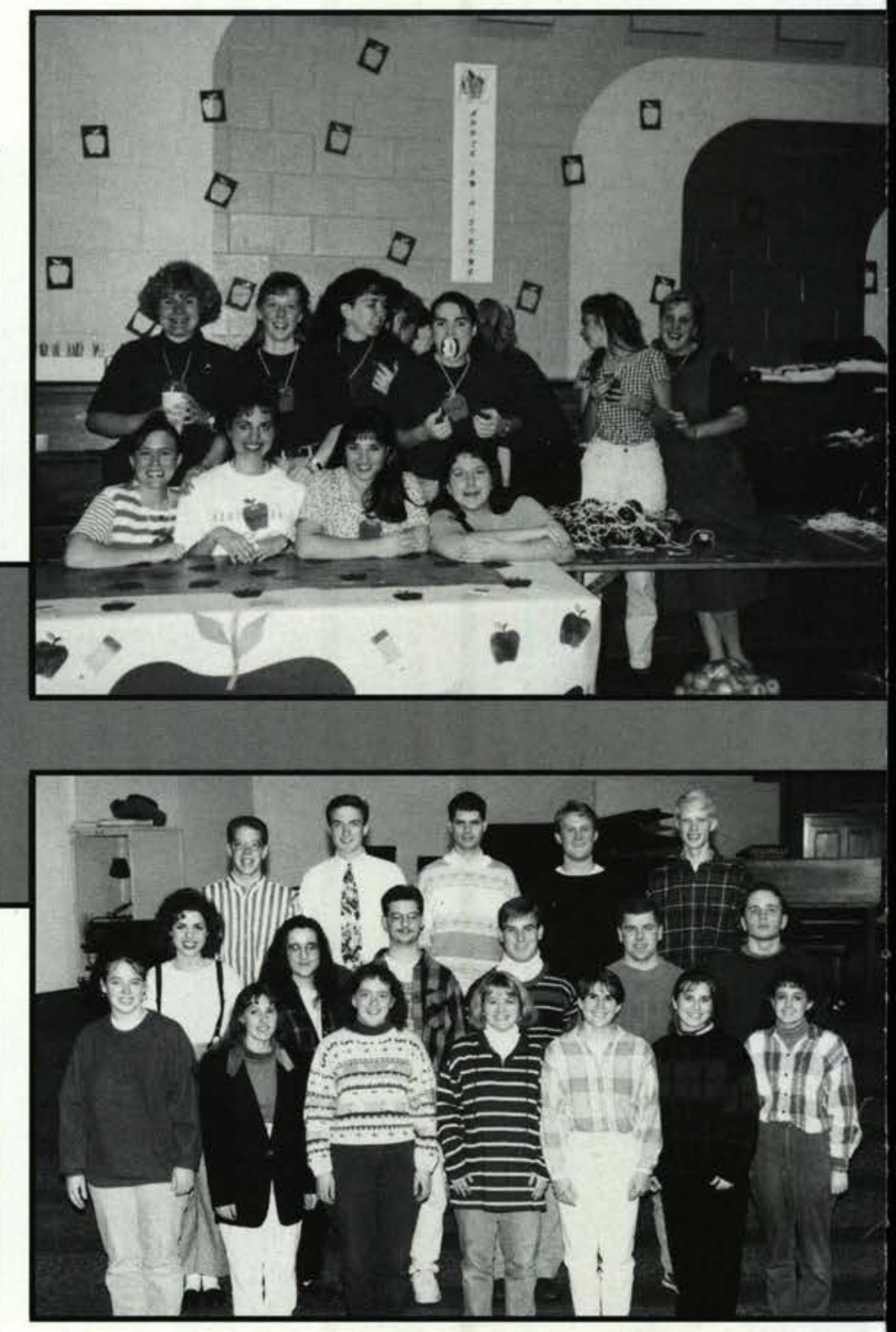

C C Republicans stimulate interest, involvement and leader ship in political affairs, keep members and other students informe about political issues, and do it with a Christian emphasis.

Row 1: Wendy Passineau, Kim Koziol, Heather MacLean, Joanna Hall, Julien Johnsor Valerie Ashurst, Angela Boyce. Row 2: Michele Picuri, Amy Clark, Harold Owen, Da Olson, David Meckley, Doug Bayler. Row 3: Doug Amundson, Jeremy Farlow, Andre Marshall, Jason Roloff, Michael Hall. Not pictured: Karen Beck, Bart Butler, Melind Bradley. 


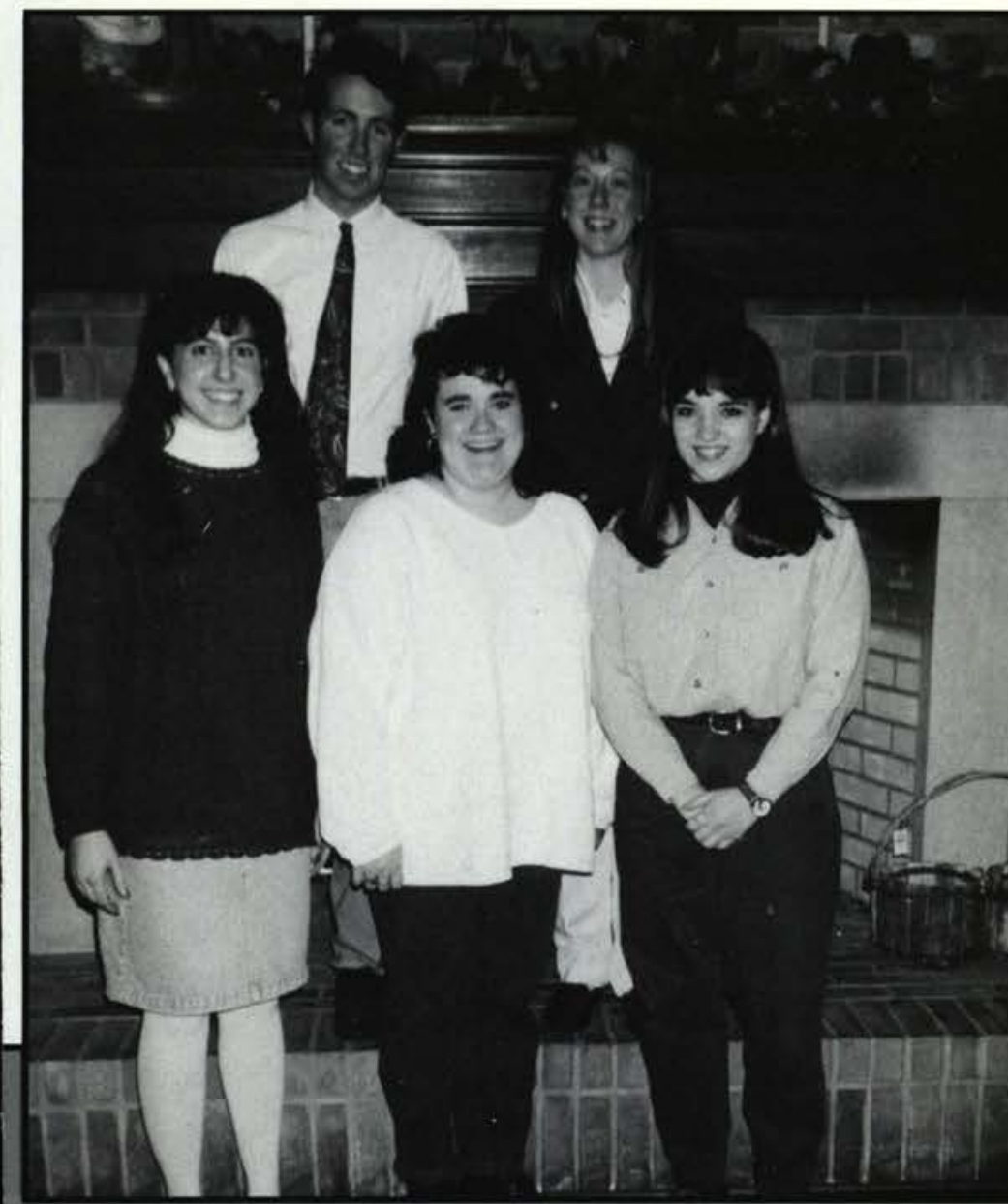

Chi Delta Epsilon students strive to increase professional awareness and development, to participate in community outreach, and to encourage each other as they prepare for a career in education.

Row 1: Cheri Wiley, Lisa Miller, Jennifer Kierstead, Janelle Reis, Jena Winters, Olivia Hammond, Lori Landwehr, Dawn Kirgan, Kathleen Holesten. Row 2: Krista Ryan, Pam Rutledge, Janine Pinkley, Andrea Nicodemus, Melissa Hadley, Jennie Fisher, Amy McDevitt, Sherri Woodard. Row 3: Brenda Royer, Amy Awabdy, Angela Meredith, Stacie Eldeen, Jennifer Keary, Jennifer Mosby, Aaron Berning, Sandy Streit, Jill Heisler. Row 4: Kara Lehman, Susan Wilkinson, Heather Comegys, Joey Decker, Rebecca Smith, Amy Owens, Lisa Warren, Tabi Leininger. Row 5: Josh Halulko, Melissa Mocny, Becky Mclntyre, Amber Snodgrass, Amie Hapeman, Stephanie Bolsem.
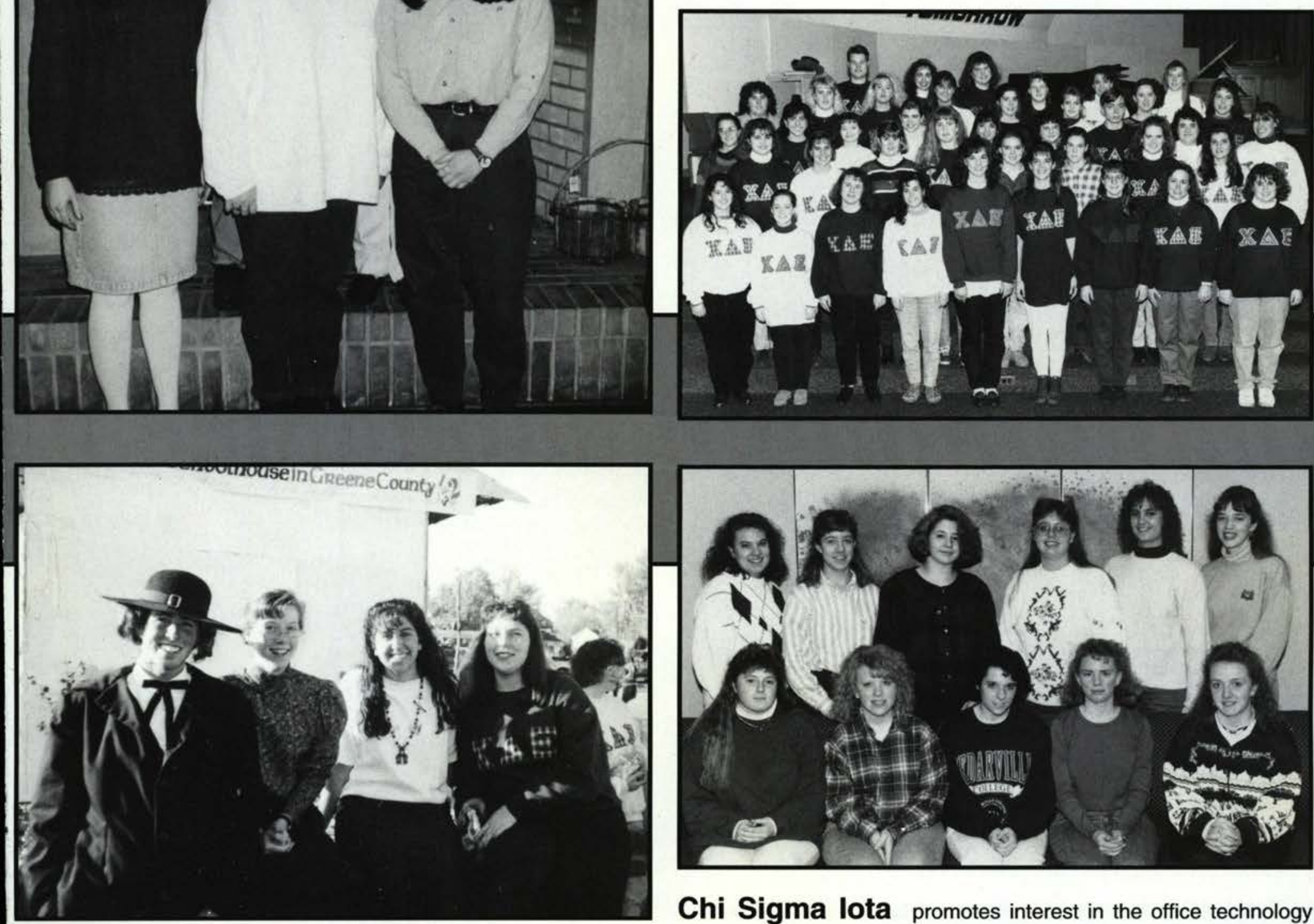

ABOVE: Chi Delta Epsilon members constructed The Second Schoolhouse in Greene County for the Homecoming Parade. Preacher: Bill Droke, Teacher: Stephanie Bolsem, Students: Amy Awabdy and Tabi Leininger.

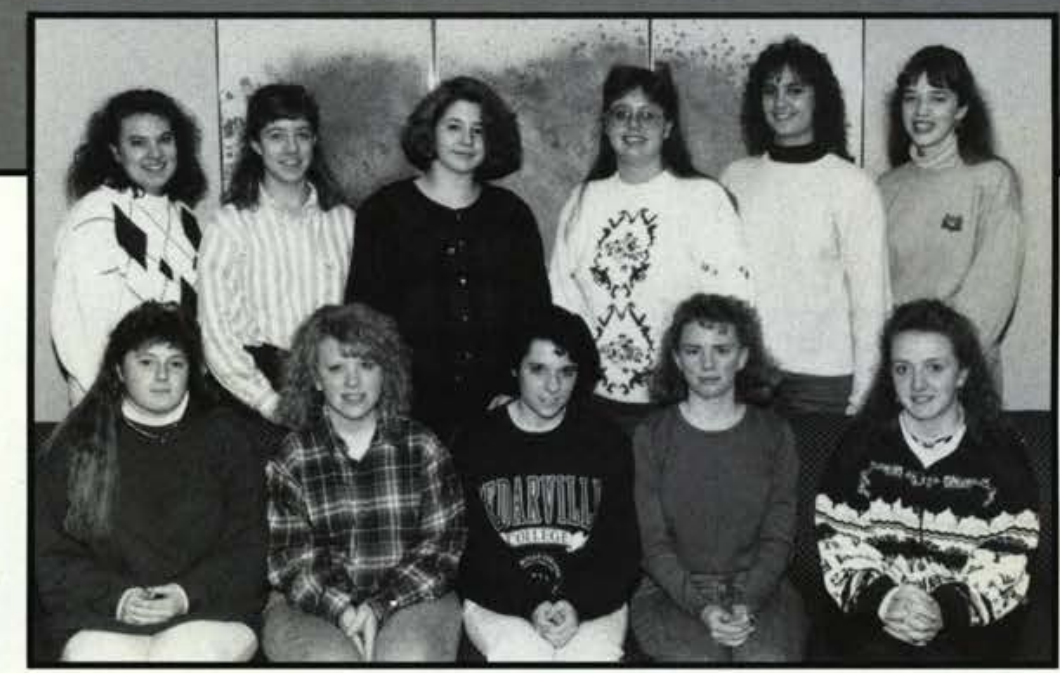

Chi Sigma lota promotes interest in the office technology profession, provides helpful information for the future, and fellowship for students with similar interests in related fields.

Row 1: Kristine Thorsen, Beth Tharp, Jennifer Staples, Roni Mower, Kristen Gault. Row 2: Traci Emes, Ruth Hamilton, Lori Shelly, Kelly Hager, Leah Hoover, Abigail Brown.

\section{Featuring:}

\section{Chi Delta Epsilon}


Chi Theta $\mathbf{P i}$ strives to provide opportunities for students in prehealth profession majors and to experience various facets of their chosen professions through special activities, speakers, and field trips.

Row 1: Dawn Merritt, Rachel Maki, Eve Edsell, Meghan Foehl, Kimberly Dorsey, Carrie Gwilt, April Johnson, Rachel Bray, Karin Moon. Row2: Martha Shrubsole, Sarah Gross, Jodie Hager, Shonda Overman, Vance Smith, Bryan Jefferies, Brian Kuvshinikov, Tom Culberson, Kerri VanderMolen, April Artman, Dave Curtis. Row 3: Heidi Opgenorth, Michelle Higgins, Summer Todd, Kim Maynard, Stephanie Mead, Atsuko Ohtake, Rachel Wirt, Tara Swiger, Gina Palumbo, Tracie Wright, Kathy Petersen. Row 4: Julie Meeden, Dave Thomas, Keri Christner, Kristin Decker, Samuel Olsen, Jay Penning, Bryan Harju, Amy Hoop, Presian Smyers, Paul Click, Jamie Dodson.
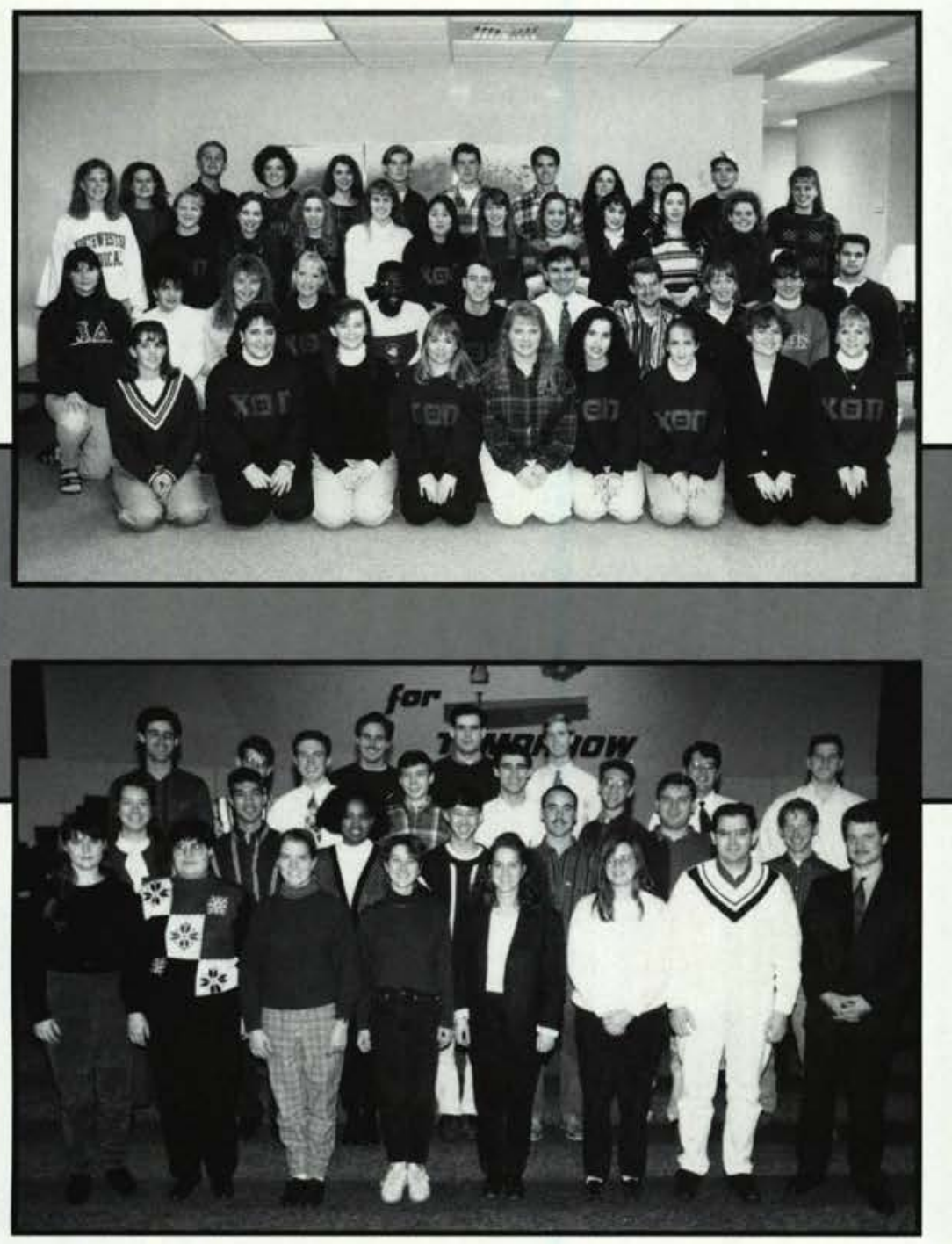

Commuter Crossroads consists of commuting students. There are special activities, newsletters, and projects provided to keep these students informed and involved in campus activities.

Row 1: Martha Shrubsole, Jennifer Shrubsole, Kimberly Bell, Jaimee Potter, Beth Ann Pickell, Carla Heim, Mike Sabella, Carl Ruby. Row 2: Christiana Gain, Raymond Townsend, DeVonne Henry, Nathan Ho, Todd Entner, David Heim, George Weber. Row 3: Linford Herschberger, Tom Culberson, Jeremy Farlow, Stephen Estep, Lowell Herschberger, Ben Stutzman, Jonathan Weber, Byron Stover. Row 4: Mike Slone, Jon Shrubsole, David Peters.
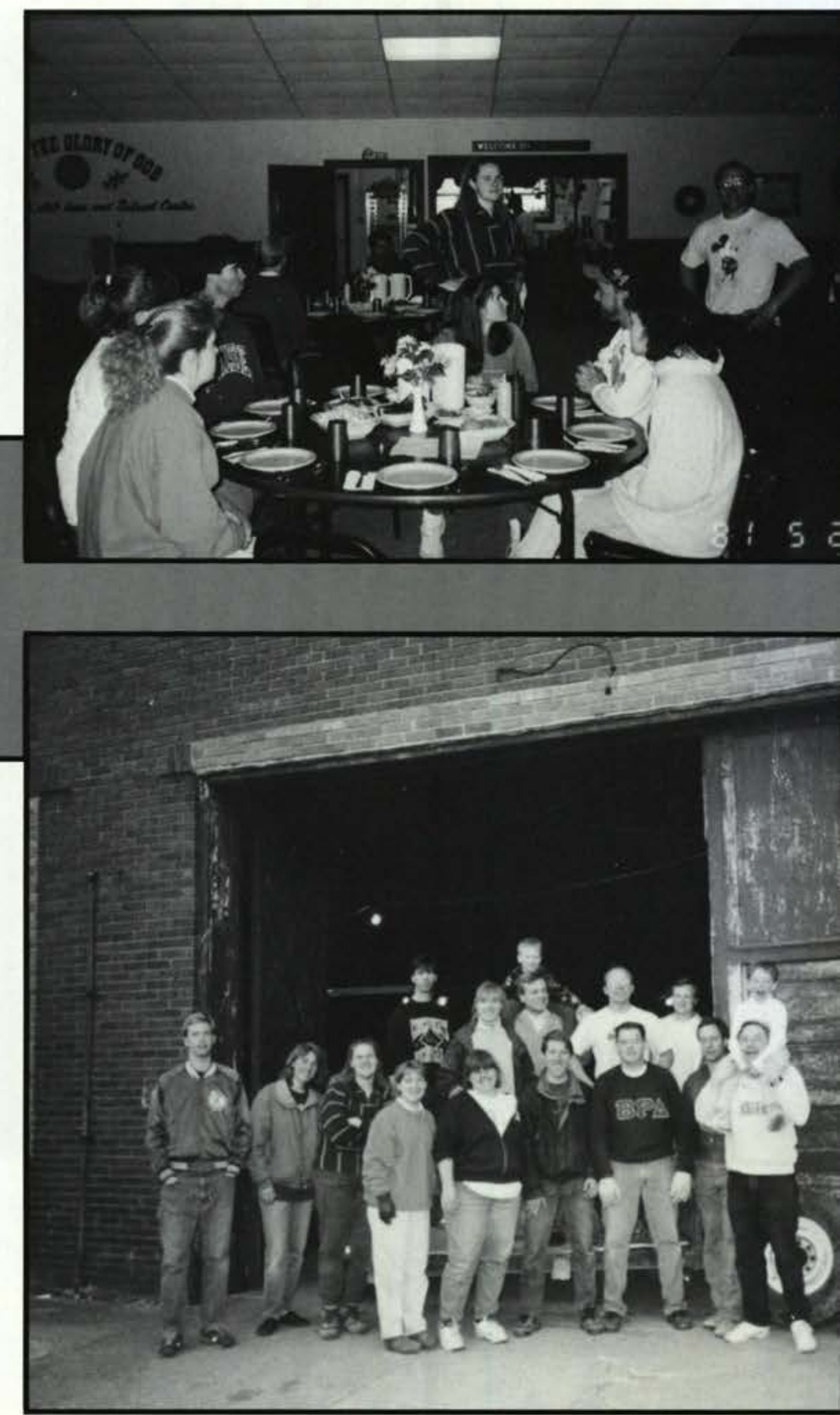


\section{Data Processing Management Association} prepares CIS students for a career in data processing by acquainting them with professionals in the field as well as various hardware and software.

Row 1: Scott Parcher, Bryan Eaton, Nathan Ho, Will Orser, Tyler Allison, Nathan Martindale.
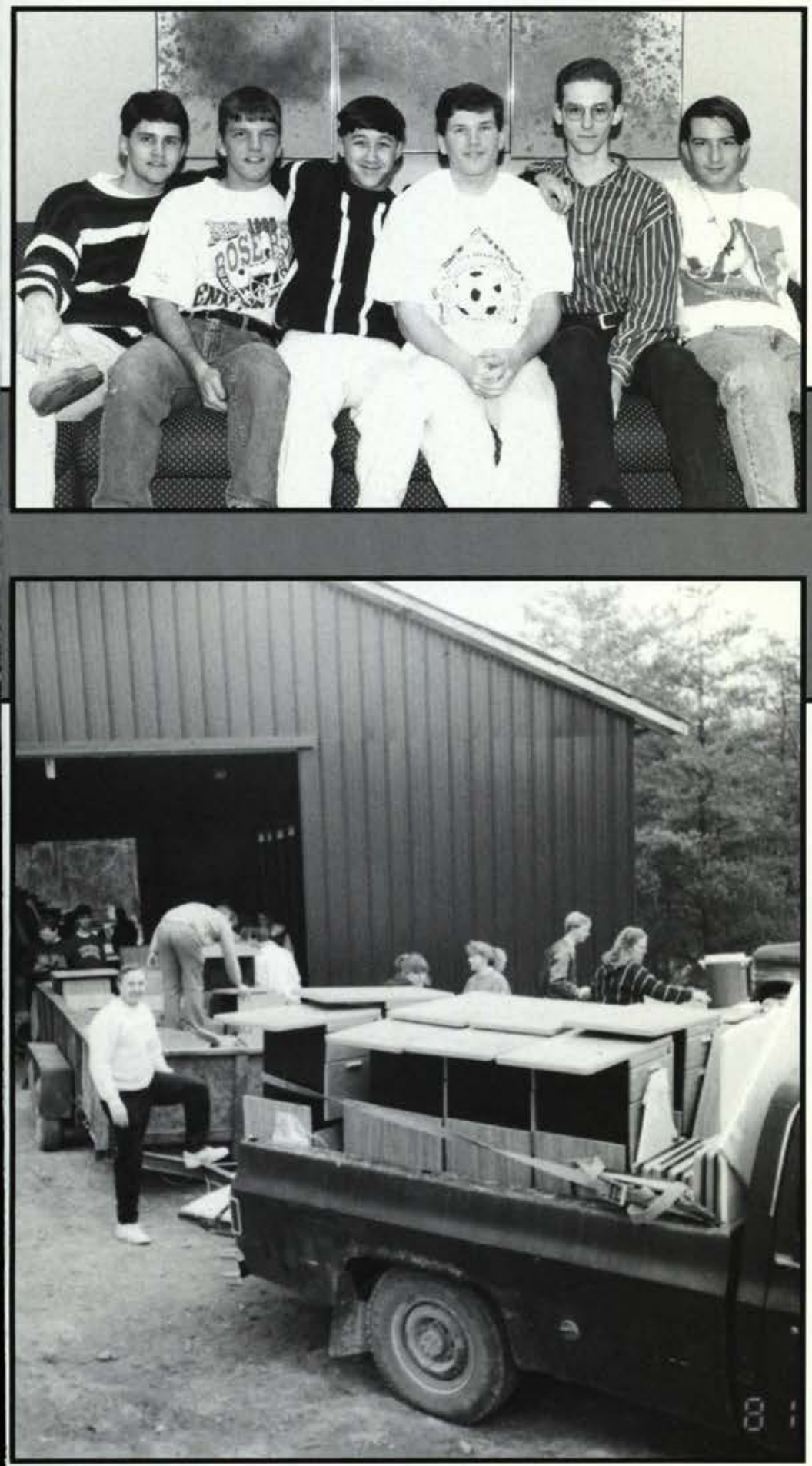

\section{Featuring:}

\section{Commuter Crossroads}

Delta Chi brings together secondary education majors from several different disciplines and prepares them to be professional and to be community servants.

Row 1: DiAnn Miller, Evelyn Brown, Tami See, Kim Huffy. Row 2: Rebekah Hoorn, Tiff Shaw, Roni Mower.
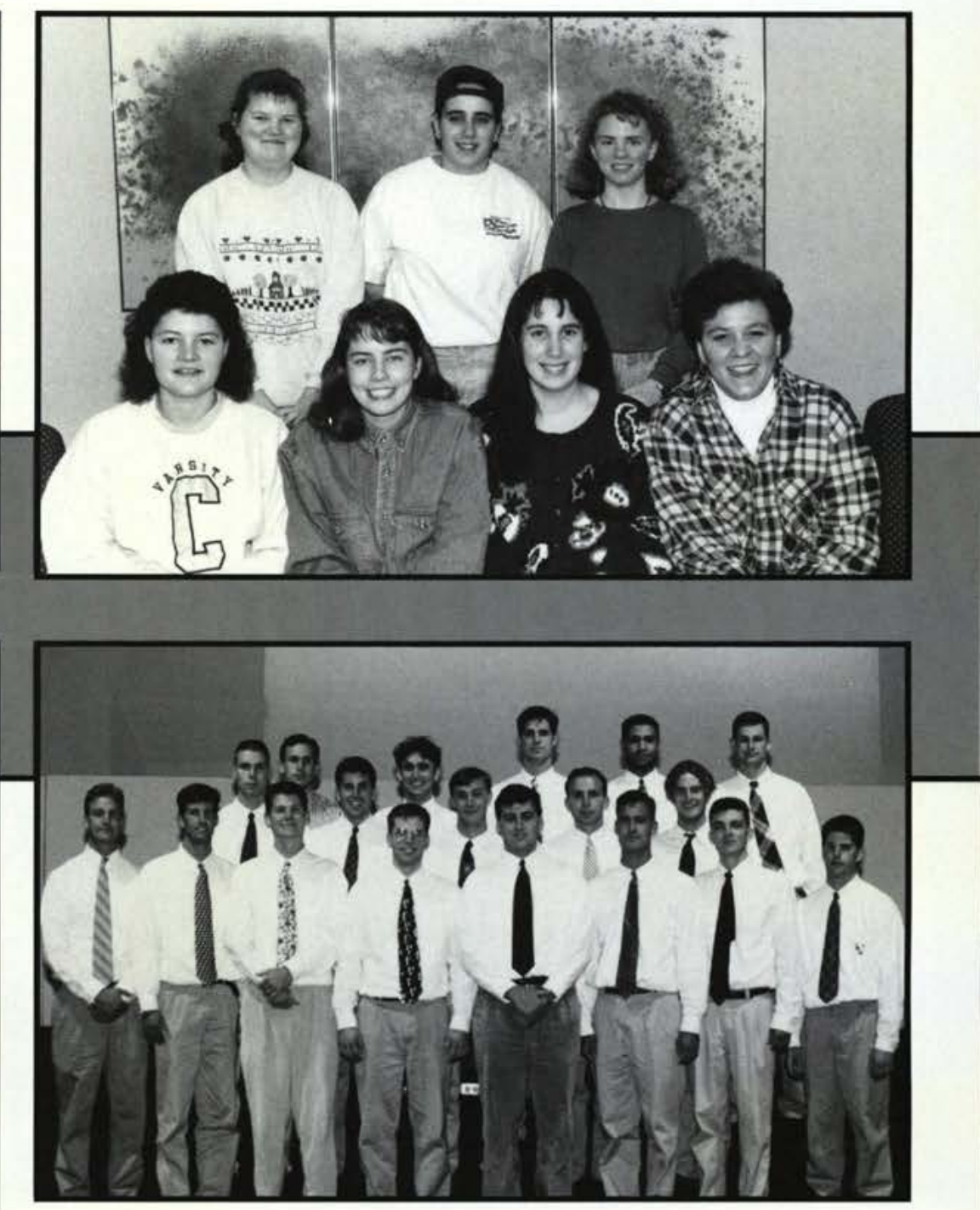

Delta Omega Epsilon provides fellowship for members in addition to the social and service benefits they provide for the college through various projects and activities.

Row 1: Mark Otto, Erin Weaver, Sean Marr, Jeff Rohm, Jim Spaulding, Brad Francis, Bill Curry, Scott Kennedy. Row 2: Brad Callahan, Greg Walker, Jon Longshaw, Brent Gibbs, Jason Quinn. Row3: Neil Brown, Charlie Dean, MattReynolds, EI Seabra, Steve Smith. 
Delta Pi Sigma prepares women for their roles after graduation and gives them opportunity to serve God by serving others.

Row1: Paula Triplett, Paula Faris, Melissa Sayre, Amanda Whitmer, Jenny Williamson, Michelle Kinley, Amy Varner, Tonya Bowling. Row 2: Rebekah Overcash, Jackie Thomson, Caron Hartkop, Mary Sweetland, Karyn Hartman, Melissa Pope, Amy DeWitt, Lynne Smith, Jen Linak.
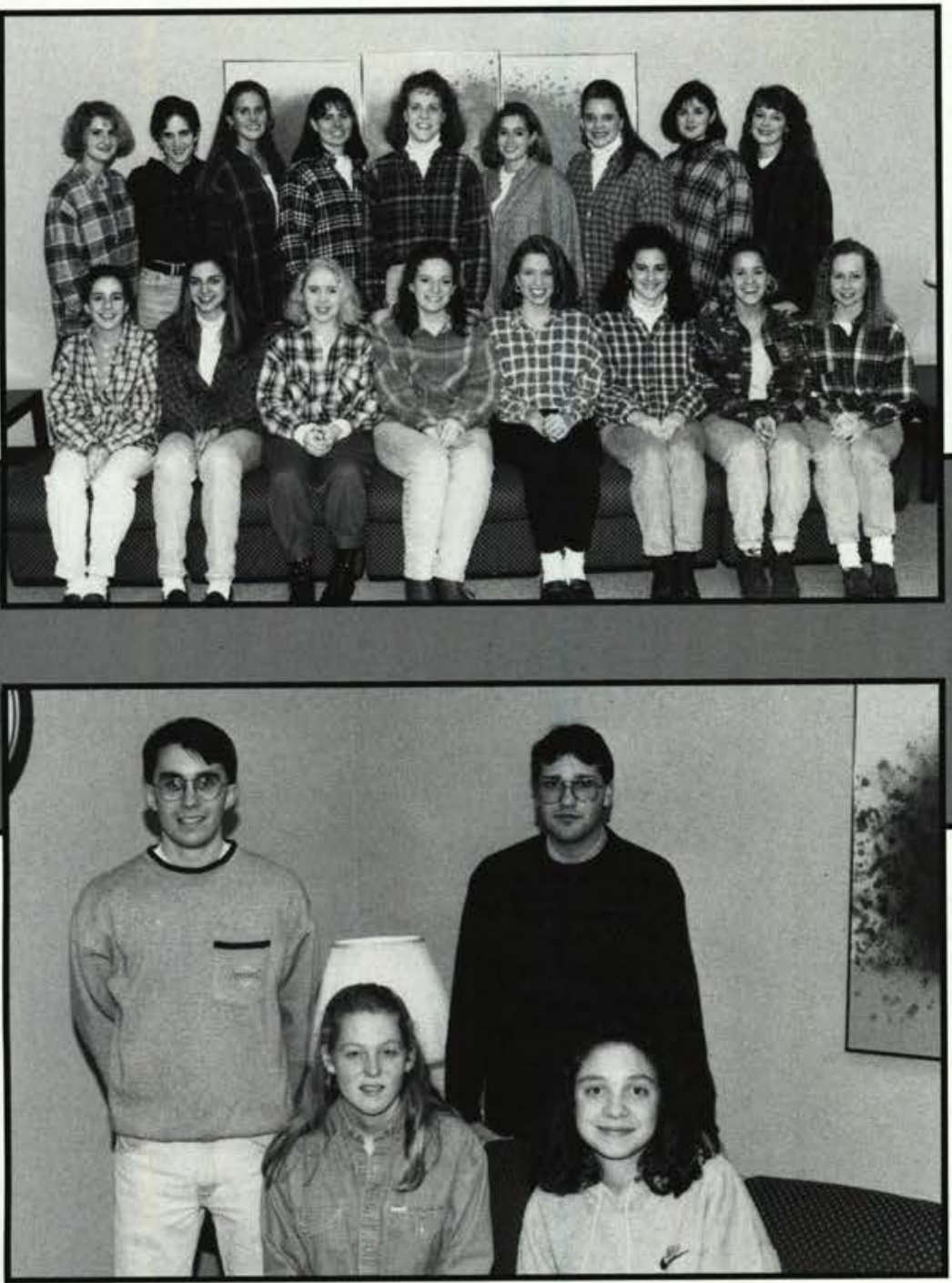

\section{Featuring: \& EMS} Alpha Delta Omega
Some of the ADO girls, April Seely, Lori Royal, Beth Schwind, Amy Cunningham, Emily Currall, Keely Waibel, and Heather Perrault, get together for a little fun.

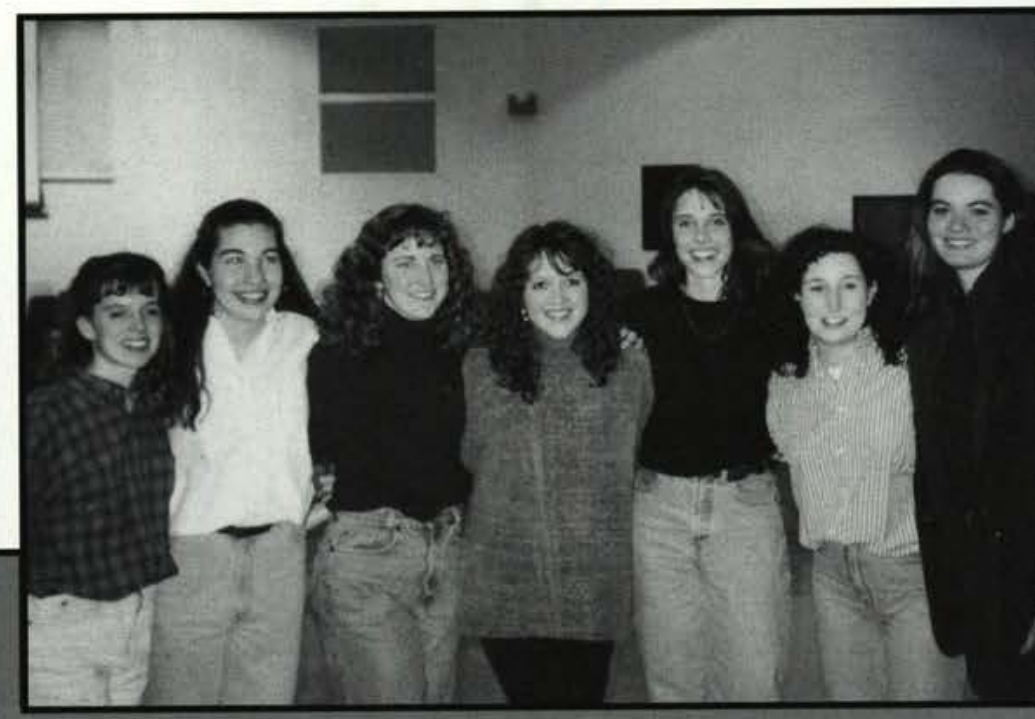

Earth Stewardship enhances the awareness, understanding, and appreciation of God's creation and promotes opportunities for Christian environmental stewardship through intellectual, recreational, and community service endeavors.

Row 1: Kim Collins, Melody Gbur. Row 2: Chris Ehlers, Jason Thompson. 
EMS (Emergency Medical Service) for trained students who provide prompt and professional pre-hospital care and transportation to Cedarville students in need.

Laurel Barnhart, Ivy Schlesener, Cara Miller, Sean Wood, Keila Whittaker, Darren Young, Michelle Zehr, Steve Burdette, Dave Curtis, Becky Gerber, Amber Rohweder.
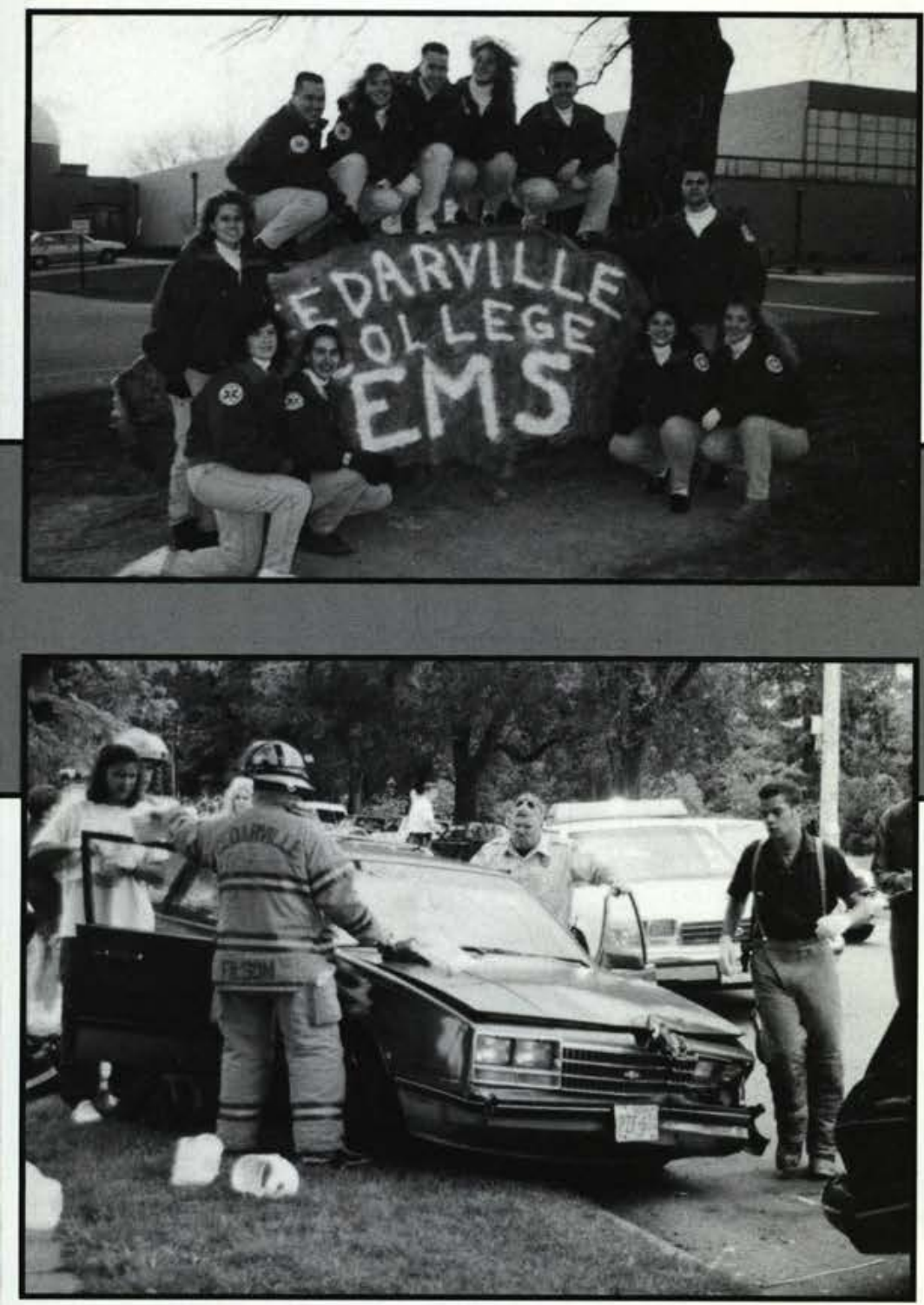

TOP RIGHT and ABOVE: The college EMS squad is also involved in helping the local volunteers as well as being the emergency volunteers for the entire campus.
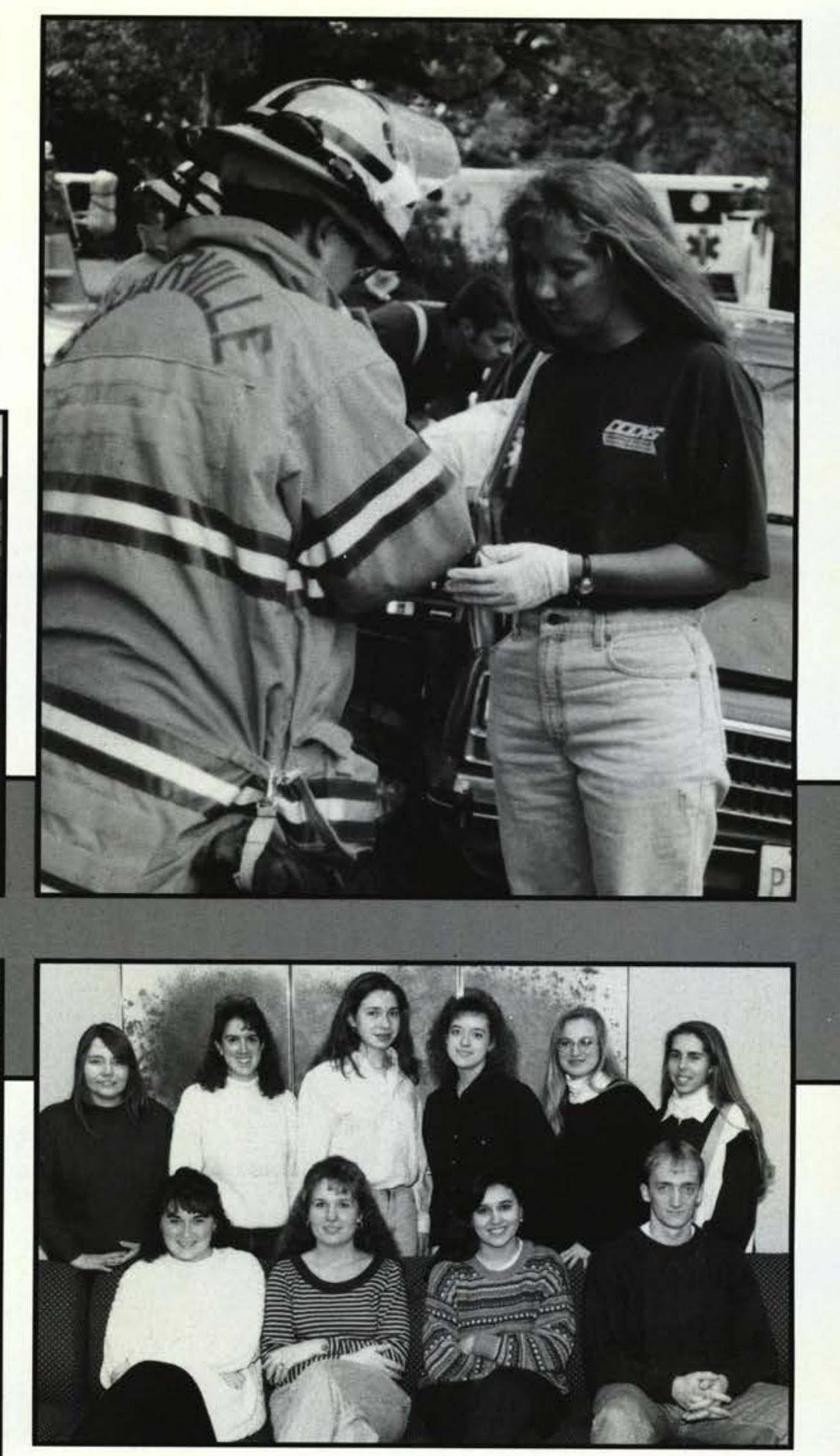

Epsilon Alpha $\mathbf{P i}$ is the social work organization designed to provide outreach opportunities with various populations and to increase professional awareness among its members.

Row 1: Joy McVey, Jennifer Sloan, Amy Hickox, Corey Schwinn. Row 2: Rebecca Combs, Colette Cassidy, Debbie Trimble, Pam Sibole, Sharon Piper, Natalie Wiewiora. 
I.E.E.E. (Institute of Electrical and Electronical Engineers) promotes technical and professional growth among electrical engineering students.

Row 1: Joel Hacker, Stephen Reiter, Robert Laramore (advisor, Tim Tuinstra, Allan McGuire. Row 2: Chris Handel, Joshua Corner, Andrew Crefeld, Ira Stevens.
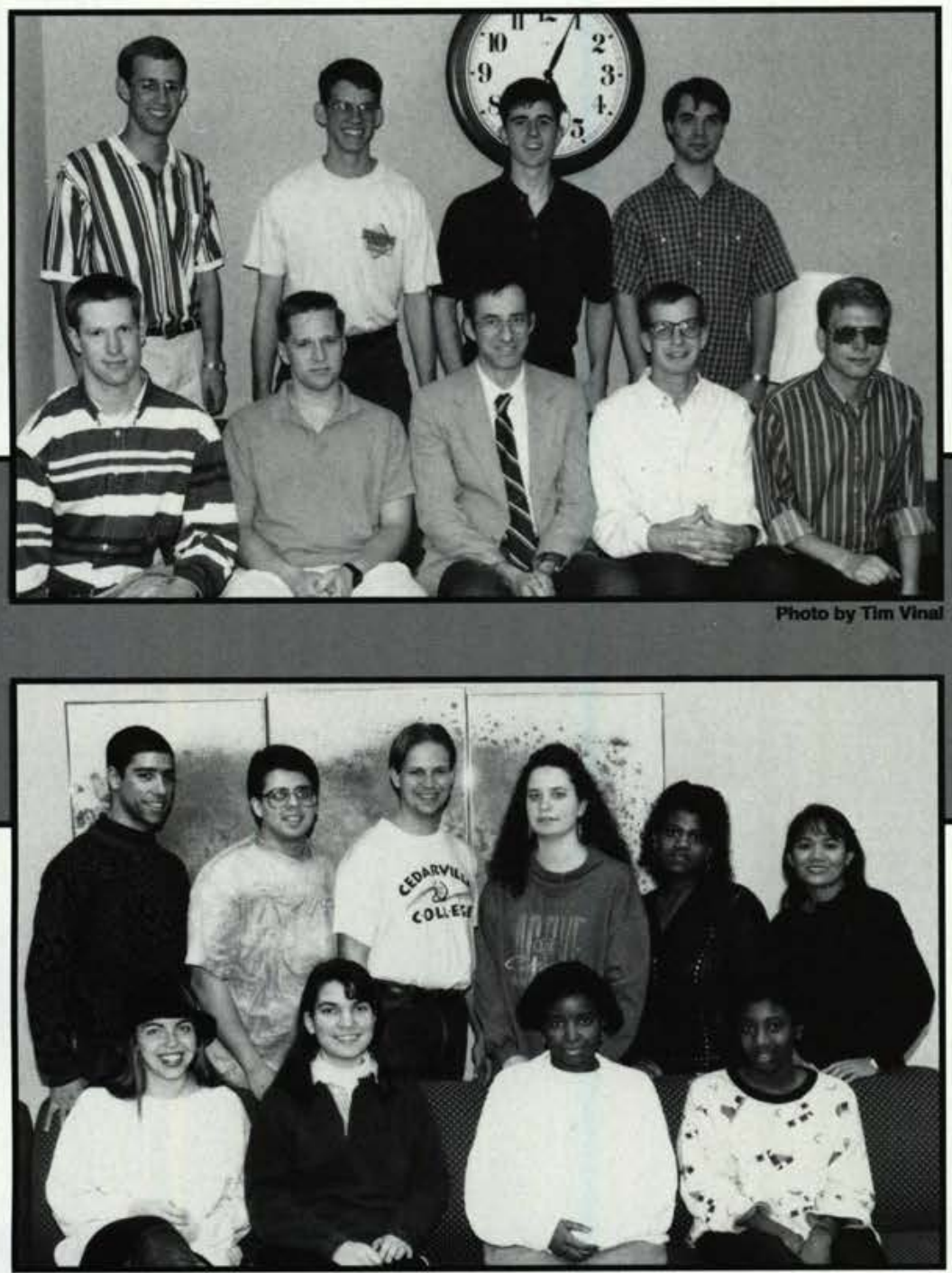

lota Chi Phi stands for Intercultural Christian Fellowship.

Diversity adds flavor to life and unity gives life stability, and it is lota Chi Phi's mission to achieve what God has stamped on the heart of every true believer and which the United States has stamped on every coin-"E PLURIBUS UNUM "- Out of Many, One.

Row 1: Elizabeth Rogers, Jill Fuller, Michelle Johnson, Kwajalein Reed. Row 2: Colin Smith, Rajan Desai, Don Smith, Marjie Chesebro, Julie Ross, Mitona Pel. Not Pictured: Connie Francis, Paige Smith.
The whole gang comes together for an official Mu Kappa Snow Camp picture.
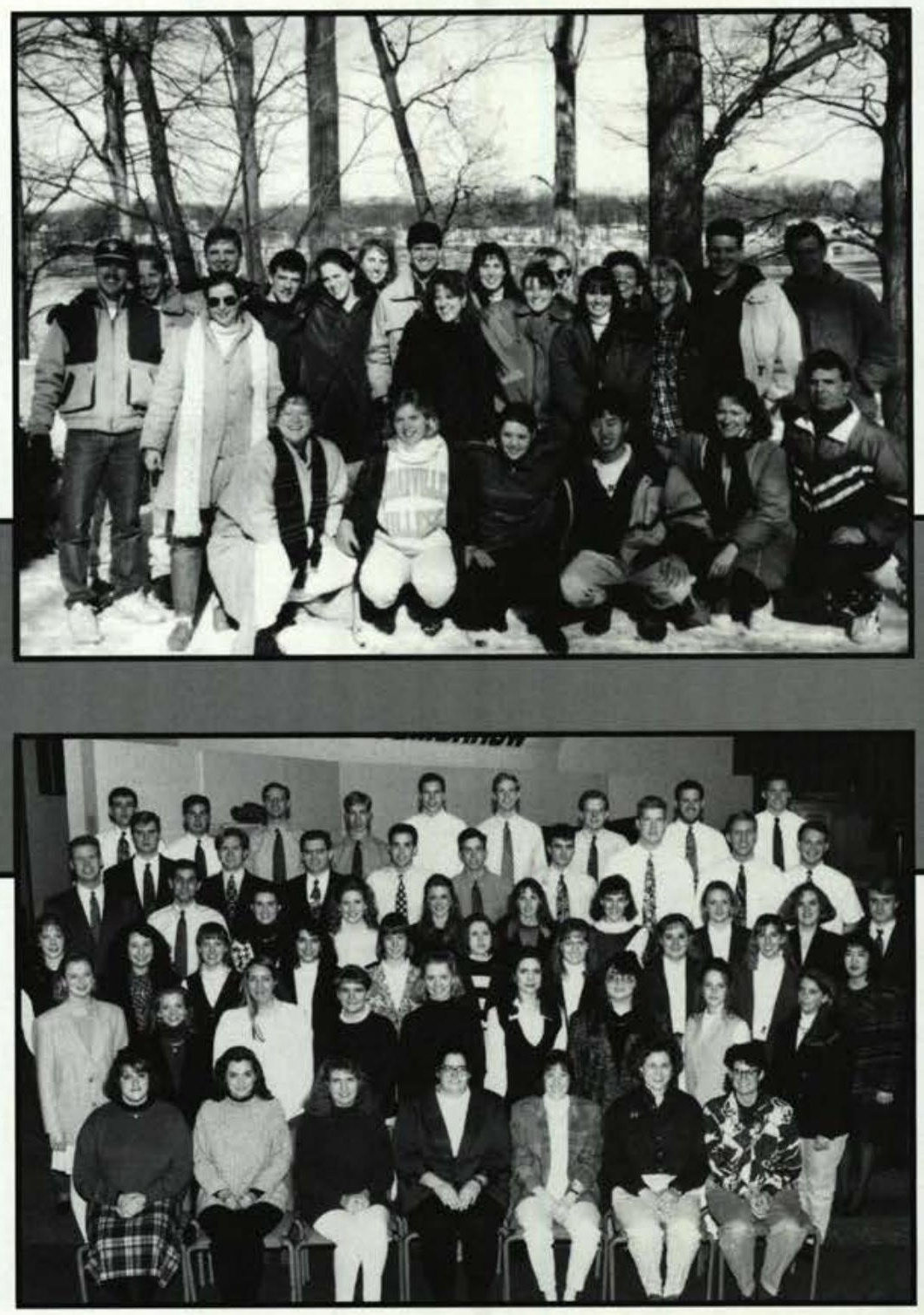

KEA (Kappa Epsilon Alpha) seeks to prepare business majors for their future careers in the business world.

Row 1: Dana Avery, Leslie Hack, Debbie Davidson, Heidi Wolters, Heather Bossley, Aimee Miller, Candi Sarber. Row 2: Krysty Bailey, Ginnie Barrett, Heidi Hoover, Elise Cook, Amy Shaneyfelt, Cindy Parson, Angie Letson, Debra Thompson, Heidi Bowen. Row 3: Cynthia Quint, Keely Waibel, Krissy Brown, Carolyn Horton, Debbie Gleichman, Erin Johns, Michelle Dick, Erin Barker, Jen VanderBush, Sarah Holesovsky. Row 4: Jason Stevens, Marcus Varotti, Sara Howell, Amy Spurling, Ann Gabriel, Kim Koziol, Tami Strong, Elizabeth Amundson, Kristy Shelford, Dan Pugsley. Row 5: Chris Wilson, Jeff Davis, Mike Sabella, Chris Anderson, Mike Young, Keith Youngblood, Scott Christner, Bart Butler, Aaron Bey. Row 6: Chris McCaskey, Bobby Thomas, Ryan Anderson, Jim Creswell, Brian Schoepke, David Peters, Chad Wingert, Chris Van Hart, Jamie French. 
Pi Delta serves as the official host to campus guests by providing tours for groups of prospective students, youth leaders, and parents.

Row 1: Heather Bethel, Julie Cooper, Leslie Wenzel, Evelyn Bussa, Amie Hapeman, Jennifer Yaggi, Tami Doden, Kim Gurry, Debi Wong. Row 2: Justin Bailey, Martha Shrubsole, Cliff Scott, Jennifer Butler, Mavis Wu, Casey Griffiths, Kristine Illjes, Mandi Secord, Karie Kuster, Debbie Kruse, Emily Currall. Row 3: Jason Stevens, Jon Misirian, Chris Anderson, Tim Tuinstra, Derek Gesler, Nathan Pascarella, Joel DeVinney.
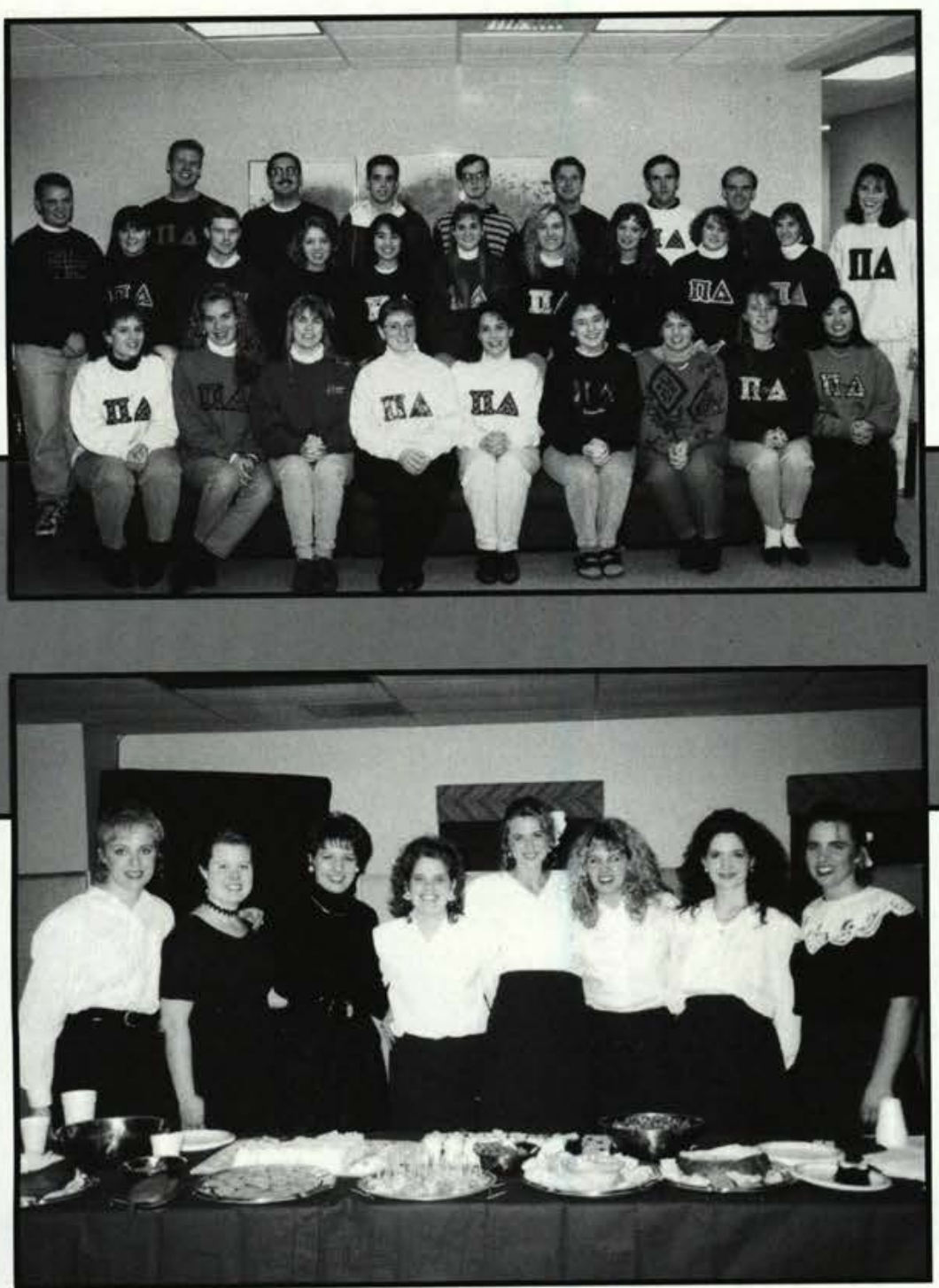

ABOVE: The servers at the Phi Gamma Psi Masquerade pose before their work begins.
Pi Sig "brothers" pose for a picture after a long, hard fall quarter.
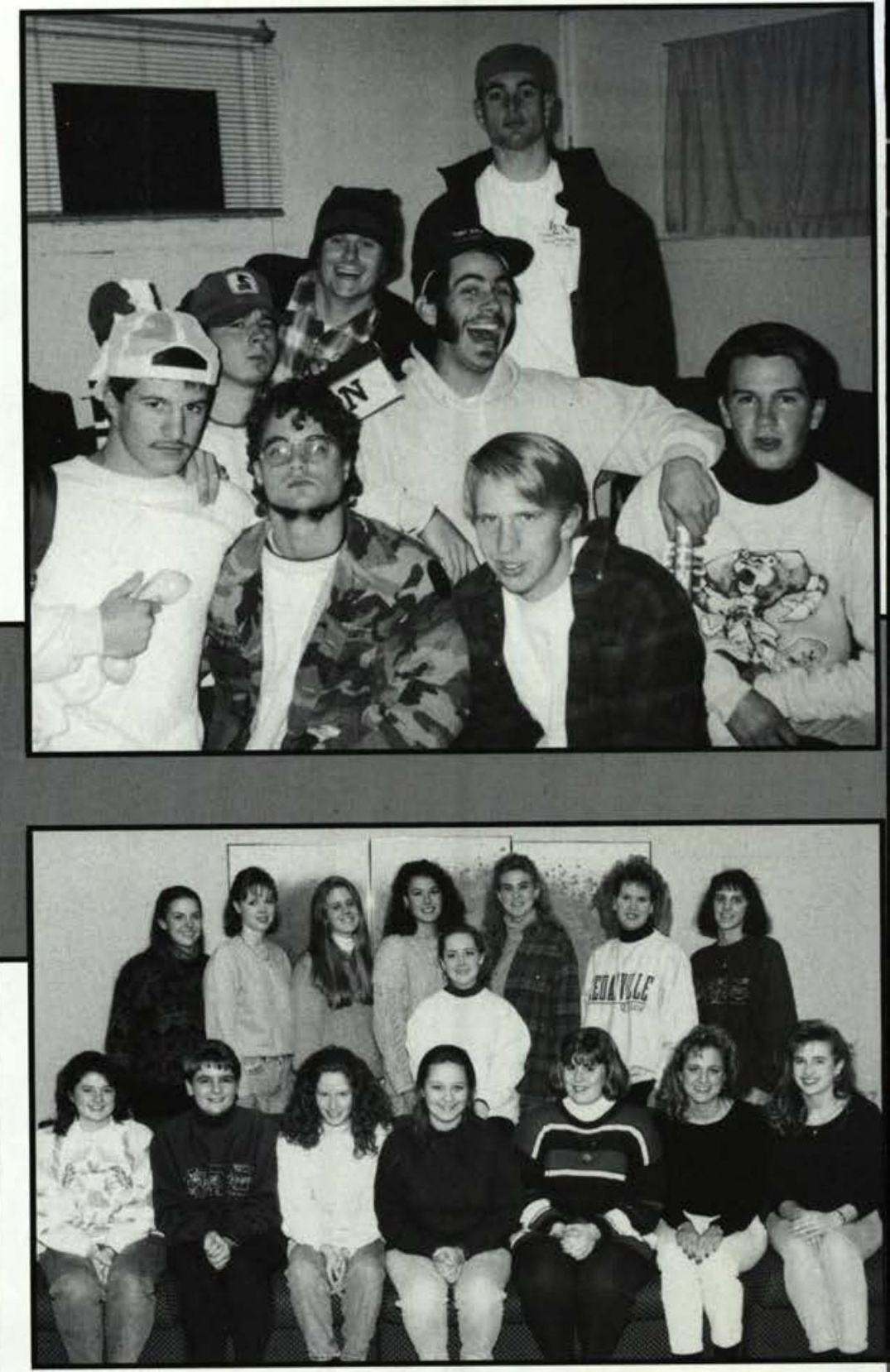

Phi Epsilon Beta is a women's organization which actively serves the local community and provides a social atmosphere which enhances the many aspects of life.

Row 1: Deb Copeland, Elise Cook, Greta Hendricks, Lea Anne Churgovich, Janine Pinkley, Noelle Reed, Sharon Burns. Row 2: Lisa Miller. Row 3: Tricia Walker, Heather Ann Brodie, Susie Rooke, Jennifer Dinelli, Alicia Elmore, Lora Losier, Janelle Jackson 
ROTC is available at Cedarville College in the branches of Army and Air Force.

Row 1: Joshua Corner, Phil Geelhood, Dan Zerby, Jessica Faber, Rychel Brickel. Row 2: Nathan James, Erik Bauer, Maria Hert, Nathan Houk, Brian McGuinness, Charlie Robinson. Row 3: Ian Hassell, Shawn Shipp, Ben Thirey, Andrew Spottswood, Dustin Hockensmith.

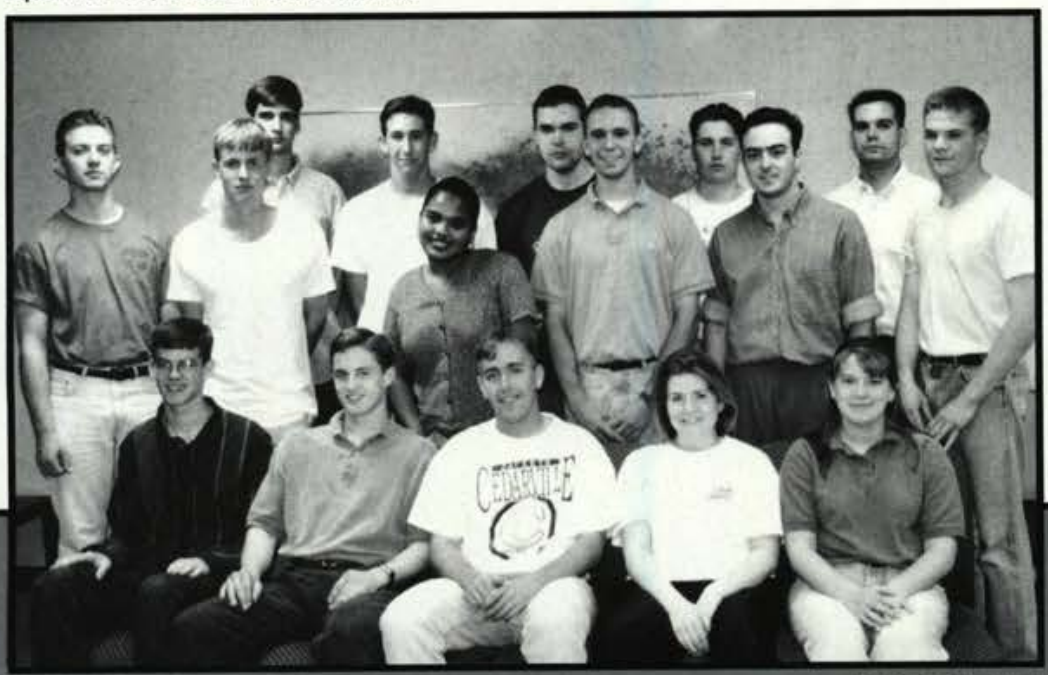

Photo by Tim Vinal

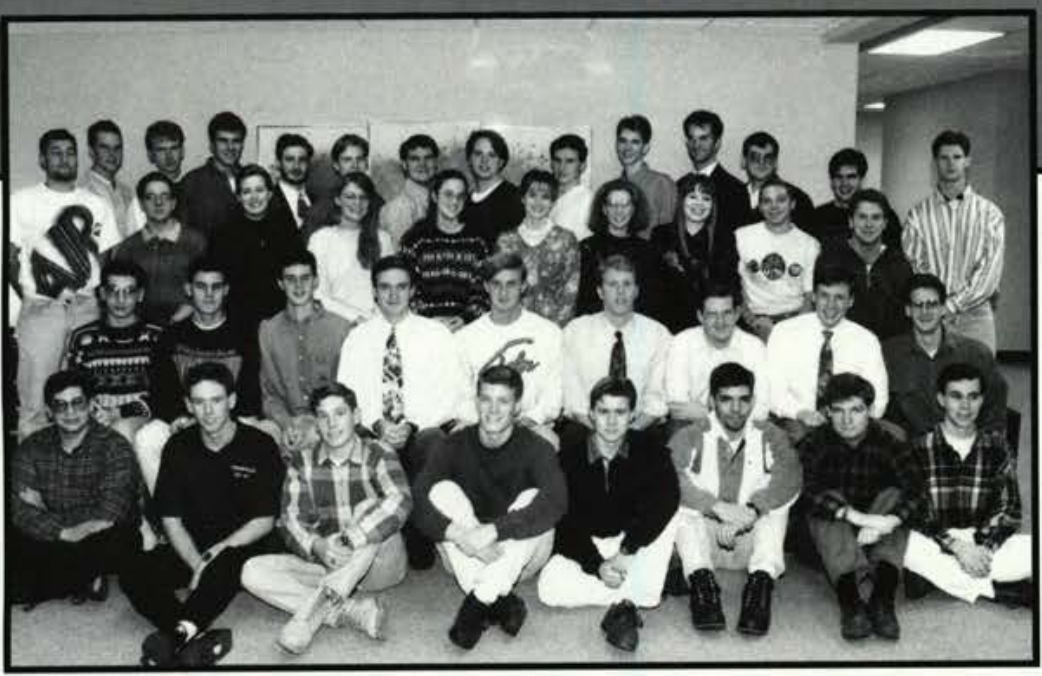

SAE (Society of Automotive Engineers) gives students the chance to learn about their future and talk to other engineers in the area by way of monthly seminars and participation in one of many projects.

Row 1: Scott Hoadley, Jonathan Glines, Scott Koziol, Joel Fuerch, Brent Ridley, Chuck Ware, David Perry, David Hoskins. Row 2: Scott Husband, Scott Judkins, Jesse Roberts, Jeremy Farlow, Paul De Kruyter, Jake Porter, Ira Bube, Rob Bouwens, Tom Mouser. Row 3: David Geiger, Jeff Mick, Cherish Clark, Becky Ivey, Andrea Osterc, Julie Armour, Natalie Vandemark, Amy Price, Philip Lehman, Derek Gesler, Eric Bedillion. Row 4: Jeff Breneman, David Preston, Matt Breneman,

Tobin Strong, Jeremy Staley, Ken Lee, Charlie Walker, Eric O'Brien, Aaron Schradin, Joe Lesko, Cliff Caldwell, Will Stoll.
The men of OPE have some fun lovin' crazy times. Row 1: Jim Patten, Brian Burns, Derek Gessler, Brian Naess, Dave Mc Murtry, Tim Nicklas, Jeff Beste. Row 2: Will Dodson, John Wambold, Chad Vitarelli, Brent Luman, Mark Stone,Dennis Moles, Tim Haylett, Dave Curtis.
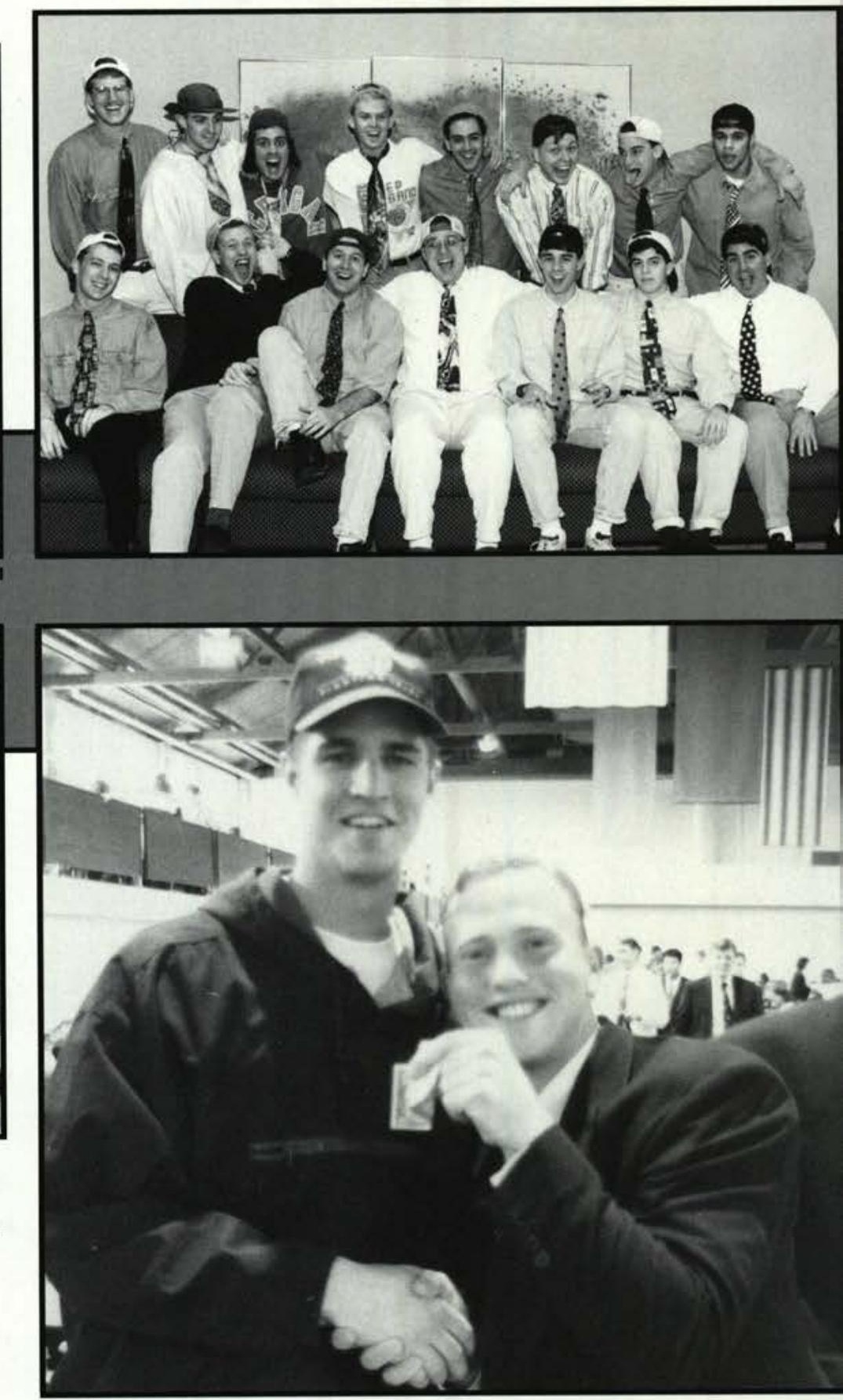

Brian Burns shakes Matt Reynold's hand and thanks him for his purchase at the OPE auctions. 
Josh Green plays cupid at Cupid's Bash.

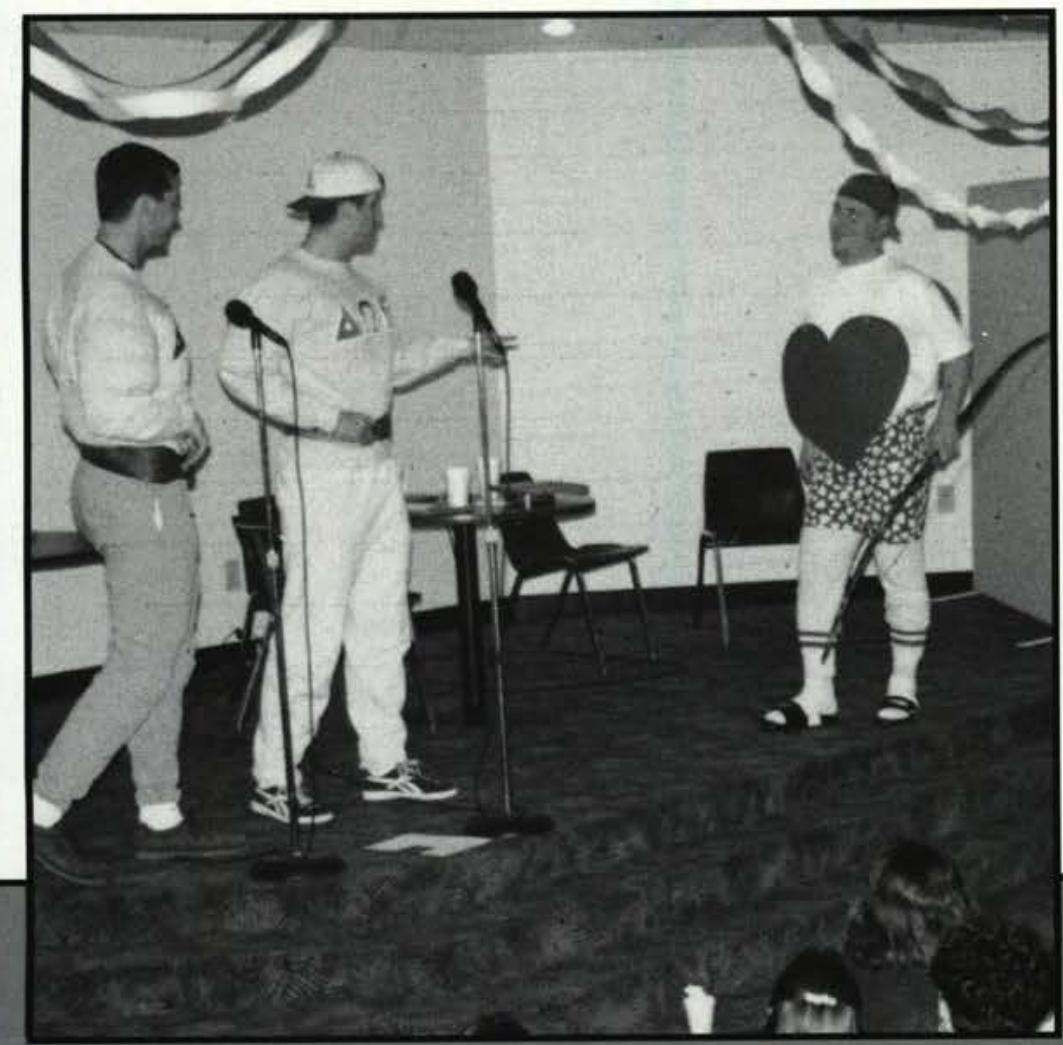

\section{Cupid's Bash}

Steve Smith and Erin Weaver put on a skit for the li'l sibs at Cupid's Bash.
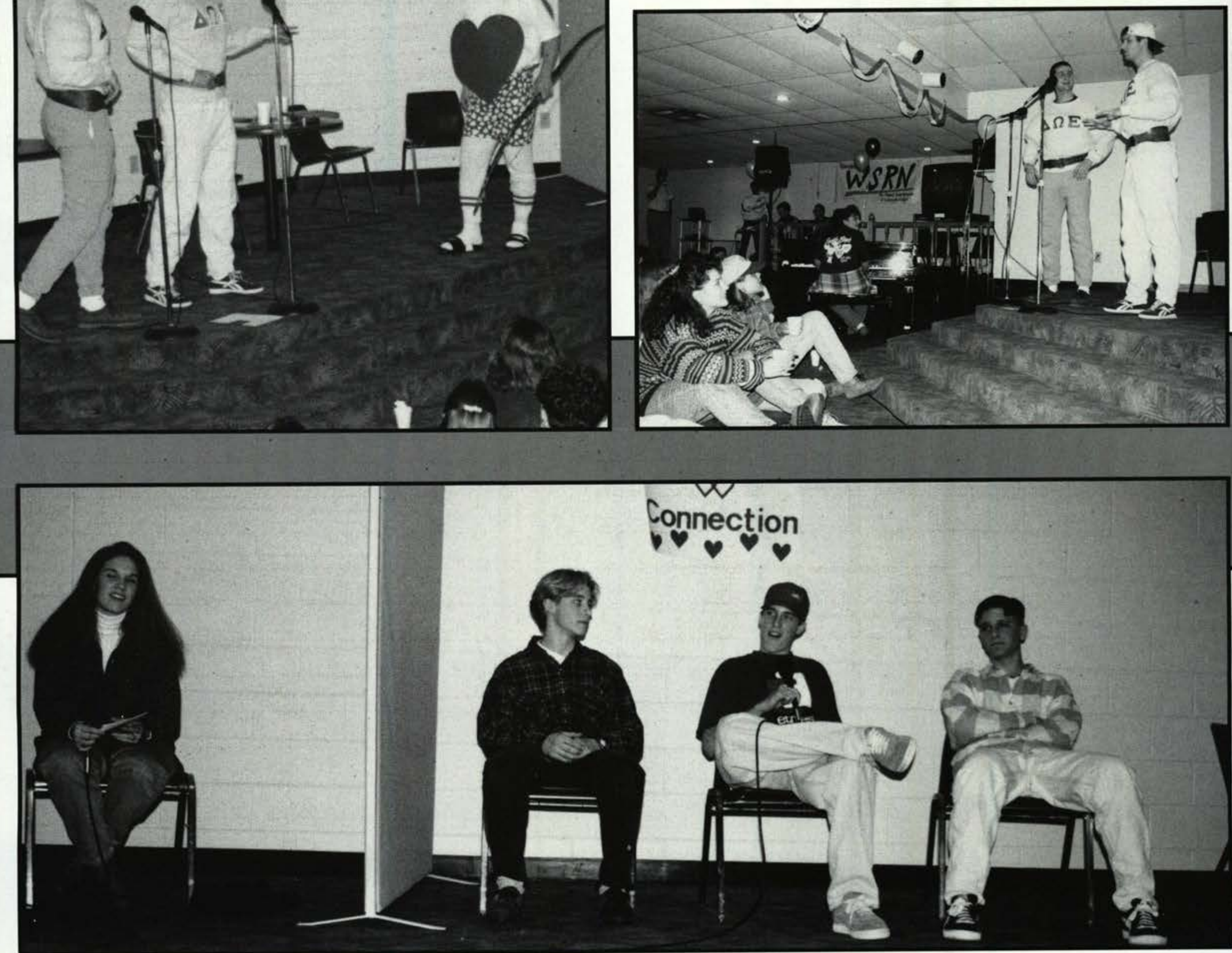

Connection

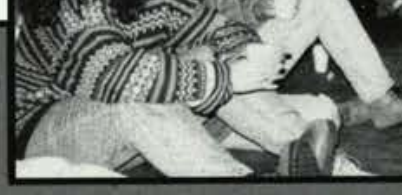

Some li'l sibs get involved in "The Love Connection."

Featuring:

Alpha Delta Omega

$\&$

\section{Delta Omega Epsilon}


Tau Delta Kappa provides an opportunity for fellowship, exchange of ideas, and support of those students enrolled in the Honors Program.

Row 1: Angela Meredith, Dacia Heil, Tiffany Hamilton, Heather Marsceau, Amy Woods, Renee Tuinstra, Natalie Wiewiora. Row 2: Ray Townsend, Nathan Ho, Amy Clark, Tim Flowers, Christina Baley, Jaime Johnson, Tammy Michaels, Tricia Rice. Row 3: Presian Smyers, Jeremy Goetsch, Ben Kanzeg, Doug Amundson, Eric O'Brien, Tami See, Brooke Higgins, Ernest Clark Jr. Not pictured: Josh Hanks.
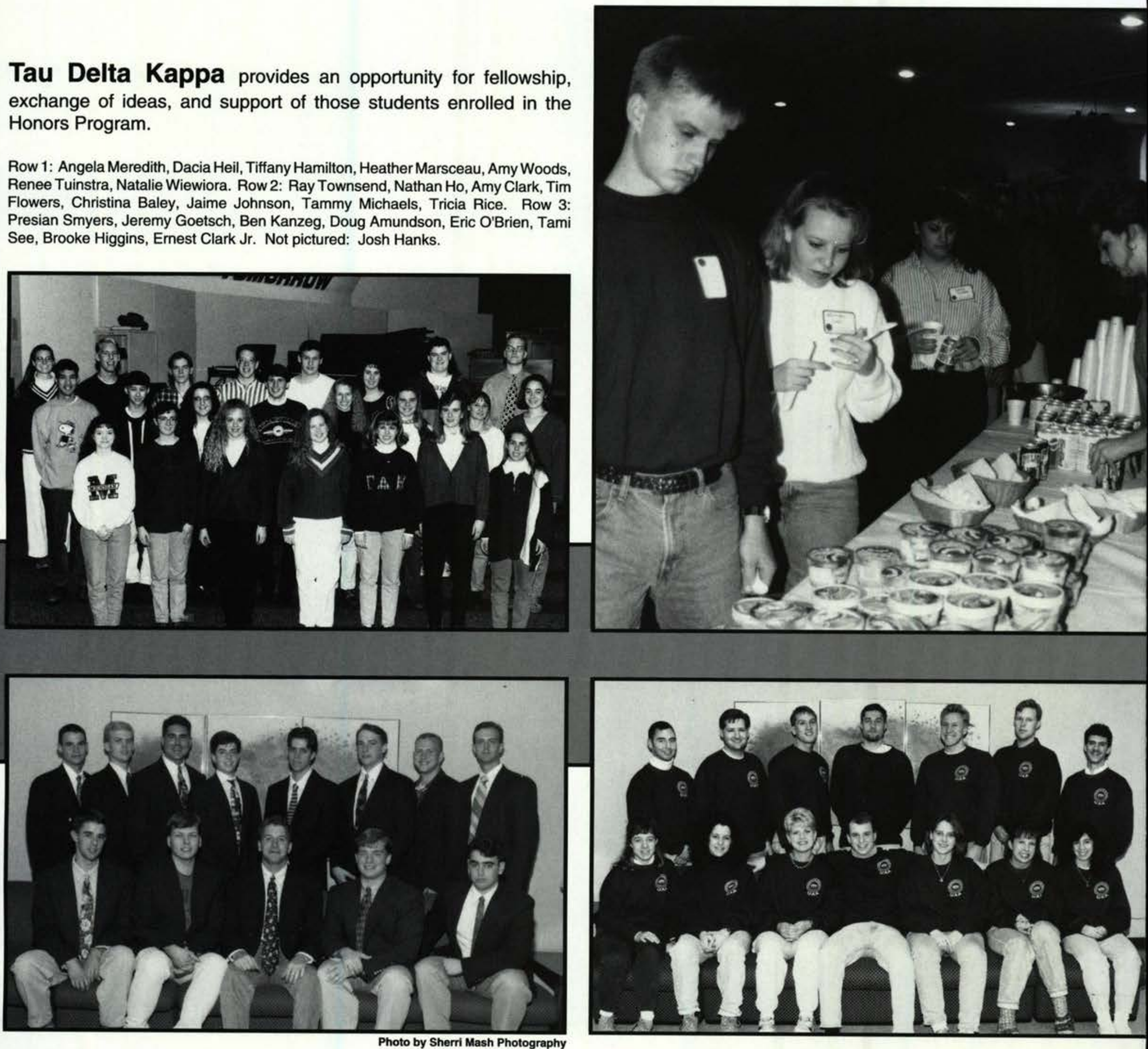

Theta Rho Epsilon (OPE) is a men's organization dedicated to accountability, building friendships, and endeavoring to have a good time.

Row 1: David McMurtry, Dennis Moles, Derek Gesler, Jim Amstutz, Chris Vitarelli. Row 2: Tim Haylett, Brent Luman, Jeff Beste (advisor), Tim Nicklas, David Junkins, Matt Thomas, Brian Burns, John Wambold.

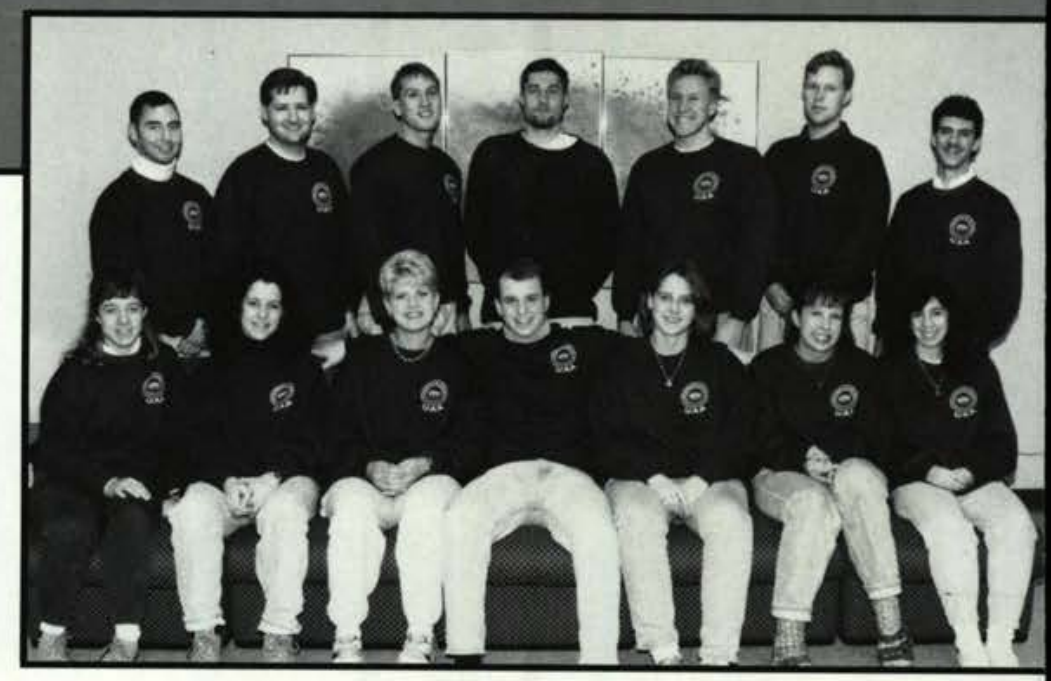

UAA (Undergraduate Alumni Association) assists the CC Alumn Association and office with activities and represents the student bod in the Alumni Association.

Row 1: Ruth Hamilton, Jodie Enterkin, Julie Plunkett, John lamaio, Kara Henry, Maggie Hofmann, Andi Schimmenti. Row 2: Brian Orme, Jeremy Spieth, Nathan Beitler, Davic Geiger, George Haines, Jeff Blackburn, Kerry Anderson. 


\section{Organizational}

\section{Fair '94}

Looking for excitement during fall quarter, many students turned out for the annual orga-

nizational fair. This is an opportunity for all of the organizations to join together and let the student body know what they are all about.

Many of the organizations sponsored some kind of activity in which the students could participate. Some of these included Gladiator fighting, Karaoke, lasso contests and many others. The highlights of the evening seemed to be the trampoline exhibit, Sumo wrestling and the Orbitron. In addition to those activities, there were food, music and caricature drawings. It was easy to see that a lot of work was put into the planning of the fair. From the response of the students, it seemed to be a big success.

Kathy Smart

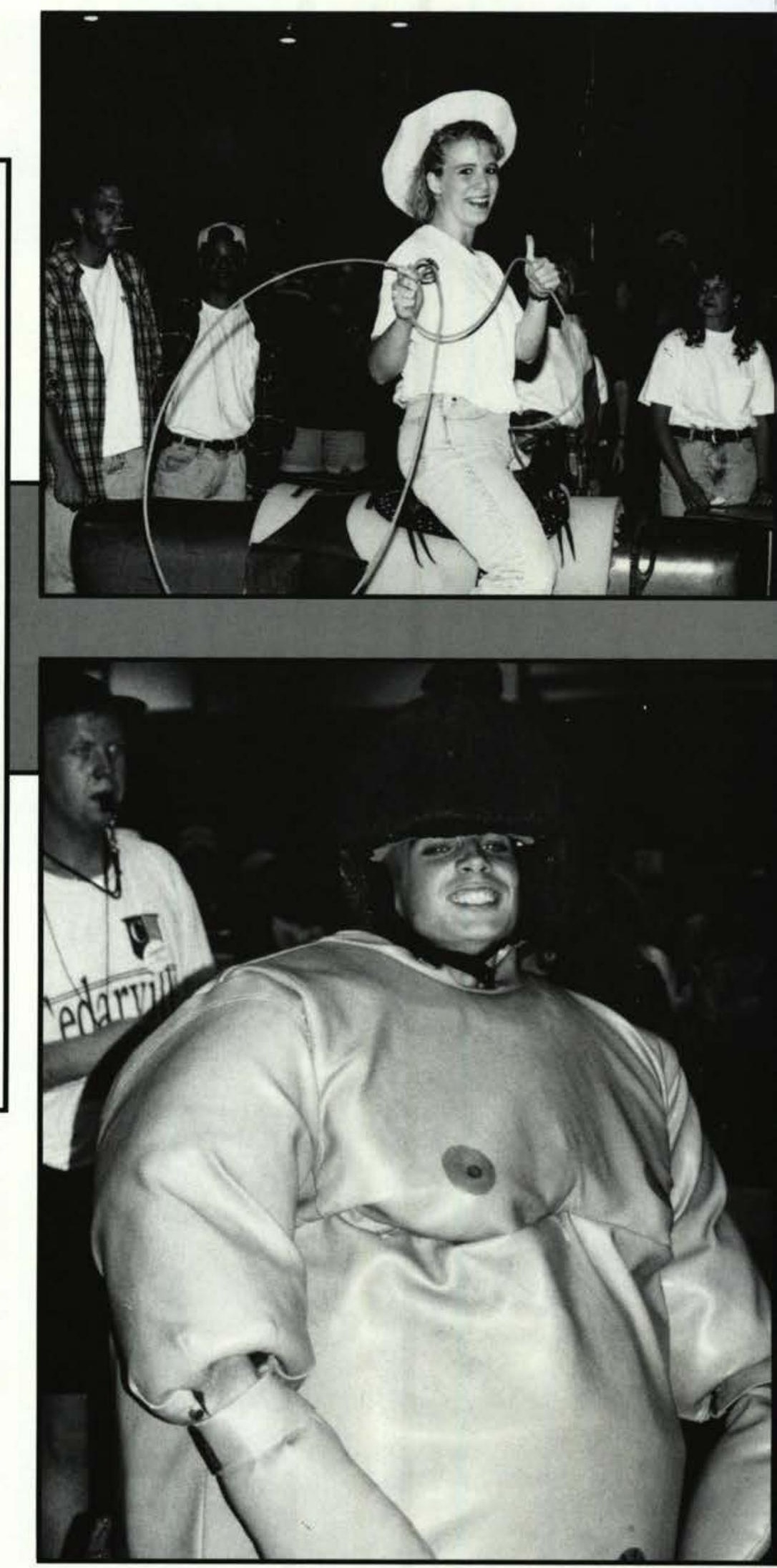



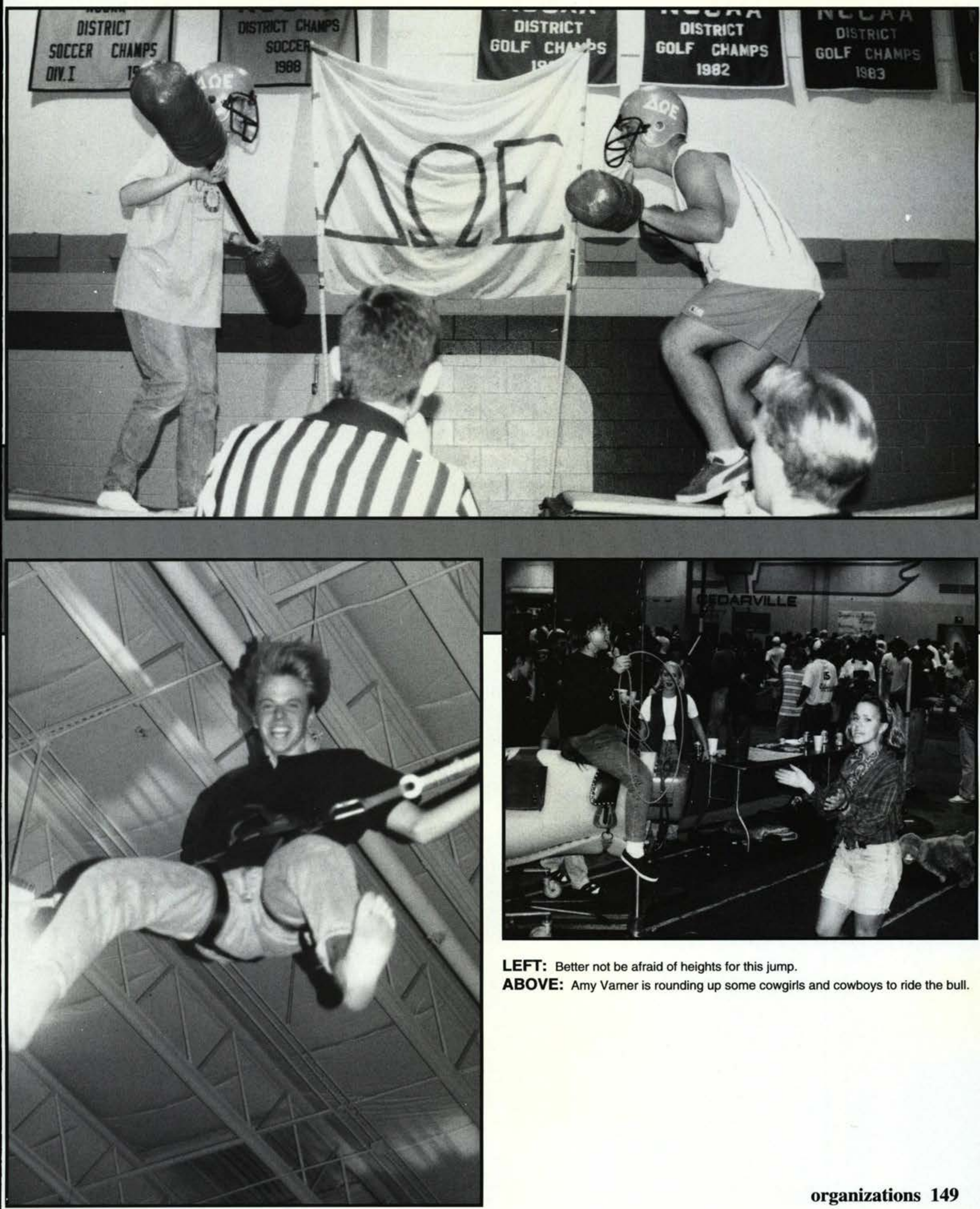

LEFT: Better not be afraid of heights for this jump.

ABOVE: Amy Varner is rounding up some cowgirls and cowboys to ride the bull. 


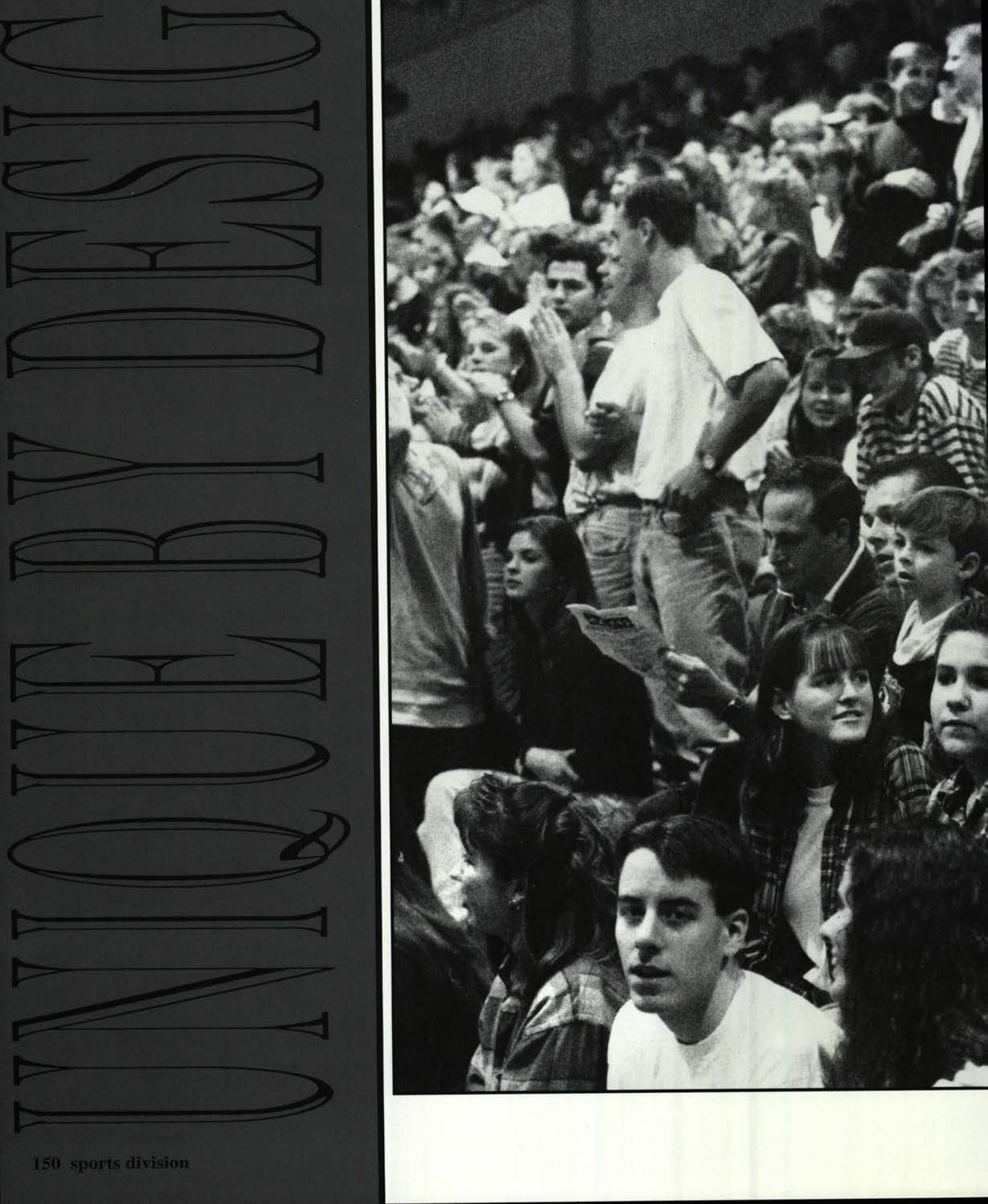




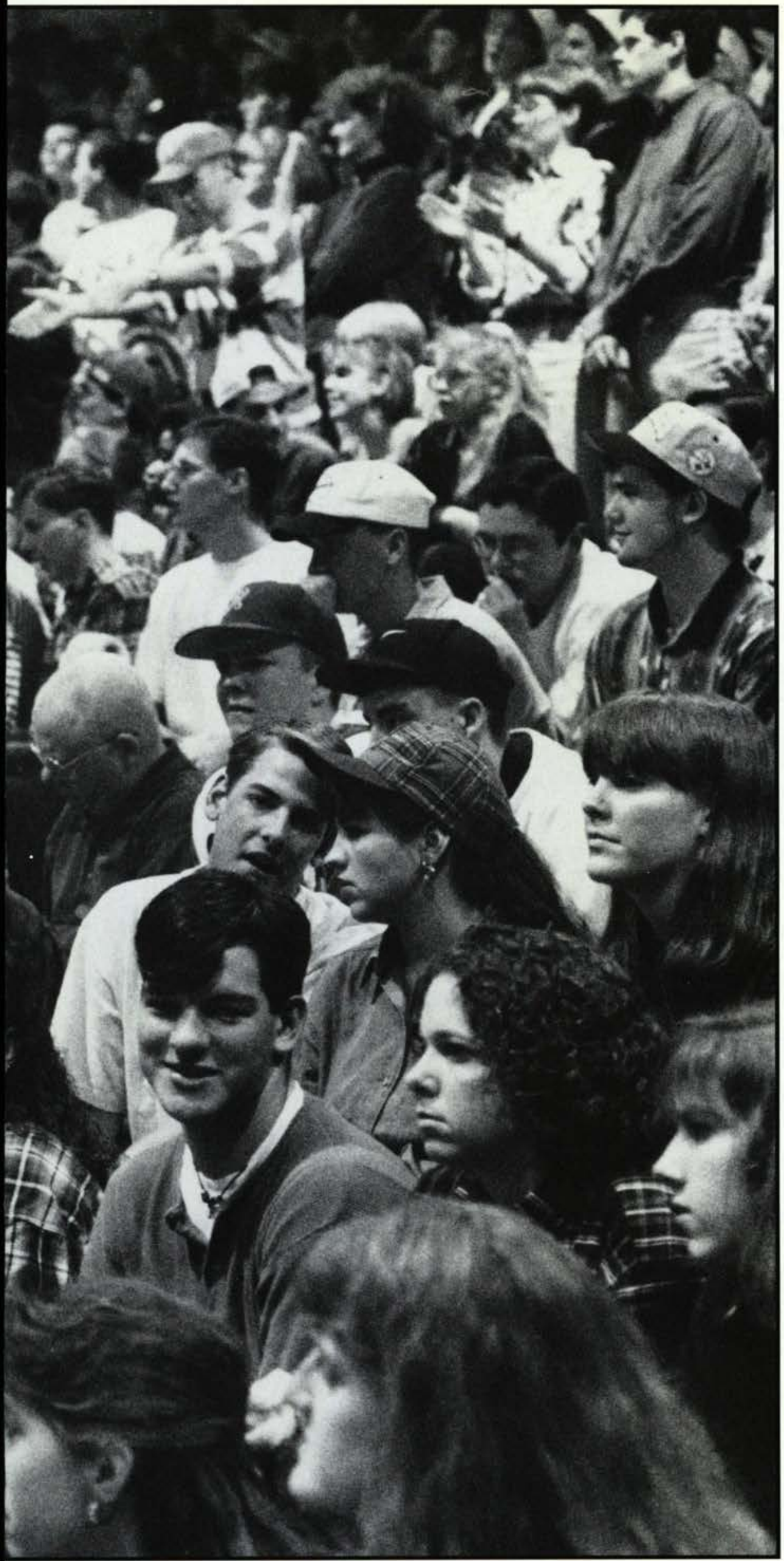

S p o r t s

152 volleyball

154 soccer

156 cross country

158 w. basketball

$160 \mathrm{~m}$. basketball

162 fans

163 spirit

164 pep band

165 club volleyball

166 track and field

168 w. tennis

$170 \mathrm{~m}$. tennis

172 golf

173 trainers

174 softball

176 baseball 
RIGHT: Cheryl Miller jumps up and pulls her arm back for the kill while teammates rush in to cover the block.

BELOW: Lana Hass gets a good

hand on the spike while teammates get down and ready to cover a block return.

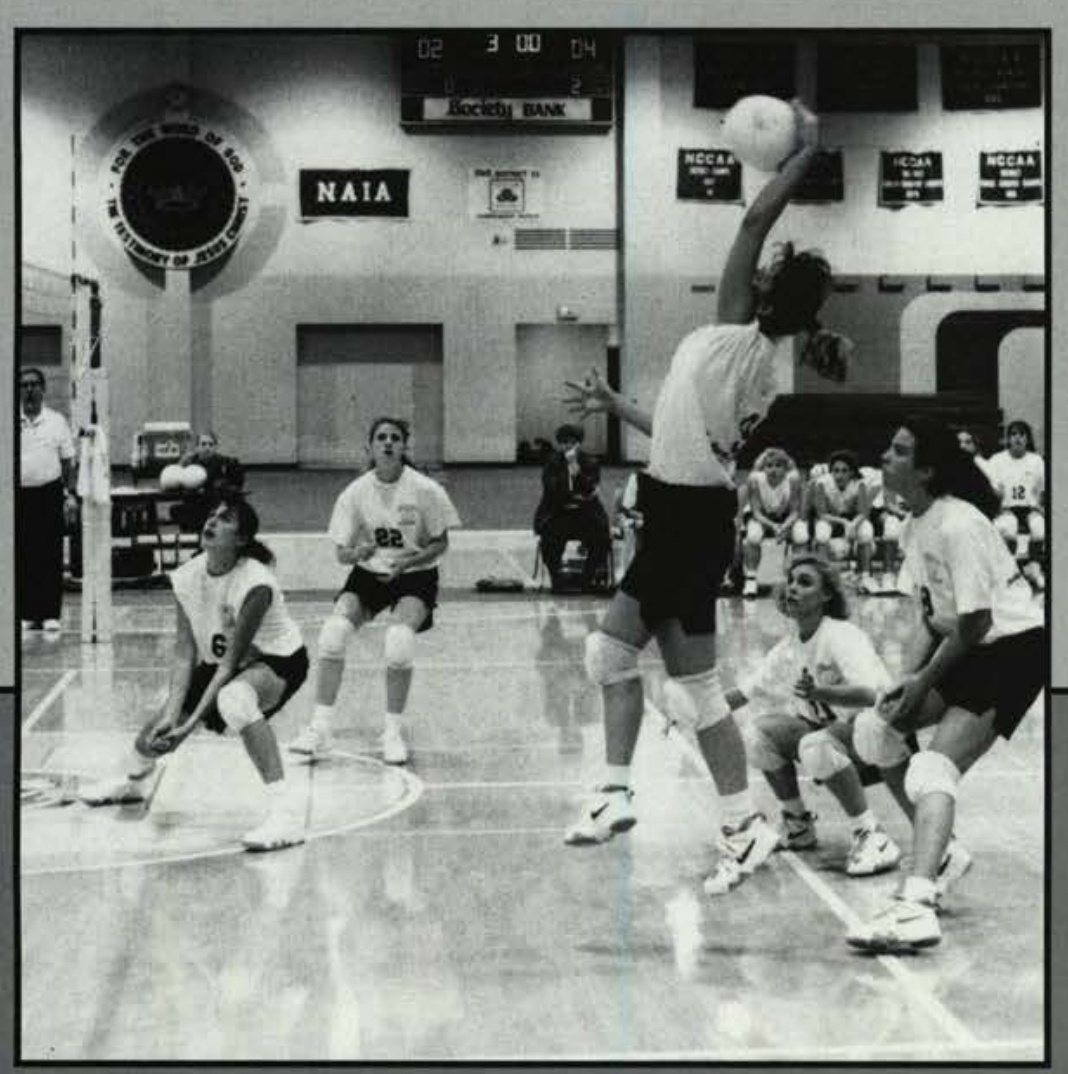

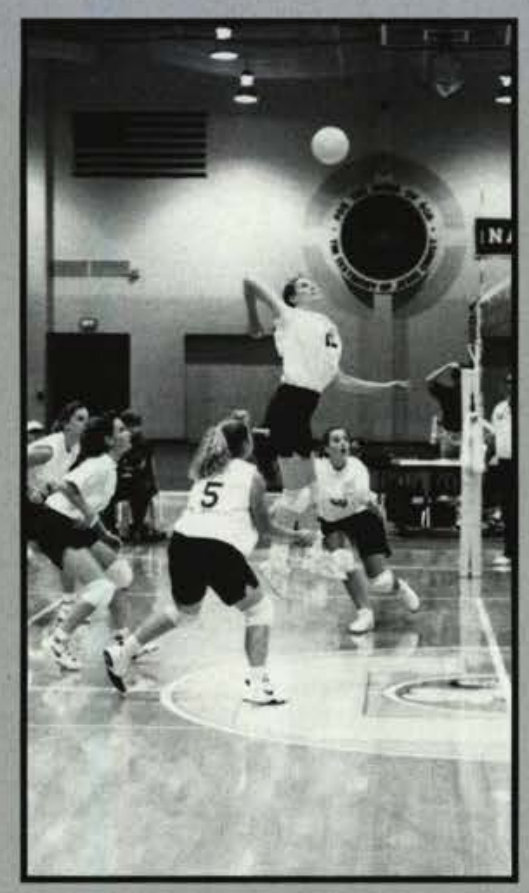

\section{Women's Volleyball Review}

Cedarville College posted its fourth straight winning season in volleyball at 25-21 overall and 7-6 in the Mid-Ohio Conference. Head coach Elaine Brown also picked up her 300 th career victory and completed her 13th season with a 313-241 record.

Junior hitter Cheryl Miller was named to the All-MOC first team after leading the Yellow Jackets with 3.52 kills and a schoolrecord 1.32 blocks per game. Her 115 block assists were also a new school mark, and she became just the second Cedarville player to surpass 1,000 career kills $(1,160)$.

Senior Lana Hass, who still has one year of eligibility left, was also selected to the All-MOC first team. She averaged 3.25 kills and upped her career total to 953 .

Junior Melissa Hartman was an All-MOC second team choice; she was tabbed to the All-NCCAA District III team. She led the squad in assists and became Cedarville's all-time leader in digs with 1,865. Hartman was also named an NAIA All-America Scholar-Athlete which is reserved for those junior and senior student-athletes who carry a minimum 3.50 cumulative grade point average.

Hartman was joined on the NAIA All-America Scholar-Athlete team by junior Laura Huggler. That twosome along with seniors Lori Royal and Cindy Hasselbring was named All-MOC Scholar-Athletes.

Hasselbring, who was playing her first season on the volleyball team and earned a starting role, also completed her fourth year on the cross country team. She set a school record with 16 blocks in just her fourth match of the season.

Hartman was named the team's MVP while Royal was honored as the lone four-year letter winner on the squad. Cedarville made it to the semifinals of the MOC tournament before being eliminated by eventual champion Mt. Vernon Nazarene.

Mark Womack

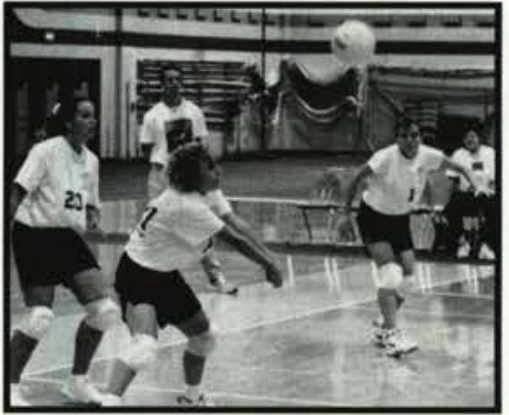

ABOVE: Marcie Duez bumps the ball up while Pam Goodwin and Sarah Jackson head towards Marcie to help out if necessary.

RIGHT: Laura Huggler hustles to bump the ball up to Cindy Hasselbring while Lisa Wierich sets up for a hit.

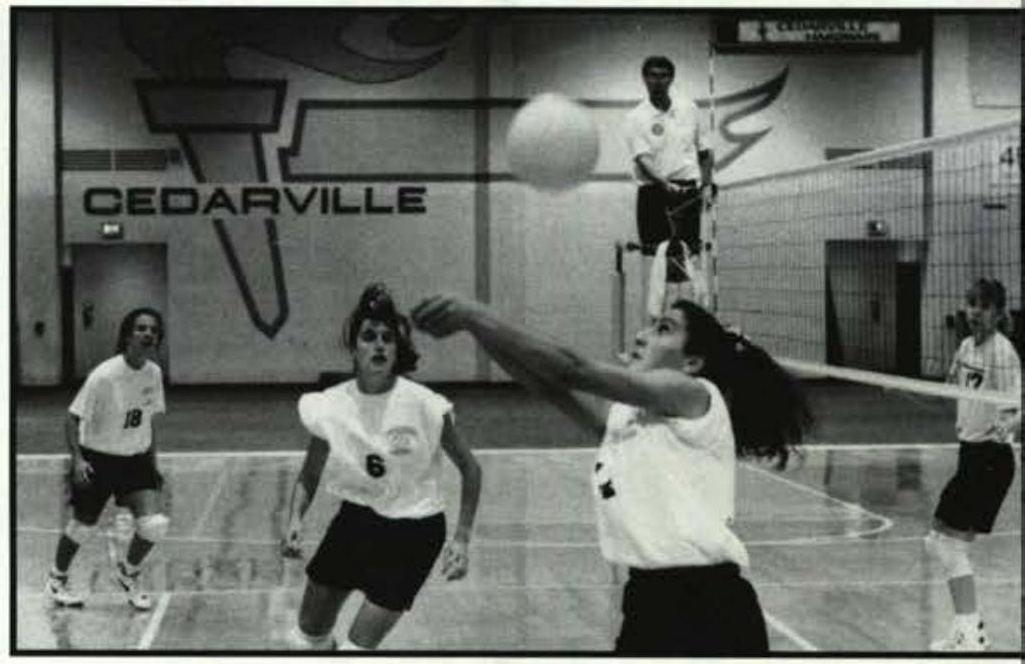


Row 1: Mark Otto, Kyle Schwendemann, Brent Casselman, Dan Lee, Matt Towle, Eric Reini, Andy Stewart, Skippy Gardner, Cliff Scott, David Rooke, Neil Brown, Ryan Mears. Row 2: Asst. Coach Phil Jones, Ellen Burkhard S.T., Ben Nordaas, Scott Vandegrift, Pete Sutton, Steve Lewis, Andy Shaw, Toran Scott, Jason Ostrander, Craig Schaap, Greg Edlund, Travis Coffin, Mike Crawford, Joel Bjerke, Paul Savard S.T., Coach John McGillivray. Row 3: Matt Pileggi, Ben Haffey, Chris Prediger, Bill Workman, Mike Shupp, Nate Auffort, Jason Shaffer, Dan Ruba, Jason Brown, Duane Stutzman, Chad Patterson.
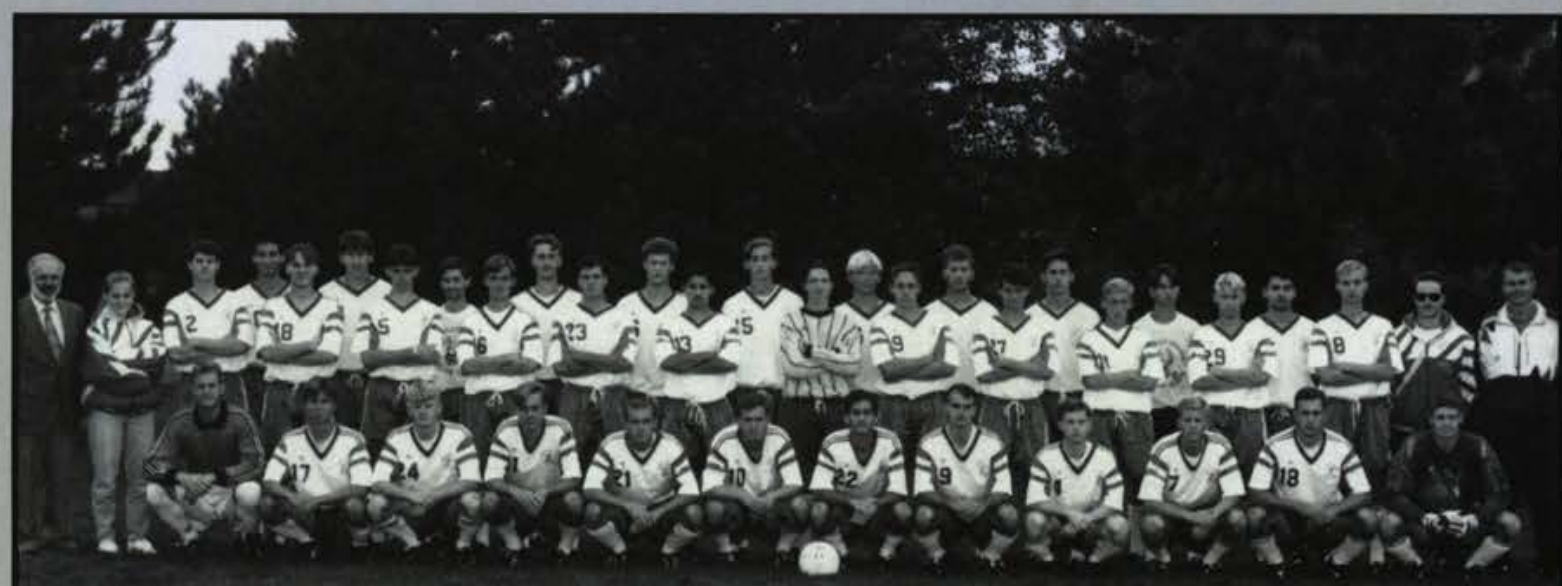

\section{Soccer}

7-9-2

0-4 Denison

1-4 Mt. Vernon Nazarene

2-1 Ohio Dominican

0-3 Tiffin

2-1 Bluffton

0-3 Walsh

0-3 Malone

3-1 Ashland

2-1 Otterbein

1-0 Huntington

1-1 Wilmington (OT)

0-1 Findlay

0-1 Rio Grande

3-0 Shawnee State

0-3 Wittenberg

0-0 Asbury (OT)

4-0 Taylor-Ft. Wayne

0-2 Asbury

RIGHT: Brent Casselman tries to out-maneuver his opponent while Kyle Schwendemann looks on.

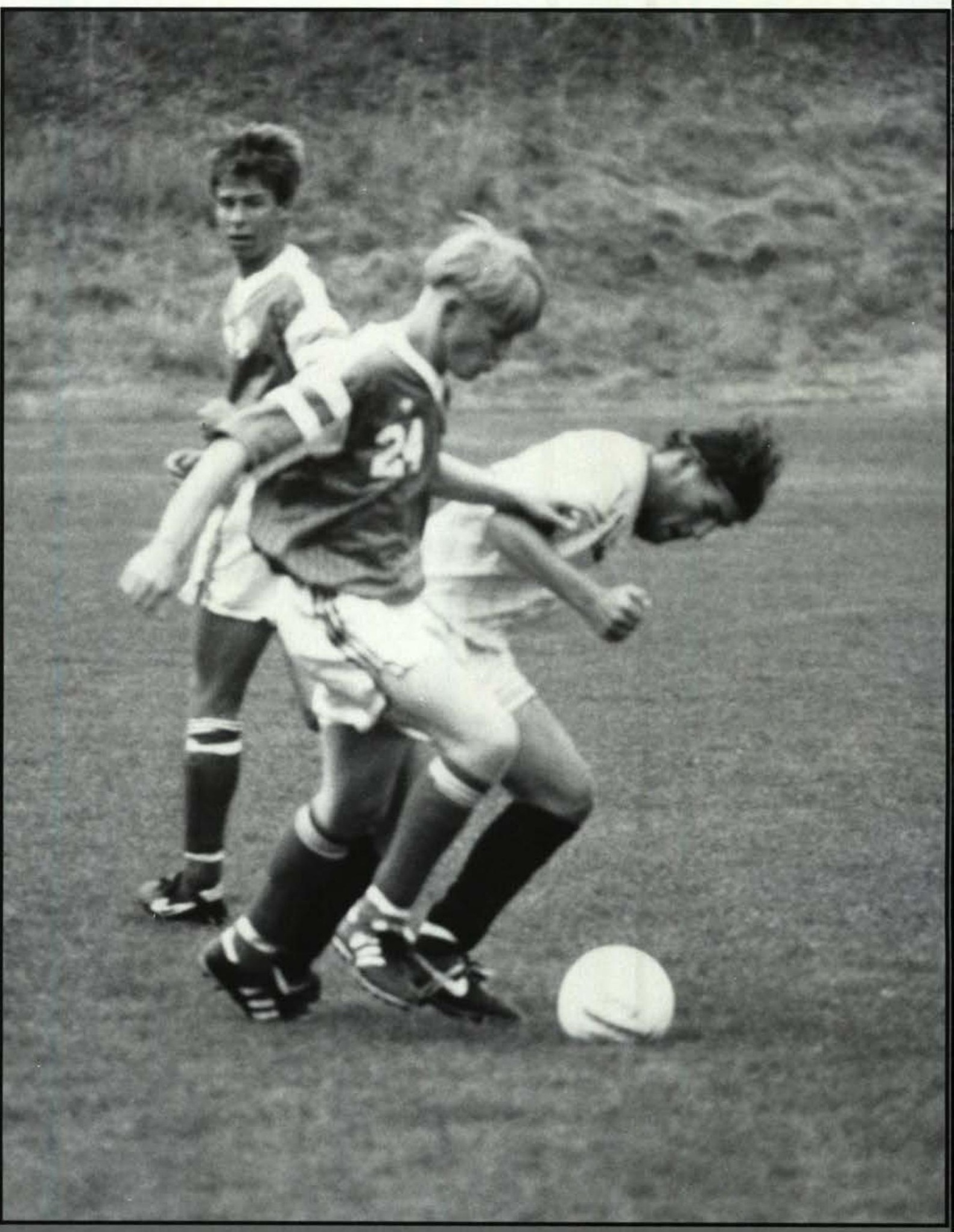




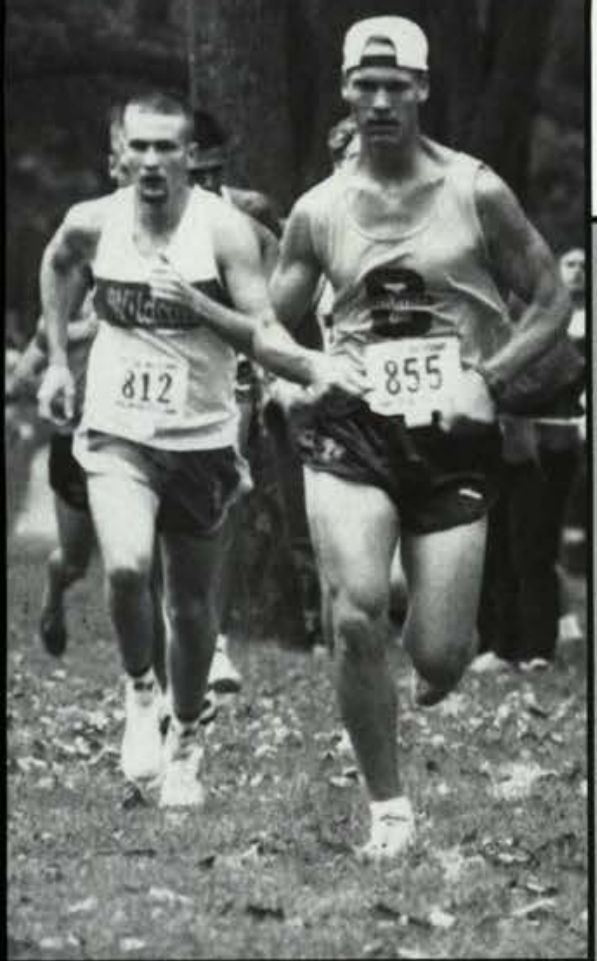

Women's Cross Country

Row 1: Kimberly Bell, Kara Malone, Kari Persons, Rachelle Elder, Julianne Pletcher, Elizabeth Stinson, Wendy Cassidy, Rebecca Jenks, Coach Elvin King. Row 2: Jennifer Zenner, Becky Woelk, Cindy Hasselbring, Laura Boothe. Row 3: Marisa Smith, Heather Cornelius, Edith Steele, Jill Zenner, Michelle Burson. Not pictured: Amy Anderson, Amy Burson, Kristen Frederick. Men's Cross Country

Row 1: Brian Hilty, Chad Eder, David Rea, Peter Simons, Chuck Lyngaas, Andrew Miller, Jason Taylor. Row 2: Coach Elvin King, Eric Crawford, James Persenaire, Josh Bell, Dale McCrory, James Cramer. Not pictured: Joshua Ausfahl, Brad Nelson, DenverSeely.
LEFT: Eric Crawford remains a few steps ahead. BELOW: Chuck Lyngass and David Rea give each other a little competitio at John Bryan Invitational.
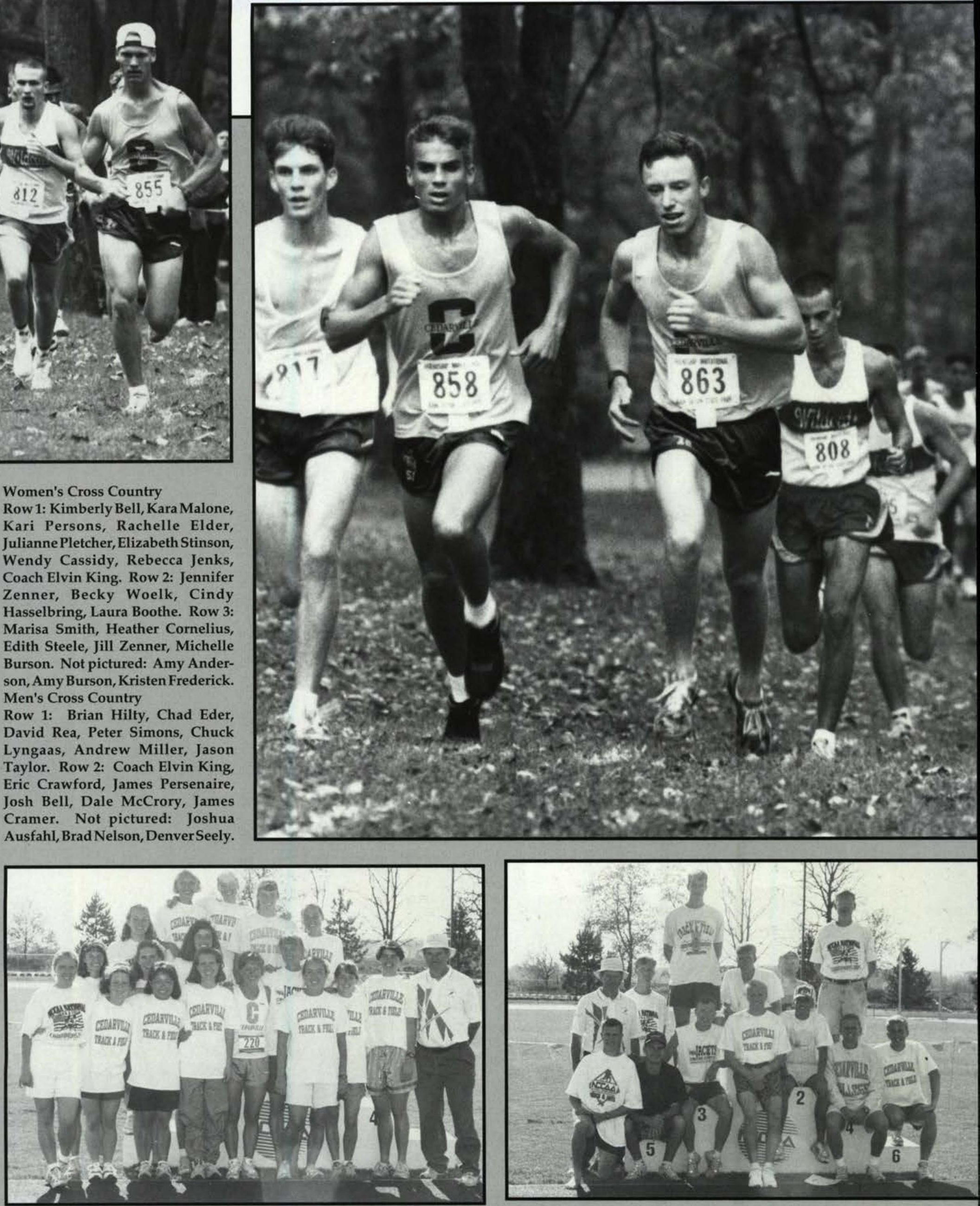


\section{Women's Cross Country Review}

The Cedarville College women's cross country team enjoyed its finest season ever in 1994 which culminated in a ninth-place showing at the NAIA National Championships. The Lady Jackets captured five team titles, including the Mid-OhioConference championship, and placed second at the NCCAA Nationals.

The women were winners in the classroom as well. They had the second-highest team grade point average (3.72) of all 35 teams at the NAIA national meet.

Sophomores Michelle Burson and Julianne Pletcher formed Cedarville's one-two punch from start to finish. They became Cedarville's first-ever NAIA women's cross country All-Americans (Top 30 finishers) as Burson placed 26th and Pletcher was 27 th. They flip-flopped the top two spots at the NCCAA Nationals and Mid-Ohio Conference championships. Burson took the NCCAA title while Pletcher copped the MOC crown which was the only time Burson did not finish as the team's top runner during the season.

The sophomore duo each ran their fastest times of the season at the NCCAA national meet which was staged in Rochester, New York. Burson toured the 5,000 meters in 18:31 while Pletcher finished in 18:35. They were joined by three other teammates on the All-America squad (Top 15 finishers). Senior Jennifer Zenner was ninth, junior Heather Cornelius placed 12th, while freshman Becca Jenks was 14th. Sophomores Kara Malone and Jill Zenner rounded out the team's top seven runners.

Jennifer Zenner earned spots on the NAIA and NCCAA AllAmerica Scholar-Athlete teams for the second consecutive year. Members of the team are juniors or seniors who carry a minimum cumulative $3.50 \mathrm{GPA}$ and make a solid contribution to the varsity team. Zenner also garnered the coveted Wheeler Award as the NCCAA's outstanding female cross country Athlete of the Year.

Besides winning the MOC title, Cedarville picked up team invitational championships at Asbury, KY; their own Friendship Invitational; Goshen, IN; and Gettysburg, PA. Head coach Elvin King was tabbed MOC Coach of the Year.

\section{Men's Cross Country Review}

Cedarville College experienced a rebuilding year in men's cross country but still flirted with making the NAIA Top 25 . Five sophomores and six freshmen were part of the 15-man roster.

Pete Simons, the lone senior on the squad, was the team's captain and top runner. He set the pace for the Yellow Jackets in every meet and even came away with two individual titles.

Simons' best outing came at Gettysburg, PA where he outran 219 other competitors by completing the 8,000 meters in $24: 31$. He also won the Goshen Invitational, placed second in the MidOhio Conference meet, plus earned NCCAA All-America honors by finishing fourth as the Jackets placed third as a team.

Two Yellow Jacket newcomers, Chuck Lyngaas and Eric Crawford, also gained NCCAA All-America status. Lyngaas placed ninth overall while Crawford was 13th.

Others to contribute on the men's varsity were freshman David Rea, sophomores Andrew Miller and Josh Bell, and junior Jason Taylor. The Yellow Jackets' lone team title came at Goshen and they finished third in four other meets.

Mark Womack
BOTTOM: Cindy Hasselbring appears to be alone in the race,or else she is just so far ahead of the rest. BELOW: Kara Malone keeps up with the pack.
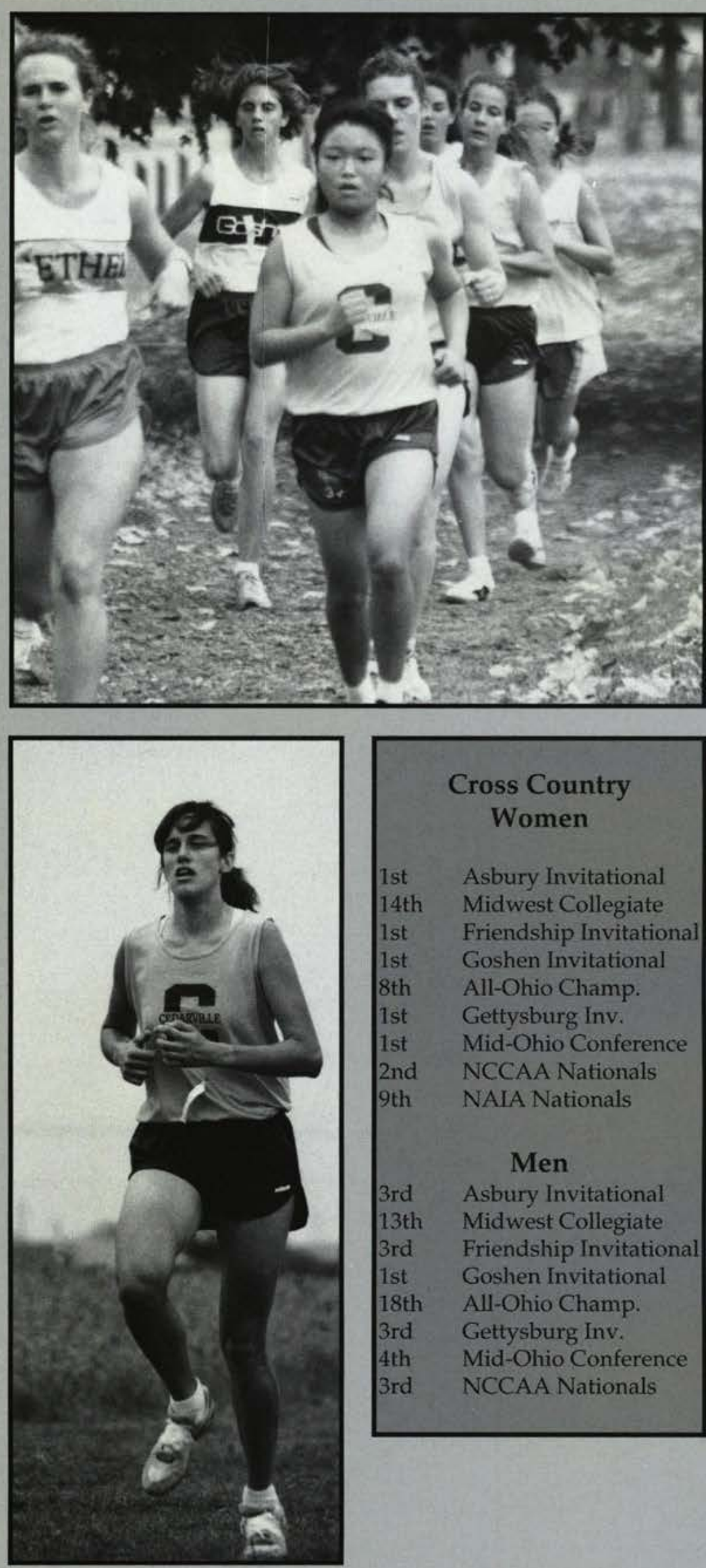

\section{Cross Country} Women

Asbury Invitationa Friendship Invitational Goshen Invitational All-Ohio Champ. Gettysburg Inv. Mid-Ohio Conference NCCAA Nationals NAIA Nationals

Men

Asbury Invitational Midwest Collegiate Friendship Invitational Goshen Invitational All-Ohio Champ.

Gettysburg Inv. Mid-Ohio Conference NCCAA Nationals Midwest Collegiate 


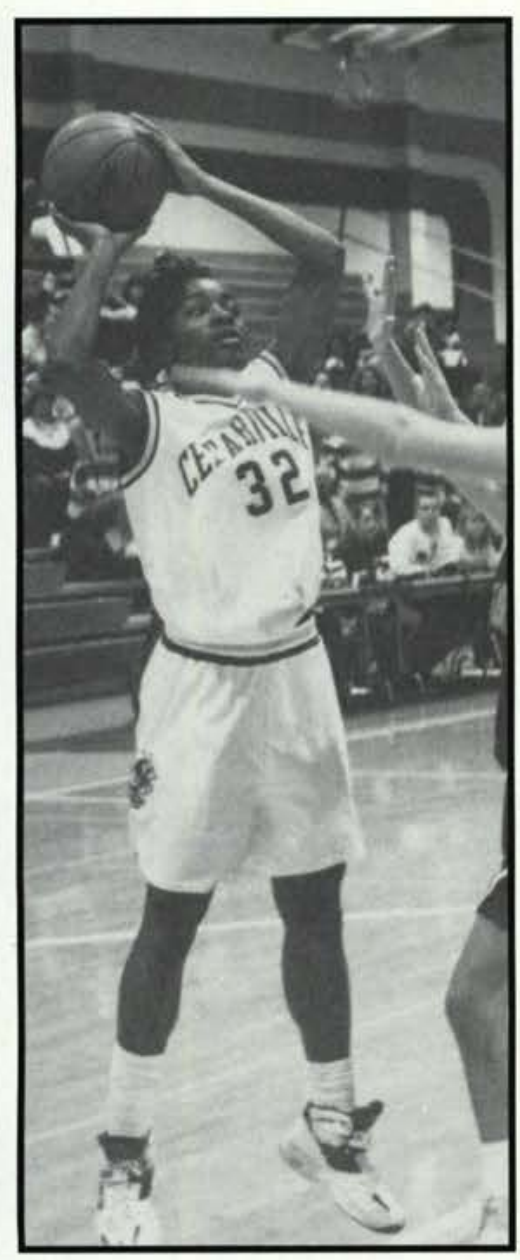

\section{W. Basketball}

20-11

54-70 Georgetown Col.

79-77 Transylvania Univ.

70-65 Taylor University

55-68 Mount St. Joseph

Concordia Classic

86-62 Wilmington College

86-56 Walsh University

79-70 Univ. of Rio Grande

59-44 Bluffton College

66-78 Tiffin University

65-45 Urbana University

64-53 Ohio Dominican

77-71 Mt. Vernon Naz.

76-82 Shawnee State

72-66 Malone College

54-83 Univ. of Findlay

62-50 Urbana University

71-63 Walsh University

67-63 Tiffin University

72-87 Univ. of Rio Grande

79-69 Ohio Dominican

77-76 Shawnee State

77-54 Mt. Vernon Naz.

59-44 Malone College

54-78 Univ. of Findlay MOC/NAIA Div. II NCCAA National

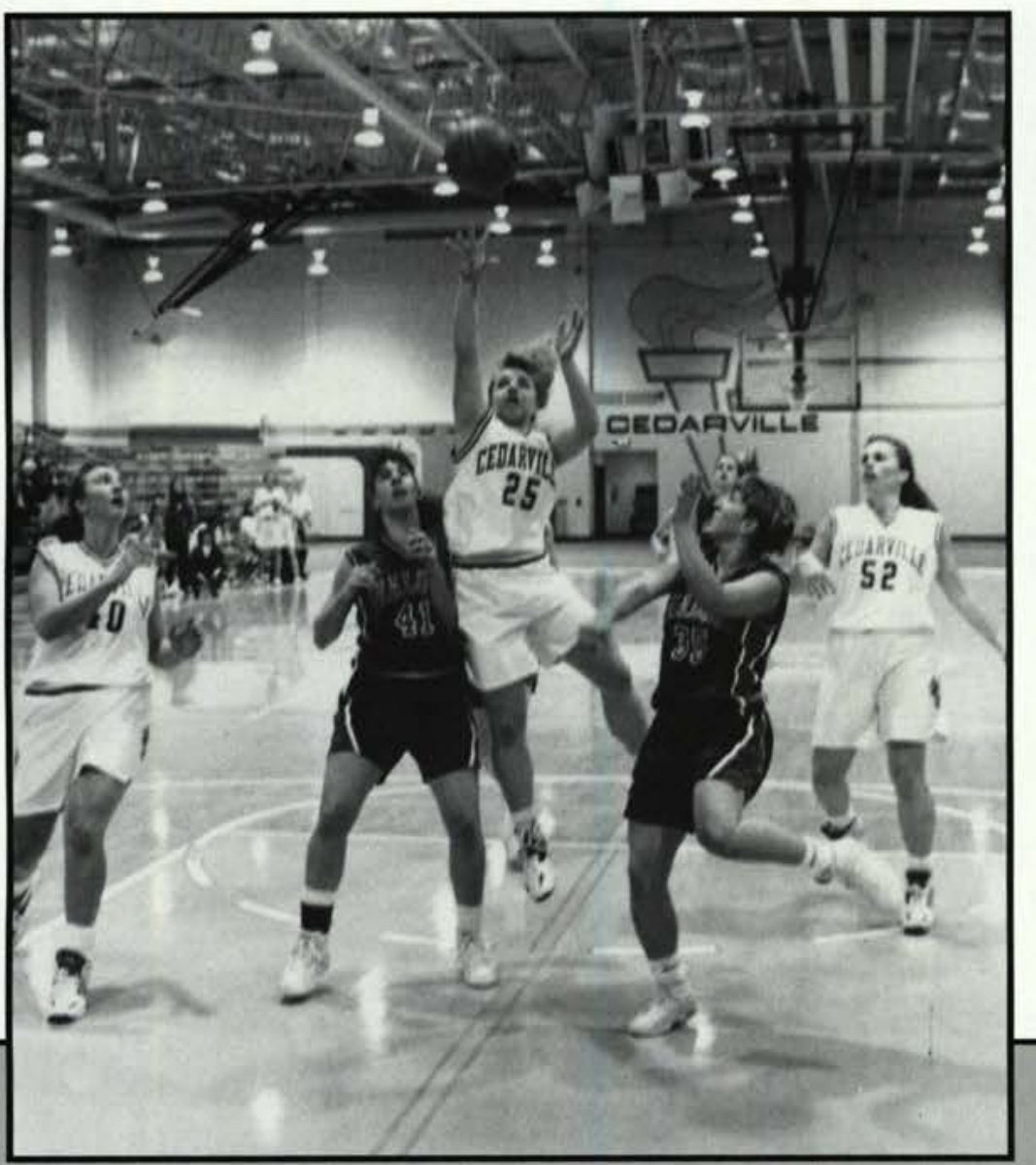

TOP: Shaundra Randolph goes up for the shot despite the hands in her face.

ABOVE: Melissa Hartman goes up hard against two opponents while Christine Copeland and Amy Bathrick come up for the rebound.

\section{4-95 Women's Basketball Review}

The Cedarville College women's basketball team put together one of the finest seasons in the program's history. The Lady Jackets matched a school record for victories in a season, advanced to the National Christian College Athletic Association tournament, and placed third in the tough ten-team MidOhio Conference behind two nationally ranked teams.

"I knew at the beginning of the season that we would do quite well," said Kathy Freese, who was voted MOC Coach of the Year. "The kids finally pulled together and that was the key. We had a close knit group, and we were real thrilled with how the season turned out."

The women weren't sure what to expect since their top scorer from the previous season did not return. But they rolled to a 20-11 overall record and a 13-5 mark in the MOC. The wins matched the effort of the 1988-89 club that was 20-10, and the conference record trailed only Findlay and Shawnee State, who at one time or another were each ranked No. 1 in the country in NAIA Division II.

Cedarville registered some impressive wins, but the highlight of the campaign came on February 9 when the Jackets upset Shawnee State 77-76 in the Athletic Center. The Bears came in ranked No. 3 and scored the first eight points of the game. However, Cedarville ran off an incredible 25 straight points and never trailed the rest of the way.

After being eliminated from the MOC/NAIA Division II Tournament, the Jackets accepted a bid to play in the NCCAA Nationals in Rochester, NY. Cedarville, seeded third in the eight-team field, opened with a 74-60 win over Judson College, (IIlinois). Eventual champion Western Baptist (Oregon) pulled out a 65-61 win in the semifinals over the Jackets, and then the women dropped the consolation game to top seed Indiana Wesleyan, 75-69.

Junior guard Melissa Hartman stepped up her game in the second half of the season and led the team in scoring at 14.2 points per game. She also set a school record from the free throw line by shooting 82.5 percent, she matched her school mark with 39 three-pointers, and she was tops in assists with 108. Hartman was named to the NCCAA All-America Second Team and to the MOC First Team.

Hartman, who was an NAIA and NCCAA All-America Scholar-Athlete, moved into fifth place on the Lady Jackets' all-time scoring list with 1,183 points. She is already the program's career leader in three-point field goals (109), assists (329), and steals (208). Her .766 career free throw accuracy is also ahead of the current school record of .725 .

Senior forward Christine Copeland closed out her career with 855 points and 908 rebounds. She ranked third on the team in scoring (11.3) and was first in rebounding (9.6). Copeland was recognized as a NCCAA All-America First Team performer and was also tabbed to the All-MOC First Team.

The other double figure scorer was junior Cindy Cremeans who averaged 13.0 points after transferring to Cedarville from the University of Findlay. She led the team in field goal percentage (.508) and averaged 16.0 points in the three NCCAA games while being named to the NCCAA All-Tournament Team.

Shaundra Randolph was the other senior on the team and was a co-captain. She started three times, averaged 5.5 points and 5.5 rebounds per game and was named to the NAIA and NCCAA All-America Scholar-Athlete teams for the second 
() 1 คी

- 으용

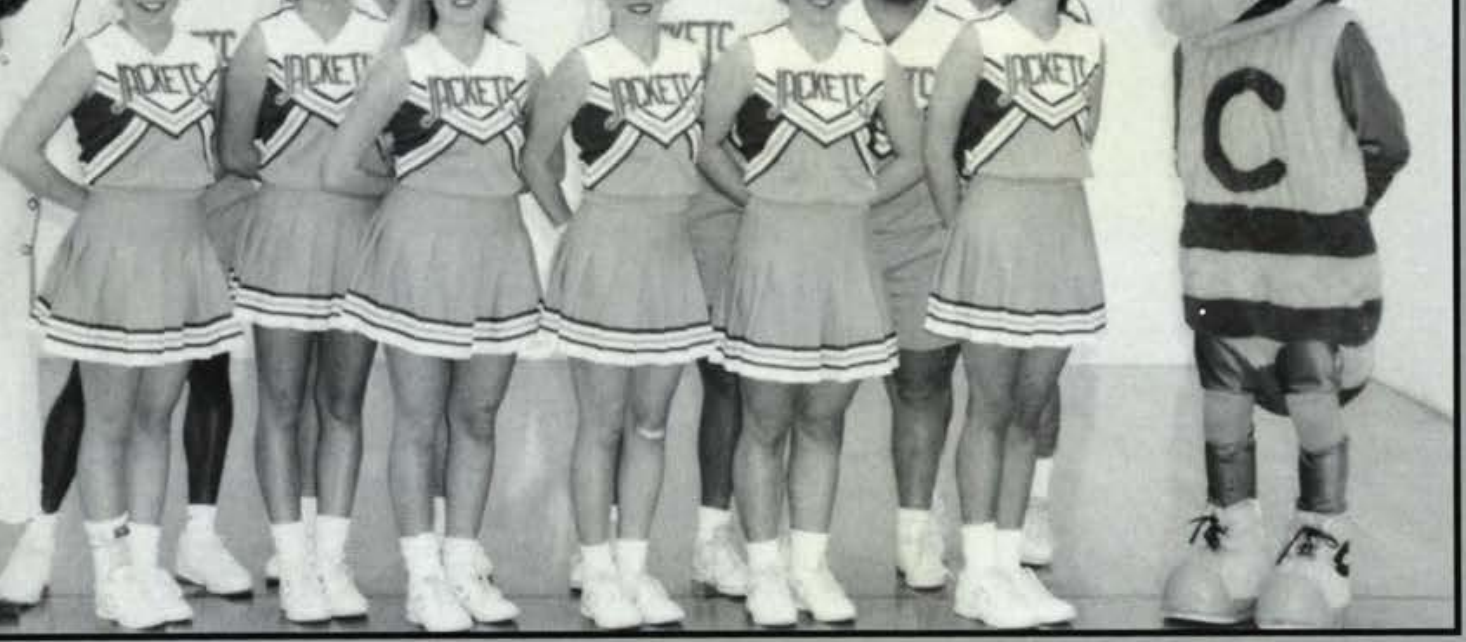

5 
Flute: Amy Awabdy, Vanessa Bateman, Jennifer Bradley, Tina Braley, Jason Brown, Saranne Bryan, JoHanna Bryer Wendy Camp, Colette Cassidy, Lori Cobb, Elise Cook, Kimberly Dorsey, Traci Durham, Kristi Gleason, Jennifer Gordey, Kelly Hager, Jennifer Henry, Renee Hiebert, Thile Holloway, Becky Ivey, Lisa Keever Libby Kennedy, Stephanie Kirk, Amy McDevitt, Patricia Noble, Janine Pinkley, Amy Powley, Shari Read, Kendra Risser, Rebekah Sorensen, Brooke Spieth, Renee Tunistra Clarinet: Melissa Armitage, Ryche Brickel, Heidi Comers, C. Dabravalskas, Cheryl Emmert, Nathan Hart, Susan Hunsaker, Kim Koziol, Karisa Linafelter, Kim Maynard, Stephanie Mead, Stephanie Moody, Brenda Royer, Lesley Shover, Rachel Soderstrom, Jeremy Spieth, Christina Stauffer, Kathy Streicker, Kris Thornsen, Stephanie Weldy, Jodi Whims, Meredith Wylie. Saxophone: Dave Arthur, Brooke Higgins, Chet Jenkins, Brenda Johnson, Jerami King, Tom Leightenheimer, Brian McGuinness, Will Orser, Persian Smyers, Jason Taylor, Jeremy Toyer, Jason Vasquez, Chad Wingert., French Horn: Jaime Bedford, Melody Brickel, Renee Brown. Trumpet: Israel Barr, Eric Bickel, Michelle Boehm, Jeff Brown, Phil

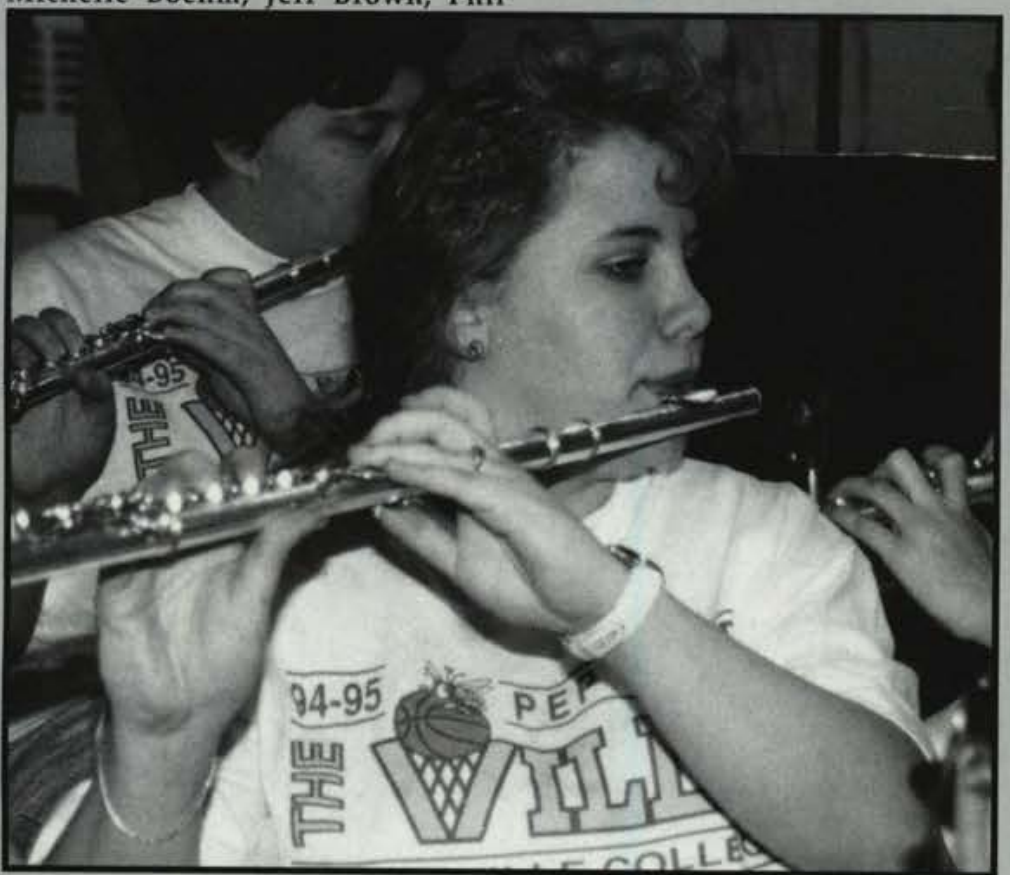

Pep Band, Pep Band, what'd ya say

We back the Jackets all the way! From the piccolos down to the tubas, all 140 members of this diverse group choose to back the Jackets at every home game. Under the direction of Mr. Mike DiCuirciand his assistants, Dr.Jim Colman and Dr. Kevin Sims, the band hoots, hollers, and plays its heart out keeping the crowd and team in good spirits. "Playing in the band causes such a rush of adrenaline!" says fifth-year senior, Jamie Potter. Even visitors notice the spice that the band adds to the whole atmosphere of the game. The fans love the music the pep band plays. There are oldies, pop music, and even an occasional rendition of "Rocky Top" for Dr. Dixon. It gives everyone a chance to jump, sing, dan ${ }_{-}$, and have a good time. Even the cheerleaders use the pep band sounds to entertain the crowd. The games just wouldn't be the same without that blaring, harmonious mixture coming from the west end of thegym, known as the pep band.

Bill Workman
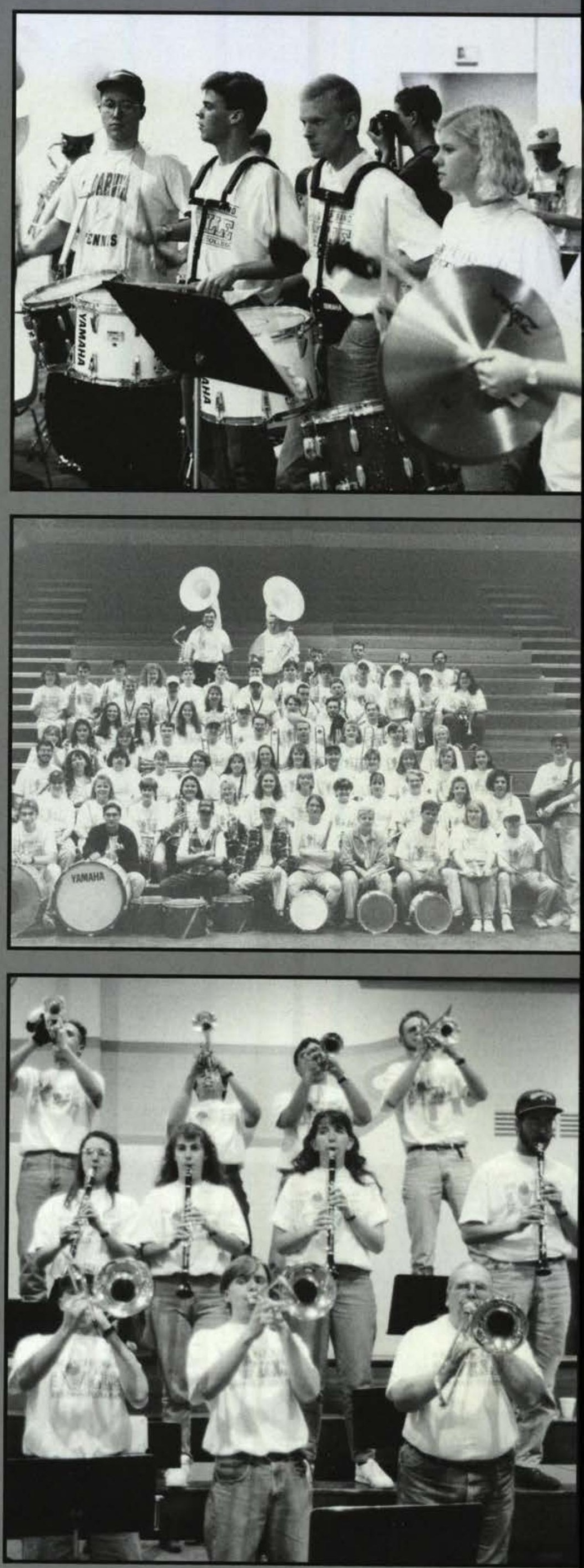
RIGHT: Sarah Jackson measures another long jump, at the indoor track meet.

BELOW: Teammates time each other and encourage them as they near the finish line.
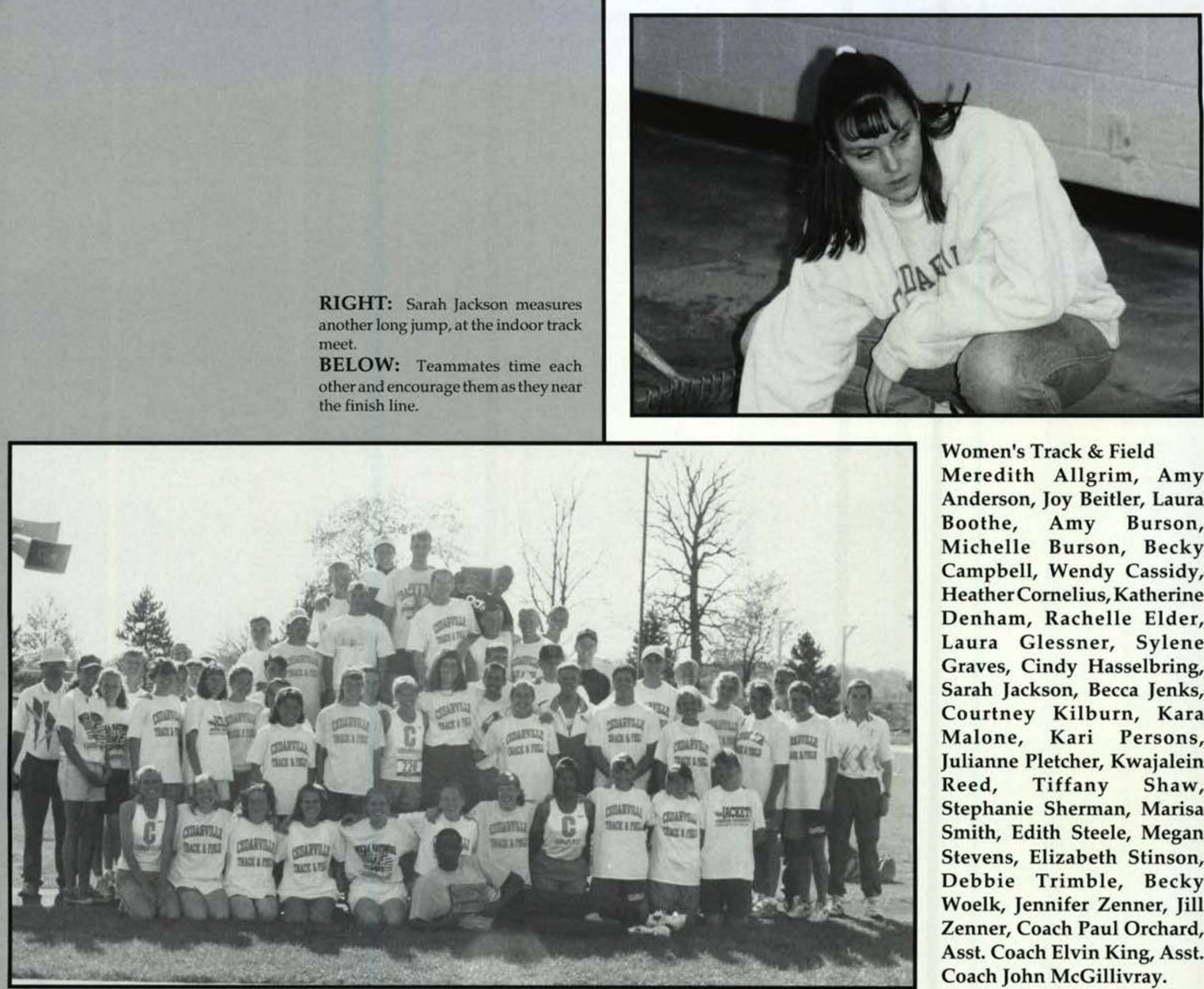

Women's Track \& Field

Meredith Allgrim, Amy Anderson, Joy Beitler, Laura Boothe, Amy Burson, Michelle Burson, Becky Campbell, Wendy Cassidy, Heather Cornelius, Katherine Denham, Rachelle Elder, Laura Glessner, Sylene Graves, Cindy Hasselbring, Sarah Jackson, Becca Jenks, Courtney Kilburn, Kara Malone, Kari Persons, Julianne Pletcher, Kwajalein Reed, Tiffany Shaw, Stephanie Sherman, Marisa Smith, Edith Steele, Megan Stevens, Elizabeth Stinson, Debbie Trimble, Becky Woelk, Jennifer Zenner, Jill Zenner, Coach Paul Orchard, Asst. Coach Elvin King, Asst. Coach John McGillivray.

Track \& Field
Women

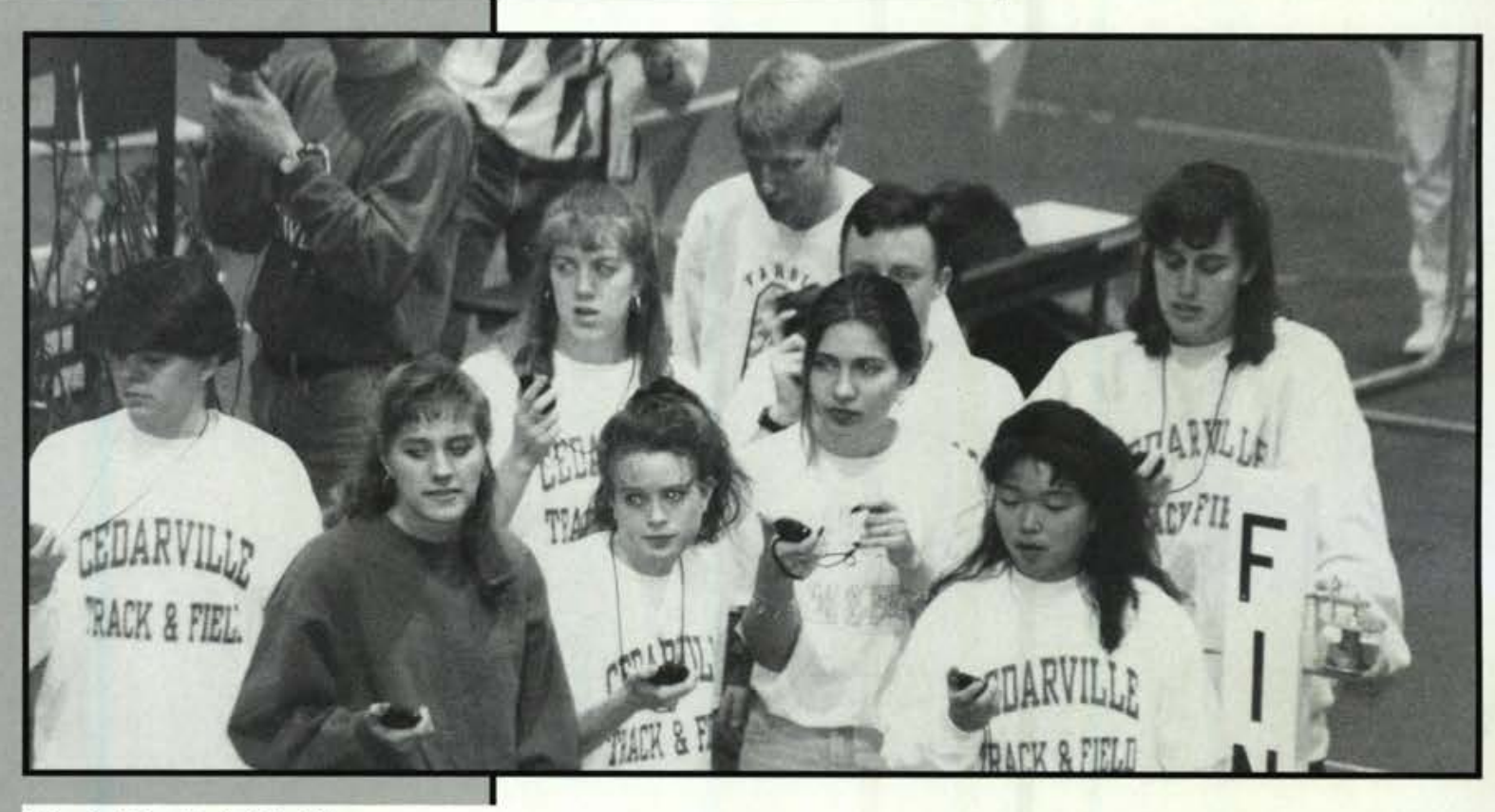

Men's Track \& Field

Doug Amundson, Joshua Ausfahl, Steve Barr, Matthew Beck, Josh Bell, Kevin Conkel, Jim Cramer, Eric Crawford, Chad Eder, Jeff Hill, Brian Hilty, Nathan Houk, Daniel Hudson, Dustin Hughes, Greg Johnson, Jason Kandel, Chuck Lyngaas, Chris Melkonian, Andy Miller, James Persenaire, Jon Plush, Bobby Polack, David Rea, Denver Seely, Peter Simons, David Swasey, Jason Taylor, Coach Paul Orchard, Asst. Coach Elvin King, Asst. Coach John McGillivray. 

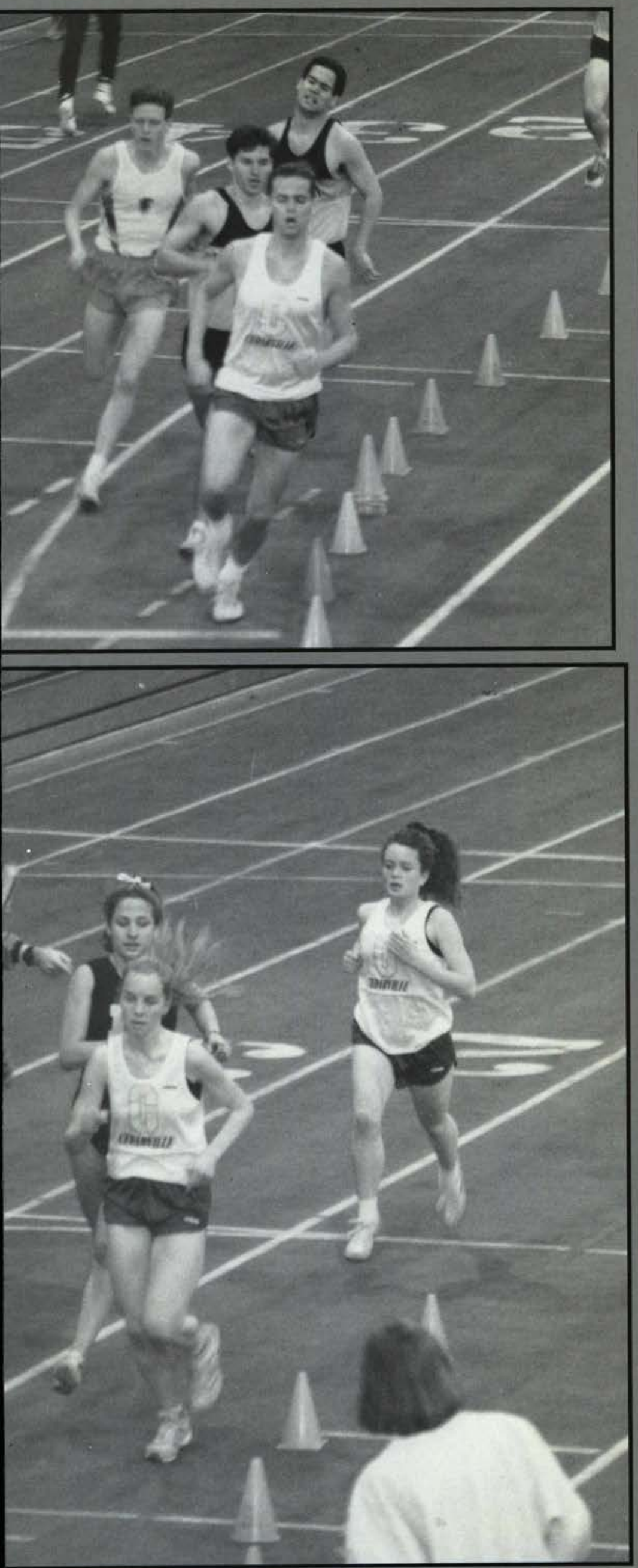

\section{Track and Field Review}

Cedarville College successfully defended its National Christian College Athletic Association women's track and field title, plus the Yellow Jackets had seven NAIA All-Americans to highlight the 1995 outdoor season. The Lady Jackets won the NCCAA banner for the fourth time by blowing away the field by 120 points on the home track. The women also won back-to-back titles in 1985 and 1986. For the second consecutive year, the Yellow Jacket men finished second in the NCCAA.

The season brought to a close the record-setting career of Stephanie Sherman. The Watertown, New York native was the NAIA Outdoor Triple Jump National Champion for the second time and broke her own school record in the process with a 42foot effort on her final jump. Sherman leaves the Lady Jackets program as a ten-time NAIA All-American.

Joy Beitler was sixth in the high jump, and Julianne Pletcher finished sixth in the 10,000 meter run as both earned NAIA AllAmerican honors (top six finishers). On the men's side, Chad Eder was second in the 5,000 meter race walk, Kevin Conkel was fifth in the marathon, Bobby Polack was fifth in the triple jump, and Pete Simons placed fifth in the 3,000 meter steeplechase.

Sherman was named the Outstanding Female Performer of the NCCAA meet after winning three individual events and being part of both winning relay teams. A ten-time NCCAA champion, she broke her own meet record in the triple jump at 38-feet and 5-inches to go along with victories in the long jump and 100 meter hurdles.

Paul Orchard was voted NCCAA Women's Coach of the Year, and senior, Jennifer Zenner, was presented the Wheeler Award as the outstanding female track and field Athlete of the Year in the NCCAA. Zenner, who was also the Wheeler Award winner in cross country, was part of the NCCAA winning $4 \times 400$ meter relay team plus was named to the NAIA and NCCAA AllAmerica Scholar-Athlete teams.

Pletcher won both the 3,000 and 5,000 meter runs in the NCCAA meet while Beitler claimed the high jump title and also ran on the $4 \times 400$ meter relay squad along with Debbie Trimble. Other NCCAA winners were Michelle Burson in the 10,000 and Courtney Kilburn in the discus. Joining Sherman on the $4 \times 100$ meter relay team were Laura Glessner, Sarah Jackson, and Sylene Graves. Tiffany Shaw and Cindy Hasselbring joined Zenner as NCCAA All-America Scholar-Athletes.

The Yellow Jacket men had five NCCAA All-Americans. The individual winners were Conkel in the 10,000 , Polack in the triple jump, and Jon Plush in the pole vault. Chris Melkonian and Linton Ellis joined Plush and Polack on the winning 4x100 meter relay unit.

During the winter indoor season, Cedarville had four NAIA All-Americans (top six finishers). On the men's side, Joe Cunningham was second in the pole vault. In the women's division, Stephanie Sherman was second in the triple jump, Joy Beitler was fourth in the high jump, and Michelle Burson placed sixth in the 5,000 meter run.

Mark Womack 


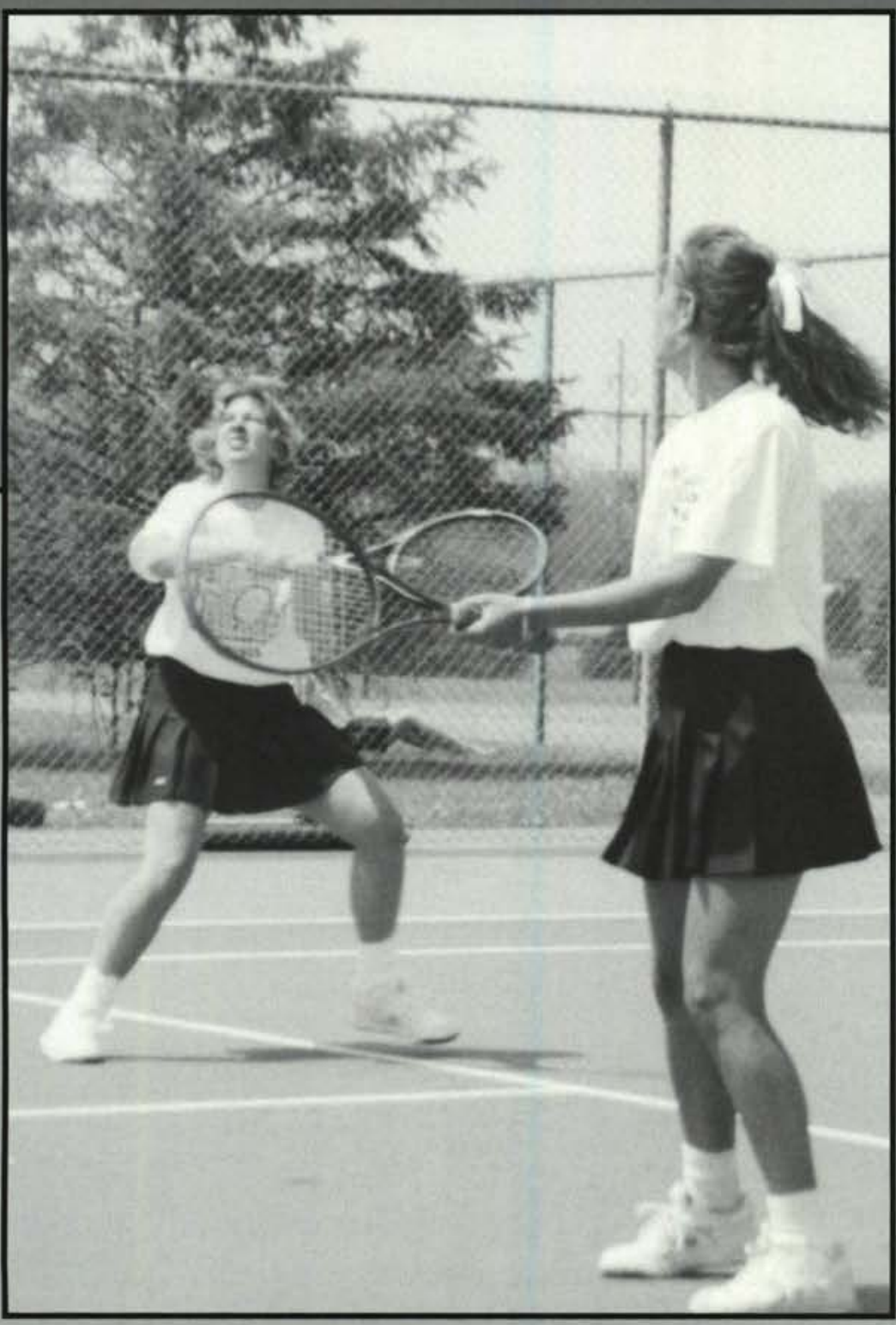

\section{Women's Tennis Review}

The Lady Jacket tennis team rolled to a 7-4 record and finished a close second in the Mid-Ohio Conference Championship. Coach Pam Johnson's unit was in the hunt for an NAIA National Tournament berth again despite being very young. The roster included two juniors, four sophomores, and four freshmen.

Junior performer, Melissa Hartman, moved up to the number one singles spot and responded with a 9-4 record to up her career mark to 31-7. She was voted to the All-MOC team in both singles and doubles. Sophomore Hasmine Gmuer earned the same honors from the MOC after going 11-3 in the number two slot. She won the Flight No. 2 singles title in the conference tournament and is now $20-5$ over her two-year career.

Sophomores Andrea Anthony, who was 9-5 in singles play, and Christine Gerard, 7-7, held down the numbers three and four positions, respectfully. Freshman Mary Wolfe achieved an outstanding rookie season by going 10-4 and winning the MOC's fifth flight. Lesley Nester, another newcomer, was $6-5$ in the number six slot.

Walsh totalled 37 points to cop the MOC Championship while Cedarville had 35 points to finish second in the six-team field. The Jackets had players in five singles finals and two doubles finals, but they were only able to claim the two singles flight championships.

The third doubles team of freshmen, Wolfe and Jodi Muehling, won their first seven matches of the season before dropping the MOC final. Hartman and Gmuer also lost in the final of the first flight and had a 6-3-record. Anthony and Gerard were 5-2 as the number two tandem.

Hartman was named an NAIA All-America Scholar-Athlete. To be named to the team, players must be a junior or senior varsity performer with a cumulative grade point average of 3.50 or greater.

Mark Womack

ABOVE: SAndrea Anthony and Chis Gerard double up to take on opponents. RIGHT: Mary Wolfe takes a few seconds to line up her hit.

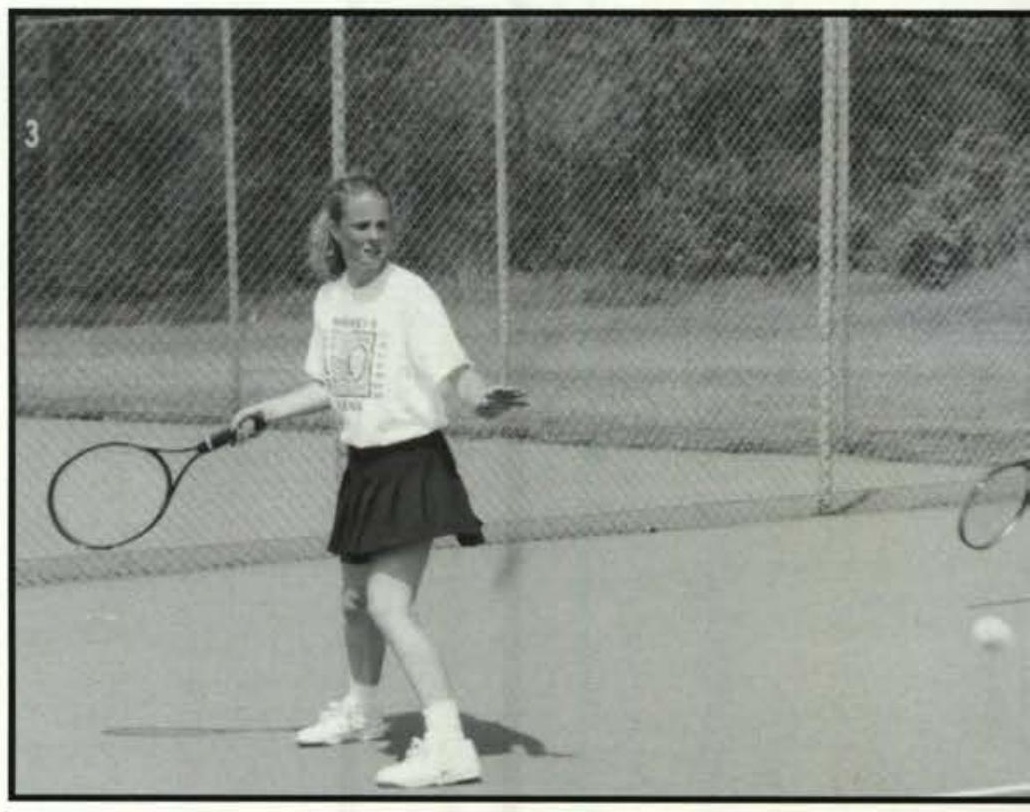




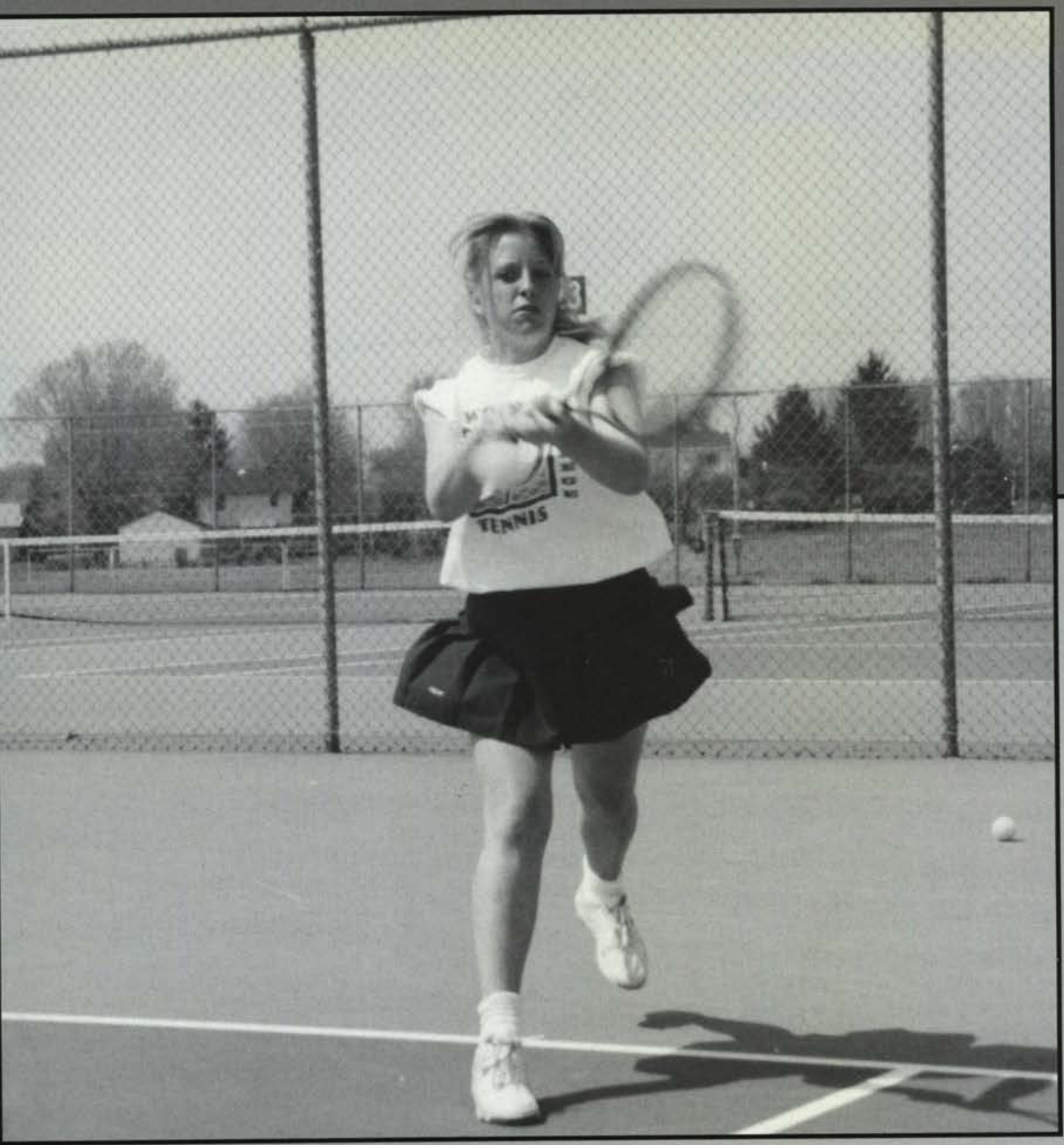

LEFT:Jodi Muehling gives a hard return hit.

\section{W. Tennis 7-4}

90 Shawnee State

72 Findlay

54 Malone

36 Wilmington

90 Earlham

$0 \quad 9$ Ohio Wesleyan

27 Walsh

90 Earlham

27 Wittenberg

90 Tiffin

81 Bluffton

44 Ohio Northern (suspended)

2/6 MOC Champ.

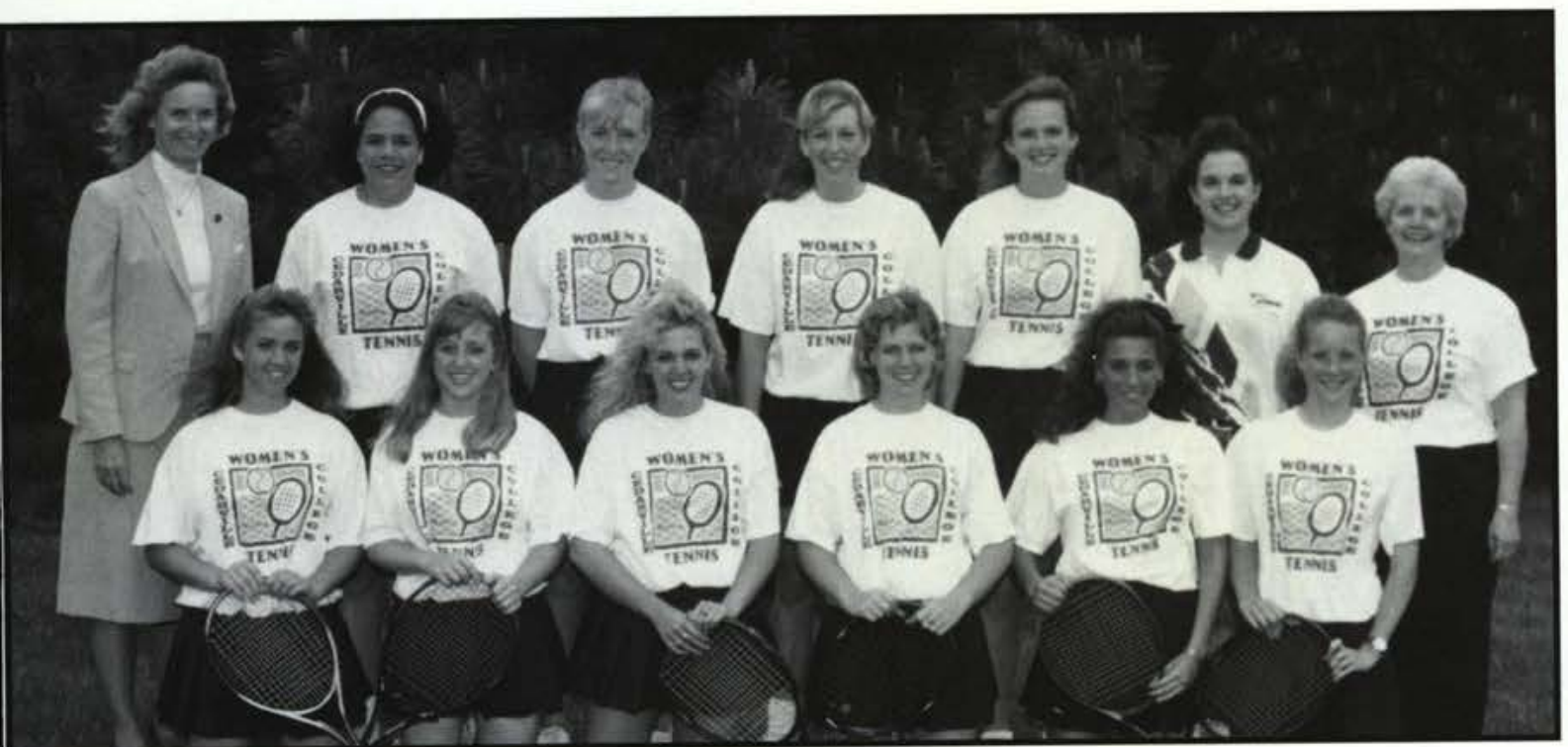

Women's Tennis

Row 1: Melissa Hartman, Jodi Muehling, Jennifer Jeremiah, Christine Gerard, Andrea Anthony, Mary Wolfe. Row 2: Coach Pamela Johnson, Hasmine Gmuer, Brooke Frazier, Kerri Vander Molen, Lesley Nester, Krystee Gehman S.T., Asst. Coach Eleanor Taylor. Not pictured: Gwen Judkins, Asst. Coach Delyte Morris. 


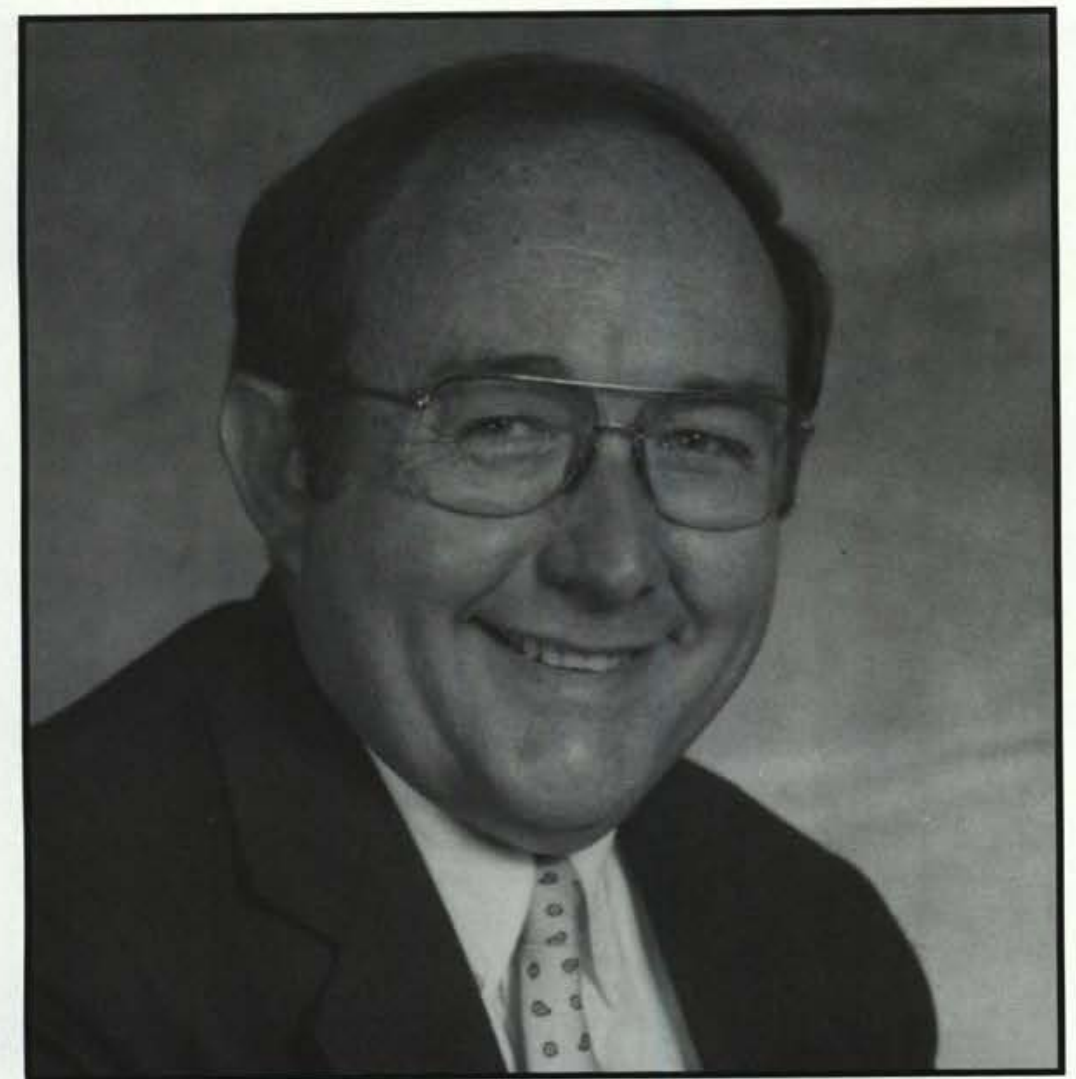

\section{Coach Murray Murdoch,}

Cedarville's head tennis coach, leaves the court after 29 very impressive years. His win-loss record ranks the men's tennis team among the college's most successful teams. His teams have held 23 NAIA District 22 and Mid Ohio Conference championship titles. The spiritual attitude of his teams on and off the court has made them good ambassadors for the Lord and the college.

Dr. Murdoch has had great enthusiasm for the sport as well as for his players through the years. As one player, Todd Entner, says, "It was a pleasure to play on Coach Murdoch's final team. More than just a coach, Dr. Murdoch has been a friend and mentor. Cedarville tennis will certainly miss this man."

\section{Men's Tennis Review}

The 1995 Cedarville College men's tennis campaign featured a number of new faces. Alan Edlund took over the head coaching position from Murray Murdoch, who landed a spot in the NAIA Hall of Fame during his legendary 29-year career. The new coach, coupled with only one returning player from the varsity, forced the Yellow Jackets into a rebuilding year by their standards.

Cedarville finished with a 6-8 record in dual match competition. The Jacket netters wrapped up the season by placing fourth out of eight schools in the NAIA Great Lakes Sectional Tournament.

Todd Entner was the lone returning varsity performer, and he responded with an outstanding effort. The senior from the Philippines played in the number five singles position last year, but this spring he was forced up to the number one spot. Entner raised his game to another level and was seeded second in the Great Lakes tournament where he advanced to the quarterfinals. He finished the season with a $12-5$ singles mark and closed out his career 43-13 overall.

Entner earned a spot on the NAIA All-America ScholarAthlete team for the second straight year. The honor is reserved for junior and senior varsity performers who maintain a minimum 3.50 cumulative grade point average.

The rest of the line-up, who had toiled in the junior varsity ranks in previous years, now had a chance to contribute. Those finishing the season on the varsity along with Entner were senior Jeff Nelson (5-8 singles record), junior Andy Kunkler (7-9), junior David Baker (2-5), sophomore Zach Ruffin (8-6), and junior Sean Fox (7-7). Ruffin and sophomore Anthony Torlone finished with the best doubles record at 4-3. Entner and Kunkler, who were 5-7 overall, advanced to the Great Lakes tournament quarterfinals.

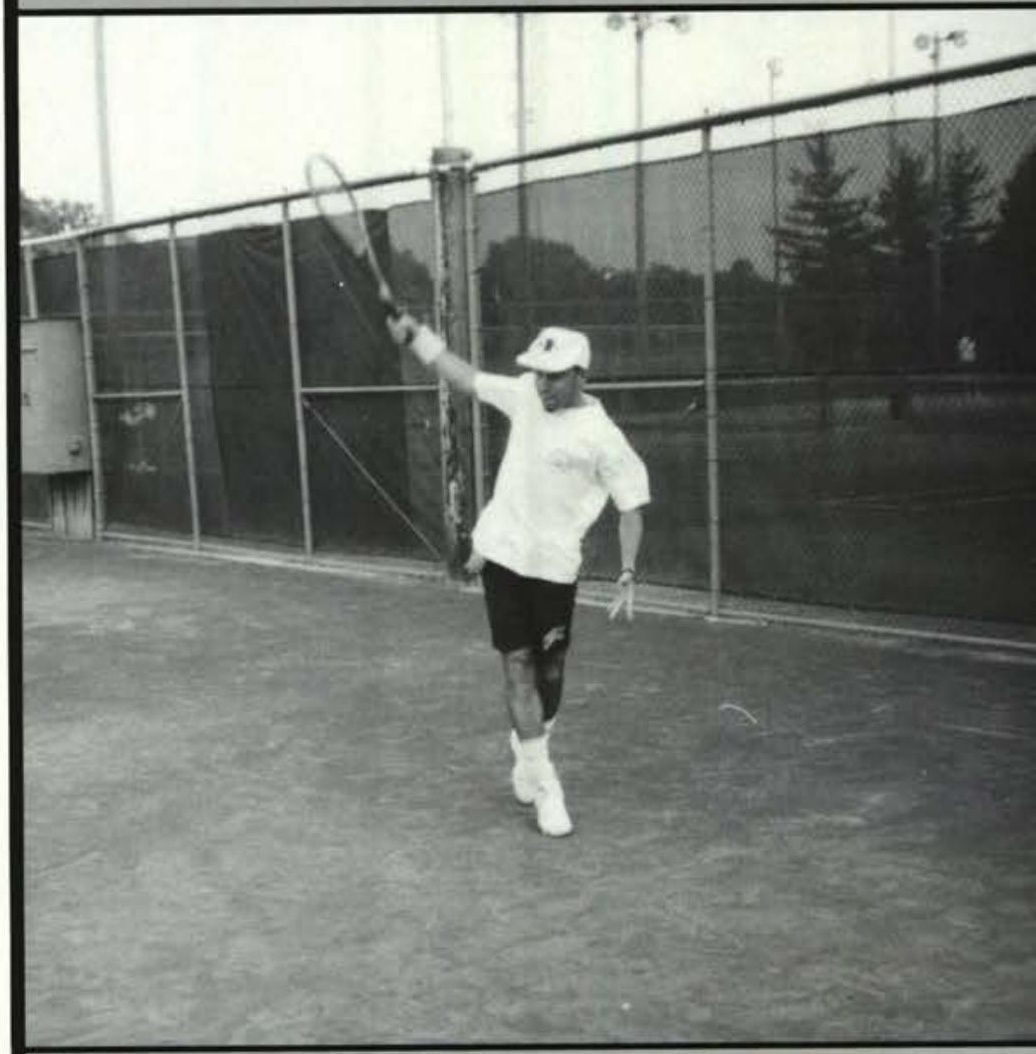




\begin{tabular}{|cl|}
\hline & Golf \\
$10 / 14$ & Ind. Wesleyan Invit. \\
$6 / 10$ & Shawnee State Invit. \\
$4 / 05$ & 14 th Cedarville Invit. \\
$8 / 11$ & Ashland Invitational \\
$4 / 07$ & Urbana Invitational \\
$14 / 15$ & Franklin Invitational \\
$11 / 12$ & Walsh Invitational \\
$9 / 11$ & Mt. Vernon Naz. In. \\
$3 / 07$ & Tiffin Invitational \\
$4 / 06$ & NCCAA District III \\
$6 / 08$ & MOC Champ. \\
\hline
\end{tabular}

10/14 Ind. Wesleyan Invit.

6/10 Shawnee State Invit.

4/05 14th Cedarville Invit.

8/11 Ashland Invitational

4/07 Urbana Invitational

14/15 Franklin Invitational

11/12 Walsh Invitational

9/11 Mt. Vernon Naz. In

3/07 Tiffin Invitational

6/08 MOC Champ.

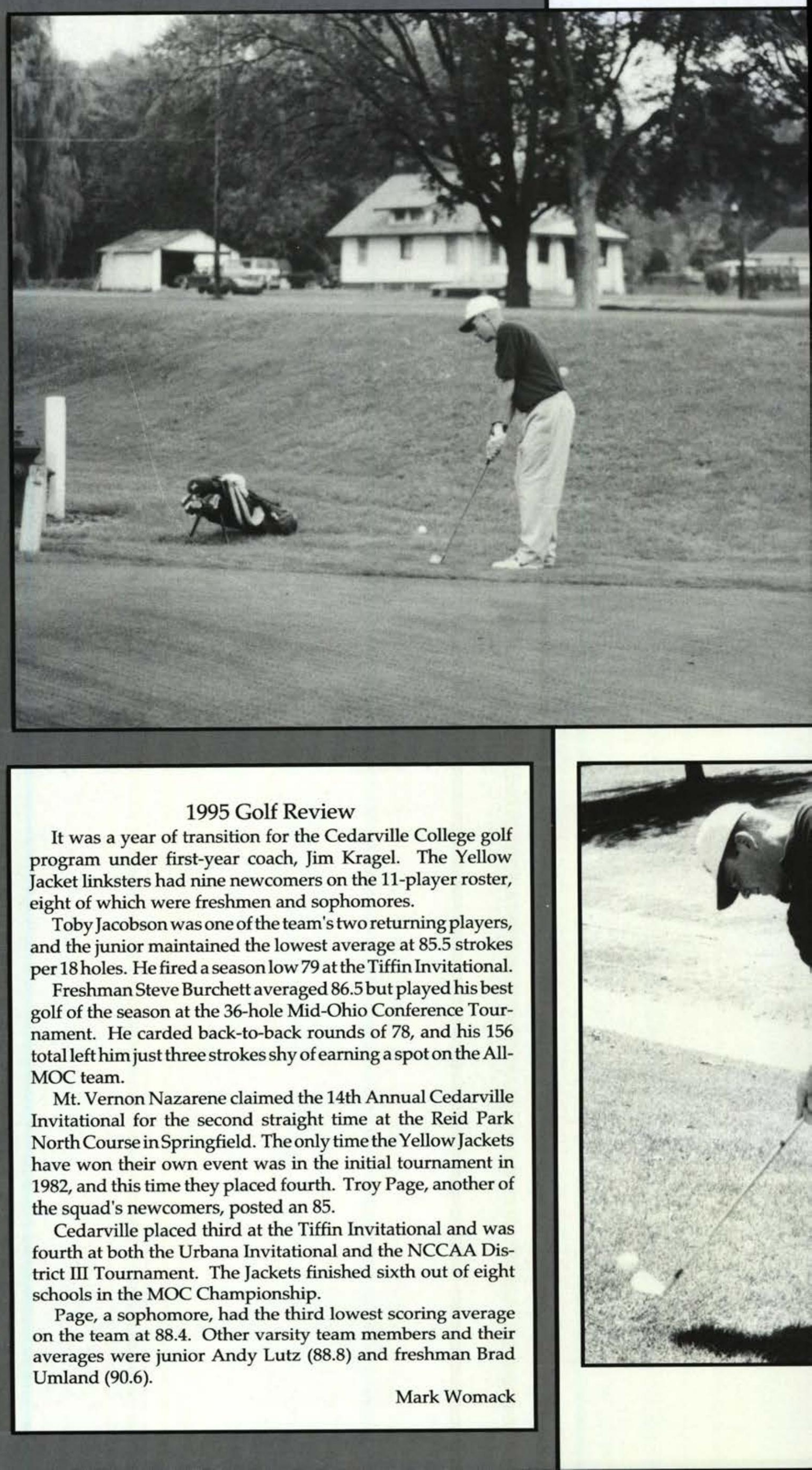




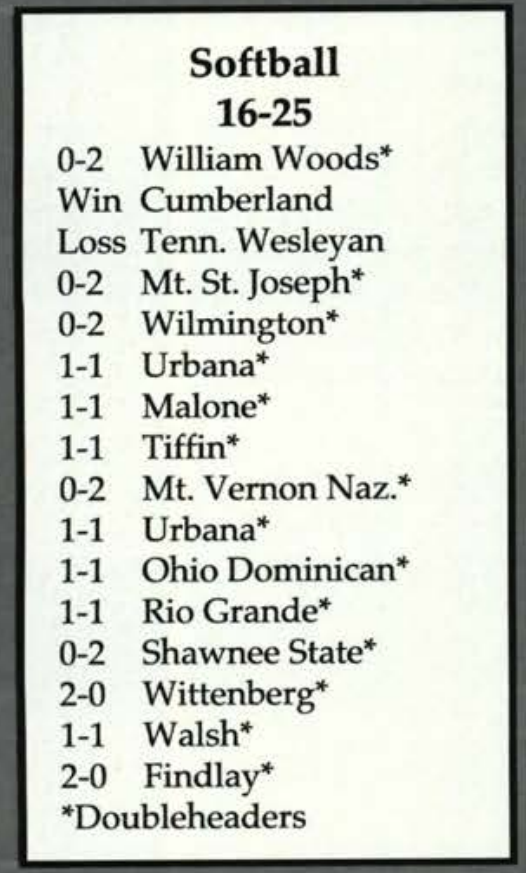

Women's Softball

Row 1: Melissa Sprankle, Michelle Dick, Amanda Mudrey, Lana Schwinn, Erika Miller, JenniferFisher, Heather Klingaman, Penni Ruhl. Row 2: Coach Kathy Freese, Cheryl Schneckenberger S.T., Jennifer Cassidy, Jennifer Sloan, DiAnn Miller, Andrea Butz, Cindy Cremeans, Shawn Bush, Asst. Coach Joy Fagan.
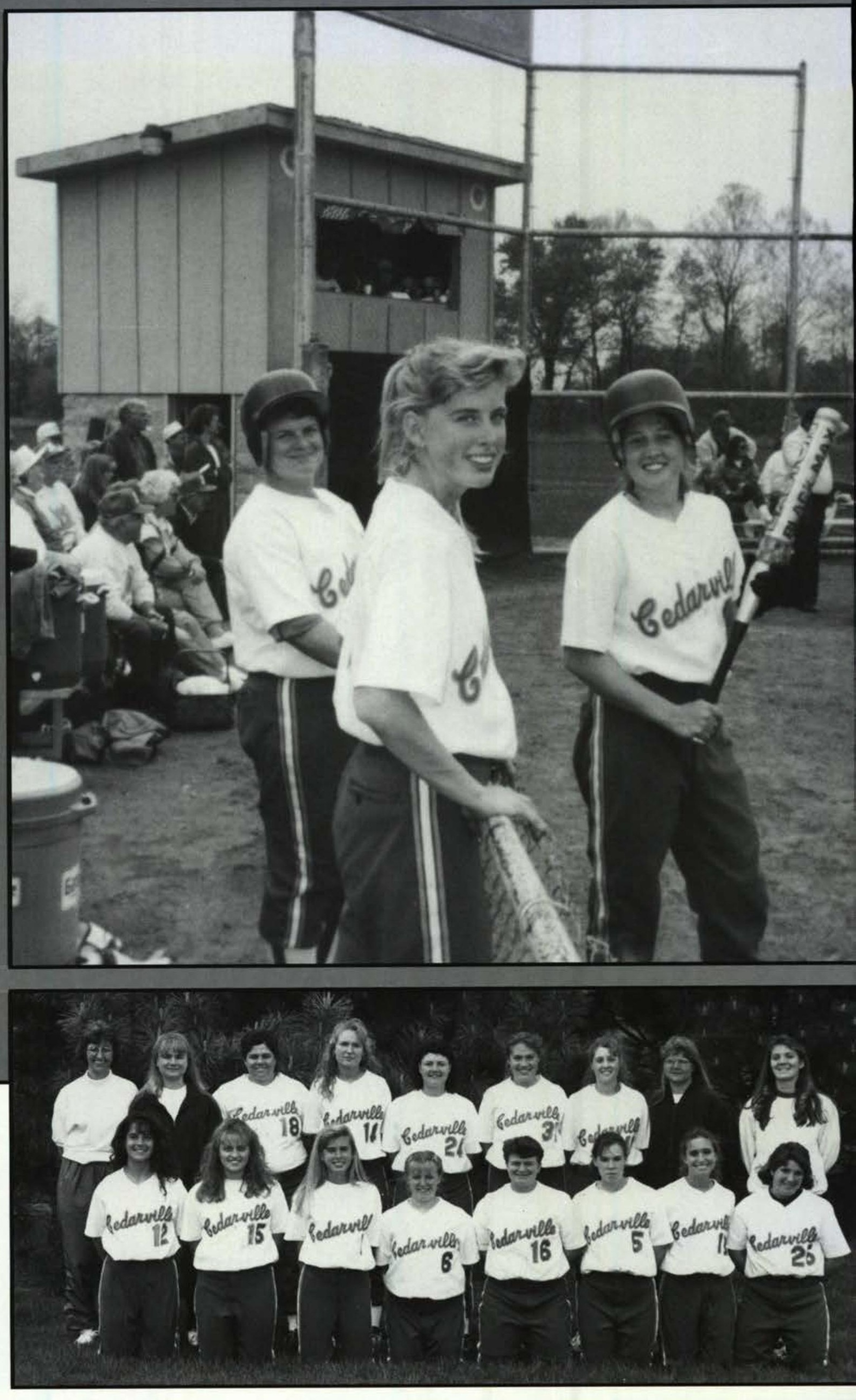


\section{Baseball}

Row 1: Matt Robinson, Dan Kaynor, David Staedtler, Dave Geiger, Clint Miller, Paul Melvin, Sean Moore. Row 2: Coach Norris Smith, Jeff Bowen, Stephen Mays, Brian Miller, John Iamaio, Dustin Hill, Josh Green, Stephanie Yankovich S.T. Row 3: Nathan Rohrer, Andy Sipes, Dave Pierce, Ben Hoffman, Travis Mulanax, Josh Lunney, Doug Ashley. Not pictured: Mark Wood.
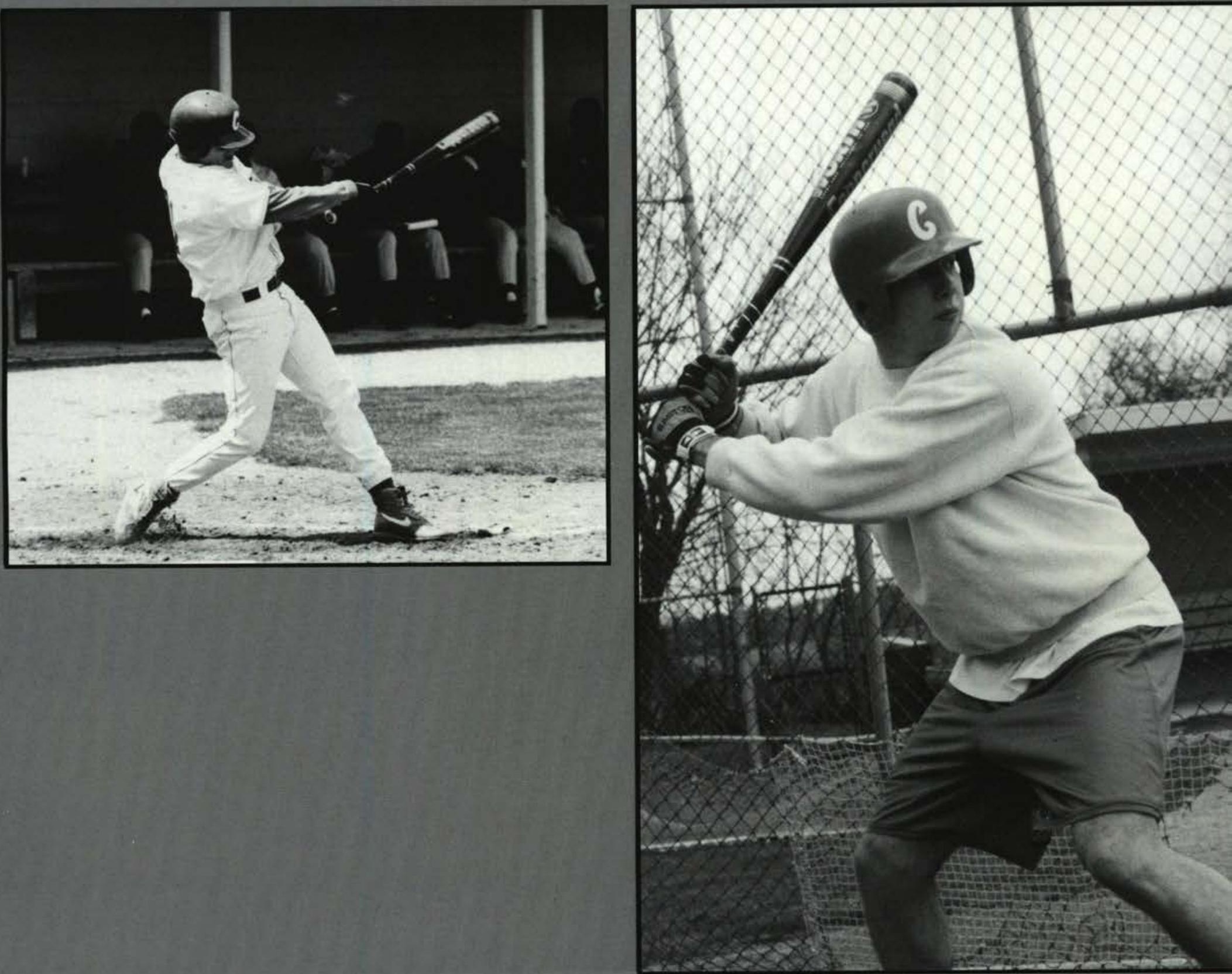


\section{Baseball Review}

The Cedarville College baseball season resulted in a 10-22 campaign, but that did not hinder the performance of junior outfielder, Steve Mays. He was voted to the All-Mid-Ohio Conference team for third consecutive year after ranking second in the league with a .420 batting average.

Mays was again tabbed the team's MVP after another outstanding season. He led the Yellow Jackets with 112 at bats, 47 hits, 29 runs scored, nine doubles, and four triples. He stole 15 bases in 18 attempts, struck out just six times in 124 plate appearances, and was one of only two players to play in all 32 games. Mays earned a spot on the All-NCCAA District I team, and he was an NCCAA All-America honorable mention choice.

Senior outfielder, David Geiger, who was the other player to appear in all 32 games, was the only other .300-plus hitter with a .356 average with seven doubles and a team-high 17 walks. He was named to the All-NCCAA District I team as was freshman infielder, Josh Lunney, who batted .296.

Junior righthander, Clint Miller, had an excellent effort on the mound with a 2.21 earned run average, but his record was just 2-6. The Jackets were 3-9 in one-run games, and Miller was on the short end of four of those close setbacks.

Matt Robinson, Jeff Bowen, and Paul Melvin joined Geiger as the seniors on the roster. Robinson was 3-2 on the mound, and Bowen stole 18 bases in 20 attempts.

Mark Womack
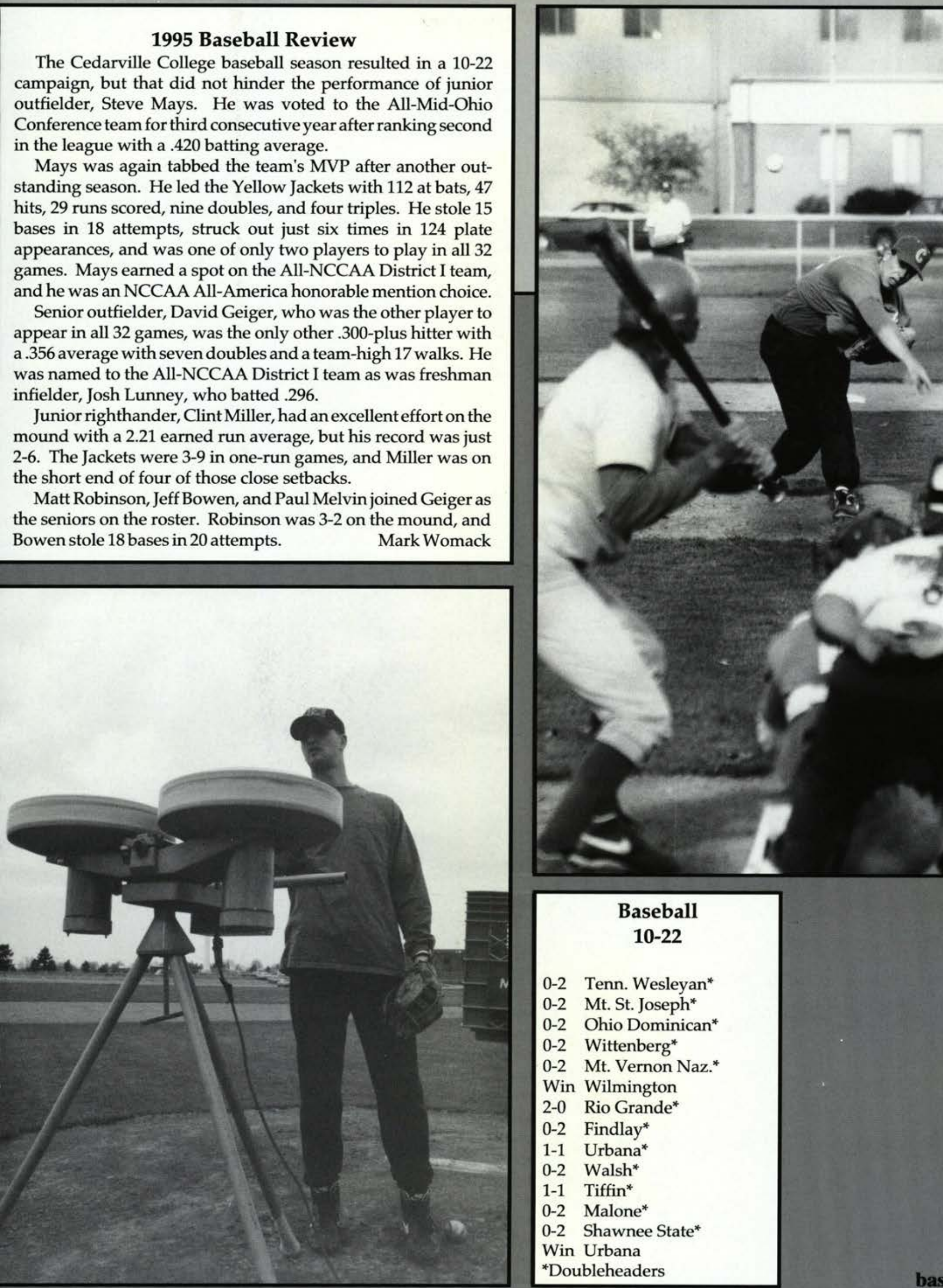


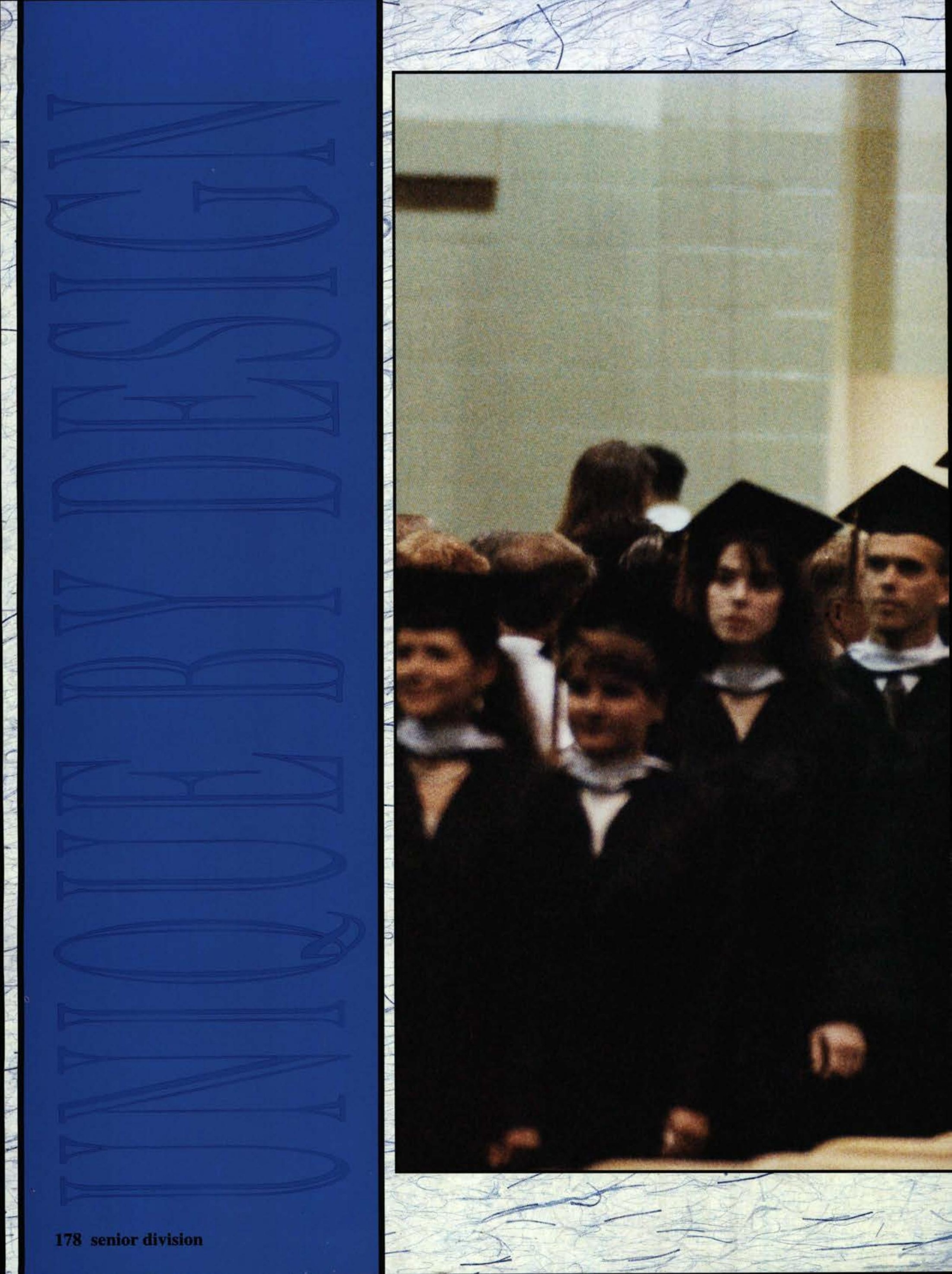





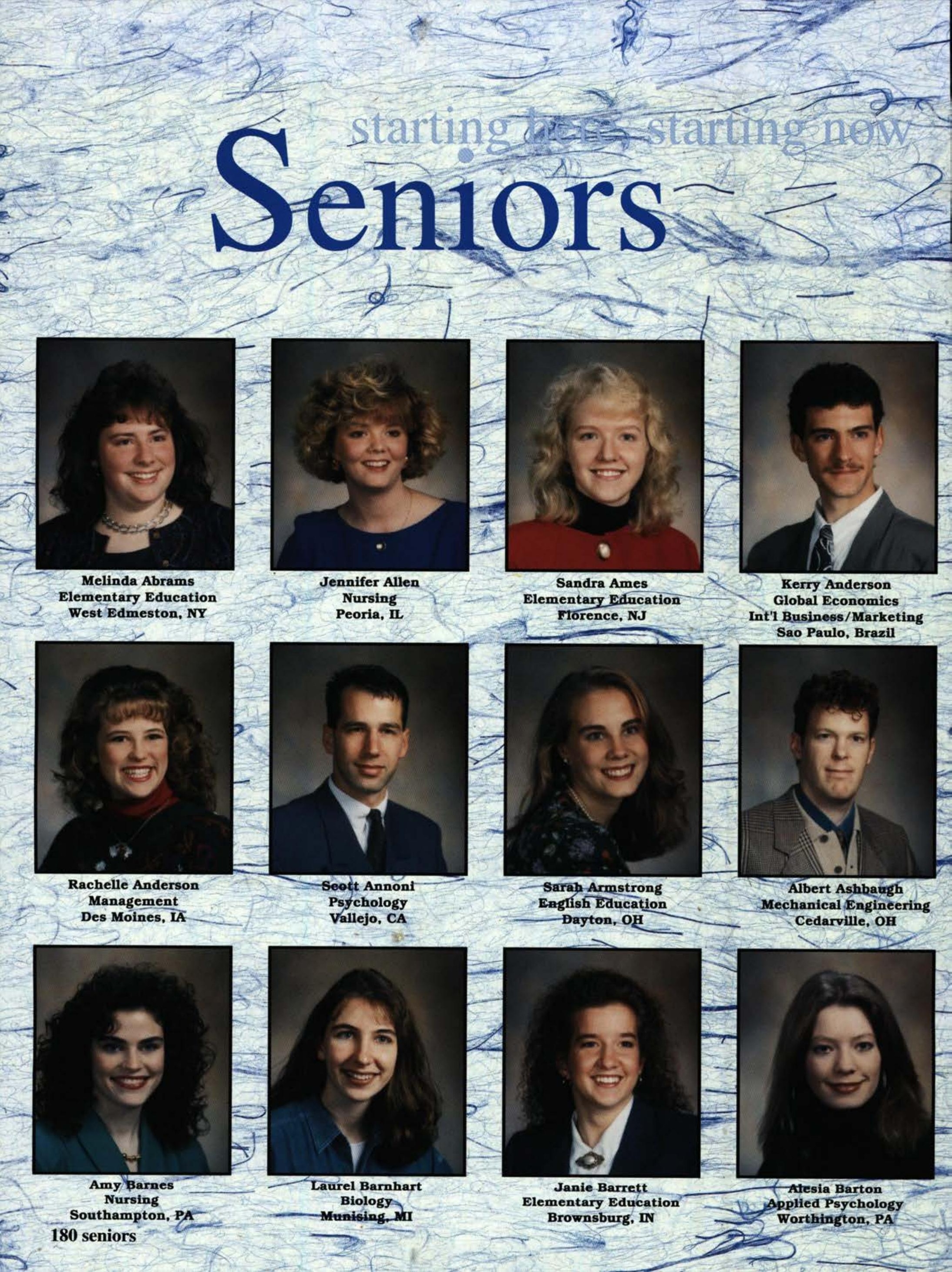




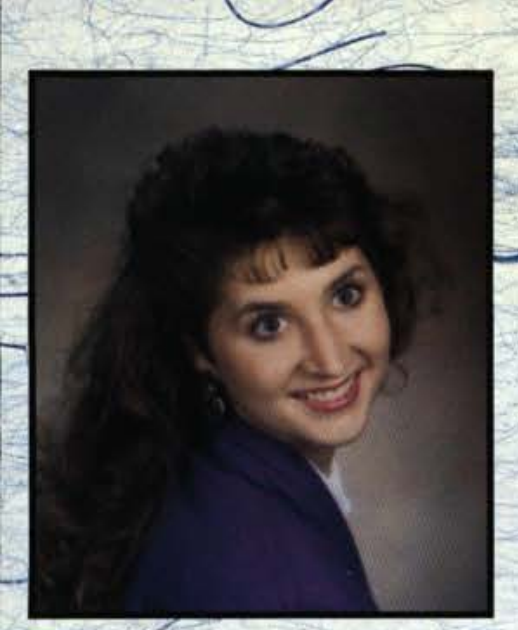

Julie Lynn BurnsCommunication Arts Alamo, CA

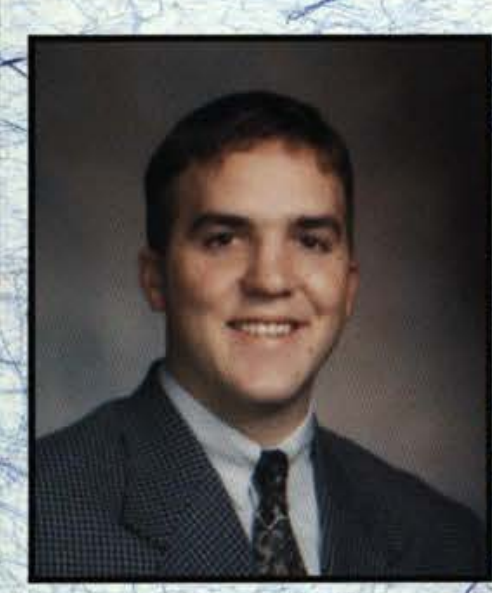

william Butts Bible, Comprehensive Aurora, $\mathrm{OH}$

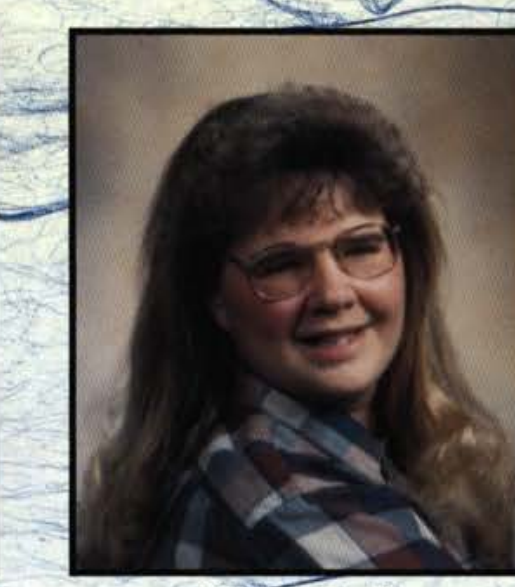

Shawn Bush
Physical Education Gallipolis, OH

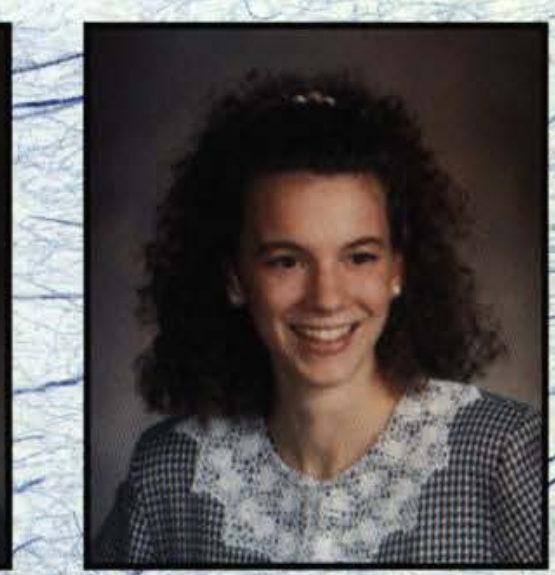

Yvonne Butts

Bible, Comprehensive

Twinsburg, OH

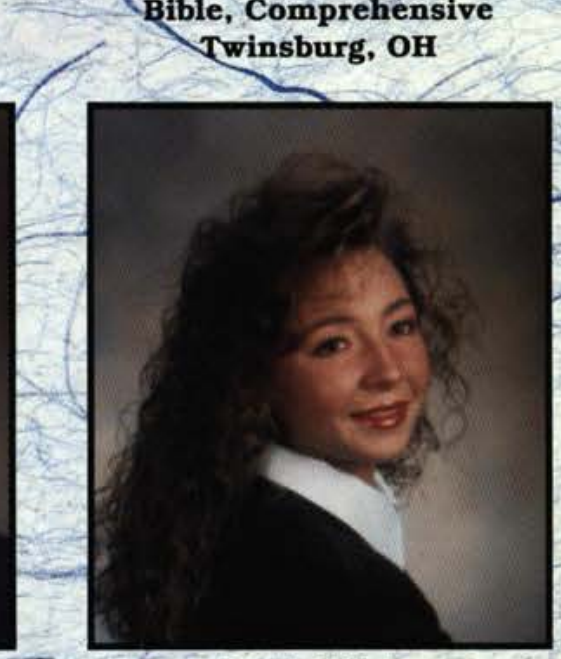

Rachel Cain

Applied Psychology Wadsworth, OI

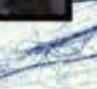

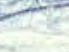

Applied Psycholo

Applied Psychology

Sciotoville, OH

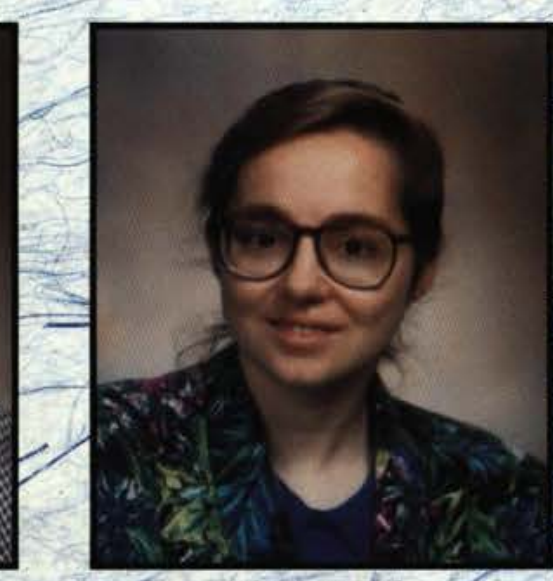

Rebecca Byler English Irwin, OHt

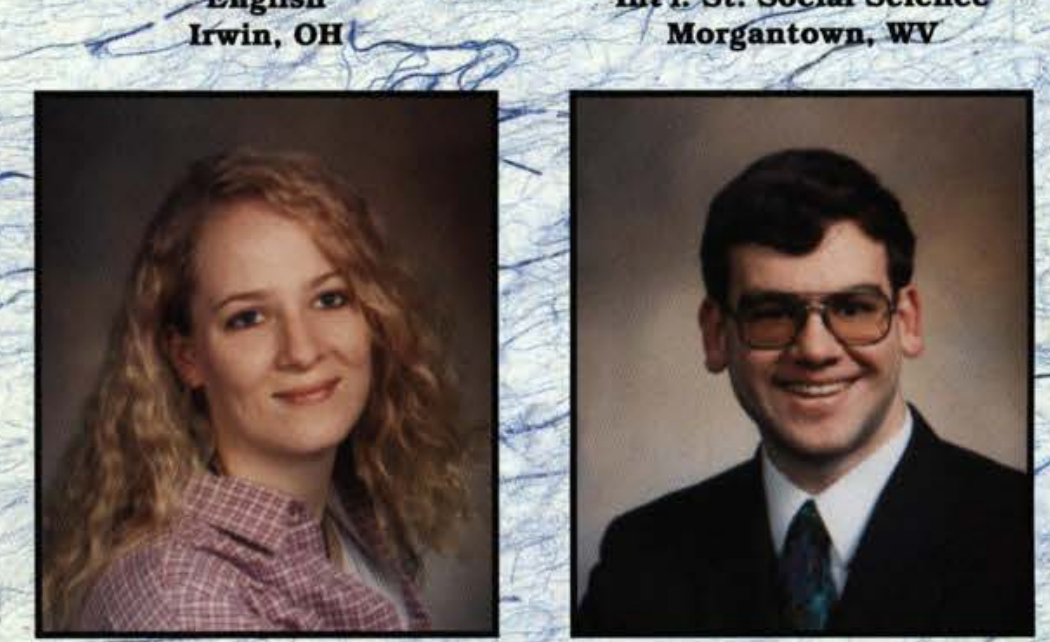

Ann Caldwell Biology

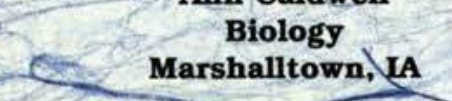

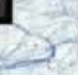

29

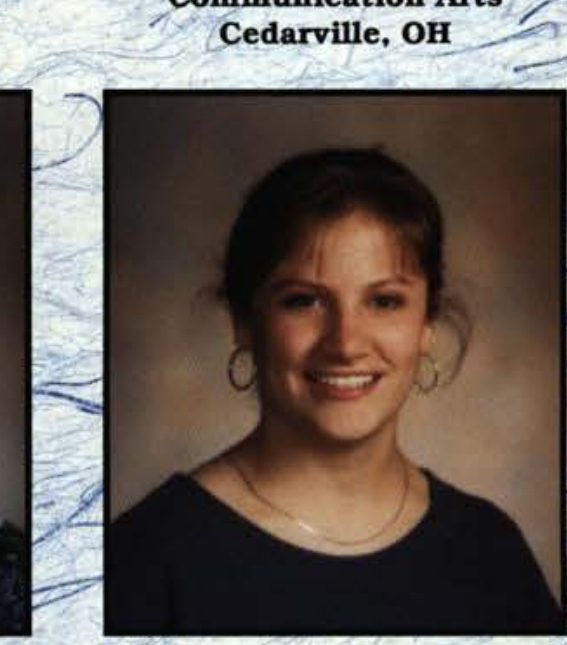

Sarah Byrer

Int1. St. Social Science Morgantown, WVV

Clifford Caldwell

Mechanical Engineering Miamisburg, OH

New Carlisle, OH
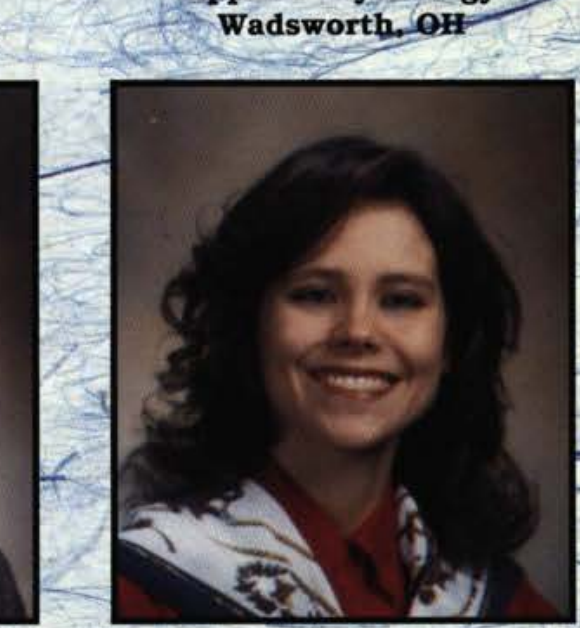

Jacqueline Call

Scott Calhoun

English

Nursing

Woodbridge, VA

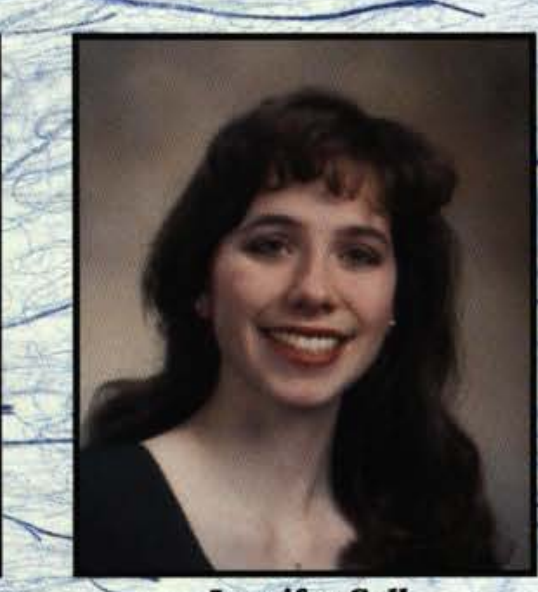

Jennifer Call

English Education Dale-City, VA

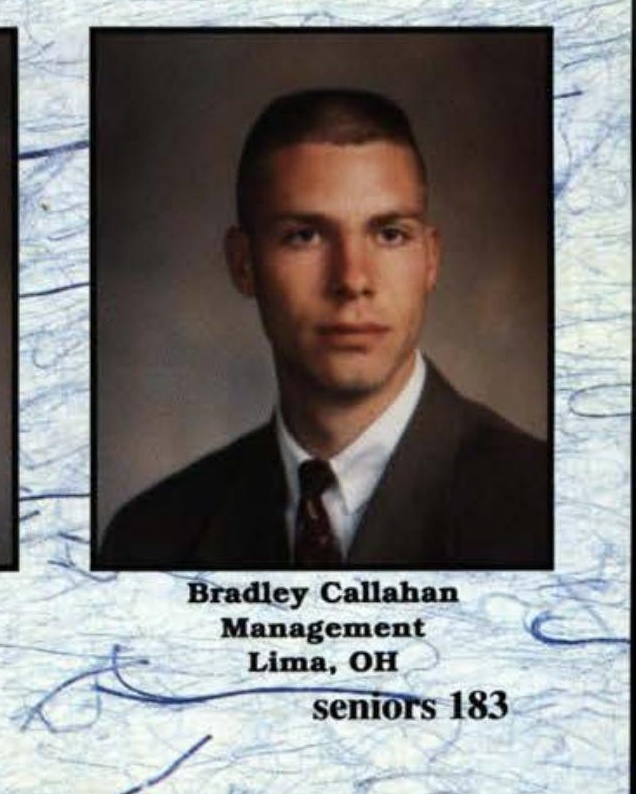




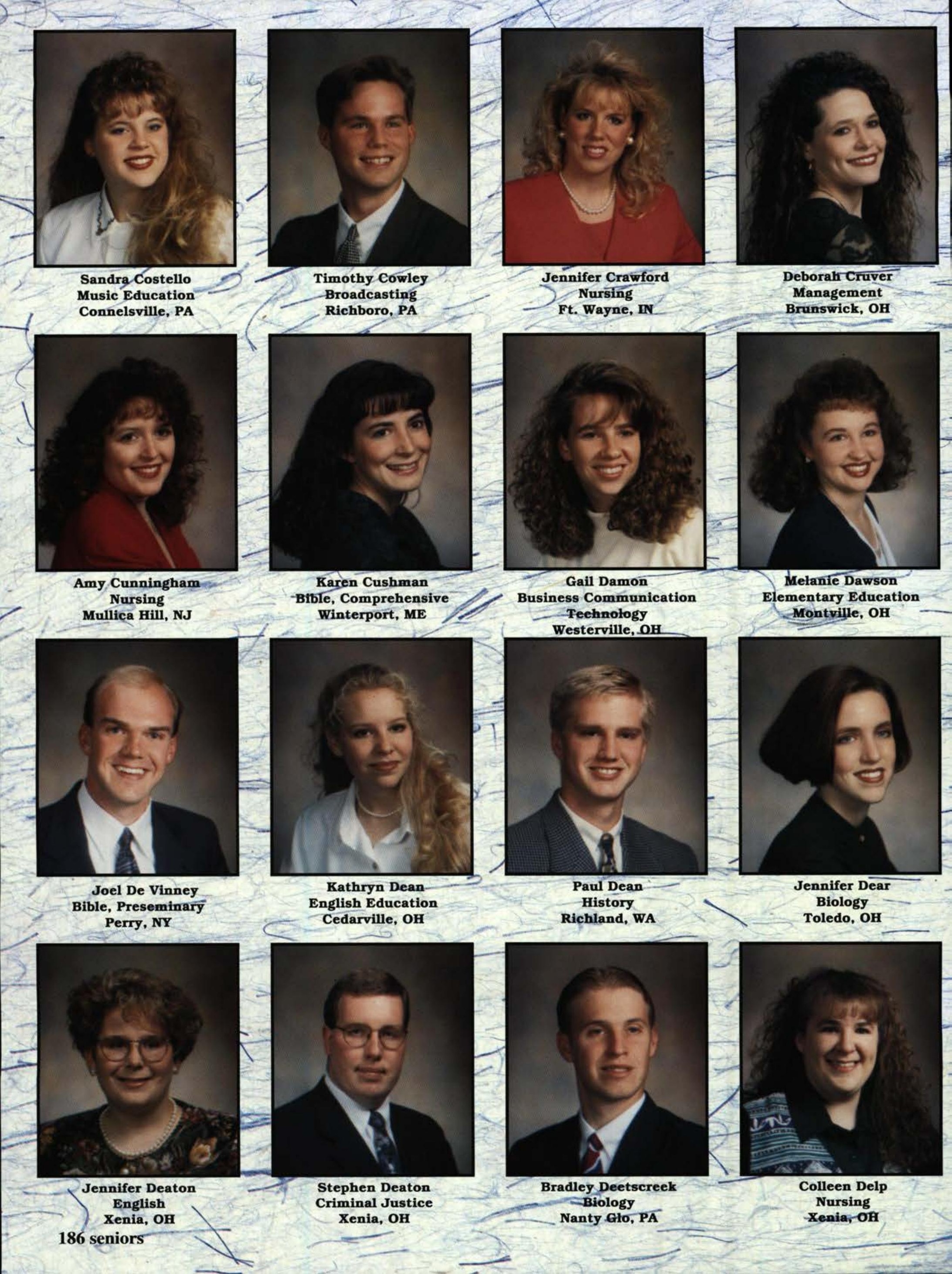




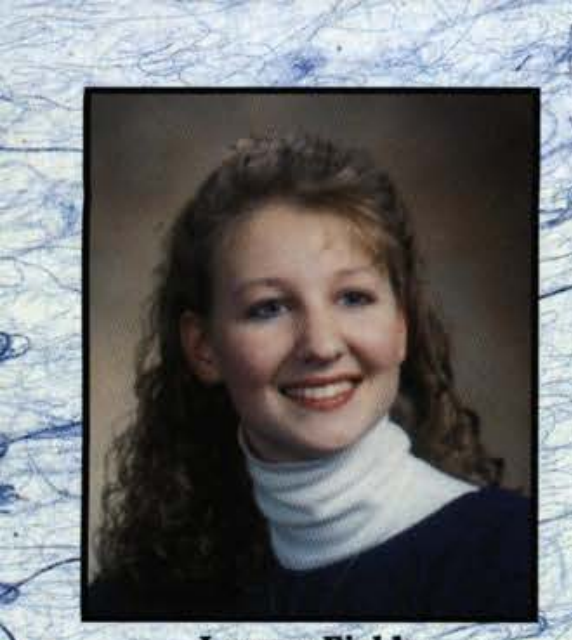

Lauren Fields

Nursing

Xenia, OH

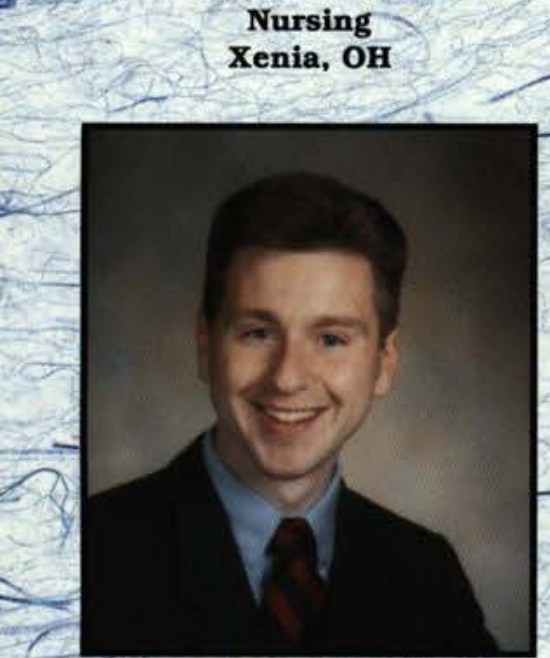

Jeffrey Fortna

Mathematics

Waterford, MI

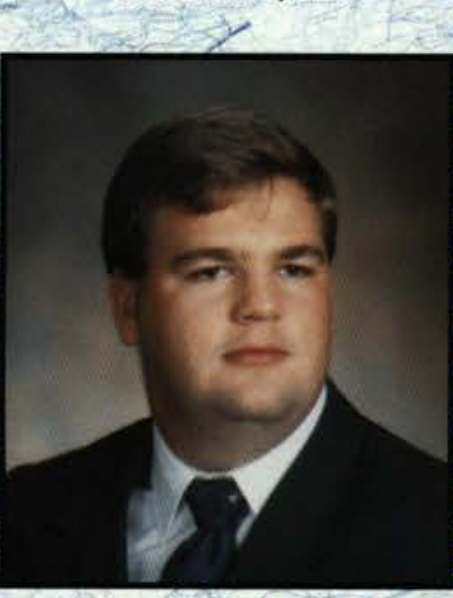

Jonathan Fraley

English Education

South Charleston, OH

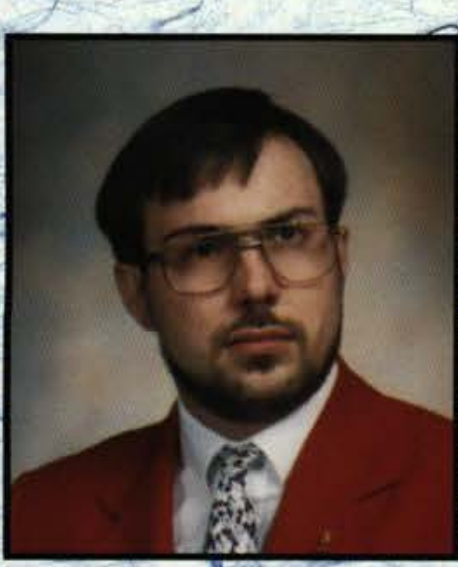

Jeffrey Gabbard

Elementary Education

Dayton, OH

188 seniors

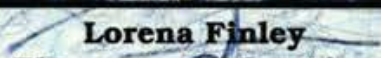

Elementaryosducation Winston-Salem, NC
Brian Fourman Applied Psychology Greenville, OH

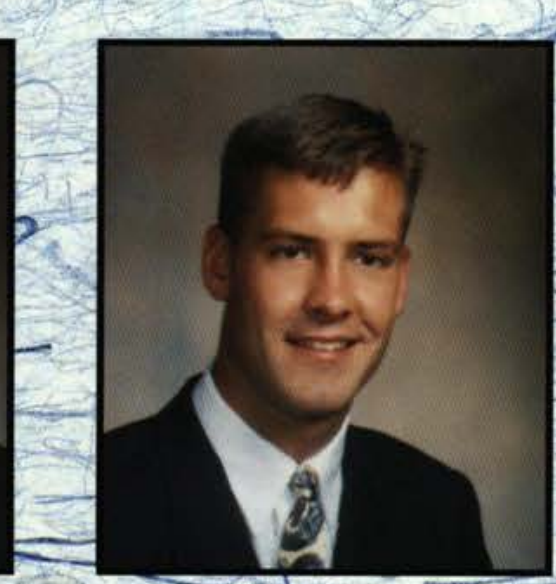

Bradiey Francis Physical Education Comp. Henderson, KY
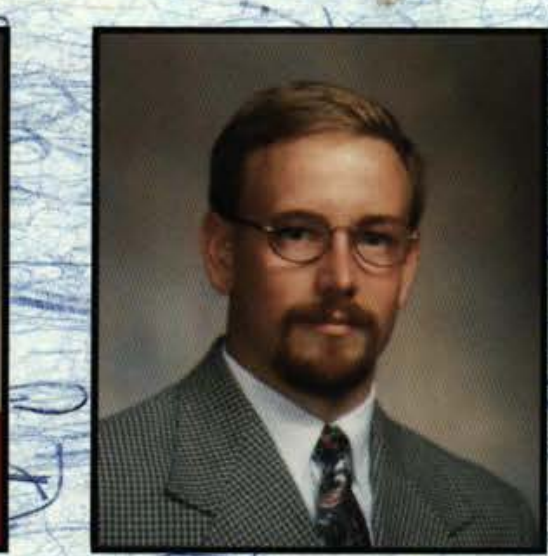

Darin Gall

Nursing Medrord, NJ

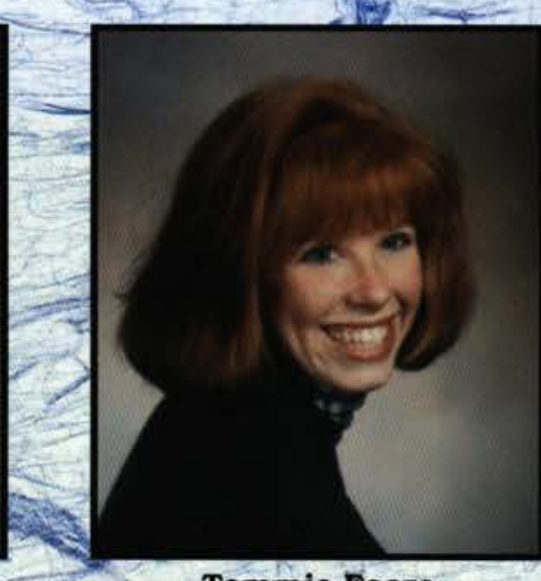

Tammie Foore

Elementary Education

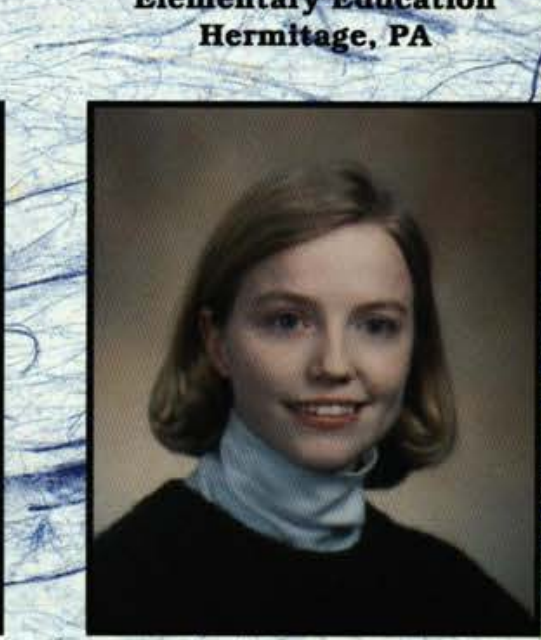

Ruth Fox

Psychelogy

Toledo, OH

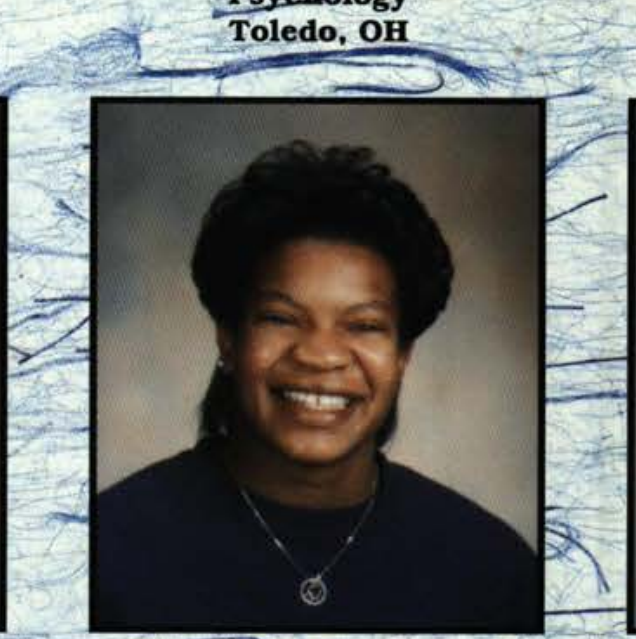

Erma Francis

Nursing

Lakeland, rL

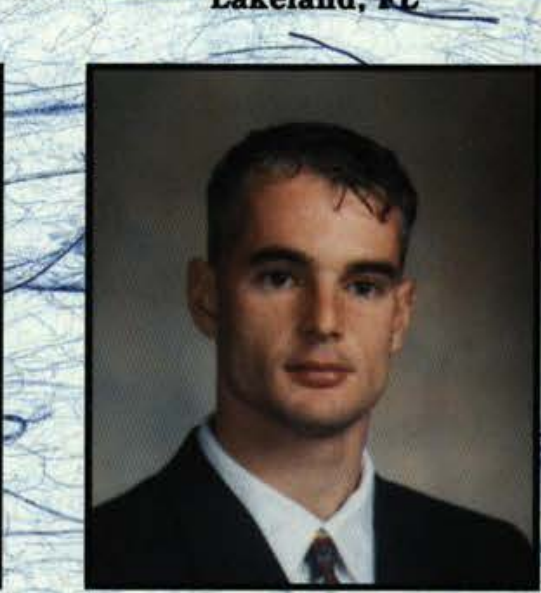

David Gardner Music Education Sarasota, FL

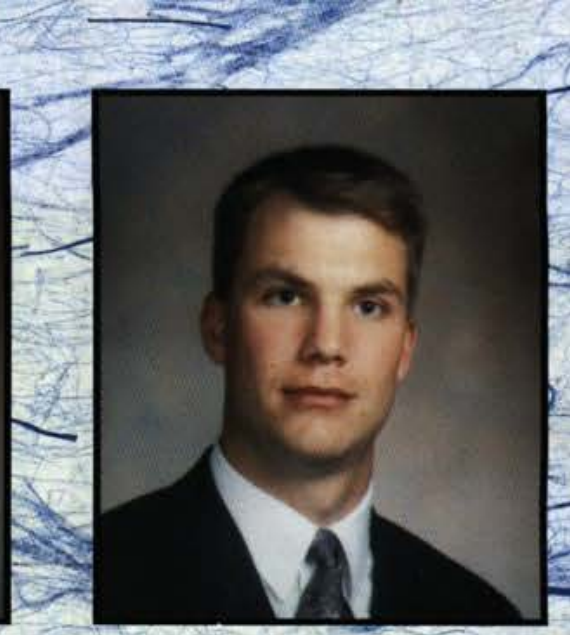

Daniel Forrest

Biology

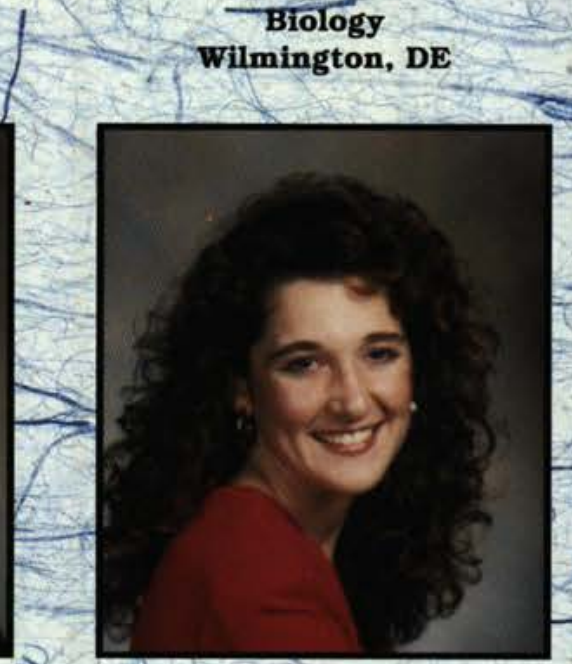

Shelley Fox

Communication Arts Pekin, II

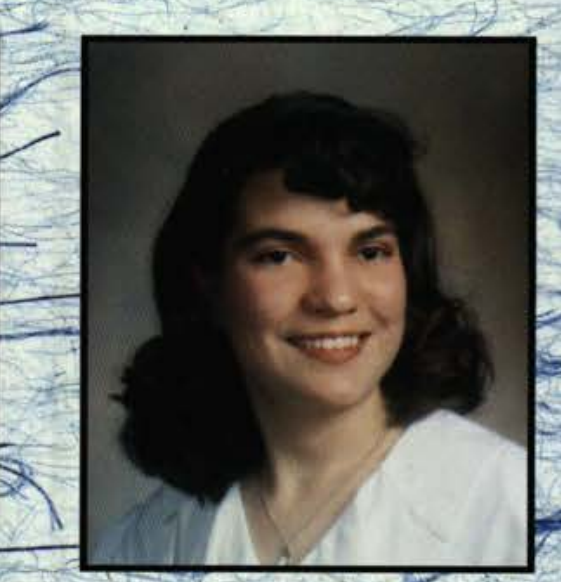

Jill Fuller. Mathematics

South Bend, IN

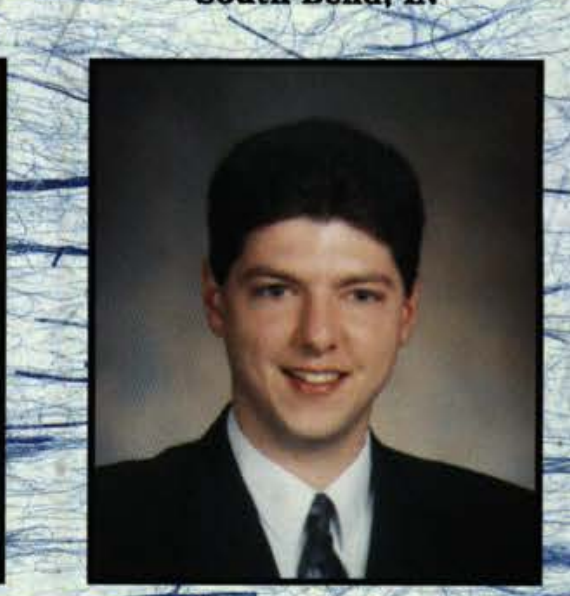

Samuel Garland Biology
Wapakoneta, OH 


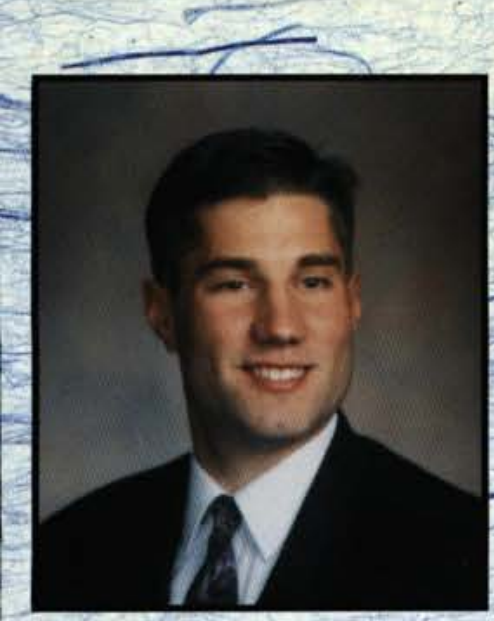

David Geiger

Mechanical Engineering Hew Carlisle, OH

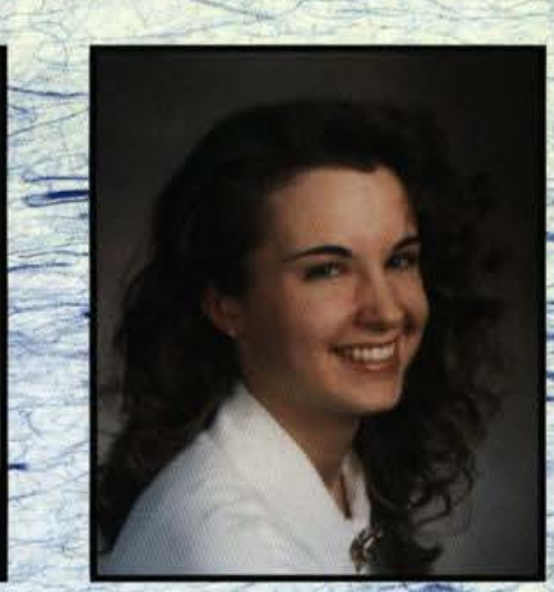

Julie Gephart

Psychology

Keedysville, MD
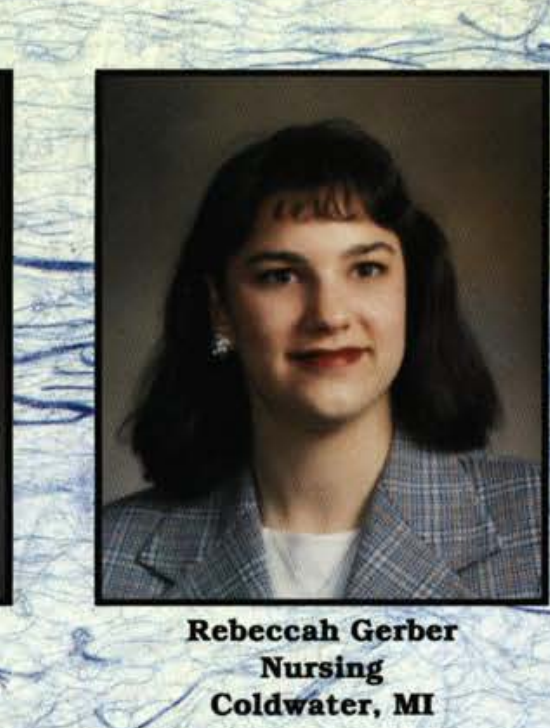

Rebeccah Gerber

Nursing

Coldwater, MI

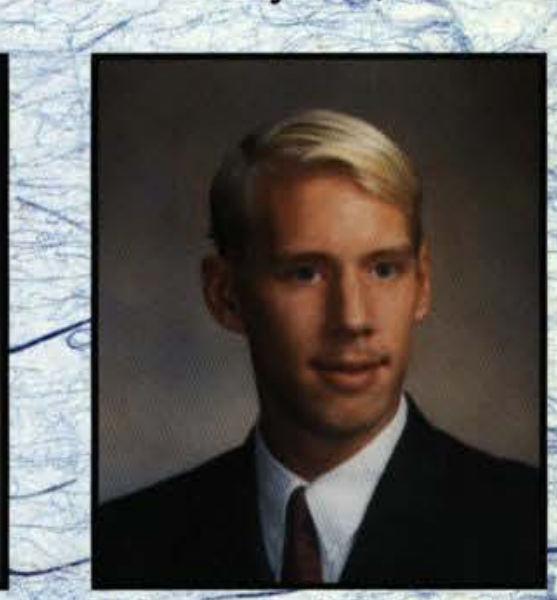

Jeremy Goetsch Philosophy

Lantana, FL

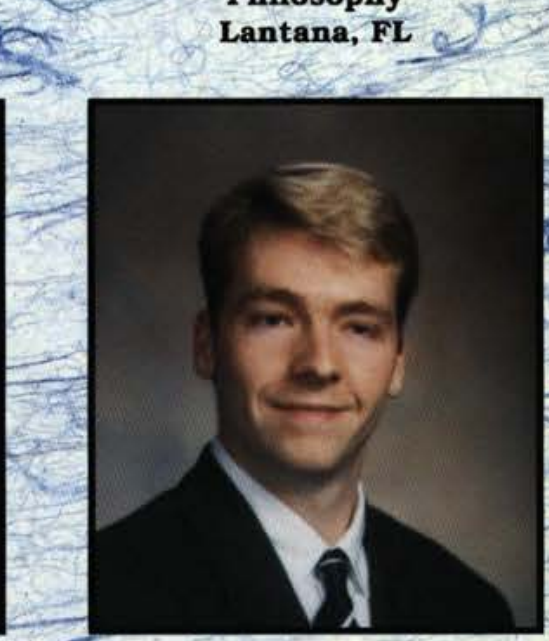

Aaron Graham

Mechanical Engineering

Cedarville, $\mathrm{OH}$

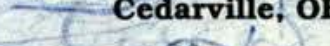

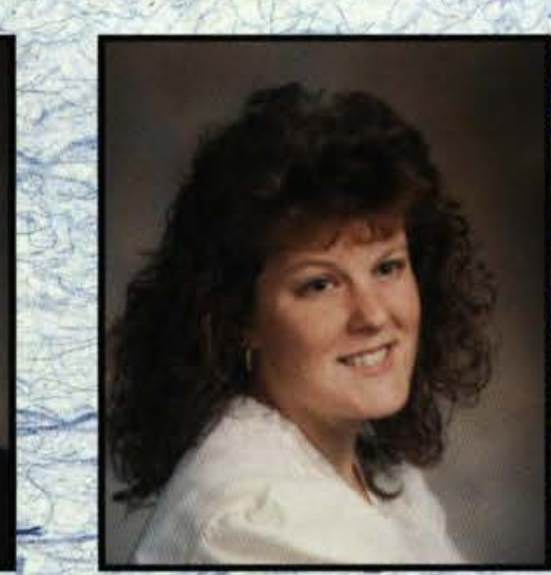

Angela Goodwin Elemetary Education

Columbus, $0 \mathrm{H}$
Derek Gesler Mechanical Engineering Lima, OH 


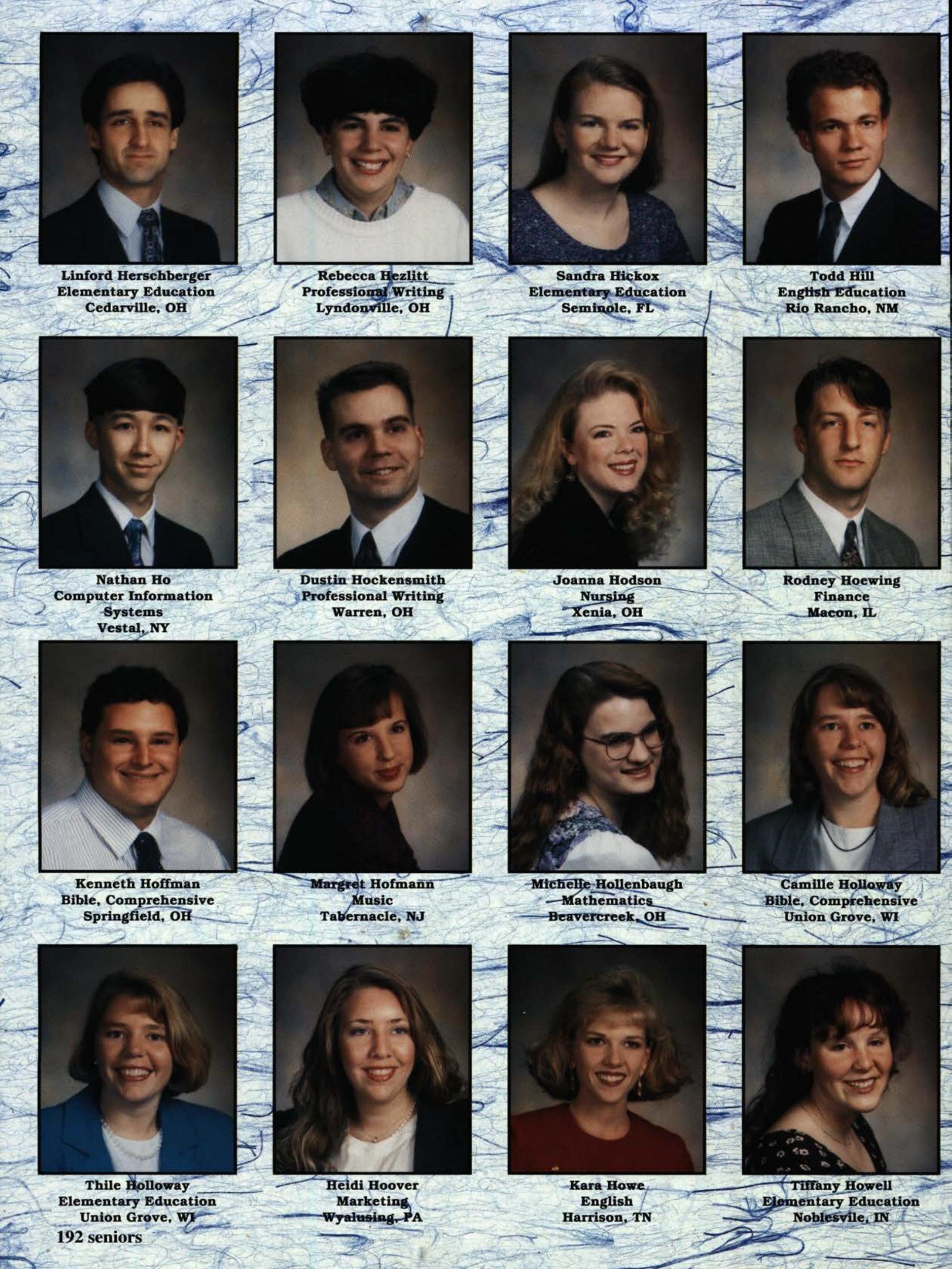




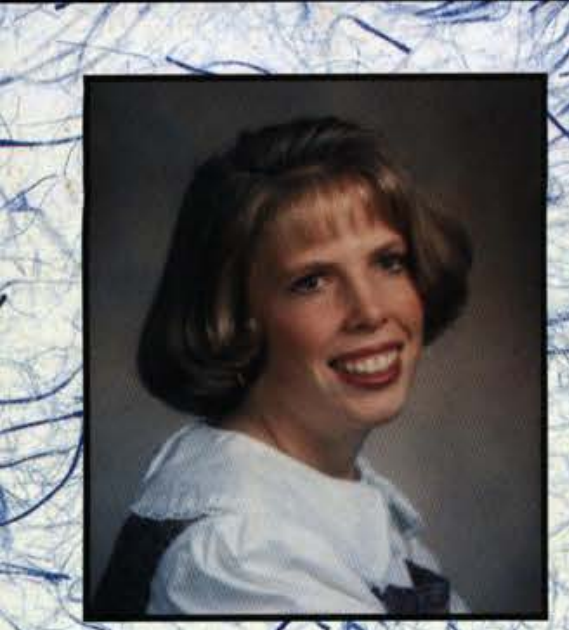

Jocelyn Kakjcuri $\%$ Elementary Education Cedarvilíe. $0 \mathbf{H}$

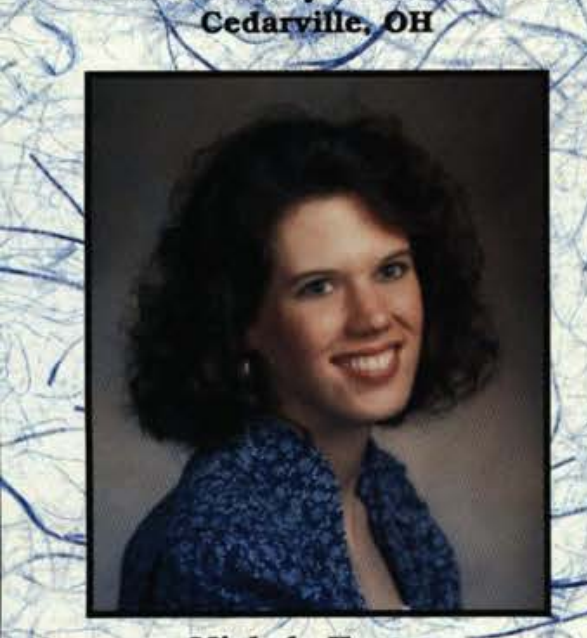

Michele Keeney Elementary Education

Carmel, IN -

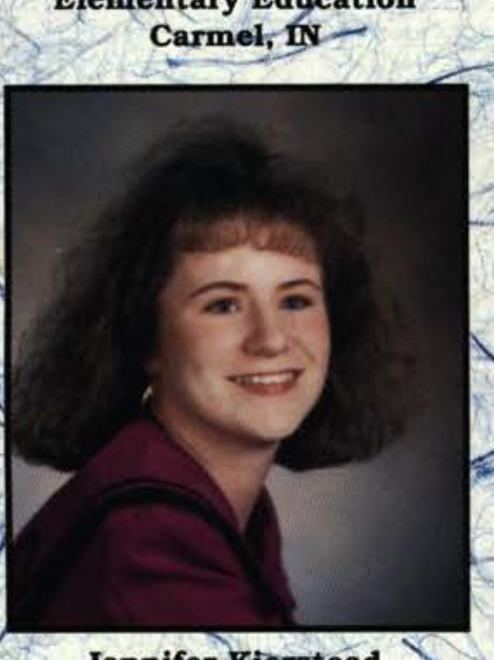

Jennifer Kierstead Elementapy Education Sandown, NH

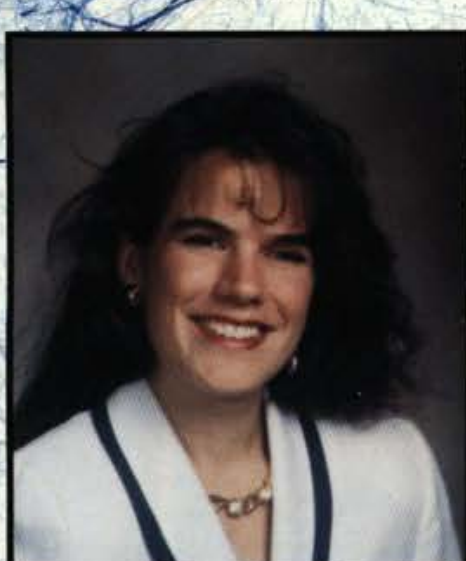

Sarah Kline Nursing Cedarville, oH 194 seniors

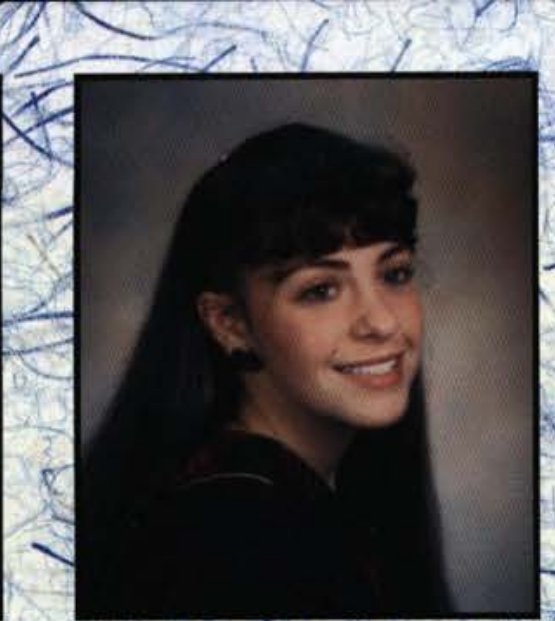

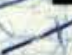

7. Nícole/ Katz Elementary Education Reynoldsburg, OH

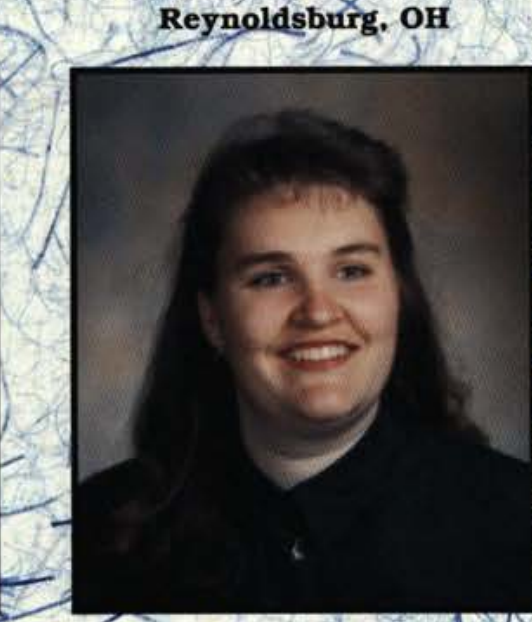

Ericka Kekic Mathematics Woodbridge, VA

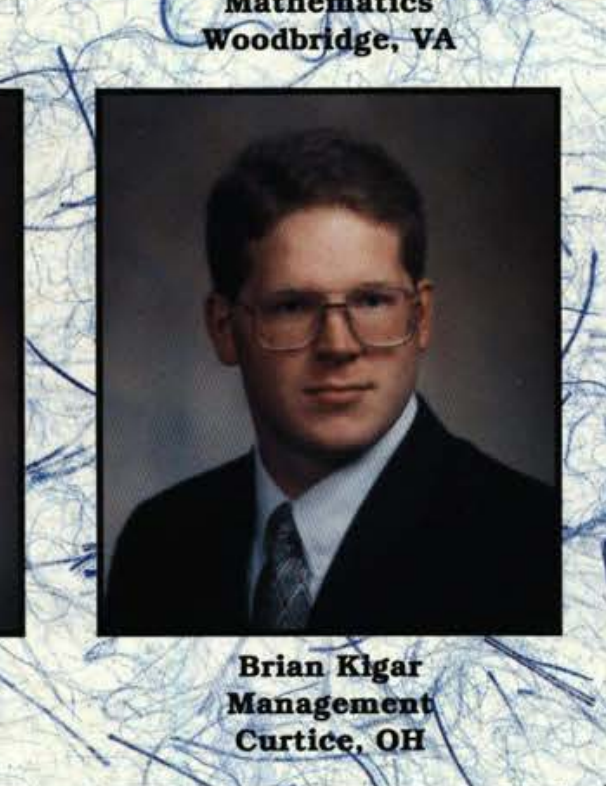

$+$
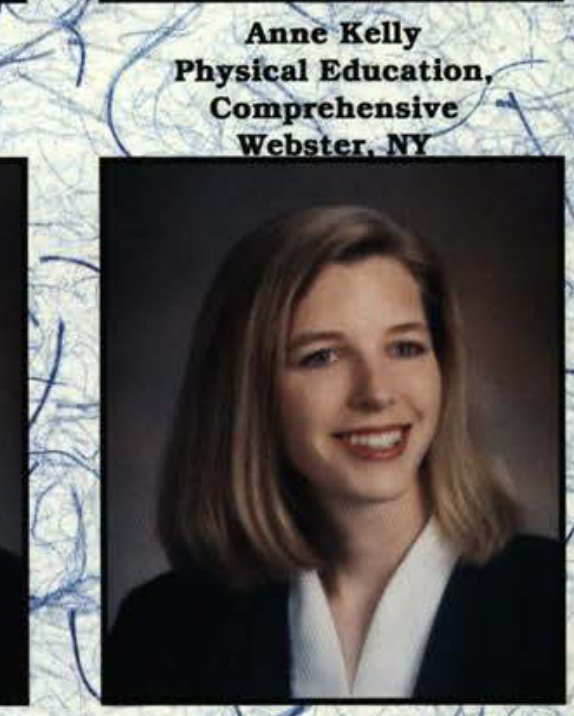

Celia King

English Education Florence, SC

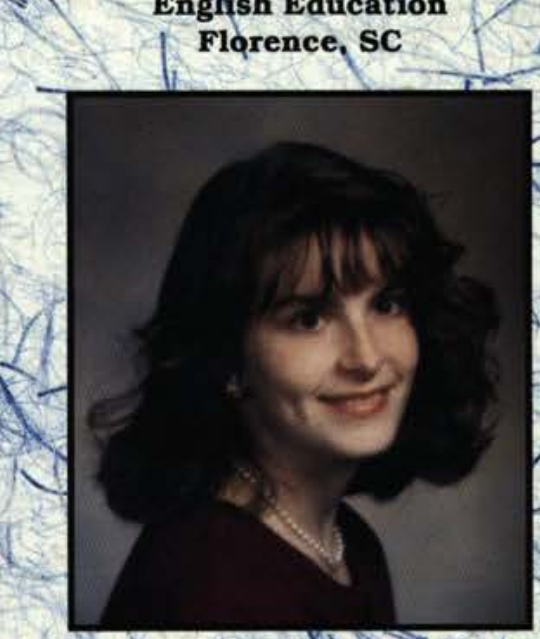

Melissa Kohlbacher Elementary Education west Valley, Nr

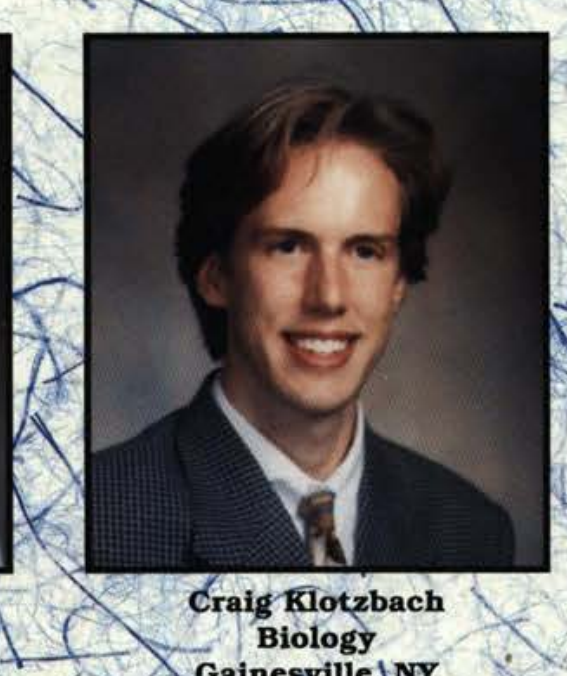
Biology
Gainesville, $\mathbf{N Y}$
Michelle Keen English Education Blaek River, NY

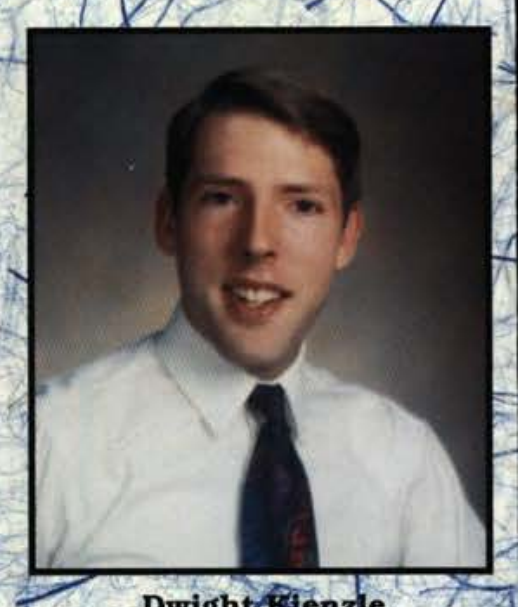

Dwight fitenzle

ounting

Silverdale WA

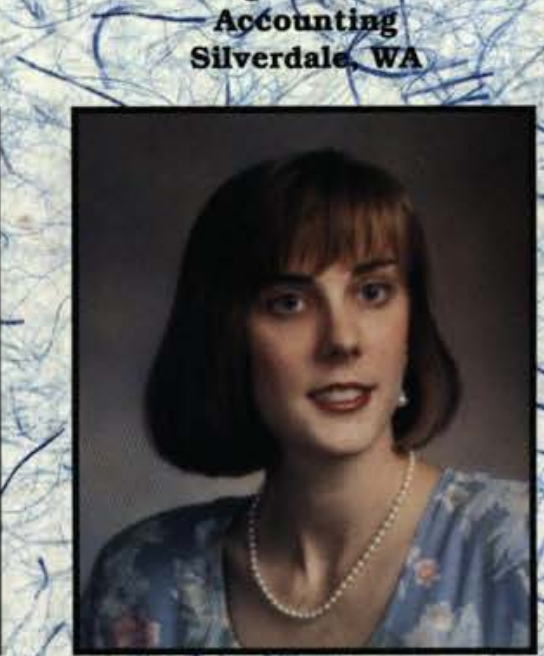

1. Stephanie Kirchoff Elementary Education Bedford, NH $3=10$ vect

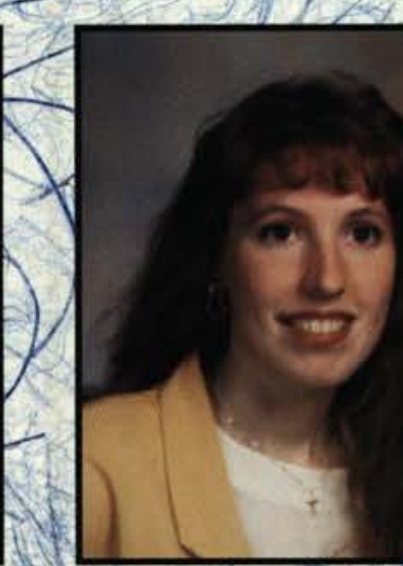

Kimberly Koziol - Accounting/Finance Adel, IA 

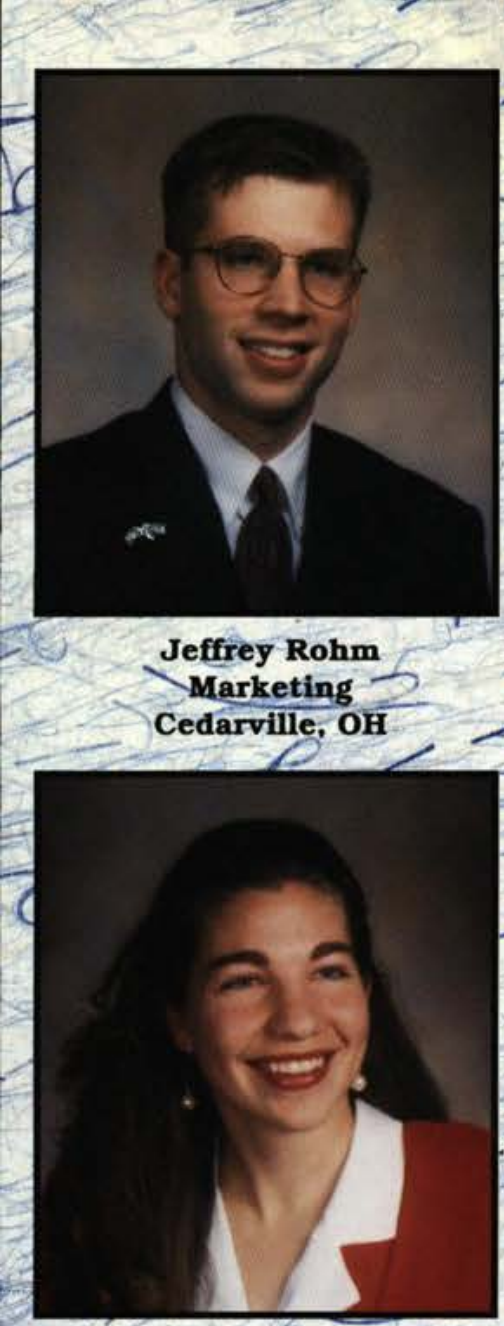

Lori Royal

Bible, Comprehensive Gharleston, IL

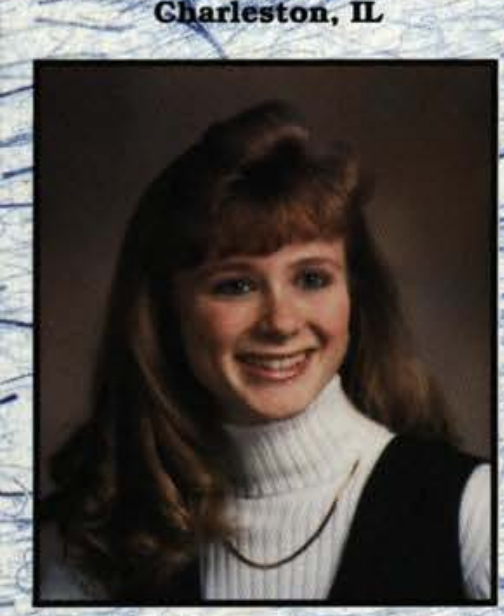

Susan Rummel Elementary Education Glen Ellyn, IL
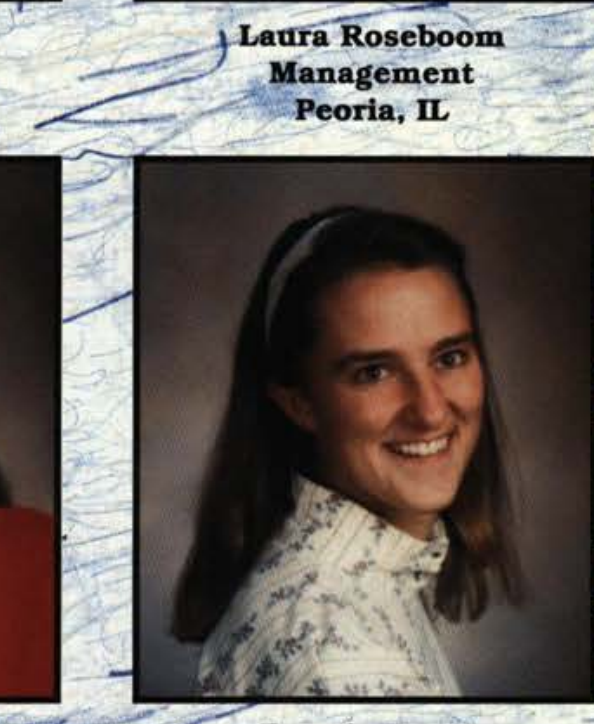

Brenda Royer Elementary Education Adel, IA
Debra Rotman Elementary Education

David Rudd Bible, Comprehensive
Muskegon, MI

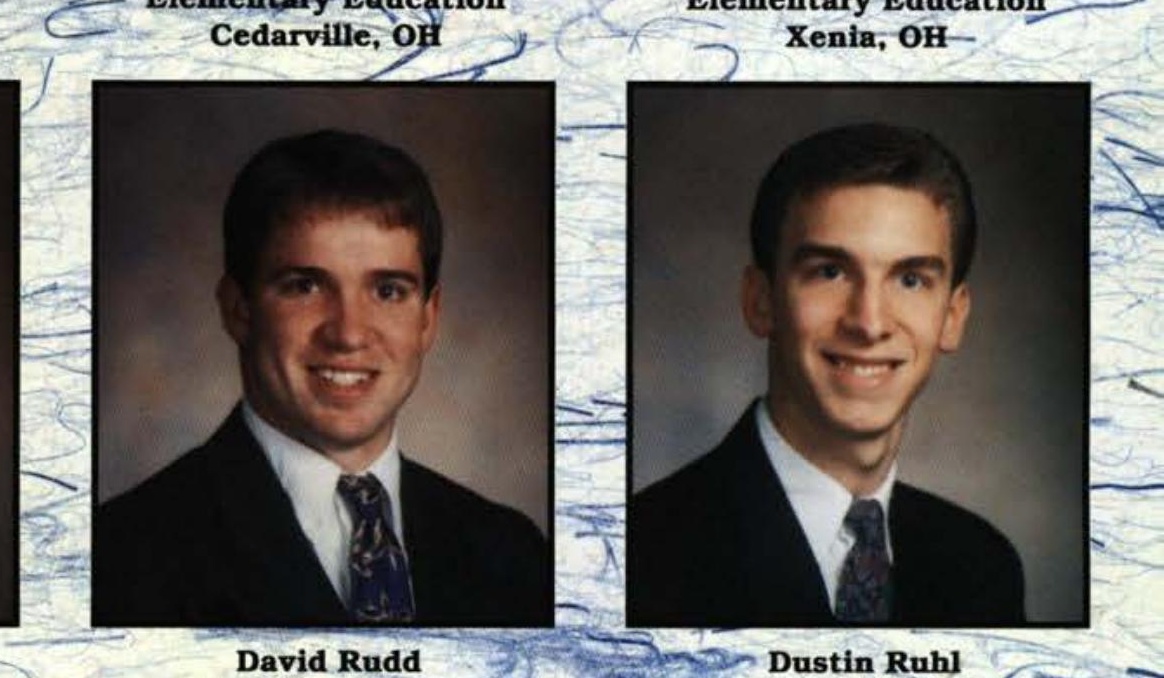

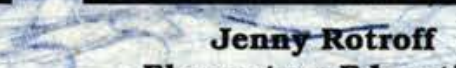

tary Education Xenia, OH -

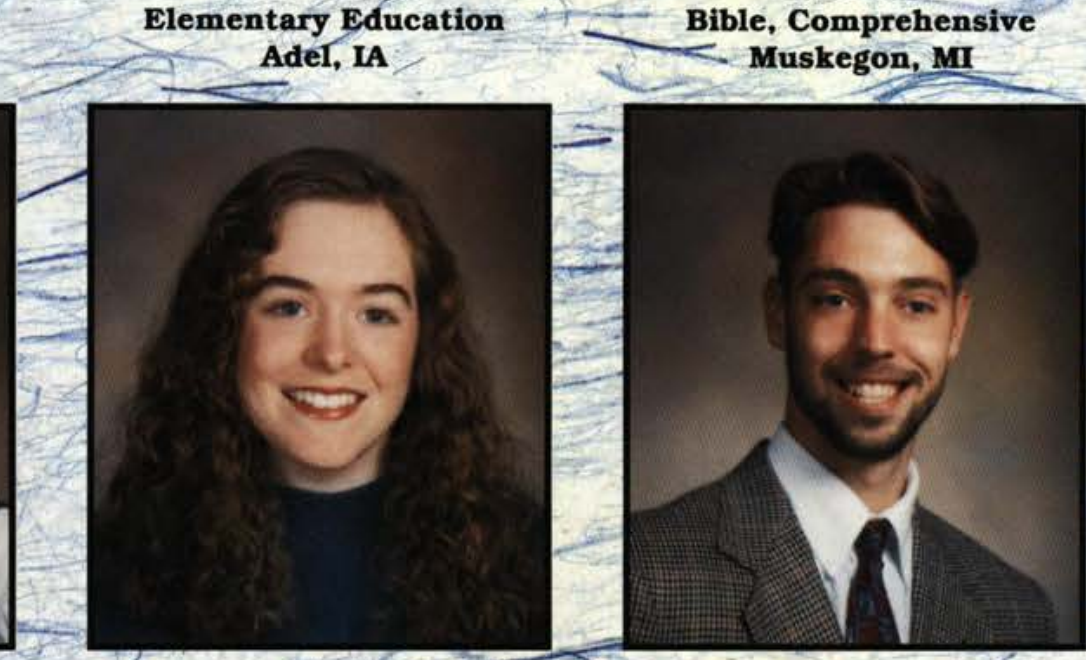

Michelle Sagraves _ Johin Sahl Celementary Education Cedarville, OH
Mathematics

Dustin Ruhl
Mechanical Engineering Derry, NH

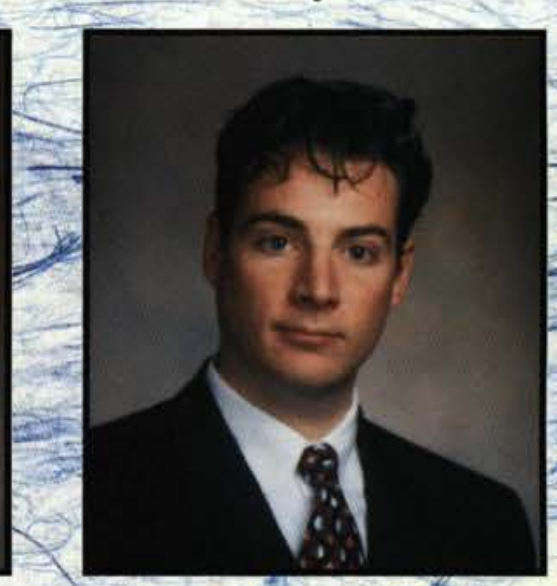

Thomas Salley Management Chattanooga, TN

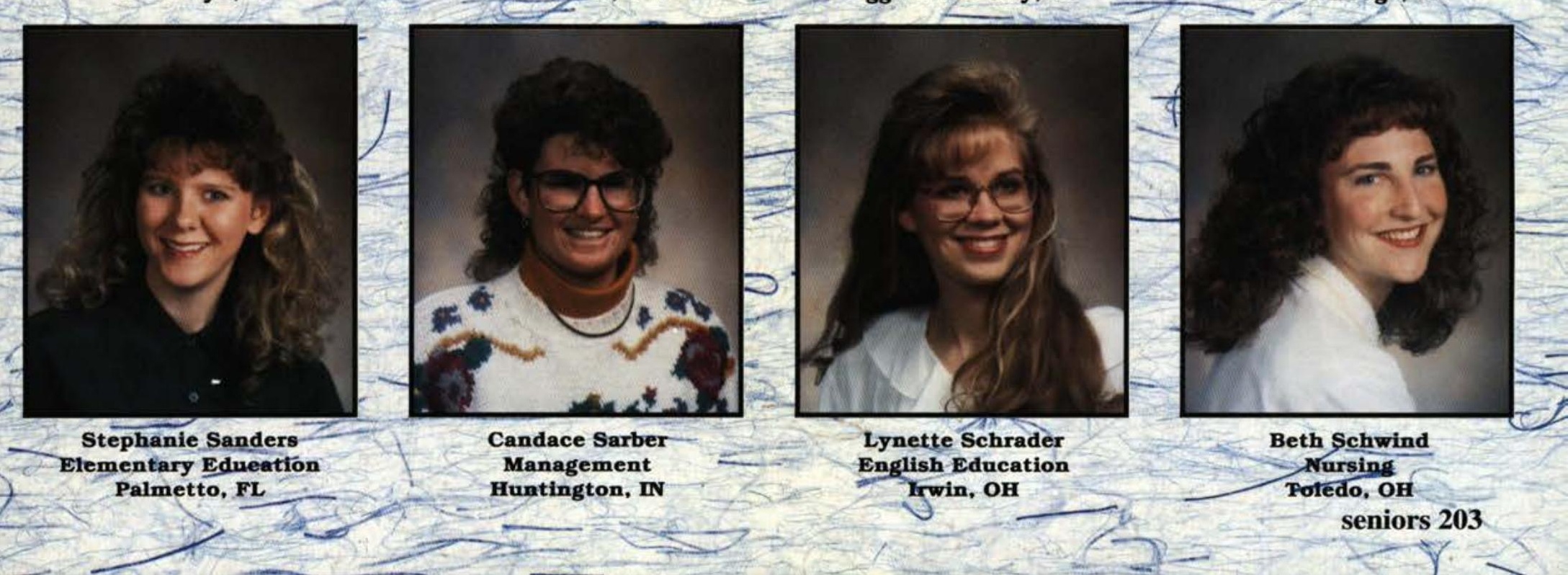



IGHT: Friends for a lifetime are made here at edarville and seniors will always remember their xperience at the 'Ville.

ELOW: Tara Wagenaar takes a break on the ixons' lawn during the reception.
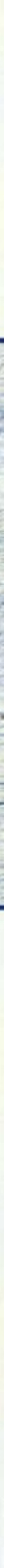

BOVE: Jennifer Zenner and Cindy Hasselbring have a picture taken with Dr. and Mrs. Dixon at the senior eception. RIGHT: Cindy Hasselbring and her brother, Blake, met Dr. Dixon years ago at an Alumni Summer inrichment Week. 

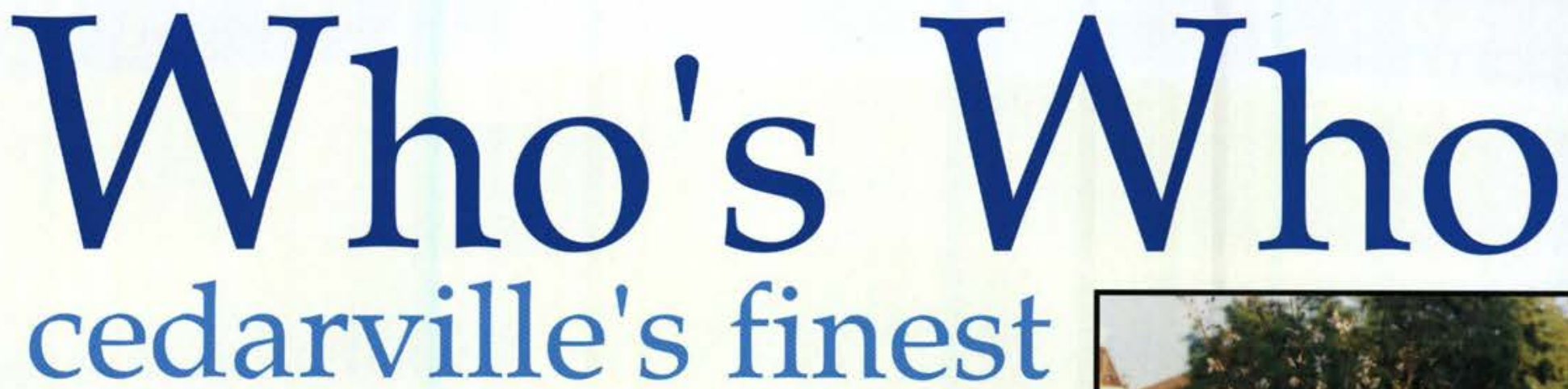

FRONT: Bill Droke, Michelle Zehr, Devon Berry, and Jen Dear.

BACK: Paige Wolfanger, Jen Butler, Jason Young, Jodi Dick, Brian Eóurman, and Chad Vitarelli.

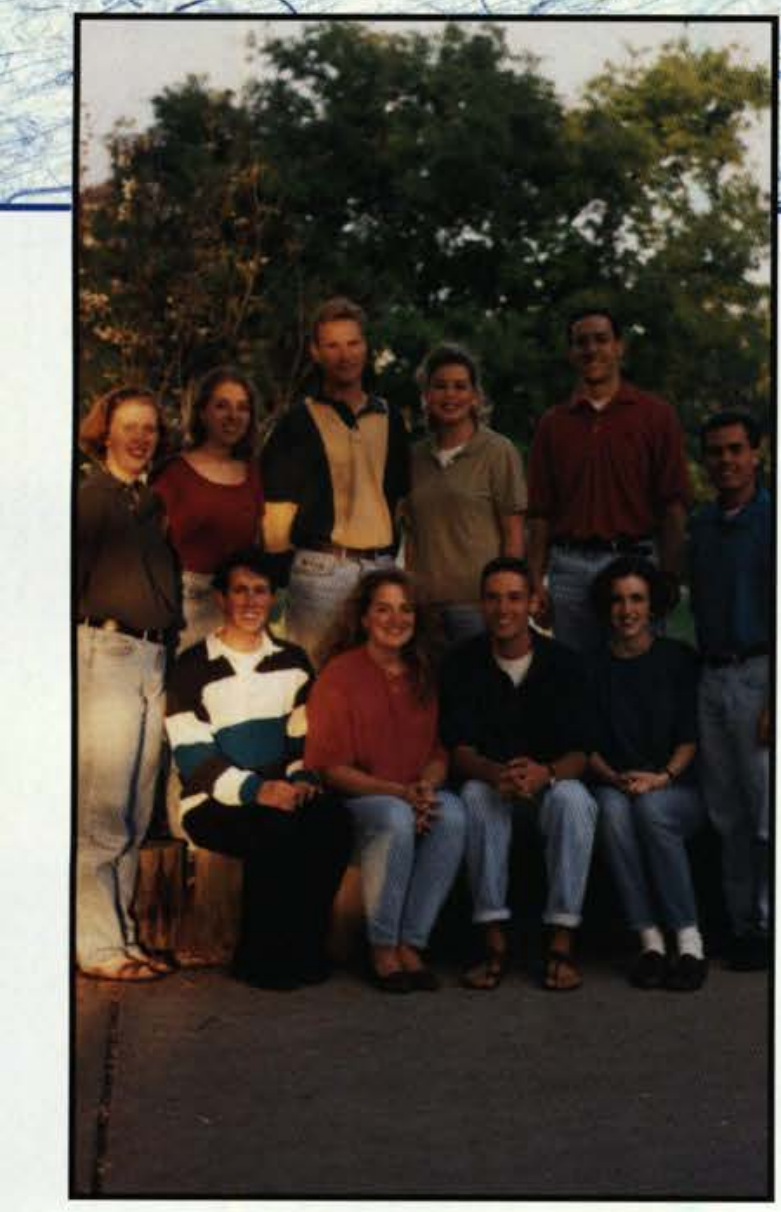

FRONT: Maria Biggs, Eric Reini, Paul Dean, and Celia King.

BACK: Erin Weaver,Tiffany Beheler, Beth Schwind, and Mike Pasquale.

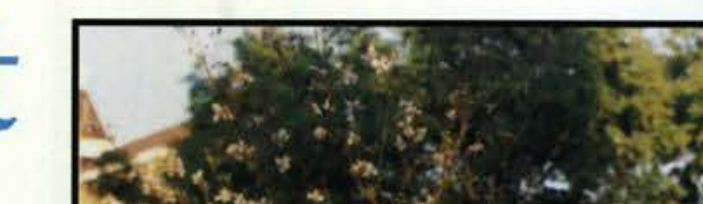


FRONT: Matt Reynolds and Randal Snell.

BACK: Kristi Coe, Lisa Coe, Debra Rotman, Mandi Secord, and Karyn Hartman.

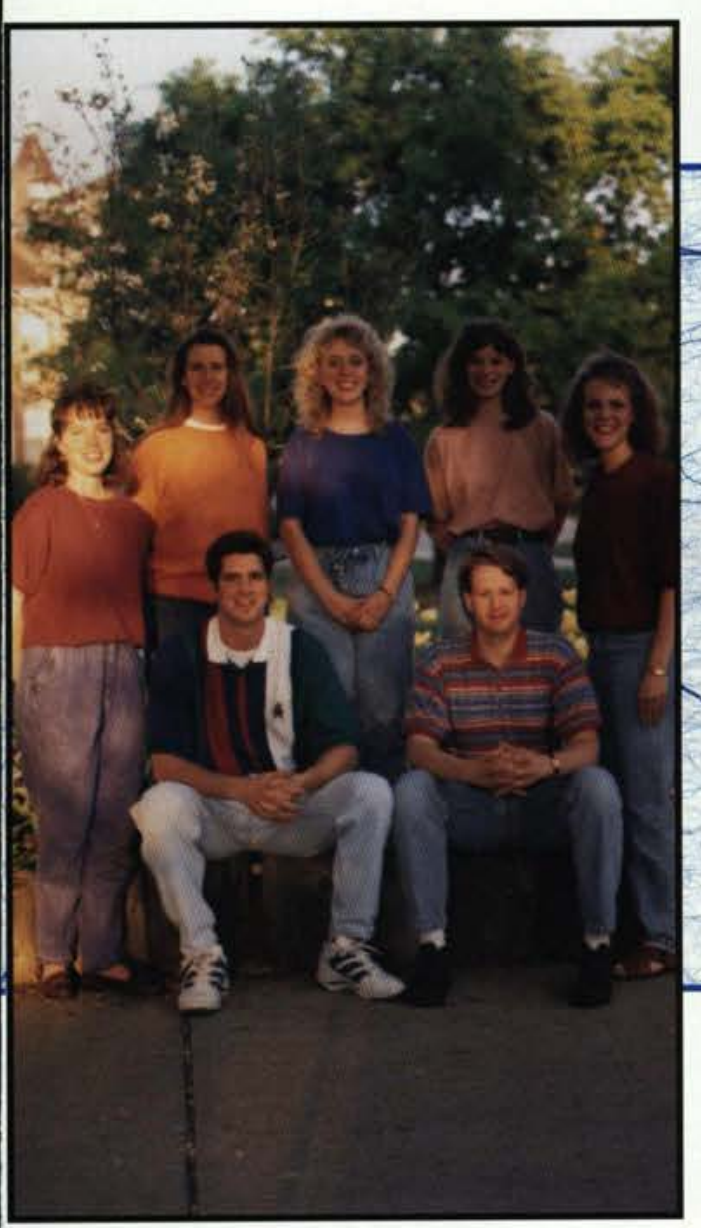

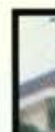
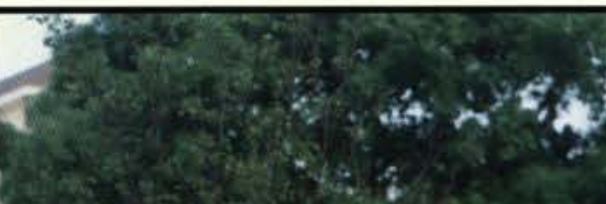

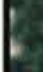

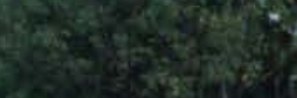
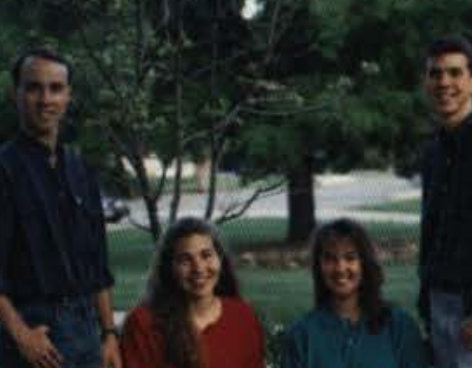

ERONT: Todd Entner, Lori Royal, Tara Prentis, and Mark Zuiderveen.

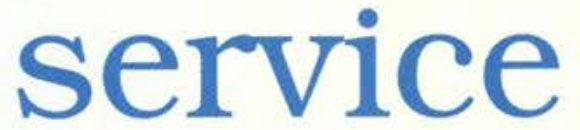

leadership
NOT PICTURED: Jen Bartosiewicz, Kevin Fath, Mark Jones, Ruth Kaercher, Brent Luman, Jonathan Misirian, Stephanie Sherman, and Erin Wawro.

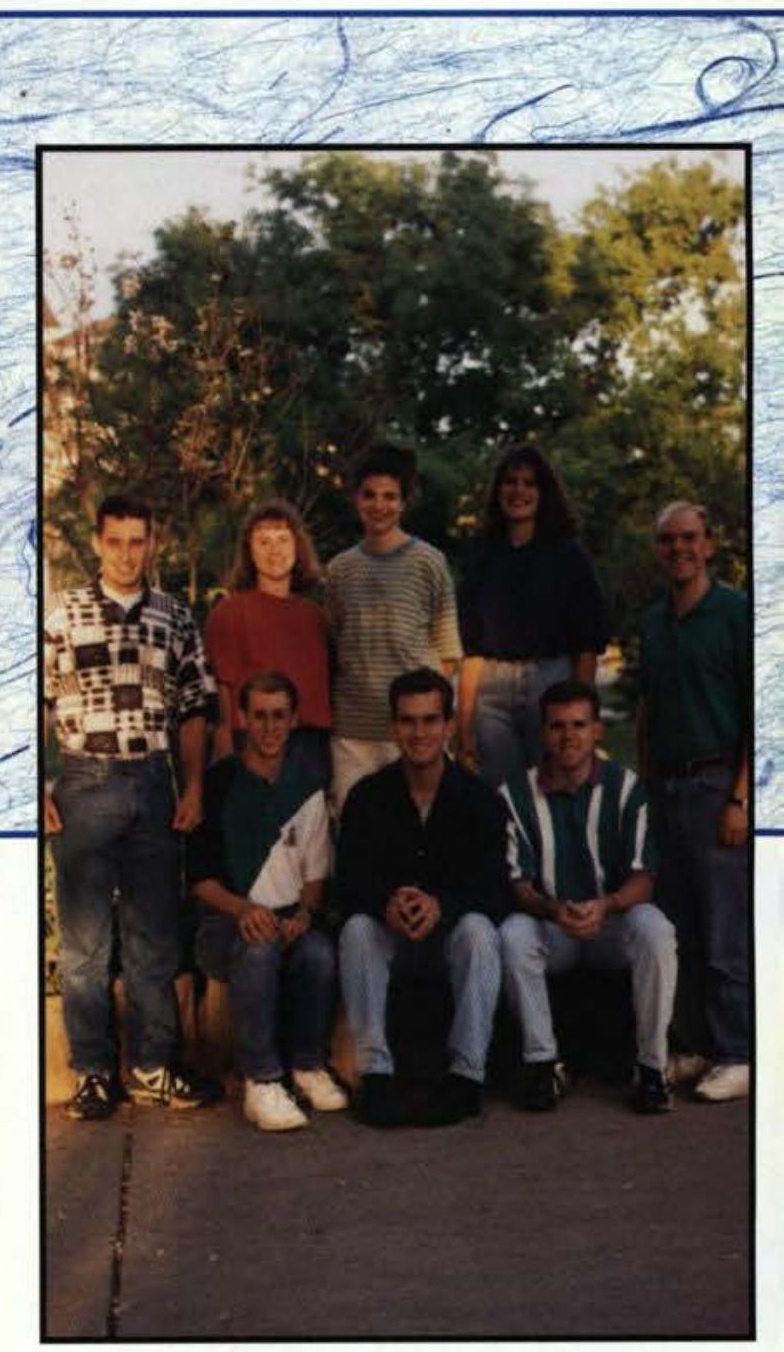

FRONT: Chris Handel, Dave Wilson, Scott Harley.

BACK: Troy Hamilton, Jen Kierstead, Amy Barnes, Sarah Kline, and Joel DeVinney. 

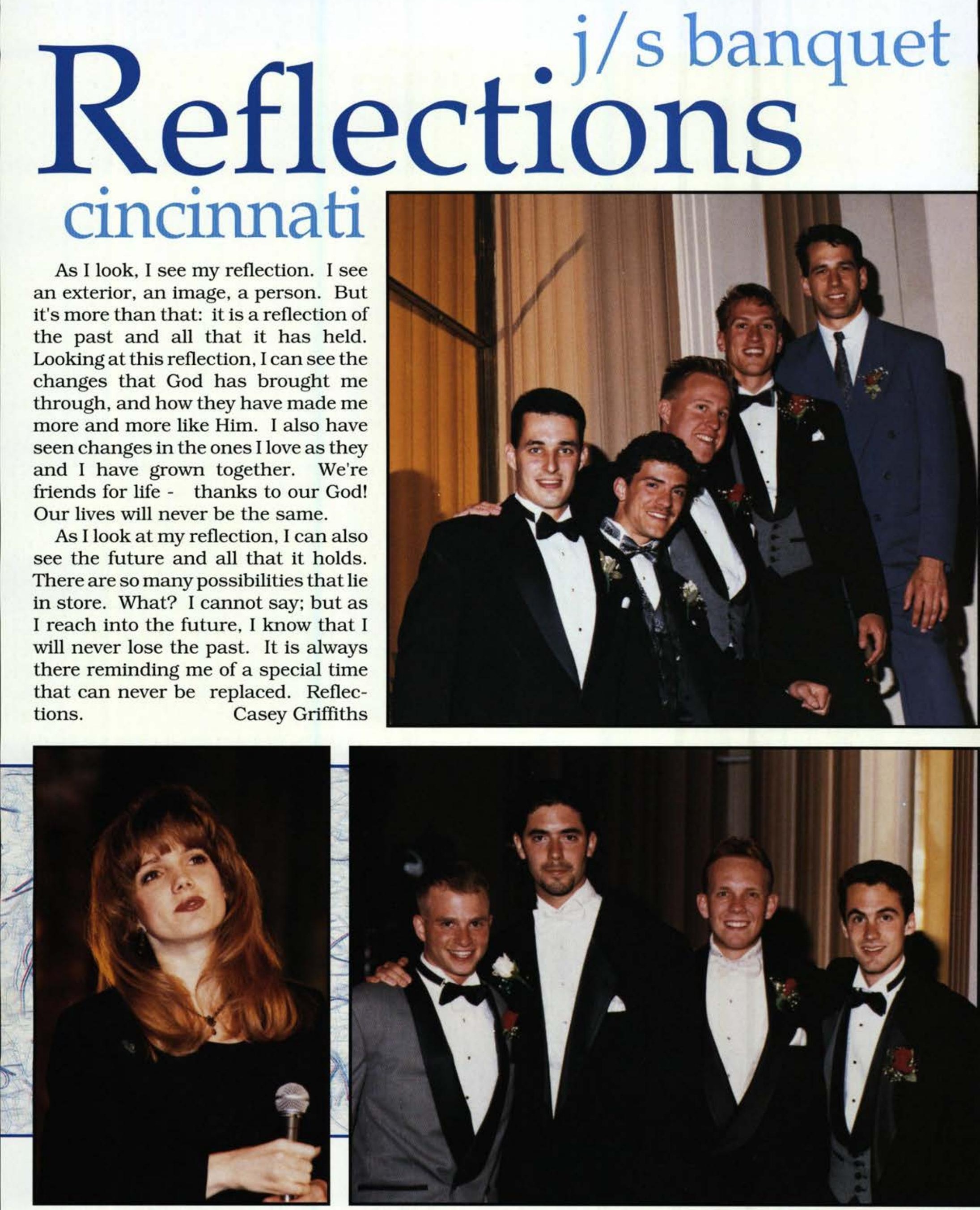

ABOVE LEFT: Cheri Keaggy provided the entertainment for the J/S banquet. ABOVE: The quartet, John Iamaio, Jeremy Haskell, 


\section{the
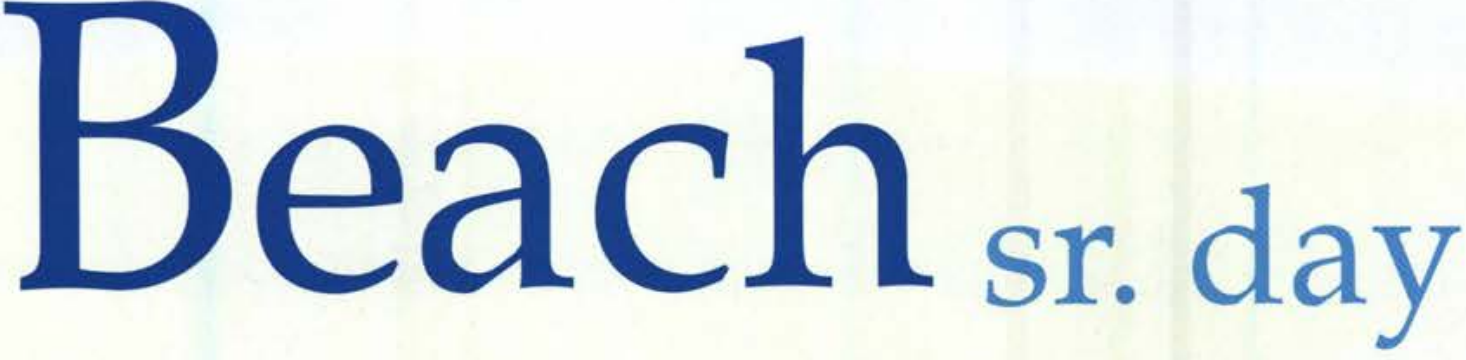

RIGHT: These seniors take a break from swimming, the slides, and wave pool to grab a bite to eat.

BELOW: Friends for life. Lori Royal, Tara Prentis, and Stephanie Sanders spend one more fun filled day together.

BOTTOM RIGHT: Seniors spent the day getting a great tan and squinting in the sun at the Beach.
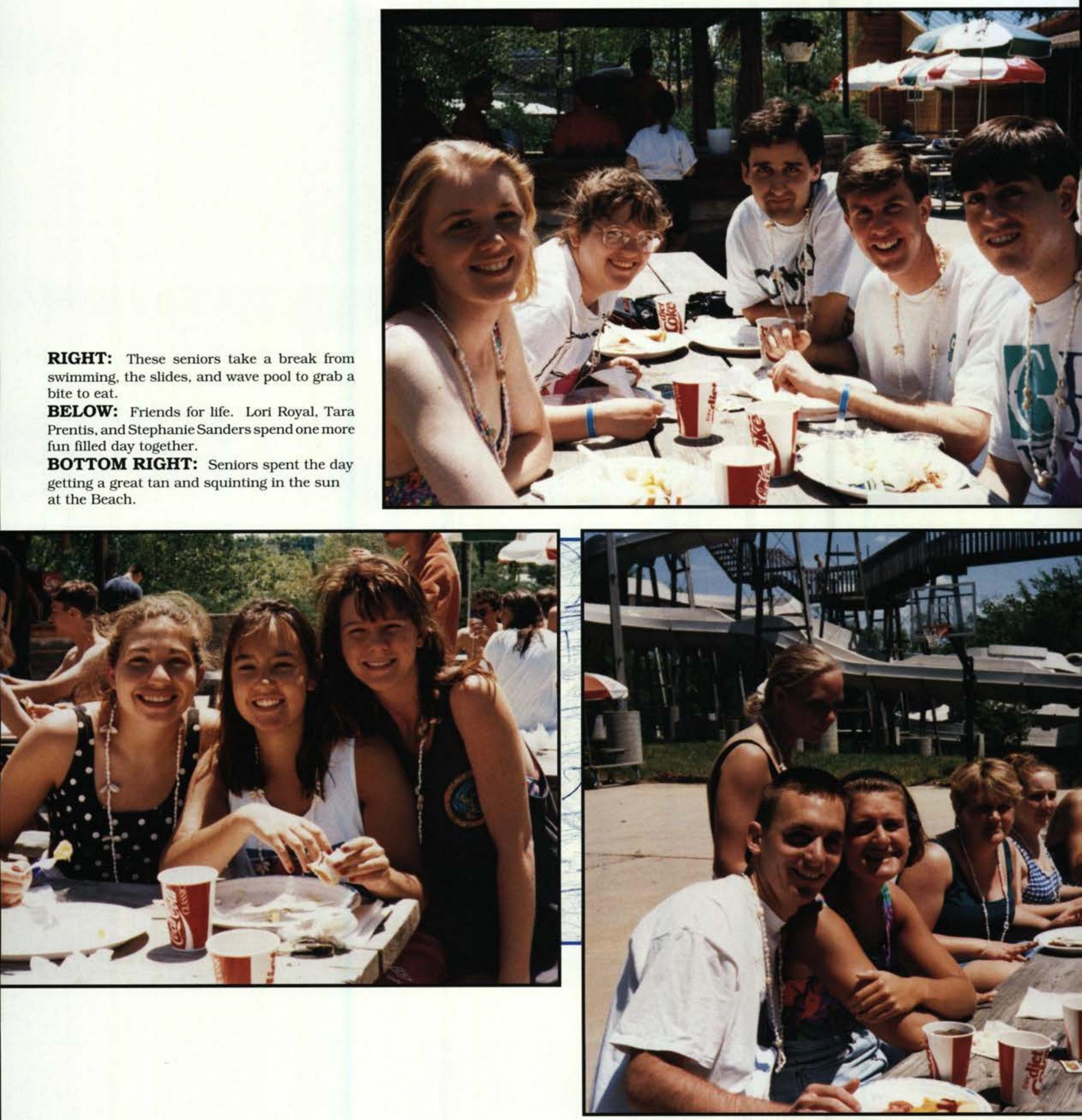


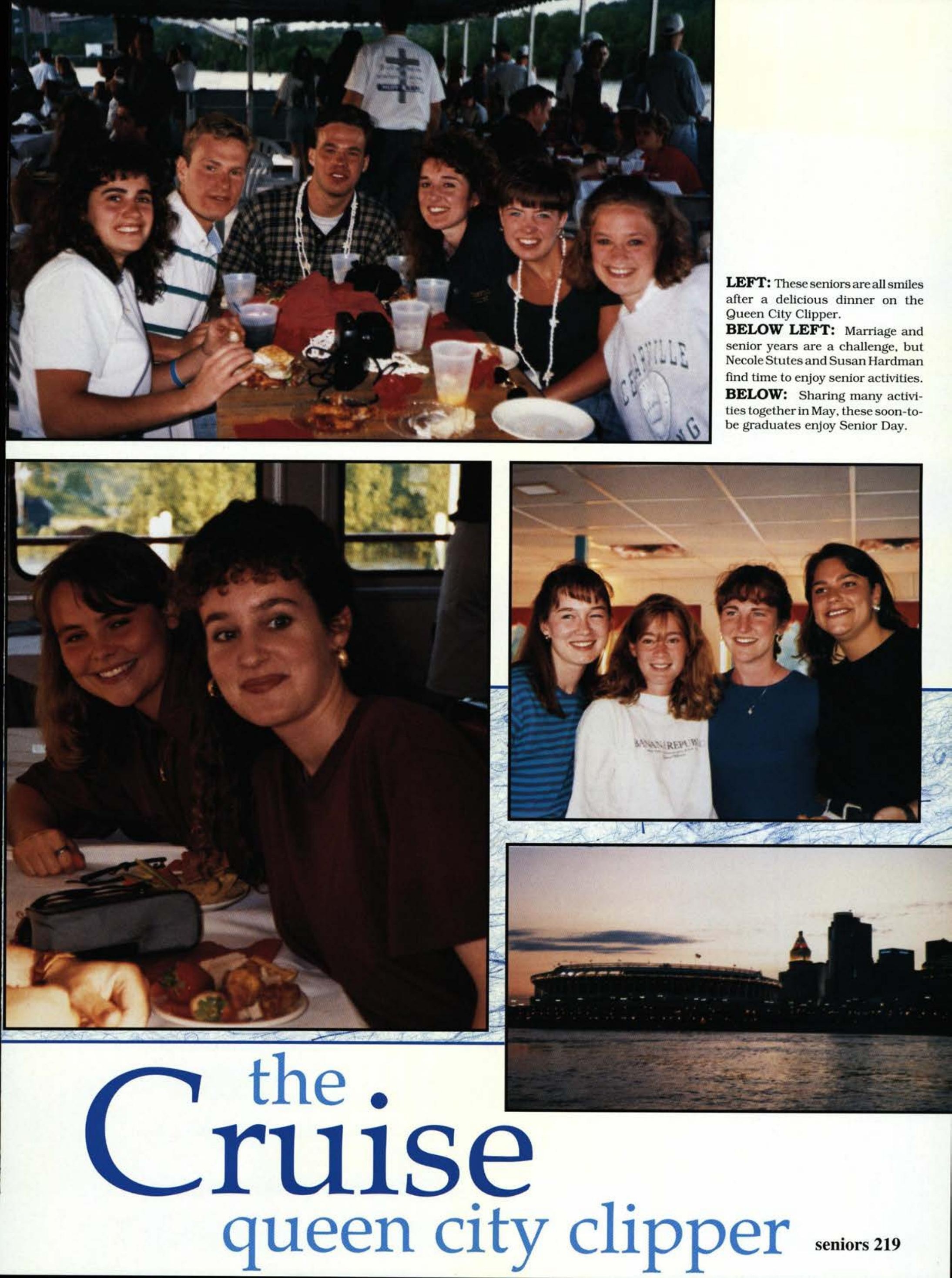



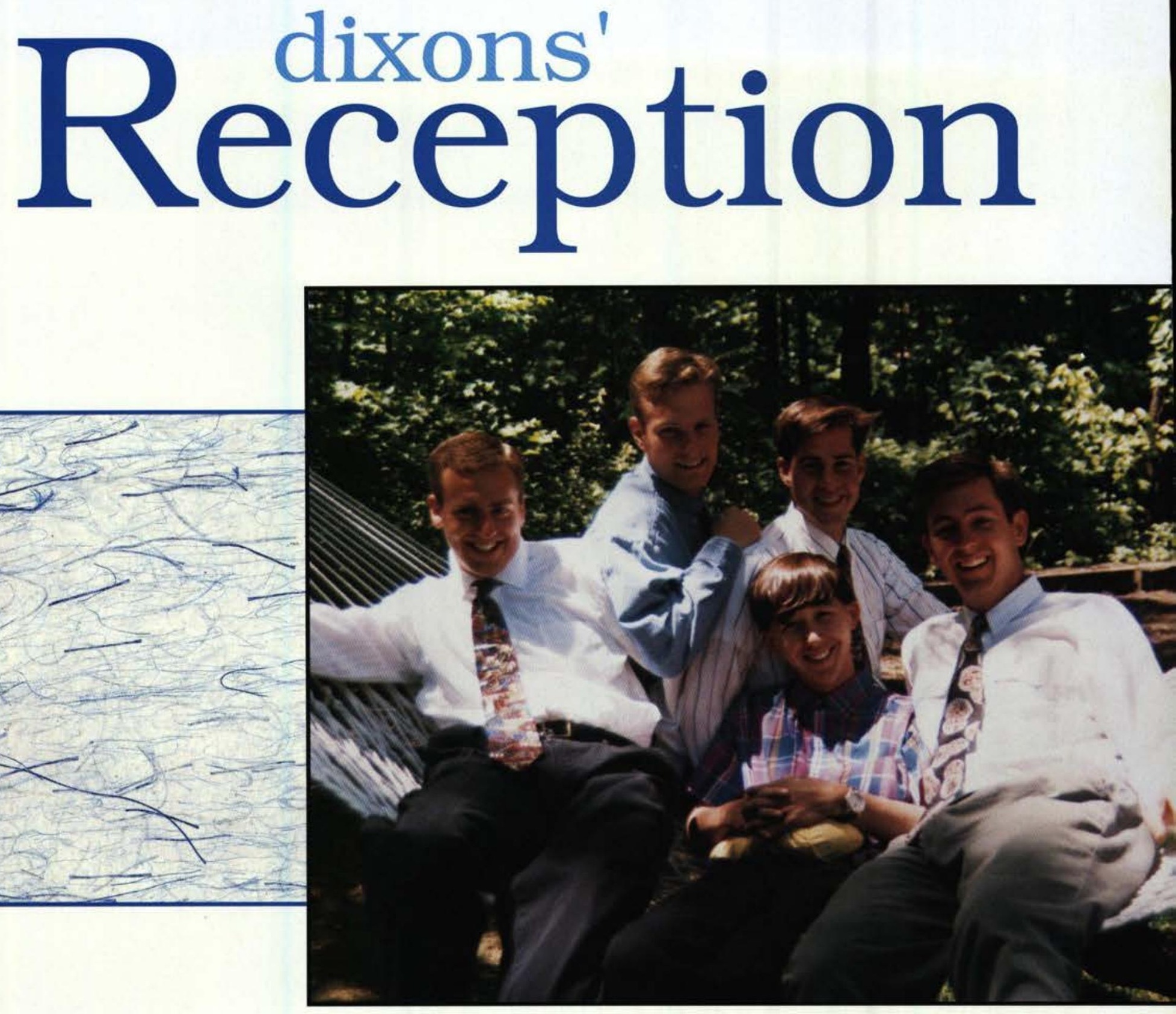

ABOVE: After four long, hard years these seniors take a break in Dixons' hammock.

RIGHT: Shaundra Randolph and DeVonne Henry enjoy a delightful afternoon at this special reception.

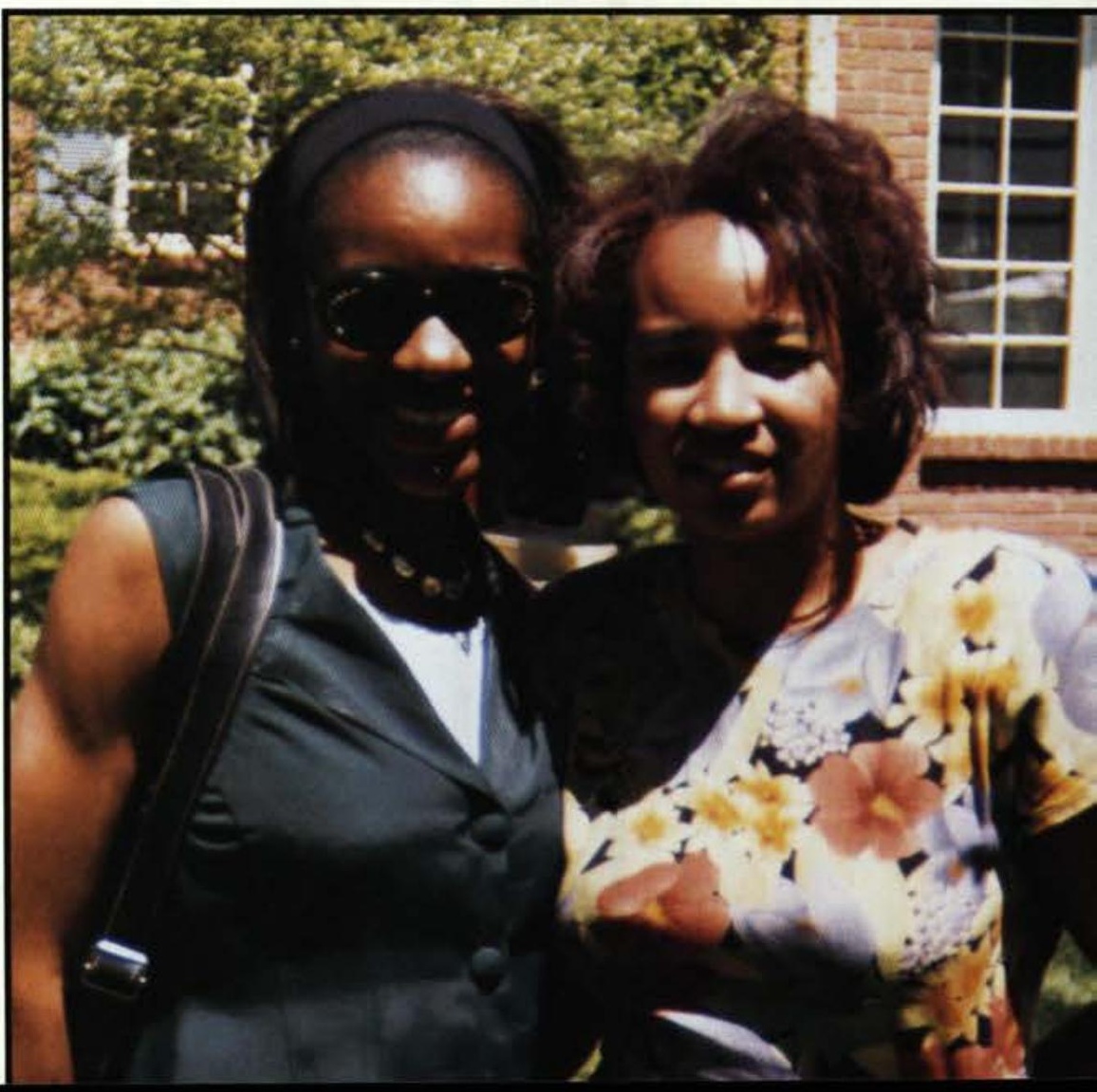




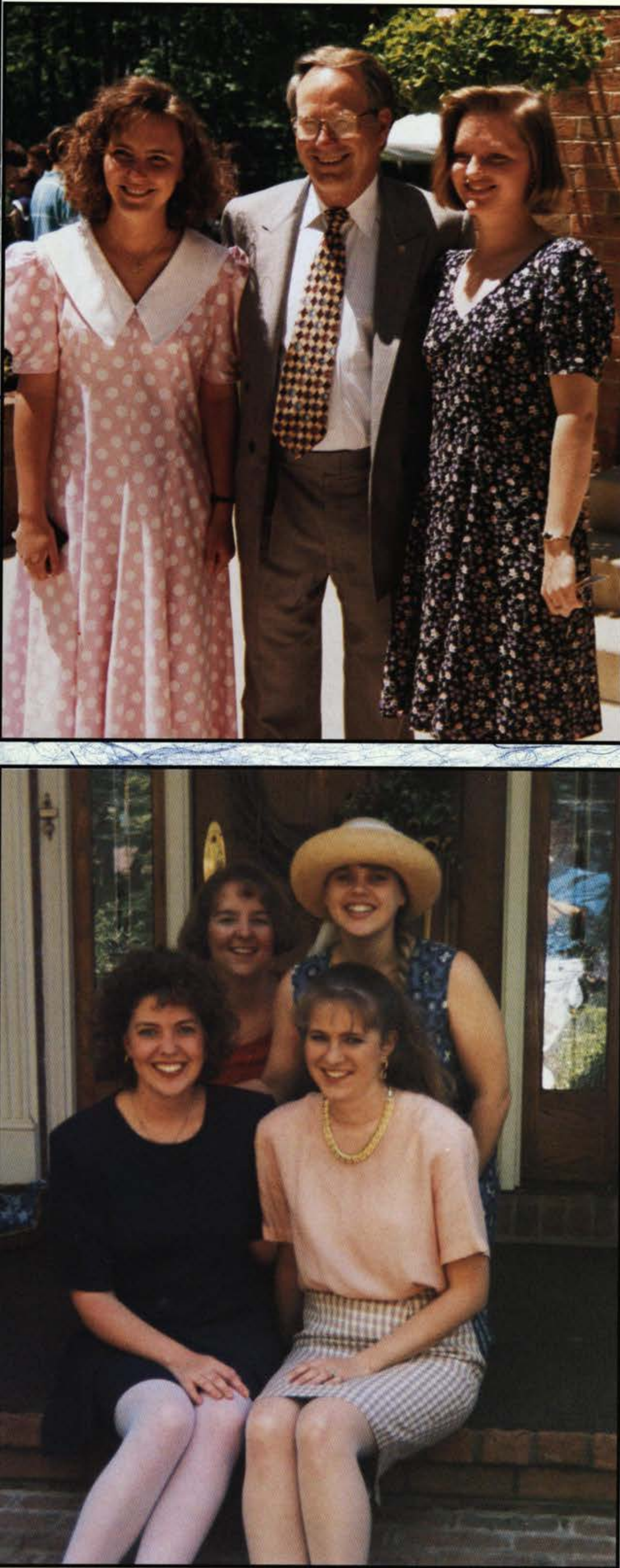

LEFT: These girls pose with Dr. Dixon, a man of great influence in many students' lives, to remember their years at Cedarville College.

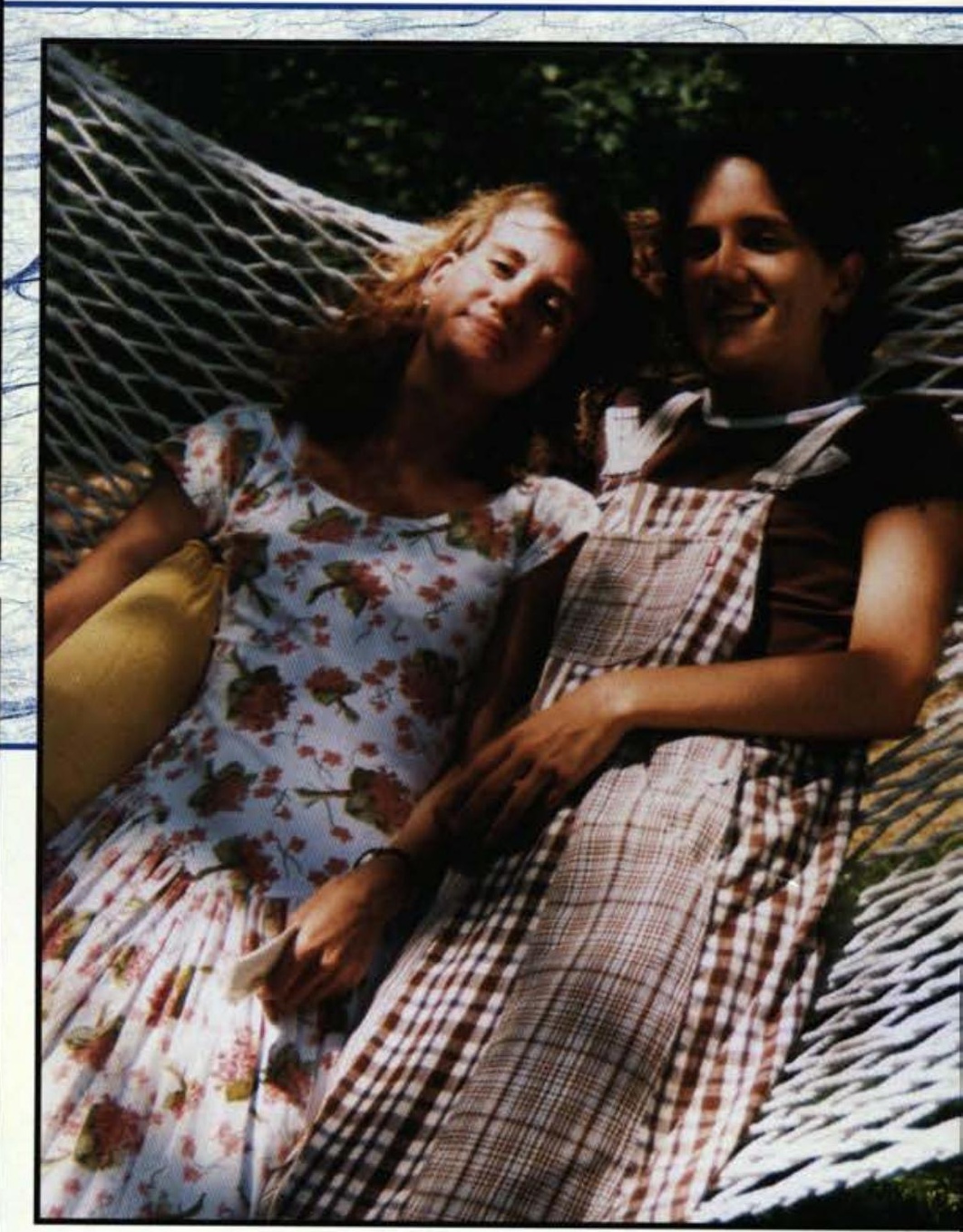

LEFT: SMILE! Graduation is next!

ABOVE: The hammock is a common spot for seniors at the Dixons'; you can relax and forget the books for an hour. 

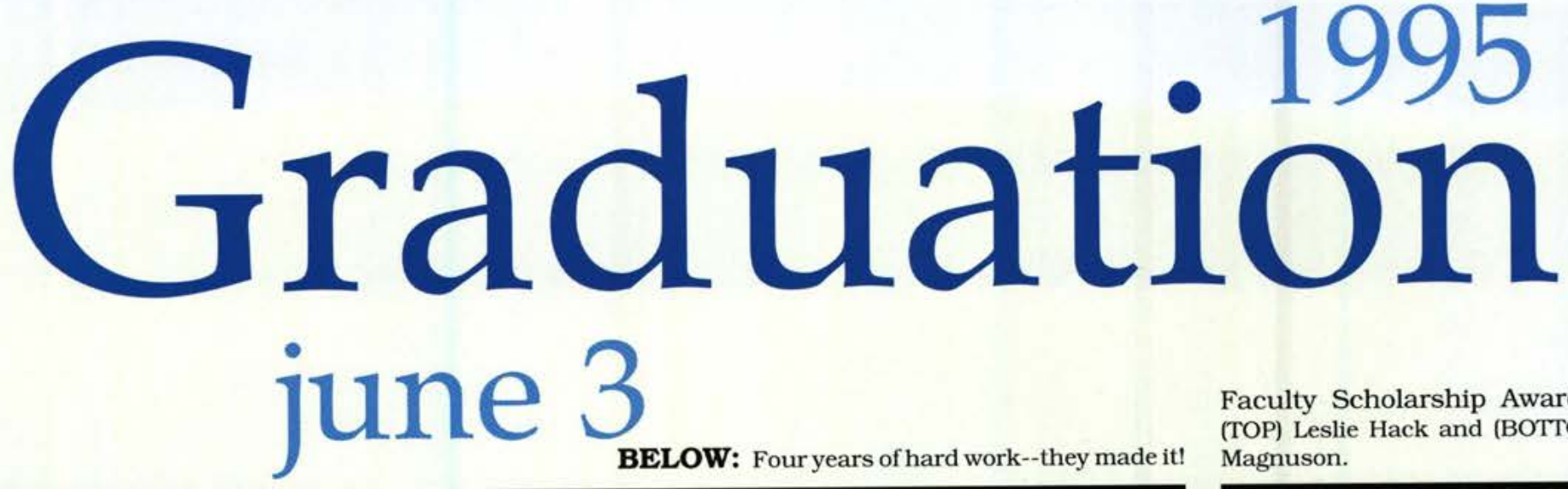

Faculty Scholarship Award Winners (TOP) Leslie Hack and (BOTTOM) Heathe Magnuson.
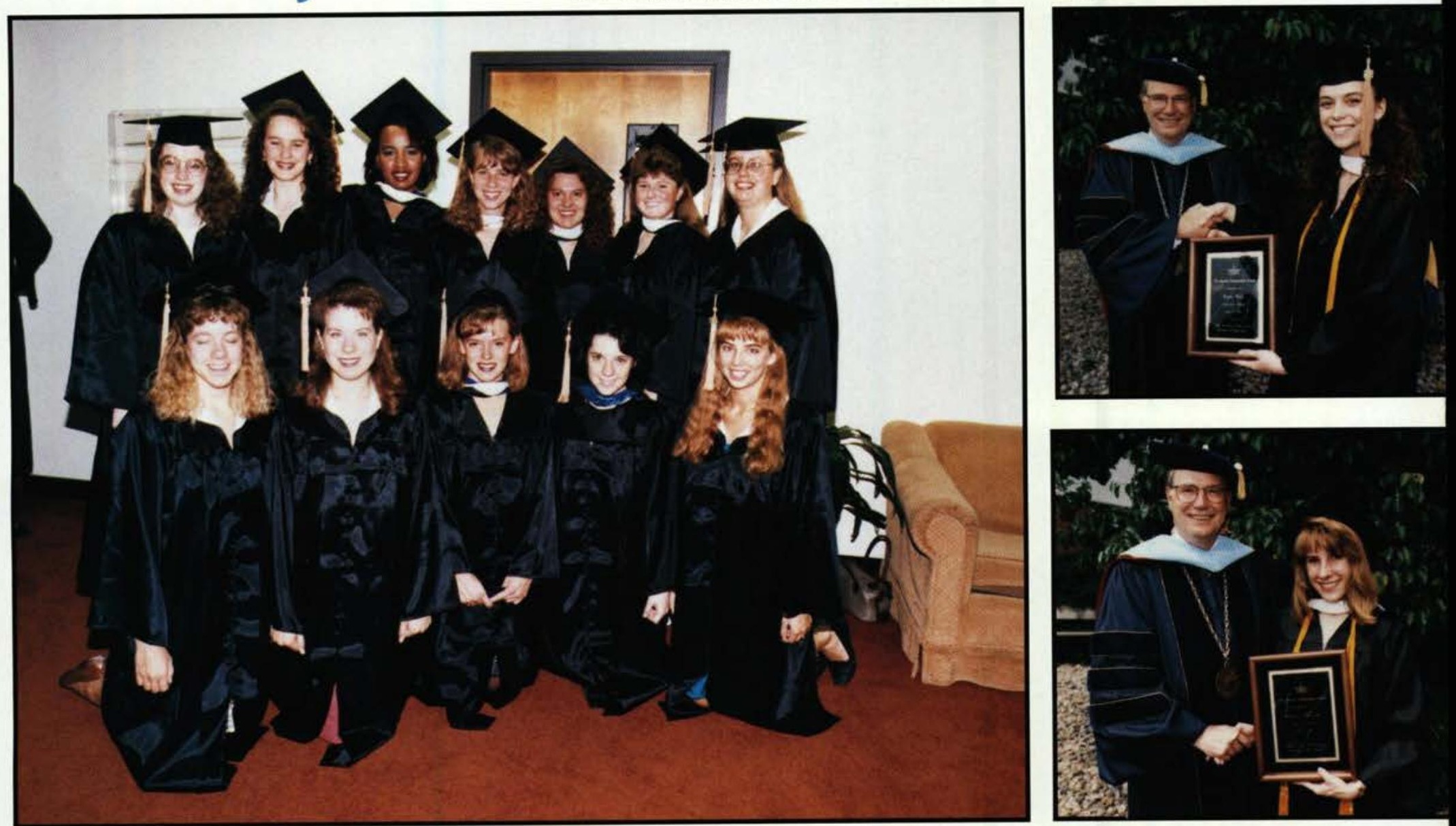

"Am I in the right row? Am I in the right seat? Is the hood straight? Am I going to trip over the floor covering?. How will I know which chair to stop by? Is the hood straight? Do I know the words to the class song? Where's my program? Which hand dor shake with and take the diploma with? Is the hood straight? How will $I$ find $m y$ family after this is all over?

The graduates' minds flew frantically over each of these thoughts a hundred times between 10:00 a.m. and noon on that last hot, muggy Saturiday morning. Afterall, none of them yanted to do anything stupid on the video tape that they'd have to try to live down for the rest of their lives.

The symphonic Winds, directed by Mr. Mike DiCuirci, preluded the cer- emony with the "Great Ceronation Hymn" and ushered the graduates in with "Sine Nomine." Dr. Eugene Apple, Chairman of the Board of Trustees, gave the invocation which was followed by the Concert Chorale's stirring performance of "A Mighty Fortress is OurGod," directed by Dr. Lyle Anderson. Dr. Paul Dixon then welcomed everyorie to the graduation ceremony. The Chorale's "Soon and Very Soon," an appropriate song for the becasion, preceded Dr. James $T$. Jeremiah's reading of Hebrews 10:19-25. Last of all, Dr. Dixon addressed the graduates and their families as each prepared to go through one of the most important changes in his lives--the final step into

adulthood.
Just before the 483 graduating oe niors stepped up to cross the stage fo: their degrees, the congregation sang "My Hope Is in the Lord." Class presi. dent, Troy Hamilton, presented the class gift, a brass replica of the schoo seal, to Dr. Dixon, and the class sang their song, "From This Moment On.' Afterward, the senior class advisor Jane Adams Smith, dedicated every one of them in prayer. The singing of the alma mater was followed by PG benediction, his last as campus pastor As the graduntes filed outside, they heard the Symphonic Winds play Pomp and Circumstance" and could barely hold in their excitement until they could celebrate with their familieswhen they found them.

(e) $x$ )
Kathy Smar

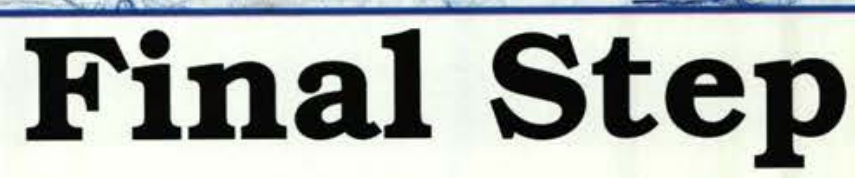


ELOW: Dave Whisman is returning to $\mathrm{s}$ seat after receiving his diploma.

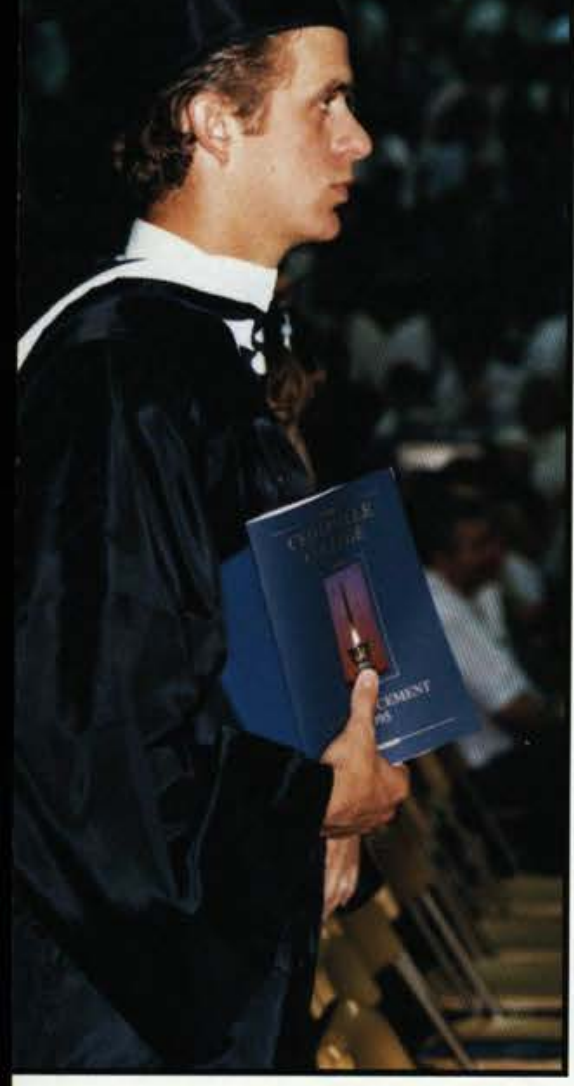

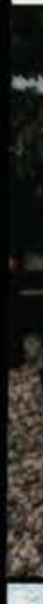
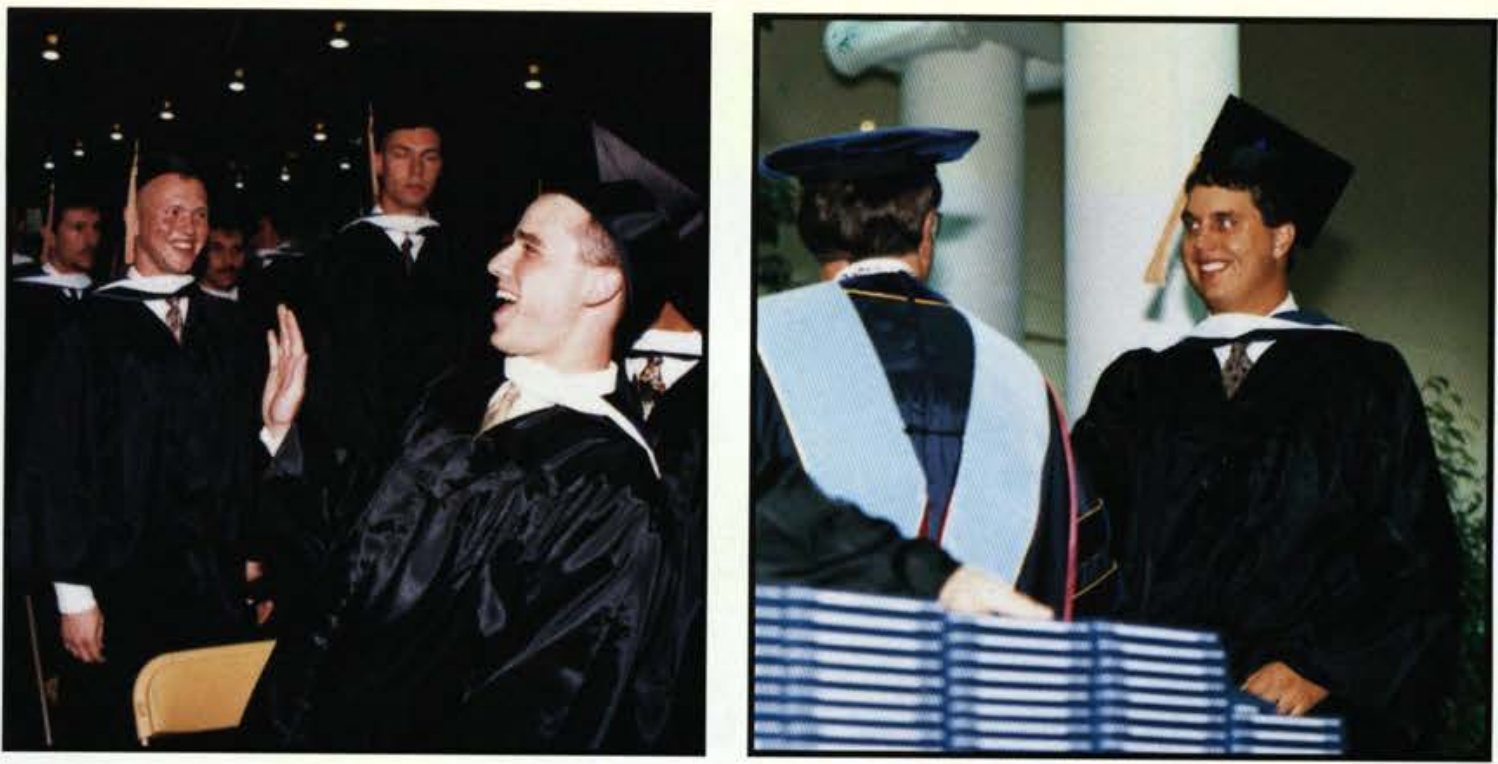

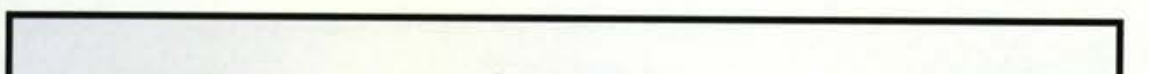

ABOVE LEFT: Brent Underwood looks to Brian Burns for the high five. ABOVE: Dave Majeski receives his diploma from Dr. Dixon, something he has looked forward to. LEFT: Friends for life are made here at the 'Ville. We must all part after graduation, but the memories will remain forever. 


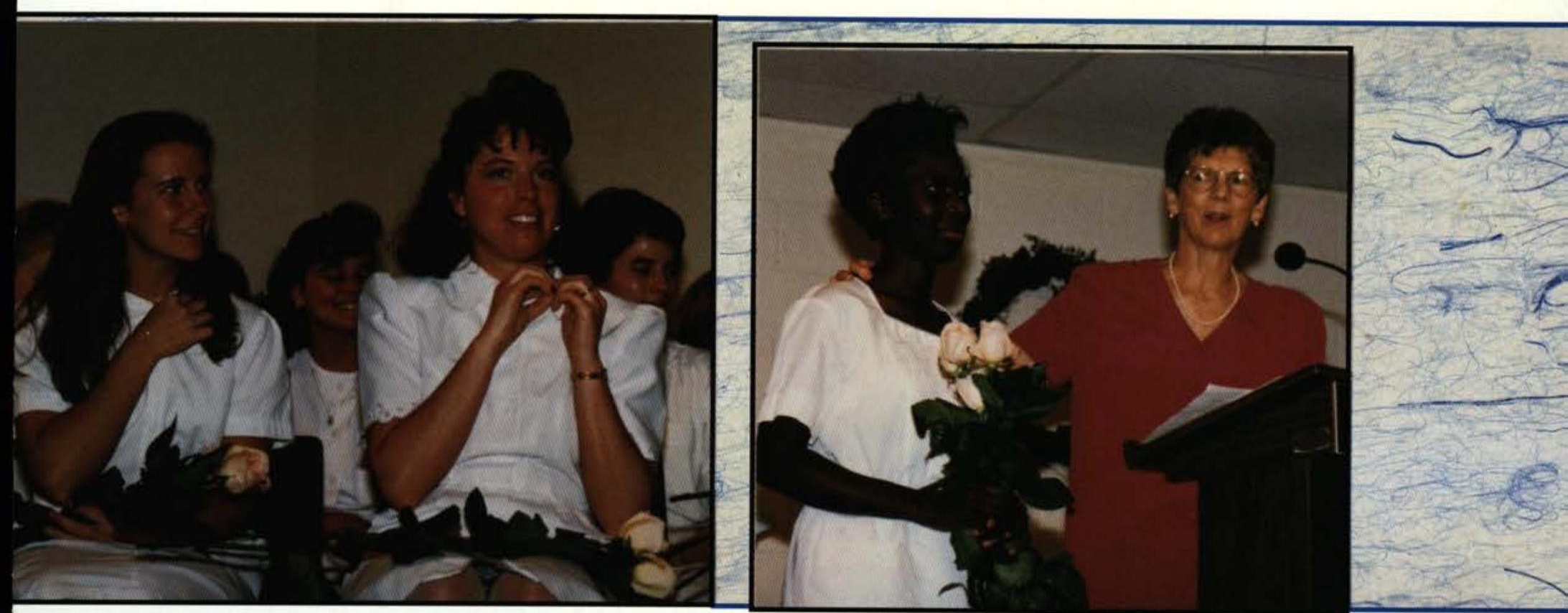

\section{OLLEGE}
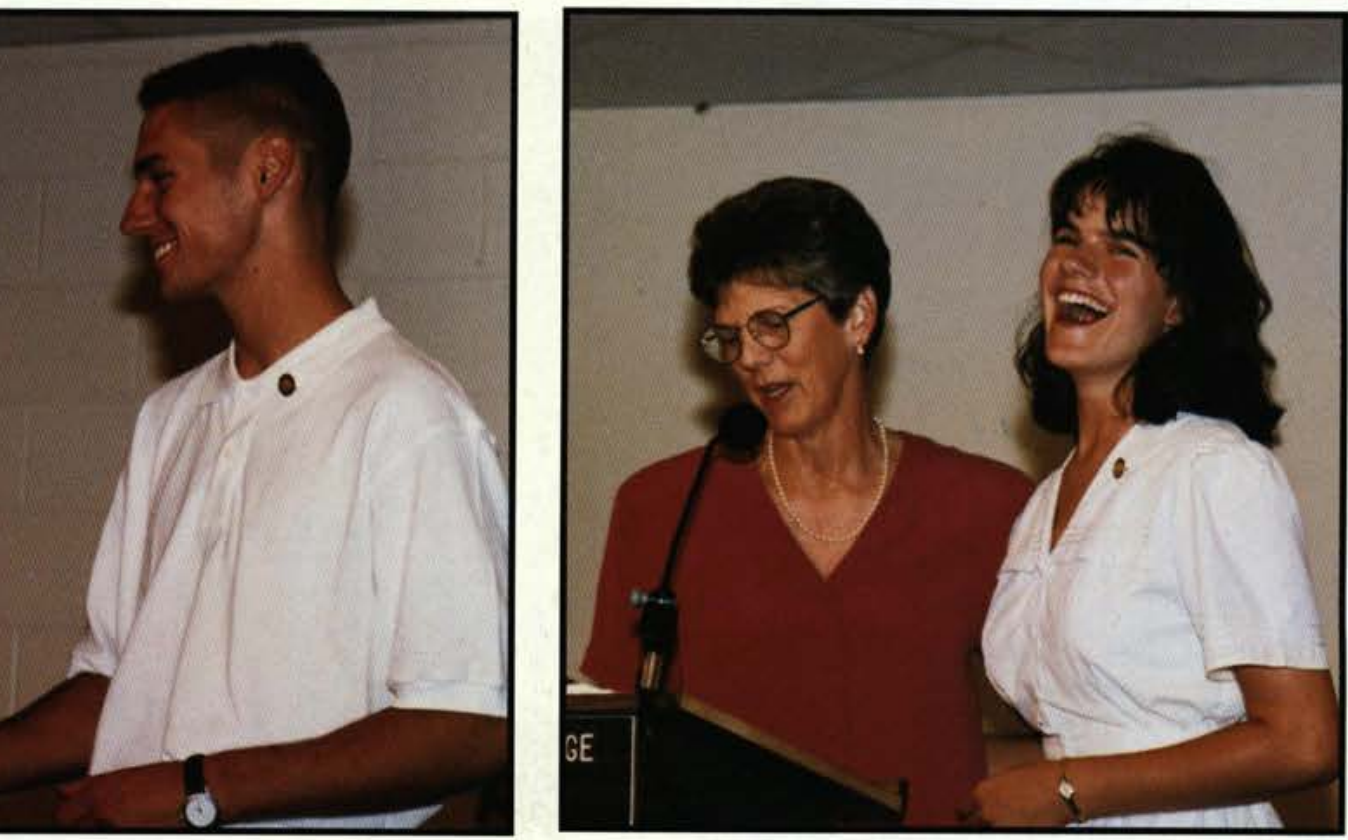

TOP LEFT: Academic Achievement Award-Kristi Walker

Coe.

TOP RIGHT: Students and professors show great pride in accomplishment.

ABOVE: Character Award-Devon Berry

LEFT: Darren Young gives a thumbs up on his way to the platform to receive his pin.

ABOVE RIGHT: Clinical Practice Award -Sarah Kline
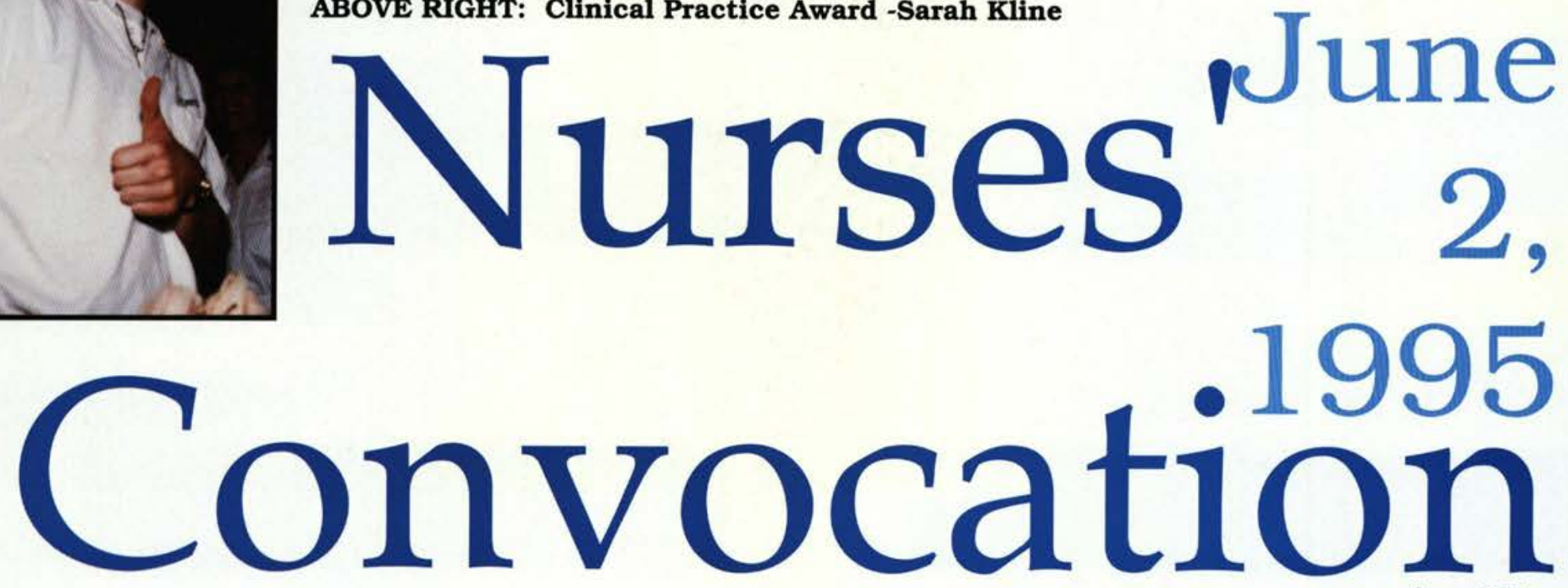

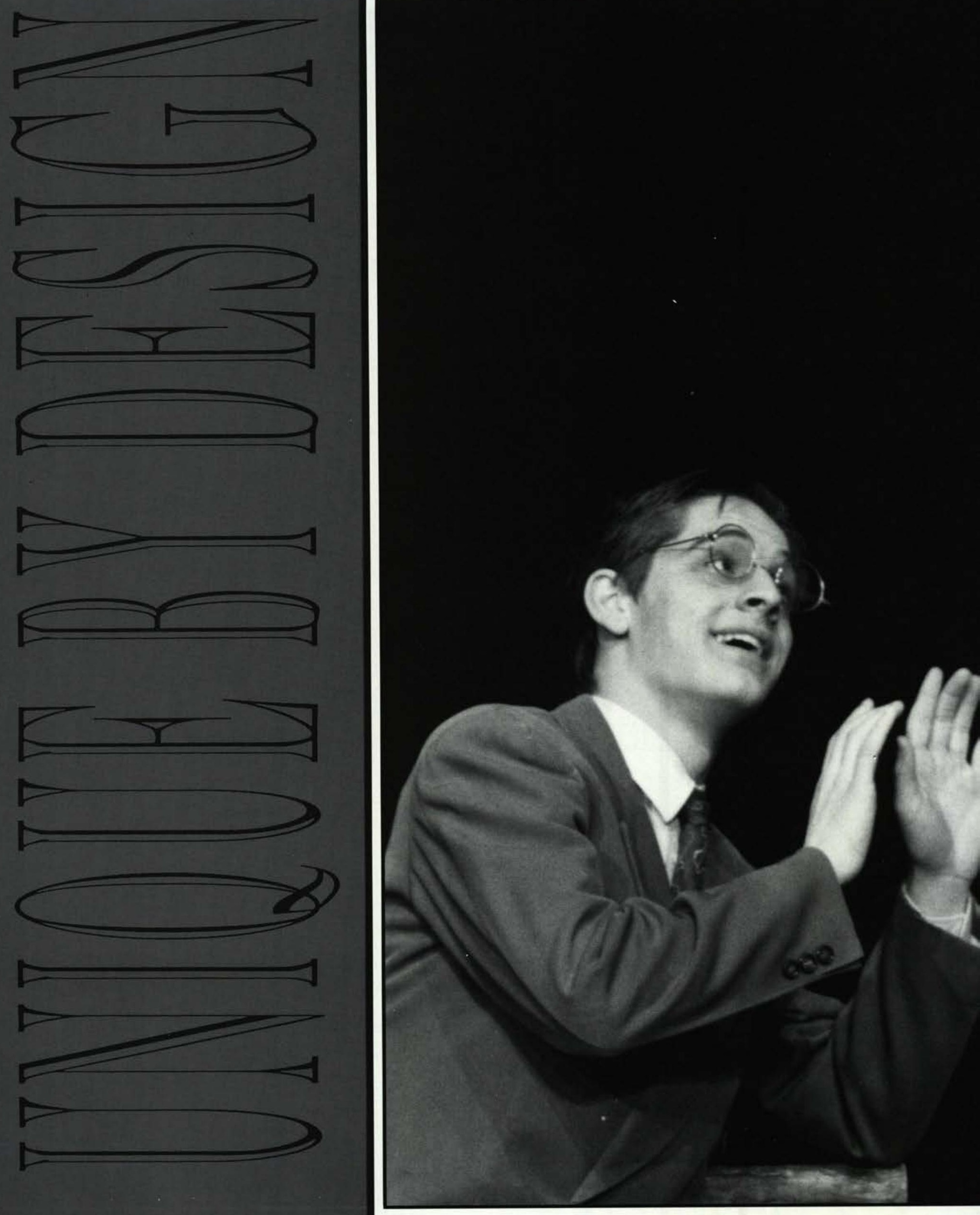

226 fine arts division 


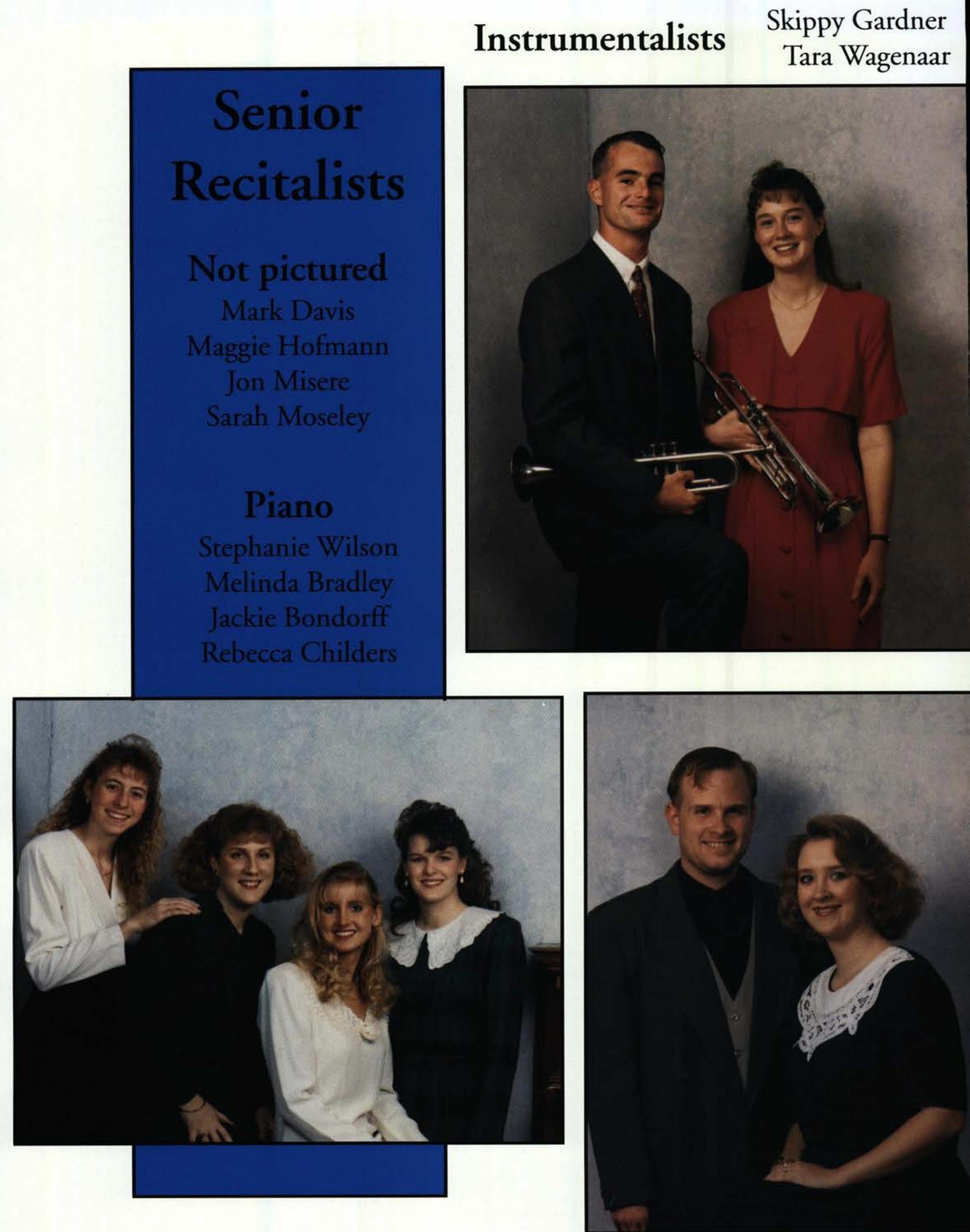

Speech

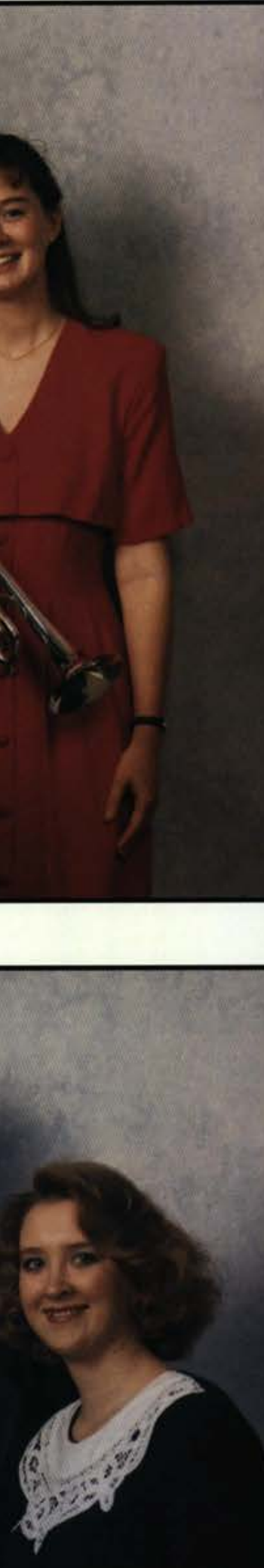




\title{
Voice
}

Wayne Morgret Sandy Costello Chad Vitarelli

\author{
Speech \\ Shelley Fox \\ Julie Lynn Burns \\ Johanna Chang
}


RIGHT: Brandon Duck is warming up for debate at Western Illinois University.FAR RIGHT: Kristin Rinehart is practicing her attitude. BELOW: Varsity Debate at Indiana State Courthouse Governor's Cup NEDA tournament.

B E L O W LEFT: Mrs.

\section{Debate}

Haffey is trying to keep the road in sight.
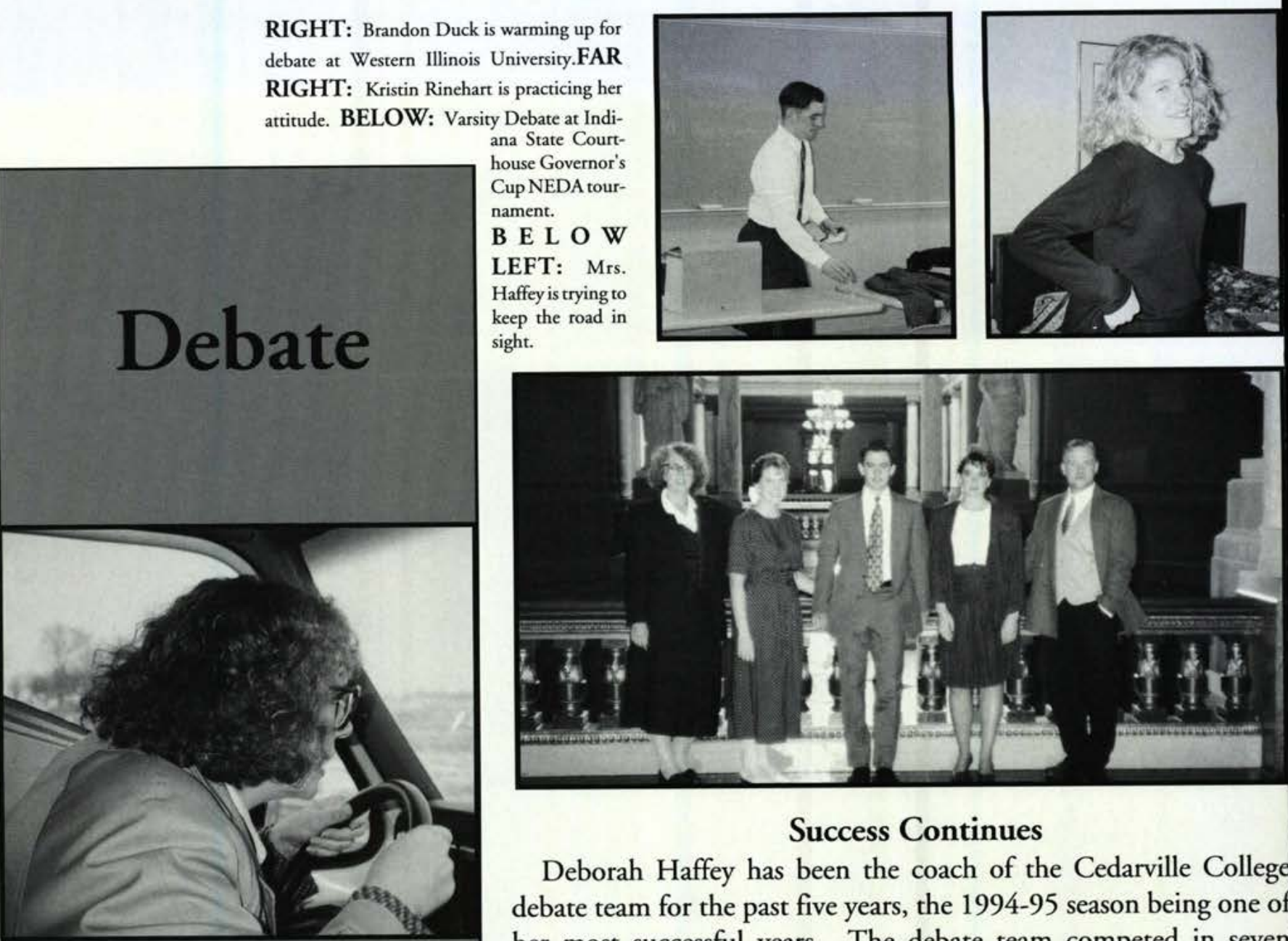

\section{Success Continues}

Deborah Haffey has been the coach of the Cedarville College debate team for the past five years, the 1994-95 season being one of her most successful years. The debate team competed in seven tournaments this year, creating much success. Virtually all the team members received speaker awards. In addition, the debate team had at least one team in the quarter final round or better at each tournament. Perhaps the biggest achievement of the year is accredited to Mrs. Haffey and the novice team when they won the National

Row 1: Joel Elmore, Brian Lanham Kristen Stanton, Mrs. Deborah Haffey, Kristin Rinehart, Pamela McClain. Row 2: Chad Cornwell, Brandon Duck.

Novice Championship. She points to two gradu-

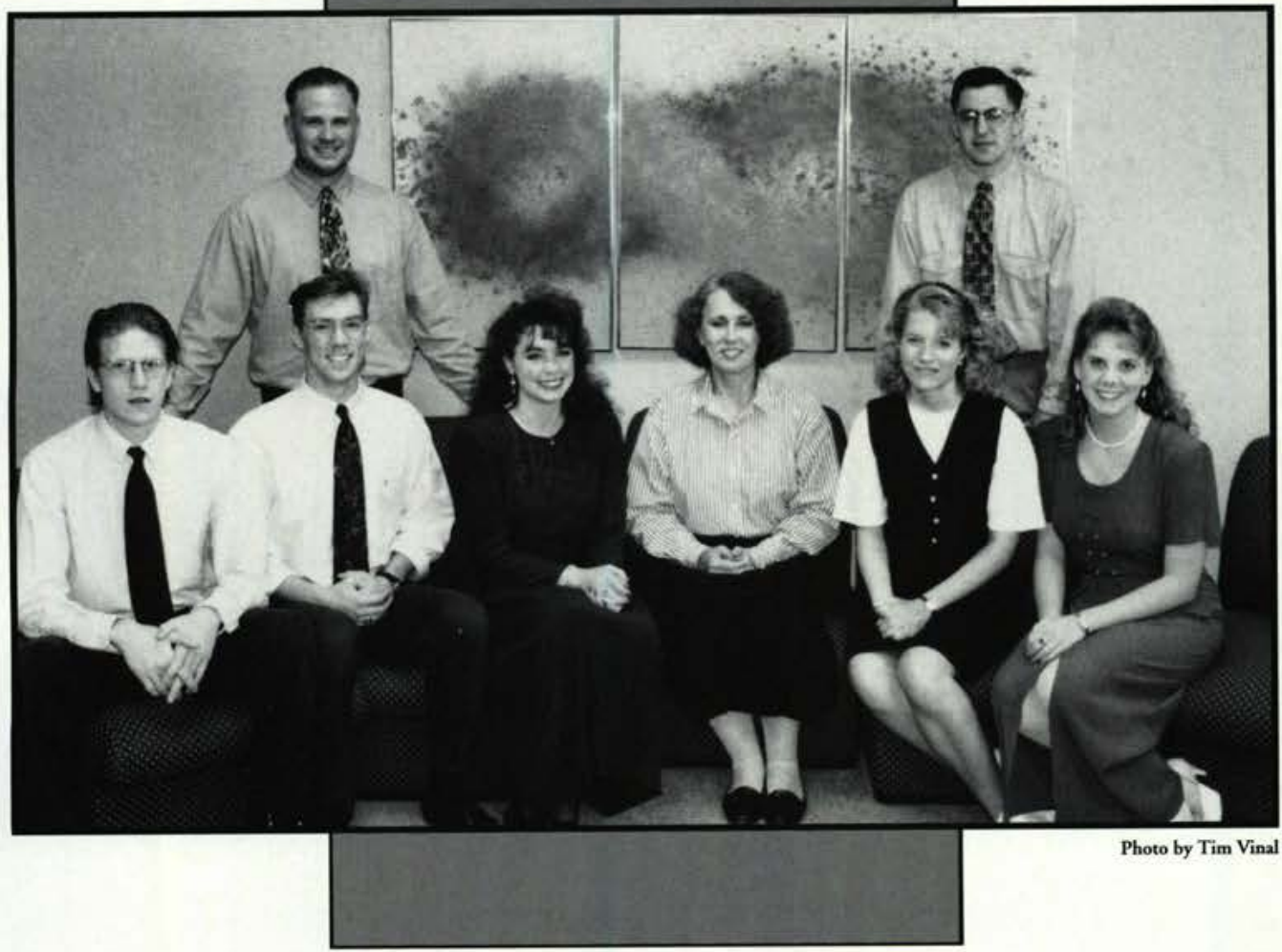
ating seniors who deserve special recognition for their work on the 94-95 debate team. Chad Cornwell, a team leader and a big help to Mrs. Haffey, played a key role on the team. Brian Lanham also contributed to the team's success. Brian received an award for the highest GPA for graduating seniors competing in debate.

This past year was filled with special moments for Mrs. Haffey and her team. Mrs. Haffey had the distinct pleasure of coaching her daughter in debate. There were also many special moments during the team's $7-8$ hour drives to various tournaments. There was a very special moment for the team at one particular tournament where two of their teams finished first and second, giving Cedarville a sweep of first and second place.

Like all other teams from Cedarville, the debate team is constantly forced to deal with people who do not have a faith in Christ. The success of the debate team is not only a testimony to the excellence of Cedarville College but alsc for the cause of Christ.

Derrick Green 


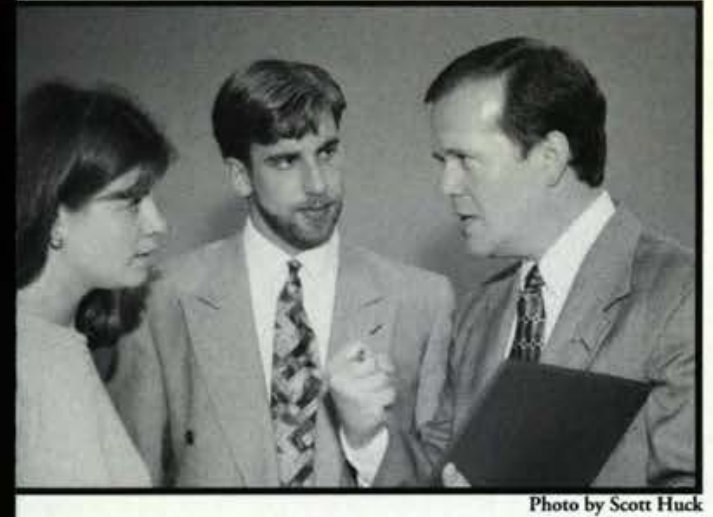

LEFT: Elizabeth Roseboom and Eric Sorensen get some instructional advice from

Dr. Robey.

BELOW: Christmas at the Robey's.

BELOW RIGHT: Faculty want to help us be the best that we can. Dr. Robey listens to a student's request for advice.

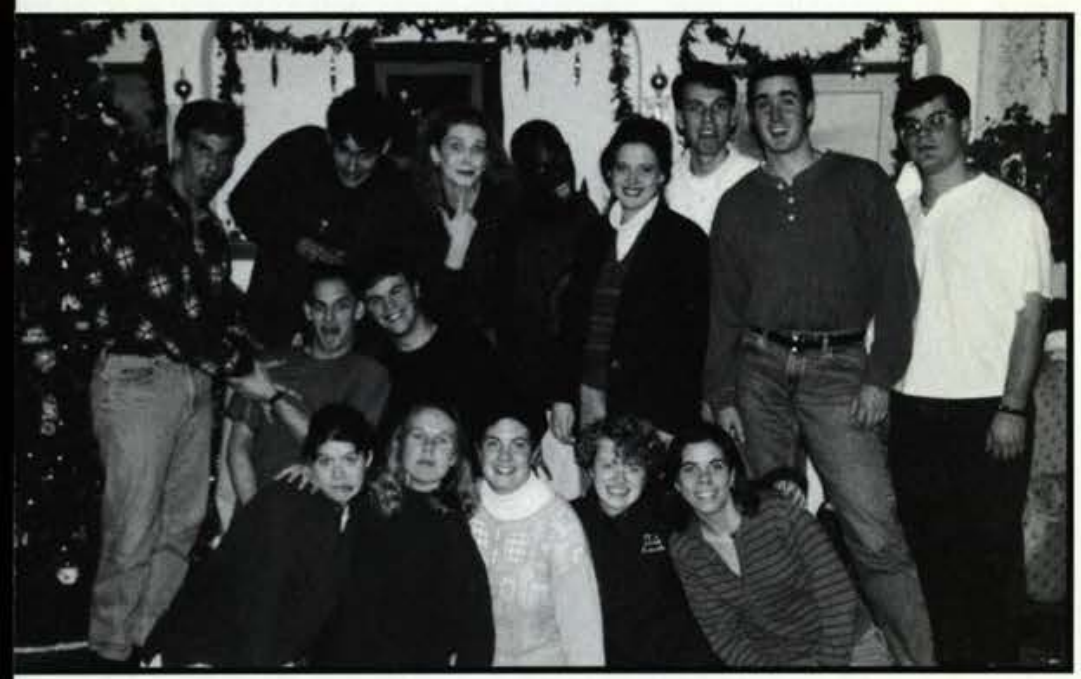

\section{A Light in the Dark}

Cedarville forensics, coached by Dr. David Robey, has won the phio State Forensics Championship five out of the past six years. his past year, the forensics team turned in a close second to Miami University of Ohio, a team that is coached by a Cedarville College orensics alumnus.

The 1994-95 forensics team consisted of 15 novice and varsity tudents. The team competed in eight tournaments his past year, finishing 4th place and higher at all ournaments. This was a very special year for the orensics team as it was the last year that Jeremy Grinnell and Mark Totten competed. Jeremy and Mark provided strong leadership for the '94-95 team. 3oth Jeremy and Mark, along with Eric Sorensen, ompeted in the National Forensics Tournament, vith Jeremy reaching the quarter final round in oetry. The team will not forget Jeremy's and Mark's ledication and hard work; the team will miss them oth.

The most important aspect of the forensics team is he opportunity to be a light for Christ. The team onsistently encounters people who do not share a aith in Christ. Therefore, the team is not just a orensics team; the team is God's representative on he forensics circuit. When other schools see the Cedarville College forensics team, they see competiion pieces that are completely void of foul language nd vulgar and obscene themes. They see a group of tudents who are not afraid to shine as a light for Christ.

Derrick Green

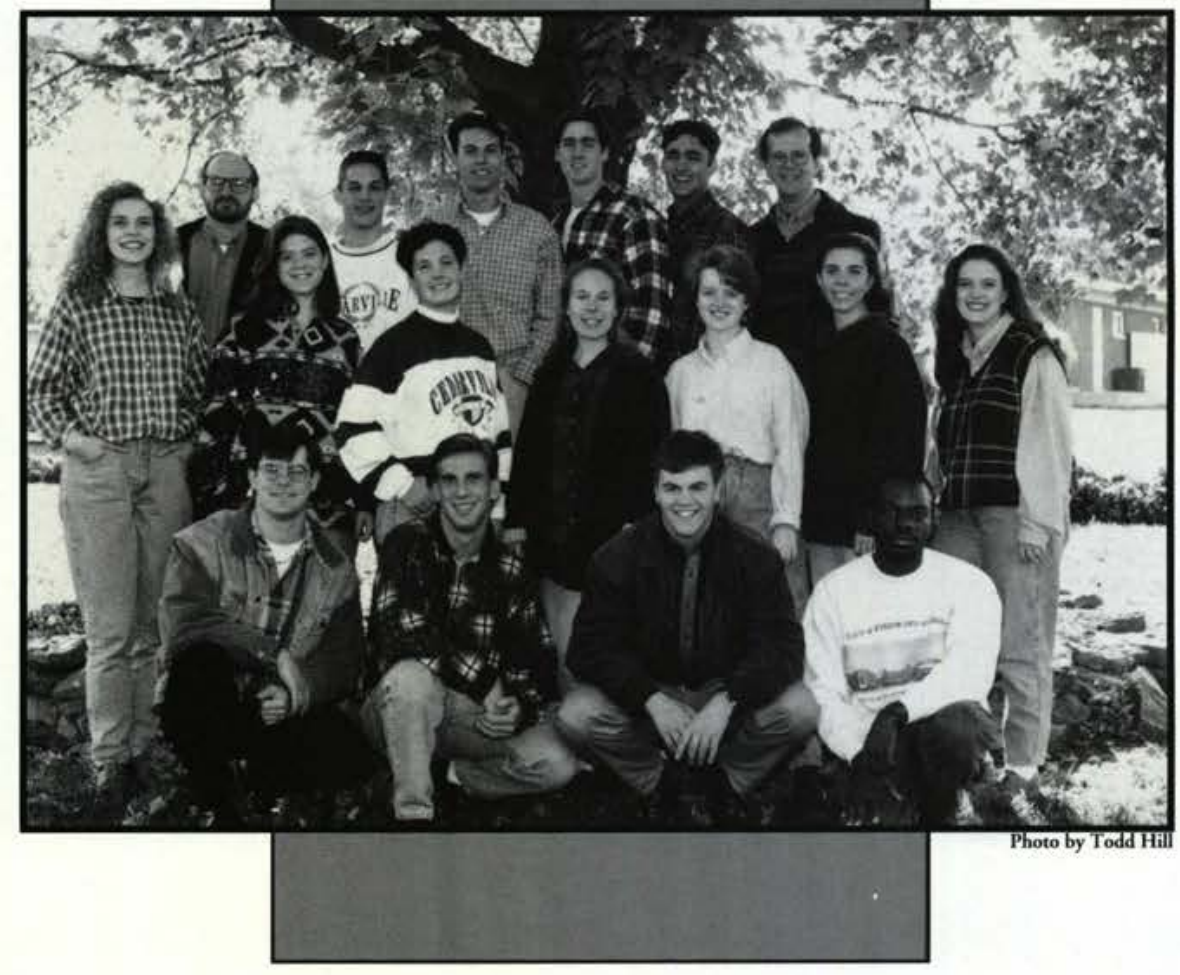




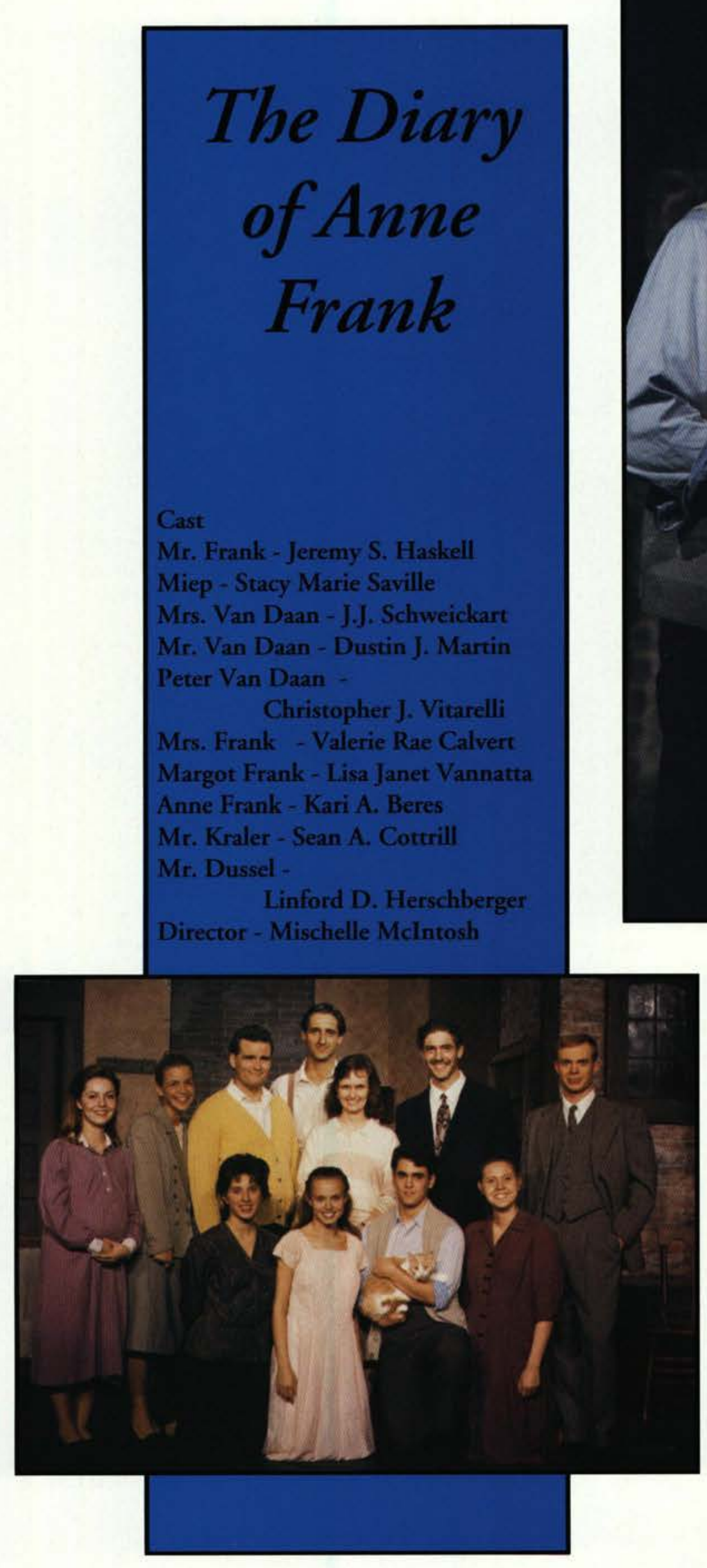

hiding place."

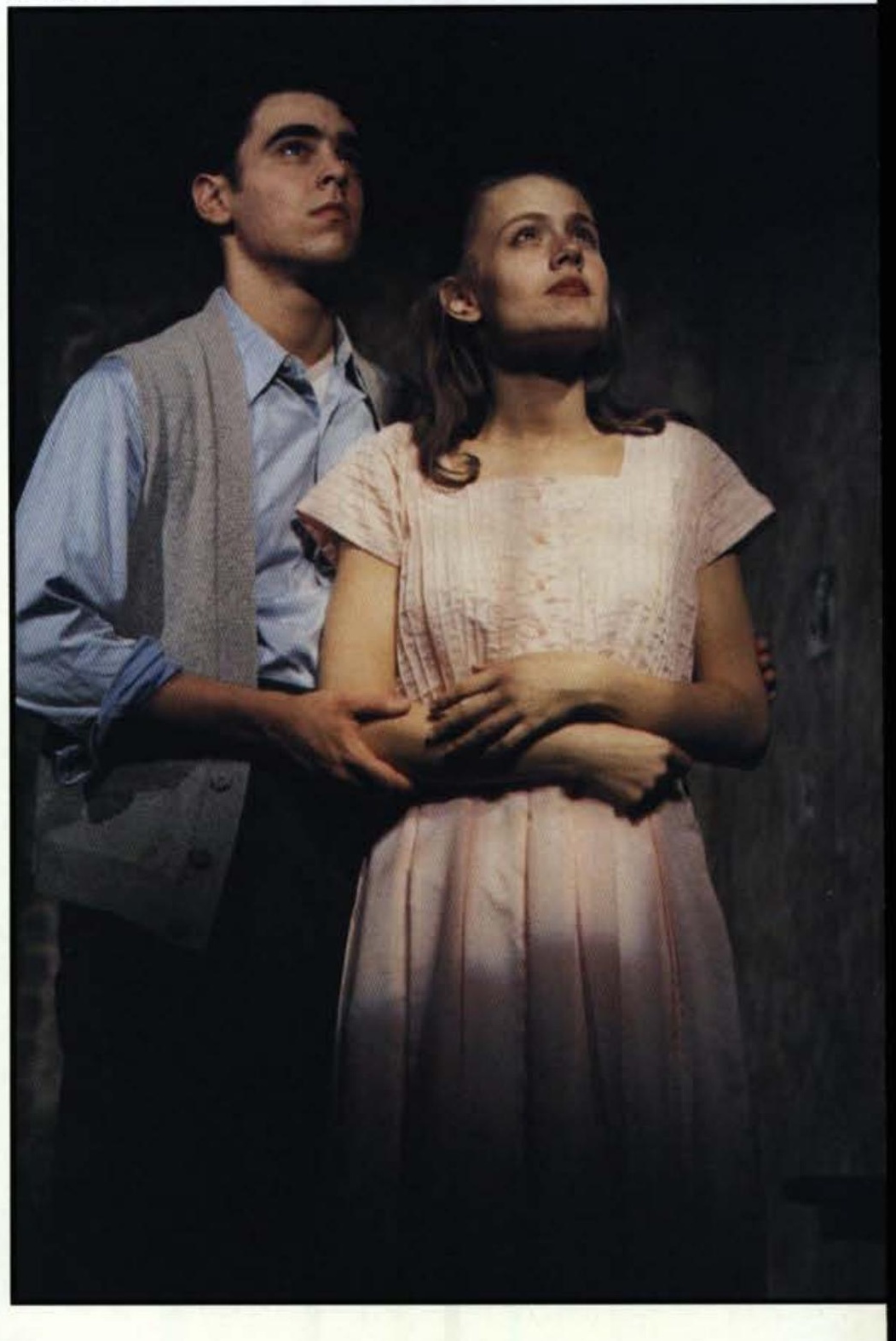

\section{The Diary of Anne Frank}

"Her voice was preserved. Out of the millions that were silenced, this voice no louder than a child's whis per.... It has outlasted the shouts of the murderers and has soared above the voices of time," said biographer Ernst Schnabel of Anne Frank.

Mischelle McIntosh directed this intensely emotional play with the hope that the audience might see more clearly the "struggles, fears, hopes, and inspiring courage of those who refused to surrender to overwhelming circumstances." And she succeeded in bringing to life the endearing Anne Frank, the loving Mr. Frank, the quiet Mrs. Frank and Margot Frank, the flirtatious Mrs. Van Daan and angry Mr. Van Daan, the peevish Mr. Dussel, and the courageous Miep and Mr. Kraler. That evening, the audience was transported back 50 years and experienced the terror, confusion, and the hopes of Anne Frank, a little girl who was as faithful to her diary as she and her family were to God Kathy Smart 
LEFT: Anne speaks her mind, as she so often did.

BELOW: Food is limited, and someone is eating it

during the night. Mr. Dussel catches the thief, Mr. Van

Daan, and there is a large food fight.

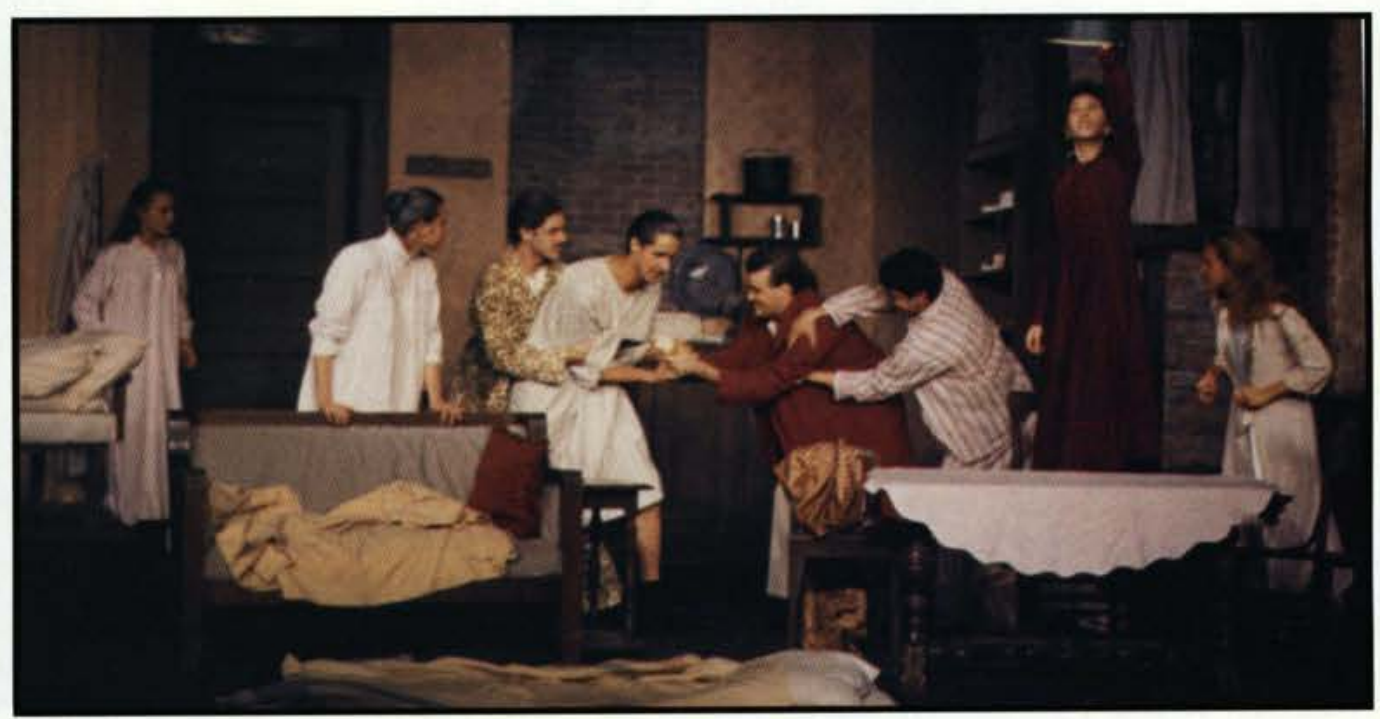

LEFT: Mr. Van Daan smells a pinch of his tobacco as the others watch. 
MATT: So now I take a big chance. I come down here to tell you I am in love for the only time in my life with a girl who sees the world exactly as I see it. I say to you, Sally, there is a life for the two of us,
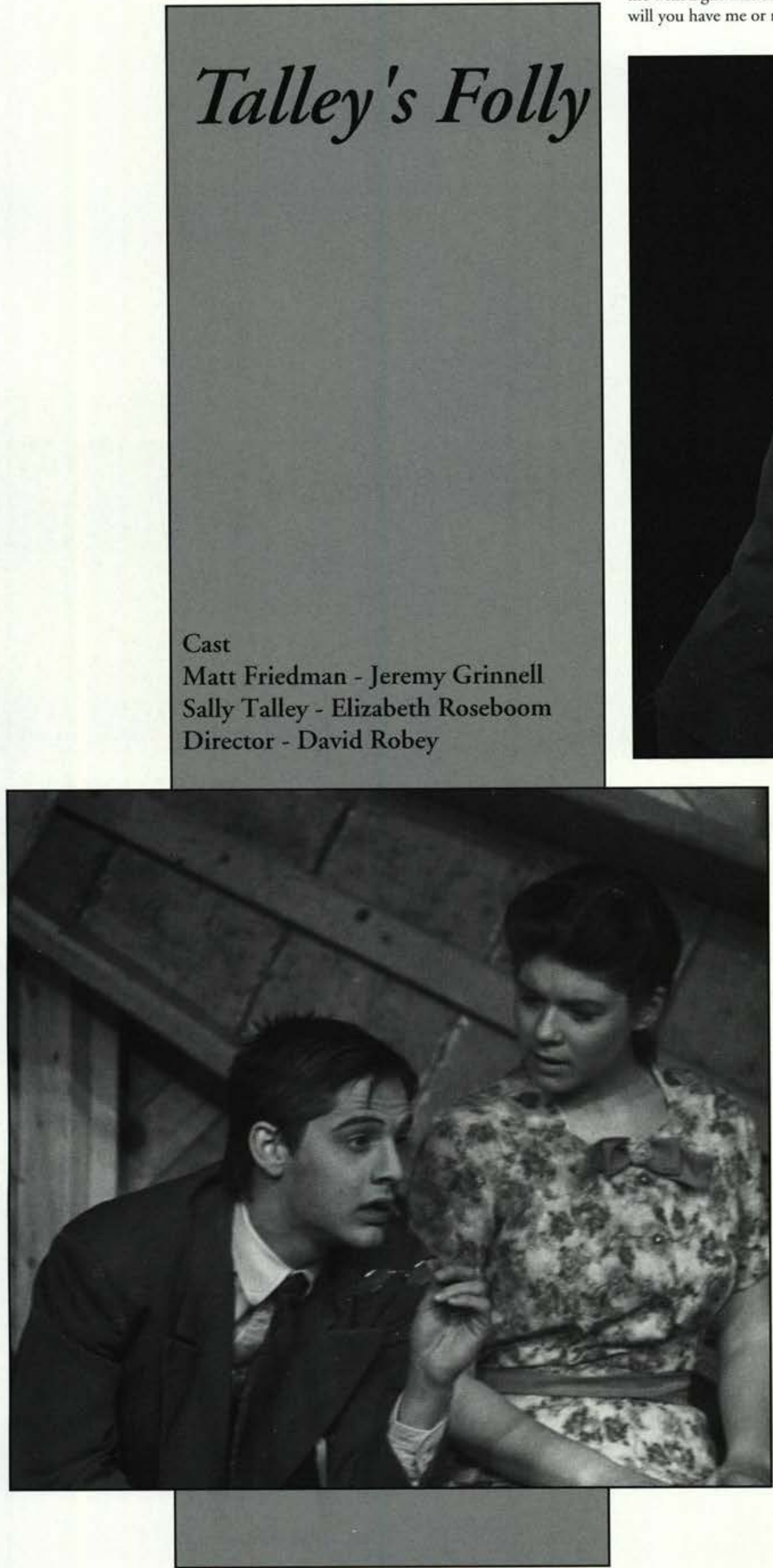

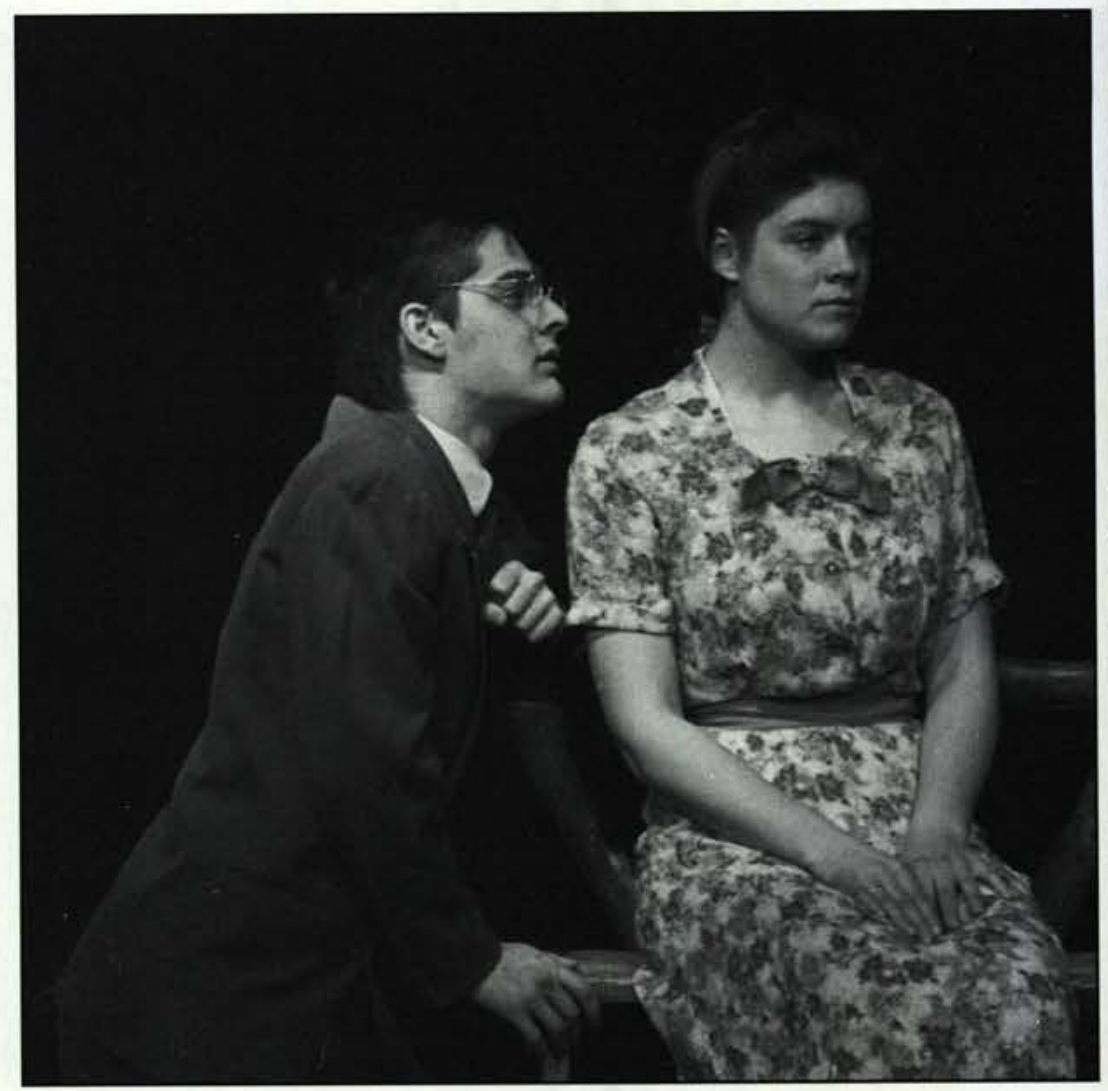

\section{Talley's Folly}

In the summer of 1943, European immigrant, Matt Friedman, meets Sally Talley, a nurse from Missouri. While they quickly develop a mutual attraction, Sally refuses to believe that she is worthy of love. As a result, Sally returns home and Matt begins a letter writing campaign. After a full year of writing, Sally still did not answer Matt's letters. Matt then decides to visit Sally at her home to settle the issue. At this point, the 97-minute drama begins.

Secluded from the rest of the world in an old boat house, Matt discovers that Sally has had great pain in "romance." To identify with her pain, he shares the sad details of the death of his family in war-torn Europe. Finally, Sally reveals her deep, dark secret: she had tuberculosis as a young woman, and due to complications of the disease, she is unable to bear children.

But this does not matter to Matt. Matt sees himself and Sally as two lonely people who have discovered the miracle of love. After all the pain they have both felt, Matt sees this love as a miracle. As the play concludes, Sally asks Matt, "Do you believe in angels?" Matt replies, "I do now." 


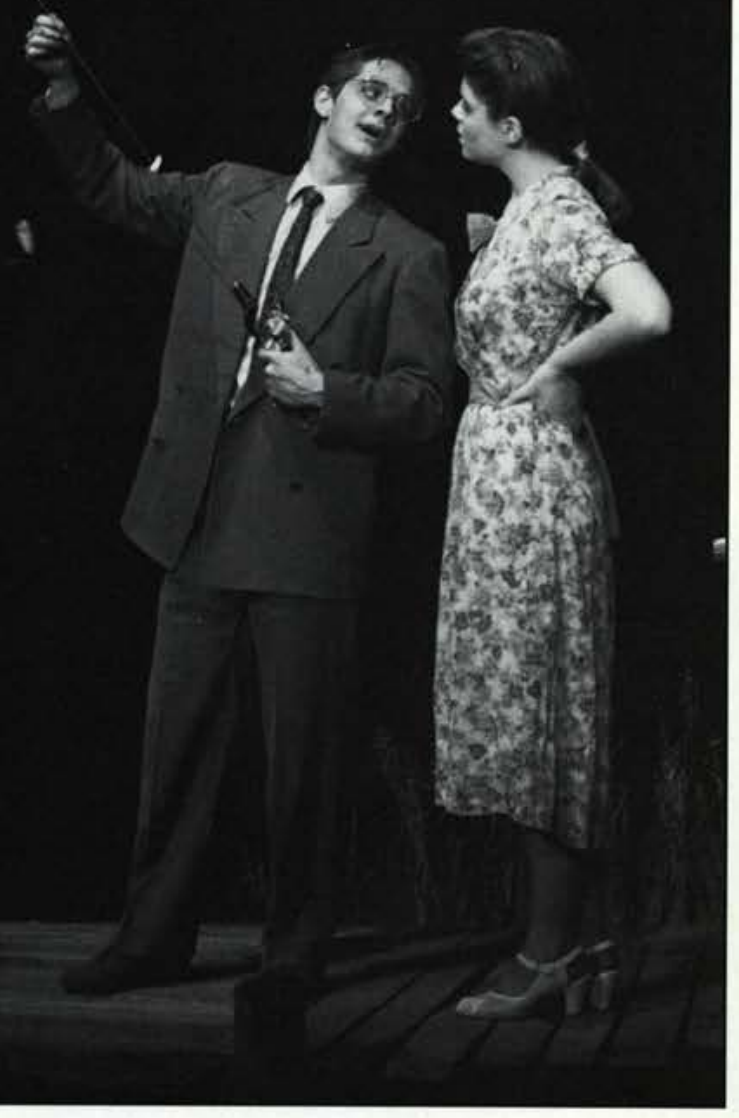

\section{LEFT:}

MATT: I am foolish to insinuate myself down here and try to feel like one of the hillbillies. Who ever heard of this Friedman? I don't blame you. I won't be Matt Friedman any more. I'll join the throng. Call myself...August Hedgepeth. Sip moonshine over the back of my elbow. Wheat straw in the gap in my teeth. I'm not cleaning my glasses, I'm fishing for..

\section{BELOW:}

MATT: (Grabbing her) Vilde chaya! You are a crazy woman! People do nor scream and yell and kick. (She stops struggling.) People are blessed with the beautiful gift of reason and communication. How can such a thing happen? When they passed out logic everybody in the Ozarks went on a marshmallow roast.

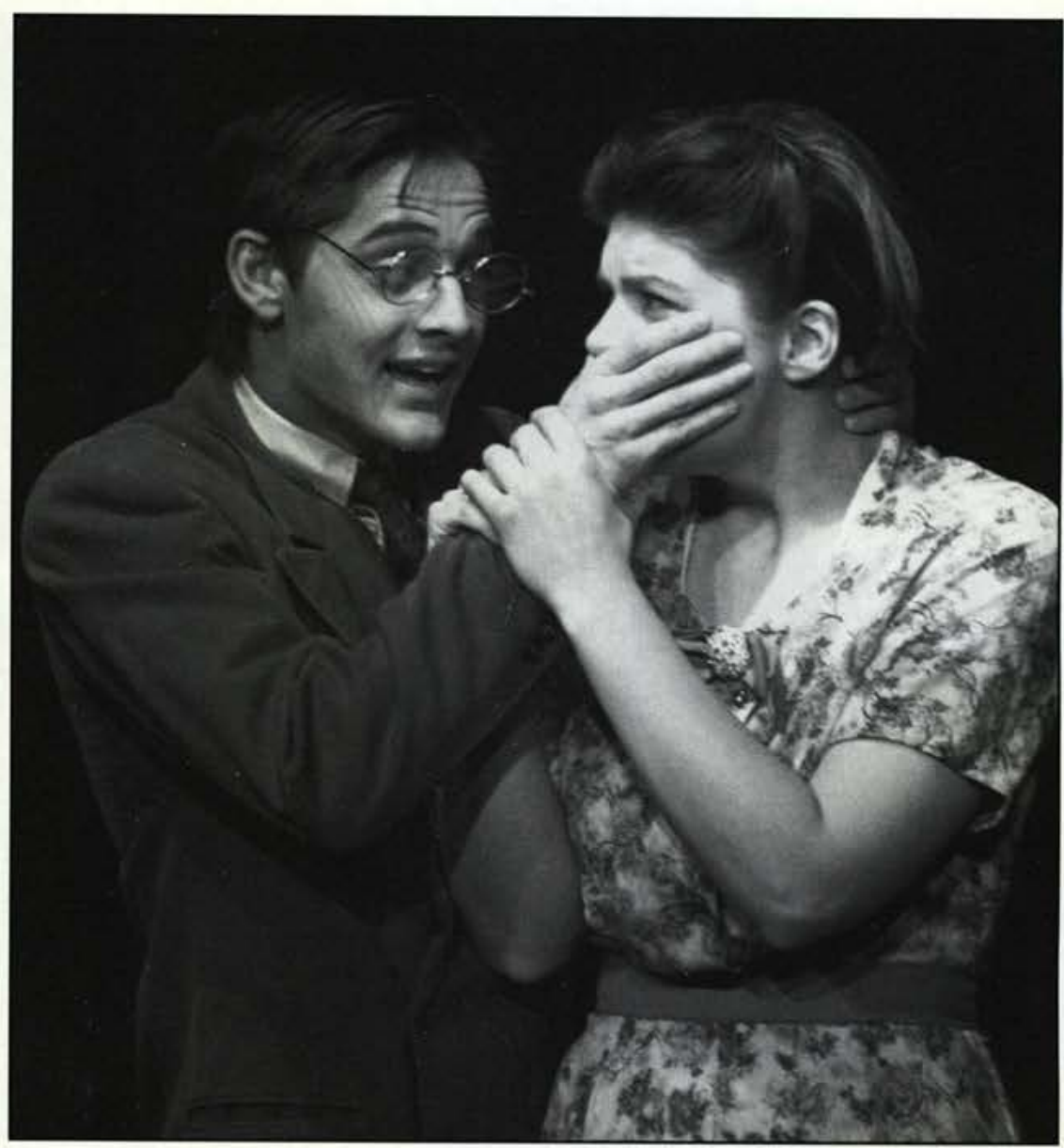

LEFT:

SALLY: I'm going to go get gasoline for your car. You need to go.

MATT: (As if skating for the edge of the pond) I'm going too fast! I don't know how to turn. Sally! I'm going to crash! Help! It's the end of a brilliant career! I can't slow down! AAAAAAAAaaaaaaaaa! (Falls down) Oh, oh... I'm serious-- Where are you going ? Sally?

SALLY: (She has stood with her arms crossed, watching him. Unmoved. Now she trurns to leave.) I'm going for your gas.

MATT: Sally? Hey, I can't run after you in these.

SALLY: Good. I'm good and sick of you running after me! (She is gone.) 


\section{Much Ado About Nothing}

A Shakespeare's romantic comedy, this play centers around the love-hate relationship of Benedick and Beatrice. It takes place in Messina, Sicily where the society thrives on gossip and deception as a way of life.

Benedick is engaged in a "war of wits" with Leonato's niece Beatrice. Claudio falls in love with Leonato's daughter, Hero; Don John swears to thwart their romance. After a masked ball, the wedding of Claudio and Hero is planned.

Don Pedro, Claudio, and Leonato ensure that Benedick (hidden in a garden arbor) hears them discuss Beatrice's presumably passionate love for him. Hero and Ursula play a similar trick on the listening Beatrice.

Don John devises a plan to trick Claudio and Don Pedro into believing that Hero is unfaithful. On the night before the wedding. Don John offers to give the Prince and Claudio proof of Hero's unfaithfulness by taking them to look into her window. They think they see Hero with another man. In fact they see Borachio, Don John's follower, exchange love vows with Hero's gentlewoman,
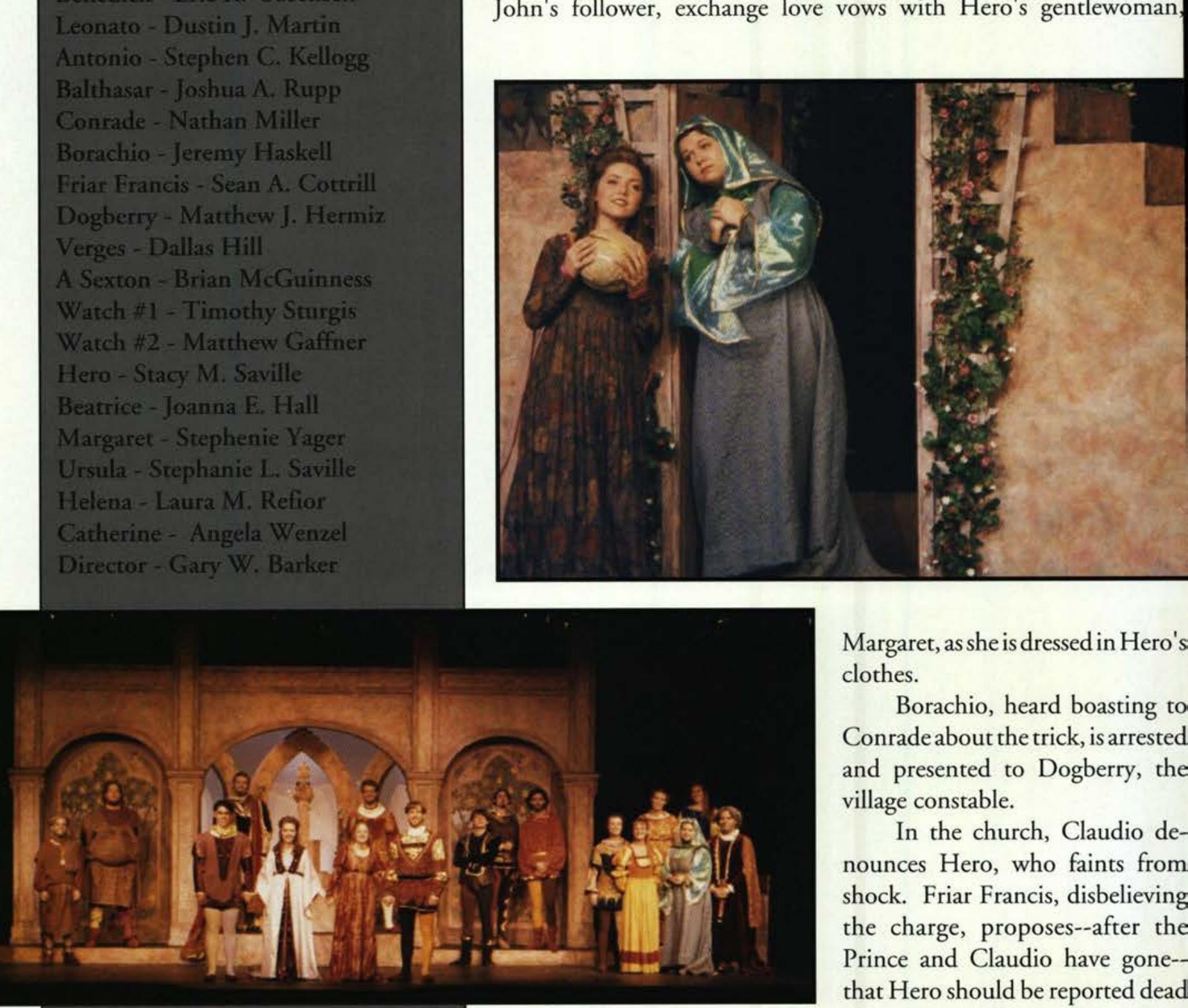

Margaret, as she is dressed in Hero's clothes.

Borachio, heard boasting to Conrade about the trick, is arrested and presented to Dogberry, the village constable.

In the church, Claudio denounces Hero, who faints from shock. Friar Francis, disbelieving the charge, proposes--after the Prince and Claudio have gone-that Hero should be reported dead and hidden until the truth is known. Beatrice, in great despair, urges Benedick to kill Claudio. At length Don John's deception is revealed, and the penitent Claudio promises to marry a niece of Leonato who is said to be the image of "dead" Hero. She is, of course, Hero herself. Beatrice and Benedick, as expected, resolve their "merry war." Don John is captured while escaping from 


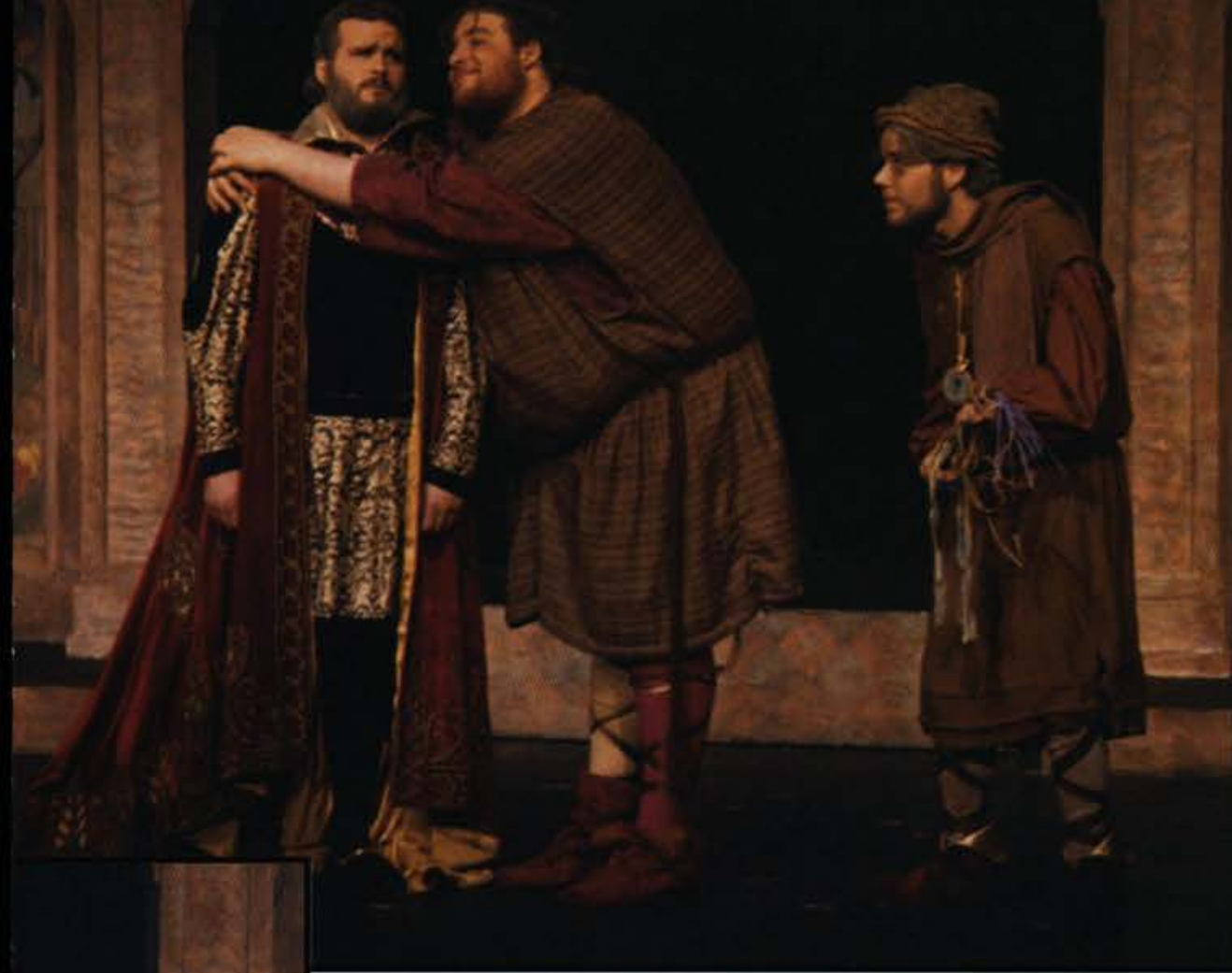

ABOVE LEFT: Dogberry and Verges beg Leonato's permission to prosecute Borachio and Conrade for their evil trick.

FAR LEFT: Hero and Ursula trick the listening Beatrice of Benedick's undying love for her.

LEFT: Don Pedro and Claudio discuss plans for the masked ball. BELOW: Bennedick and Beatrice have revealed love letters they had written in secret and share the amusement in what the other wrote.
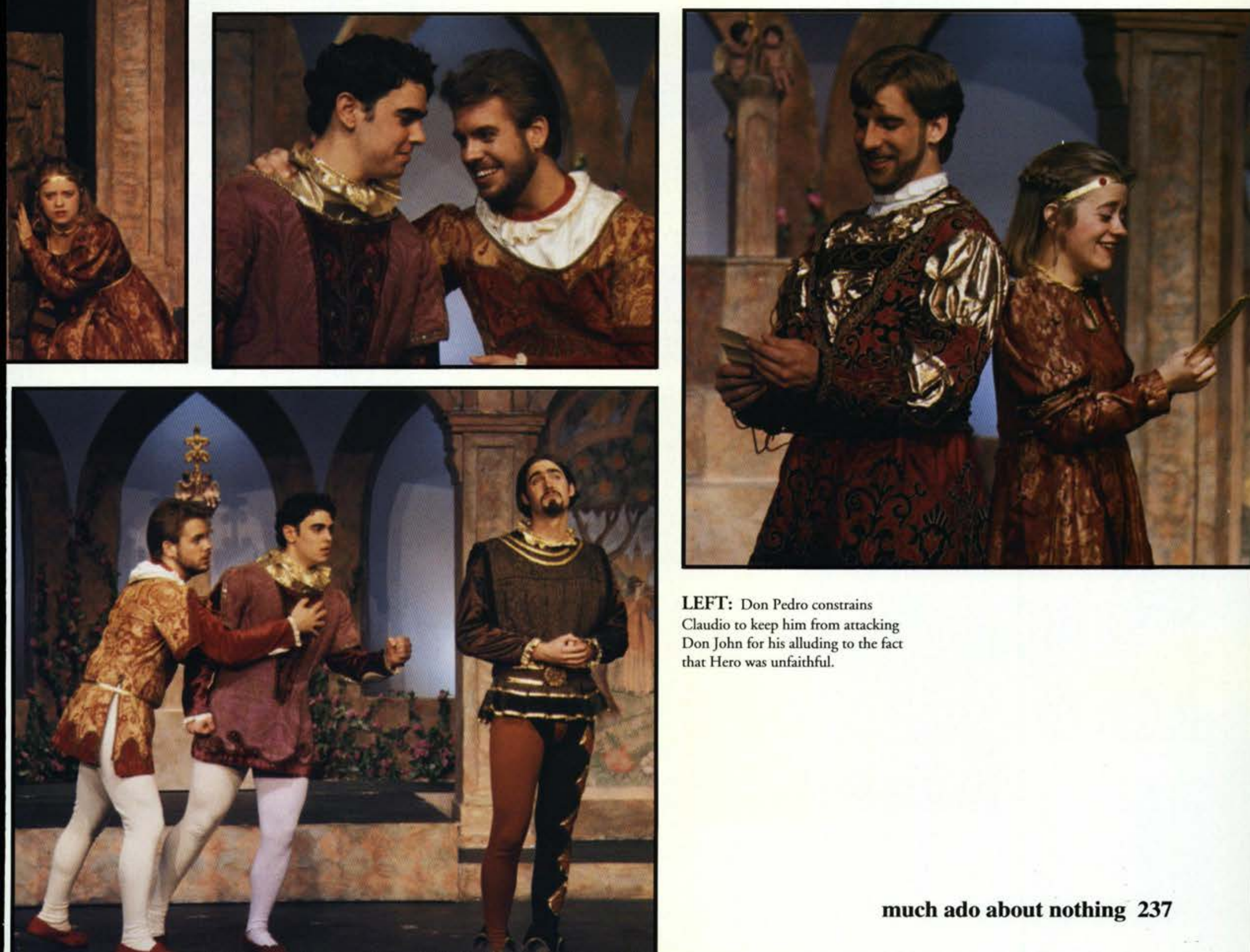

LEFT: Don Pedro constrains

Claudio to keep him from attacking

Don John for his alluding to the fact

that Hero was unfaithful. 


\section{Vocal}

\section{Concert Chorale}

Soprano: Beth Abbas, Lori Anderson, Joy Borkholder, Joy Brandon, Lisa Branon, Cari Buck, Julie Burns, Taryn Campbell, Johanna Chang, LeaAnne Churgovich, Sandy Costello, Christine Dabravalskas, Carey Daniels, Debbie Fox, Rachel Henricks, Jody Hovis, Heather Johnson, Deborah Kruse, Kathryn Larsen, Sarah Lightly, Marne Loomis, Amanda Orme, Rebekah Overcash, Laura Refior, Stephanie A. Sherman. Alto: Rebecca Appel, Jackie Bondorff, Jill Brown, Kelly Cast, Nicole Cooley, Julianne Edgerton, Andrea Eimers, Nicole Hernandez, Kristen Houlihan, Jill Hunsberger, Christina Jackson, Julie Jaskilka, Bethann Mohn, Jessica Nuzum, Janet Potts, Krista Ryan, Lori Scheumann, Jessica Schuring, Nadine Tomsa, Jamie Weiss, Janeen Whitney, Becky Wine, Stephanie Yankovich. Tenor: Eric Anderson, Jason Atwell, Steve Caton, Dave Heim, Linford Herschberger, Ryan Huebner, Bradford Illian, Vance Smith, Ryan Snedaker, Andy Stuart, Chad Vitarelli, Jonathan Weber, Steven Weber. Bass: Ryan Burkhard, Sean Cotrill, Joshua Hanks, David Hoskins, Adam Kane, Steve Kreitzer, Wayne Morgret, Brian Naess, David Paulus, Chuck Quarles, Chris Rayder, Doug Rose, Josh Rupp, Scott Shaw, Mark Zuiderveen. Director: Lyle Anderson.

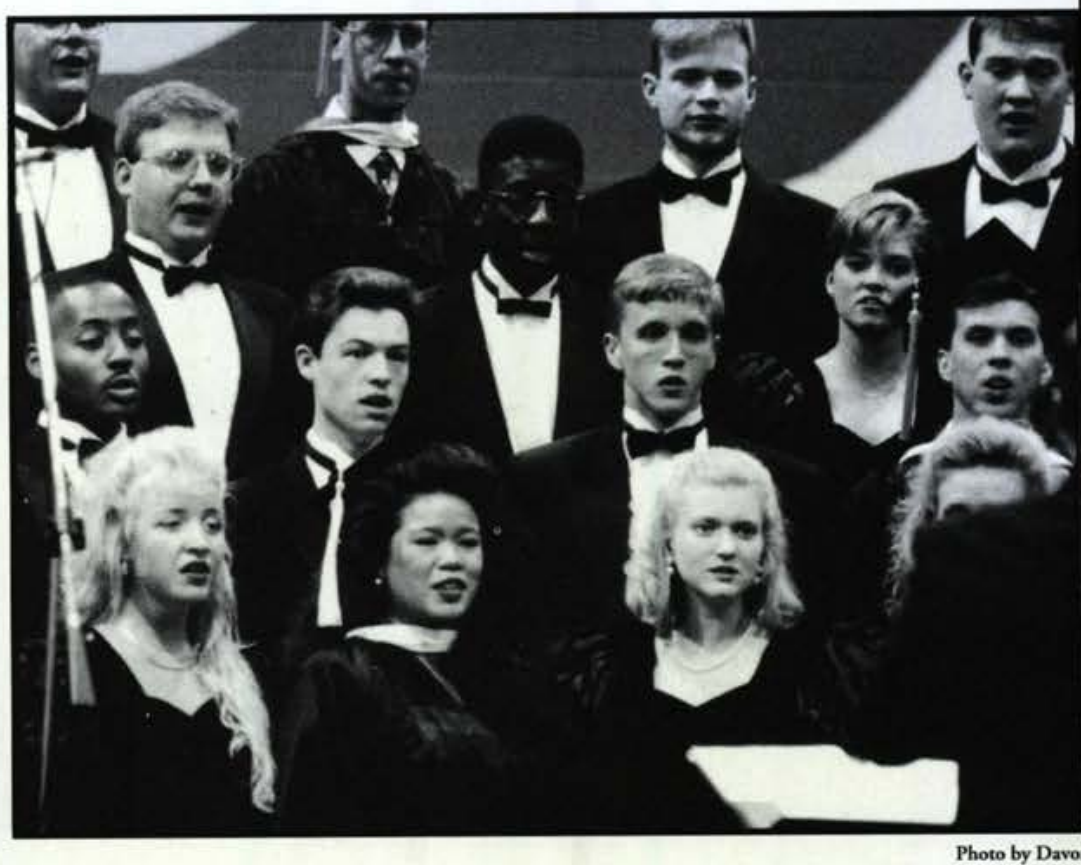

Each year, the Concert Chorale escapes from college life and take a week-long tour. This year, Dr. Lyle Anderson engulfed a huge undertaking by planning an exciting international tour to the Czech Republic. Fifty members of the chorale, along with Dr. and Mrs. Anderson, left for Europe and their first foreign tour, February 20-27, 1995.

Each day, the chorale members toured the city of Prague in the mornings, shopped in the afternoons, and performed concerts in the evenings. The Concert Chorale had unique opportunities to witnes when they had dinner with the prestigious Children's Choir of Prague and also a local high school choir. Many chorale members made lasting friendships during these special times.

During the week, the chorale traveled to a small city called Borno They performed two concerts in the city, one in a Baptist church anc the other one in a cathedral. The hotel that the group stayed in wil remain a special memory because it was there that Dr. and Mrs Anderson talked exten

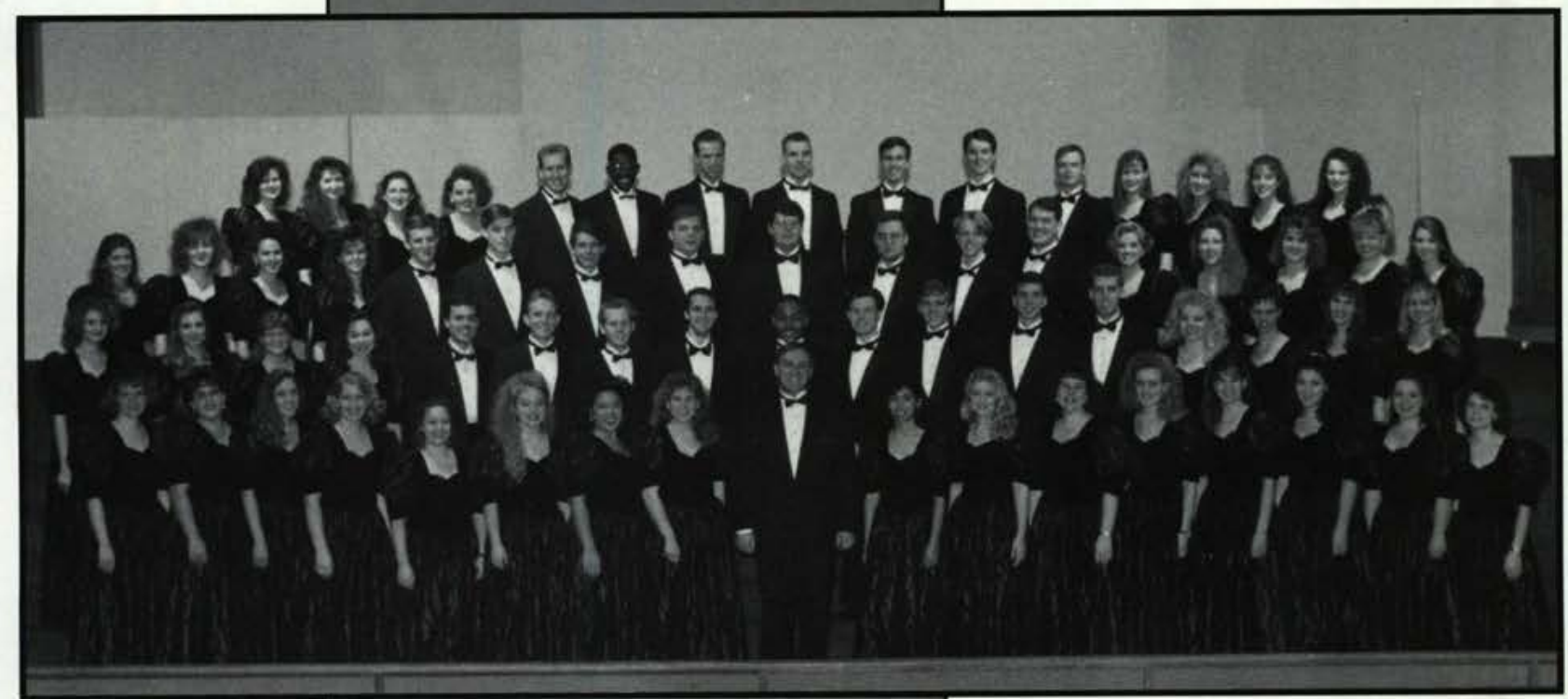
sively with Karel, the chorale's tour guide. Chorale members scatterec throughout the hotel res taurant and prayed for the Andersons as the couple witnessed to Karel abou the Lord.

The most exciting part, however, was hearing chorale member Chuch Quarlessharehow the Lor used him to lead the hote clerk, Vladimir, to the Lord. The chorale mem bers celebrated this grea news just like the angels do Photo by Scott Huck in heaven when one comes to know Christ.

The Czech Republic trip affected each member of the chorale in different ways. Although the members worked hard to be a gooc testimony, they will all agree that all the glory belongs to the Lord. 


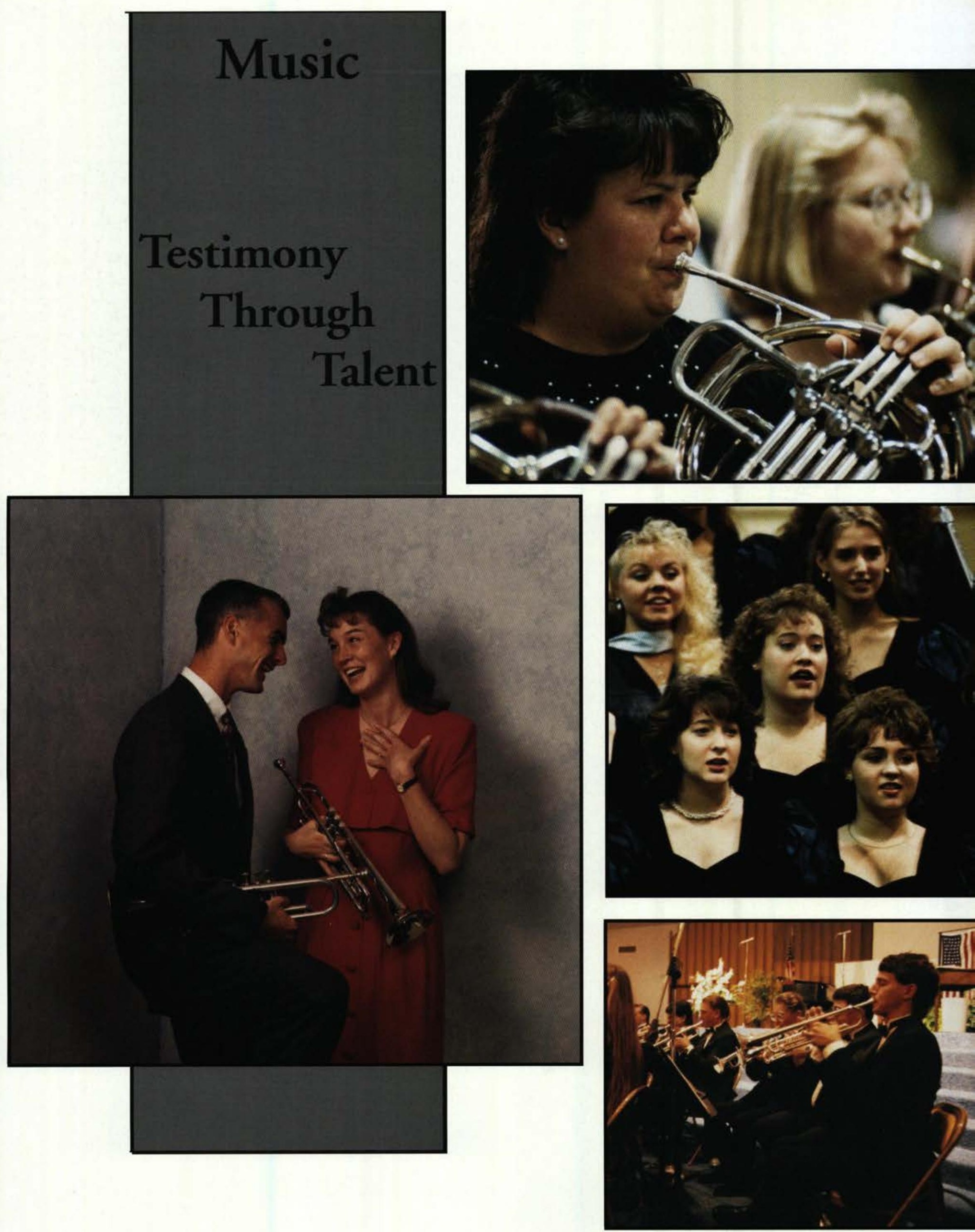




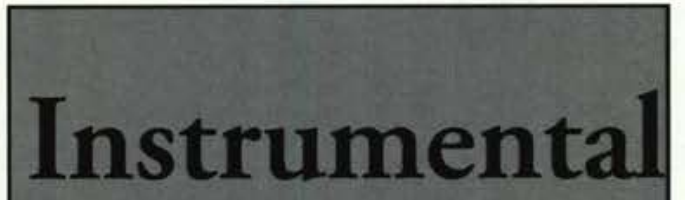

\section{The String Ensemble}

Row 1: Marla Perkins, LeaAnne Churgovich, Nicole Cooley, Heidi Hoover, Daniel Gain. Row 2: Jessica MacPherson, Amy Shaneyfelt, Emily Williams, Michael Pasquale, Kathryn Rodgers. Not pictured: Rachel Chambers, Jamie Whitmore, Amanda Whitmer, John Maskill, Jaime Bedford, Rachel Wirt, Ben Vawter.

\section{Saxophones}

Left to Right: Chet Jenkins, Bre Pfeiffer, James Dyer.

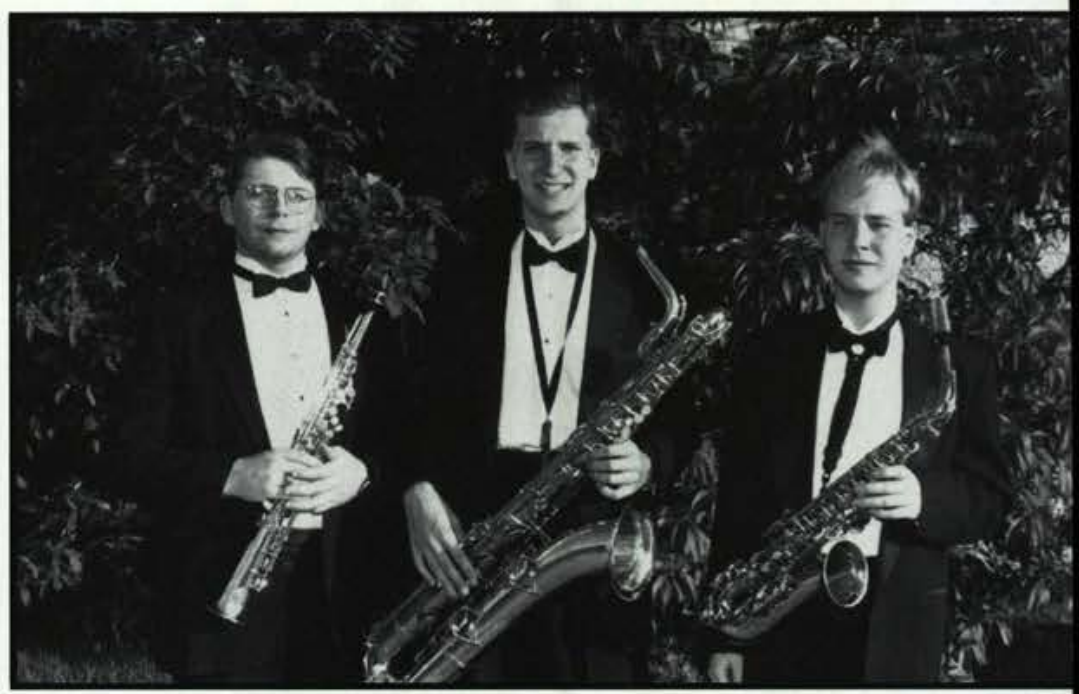

Chamber Music Night

Every January, musicians on campus anticipate the annual Cham ber Music Night. Professors Jerry and Kathryn Rodgers, assistan professors of instrumental music, led this special night. The program marked a special occasion for the performing instrumentalists becaus the students composed the entire program themselves with only some coaching from th music faculty. The program mainly high lighted smaller ensembles such as duets, trios quartets, and quintets, but a few numbers hac larger groups up to fifteen members.

This program, designed to provid opportunities for the college musicians, al lowed the students the opportunity to play ir small groups in front of their peers. These groups included the Symphonic Band anc the String Ensemble.

The musicians performed well for the Cedarville family, leaving a memorable nigh behind them. All participants enjoyed the touch of classical music.

Lynda Gavitt 

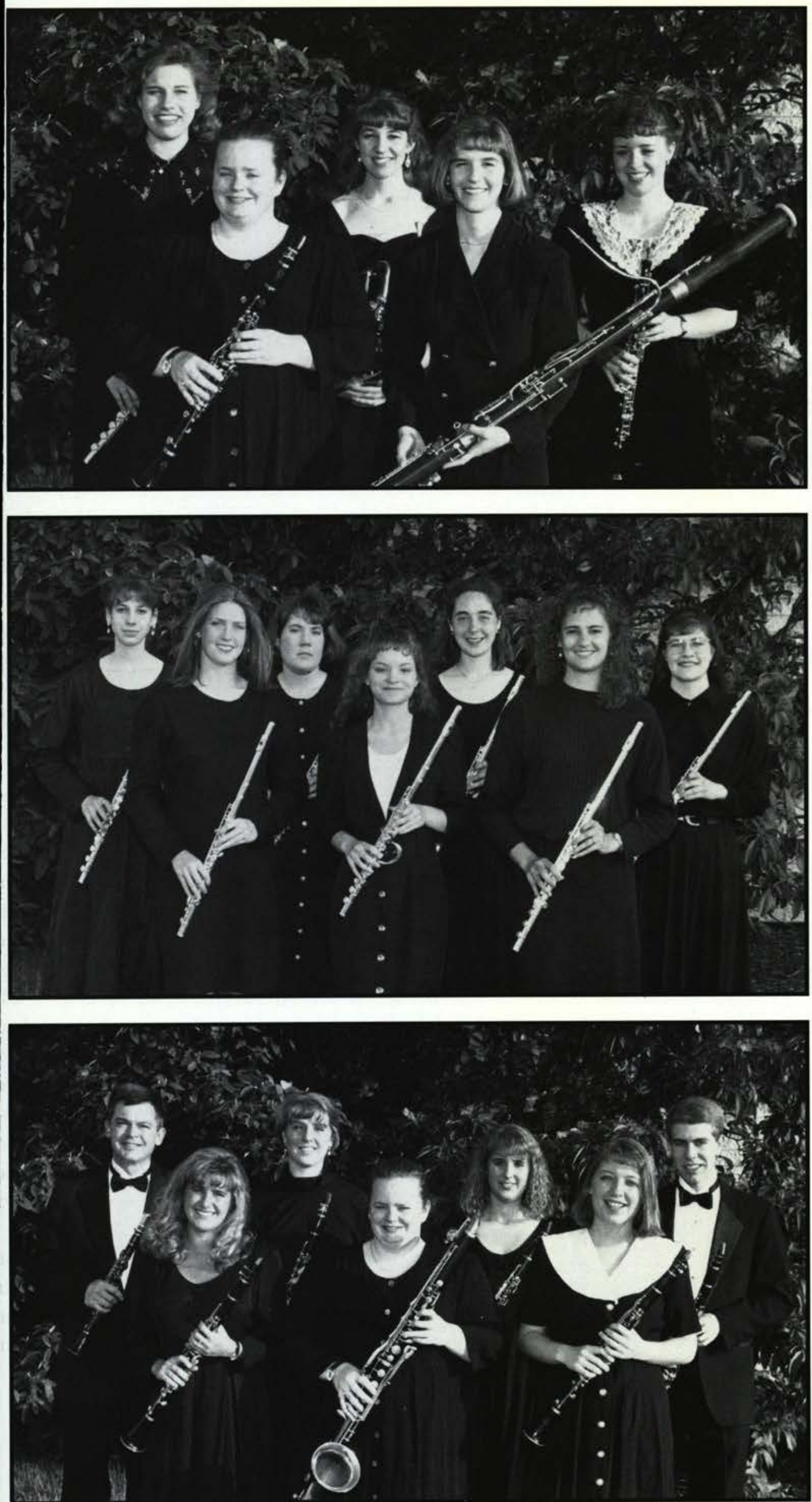

\section{Woodwind}

\section{Ensembles}

Not pictured: MaggieHofmann, Sally Hutchins, Tim Miller, Lesley Shover, Jason Vasquez.

\section{Woodwind Quintet}

Row 1: SallyHutchins, Deborah Kruse. Row 2: Damara Klaasen, Rachel Wirt, Sarah Moseley.

\section{Flutes}

Row 1: Kim Guyn, Angela Meredith, Leah Hoover. Row 2: Erica Hunter, Angela Chapman, Jacquie Gathany, Julie Jouwstra.

\section{Clarinets}

Row 1: Rachel Soderstrom, Sally Hutchins, Karisa Linafelter. Row 2: Jerry Rodgers, Elizabeth Parr, Michelle Delaney, Nathan Hart. 


\section{Parent}

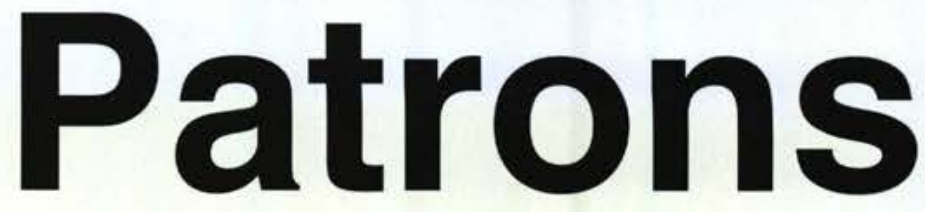

The 1995 Miracle staff offers a special thank you to allthose parents and churches who through their gener ous gifts made this Miracle possible. Without their help many special elements of this yearbook such as extra color pages, photography or design elements would be greatly reduced or eliminated. Thank you!

Mr. \& Mrs. Daniel R. Acton Normal, IL

Mr. \& Mrs. Harlan G. Albee Kent, WA

Dr. \& Mrs. Jerry Annoni Vallejo, CA

Mr. \& Mrs. Abraham Awabdy Clifton Park, NY

Mr. \& Mrs. David C. Bartlett Alton, IL

Mr. \& Mrs. William Berkheiser Rochester, NH

Mr. \& Mrs. Mark Blackburn Westerville, $\mathrm{OH}$

Mr. \& Mrs. Carl R. Bondorff Rockaway, NJ

Dr. \& Mrs. Randy M. Bork Lapeer, MI

Mr. \& Mrs. Dale Borkholder Palatine, IL

Mr. \& Mrs. Randy Bouwens Wayland, MI

Mr. \& Mrs. Melvin Burkley Flushing, MI

Mr. \& Mrs. Marlo B. Bush Gallipolis, $\mathrm{OH}$
Mr. \& Mrs. Greg Campbell

Keeseville, NY

Mr. \& Mrs. John Check

Ontario, NY

Mr. \& Mrs. John W. Christie

Caribou, ME

Mr. \& Mrs. Gary Coe

Wyoming, MI

Mr. \& Mrs. Dawood Issa Dawood Al Ain, U.A.E.

Mr. \& Mrs. Wally Decker

Fort Morgan, CO

Mr. \& Mrs. Robert Denges

Hudson, $\mathrm{OH}$

Mr. \& Mrs. Richard S. DeWitt Lockport, NY

Mr. \& Mrs. Alfred Dodson

Danville, IN

Mr. \& Mrs. Karlis Ezerins

Marysville, $\mathrm{OH}$

Mr. \& Mrs. Dean C. Ferguson Wakarusa, IN

Mr. \& Mrs. Dave Gosman Madison, IN

Mr. \& Mrs. Ed Gray

Waldwick, NJ

Mr. \& Mrs. Cliff Graybill
Goshen, IN

Dr. \& Mrs. Robert R. Griffith Spring Valley, $\mathrm{OH}$

Mrs. Emily C. Gurry

Westfield, NJ

Mr. \& Mrs. David Hangosky

Chesterland, $\mathrm{OH}$

Mr. \& Mrs. Don Harju

Hudsonville, MI

Mr. \& Mrs. Steve Hartkop

Medina, $\mathrm{OH}$

Dr. \& Mrs. Marc Haseltine

Brookhaven, PA

Mr. \& Mrs. Ron Hasselbring Milan, MI

Mr. \& Mrs. Terry Henricks Archbold, $\mathrm{OH}$

Mr. \& Mrs. Gary Hickox Roanoke, VA

Mr. \& Mrs. Bill Hillman

Morton, IL

Mr. \& Mrs. Harry D. Howe Indianapolis, IN

Dr. \& Mrs. Jim Hunter

Elyria, $\mathrm{OH}$

Mr. \& Mrs. Masakatsu lkeda 
Hokkaido, Japan

Mr. \& Mrs. Richard Jackson

Quincy, IL

Mr. \& Mrs. Spencer Jackson Lewisberry, PA

Mr. \& Mrs. Y.O. Jim

San Nicholas, Aruba

Mr. \& Mrs. Tim Johnson

Rittman, $\mathrm{OH}$

Dr. \& Mrs. Richard F. Judkins Perrysburg, $\mathrm{OH}$

Mr. \& Mrs. Timothy Kelly Boca Raton, FL

Mr. \& Mrs. David Kuiken Bourbonnais, IL

Mr. \& Mrs. Dennis R. Kuyper Creston, IA

Mr. \& Mrs. Robert F. Landrum Ypsilanti, MI

Mr. \& Mrs. Rene Landwehr Howards Grove, WI

Mr. \& Mrs. Walter Lankford Bensalem, PA

Mr. \& Mrs. James Latourelle Chatham, MA

Mr. \& Mrs. John LeBlanc Gallipolis, $\mathrm{OH}$

Mr. \& Mrs. Thomas G. Lensch Spring Valley, $\mathrm{OH}$

Mr. \& Mrs. John Longshaw Shamong, NJ

Mr. \& Mrs. Thomas Luther
Wichita, KS

Dr. \& Mrs. William Lyons

Palo Cedro, CA

Mr. \& Mrs. Douglas MaGee

Elyria, $\mathrm{OH}$

Mr. \& Mrs. Roger N. Marland

Plattsburgh, NY

Mr. \& Mrs. Cliff Marr

Windham, ME

Chpl. and Mrs. James McConnell Springfield, MO

Mr. \& Mrs. Stan Michaleski

Gaithersburg, MD

Ms. Clara Michael

Morgantown, WV

Ms. Carole A. Miller

Shiremanstown, PA

Mr. \& Mrs. Chuck Miller

Mokena, IL

Mr. \& Mrs. Tom Miller

Monroeville, $\mathrm{OH}$

Mr. \& Mrs. Curtis Muehling

Sandusky, $\mathrm{OH}$

Mr. \& Mrs. Charles J. Murphy

Marydel, MD

Mr. \& Mrs. Larry L. Niehaus

Maytown, PA

Mr. \& Mrs. Alan Noble

Westwood, NJ

Mr. \& Mrs. Jawad Nunes

Burlington, WI

Mr. \& Mrs. David A. Orser
North Syracuse, NY

Mr. \& Mrs. George Osuch

Sandyhook, CT

Mr. \& Mrs. Steven Perler

Madison, CT

Mr. \& Mrs. Mike Perry

Adrian, Ml

Dr. \& Mrs. Russell D. Pierce

Sinking Spring, PA

Mrs. Nancy E. Plush

Heath, $\mathrm{OH}$

Mr. \& Mrs. Christopher Prentki Wilmington, DE

Mr. \& Mrs. Myron A. Preston Midland, MI

Dr. \& Mrs. Ronald W. Reed Reading, PA

Mr. \& Mrs. Gerald Reynolds Norwood, $\mathrm{OH}$

Mr. \& Mrs. Robert Rice Rockville, MD

Mr. \& Mrs. Kenneth Richards Muscatine, IA

Mr. \& Mrs. Dale Robinson Powell, $\mathrm{OH}$

Ms. Marianne Robinson Dublin, $\mathrm{OH}$

Mr. \& Mrs. John Robinson Verona, PA

Dr. \& Mrs. Val Roloff

St. Charles, MO

Mr. \& Mrs. Gary Ruhl 
Derry, NH

Mr. \& Mrs. Gary Rutledge

Rochester Hills, MI

Rev. \& Mrs. Glenn E. Saunders Racine, WI

Mr. \& Mrs. Steve Schaneman Douglas, WY

Mr. \& Mrs. Lorne Scharnberg Des Moines, IA

Mr. \& Mrs. Bob Scott

East Grand Rapids, MI

Mr. Murray A. Scott

Clawson, MI

Ms. Icilin Senior

Mahwah, NJ

Mr. \& Mrs. John Shelford

Naples, FL

Dr. \& Mrs. William Sherman

Watertown, NY

Mr. \& Mrs. R.J. Sivic

Frostburg, MD

Mr. \& Mrs. Jerry Snell

Mason, $\mathrm{OH}$

Mr. \& Mrs. Paul R. Snowden

Mason, $\mathrm{OH}$

Mr. \& Mrs. Jack Snyder

Patoka, IN

Mrs. Lori Spaulding

Orient, $\mathrm{OH}$

Mr. \& Mrs. David Spencer

Kent, $\mathrm{OH}$

Mr. \& Mrs. J. Sprankle III
Chesapeake, VA

Mr. \& Mrs. William K. Stanley Herndon, VA

Mr. \& Mrs. Gerald Stanton

Defiance, $\mathrm{OH}$

Mr. and Mrs. Richard Stitzel

Burlington, $\mathrm{CO}$

Mr. \& Mrs. Charles Stover

Norwalk, IA

Mr. \& Mrs. Jerry Streicker

Reisterstown, MD

Mr. \& Mrs. Howard Sutherland

Parma, $\mathrm{OH}$

Mr. \& Mrs. Keith Svedsen

Algonquin, IL

Mr. \& Mrs. Donald Townsend Indianapolis, IN

Mr. \& Mrs. Jim VanHart

Conklin, NY

Mr. \& Mrs. Gary Vandemark

Grand Blanc, MI

Mr. \& Mrs. Mark Verwys

Grand Rapids, MI

Mr. \& Mrs. Thomas Waechter

Silver Lake, $\mathrm{OH}$

Mr. \& Mrs. J. Bruce Walter

Millersburg, PA

Mr. \& Mrs. Chuck Wambold

West Carrollton, $\mathrm{OH}$

Mr. \& Mrs. Paul Ward

Columbus, $\mathrm{OH}$

Mr. \& Mrs. Daniel Wenger
Berne, IN

Mr. \& Mrs. Charles L. Wheeler Birch Run, MI

Mr. \& Mrs. Norman J. White Dundee, NY

Mr. \& Mrs. Dave Whitten

Davidson, MI

Dr. \& Mrs. Kenneth N. Wiesert Indianapolis, IN

Mr. \& Mrs. Ernest Wilson

Frankfurt, IN

Mr. \& Mrs. Ronald Wilson

Windham, ME

Mr. Donald R. Wingert

Mechanicsburg, PA

Mr. \& Mrs. Jack Winters

Elizabethtown, PA

Mr. \& Mrs. David Wong

Caldwell, ID

Mr. R. Barry Wright

Oshawa, Ontario

Mr. \& Mrs. Warren Yeakel

Flat Rock, MI

Mr. \& Mrs. LeRoy Young I

Wellsboro, PA

Mr. \& Mrs. Terry Young

Erie, PA

Mr. \& Mrs. Larry Zuiderveen Warsaw, IN 


\section{Church Patrons}

Berea Baptist Church Berea, $\mathrm{OH}$

Berean Baptist Church

Brunswick, ME

Calvary Baptist Church

Radford, VA

Campus Baptist Church Ames, IA

First Baptist Church of Cass City Heritage Baptist Church Cass City, MI

First Baptist Church

Creston, IA

First Baptist Church

Eden, NY
Foothills Baptist Church

Hardy, AR

Grace Baptist Church

Cedarville, $\mathrm{OH}$

Grace Fellowship Church

Oak Forest, IL

Hagerstown Bible Church

Hagerstown, MD

Clarks Summit, PA

People's Baptist Church

Newfield, NY

Saylorville Baptist Church

Des Moines, IA
Shawnee Hills Baptist Church Jamestown, $\mathrm{OH}$

Sheffield Chapel

Sheffield, MA

Shoaff Park Baptist Church Fort Wayne, IN

Southgate Baptist Church Springfield, $\mathrm{OH}$

Temple Baptist Church Portsmouth, $\mathrm{OH}$

Washington Heights Bapt. Ch. Dayton, $\mathrm{OH}$

Wheelersburg Baptist Church Wheelersburg, $\mathrm{OH}$ 
Baer, Allison ...................................46

Bailey, Justin $58,112,140$

Abbas, Bethany $.70,141$ Abrams, Melinda ................102,180

Acton, Racha .... 5, 32, 70, 106, 123 Ager, Merlin .................................38 Ager, Ruth

Akerberg, Arik

... 42

Akom, Stephanie

Alderfer, A 128

Alexander, Heather ....................143

Alexander, Matthew .........................58

Allen, Clayton .................................46

Allen, Dawn ………………........70

Allen, Jennifer

180

Allen, Kerry 58, 104

Allgrim, Meredith

.135

Allison, Tyler

Allport, Charles

Alyn, Irene

Ament, Robert

Ames, Sandra

Amos, Elizabeth ………………...58

Amos, Josh ............ 46, 94, 116, 127

Amstutz, James .....................46, 146

Amundson, Doug 58, 62, 127, 132, $146,147,163$

Amundson, Elizabeth ….......70, 138 Anderson, Amy ………....58, 147 Anderson, Christopher .......70, 138, 140,147

Anderson, Eric ............70, 110, 216

Anderson, John ........................... 46

Anderson, Kerry 87, 125, 146, 180 , 216

Anderson, Lori ....................58, 113

Anderson, Lyle

Anderson, Rachelle ................... 180

Anderson, Ryan .... 46, 89, 125, 138

Anderson, Stephanie

Andresen, Daniel

Andrews, Adria .......................58, 91

Andrews, Frances

Angelone, Jessica ………………….......46

Anglea, John

Anglund, Erik

Anna, Jonathan . 70, 92, 94, 125

Annoni, Scott ........17, 94, 180, 216

Anthony, Andrea .................58, 169

Anthony, Darla ………….....70, 101

Appel, Rebecca

.... 113

Apple, Eugene

Appleton, Amy

Armistad, William .

Armitage, Melissa

Armour, Aaron ..........58, 113

Armour, Julie .14, 46, 94, 142, 145

Armstrong, Kevin ..........................46

Armstrong, Sarah ….................. 180

Arthur, David ................................. 46

Artman, April ...............70, 134, 159

Ashcraft, Chris .................... 46, 128

Ashley, Douglas ...................70, 176

Ashurst, Valerie ..... 58, 65, 97, 130,

131,132

Atwell, Jason

Auffort, Nate ................................. 158

Augustine, Johannah ....................58

Ausfahl, Joshua .............................. 46

Austin, Amanda .................. 46, 127

Austin, Graig ...............................58

Avery, Dana …………….....70, 138

Avery, Jill ..................................5 58

Awabdy, Amy .... 70, 101, 132, 133 , 204

Awbrey, Jeremy ...................70, 104

B

Baab, Rick

Bader, Micheal

Bader, Ronald

. .58

248 index

42
$58,90,138$

Baise, Barbara

..... 42

ise, Louann .

aker, David

Baker, Janette

Baker, Julie

Baker, Sue

Baldwin, Marth ....38, 94

Baley, Christina

42,159

Ballard, Stanley

58,146

Bancett, Ginnie

Bandy, Kimberly

Barber, Carilyn

Barker, Erin.....

Barker, Gary

...... 40

arnes, Amy ... 12, 13, 14, 180, 21

Barnes, Jill ..

Barnett, Holly

Barnhart, Laurel ... 125, 137, 180

Barr, Israel.

Barr, Steve

Barrets, Janic

Bartholomew, Raymond .............39

Bartlett, Bradley ..

Barton, Alesia

46

Bartosiewicz, Jennifer 132, 181, 223

Baslock, Heather

Baslock, Rhonda

Bassett, Philip

Batchelder, Rachel

Bateman, Venessa

Bathrick, Amy $2.58,147,158,159$

Bathrick, Sara .............................. 46

Bauer, Erik

Baughman, Melissa

Bayer, Allison.....

Bayler, Douglas ........125

Beal, Mary Beth 58,8

Bean, Shannon

Beaty, Carrie

....58

Beck, Jamie

Beck, Karen

Beck, Matthew

..... 181

Bedford, Jaim

46,89

Bedillion, Eric

... 46,94

Beich, Rob

Beikert, Bob

Beikert, Grace

Beitler, Joy

Beitler, Nathan ... 17, 146, 181, 216

Bejec, Dwight

Bell, Joshua ….....................62, 156

Bell, Kimberly .............58, 134, 156

Bendt, Sarah

........46

Bennett, Alicia .

Bennett, Scott ..............70, 97, 143

Bennick, Kristina ....................70, 89

Benson, Jennifer ..................92, 129

Beres, Jennifer ....................46, 129

Beres, Kari ....................21, 70, 232

Bergandine, Brent ……………..... 58

Bergen, Robert .....................70, 104

Berkheiser, Rebecca ...........181, 212

Bernhard, William

…........ 8

Berry, Devon .... 181, 205, 214, 225

Bertelson, Anthea

Beshaw, Harold.

... 181

Beste, Jeff ....................42, 142, 146

Bethel, Heather .............58, 62, 140

Bey, Aaron ..........70, 104, 130, 138

Bibler, Christopher ................ 58, 94

Biddle, Amy

Biddle, Andrew

181

Bielek, Robert

Bielo, Allyson .................................46

Bierly, Almeda

Bigam, Jeffrey

Biggs, Maria

Bingham, Jeff

Bishop, David

Bishop, Necia

Bjerke, Joel .

Blackburn, Jeffrey ……......... 146, 181
Barrett, Virginia . . 58, 65, 131, 138

Jennifer .........58, 61, 93 Brian .................................. 42

Blansette, Michael ................70, 102

Blanton, Mary Jo

...... 58

Blevins, Beth

42,123

Bliss, Carol

....... 42

Blumenstock, Helen

.104

Blumenstock, Rich

Boehm, Matthew

Boehm, Michelle

Boertje, Julia 46,86

Boggs, Philip ........58, 92, 128, 165

Bohlen, Angela ………………......58

Bohs, James...

Bolha, Claire

Bolhuis, Nathan ..................70, 102

Bollman, Jill .

Bolsem, Stephanie ................70, 133

Bolt, Jennifer.

........ 58

Bond, Kathryn ................. 106, 182
Bondorff, Jacqueline ... 14, 182, 228

Bonenberger, Omer ....................... 38

Bonga, Janet ...........................70, 89

Bonner, Michael

Boone, Elizabeth

Boothe, Laura......

Borgman, Darlene

Bork, Rebecca ……...............46, 105

Borkholder, Jackie ...................... 148

Borkholder, Joy …………....70, 113

Borling, Scott .......................70, 102

Borton, Dacia ……………....12, 182

Borton, Jason

117,182

Bosma, Janice ............................. 40

Bossley, Heather ....21, 70, 96, 122 .

$123,138,143$

Bossley, Heidi ......... 18, 65, 70, 123

Bouwens, Robert .... 58, 87, 94, 142

Bovay, Becky .................21, 46, 95

Bowen, Heidi .......32, 70, 103, 106,

$122,131,138$

Bowen, Jeff,

Bower, Julie

Bowersox, James

Bowling, Tonya

136,182

Boyce, Angela

Boyd, David ....

Boyd, Gordon

Boyer, Lorraine

Boyer, Wendy

Bradds, Connie

Bradley, Jeff.

Bradley, Jennifer

Bradley, Melinda

Bradley, Rebecca

Bradley, Scott ...

Bradstreet, Shawn

Brainard, Matt ...

Braithwaite, Edwin $58,104,132$

Braley, Christina

Brandenburg, Molly

Brandmeyer, Larry

Brandon, Carl

Brandon, Joy

Branon, Lisa .

Braswell, Dan

Bray, Rachel

Brazalovich, Deborah …..46, 13

Breneman, Jeffrey ................70, 142

Breneman, Matthew ...70, 130, 142

Brent, David .................................. 87

Brentlinger, Beth ……………............46

Bresson, Francis ……………….... 8

Brewer, Stacy .

Brickel, Melody

Brickel, Rychel

46,101

Bridewell, Tina

Briggman, Anthony

Briggs, Christine

Brinkley, Chris

Brockman, Tonya

Brodie, Heather ..

Broeckert, Hannah

Brower, Julie 
Collier, Suzanne

Collins, Kimberly .........59, 102, 136 Colman, James ....................40, 139 Combs, Rebecca ….............137, 185 Combs, Sharron ......................... 59 Comegys, Heather 59, 89, 132, 133 Comer, Bethany ..........2, 32, 47, 49 Comers, Heidi ......................71, 101 Comfort, Paul .............................71 Comfort, Rebecca ...........47, 88, 94 Commons, William ........................8

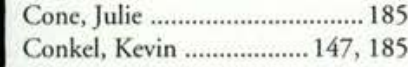
Conley, Bobbi ...........................185

Conner, Kimberly ...................... 185

Conway, Janet .............................. 40

Cook, Elise ................138, 140, 185

Cook, Lisa ……………......... 47,67

Cook, Rachel ...............................47

Cooley, John ..................................

Cooley, Nicole ………........59, 242

Cooper, Andrew ....................47, 87

Cooper, Benjamin ......59, 130, 147

Cooper, Julie71, 92, 125, 129, 140,

143

Copeland, Christine ...71, 158, 159

Copeland, Deborah .............59, 140

Copeland, Jennifer ….............21, 71

Cornelius, Heather …….....147, 156

Corner, Joshua ............71, 138, 142

Cornwell, Chad ......... 185, 228, 230

Costello, Sandra ................186, 229

Cottrill, Sean ..............71, 232, 236

Courtright, Timothy ....................71

Courtwright, Amanda .................. 47

Cousens, Andrew …………...........47

Couser, Gregory ………….............. 38

Coverdell, Ryan ........... 47, 130, 147

Cowley, Timothy .....139, 147, 186

Coy, Ronald

Coy, Sherry ....

Crabtree, Patricia

..... 42

Cramer, James...

Cramer, Kathleen ...

$. .71,156$

Crawford, Amy

71,90

Crawford, Eric $\quad 47,156$

Crawford, Jennifer .....31, 113, 186

Crawford, Mike ...................47, 154

Crecco, Mia …….......................71

Crefeld, Andrew ...71, 94, 106, 138

Cremeans, Cindy .......47, 159, 174

Creswell, Jim ………............ 47, 138

Crider, Jonathan .................90, 129

Croft, Chad ................................59

Cronk, Kori

Crowe, Jenna

Crozier, Cory

Cruver, Deborah . 129, 186

Culberson, Thomas .......59, 93, 134

Cullins, Cari

Cunningham, Amy .. 136, 186, 205

Cunningham, Jeffrey ................... 42

Cunningham, Joe ……………......71

Cunningham, Renee ...........59, 100

Currall, Emily 2, 71, 129, 136, 140

Curry, Bill ...................14, 135, 160

Curry, Marie ..................................60 60

Curtis, David 71, 91, 134, 137, 142

Curtis, Melody

Cushman, John ............................4 47

Cushman, Karen ..................186, 214

Cushman, Mark …................47, 94

Custer, Gabriel ................................ 47

\section{D}

Dabravalskas, Christine .....71, 125, 139

Damon, Gail .......................61, 186

Damron, Mark

Daniels, Carey

Daoud, John

Dato, Jamic

Daugherty, Ryan

Davids, Charstic ..

Davidson, Debbie avidson, Lisa _.............39, 127, 141 avies, Jason 128,141 Davis, A'Linda ...............................60 60 Davis, Amy …………………….....71 Davis, Jeff ……………......60, 138 Davis, Jerra ……………….....60, 96 Davis, Keith ………………….....42 Davis, Larry ……………............71 Davis, Leslie ………................... 91 Davis, Rachel ...............................60 Davis, Seth .........................71, 128 Davis, Timothy .............................71 Dawkins, Jesse ...............................66 Dawson, Melanie .....113, 126, 186 De Clark, Sherri ................2, 32, 60 De Kock, Carrie .................... 47, 65 De Kruyter, Paul ......................... 142 De Usanio, Toni ......................... 48 De Vinney, Joel 140, 186, 215, 224 De Witt, Amy .......................... 104 Dean, Charles ...... 28, 71, 135, 231 Dean, Jennifer ....................131, 146 Dean, Kathryn .............................186 Dean, Paul ................146, 186, 214 Dear, Jennifer .....................186, 214 Deaton, Jennifer .........................186 Deaton, Stephen .......................... 186 Decker, Jennifer ............................ 48

Decker, Joey .........................48, 133

Decker, Kristin …………......71, 134

Deetscreek, Bradley .................... 186 Deister, Andy ...............................60 Delaney, Michelle ...............86, 243 Delich, Jodie ………....71, 122, 143 Delp, Colleen . ... 186

Denges, Mark...

$. .60,65$

Denham, Katherine

Denlinger, David .........................42
Derstine, Damon .......60, 128, 141

Desai, Rajan ................. 45, 100, 138

Detwiler, Jill .

$.45,100,138$

Deugan, Jason

Devereaux, Lisa ......................................

Dewald, James.... 48, 100, 128, 231

Dewar, Monique ..........60, 95, 125

Di Cuirci, Michael ..

$18 . . .$.
187,214

Dick, Jodi .......................187, 214
Dick, Michelle .....60, 86, 138, 174

Dietterick, Lisa ...............................71

Dietterick, Lynn ................................... 60

Diller, Ben

Dillon, Bethel …………………...... 43

Dimler, Gregory ...28, 71, 231, 236

Dinelli, Jennifer .................61, 140

Divan, Linda .................................43

Dixon, Paul .....9, 27, 69, 213, 221, 223

Doak, Gregory

Doden, Daryle

Doden, Tamara 71, 140,141

Dodson, Jamie ..................... 48, 134

Dodson, William .............. 142, 187

Dolf, Shelley .......................60, 96

Doran, Stephen ………………......60

Dorsey, Kimberly ........72, 122, 134

Douglas, Cheri …………………... 48

Douglas, Daniel ...................60, 104

Driesbach, Jason ............................72

Droke, William .. 88, 133, 187, 214

Drowden, Joanna ........................ 143

Drullinger, David ...................38, 160

Drury, Patrick ………………….... 43

Duck, Brandon ..................126, 230

Duez, Marcie ..............14, 152, 153

Dukes, Michael ………………..... 60

Dunham, Aaron ......................48, 88

Dunkelberger, Jeffery ....................60

Dunlap, Kari …………………....159

Durham, Cathleen …….............139

Durham, Richard ................41, 139

Durham, Traci .............................60

Dutcher, Jennifer ..........................72

Dutil, Kevin .................72, 130, 145

Dye, Sarah .............................. 187

Dyer, James ...........................60, 242

Fleming, Andrew.

Flentge, Dennis

Flowers, Timothy

\section{E}

Eaby, Joel .........................................4 48 Eads, Nathan 93,187

East, Randall

Eaton, Bryan ………….......135, 187

Eckstein, Sharon

$.72,156$

Eder, Chad .......................72, 156

Edlund, Alan ..

Edlund, Greg .

... 171

Edsell, Eve .....................72, 84, 134

Edwards, Heather ............................60

Ehlers, Christopher ..............72, 136

Ehlers, Marnie ................60, 89, 102

Eimers, Andrea ............94, 106, 211

Eimers, Leroy …………………...... 40

Eimers, Sharon ………………….....38

El-Khouri, Renee …………….......72

Eldeen, Carrie ..

Eldeen, Stacie .......................48, 133

Elder, Rachelle …………...... 48, 156

Elliott, Jeff

...... 88

Ellis, Linton ................................ 160

Elmore, Alicia ...... 2, 5, 32, 72, 116,

125,140

Elmore, Floyd

Elmore, Joel

Elmore, Pamela

Emery, Robert

Emes, Traci .......125, 126, 133, 187

Emmert, Cheryl

Engelmann, James

Engle, Michael

English, Leah

Enterkin, Jodie ...............72, 90, 146

Entner, Sandra ........................... 38

Entner, Todd .. 125, 134, 139, 171, $187,215,223$

Epp, Kurtis...

Erickson, Todd

Estep, Stephen

Estes, Daniel

Etchison, Lon

Evans, Brad

Evans, Lydia

Evans, Tony .

Everson, Shellene

Evilsizor, Amy .

Ewing, Christin

Exline, Brian

Ezerins, Karla

Foeldvari, Laura

Foerch, Joel ...

Foore, Tammic

Foote, Amanda

Forrest, Daniel

Forsberg, Brian

Fortna, Jeffrey

$122,188,205$

Fourman, Heather

29, 188,214

Fourman, Matthew

48,160

Fox, Debbie

$\ldots 60,163$

Fox, Diione

$48,93,141$
$\ldots . .88,188$

Fox, Sean

86,171

Fox, Shelley .. 12, 31, 188, 214, 229

Fraley, Dara

Fraley, Jonathan

..... 188

Fraley, Melanic

72,159

Frampton, Kyle

Francis, Bradley .

.... 60

Francis, Erma

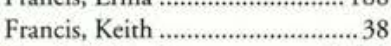

Frank, Deborah ....................72, 86

Frank, Dwayne ……………….......38

Frazier, Brooke .............60, 90, 169

Frazier, Garth .............................39
Frederick, Kristen

Freese, Kathleen ..........39, 159, 174

French, Jamie ..............72, 104, 138

French, Robin ...............................48

Friemel, Valerie …………………...72

Fryman, Megan ............................... 48

Fuerch, Joel .....

Fulkerson, Penni ..........60, 101,145

Fuller, Jill ................100, 138, 188

Funtik, Lynne

Futrell, Ryan

\section{G}

Gabbard, Jeffrey ……................ 188 Gabriel, Angela .....72, 86, 138, 141 Gadsby, James …..................72, 128 Gaffner, Bethany ………………......48 Gaffner, Matthew .................72, 236 Gaffner, Michelle ……………..... 127

Gain, Christiana ............ 48, 94, 134 
Habegger, Jennifer ......... 14, 72, 86 Hable, Nathan ..............................61 Hack, Leslie ..............138, 190, 222 Hacker, Joel ......................131, 138 Hackney, David ...............................72 Hadinger, Mitchel ......................... 49 Hadley, Melissa .... 72, 94, 133, 147 Haffey, Benjamin ............... 49, 154 Haffey, Deborah …………...........230 Hager, Jodie ......................... 49, 134 Hager, Kelly ................88, 133, 211 Hagerman, Catherine ................. 190 Hague, Keith ... 43 Haines, George . 17, 146, 190, 216 , 224

Haley, Jennifer

Halk, Marsha

Hall, Joanna ..........61, 91, 132, 236

Hall, Michael ..............72, 127, 132

Hall, Mike.

Halsey, Joanna .................49, 65, 88

Halsey, Joseph ............................... 41

Halulko, Josh .................. 49, 94, 133

Halverson, Stephanie ..................... 43

Hamer, Craig …….............111, 130

Hamer, Keith ….........72, 130, 147

Hamilton, Lori ....................... 49, 94

Hamilton, Ruth ... 17, 96, 133, 146, 211

Hamilton, Tiffany . 14, 49, 94, 141, 146

Hamilton, Troy.94, 126, 128, 190 , 215,216

Hammond, Olivia ................73, 133

Hamrick, Anna …………..... 49, 88

Handel, Christopher 131, 138, 190, 215

Hangosky, Jennifer ..

... 49

Hanks, Josh

Hansell, Timothy

49,87

Hansen, Dustin

49,61

Hapeman, Amie ...30, 73, 105, 125 , $129,133,140$

Hardman, Susan ...............191, 219

Harju, Bryan ................73, 110, 134

Harju, Cara .................... 49, 89, 141

Harlan, Anna ........................... 49, 91

Harley, Scott .

215

Harmon, Marie

Harner, Amy

191

Harner, Sandra

...39

Harriman, Brian

Harrison, Aaro

49,91

Harrison, Angela

49,86

Harrison, Donna

.... 43

Hart, Nathan

$45,49,243$

Hartkop, Caron

.... 61,136

Hartley, Scott .............. 25, 145, 191

Hartman, Karyn . 12, 136, 191, 215

Hartman, Melissa 61, 73, 153, 158, 159,169

Harty, Jim

Haseltine, Todd

Haskell, Jeremy . 73, 124, 125, 129 , $141,216,232,236$

Hass, Lana5, 32, 73, 147, 152, 153. 200,212

Hasselbring, Cindy... 129, 147, 152, $153,156,157,191,213$

Hassell, Ian

Hassenzahl, Kelby .......................1, 88

Hassenzahl, Timothy ....................73

Hastings, Jonathan ..............87, 191

Hastings, Julie ........................61, 86

Hasty, Joy .......................... 49, 147

Hatcher, Karen .............73, 101, 113

Hatfield, Dan .

....65

Hauter, Sara ……………….... 45, 49

Hawkins, E. L.

$1 . .8$

Hayden, Roger ....................191, 214

Hayes, Karen ................................73

Haylett, Timothy .61, 90, 142, 146

Hazen, Marinus ............................... 38

250 index
Helmick, Larry .

40

Helmuth, Barba

45,49

Hendricks, Greta ........140, 143, 191

Henney, Dawn ...............................73

Henniger, James ............................... 8

Henricks, Rachel ........61, 113, 141

Henry, Chad ................................61

Henry, De Vonne 2, 134, 191, 220

Henry, Jennifer .................131, 191

Henry, Kara ........................ 146, 191

Henry, Sara .................................. 49

Hermiz, Matthew ..................61, 236

Hermiz, Matthew J. ....................236

Hernandez, Nicole ..............73, 106

Herr, Ruth ..........................61, 88

Herschberger, Linford ......130, 134 ,

$139,192,232$

Herschberger, Lowell25, 61, 62, 90 134

Hershner, Mark …......73, 100, 147

Hert, Maria ......................... 49, 142

Hetzler, Misty ……….............73, 92

Hewitt, Melissa ...........................62

Hezlitt, Rebecca ..........91, 143, 192

Hickox, Amy .......................62, 137

Hickox, Sandra

.... 192

Hicks, Daniel

.49, 94

Hicks, Heather

61,73

….....96, 211

Higgins, Brooke .......... 49, 145, 146

Higgins, Michelle .49, 94, 101, 134

Hill, Alicia .....................50, 97, 125

Hill, Dallas ..................62, 130, 236

Hill, Dustin …………………..... 176

Hill, Natasha …..................125, 139

Hill, Todd .........................................

Hillman, Christy ....................73, 92

Hillman Jr., Geoffrey ....................50

Hilty, Brian ...................................156

Hintz, Matthew ............................... 62

Hintz, Melissa …………………....62

Hively, Melissa ...............................62

Hjembo, Jonathan .................... 4, 62

Ho, Nathan ......101, 134, 135, 146, 192

Hoadley, Kristine ...........................73

Hoadley, Scott ....................62, 142

Hochstettler, Trish .......................8 88

Hock, Jeff ..........................139, 165

Hockenberry, Lori ..................62, 95

Hockensmith, Dustin 142, 143, 192

Hodel, Emily ...............62, 69, 100

Hodson, Carolyn ........................... 43

Hodson, Joanna ...........................192

Hoecke, David ...............................43

Hoewing, Rodney ....................... 192

Hofert, Brian ................................50

Hoffman, Ben .....................73, 176

Hoffman, Beth ......................62, 91

Hoffman, Kenneth ……............. 192

Hoffman, Randy ..........................73

Hofmann, Margret .............146, 192

Hohman, Carolyn .............................73

Hohman, Sherene ……………....73

Holesovsky, Sarah ........62, 86, 138

Holesten, Kathleen ...................... 133

Hollenbaugh, Michelle ............... 192

Holloway, Camille ......................192

Holloway, Thile ………………....192

Holt, Bruce ……………………....73

Hoop, Amy ……………......73, 134

Hoorn, Rebekah _...............73, 135

Hoover, Heidi .. 131, 138, 192, 242

Hull, Gary...

Huns Barger, Lisa Jacobson, Jodic ................................ 88
Hoover, Leah .......73, 96, 133, 243 Hoppe, elly ..................................50 Hord, Kimberly ………...............73 Horne, Jennifer ....61, 74, 125, 127 Horton, Carolyn ..........62, 90, 138

Hoskins, David .... 50, 74, 100, 142

Hotchkiss, Timothy ...50, 125, 165 Houck, Daren

Houk, Nathan ............ 50, 128, 142 Houlihan, Kristen ........................74

Housten, Kathleen ……...............50

Hovis, Jody

$50,89,141$

Howard, Joel

62,106

Howard, Ken

50,96

Jenista, Todd

.74

Howe, Abigail

192

Howe, Karisa ....................61, 62, 125

Howell, Sara ...62, 65, 90, 131, 138

Howell, Tiffany .......................... 192

Hoy, Bowe ...........24, 74, 125, 126

Huber, Daniel .............62, 104, 128

Huber, Patricia

... 43

Huck, Scott ................................. 43

Huddleston, Karmen ............62, 163

Hudson, Daniel .................... 50, 94

Huebner, Ryan ............29, 111, 128

Huffman, Nathan ................74, 160

Huffnagle, Kimbra .................50, 94

Huffy, Kim ...............100, 135, 139

Huggler, Laura ... 74, 147, 152, 153

Hughes, Dustin ………............. 4, 62

Hulbert, Craig ............62, 130, 147

..... 43

Humphreys, Amy ............................74

Humphreys, Donald ......................39

Hunsaker, Amy ......................62, 96

Hunsaker, Susan .................... 45, 62

Hunsberger, Angela .. 129, 185, 193

Hunsberger, Jill .

193
$\ldots .50$

.... 43

Hunt, Leigh

Hunt, Robert .

43

Hunter, Erica .................50, 96, 243

Hurd, Jonathan

.... 50

Hurst, Amy

Hurt, Keith

94,193

.

Husband, Scott ..50, 113, 128, 142

Hutchins, Sally ...........74, 139, 243

Hurtson, Chris 102

Hyback, Cheryl ........................... 193

Iamaio, John 17, 74, 129, 146, 176, 216

Ikeda, Kouichi

$62,94,139$

Ikeda, Yoshimi

$.2,62,139$

ian, Bradford

$89,140,193$

Ingalls, Jennifer

... 62,141

Inion, Brenda

$50,65,88$

Ireland, Drew

62,93

Iten, Bradford ............130, 147, 193

Ivey, Becky ..................50, 142, 145

\section{$J$}

Jackson, Christina ……………....62 Jackson, Janelle .........129, 140, 193 Jackson, Jonathan ……………......74 Jackson, Sarah ...........152, 153, 166 Jackson, Steve .........................74, 127 Jacobs, Jack Jacobson, Toby ..................74, 173 Jagger, Emily ..................... 193, 214 James, Nathan ......................74, 142 James, Rob …...................103, 128 James, Robert ..... 193 Jaskilka, Julie …………….......50,89

Jefferies, Bryan …………......74, 134

Jeffery, Julie

........ 62

ks, Rebecca

156

Jenks, Sarah ....................62, 94, 106

Jenks, Stephen

Jensen, Naomi ...................139, 193

Jeremiah, Jennifer $50,103,141,169$

Jex, Aaron ......... 45, 74, 94, 96, 128

Johns, Erin …………....50, 94, 138

Johnson, Angela ………….....63, 88

Johnson, April .....................50, 134

Johnson, Brenda ..................50, 102 
Lawson, Amy ..

Leach, Gary ..

LeBlanc, Kirk

Lee, Carol .

$.51,111$

Lee, Daniel ... 63, 88, 147, 154, 15 Lee, Ken ..............75, 104, 130, 142 Lee, Patricia

$63,105,132,133$

Lehman, Kara ......63, $105,132,13$ Lehman, Mina ............................ 90
Lehman, Philip ..................75, 142 Lehmann, Brian .......................... 5 Lehmann, Brian .............................
Lehr, Barrett ................................. 79 Leibold, Kimberly

Leinbach, Jodi ...

Leininger, Tabitha75, 91, 102, 132 13

Lemmon, John ............................ 5

Lempner, Michael ....................... 63

Lenhart, Adam . 132, 141, 143, 19

Lenhart, Angela

Lenhart, Karrie ,

63,89

Lenhart, Rebeco

.6. 196

Lepak, Lesa .

Leslie, Andy ........................... 165

Letson, Angie ...............63, 91, 138

Leuck, Nellie.

Lewis, David

Lewis, Ed ...

$\mathrm{Li}$, Chris .

75,154

Lightly, Sarah

51,113

Linafelter, Karisa 51, 102, 143, 243

Linak, Jennifer

Linak, John .

Lindaberry, Betsy

136,196

Linley, Michell

63,91

Linn, David.

Lloyd, Joseph

Loach, Barbara

Lodge, Rebecca

Longo, Michael

Longshaw, Jon ...................75, 135

Loomis, Marne. 125, 129, 196, 21

Lopez, Hugo

Lopez, J. Michael

Lorinovich, Melissa .

Losee, Nichole.

... 51,89

Losier, Lora

140,196

Lotz, Laura

86,196

Lozier, Todd

Lubbers, Chad.

Ludwig, Sara

Luke, Derek

Luman, Brent ..
Lunney, Joshua

Luo, Dali

Luo, Ling

Lutz, Andy .

Lutz, Jennifer ............................... 5

Lyngaas, Chuck .. 51, 148, 156, 17

Lyons, Marie ...................... 51, 159

Lytwynec, Jennifer .........21, 65, 75

\section{M}

Ma Gee, Rebecca ........................196

Mac Donald, Robert ....................75

Mac Farquhar, Jennifer .............. 196

Mac Lean, Heather .......63, 89, 132

Mac Pherson, Jessica ...........94, 242

Madding, Danielle .............93, 196

Maddox, Miriam ……………......... 40

Magin, Sharon .............................63 63

Magnuson, Heather ..........196, 222

Mahnke, Andy ..............................4 44

Maile, Miekka ……………..........63

Majeski, David ..................196, 223

Maki, Laura ................................75

Maki, Rachel ..................63, 93, 134

Malar, Jill ……….........75, 141, 143

Malone, Joel ...................63, 66, 86

Malone, Kara .....63, 147, 156, 157

Manifold, Chad.

Mann, Matt
Merchant, Steven ...................52 243

Merritt, Dawn .....75, 87, 124, 125 , 134

Meyer, Matt …….......125, 131, 147

Meyers, Angela ….................52, 95

Meyers, Melissa …....................... 197

Michael, Billie ..............................64

Michaels, Tammy52, 104, 145, 146

Michaleski, Carin ........................ 91

Mick, Jeffrey ………..........52, 142

Migaj, Andrea

.....64

Martin, Kenneth .............................51

Martin, LaRae ..............................75

Martin, Laura ……………….........63

Martin, Lisa ..............................159

Martindale, Nathan .................... 135

Marvin, Saundra ……................. 197

Mascall, Lisa ..........................61, 63

Maskill, John,

.....63

Mathews, Mark ...............................44

Mattison, Adam …………………...75

Mattke, Brenda …...............75, 102

Mattke, Sarah ......

Mattson, Philip

63,111

Matula, Tammi ...................51, 159

Maxie, Wayne

......... 44

Mayer, Veronica …..............63, 125

Maynard, Kim …………......51, 134

Mays, Stephen …………......75, 176

Mazelin, Janelle

... 197

Mazelin, Mark

197

Mc Auley, Ruthan

Mc Cain, Alan.

Mc Cammack, Rya

Mc Carty, Jennifer

44

Mikesell, Shawna .......................44 44

Milentis, Kristina ...........75, 97, 141

Miller, Abby ………...........52, 93

Miller, Aimee ........... 138, 143, 197

Miller, Amy ……...................75, 86

Miller, Andrew ................4, 64, 156

Miller, Benjamin .................64, 112

Miller, Brent ………………...... 160

Miller, Brian ……………………176 176

Miller, Bryan ……................52, 165

Miller, C. Eugene

Miller, Cara .................61, 64, 137

Miller, Cheryl ......44, 75, 152, 153

Miller, Clint .......................141, 176

Miller, Douglas ...................... 41, 44

Miller, Eric ....................86, 145, 198

Miller, Erika ………....64, 147, 174

Miller, Jeffrey ………………...... 198

Miller, Kimberly ..................75, 113

Miller, Kyle .................................... 52

Miller, Laura ………………….... 198

Miller, Linda ……...................64

Miller, Lisa .................32, 133, 140

174, 198

c Caskey, Christopher 36, 64,

Mc Chesney, Stephanie .............197

Mc Clain, Pamela ................. 75, 230

Mc Cleese, Michael ....75, 130, 147

Mc Clintock, Anne ………….......51

Mc Comb, Gordon

...64

Mc Coy, Julie.

Mc Crory, Dale ....................51, 156

Mc Cullough, Danette ........64, 104

Mc Dale, Rob ………...............127

Mc Dermitt, Noel .................. 51, 89

Mc Devitt, Amy .............64, 86, 133

Mc Dole, Robert .............51, 94, 95

Mc Dowell, Shawn ………….......197

Mc Ewen, Dayton …………….... 197

Mc Fadden, Chad ..........................64

Mc Gillivray, John ...............39, 154

Mc Goldrick, James ...................... 41

Mc Gowan, Michelle ................... 197

Mc Guinness, Brian ...75, 142, 236

Mc Guire, Allan .................131, 138

Mc Guire, Brandon .

..... 64

Mc Guire, Larry ............................ 197

Mc Intosh, John

Mc Intosh, Mischell .......................44

Mc Intyre, Becky ..................75, 133

Mc Kanna, Brent ..........................75

Mc Kay, Melodie ………..........51, 86

Mc Kinley, Dawn ........................ 197

Mc Kinney, Robert ………...........51

Mc Kinnon, Kyle ....................... 160

Mc Leod, Peter

Mc Macken, Megan

Mc Millan, Nancy

.... 52

Mc Murtry, Dave ........................142

Mc Murtry, David ...............75, 146

Mc Niece, Amy ...............................75

Mc Pherson, David ...................... 52

Mc Pherson, Melinda .................. 197

Mc Quinn, Ethan ...............52, 147

Mc Vey, Diana ………................. 197

Mc Vey, Joy ………..................137

Mead, Stephanie ..64, 92, 104, 134

Mears, Ryan ...............................154

Meckley, David .............52, 97, 132

Medlong, Sarah ……….......... 52, 86

Meeden, Julie ………....64, 106, 134

Megilligan, Sharla ......................64

Melkonian, Christopher ......75, 147

Melvin, Paul .......................176, 197

Mennenga, Monica ......64, 65, 163
Miller, Matt …………………. 171

.. 198

Miller, Michelle

. .185

Miller, Mindy

....52

Miller, Nathan ...75, 130, 147, 236

Miller, Sara ….............52, 130, 147

Miller, Susan ………............75, 111

Miller, Tim .

102

Milligan, William ...............141, 198

Mills, David ......................................38

Mills, Jared ……………………....... 75

Miner, Paul .......................143, 198

Misere, Jonathan ...............139, 198

Misirian, James

52,128

.

.... 140

Mitchell, Donna ................75, 88, 94

Mitchell, Joel .................................. 64

Mitchell, Kristi ...............................91

Mitchell, Mary .............................. 44

Mitchell, Melanie ................89, 198

Mocny, Melissa ……….......76, 133

Moe, Douglas .................76, 93, 128

Mohn, Bethann ….................76, 106

Moles, Dennis .............45, 142, 146

Moll, Keadra .................................76

Monge, Winona ...........................91

Monroe, Allen ……………..... 6, 7, 41

Monroe, Beverly …………..........6,7

Moody, Stephanie …….........52, 91

Moon, Elizabeth ……….....143, 198

Moon, Karin .................64, 93, 134

Moon, Katie ..........................52, 104

Mooney, Bradley ..................22, 198

Moony, Melissa …………………....... 86

Moore, David ..................... 2, 52, 95

Moore, Deidre .................. 143, 211

Moore, Sean ……………............176

Morales, Michael .......................... 198

Moreland, Kurt ……………………....... 38

Morgan, Jennfier ............................64

Morgret, Wayne .....................76, 229

Morris, Michael ....................64, 89

Mosby, Jennifer .............76, 91, 133

Moseley, Sarah . 100, 139, 198, 243

Mosley, Donald ........................... 198

Most, Aaron ................................. 198

Moulson, Steve

$64,84,128$
Miller, Michael

Mottin, Christine

Ormsbee, Dave
Orser, William

........ 141

Osborn, Daniel ………………5 52

Osterc, Andrea .............52, 142, 145

Ostrander, Jason ........................1 154

Osuch, Dean ………....76, 101, 102

Otten, Timothy ..........................64

Otto, Mark ......... 16, 117, 135, 154

Overcash, Rebekah ...........136, 199

Overdorf, Timothy ......................64

Overman, Shonda ….............52, 134

Owen, Harold .......................52, 132

Owens, Amy ……................76, 133

Owens, Andrea

$.52,95$

Murphy, J. Dale

Murphy, John

199 
Phipps, James ........................38, 160 Phipps, Lori

Phipps, Shann

........................ 41

Pickell, Beth Ann ........89, 134, 200 Pickell, Melinda ......32, 54, 67, 113 Pickens, Jon

88

Picuri, Michele ...........64, 131, 132

Pierce, Christina …………………..54

Pierce, David .........................64, 176

Pierce, Stephen ................................ 86

Pierson, Ruthanne ...................54, 87

Pifer, Hilary

54,100

Pileggi, Matt ………........154, 165 Pinkley, Janine ....21, 76, 102, 133 , 140

Piper, Sharon ……............137, 201

Pirrie, Kimberly

...201

Pitcher, Nicholla

Pitonyak, Melissa

Pletcher, Julianne

Plunkett, Julie ......17, 76, 132, 146

Plush, Jonathan ...........................20

Poe, Justin ……………..........54, 89

Poivesan, Nathan …………….....76

Polack, Bobby ....................160, 161

Polgardy, Samantha .............. 54, 94

Pollard, Meredith .......66, 147, 153

Pool, Tamara ………………...... 201

Pope, Melissa ……………...76, 136

Pope, Shannon ………………......76

Popp, Pamela ………………...... 201

Porrett, Jeremy .

66,95

Porter, Erica ..........76, 94, 104, 147

Porter, Jake ……….............54, 142

Porter, Jennifer ............................201

Porter, Richard .

Potter, Cynthia ……………....45, 54

Potter, Gerry

Potter, Jaimee ……........76, 89, 134

Potts, Jenet ...................................76

Powell, Elisabeth .................91, 201

Powell, Mary .

Powell, Sarah

..... 54

Powers, Ed

66,91

Powers, Laura

Pratt, Sandra ..............................40

Prentis, Tara ..... 130, 201, 215, 218

Preston, David ............76, 130, 142

Price, Amy …........54, 94, 142, 145

Price, Beth .........................54, 127

Price, Krista ................66, 112, 231

Printy, $\mathrm{Ma}$.................................... 45

Proudfoot, Denise ……………....76

Prugh, Ruth

Pryor, Nicole

Pugsley, Daniel _..... 138, 143, 201

Purdy, Kelly ...................................66

\section{Q}

Quarles, Charles ..................66, 113

Quick, Kimberly ...........................76

Quinn, Jason ................76, 135, 160

Quinn, Matthew .......................201

Quint, Cynthia .......21, 61, 76, 138

\section{$R$}

Raby, Jonathan

Radcliff, Lisa

Radford, Nathan .......................54, 91

Radford, Sara ………….......78, 112

Rafferty, Seth ........................54, 87

Rahilly, Sharon .

Randall, Allison

.. .66

Randall, Lee ......

.201

Randolph, Shaundra 158, 159, 201, 220

Rang, Joshua ......31, 160, 173, 201

\section{2 index}

Be, Brenden

as, Melanie ……….......78, 94, 141

Rasey, Tamara …………………..... 44

Ray, Cynthia .................................201

Rayder, Aaron .............................143

Rayder, Christopher

.... 78

, David ……………....54, 156

Read, Brian .............................. 90, 128

Read, Shari ...................66, 97, 100

Ream, Angela ................78, 92, 202

Rearick, Robert ..........................202

Reda, Jamin …………..........54, 94

Redford, Maria ………….....78, 102

Reed, Jennifer ............. 5, 24, 32, 54

Reed, Kwajalein .................138, 139

Reed, Melissa ........................61, 78

Reed, Monique …………………....66

Reed, Noelle................78, 140, 143

Reese, Jim

.... 54

Reese, Pete ……………….........44, 160

Refior, Laura ...........54, 94, 96, 236

Reich, Rob .................................66

Reilly, Jennifer …………………....66

Reimers, William ……...............202

Reiner, Daniel ...............................202

Reinhardt, Jon ...............................78

Reini, Eric ...2, 112, 117, 154, 202, 214

Reis, Janelle .................66, 132, 133

Reiter, Stephen ..................138, 202

Remiger, Christine …………........54

Remington, Cathy .......................202

Rexford, Matt ……………….....111

Reynolds, Matthew ...31, 135, 142,

$160,202,215$

Ribeiro, Rebecca …………….......54

Riblet, Jared ...............................202

Rice, Jennifer ...............................202

Rice, Patricia ……………………....54

Rice, Tricia …………………....146

Rich, Angela ……………………....78

Rich, Becky ...........................65, 78

Richard, John …..................66, 127

Richards, Thomas ………….66, 97

Richardson, Curtis .........................78

Richardson, Matthew …………......54

Rickard, Donald .............................9

Riddle, Gregory ................................... 202

Ridley, Brent ......................66, 142

Riggs, Jack ........................................ 38

Rinaldi, James …………................... 44

Rinehart, Ann ........................202

Rinehart, Fred ...........................202
Rinehart, Hillary .........89, 143, 202

Rinehart, Kristin .........78, 131, 230

Rising, Chrissy ..............................54

Risser, Kendra .................................66

Ritchey, Heather ……………........66

Ritchie, Leah ……………….........54

Rizer, Charity .......................54, 100

Robar, Scott ...............................202

Robbins, Michelle …………........78

Roberts, Aaron ............78, 125, 143

Roberts, Chasta .......................55, 91

Roberts, Jesse …………......78, 142

Roberts, Micah ..............................55

Roberts, Shawna ............................55

Robertson, Karen ……….......78, 95

Robey, Beverly ...............................44

Robey, David .......................38, 231

Robey, Jared .................................78

Robey, Jeff ……….......................14

Robinson, Charles .......55, 102, 142

Robinson, Matthew... 95, 147, 176,

202

Robinson, Winona ..........33, 78, 89

Roby, Julie

Rodgers, Jerry ............................5 131, 243

Rodgers, Kathryn ………..... 40, 242

Rogers, Elizabeth ........... 55, 95, 138

Rogers, Gordon ....66, 94, 125, 130

Rogers, Jennifer ……………….......78

Rogers, Lynn ..................................... 8

Rogers, Rachel ............................. 66

Rohlfs, Matt

.- .66
. .55

Schrader, Lynette

$.67,142$

hm, Stacy.

66,131

Rohrer, Nathan ……………....78, 176

Rohweder, Amber 17, 78, 137, 141

Rollins, Bonnie

Roloff, Jason ...

78,132

Roloff, Jennifer

78,103

Romaine, Douglas

66, 86

Rooke, David

55,154

Rooke, Susan

$32,78,140$

, Doug

Roseboom, Elizabeth.66, 102, 231, 234

Roseboom, Laura

.203

Rosencrantz, Rene

Rosenvold, Darin ….......... 55, 160

Ross, Anthony .

.. .66
.78

78

Ross, Julie ……………......55, 138

Ross, Rachel

$.78,92$

Rotman, David

....38

Rotman, Debra

......203

roff, Jenny

Rowley, Brian

$79,86,100$

Royal, Lori129, 136, 143, 147, 153, 203, 215, 218

Royer, Brenda

133,203

Ruark, Rachel

55,104

Ruba, Chrystie

67,154

Ruby, Carl

... 134

Rucker, Paula

....67

Raniel …u.............5

Rudd, David

.203

William ………………..... 8

Rudolph, Christopher ...........79, 90

Ruetz, Benjamin

Ruffin, Benjamin

$.67,171$

Ruhl, Dustin .

130,203

Ruhl, Kimberly

Ruhl, Penni .

Rummel, Susan

... 174

Rupp, Joshua

32,203

Russell, Jayne

67,236

Russell, Theodore ..........................67

Ruth, Monica .....................67, 127

Rutledge, Pamela ...........61, 79, 133

Ryan, Krista . 15, 79, 103, 112, 133

\section{S}

Sabella, Michael 79, 126, 128, 134,

138

Sagraves, Michelle ... 203

Sagraves, Thomas

...79

Sahl, John

..... 203

Salvaggio, Carla $\quad 55,159$

Sanders, Stephanie ........... 203, 218

Sanders, Teena

SanGregory, Sam .......................... 39

Sarber, Candace ........138, 143, 203

Saunders, Jeff

67,128

Sava, Gabriel

Savage, Rache

Savard, Paul

Saville, Stacy ........55, 92, 232, 236

Saville, Stephanie 55, 130, 147, 236

Sayre, Melissa ......................67, 136

Scearce, Buddy

...... 55

Schaap, Craig .....67, 112, 147, 154

Schaneman, Troy ………………..79

Scharnberg, Lorne ………………...... 8

Scharnburg, Mark …………....3, 65

Scheffel, Hearher ………........... 153

Scheumann, Lori ............15, 79, 113

Schimmenti, Andrea .79, 105, 127 ,

146

Schlesener, Ivy …………......67, 137

Schneckenberger, Cheryl ... 79, 159,

174

Schoepke, Brian .........55, 130, 138

Schrader, Jessic 
Stanton, Jeff

tanton, Kristen

$\ldots .80,230$

aples, Jennifer.

133,206

Staples, Joanna ………………..... 80

Stark, Aaron ................................206

Stark, Neal ……………...........56

Starkey, Jeff .................................68

Starrett, Julie …………......... 80, 90

Statzman, Ben ……..................... 45

Stauffer, Christina …............68, 100

Stauffer, James ............................45 45

Steele, Edith …………….......... 68, 156
Steenwyk, Eric ……………. 56, 91

Steiner, Janelle ………………....... 80

Stern, Kevin …………………..56

Sternad, Samantha ...............68, 125

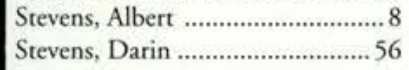

Stevens, Ira ………………...... 138

Stevens, Jason .... 80, 102, 111, 131,

138,140

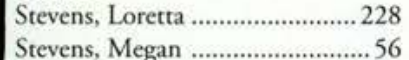

Stevens, Megan ……...................56

Stewart, Andrew 113, 154, 206, 155

Stewart, Ben ............................ 141

Stewart, Elizabeth ...56, 91, 94, 139

Stewart, Melinda ……………........6

Stiles, Robert .................................68

Stille, Heather ……………….............. 68

Stinson, Elizabeth ................68, 156

Stock, Michelle ……………....56, 94

Stoll, Will ........................130, 142

Stoll, William .....................................

Stone, Alison ……………......32, 56

Stone, Elizabeth

Stone, Mark ....

Stone, Michael

Stout, Aimee

Stover, Byron

$. .80,142$

......56, 112

Street, Jom

Streetman, Paul ....................80, 102

Streicker, Kathleen ………...........207

Streit, Nikki .

...56,87

Streit, Sandra..

$80,86,133$

Stribling, Diane ............................. 40

Strong, Lynette ………........80, 102

Strong, Randall ...........................56

Strong, Tamara .............80, 84, 138

Strong, Tobin ......68, 87, 128, 142

Stroven, Abby ………...............56

Strychalski, Christopher ...............56

Stryker, Amy …............................. 80

Stuart, Andrew ………………......56

Stuenzi, Jessica .............................56

Sturgis, Timothy ...............231, 236

Stutes, Christin …………........... 207

Stutes, Necole ………........207, 219

Stutzman, Benjamin ..............68, 94

Stutzman, Duane .......68, 141, 154

Stutzman, Marthew ………...56, 128

Sulish, Jason ………………....... 80

Sullivan, Daniel .............................56

Summers, Jennifer .........................6 68

Sutherland, Robert ............136, 207

Sutter, David ................................207

Sutton, Peter ........56, 88, 127, 154

Svendsen, Sarah ..........................56

Swanson, Brodie ..................68, 173

Swanson, Kevin ………………....... 80

Swanson, Rob ………………......... 84

Swasey, David ................. 4, 68, 147

Sweeney, Deborah ……….............6 68

Sweetland, Mary ......136, 147, 207

Sweetser, Wesley ………................. 38

Swigart, James ............................ 207
Swiger, Tara .................68, 96, 134

Tabberer, Brenda ................56, 100

Tague, Brian .....

Talladay, Kristin

.... 207
145
Vander Bush, Jennifer .. 56, 96, 138

Vander Linden, Mark ................... 68

Vander Molen, Kerri .....65, 69, 90,

134, 169

Vander Wal, Harry .............80, 102

Vannatta, Lisa ....................69, 232

Varner, Amy ......... 80, 88, 136, 149

Varotti, Marcus ................... 80, 138

Varotti, Susan ……………….......... 45

Vaughn, Angela ……......................57

Vaughn, Kevin ............................... 80

Vawter, Ben ..................................57

Veach, Amanda ............69, 84, 231

Velpe, Amy .................................... 45

Veneberg, Kimberlee ....................209

Vernier, Paul .................................... 8

Verwys, Jeremy …………....80, 163

Vickman, Bonnie ……………….....45

Vickman, Jeffrey ………………..... 45

Vickman, Kenneth ......................... 45

Vinal, Tim …….....................122

Vitarelli, Chad. 111, 142, 209, 214,

229

Vitarelli, Christopher ..28, 57, 146,

232, 236

Vivian, Elizabeth .............................. 80

Voigt, Rebecca .................................57

Volante, Judy ……………..........209

Volpe, Amy ………................57, 96

Vore, Rhonda

57,96
$\ldots . .57$

Thomas, Scott .................................68

Thompson, Cynthia ...................207

Thompson, Debra ……........104, 138

Thompson, Diana …………....... 104

Thompson, Greg ……….......56, 160

Thompson, Jason ..............136, 208

Thompson, Matthew …………....56

Thomson, Jacqueline ……….....208

Thomson, Scott .............................68

Thorsen, Kristine …...........133, 208

Thunder, Veronica ........65, 80, 141

Tilley, Amy ………………….......56

Timblin, Jennifer .........80, 91, 139

Tocknell, John ............................... 45

Todd, Summer .....................80, 134

Tolen, Grady ............................... 109

Tomsa, Nadine …................80, 139

Toomey, Crystal ............69, 80, 100

Torlone, Anthony .......68, 112, 171

Totten, Mark ............................. 231

Towle, Matthew .68, 147, 154, 155

Townsend, Raymond .68, 134, 146

Townsend, Sarah ..........................56

Toyer, Jeremy …………...56, 89, 96

Tregay, Flynn …………....... 80, 102

Trimble, Debbie ………………...1 137

Trimble, Melany ..................80, 139

Triplett, Paula ...............17, 136, 208

Trost, Trisha ……………....56, 112

Truax, Darren ………........129, 208

Tuinstra, Echo ………......80, 2102

Tuinstra, Renee ....................68, 146

Tuinstra, Timothy80, 93, 131, 138 , 140

Turner, Hannah

68,87

Tyler, Donald ...

\section{$U$}

Umbaugh, Earl

Umland, Brad .....................56, 173

Underwood, Brent ............208, 223

Usita, Lemuel ....................111, 208

\section{V}

Vaduva, Virgil...

\section{W}

Wabeke, Angela …..........33, 69, 89

Waddington, Leann ......................57

Waechter, Holly ..........................57

Wagenaar, Tara 139, 209, 213, 228

Wagner, Trudee ............................45

Waibel, Keely ..61, 65, 69, 90, 129,

131, 136, 138

Wainwright, Kathy...

W/albright, Kathry ................8 80

Waldock, Nathaniel ......57, 89, 139

Walker, Charlic ............69, 87, 142

Walker, Dick...

$69,87,142$

Walker, Greg ………………....... 135

Walker, Ronald ..............................38

Walker, Tricia ..2 2, 32, 81, 140, 143

Wallace, Heather ................. 89, 209

Wallis, Joel ..................................209

Wallis, Philip .............57, 130, 147

Walter, Dana ……………….......57

Wambold, Eric ..............................69

Wambold, John 45, 142, 146, 209, 214

Wannemacher, Amy ......................93

Ward, Sally .........................57, 104

Ware, Charles …….............69, 142

Ware, Karen ..........................57, 104

Ware, Paul ……………………....... 45

Ware, Tim .........................69, 160

Warnken, Sarah ............13, 14, 101

Warnshuis, James ................ 128, 209

Warren, David ................................. 38

Warren, Lisa ......................... 57, 133

Warren, Mark …………………....57

Warren, Pat ................................... 45

Warriner, Jennifer ................ 81, 111

Warriner, Kelly ..............................57

Washburn, Jeremy ……………......81

Wawro, Kristen ...................... 81,88

Weaver, Erin ... 126, 135, 144, 209 , 214

Weaver, Paul

Weaver, Tamara

. .69

Weaver, Wendy

Webb, Lee ....................................... 45

Weber, George ….......69, 134, 139

Van Gorp, Traci 208

Van Hart, Christopher . 80, 89, 138

Van Heukelum, Jason ............45, 68

Van Loo, Scott ...................56, 160

Van Til, Holly ..........................61, 80

Van Wormer, Lisa ......................... 68

Vandegrift, Scott 56, 125, 127, 128, 154

Vandemark, Natalie ..68, 101, 142 ,
Weber, Jonathan .69, 87, 125, 128 , 134

Weber, Laurie

Weber, Rhonda

Weber, Steven

..........57

Weber, Tracy .................69, 93, 125
………………........

Wolfe, Mary

Wolfe, Mary

Womack, Glenda

Womack, Jay.

152,153

Weirich, Lisa .

...69, 104

Weiss, Jamie

Weldy, Stephanie ……………….....69

Welker, Jacqueline .....................209

Welner, Robert ………………......57

Wenzel, Angela ....57, 69, 231, 236

Wenzel, Leslie ......81, 92, 129, 140

West, Kristi .

$\ldots 2,81$

West, Linda .

West, Michele

..... 45

West, Nellie

....81

Wetzel, Daniel

24,40

Wetzel, Phyllis

......... 45

Whalen, Steve ..................102, 209

Whinnery, Joseph ……………..... 57

Whisman, F. David ........... 209, 223

White, Adam ............................. 57

White, Brian ......69, 104, 125, 126

White, Marlo ……….................57

White, Matthe

Whitman, Jennifer

...69, 104

Whitmer, Amanda ..............81, 136

Whitmore, Jamie ......................... 163

Whitmore, John ........................... 41

Whitney, Beth.

Whitney, Janeen .

$\ldots .22,113$

Whittaker, Keil

137, 209

Whitten, Alissa $.69,96,125$

Wick, Jared .

Wickholm, Joy ..............................57

Wiedemann, Jody ......................209

Wiedemann, Todd ....................... 81

Wiersbe, Warren .....

69,95

Wiesert, Gregory .................. 69, 95

Wiewiora, Natalie .81, 89, 90, 137, 146

Wigg, Sharon

. .57

Wiggins, Robert ............................41 


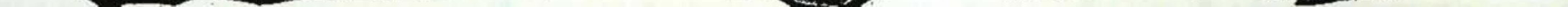



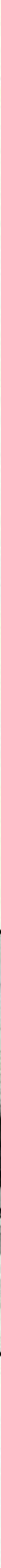

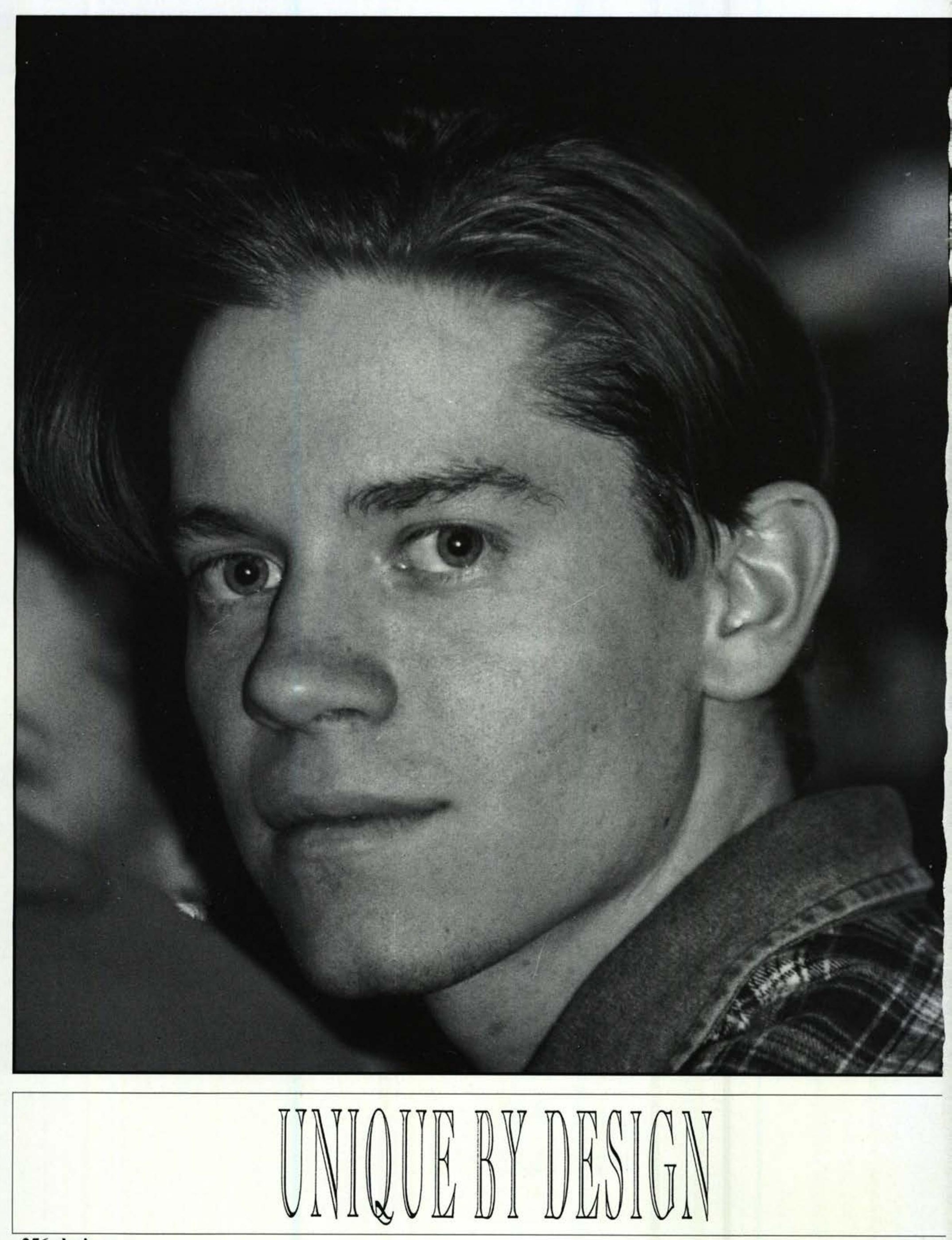

256 closing 

